UNIVERSIDAD NACIONAL DE EDUCACIÓN A DISTANCIA

DEPARTAMENTO DE PREHISTORIA Y ARQUEOLOGÍA

FACULTAD DE GEOGRAFÍA E HISTORIA

\title{
LA OCUPACIÓN HUMANA DEL TERRITORIO DE LA \\ COMARCA DEL RÍO GUADALTEBA (MÁLAGA) \\ DURANTE EL PLEISTOCENO
}

TESIS DOCTORAL

LIDIA CABELLO LIGERO

LICENCIADA EN HISTORIA

MADRID 2015/2016

DIRECTOR: JESÚS F. JORDÁ PARDO

COODIRECTOR: SALVADOR DOMÍNGUEZ-BELLA 



\section{AGRADECIMIENTOS}

Esta tesis doctoral es fruto de un trabajo conjunto en el que se implicaron muchas personas, siempre dispuestas a ayudarme. Sin financiación alguna, tuve que asumir en la mayoría de las ocasiones todos los gastos que conlleva un estudio como este, lo que suponía a su vez no poder dedicarme a tiempo completo a mi tesis doctoral. Es por ello, por lo que quiero agradecer infinitamente a varias personas y entidades que, de forma desinteresada, me brindaron su ayuda y colaboración durante mi investigación.

Me gustaría agradecer, en primer lugar a mi director Jesús Jordá Pardo y a mi codirector Salvador Domínguez-Bella, por aceptar formar parte de este trabajo y desarrollar mi investigación bajo su dirección, por su ayuda, por sus consejos y por sus correcciones, sin las cuales este trabajo no hubiese sido posible.

Mencionar a varios organismos, como el Ayuntamiento de Ardales y a su antiguo alcalde, Juan Calderón, quién me prestó siempre su apoyo, incluso facilitándome una de las instalaciones del ayuntamiento para mi investigación. Al Centro de Interpretación de la Prehistoria de Ardales y a la alcaldesa Maria del Mar González. Importante para mí, fue el buen acogimiento y la cooperación que sentí en el museo arqueológico de Teba de manos de su director José Berdugo y José Camarena.

Agradecer también la ayuda inestimable del catedrático de la Universidad de Cádiz, José Ramos, por sus consejos y por su continua colaboración, siempre disponible para ayudarme en todo lo posible.

A mis compañeros, Serafín Becerra, con quien he pasado muchas horas trabajando, tanto en el laboratorio de la Universidad de Cádiz, como en las jornadas de campo y Ana Doyagüe, por su apoyo en la elaboración de las láminas delgadas y por acogerme en su casa durante las semanas que pasé en Cádiz. Agradecer igualmente la amabilidad y el cariño que he sentido siempre, durante la elaboración de mi tesis doctoral, a Puri García y Ana Durante. Gracias por hacerme las estancias más agradables.

No me gustaría olvidarme tampoco de Juanjo Durán y Pedro Robledo, por su ayuda y sus buenos consejos para los trabajos de campos. 
También me gustaría agradecer a mis compañeros participes directos de este trabajo, siempre interesados en el avance de mis investigaciones, y acompañándome en algunas jornadas de campo, me refiero a Isabel Berrocal, Mayte Díaz, Patricia Ledesma, Cosme Padilla, Cristóbal Leal, Gerardo Anaya, Manolo Becerra, Lidia Berrocal, Mari Cobos, Francisco Berrocal, Antonio Aranda y Mercedes Álvarez.

Y sobre todo quiero agradecerle a mi familia todo lo que han hecho por mí. Especialmente a mis padres, José y Paqui, porque no olvido las muchas horas trabajando para que sus hijas pudieran estudiar y labrarse un futuro, para mí son un ejemplo de trabajo, educación, superación y humildad, algo que me inculcaron desde pequeña y que me ha servido a lo largo de mi vida. El apoyo de mis hermanas, Jessica y Rosi, y a Alberto, con quién comparto todo y a quién quiero agradecer su incalculable paciencia durante estos años.

No quiero terminar estas palabras de agradecimiento sin mencionar a dos personas muy especiales e importantes para mí, Pedro Cantalejo y M. Mar Espejo. Os tengo que dar las gracias por muchas cosas, por vuestra confianza, por vuestra amistad, por vuestra ayuda y colaboración, pero sobre todo por sentirme siempre querída.

Muchas gracias de corazón a cada uno de vosotros.

"No saber lo que ha sucedido antes de nosotros es como ser incesantemente niños" Marco Tulio Cicerón Dialogos del Orador 


\section{ÍNDICE}

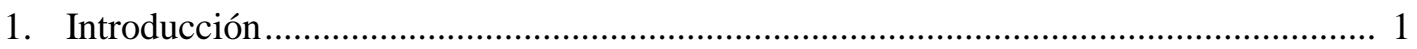

1.1. Hipótesis de trabajo y objetivos ..................................................................... 3

1.2. Elección de la zona de estudio: el valle del bajo Guadalteba y bajo Turón............ 4

1.3. Antecedentes sobre la arqueología de la zona ...................................................... 6

1.3.1. Historia de la investigación en la zona.......................................................... 7

1.3.2. La secuencia arqueológica del bajo Guadalteba y bajo Turón: estado de la cuestión .................................................................................. 10

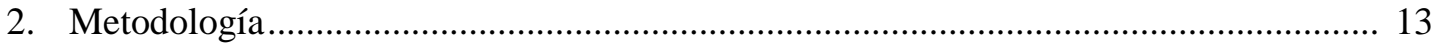

2.1. Planteamientos teóricos

2.1.1. El registro arqueológico de superficie: valoración crítica......................... 14

2.1.1.1. Argumentos en contra del registro de superficie ............................... 17

2.1.1.2. Argumentos a favor ......................................................................... 19

2.1.1.3. Antecedentes sobre el estudio de registros arqueológicos de superficie a nivel mundial, nacional y autonómico............................ 21

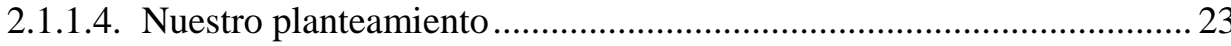

2.1.2. La recuperación del registro arqueológico: la prospección ............................ 31

2.1.2.1. Fundamentos teóricos y métodos de prospección................................. 34

2.1.2.2. Estrategia de prospección en nuestro caso ......................................... 37

2.1.2.3. Método de excavación................................................................. 40

2.1.2.4. Aplicación de la geoarqueología a la prospección ................................ 46

2.1.3. Territorialidad, aprovisionamiento de recursos y movilidad....................... 48

2.1.3.1. Modelos existentes sobre territorio y uso del espacio desde la Antropología y desde la Arqueología .................................................. 49

2.1.3.2. Modelo asumido por nosotros ............................................................. 58

2.2. Metodología de trabajo

2.2.1. Trabajo de gabinete: de los planteamientos iniciales a la presentación de la memoria. Uso de informática, de cartografía, de fotos aéreas y

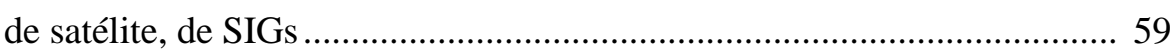

2.2.2. Trabajo de campo: Las campañas de campo y sus resultados.................... 63

2.2.3. Trabajo de laboratorio: estudio de las colecciones líticas ........................... 66

2.2.3.1. Planteamientos teóricos y metodológicos para el estudio de las

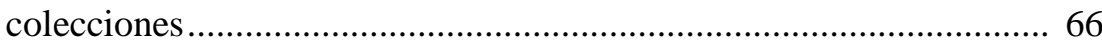

2.2.3.2. Planteamiento teórico y metodológico aplicado al estudio de nuestras colecciones líticas 
2.2.3.2.1. Aprovisionamiento de materias líticas, técnicas de identificación de materias primas

2.2.3.2.2. Explotación y configuración de las industrias líticas: tipología, sistema lógico analítico, utilización, abandono y procesos postdeposicionales........................................................... 81

3. El medio natural de la zona de estudio ......................................................................... 97

3.1. Encuadre geológico general en Iberia y en las Cordilleras Béticas ...................... 97

3.1.1. Geología: estratigrafía, litología, tectónica .............................................. 101

3.1.2. Geología de detalle de la zona de estudio ................................................. 107

3.2. Geomorfología

3.2.1. Encuadre geomorfológico general en Iberia y en las Cordilleras

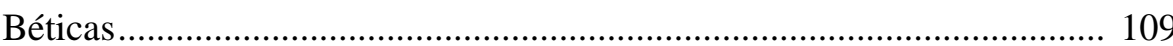

3.2.2. Geomorfología de detalle de la zona de estudio .................................... 111

3.2.2.1. Las superficies antiguas ..................................................................... 112

3.2.2.2. Los valles fluviales y las terrazas, el valle del Guadalteba................ 113

3.2.2.3. Las formas kársticas ...................................................................... 114

3.3. Marco cronológico general y escalas cronoestratigráficas utilizadas.................... 115

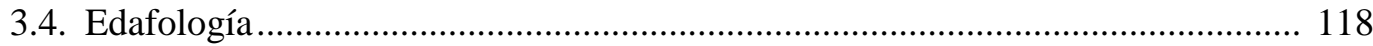

3.5. Geografía …………………......................................................................... 119

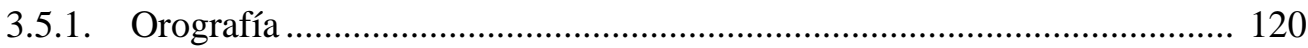

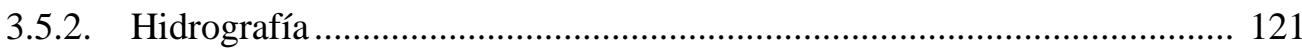

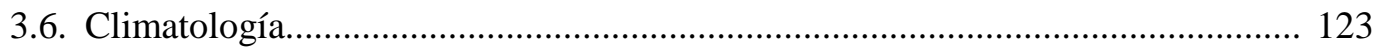

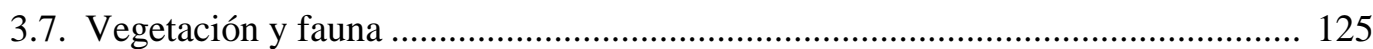

3.8. Poblamiento humano y redes de comunicación. El impacto humano en el paisaje 126

4. Presentación de los datos

4.1. Los afloramientos de materias primas

4.1.1. Los afloramientos con materiales en posición primaria o

semi-primaria (afloramientos rocosos y sus depósitos de vertiente)............ 129

4.1.1.1. La Atalaya (Cañete la Real)......................................................... 131

4.1.1.2. Herriza de La Lapa (Cañete la Real) ............................................. 135

4.1.1.3. La Mogea (Cuevas del Becerro) .................................................... 138

4.1.1.4. Los Canchos (Serrato-Ronda) .................................................... 139

4.1.1.5. Los Madroñales (Almargen) ......................................................... 143

4.1.1.6. Parque eólico Los Madroñales (Almargen) .................................. 146

4.1.1.7. El Azulejo (Ardales) ...................................................................... 150

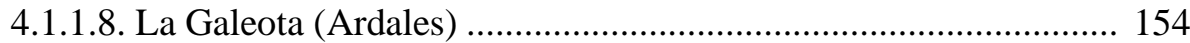


4.1.1.9. Castillo del Turón (Ardales) ........................................................ 157

4.1.1.10. Herriza del Carnero (Casarabonela) ............................................. 160

4.1.1.11. Sierra Valle de Abdalajís ............................................................. 161

4.1.1.12. Sierra de Humilladero................................................................... 164

4.1.2. Los afloramientos con materiales en posición secundaria

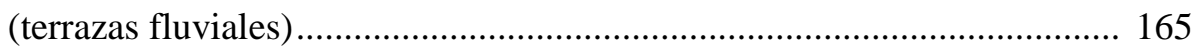

4.1.2.1. Terraza de Las Grajeras (Ardales) ............................................ 165

4.1.2.2. Terraza de Peñarrubia (Campillos) ............................................. 167

4.1.2.3. Terraza Casilla Vallejo (Teba) .................................................. 170

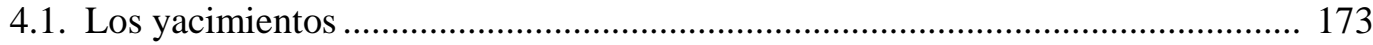

4.1.1. Cuenca del Turón ...................................................................................... 173

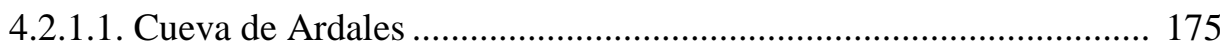

4.2.1.2. Cucarra (Ardales) ....................................................................... 182

4.2.1.3. Depósitos de Hoyos de Barbú (Ardales) ........................................... 191

4.2.1.4. Terraza arroyo Cantarranas (Ardales) ............................................... 199

4.2.1.5. Depósito del Hundilón (Ardales) ...................................................... 203

4.2.1.6. Terraza de Morenito (Ardales)........................................................ 210

4.2.1.7. Llanos de Belén (Ardales).............................................................. 218

4.2.1.8. Terraza de Las Grajeras (Ardales) .................................................. 225

4.2.1.9. Raja del Boquerón (Ardales)............................................................ 233

4.2.1.10. Lomas del Infierno (Ardales) .......................................................... 240

4.1.2. Cuenca del Guadalteba ....................................................................... 249

4.2.2.1. Terraza de La Puente (Teba) ............................................................ 250

4.2.2.2. Sima de Las Palomas (Teba) ........................................................ 257

4.2.2.3. Terraza de Peñarrubia (Campillos) ................................................. 281

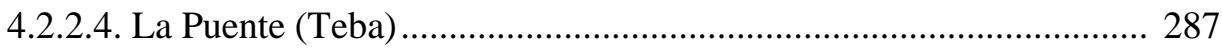

4.2.2.5. PEMA4 (Almargen) ........................................................................ 294

4.2.2.6. Hallazgos aislados ........................................................................ 307

4.2.2.6.1. Bifaz de Nina Alta (Teba) ................................................. 307

4.2.2.6.2. Bifaz de Fuentepeones (Cañete la Real)............................. 308

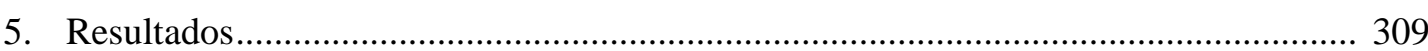

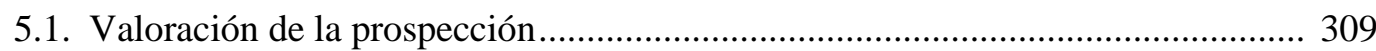

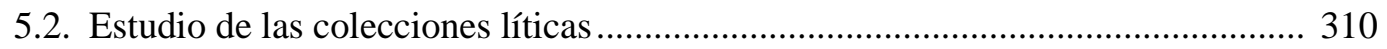

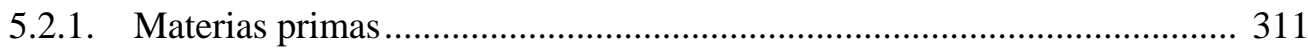

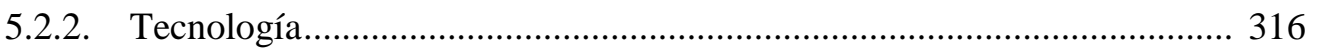

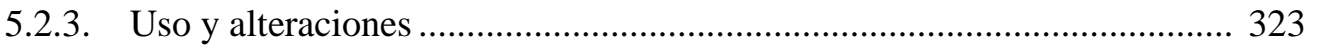




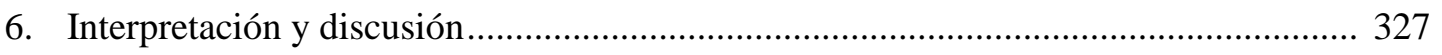

6.1. El contexto de las evidencias ............................................................................ 329

6.2. Características tecnológicas ................................................................................. 331

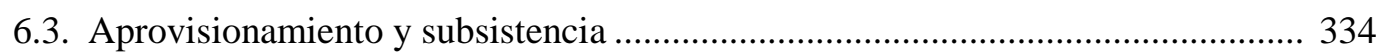

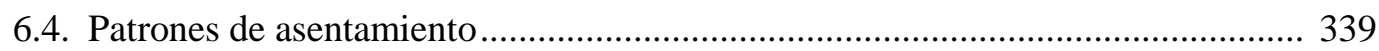

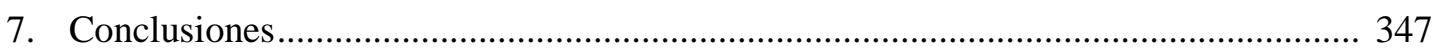

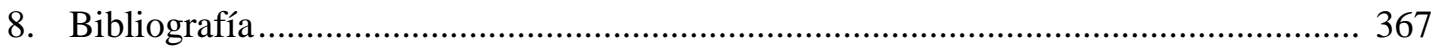

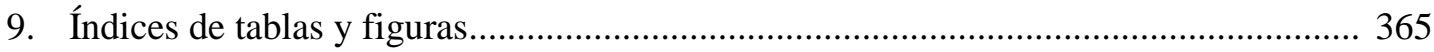





\section{Introducción}

El marco geográfico en el que se desarrolla este estudio se sitúa en la comarca del río Guadalteba, en el interior de la provincia de Málaga (figura 1), donde se produce la confluencia de los ríos Guadalteba y Turón, objeto de nuestra investigación, y del río Guadalhorce. Este hecho dota a la zona de una excelente situación estratégica como corredor natural, propiciando una importante diversidad geológica y biológica con zonas de montaña, piedemonte y valle, así como espacios lacustres, que configurán una región con unas características especiales, que permitiría el abastecimiento de recursos, tanto bióticos como abióticos, de los distintos grupos de cazadores-recolectores que ocuparon la zona durante el Pleistoceno. Una ocupación reflejada en las diferentes evidencias arqueológicas existentes, tanto en yacimientos al aire libre como en cueva.

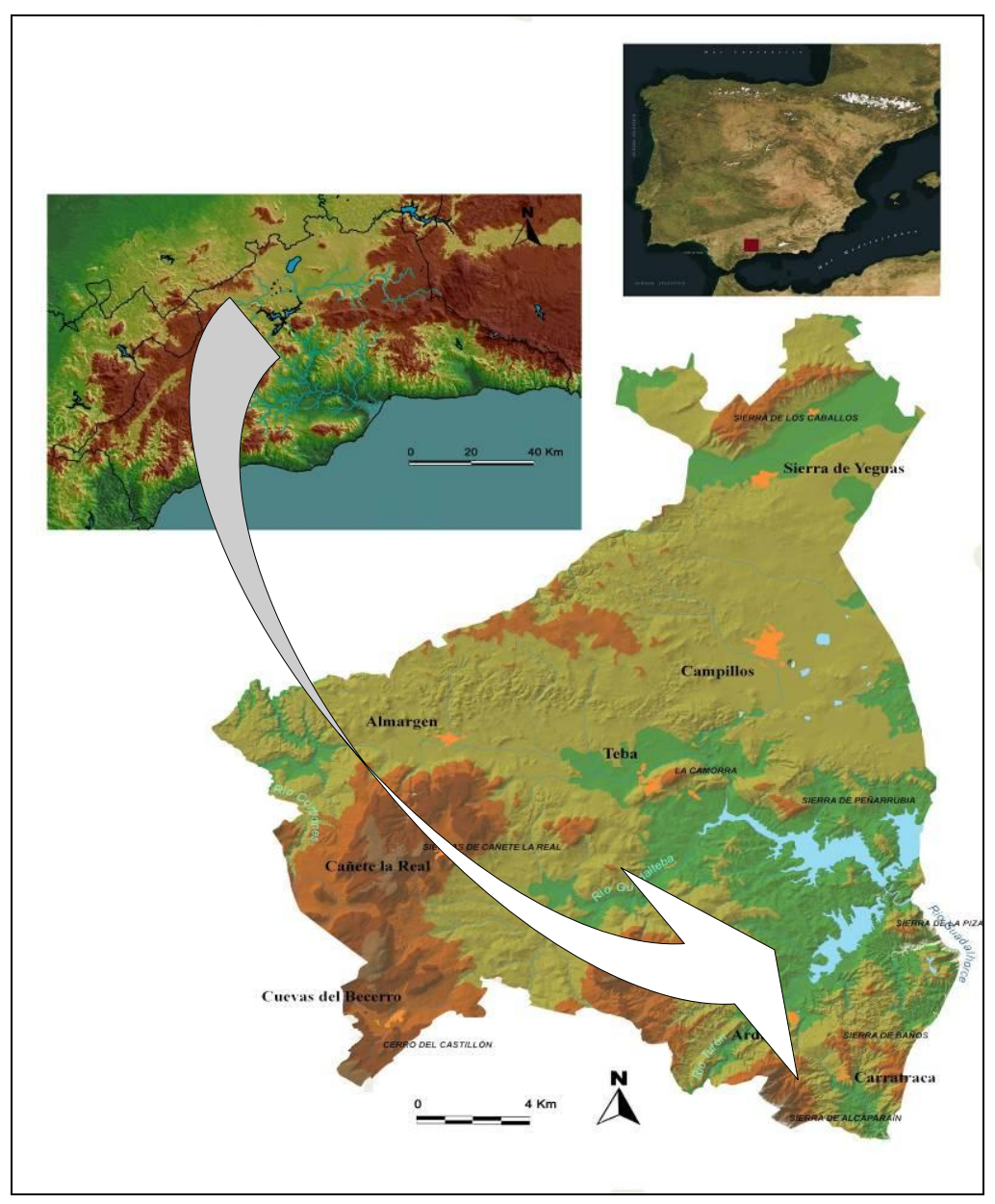

Figura 1: Mapa de situación de la comarca del Guadalteba, en

Málaga y España (elaboración propia). 
El río Guadalteba nace en la sierra de los Merinos (Serranía de Ronda) en las proximidades del municipio de Serrato, por la confluencia del río de las Cuevas y el riachuelo de Serrato. Con una cuenca de unos $500 \mathrm{~km}^{2}$ y un recorrido de $45 \mathrm{~km}$, atraviesa los términos municipales de Ronda, Cuevas del Becerro, Cañete la Real, Teba y desemboca en el embalse del mismo nombre, en el término municipal de Campillos. Constituye un espacio de frontera entre el altiplano de la comarca de Antequera y las sierras rondeñas, y sirve de nexo de unión entre el territorio del interior de la provincia de Málaga y las vertientes mediterránea y atlántica del sur de la Península Ibérica.

El río Turón nace en la sierra de las Nieves, denominado en su nacimiento como río El Burgo, cambia su nombre al llegar a la sierra de Alcaparaín, próxima a Ardales, denominándose río Turón. Con una cuenca menor que el Guadalteba y un trazado más lineal (Medianero Soto et al., 2012: 61) discurre por las sierras de El Burgo y Ortegicar en la margen izquierda, y por las sierras de Cabrilla, Prieta y Alcaparaín hasta desembocar en el embalse del Conde del Guadalhorce, recibiendo el aporte de numerosos arroyos.

El material arqueológico recogido durante trabajos realizados sobre todo en los años 80 del siglo pasado por el equipo de investigación arqueológica de Árdales, encabezados por M. M. Espejo, P. Cantalejo y J. Ramos entre otros, presenta un magnifico muestrario con grandes posibilidades, para el estudio de los grupos del Paleolítico de la zona (Medianero Soto et al., 2005, 2006; Morgado Rodríguez et al., 1995).

El trabajo que aquí presentamos pretende establecer la relación entre los grupos humanos paleolíticos que ocupaban la zona del bajo Guadalteba y bajo Turón y los recursos existentes, con el objetivo de caracterizar los patrones de asentamiento de los cazadores-recolectores durante el Pleistoceno, en función de las áreas de captación de materias primas minerales, mediante su interpretación y caracterización, a través del estudio del registro arqueológico y la identificación de los posibles lugares de aprovisionamiento.

En la actualidad, ambos ríos (Guadalteba y Turón) se encuentran unidos a través de un embalse que recoge sus aguas, lo que dificulta la posibilidad de localizar nuevos yacimientos próximos a su margen, ya que de existir estarían, hoy día, bajo las aguas del embalse del Guadalhorce. 
La importancia de los ríos Guadalteba y Turón como zona de abastecimiento, la atestiguan las evidencias arqueológicas localizadas en sus proximidades, como la Sima de Las Palomas, también denominada por otros autores Sima del Sílex (García Alfonso et al., 1995) dentro de complejo de Las Palomas (Teba) (Ferrer Palma et al., 1986/87), o en la Cueva de Ardales, ambos yacimientos con estratigrafía, así como en las numerosas terrazas fluviales (Recio Ruiz, 2000) y en hallazgos aislados como el bifaz de Nina Alta, en el arroyo de Nina (Teba) o el de Fuentepeones (Cañete la Real). Sin embargo, los restos localizados no eran suficientes para establecer hipótesis certeras sobre estas ocupaciones prehistóricas, dado que en aquellas investigaciones se trató la zona como un territorio de ocupación secundaria y marginal (García Alfonso et al., 1995).

Con este trabajo, pretendemos localizar nuevas evidencias arqueológicas que nos permitan demostrar la importancia territorial de la zona y establecer un nexo de unión entre los diferentes yacimientos, en relación a las materias primas, para comprender la movilidad de los grupos humanos del Pleistoceno en esta área del interior de la provincia de Málaga.

\subsection{Hipótesis de trabajo y objetivos}

Como hipótesis de trabajo nos planteamos la posibilidad de que exista una relación directa entre los yacimientos adscritos al Paleolítico durante el Pleistoceno con zonas de aprovisionamiento de materias primas líticas localizadas en terrazas y afloramientos rocosos cercanos a estos yacimientos, que explicarían los patrones de asentamiento de estos grupos humanos en función de los recursos abióticos y bióticos existentes.

Por ello, el principal objetivo de esta tesis, radica en caracterizar los patrones de asentamiento de los cazadores-recolectores durante el Pleistoceno en la zona del bajo Guadalteba, bajo Turón y su entorno, a partir de la interpretación de las áreas de captación de materias primas, a través del estudio de los yacimientos de esa cronología, fundamentalmente las terrazas fluviales con material arqueológico, del estudio de los materiales recogidos en superficie desde los años 80 del siglo $\mathrm{XX}$ y de los nuevos recogidos durante el desarrollo de esta tesis, que permitan poner en conexión los antiguos materiales con los modernos, y proponer un modelo de movilidad de los grupos de cazadores-recolectores. 
Como objetivos secundarios, que permitan el desarrollo de este trabajo, destacamos los siguientes:

- Describir, analizar e inventariar los yacimientos y sus restos arqueológicos, valorando el potencial arqueológico. Para ello, es necesario hacer una recopilación de todos los yacimientos paleolíticos conocidos, y de los estudios realizados en ellos, durante los años 80 del siglo XX e incorporar los yacimientos localizados durante el desarrollo de nuestra investigación, en el caso de nuevas localizaciones.

- Definir la secuencia cronológica de los yacimientos que permita su comparación con las secuencias cronológicas de otras zonas geográficas del entorno geográfico.

- Analizar el registro arqueológico, con el apoyo de otras disciplinas tales como la Geoarqueología o la Arqueometría.

La consecución de este trabajo presenta una doble línea de actuación; por un lado, una prospección superficial selectiva en aquellas zonas donde se localizaron yacimientos arqueológicos con el fin de constatar la adscripción cronológica de los enclaves y por otro, una prospección arqueológica superficial intensiva en las zonas no prospectadas, ante la posibilidad de la existencia de nuevos yacimientos en superficie que permitirá ampliar el número de localizaciones paleolíticas, con el fin de demostrar si los grupos de cazadores-recolectores tuvieron una continuidad o no en la utilización del entorno durante el Pleistoceno en este espacio geográfico.

\subsection{Elección de la zona de estudio: el valle del bajo Guadalteba y valle del bajo Turón}

Existen varios motivos para la elección de esta zona como área de estudio. Uno de ellos es su gran riqueza arqueológica, con la existencia de numerosos yacimientos adscritos a diferentes cronologías culturales. De estos, los principales son la Sima de Las Palomas, y que forma parte de un complejo kárstico denominado cueva de Las Palomas (Teba) (Ferrer Palma et al., 1986/87, 1978; Medianero Soto et al., 2011), y la Cueva de Ardales (Ramos Muñoz et al., 2014), hoy en día referente para los estudios de Paleolítico superior, a lo que se le une que en ella es donde se iniciaron los estudios sobre el Paleolítico de la zona, ambas objeto de nuestra investigación entre los años 2011-2014, y parte del Proyecto General de Investigación iniciado en el año 2015. 
Por otra parte, debo mencionar mi vinculación personal con la zona de estudio y mi participación como arqueóloga en varias actividades puntuales realizadas en ambas cuevas. Junto con los trabajos geoarqueológicos y arqueométricos sobre las materias primas líticas, realizamos diferentes muestreos geológicos con el objeto de poder establecer las principales áreas fuentes geológicas de estas materias primas líticas (Domínguez-Bella et al., 2014: 148), en colaboración con distintas entidades, como el Neanderthal Museum de Mettmann (Alemania) o las universidades de Cádiz y Málaga, en el marco de las actividades arqueológicas llevadas a cabo entre los años 2011-2014. Junto a estas actividades también participé, en el año 2014, como colaboradora, en el marco del proyecto del IGME para la elaboración de la cartografía geomorfológica de la Cueva de Ardales, dirigido por J.J. Durán y P. Robledo.

Finalmente en el mes de junio del año 2015 fueron aprobadas dos prospecciones arqueológicas, una en la cuenca del río Turón bajo mi dirección y otra en la cuenca del río Guadalteba, bajo la dirección de Serafín Becerra Martín, en el marco del Proyecto General de Investigación: Las sociedades prehistóricas (del Paleolítico medio al Neolítico final) en la Cueva de Ardales y Sima de Las Palomas de Teba (Málaga). Estudio geoarqueológico, cronológico y medioambiental. Las prospecciones se iniciaron a finales de agosto, por lo que el número yacimientos aquí expuestos son provisionales ya que el estudio continuará hasta concluir la primera fase del Proyecto General de Investigación.

Debido a la variedad ecológica existente en la zona por la confluencia de los ríos Guadalteba y Turón, y a la importancia de la misma como paso natural entre la vertiente atlántica y la mediterránea, el área de estudio se convierte en un punto clave de contacto entre seres humanos y comunidades vegetales y animales. De esta biodiversidad serían conscientes estos grupos humanos, así como de la importancia de los afloramientos minerales, de gran calidad, existentes en áreas cercanas, que facilitarían en gran medida el aprovisionamiento de material lítico sin necesidad de realizar largos desplazamientos para su obtención. A todo esto hay que añadir la existencia de numerosas zonas lacustres, las cuales albergarían gran cantidad de fauna susceptible de ser cazada.

Con todo, nos encontramos con un variado ecosistema que permitiría a los grupos humanos del Pleistoceno la obtención de diferentes recursos, hecho que favorecería la habitabilidad de esta zona. 
Los estudios de los años 80, realizados por el equipo de investigación arqueológica de Árdales (Espejo Herrerías et al., 1988, 1989, 1990), supusieron un cambio importante en el conocimiento de la Prehistoria en este espacio del interior de Málaga, desconocido y falto de investigación hasta ese momento. La continuidad de los estudios se manifiesta por las numerosas publicaciones existentes (Cantalejo Duarte, 2007; Cantalejo Duarte et al., 2006, 2004, 2003). Sin embargo, aún existe un vacío importante de información sobre los grupos paleolíticos de la zona que hace necesaria, no sólo una revisión, sino además nuevos estudios que verifiquen la existencia de una ocupación humana durante el Pleistoceno.

\subsection{Antecedentes sobre la Arqueología en la zona}

De no ser por el trabajo del abate Henri Breuil en la cueva de Árdales (Breuil, 1921; Breuil et al., 1929) y de su posterior publicación, el estudio de la zona no se hubiera llevado a cabo con el mismo interés con el que se realizó, aunque existían referencias anteriores a la misma, como las de S. de Miñano (Miñano, 1826), F. Tubino y Oliva, quien según L. Siret estudio los materiales arqueológicos y antropológicos de la entrada (Siret, 1891-2001), las de P. Madoz (Madoz, 1845) o las de G. Puig y Larraz en la segunda mitad del XIX (Puig i Larraz, 1896), no será hasta 1921, con H. Breuil, cuando se inician los verdaderos trabajos prehistóricos de la zona (Cantalejo Duarte et al, 2014: 35).

Es importante mencionar la gran labor de investigación y estudio que se generó en la zona desde los años 80 , en un intento de comprender las sociedades del paleolítico y sus formas de vida. Gracias a esos estudios (Espejo Herrerías et al., 1988, 1989, 1990) fue posible la localización de un importante número de yacimientos vinculados a la Prehistoria, los cuales han colocado a esta zona como un referente para la realización de nuevos estudios sobre las sociedades del Paleolítico, como lo atestiguan las actividades arqueológicas puntuales llevadas a cabo en colaboración con varias instituciones y universidades desarrolladas entre los años 2012-2014. 


\subsubsection{Historia de la investigación en la zona}

Si revisamos los trabajos existentes en la zona vemos como las prospecciones superficiales han primado sobre las excavaciones, en la mayoría de los casos debido a la falta de financiación por parte de los organismos competentes, imposibilitando contrastar la información del registro arqueológico de superficie con los resultados de una excavación. Sin embargo, estos estudios permitieron la localización de un elevado número de yacimientos vinculados, en su mayor parte, a zonas de obtención de materias primas, sobre todo asociadas a los márgenes de los ríos y que, de no ser por ellos nunca se hubiesen estudiado, dando lugar a un vacío de información.

Aunque ya existían referencias a la cueva de Ardales con anterioridad al siglo XX (Miñano, 1826; Siret, 1891-2001; Madoz, 1845; Puig i Larraz, 1896), los primeros trabajos fueron los del abate H. Breuil, cuando en 1918 visitó la cueva de Árdales, junto a su discípulo, M. Such, y descubrieron un importante conjunto de pinturas paleolíticas. Sus descubrimientos se publicaron en un artículo conjunto con las pinturas de la cueva del Higuerón (Rincón de la Victoria, Málaga) en la revista L'Anthropologie en París en 1921 (Breuil, 1921), lo que supuso su inclusión en los primeros listados de monumentos nacionales y en el manual de H. Obermaier El hombre fósil de 1925 (Obermaier, 1925; Cantalejo Duarte et al., 2014).

Posteriormente, en los ochenta del siglo XX, continuó los trabajos el equipo de Árdales (Espejo Herrerías et al., 1988) con una importante labor de recuperación del yacimiento, ampliando el conocimiento sobre arte rupestre paleolítico, recopilando todas las representaciones y haciendo un estudio exhaustivo e ininterrumpido, durante años posteriores, con numerosas publicaciones y la realización de un proyecto para la reproducción fotográfica del arte prehistórico de la Cueva de Ardales en 2002 y 2003 (Cantalejo Duarte et al., 2006).

Entre los años setenta y ochenta, se inician los trabajos de excavación en la cueva de las Palomas de Teba por el equipo de investigadores de la Universidad de Málaga (Ferrer Palma et al., 1986/87-1978), los resultados obtenidos enmarcaban al yacimiento dentro de los horizontes del Neolítico y Calcolítico.

A partir de ese momento surgen nuevas propuestas de estudio que se materializaron en varias campañas de prospección, como la prospección arqueológica superficial en el valle del Turón, entre los años 1987-1989, dirigidos por J. Ramos y M.M. Espejo (Espejo Herrerías et al., 1990), que dejaron de manifiesto la gran 
importancia estratégica y la riqueza arqueológica de la zona, con la localización de un gran número de yacimientos de diferentes cronologías. Sin embargo, hasta ese momento, son pocos los yacimientos vinculados al Paleolítico en comparación con los de la Prehistoria reciente.

Igualmente a finales de la década de los ochenta, del siglo $\mathrm{XX}$, se localizaron industrias líticas talladas en las terrazas de la margen izquierda del río Guadalteba, mediante prospecciones superficiales realizadas por F. Medina y C. Barroso, adscritas a Paleolítico medio, aunque los resultados de las mismas no han sido publicados (Medianero Soto, et al., 2006). En esta misma década y en la posterior, se localizaron en las terrazas de este río productos líticos tallados vinculados a diferentes cronologías (Vallespí Pérez, 1988; Espejo Herrerías et al., 1990; García Alfonso et al., 1995). Destacar también el estudio de E. García, A. Morgado y E. Martín en el marco de un estudio general del municipio de Teba, sobre las ocupaciones prehistóricas en el valle del Guadalteba (García Alfonso et al., 1995). Más tarde, en 1999, a consecuencia de la construcción de la carretera Málaga-Campillos, en el bajo Guadalteba y del descenso del nivel del pantano, se produjo la aparición fortuita de varios útiles, de tipología variada, recogidos en superficie y que formaban parte de un revuelto originado por los desmontes de las obras. El estudio de estos materiales realizado con ayuda del geólogo J.J. Durán, puso de manifiesto la gran importancia del yacimiento, situado en una terraza fluvial con útiles en conexión estratigráfica con los sedimentos fluviales. Un reconocimiento de campo más extenso evidenció, desde la óptica geomorfológica, la existencia de más depósitos arqueológicos afectados por la construcción de la nueva carretera (Medianero Soto et al., 2006).

En el año 2000, se preparó un proyecto de estudio geoarqueológico de las terrazas cuaternarias con industria lítica del río Guadalteba, bajo la dirección de J.J. Durán y J. Ramos, pero ante la respuesta negativa de la Junta de Andalucía, se encauzó en el programa formativo de la Escuela Taller del Consorcio Guadalteba, permitiendo que se realizaran estudios de forma sistemática de la zona conocida como terrazas de Peñarrubia (bajo Guadalteba) (Medianero Soto et al., 2012). Se documentaron las terrazas existentes, que se zonificaron con polígonos geométricos y se establecieron secuencias estratigráficas en la intervención de la plataforma de Peñarrubia (Medianero Soto et al., 2001 y 2002). Con posterioridad, no se han realizado más estudios sobre las terrazas de Peñarrubia, aunque se ha recogido material lítico de la misma, dado que el efecto erosivo del oleaje de las aguas del embalse provoca el desprendimiento de las 
terrazas, con presencia de materiales del Paleolítico inferior, como hendedores y bifaces, junto a industrias del Paleolítico medio.

Además de estos estudios, es conveniente mencionar la existencia de hallazgos fortuitos por parte de vecinos de la zona, en el complejo de la cueva de Las Palomas, como el material lítico de la Sima de Sílex (García Alfonso et al., 1995), denominada posteriormente Sima de Las Palomas (Weniger et al., 2014), muy cercana a las terrazas del río Guadalteba, adscrito a Paleolítico medio, y que está en proceso de estudio dentro de las actividades arqueológicas puntuales y de Proyecto General de Investigación, que se llevan a cabo en la zona de estudio. En este contexto son importantes las numerosas terrazas colgadas cercanas al río, de las cuales también se han obtenido material lítico.

Recientemente, aunque las excavaciones son casi inexistentes, se han realizado numerosas prospecciones superficiales asociadas en su mayoría a la implantación de parques eólicos en la zona, lo cual ha ampliado el número de yacimientos recopilados con respecto a las prospecciones de los años 80 .

En el año 2011 se llevó a cabo una intervención arqueológica en la Sima de Las Palomas de Teba, enmarcada dentro de las actividades puntuales en colaboración con el Neanderthal Museum de Mettmann (Alemania). En esta intervención se pudo obtener una estratigrafía de la sima, que proporcionó material lítico, óseo y restos de hogares. Entre el material óseo, se localizó una mandíbula de un individuo infantil de Homo sapiens. Esto indica la importancia de la cueva durante el Pleistoceno medio y superior como posible zona de hábitat en un área muy cercana al río objeto de nuestro estudio.

Además, se obtuvo una importante colección lítica, con numerosos restos de talla y útiles, cuyo estudio ha permitido establecer las características de la talla lítica y el abastecimiento de materia prima entre otros aspectos, y conocer las vías de movilidad o de tránsito de estos grupos en el entorno. En los últimos años, se están ampliando los estudios geoarqueológicos, con la aplicación de la tecnología de espectroscopia Raman a la caracterización mineralógica de los productos líticos de las industrias asociadas a las terrazas cuaternarias (Medianero Soto et al., 2012). 


\subsubsection{La secuencia arqueológica del bajo Guadalteba y bajo Turón: estado de la cuestión}

Los numerosos restos arqueológicos localizados en la zona del bajo Guadalteba, del bajo Turón y sus proximidades atestiguan la importancia de la zona durante la Prehistoria. Las primeras evidencias arqueológicas de la actividad humana en la zona se remontan al Paleolítico inferior, con una cronología entre 500.000 años y 100.000 años, corresponden a un amplio registro de cantos tallados, lascas retocadas y algunos bifaces. Los materiales apuntan a un Achelense, cuyas herramientas están asociadas a técnicas de talla arcaizantes (Cantalejo Duarte, 2007).

El estudio de las formaciones de los espeleotemas de la Cueva de Ardales, permitió la localización de tres generaciones entre el límite Pleistoceno medio-superior, cuya edad de mínima antigüedad se pudo remontar al Pleistoceno medio. Las muestras obtenidas de esta fase más antigua ofrecen una edad de crecimiento entre 123.000 años a muro y 89.200 a techo, corresponde con la última interglaciación (OIS 5), con un clima cálido y húmedo con características cercanas a las subtropicales (Durán Valsero et al., 1992).

Los yacimientos de este periodo, se concentran en las terrazas cercanas a la zona de Peñarrubia (Campillos) con cotas de $+80 \mathrm{~m},+80-60 \mathrm{~m},+45-35 \mathrm{~m},+30 \mathrm{~m},+20 \mathrm{~m}$, +15-7 m, +3-2 m sobre el río, el arroyo de Nina Alta (Teba), Fuentepeones (Cañete la Real) y en terrazas colgadas en diferentes puntos del río Guadalteba, en la zona de Cañete la Real, y en las terrazas colgadas del río Turón, como Las Grajeras o Morenito, todas ellas en el término municipal de Ardales, con algunos materiales atribuidos al Paleolítico inferior.

También se conservan en estas terrazas, industrias relacionadas con el Paleolítico medio con una cronología entre 100.000 años a 50.000 años. Restos de este periodo se han localizado en la Sima de Las Palomas (Teba), en las terrazas de Peñarrubia, en algunas laderas montañosas próximas a las sierras como es el caso del Tajo del Molino (Teba), en Huertas de Peñarrubia, La Capellanía 2, La Capellanía 3, Cerro del Almendro 1 y 2 (Campillos), Cucarra, Olivar de Currito, Lomas del Infierno o Raja del Boquerón (Ardales).

La ocupación humana continúa en el Paleolítico superior en la Sima de Las Palomas (Teba). En las zonas próximas al bajo Guadalteba también existen numerosos yacimientos de este periodo superior, que evidencian la frecuentación de este espacio a lo largo del Pleistoceno. Aunque se han documentado y estudiado algunos de los 
yacimientos conocidos, la aparición constante y en ocasiones fortuita, de restos tecnológicos en los valles del río Guadalteba y Turón, atribuidos al Paleolítico permitiría ampliar el conocimiento de estos grupos de cazadores-recolectores en esta zona.

Durante el Neolítico, entre 7.000 y 5.000 años, aparecen los primeros asentamientos situados en las orillas de los ríos. Destacan como yacimientos de esta fase la cueva de Las Palomas (Teba) (Ferrer Palma et al., 1986/87), los conjuntos rupestres esquemáticos del Tajo del Molino (Teba) (Cantalejo Duarte, 2007) y Llano de la Espada (Teba) (Morgado Rodríguez et al., 2005), los restos de la cueva de Alcaparaín, y los de la Cueva de Ardales, Puerto de las Atalayas, abrigo del Parque Ardales, Tajos del Almorchón, Olivar de Currito o Lomas del Duende.

El Calcolítico es el periodo con una mayor ocupación de la zona. Su fase más antigua la encontramos en la Hoz de Peñarrubia (Campillos). El mundo espiritual y simbólico de esta época está representado por el ídolo de la cueva de Las Palomas (Teba), las pinturas esquemáticas del Tajo del Molino (Teba) donde existen varios abrigos con representaciones de ídolos placa en rojo y restos de antropomorfos pintados (Cantalejo Duarte et al., 2006) o la necrópolis colectiva de las Aguilillas (Campillos), donde hay representaciones de varios antropomorfos grabados de tipo ancoriforme (Espejo Herrerías et al., 1994), los Castillejos (Teba), castillo Peña de Ardales, Cueva de Ardales, cerro del Mirador, restaurante el Mirador o taller del castillo Turón (Ardales).

Los momentos de Bronce inicial no se han documentado por el momento en la zona del bajo Guadalteba. El Bronce final pleno- Bronce final reciente-Hierro está representado por los yacimientos de la zona, Hoz de Peñarrubia (Campillos), plataforma río de la Venta (Teba), los poblados fortificados y aldeas agrícolas del Castillón de Gobantes (García Alfonso, 2007), Plataforma de Peñarrubia, Eras del Guadalteba, Playas del Guadalhorce (Campillos), Peña de Ardales, Raja del Boquerón, Las Grajeras, Laderas del Boquerón, Morenito, Los Caserones, Lomas del Infierno (Ardales).

En época ibérica (siglos IV al II aC.) el control del territorio lo ejercía el oppidum del Castillón de Gobantes (Campillos), por su situación estratégica dentro del territorio y por la gran cantidad de material arqueológico hallado, junto a torres y murallas que evidencian un sistema defensivo (Cantalejo Duarte, 2007), los oppida de Peña de Ardales y de Sábora (Cañete la Real) o Los Castillejos (Teba). 
Los restos arqueológicos de época romana presentan una continuidad con la época ibérica por lo menos hasta el siglo I dC, están documentados en el cerro de San Eugenio o la necrópolis de Peñarrubia (Medianero Soto et al., 2005), Eras de Peñarrubia, cerro del Almendro (Campillos). La posterior cristianización del territorio propició el asentamiento en zonas rurales. Destacan varios yacimientos en Peñarrubia con varias necrópolis visigodas, como la que se excavó en Eras de Peñarrubia (Campillos) (Serrano Ramos et al., 1983), el yacimiento del Tesorillo (Teba) (Serrano Ramos et al., 1985) o Parque Guadalteba (Campillos) (Medianero Soto, 2006). De la edad media apenas existen restos de alguna torre vigía, como la de Munt Rubí (Teba), sí existen castillos y aldeas fortificadas repartidas por la zona, como la ciudad-fortaleza de Bobastro (Ardales).

Desde el final de la guerra con el reino nazarí de Granada, uno de los principales problemas fue la desertización de la tierra y los pueblos. En el intento de solucionar este problema, durante el siglo XVI, se llevan a cabo políticas para favorecer la repoblación. Se conserva un legado arquitectónico vinculado a los núcleos de población, como edificios militares, molinos, iglesias o conventos. En el bajo Guadalteba, el único testimonio lo encontramos en la iglesia de Peñarrubia (Campillos) hoy en día sumergida bajo las aguas del pantano del Guadalteba, o el molino del Tajo de la Venta (Teba) (Cantalejo Duarte, 2007).

Todo este elenco de yacimientos arqueológicos evidencia la importancia de la zona, debido a su gran riqueza y posición estratégica como zona de paso entre la zona de la costa y el interior. Ante esta situación, es probable que con el desarrollo de nuevos trabajos de prospección permitan ampliar la secuencia arqueológica, por lo que resulta evidente la necesidad de profundizar en el estudio del poblamiento prehistórico de este territorio del interior de la provincia de Málaga. 


\section{Metodología}

La metodología de este trabajo sigue el método hipotético-deductivo: buscamos obtener un modelo explicativo provisional, a partir de unas hipótesis, el cual será contrastado durante el desarrollo de nuestra investigación, para obtener un modelo definitivo.

La investigación conlleva una estrategia que contempla varias fases:

- Estudio del medio natural de la zona del bajo Guadalteba y bajo Turón, para profundizar en el conocimiento del territorio que habitaron los grupos humanos del Paleolítico, con objeto de poder establecer posteriormente una relación entre territorio y grupos humanos.

- Estudio del registro arqueológico conocido y obtención de nuevos registros mediante la realización de muestreos arqueológicos y geológicos y la prospección de superficie en la que aplicaremos nuestros planteamientos. En este sentido se realizará una revisión crítica de los argumentos, tanto a favor como en contra, esgrimidos por los diferentes autores sobre la validez de los datos de prospección en la interpretación arqueológica. Además, se definirán los métodos y técnicas que se seguirán en el estudio del registro arqueológico, que contarán con el apoyo de otras disciplinas, como la Geoarqueología, la Arqueometría, la Tafonomía o la Antropología.

- Estudio del material lítico, para lo que se establecerá igualmente un planteamiento teórico y metodológico a seguir, en el que se incluirán diferentes aspectos como el aprovisionamiento de materias primas líticas, su caracterización arqueométrica, la determinación de áreas fuente y las técnicas de explotación y configuración, y los procesos tafonómicos sufridos por el material arqueológico, entre otros. La utilización de las técnicas en Arqueometría, nos permitirán obtener datos empíricos que confirmarán o no la circulación y movilidad de las materias primas, vinculadas a los grupos que frecuentaron la zona del bajo Guadalteba y bajo Turón.

- Exposición, valoración, interpretación y discusión de los datos obtenidos, verificación de la hipótesis de trabajo o modificación de la misma para ajustarla a la realidad observada y obtención de un modelo explicativo que permita una mejor comprensión del poblamiento durante el Paleolítico en el territorio. 


\subsection{Planteamientos teóricos}

\subsubsection{El registro arqueológico de superficie: valoración crítica}

A nivel general, el registro arqueológico se puede entender como el conjunto de elementos materiales producto del trabajo humano o afectados por este, susceptibles de ser transformados por procesos naturales y humanos, que se hallan en el subsuelo, sobre la superficie e incluso parcial o completamente sumergidos bajo el agua (Arduengo García, 2007: 3-4).

Según L. Binford, "el registro arqueológico no se compone de símbolos, palabras o conceptos, sino de restos materiales y distribuciones de materia" (Binford, 1994: 23). Para este autor, el registro arqueológico reflejaba un sistema cultural y para entenderlo era necesario averiguar cómo llegaron a existir esos materiales, como se han modificado y como adquirieron las características que poseen según las ve el arqueólogo.

También se puede decir que "la evidencia material constituye la evidencia arqueológica formada en su gran mayoría, por restos materiales de distinto tipo. Dicha evidencia junto con los procesos de formación (tanto naturales como culturales) que actuaron sobre ella durante todo el tiempo que estuvo enterrada o abandonada constituyen el registro arqueológico" (Bellelli, 2001: 63).

Otros autores como R. C. Dunnell y W. S. Dancey, consideran que el registro arqueológico se define como una distribución más o menos continua de artefactos sobre la superficie de la tierra, con características de densidad muy variable "the regional archaeological record is defined '... as a more or less continuous distribution of artefacts over the land surface with highly variable density characteristics" (Dunnell et al., 1980: 272).

Tradicionalmente la arqueología se había servido del registro arqueológico procedente de la excavación arqueológica, valorando en menor medida las aportaciones de los estudios de superficie, atribuidos en su mayoría al trabajo de anticuarios y aficionados. La toma de datos, se centraba únicamente en el yacimiento, sin tener en cuenta el contexto en el que se insertaba. La visión que sobre el registro arqueológico se planteaba desde las posturas de la arqueología histórico-cultural en los siglos XIX y $\mathrm{XX}$, se basaba en la idea de que los objetos, desde una posición empirista, constituían o constituyen la expresión material de los pueblos del pasado, considerándolos como poseedores de información explicita. Con este tipo de concepción, desde claros enfoques nacionalistas, se limitaba la explicación del registro arqueológico, propiciando 
en ocasiones resultados poco favorables, dirigidos a obtener una superioridad cultural de unos grupos en detrimento de otros.

Frente a este tipo de visión de la arqueología tradicional, se postuló una nueva corriente de pensamiento, la Nueva Arqueología, de manos de L. Binford, la cual buscaba explicar el yacimiento desde perspectivas de cambio y continuidad, a diferencia del enfoque histórico-cultural que era difusionista y sobre todo buscar una explicación a los datos obtenidos y no acumularlos como meras estadísticas. Los estudios del proceso de formación del registro arqueológico surgen de manos de esta nueva corriente, basándose en el método hipotético-deductivo, prestando especial atención a aspectos tales como las relaciones entre los yacimientos o con el entorno medioambiental, no tomadas en cuenta en la arqueología histórico-cultural.

Desde esta perspectiva, lo interesante radica en la importancia que se le otorga al territorio en el entorno del yacimiento, por supuesto es importante el yacimiento en sí, pero si no se estudia el territorio o el medio en el que se inserta, la información que se extrae del estudio de su registro arqueológico se encuentra incompleta. Desde esta visión y teniendo en cuenta las numerosas críticas a las que se vio sometida esta nueva corriente, y su posterior decadencia en los años 80, es importante su aportación como una nueva visión de entender la arqueología y sobre todo el yacimiento y sus procesos de formación. A partir de entonces, empiezan a surgir nuevas corrientes de pensamiento para romper con las posturas de la arqueología tradicional, surgen los arqueólogos funcionalistas, procesualistas, los neo-marxistas, los postprocesualistas, y la arqueología social latinoamericana vinculada al materialismo histórico. Con la aparición de dichas corrientes se empezará a asistir a una nueva forma de concebir la arqueología y sus formas de estudio, entrando en continuos debates en un intento de defender sus hipótesis y teorías, sin embargo, a pesar de las diferentes opiniones surgidas, en cualquier estudio arqueológico, la importancia del registro arqueológico es fundamental.

Para estudiar el registro arqueológico se deben tener en cuenta los procesos de formación del mismo y, de igual modo, hay que distinguir la existencia de dos tipos de registro arqueológico; por un lado, el procedente de la excavación y por otro, el registro arqueológico de superficie.

En el caso del registro de superficie, presenta diferencias respecto al primero. $\mathrm{Si}$ bien, el registro arqueológico vinculado a una excavación aparece con una estratigrafía, donde los materiales son recogidos en posición primaria, en la mayoría de las ocasiones, 
existen unos datos imposibles de obtener a través del registro de superficie, como puede ser la estructura interna del yacimiento, el número y la profundidad de las diferentes ocupaciones, la complejidad del registro arqueológico, la funcionalidad o las características de los materiales, entre otros (Ruiz Zapatero, 1996: 10). No hay que obviar que el registro de superficie también supone una importante fuente de datos, el cual no es independiente de los depósitos arqueológicos y su estudio debe constituir el paso previo para el proceso de investigación. Así lo expone S. Roskams " $L a$ localización de yacimientos en el paisaje es un aspecto importante de la investigación arqueológica por su propio derecho, así como un requisito previo para empezar cualquier proyecto de excavación” (Roskams, 2001: 58). Conformaría así un registro peculiar que contiene una información legible y específica en su contexto.

El estudio del registro arqueológico de superficie lleva a tener en cuenta una serie de procesos de formación y transformación que condiciona al propio yacimiento, tales como los procesos deposicionales y postdeposicionales. Es más, los yacimientos con estratigrafía también pueden aparecer con alteraciones postdeposicionales, generando una alteración del registro arqueológico, al igual que puede ocurrir con el registro arqueológico de superficie. Como bien lo expone Butzer "muchos yacimientos comprendidos en el horizonte A (yacimientos sepultados) de un suelo deberían considerarse yacimientos de superficie, cuando han sido mezclados y enterrados en el suelo como resultado de la acción de las lombrices” (Butzer, 2007: 142). Y no sólo por estas causas sino que existen una gran variedad de factores, tales como la congelación del suelo, los movimientos masivos (debido a las pendientes o a la solifluxión), la erosión eólica, la deformación, o las acciones humanas, entre otros, que pueden afectar en mayor o menor medida a cualquier tipo de yacimiento, ya sea en superficie o asociado a una estratigrafía.

Aunque la mayoría de los autores consideran poco fiable dicho registro, no debería obviarse, dado que gran parte de los yacimientos de Paleolítico inferior y medio, están en superficie. No prestar la debida atención a esta circunstancia puede llevar a perder un número importante de los yacimientos vinculados a este periodo. Como dije con anterioridad, la proliferación de distintas corrientes de estudio, ha generado la existencia de defensores y detractores del registro arqueológico de superficie, por lo cual haré un breve repaso sobre algunos argumentos a favor y en contra de este tipo de estudios. 


\subsubsection{Argumentos en contra del registro de superficie}

El principal problema que se nos presenta en el estudio del registro arqueológico de superficie es su variabilidad, ya mencionada por L. Binford (Binford, 1994). Esta, viene generada por las diferentes transformaciones de dicho registro, originadas por los diferentes procesos postdeposicionales o las formas de actuar de una cultura en un entorno a lo largo del tiempo, antes de su abandono definitivo. Debemos ser conscientes de que la variabilidad del registro arqueológico no siempre es reflejo de una diferencia cultural, ya que un mismo grupo social puede producir restos materiales diferentes dependiendo de las actividades que desarrollen o del entorno en el que se encuentren, también puede ocurrir que se lleven a cabo diferentes estrategias de elaboración para realizar semejantes actividades (Bellelli, 2001: 64). Por tanto, es muy importante tratar de interpretar correctamente dicha variabilidad cultural, de ahí la necesidad de recurrir a la ayuda de otras ciencias en el intento de una correcta interpretación del registro arqueológico junto a la pericia del arqueólogo.

Este problema no es nuevo, pues ya suscitó en los años 60 del siglo pasado, sus primeros debates y polémicas de manos de L. Binford (Binford, 1994) al cuestionar la interpretación que se le había dado al Musteriense, definido y caracterizado por F. Bordes (Bordes, 1961), ya que para este último, los distintos instrumentos de piedra eran originados por diferentes grupos culturales, atribuyendo los conjuntos arqueológicos con diferentes rasgos técnicos a culturas diferentes. Sin embargo, para L. Binford cada yacimiento, el uso del espacio y la tecnología del Musteriense era una respuesta específica a unas circunstancias concretas, creía además que la tecnología empleada en la elaboración de utensilios era lo suficientemente flexible como para poder enfrentarse a las variaciones locales y que las mismas actividades podían desarrollarse en otros lugares con útiles diferentes (Orellana, 1995-1996: 22). Según este criterio, resulta de extrema importancia la necesidad de una metodología clara a la hora de estudiar el registro arqueológico.

Existe una gran desconfianza sobre las posibilidades que este tipo de estudios presenta a la hora de ofrecer información de calidad sobre los modos de vida de los primeros grupos humanos, lo que lleva a muchos paleolitistas a rechazar los datos del registro arqueológico de superficie, ya que los consideran de poca utilidad (Diez Martín, 1997: 10). Hay investigadores que se excluyen incluso de denominarlos como yacimientos "estos conjuntos de restos aislados, descontextualizados y desprovistos de 
relaciones mutuas, no aportan ningún valor significativo y no consideramos, consiguientemente, que deban calificarse como yacimientos", ya que al aparecer sin contexto estratigráfico presentan serias limitaciones que imposibilitan ofrecer una información rigurosa (Jiménez Manzanares et al., 1995: 97).

La mayoría de los autores consideran inferiores a los conjuntos de superficie respecto a los extraídos a través de la excavación, al carecer de una estratigrafía que explique el proceso sedimentario e histórico del yacimiento (Gutiérrez Soler et al., 2007: 783), del mismo modo, opinan que carecen de potencial analítico al escaparse del control cronológico (Diez Martín, 1997: 11), además de la imposibilidad de disponer de otros referentes tales como datos faunísticos o polínicos. Consideran algunos, que "el estudio del Paleolítico Inferior y Medio basado en la consideración de las terrazas fluviales como estratos arqueológicos, puede llevar a [...] errores de determinación cultural" (García Alfonso et al., 1995: 42). Otro de los aspectos negativos del registro arqueológico de superficie viene dado por la incapacidad de aportar datos concluyentes, más allá de los meros datos analíticos de la industria recuperada, "sirven básicamente para atestiguar la presencia humana en una zona determinada, sin que existan garantías de que permitan asegurar la homogeneidad, representatividad y sincronía de los elementos que conforman las serie líticas superficiales" (Martín Blanco et al., 1994: 36). Incluso presenta una escasez de contenido metodológico en el diseño de su investigación (Gándara Vázquez, 1981), incapaces de reflejar de manera adecuada la complejidad de los fenómenos arqueológicos (Querol Fernández, 1990), limitándose a series líticas con una carencia de otros vestigios, que permitan elaborar hipótesis acerca de las actividades económicas de los yacimientos ni las relaciones de subsistencia entre el medio y los grupos humanos, convirtiéndose en " yacimientos muy problemáticos, con un nivel de información mínimo y que cuentan con una única fuente de inferencias (la industria)" (Martín Blanco et al., 1994: 36). Otro factor negativo del registro de superficie es la pericia del prospector a la hora de establecer diferencias dentro del yacimiento detectado, puesto que están influidos por la subjetividad del mismo (Diez Martín, 1997: 11). M. Santonja, por su parte considera que los yacimientos al aire libre presentan un problema fundamental "es el de la homogeneidad de las series, sujetas a contaminaciones y mezclas de industrias que sólo hasta cierto punto pueden estimarse a través de tets objetivos...." (Santonja Gómez, 1992: 41). 
Otro de los problemas que se presentan en la interpretación de los yacimientos superficiales es según F. Burillo, su "actualismo, o la creencia de que la manifestación que presentan en superficie los restos arqueológicos son fiel reflejo de las características del yacimiento al que pertenecen, de forma que no existe alteración ni en su delimitación ni en la ubicación de sus materiales" (Burillo, 1997: 120), es por ello por lo que en el estudio de los registros de superficie deben de ser objetivo prioritario comprender no sólo el yacimiento, sino además qué cambios físicos se produjeron en él. No extraña, que los estudios de yacimientos en superficie estén relegados en la mayoría de los casos a un segundo plano, ya que es necesario contar no sólo con una metodología clara, sino con otros recursos procedentes de otras ciencias, como la Geoarqueología o la Arqueometría, que permitan comprender el yacimiento y las alteraciones sufridas, permitiendo establecer una interpretación o incluso una delimitación del mismo, que sea la correcta.

\subsubsection{Argumentos a favor}

Los estudios del registro de superficie cobraron importancia de manos de la arqueología espacial o procesual, para quienes los registros de superficie constituyen un referente en el estudio de las sociedades de cazadores-recolectores del Pleistoceno, considerando a la industria como la unidad básica de investigación, centrándose en los estudios del entorno del yacimiento, en este, y en la frecuencia de distribución de los sitios y los artefactos. Pero sobre todo, buscan establecer la obtención de datos sobre la movilidad, el abastecimiento de materias primas o el uso del territorio por los grupos de cazadores-recolectores: "Desde la perspectiva del registro arqueológico superficial tanto los grupos humanos como los artefactos, el carácter de movilidad o el medio ecológico son componentes que están continuamente interactuando, por lo que la relación entre las cualidades del territorio y los materiales culturales es ya de por sí una fuente de información válida” (Diez Martín, 1997: 24).

Aunque la mayoría de los yacimientos del Paleolítico se encuentran en cuevas, la proliferación de sitios al aire libre está aumentando, sin olvidar la posibilidad de que la mayor parte de las actividades que realizaban estos grupos humanos sería al aire libre, así el conocimiento de este tipo de yacimientos en su mayoría no asociados a una estratigrafía es fundamental para obtener una visión más aproximada de las actividades que llevaban a cabo estas sociedades del Pleistoceno. 
Es bien conocida la rotunda reticencia a los estudios del registro arqueológico de superficie. A pesar de esto, decir que en el caso de los yacimientos del Paleolítico sobre todo inferior y medio, resulta difícil encontrar yacimientos con una estratigrafía; un ejemplo lo encontramos en las terrazas del Guadalteba, aquí los numerosos restos arqueológicos están dispersos en su mayoría.

El estudio de este tipo de registro presenta "una capacidad para tratar con un gran número de yacimientos, que no hay que olvidar seguramente no serán excavados nunca; en segundo lugar, por sus posibilidades para realizar inferencias de los sitios y permitir el trabajo dentro de marcos regionales; y por último por ser el mejor instrumento para la protección del patrimonio arqueológico, mediante detallados inventarios...." (Ruiz Zapatero, 1996: 17).

Algunos autores como M. Santonja, apuntan que el estudio de los yacimientos al aire libre pueden aportar información "siempre que se parta de un análisis detenido del grado de representatividad de la muestra y de su pertinencia para obtener una información determinada" (Santonja Gómez, 1992: 41). Además, existen yacimientos donde los conjuntos conservados dentro de una estratigrafía presentan problemas similares a los yacimientos superficiales, ocasionados por los procesos postdeposicionales, tan intensos como pueden haber ocurrido en los superficiales (Butzer, 2007). Debido a que estos procesos afectan a la mayoría de los yacimientos, ya sean con estratigrafía o superficiales, no se deben despreciar los datos aportados por el registro arqueológico de superficie, sino que más bien se deben tener en cuenta en el proceso de investigación de cualquier yacimiento, sobre todo porque muchos de los yacimientos adscritos a momentos del Pleistoceno inferior y medio, se encuentran en superficie, de ahí la necesidad de una metodología clara y un trabajo interdisciplinar para conocer los procesos de alteración de un yacimiento, establecer las hipótesis y conclusiones necesarias y así entender la utilidad y función del yacimiento, sin llevar a cabo una excavación.

Existen yacimientos en superficie con unas características especiales que permiten compararlos e incluso tener la misma importancia que lugares con estratigrafía ya que "la comparación de nuestras estaciones con sitios estratificados [...] nos ha demostrado que las colecciones de superficie podian dar resultados muy parecidos al producto de una excavación y que las muestras así constituidas presentan, al menos en ciertos casos, un ejemplo fiel de la composición original de los complejos correspondientes” (Fernández Caro, 2007: 1995). Otros autores como R. C. Dunnell, 
expone muy acertadamente, la idea de que los yacimientos en posición estratigráfica fueron en su día yacimientos en superficie (Dunnell, 1992: 35), con lo cual ambos se vieron sometidos a unos procesos de transformación, quedando algunos enterrados y otros permaneciendo en la superficie. De esta manera y teniendo en cuenta los diferentes procesos, tanto deposicionales como postdeposicionales, cada yacimiento tendrá unas características propias independientemente de si se encuentra asociado a una estratigrafía o no, por lo que no se debe de menospreciar ninguna de las localizaciones arqueológicas en el proceso de investigación, y que en el caso de que no tenga la entidad suficiente como para considerarlas un yacimiento, no se obvien, sino que se incluyan, ya que pueden indicar lugares de actividad humana.

Lo importante del registro arqueológico de superficie es que se pueden obtener datos sin un coste económico elevado respecto a la excavación; para algunos autores, podría ser una técnica que podría llegar a desarrollarse independientemente de la excavación, proceso mucho más complejo a nivel logístico y económico (Renfrew et al., 2007) además, resulta indispensable para detectar a simple vista yacimientos en zonas donde existe un vacío de información arqueológica, resultando menos agresivo que la excavación arqueológica.

\subsubsection{Antecedentes sobre el estudio de registros arqueológicos de superficie a nivel mundial, nacional y autonómico}

Los antecedentes sobre el estudio del registro arqueológico de superficie hay que buscarlos en los estudios regionales llevados a cabo por G. Willey en 1953 en el valle del Virú (Perú), el primero en incorporar una fase de reconocimiento arqueológico a su proyecto de investigación y por W.T. Sanders en la Cuenca de México, ambos sobre el estudio de los patrones de asentamiento (Renfrew y Bahn, 2011: 77). Otros estudios regionales tempranos fueron los realizadas por L. Spier en la ruina de Zuni en 1916, concentrado sobre todo en la cronología, los estudios regionales de R. J. Braidwood en el llano de Antioquia en 1937, los de R. L. Beals, G. W. Brainerd y W. Smith, en el norte de Arizona en 1945 o el de P. Phillips, J. A. Ford, J. B. Griffin en el valle bajo del Missisippi en 1951 (Ammerman, 1981: 65).

A partir de los años 60 y 70 del siglo XX, las prospecciones arqueológicas de carácter científico tienen un amplio desarrollo en Inglaterra y norteamérica con la aparición de la Nueva Arqueología. 
En España el primer proyecto de prospección se realizó en 1972 por G.A. Clark al norte de Burgos, pero su publicación en una revista en inglés de la Universidad de Arizona hizo que no tuviese apenas relevancia en nuestro país (Ruiz Zapatero, 1996: 8).

No será hasta los primeros años de la década de los 80 del siglo XX, cuando las prospecciones de carácter científico inician su andadura de manos de la Arqueología Espacial (García Sánchez, 2012: 142), procedente de la Nueva Arqueología, y estimulados por la Primera Reunión de Metodología Prehistórica que se celebró en Soria y por los Coloquios de Arqueología Espacial organizados por el Seminario de Arqueología y Etnología Turolenses (Gutiérrez Soler et al., 2001).

Se asiste a un interés por los paisajes arqueológicos recurriendo a la prospección arqueológica de superficie dentro de la metodología de análisis espacial. Destacan a nivel nacional investigadores como A. Ruiz desde Jaén, F. Burillo desde Teruel, E. Cerrillo desde Extremadura, F. Criado desde Santiago y G. Ruiz Zapatero desde Madrid (Ruiz Zapatero, 1996:8).

A partir de ese momento, la Arqueología no se centra únicamente en el yacimiento sino en el espacio donde se encuentra, lo que permite medir la relación de estas sociedades con el medio ambiente, ya que la localización de artefactos arqueológicos por medio de la prospección, aunque no se consideren yacimientos, "representan una actividad humana significativa" (Renfrew y Bahn, 2011: 77), y la interpretación y descripción del ecosistema al que pertenecieron los distintos yacimientos hace cada vez "más evidente que la unidad básica de estudio arqueológico ya no es el yacimiento sino la región" (Morales Hervas, 2000: 357). Se pretendía la búsqueda de yacimientos que sirviesen de base para establecer patrones de asentamiento, influenciados por la obras de Clarke, Hodder y Orton como "Análisis Espacial en Arqueología” (García Sánchez, 2012: 142).

A nivel provincial y sobre todo local, las primeras prospecciones fueron realizadas desde principios de los 80 del siglo $\mathrm{XX}$, la mayor parte de estas se realizaron en el marco de actividades de urgencia, ligadas al desarrollo de los Planes Generales de Ordenación Urbana (PGOU), las Normas Subsidiarias de Planeamiento (NSP) o los Planes Especiales (PE). Las prospecciones llevadas a cabo deben entenderse como una nueva forma de comprender el medio ambiente donde se articulan estas sociedades, “con la intención de aprehender, desde una visión totalizadora del proceso histórico, los diferentes espacios donde el hombre, como miembro de una sociedad ejercita sus capacidades para arrancar a la naturaleza los bienes que representan sus condiciones 
de vida material, es decir, los espacios de asentamiento, captación, transformación e intercambio de productos" (Recio Ruiz, 1995-1996: 262)

Debemos citar algunas de ellas realizadas en la provincia de Málaga como las de A. Recio en 1987 y E. García en 1992 en Álora, por S. Pozo en Villanueva de Algaidas, A. Baldomero en 1993 en Colmenar, las de F. Medina y C. Barroso en la zona de Peñarrubia (Campillos) a finales de los ochenta y sobre todo las realizadas por $\mathrm{M}$. Espejo, P. Cantalejo y J. Ramos en Ardales entre los años 1987 y 1989, o en el Burgo y Casarabonela entre los años 1990 y 2004 (Recio Ruiz, 1995-1996: 262).

Desde los primeros estudios del registro arqueológico de superficie hasta los momentos actuales, se ha asistido a un profundo cambio donde los datos obtenidos por medio de las prospecciones han adquirido una mayor valoración, lo que permite un mayor conocimiento "sobre la organización del territorio, especialmente la ocupación y el poblamiento a lo largo del tiempo" (García Sánchez, 2012: 143) independientemente de su adscripción cronológica, siendo de mayor importancia las vinculadas con poblaciones del Pleistoceno por su mayor dificultad a la hora de interpretar el territorio donde se articulaban estos grupos humanos.

\subsubsection{Nuestro planteamiento}

En el desarrollo de la investigación arqueológica es importante clarificar los objetivos y la metodología a seguir. Uno de nuestros objetivos principales consiste en caracterizar los patrones de asentamiento a partir de las áreas de captación de materias primas primarias o secundarias, mediante su interpretación a través del estudio de los yacimientos y de los materiales adscritos a ellos, tanto de los recogidos en prospecciones anteriores a la elaboración de esta tesis como los localizados en las prospecciones y muestreos geoarqueológicos durante el desarrollo de este trabajo.

Cuando se hace referencia a los grupos humanos de cazadores-recolectores, sobre todo a las poblaciones del Pleistoceno inferior y medio, las dificultades a la hora de analizar el registro arqueológico impide en ocasiones la clasificación de estos lugares como yacimientos, en relación a los artefactos recogidos o visualizados en superficie. Sin embargo, su localización supone desde la Arqueología Espacial una fuente importante de conocimiento ampliando espacios que con anterioridad se pensaban vacios, estableciendo una relación entre estos grupos humanos y el territorio donde viven, por el que se mueven y de donde obtienen los recursos necesarios para su 
subsistencia, ahora lo importante no es el yacimiento en sí sino el espacio-territorio donde se ubica.

Desde el surgimiento de la Nueva Arqueología y sobre todo con la Arqueología del Paisaje, la prospección se convierte en una herramienta de gran utilidad donde la localización y el estudio de yacimientos o sitios arqueológicos nos permiten explicar o interpretar el comportamiento territorial de estos grupos humanos (Diez Martín, 2007).

A lo largo de este trabajo se hace referencia a términos tales como, paisaje, espacio, territorio, yacimiento arqueológico, patrones de asentamiento o fuentes de aprovisionamiento primario y secundario, que definiremos a lo largo de este capítulo.

La noción de paisaje tuvo su origen en el siglo XVII a través del arte y más concretamente la pintura, trasladándose después a la arquitectura y posteriormente a la jardinería inglesa, la idea de paisaje comienza a tomar fuerza con la institucionalización de la Geografía a principios del siglo XIX. Así la escuela francesa de geografía de Vidal Blache consideraba el paisaje como reflejo de un estilo particular de la organización espacial (Villafañez, 2011: 137). Sin embargo, aunque el concepto fue definido y utilizado inicialmente por las ciencias sociales y su marco intelectual proceda del debate entre el determinismo ambiental de F. Ratzel y E. Durkheim, la primera definición formal procede del trabajo de geografía de C. Sauer (1925), desde una corriente empirista, donde se restaba importancia a los aspectos subjetivos del paisaje y lo consideraba como un área objetiva que debía ser estudiada científicamente desde la observación (Anschuetz et al., 2001: 7-8).

Según F. Criado existen tres formas distintas de entender este concepto: "una empirista, en la que el paisaje aparece como una realidad ya dada y que por diferentes razones se niega a sí misma; una segunda sociológica que explica el paisaje como el medio y el producto de los procesos sociales, y una tercera culturalista que lo interpreta como la objetivación de las prácticas sociales tanto de carácter material como imaginario” (Criado Boado, 1995: 76).

Desde la Arqueología del Paisaje se entiende como "una construcción cultural que sintetiza relaciones sociales, económicas y ecológicas a través del tiempo" (Jordá Pardo et al., 2012: 216)

En virtud de lo anteriormente expuesto, el paisaje no es sinónimo de medio ambiente (Anschuetz et al., 2001: 4) y constituye "una impronta en el espacio" (Diez Martín, 2007: 3) donde quedan plasmadas las actividades humanas ya sean puntuales o continuas en relación con el medio natural en el que se realizan. 
Hemos visto como el concepto de paisaje se vincula al de espacio e incluso puede considerarse este último como un elemento del mismo. Serán los geógrafos anglosajones durante la primera mitad del siglo XX, cuando empiezan a desarrollar una noción de espacio que lo vincula a la dimensión espacio-temporal junto a otros aspectos como los psicológicos y los perceptuales (Gianotti García, 2004: 260).

La idea de espacio surge en el mundo occidental desde una visión capitalista de propiedad, entendido como un territorio de explotación y dominación constituyendo una condición infraestructural básica para el desarrollo de la revolución industrial y el capitalismo (Criado Boado, 1995: 79).

La perspectiva espacial en Arqueología se ha nutrido de la Ecología y la Biología que unido a la aspiración de la cientificidad y la crisis ecológica de los años 70 y 80 se han notado en todas aquellas aproximaciones que reafirman la noción de espacio como un territorio-ambiente explotado y al que las sociedades se adaptaron (Gianotti García, 2004 :260-261). Desde la Arqueología, constituye un elemento clave dentro del registro arqueológico (Diez Martín, 2007: 2), cuyo estudio permitirá comprender los distintos procesos de cambio desde un punto de vista cultural, tecnológico o adaptativo de los grupos humanos de la Prehistoria.

Del mismo modo que el espacio constituye un elemento del paisaje, el concepto de territorio está vinculado a ambos. Aunque abordaremos este concepto más ampliamente en el apartado 2.1.3.1, es preciso mencionar que será con la aparición de la Nueva Arqueología cuando se asiste a una nueva definición del mismo, entendiéndolo "como un conjunto de recursos que ha de estar en equilibrio con la comunidad" (Orejas, 1991: 202), para nosotros cuando hablamos de territorio hacemos referencia al espacio habitado y explotado por los grupos humanos donde el ser humano deja su huella en lo que denominamos yacimiento arqueológico.

Aunque numerosas son sus definiciones será con la Nueva Arqueología cuando adquiera una mayor relevancia y deje de ser exclusivo al área que se excava para prestar atención a la escala territorial del mismo. La evolución del concepto ha ido unido a "una definición cada vez más precisa de la complejidad de la entidad del registro arqueológico [..] y del desarrollo de una arqueología off site a la que no es ajena la creciente importancia de la Geoarqueología en los estudios sobre los paisajes antiguos" (Ruíz del Árbol, 2005: 21). 
M. A. Querol entiende por yacimiento arqueológico "el lugar en el que se encuentran, en cualquier posición, restos de actividad o de presencia humanas cuyo estudio con determinadas metodologías permite reconstrucciones de interés histórico y social” (Querol Fernández, 2010: 205).

Butzer lo define como "el registro tangible de un lugar de actividad humana en el pasado" los cuales varían en escala, y abarcan desde los sitios en los que realizan una única actividad hasta el asentamiento propiamente dicho (Butzer, 2007: 271).

En líneas generales y según G. Ruiz Zapatero todas las denominaciones coinciden en que se trata de "un lugar de concentración de materiales arqueológicos y restos de actividad humana" (Ruiz Zapatero et al., 1988: 48), donde los artefactos constituyen los elementos más visibles de un yacimiento ya sea en superficie o bajo ella y que la mejor manera de detectarlos es a través de la prospección arqueológica.

Sin embargo, existían lugares no considerados yacimientos a los que se les denominó como "nonsite" u "off-site", que suponían varios enfoques al paisaje y que aparecieron al considerar la distribución y alcance de los restos arqueológicos que no coincidían, ni espacial ni temporalmente, con los tipos de yacimientos reconocidos (Anschuetz et al., 2001: 5) y que nosotros denominaremos hallazgos aislados. Autores como F. Plog o H. E. Hill, opinan que una de las formas de diferenciarlos es según la densidad de artefactos que aparecen en un $\mathrm{m}^{2} \mathrm{o}$ por unidades de prospección como Astill o Davies (Ruíz Zapatero et al., 1988: 48). Para M. Schiffer los yacimientos o "site" son lugares de una alta densidad de artefactos mientras que los hallazgos aislados o "nonsite" son zonas de baja densidad de artefactos a los que prefiere denominar como "low density artefact scatters" or "sites of low obtrusiveness" (Shiffer et al., 1978: 2)

Vemos como en la mayoría de los casos la distinción se hace en función del número de fragmentos que aparecen, según M. Ruíz del Árbol esto puede inducir a error ya que estos materiales en superficie no son homogéneos y por tanto no puede considerarse un "criterio único" el número de artefactos para definir si se trata de un yacimiento o un hallazgo aislado (Ruíz del Árbol, 2005: 22). Sin embargo, y aunque el definir un yacimiento en función del número de artefactos puede ser engañoso, sobre todo si son superficiales, lo cierto es que en el desarrollo de cualquier trabajo de campo en investigación arqueológica y sobre todo tal y como se desarrollan hoy en día las prospecciones modernas es necesario ese criterio de densidad o cantidad de artefactos para distinguir entre yacimiento y hallazgo aislado. Aunque somos conscientes de que algunos autores consideren a los hallazgos aislados insuficientes para la investigación 
arqueológica, como dije anteriormente, son importantes puesto que "proporcionan información válida respecto a la explotación humana del entorno" (Renfrew y Bahn, 2011: 73), pudiendo en algunos casos establecer modelos de distribución dentro de un territorio, si sólo se estudiase un único yacimiento arqueológico en función de la concentración de los artefactos no se tendría una visión global de cómo actúan los grupos de cazadores-recolectores en un entorno, o dicho de otro modo tal y como lo exponen R. Dunnell and W. Dancey "excludes nearly all direct evidence of the actual articulation between people and their environment", es decir, excluiría casi toda la evidencia directa de la articulación real entre las personas y su entorno (Dunnell et al., 1983: 271-272).

En nuestro caso, consideramos el yacimiento como el lugar o sitio donde se observan una o varias actividades ya sea de una manera puntual o continua en un territorio, entendidas como lugares de talla, hábitat, cazaderos, etc., en función de los artefactos localizados.

Existen dos tipos de yacimientos, los localizados en cuevas y los que están al aire libre, ambos a su vez se subdividen en aquellos que se encuentran en superficie o con estratigrafía (Blanco Fernández, 2010: 114). En este proyecto de tesis se estudiarán datos de ambos tipos de yacimientos unos con estratigrafía y otros superficiales junto con aquellos hallazgos aislados, de este modo generar una visión global de la ocupación del territorio así como una interpretación de los posibles patrones de asentamiento y movilidad por los grupos de cazadores-recolectores del Pleistoceno de esta zona del interior de Málaga.

A principios del siglo $\mathrm{XX}$, los geógrafos y los arqueólogos británicos fueron los primeros en usar mapas de distribución y las primeras aproximaciones a los patrones de asentamiento "se inspiraron en los esfuerzos pioneros de Steward y Clark, en antropología ecológica, que considera las relaciones entre la estructura y la organización la subsistencia de un grupo cultural en el marco de su medio ambiente" (Anschuetz et al., 2001: 11-12).

Sin embargo, el concepto fue introducido por primera vez a mediados del siglo pasado en la disciplina antropológica, posteriormente su definición desde el ámbito de la arqueología ha suscitado un intenso debate, originado por la utilización del término desde diferentes corrientes de pensamiento, como la Nueva Arqueología, el Evolucionismo cultural o el Postprocesualismo, por constituirse en la "base primordial 
de cualquier investigación integral que intente abordar desde una perspectiva arqueológica procesos sociales de cualquier tipo en su dinámica histórica” (Salazar, 2008: 247). Aunque se menciona a G. Kossinna como el primero en utilizar el término (Prieto Rodríguez, 2011: 117), la comunidad científica está de acuerdo en reconocer que los trabajos de G. Willey en el valle del Virú en Perú (1953), constituyen el prototipo de estudio de los patrones de asentamiento (Renfrew y Bahn, 2011: 77). Después del trabajo de G. Willey las bases intelectuales del estudio de los patrones de asentamiento fueron evolucionando en paralelo al avance de la Nueva Arqueología, hubo un cambio de mentalidad dejando atrás las meras descripciones de cómo se "distribuían los yacimientos y de las jerarquías orgánicas para evaluar y estudiar los patrones arqueológicos subyacientes, observados en tiempo y espacio de forma multivariada y dinámica" (Anschuetz et al., 2001: 13).

La aplicación de este tipo de estudio en el campo de la Arqueología supuso un gran cambio en la investigación donde se empezó a "analizar sistemáticamente el espacio y a leer en su estructuración aspectos económicos y sociales" (Salazar, 2008: 246).

Dentro de la Arqueología del Paisaje el espacio se convierte en el agente principal para el estudio de los patrones de asentamiento, esta disciplina considera que en el estudio del espacio, pueden "leerse la totalidad de variables sociales, sin reducirlas a determinismos que reproducen la dicotomía entre naturaleza y cultura, propia de la modernidad, que fue aplicada a los estudios de sistemas de asentamiento a partir de la década de 1960” (Salazar, 2008: 249).

En este sentido autores como K. Butzer propone un modelo de escalas sobre los asentamientos y sus redes para los grupos paleolíticos en una región y establecer la relación entre los asentamientos y el medio ambiente (Ordoño, 2008: 87) utilizando la terminología de escala interna de Clarke (Butzer, 2007: 272-273) y distinguiendo entre:

- Microescala: Patrones de actividad intrayacimiento, entendidos como los contextos individuales dentro de un asentamiento.

- Semimicroescala: Agregación del yacimiento y su función dependiendo de si su actividad es una sola o son varias.

Dentro de los yacimientos con una actividad limitada nos encontramos con:

- Talleres, son sitios localizados en zonas con existencia de fuentes de material lítico, lechos fluviales o afloramientos en posición primaria y especializados en el 
trabajo preliminar de piedra que se caracterizan por la existencia de lascas y esquirlas del proceso de talla.

- Cazaderos o zonas de descuartizamiento, localizados en zonas donde hay accidentes topográficos. Son zonas donde se lleva a cabo una manipulación preliminar de los cadáveres, donde suelen aparecer restos de animales incompletos y en dispersión, la industria lítica asociada a este tipo de yacimientos son principalmente de filo cortante con algunos proyectiles.

Los de actividades múltiples corresponderían con los campamentos de corta duración, cercanos a recursos bióticos y abióticos o al abrigo que habitan. Pueden contener restos de fauna de pequeño tamaño, con presencia y diversidad de artefactos líticos, junto con hogares o algún tipo de estructura. Los de larga duración son asentamientos más complejos con una diversificación de actividades que se reflejan en la concentración de útiles especializados, se ubican por regla general cerca de un curso fluvial y de los recursos alimenticios, les sirven de refugio para protegerse del tiempo y otros depredadores y puede ser al aire libre o en cuevas. Con presencia abundante de restos de fauna y un utillaje lítico variado donde abundan los útiles cortantes y raspadores. En ocasiones estos campamentos puede ser reocupados debido a su situación estratégica bien por su cercanía a zonas de abastecimiento de agua o a zonas de caza y marisqueo.

- Macroescala: Patrones entre yacimientos, donde encontramos varios lugares de actividad limitada y múltiple, de duración variable, enmarcados en un área funcional con diferentes características bióticas. La disponibilidad de recursos tanto bióticos como abióticos dentro de esta área funcional y el desplazamiento de estos grupos en función de los mismos generarán unos patrones de movilidad que serán distintos dependiendo de los recursos que pueden ser aprovechados.

En relación a estos recursos hay que diferenciar si se trata de fuentes de aprovisionamientos primario, entendidas como aquellos lugares donde las rocas aparecen en su lugar de origen y que no ha sufrido ningún proceso de transporte geológico (Carrión Méndez et al., 2004: 2) y fuentes de aprovisionamiento secundario, aquellos lugares donde los materiales han sufrido un proceso de sedimentación después de que han sido transportadas y erosionados por procesos naturales como el transporte de los ríos, arroyos, o las acciones glaciares, desde su lugar de origen primario. Entendemos el aprovechamiento secundario como un proceso de 
recolección de rocas o cantos de litologías variadas de diferentes formas y tamaños, muchos de ellos localizados en los depósitos fluviales. Estos recursos tienen una amplia distribución territorial y la identificación del área fuente dependerá en gran medida del nivel de contextualización del ámbito geológico del que procede (Mangado Llach, 2002).

Los materiales localizados en depósitos de tipo secundarios superficiales aparecen "junto a abundantes bloques de materia prima en bruto (sílex) procedentes del desmantelamiento de los niveles silíceos de los relieves estructurales" (Conde Ruíz et al., 2002: 151) o del propio desmantelamiento de terrazas fluviales a las que están asociados, junto a la materia prima como el sílex son abundantes las areniscas compactas, las cuarcitas o las calizas.

Los materiales arqueológicos asociados a estas fuentes de depósitos secundarios presentan en la mayoría de los casos alteraciones ocasionadas por las alteraciones postdeposicionales del depósito, como un alto rodamiento. Los depósitos secundarios asociados a terrazas han sido infravalorados en las investigaciones tradicionales, ya que al ser depósitos superficiales y por tanto alterados no eran muy fiables, sin embargo si establecemos una conexión geológica y comparamos el material geológico y arqueológico se puede obtener una información muy valiosa, y presentan ciertas ventajas si los comparamos con los depósitos primarios, estas ventajas son mencionadas por J. Mangado, con quien coincidimos al afirmar que las rocas que aparecen en posición secundaria han sufrido un desgaste por lo que no presentan fisuras y por tanto se pueden obtener herramientas resistentes, el material es muy visible y permite una selección de la roca idónea, los procesos de transporte generan una variedad litológica, donde la extracción es más fácil, por lo que influye en un menor tiempo de trabajo y en un acceso más directo a la materia prima (Mangado Llach, 2002: 10).

El estudio de las fuentes de tipo primario y secundario nos permitirá establecer unas estrategias de explotación de dichos recursos por parte de los grupos humanos del Pleistoceno y las diferencias que puedan existir entre las estrategias de los grupos del Paleolítico inferior, medio y superior y determinar que el aprovisionamiento de materias primas tanto en depósitos primarios como secundarios es principalmente local con una utilización intensiva de las terrazas fluviales desde momentos del Paleolítico inferior hasta la Prehistoria reciente. 


\subsubsection{La recuperación del registro arqueológico: la prospección}

Siguiendo a Ruiz Zapatero, la prospección de superficie se define como "el camino más importante para descubrir yacimientos y acercarse a la arqueología del paisaje como estudio del conjunto de rasgos del mundo real que dan carácter y diversidad a la superficie terrestre sobre la que viven las comunidades humanas" (Ruiz Zapatero et al., 1988: 46).

Se establece como la "aplicación de un conjunto de técnicas para optimar las probabilidades de descubrimiento de los materiales culturales que caracterizan el registro arqueológico en el ámbito de un espacio geográfico conceptualmente definido" (Gallardo et al., 1986: 410), considerándose "una estrategia metodológica, en general de carácter no destructivo que permite obtener datos a diferentes escalas, en el orden de estimar, evaluar e interpretar el registro arqueológico” (Gianotti García, 2004: 262).

Desde los inicios de la investigación arqueológica, en el siglo XIX, la prospección se consideraba una actividad secundaria dentro de la arqueología, subordinada de la excavación, realizada en la mayoría de las ocasiones por aficionados que desde sus centros locales inventariaban los yacimientos en la forma de las antiguas cartas arqueológicas (Ruiz Zapatero, 1996: 7). Con anterioridad a finales de los años 70, del siglo $\mathrm{XX}$, el interés principal era el estudio y excavación de los yacimientos conocidos. Los trabajos de prospección eran poco frecuentes, limitándose a la localización de yacimientos con cierta entidad y con posibilidad de ser excavados, por entonces, primaban los resultados obtenidos en las diferentes excavaciones sin establecer conexiones entre zonas próximas y no excavadas.

El limitarnos exclusivamente a las secuencias excavadas, impide obtener datos suficientemente representativos y establecer conclusiones válidas, ya que la información obtenida por muy completa que sea, nunca podrá integrase en el contexto del comportamiento regional, puesto que si se menosprecia esta dimensión regional del registro arqueológico, se arriesga "a ofrecer explicaciones limitadas sobre el comportamiento territorial de los primeros humanos” (Diez Martín, 2007: 10).

La intención de desarrollar un marco teórico y específico de la prospección supuso una ruptura con la Arqueología tradicional y se inició en los años 60 con la aparición de la Nueva Arqueología, de manos de varios arqueólogos anglosajones, L. Binford, D. L.Clarke o C. Renfrew. Esta nueva corriente concebía la cultura como 
sistemas distintos de adaptación al medio, todos los cambios culturales y la evolución técnica se producían para hacer frente al desequilibrio entre un aumento de población y unos recursos limitados, donde el territorio y el paisaje se convierten en una nueva fuente de datos que permiten extraer información independientemente de la excavación.

A partir de ese momento comienza un importante desarrollo en la tradición norteamericana y británica, donde la prospección se convierte en objeto de debate, el cual servirá para establecer sus bases e introducirla dentro del cuerpo metodológico de la disciplina arqueológica (García San Juan, 2004; 2), con posterioridad se expande a otros países como Escandinavia, Francia y España (Ruiz Zapatero et al., 1988: 47). Este impulso fue debido principalmente a una serie de circunstancias referentes al estudio de aspectos que no se tuvieron en cuenta con anterioridad, tales como, el estudio focalizado hacia los yacimientos y los contextos ambientales y territoriales en lugar de centralizarlos en los materiales y las piezas excepcionales; el replanteo de los métodos tradicionales, que suponían la destrucción de los yacimientos, los cuales impulsaban la búsqueda de métodos no destructivos; o "el desarrollo de la arqueología de gestión, cuyas necesidades impulsaron la búsqueda y el perfeccionamiento de metodologías de trabajo más ágiles y económicas" (San Miguel Mate, 1992: 36) y que explican este interés por la prospección.

En España habrá que esperar a principios de los 80 del siglo XX para que la prospección comience su andadura de manos de la Arqueología Espacial, incluida dentro de la Nueva Arqueología, a partir de este momento adquiere una mayor importancia gracias a nuevos investigadores que se replantean nuevas propuestas teóricas, interesándose por la lectura espacial del paisaje, en contraposición con la arqueología tradicional, entre los que se encuentran A. Ruiz, F. Burillo, F. Criado o G. Ruiz Zapatero entre otros. Para este último, el desarrollo de la prospección debe "entenderse como un resultado positivo más, del proceso de renovación teórica y metodológica de la arqueología española de los años 80” (Ruiz Zapatero, 1996: 9).

Los primeros trabajos de prospección buscaban como objetivo principal "el reconocimiento sistemático de regiones, incluyendo en la planificación criterios históricos, culturales y arqueológicos más allá de los anacrónicos límites administrativos, en busca de yacimientos que sirviesen de base para el estudio de los patrones de poblamiento, todo ello influido por las obras de Clarke, Hodder y Orton" (García Sánchez, 2012: 142). 
En la actualidad, la prospección arqueológica está formando parte, cada vez de forma más amplia, del mundo de las actividades arqueológicas, debido a los reglamentos arqueológicos oficiales. Sin embargo, se considera un mero trámite para la localización en superficie de yacimientos. "Los proyectos pretendían en su formulación extraer información de los datos arqueológicos en superficie [..] la realidad de las actividades realizadas, $y$ de las publicaciones presentadas, revelan una creciente despreocupación por este tipo de actividades y las posibilidades que ofrecen para el conocimiento del pasado[... " (Cámara Serrano, 2011: 191).

La aparición de nuevas técnicas y de nuevas metodologías como la prospección geofísica o la fotografía aérea, entre otros, ha supuesto un impulso para la prospección de superficie. Constituye una importante herramienta de localización de yacimientos y debe utilizarse en los estudios arqueológicos como fase previa a cualquier intervención arqueológica, a pesar de su dificultad para explicar con seguridad el yacimiento originada por procesos postdeposicionales o incluso contemporáneos a la utilización del mismo. Resulta imprescindible para localizar yacimientos al aire libre, en los que los restos culturales afloran a la superficie debido a la erosión de la matriz de sedimentos que envolvían el material o al afloramiento de materiales sepultados como consecuencia de las perturbaciones ulteriores (Butzer, 2007).

Con el surgimiento de la Nueva Arqueología, y las nuevas líneas de investigación como la Arqueología Espacial o la Arqueología del Paisaje, la prospección ocupa un lugar predominante en los estudios territoriales del Paleolítico.

Así pues, los resultados de la prospección de superficie proporcionan información detallada con la que definir las zonas más propicias para la investigación arqueológica, obteniendo un conocimiento previo de la configuración de los depósitos localizados bajo el terreno (Roskams, 2001: 64), y estudiar las interacciones entre un grupo y un paisaje. 


\subsubsection{Fundamentos teóricos y métodos de prospección}

El inicio de cualquier prospección arqueológica debe llevar aparejada una planificación. Son importantes las características del territorio sobre el que se va a realizar el estudio, así como un estudio documental de dicho espacio que abarque varios aspectos tales como, la Historia o la Arqueología entre otros. Todo ello dentro de un marco teórico y metodológico que defina los objetivos y las fases de trabajo a seguir, para garantizar la rigurosidad del mismo.

Se parte de la idea de que no existe un modelo de prospección y de que cada estrategia dependerá de las características de la zona y de los intereses del investigador (Chapa Brunet et al., 2003).

Antes del inicio de cualquier prospección se deben valorar ciertos aspectos que limitan el trabajo del prospector, definidos por M. B. Schiffer (Schiffer et al., 1978) y que afectan al desarrollo de la actividad. El resultado final, puede estar condicionado por factores externos al investigador, de ahí la necesidad de un amplio muestreo del área en estudio. Estos aspectos son:

- Obstrusividad o perceptibilidad, se relaciona con la naturaleza de los restos arqueológicos y su "sensibilidad" para ser descubiertos por una técnica específica (Gallardo et al., 1986: 410) como puede ser la prospección terrestre, prospección aérea, etc.,.

- Visibilidad, o variabilidad del medio físico de cara a la localización de yacimientos arqueológicos (Ruiz Zapatero et al., 1988: 51).

- Accesibilidad del terreno, cada territorio o área de estudio presenta unas características físicas que influyen en el resultado del trabajo. Para Schiffer existen cinco factores que inciden negativamente para la accesibilidad del terreno "climate, the biotic environment, terrain, extent of roads and landholding patterns" (Schiffer et al., 1978: 9).

Además de estos factores, existen otros que afectan a nuestro trabajo, como pueden ser las labores agrícolas, las construcciones modernas, o la propia naturaleza, que condiciona el registro arqueológico (Gómez Tarazaga, 2006: 249).

La elección del área a estudiar, constituye uno de los primeros pasos en el desarrollo de nuestro trabajo, "ya que condiciona de una forma directa el tipo de investigación de superficie y permite descubrir el grado de investigación con el que se puede prospectar a diferentes escalas y porque es interesante discutir qué escala resulta adecuada para los diferentes objetivos de distintos programas de investigación" 
(Ruiz Zapatero, 1996: 11), estableciendo los límites de la misma ya sean arbitrarios, culturales o naturales.

Los límites arbitrarios estarán condicionados por las superficies sobre las que se desarrollará la actividad. Se trata de divisiones administrativas, como pueden ser los términos municipales, culturales, donde la delimitación presenta una fuerte entidad cultural y, por último, los naturales, basados en la elección de un área por unidades geográficas, siendo los resultados más coherentes (Ruiz Zapatero, 1983).

Una vez clarificada el área de estudio procedemos al trabajo de gabinete, examinando toda la información previa obtenida a través de cartografía, estudios geológicos y edafológicos, fotografía aérea, ortofotografía, fuentes escritas y orales o la toponimia, para con posterioridad desarrollar el trabajo de campo. Obtenida toda la información previa, se hace necesario elegir el método de prospección a elegir, ya sea una prospección extensiva, basada en los trabajos desarrollados sobre una zona o región común, la cual ofrece resultados muy rápidos y con poco esfuerzo, pero con el inconveniente de que dichos resultados son muy generales y ofrecen una visión sesgada del patrón de asentamiento (Cerrato Casado, 2011: 13), o una prospección intensiva, centrada en una microrregión a pequeña escala, cuyos resultados son de una mayor calidad que las extensivas.

El siguiente paso consiste en establecer el tamaño del área a prospectar dependiendo de tres niveles (grande, mediano y pequeño), todo ello determinado por la flexibilidad del terreno, entendiendo como tal el clima, la topografía, la vegetación, las vías de comunicación, y los recursos humanos utilizados en las tareas de prospección.

En general, la prospección extensiva se emplea en áreas de tamaño grande (entre 2000 y $\left.300 \mathrm{~km}^{2}\right)$, utilizándose para áreas de tamaño pequeñas $\left(\leq \mathrm{a} 50 \mathrm{~km}^{2}\right)$ la intensiva. En cuanto a las áreas de tamaño mediano hay que optar por técnicas de muestreo dirigido cuando se trate de un solo prospector y de muestreo probabilístico cuando se trate de equipos (Ruiz Zapatero, 1996: 11).

Con posterioridad, describir los tipos de prospección a desarrollar (dentro de intensivas) ya sea de cobertura total o de muestreo. La de cobertura total, abarca el total del área a estudiar, por regla general, se utiliza para zonas con una extensión pequeña, por el contrario en la prospección de muestreo se debe delimitar el terreno y establecer las áreas más importantes. Este está dividido en otros dos sistemas, el dirigido, aquél 
que se dirige a uno o varios puntos concretos, o probabilístico que emplea varias técnicas tales como:

- La fracción de muestreo, se trata del porcentaje que se prospecta en relación al total del área elegida (Ruiz Zapatero, 1983), que debe ser lo suficientemente amplia para dar datos de interés.

- La unidad de muestreo, es decir, el tamaño y la forma de la fracción de muestreo, con dos tipos: las cuadrículas, que deben adoptar un módulo pequeño desde 0,1 a $1 \mathrm{~km}$ (Ruiz Zapatero, 1983), se utilizan para cubrir de una forma homogénea áreas mayores (Gianotti García, 2004: 264), y los transectos, de tamaño pequeño con de $1 \times 5-6 \mathrm{~km}$ (Ruiz Zapatero, 1983), esta cubre grandes extensiones, siendo fácil de delimitar y cubrir en el campo, "la ventaja es que por su extensión permite cubrir ambientes diferentes, de esta manera la estimación relacionada con la variabilidad del registro arqueológico y los parámetros arqueológicos y generales de una región será más acertada” (Gianotti García, 2004: 264).

- Técnicas de muestreo: (figura 2)

A. Muestreo aleatorio. Se trata de un sistema de elección de la muestra al azar.

B. Muestreo estratificado. En él las muestras se establecen por niveles según la probabilidad de hallazgo.

C. Muestreo sistemático. Las cuadriculas o transectos se dispersan de manera regular, según un intervalo fijo.

D. Muestreo sistemático estratificado no alineado. Se divide la zona en cuadriculas, a continuación se toman muestras aleatorias dentro de cada una de estas cuadriculas.

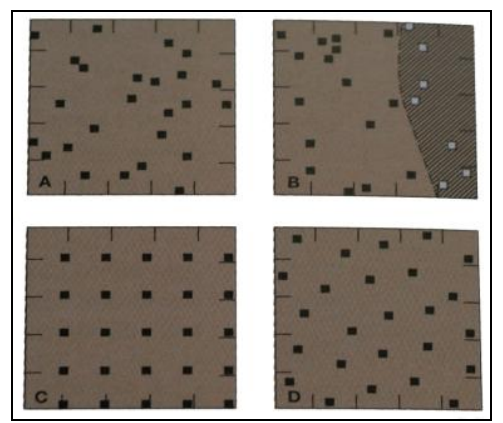

Figura 2. Tipo de muestreo: A: Muestreo aleatorio, B: Muestreo estratificado, C: Muestreo sistemático, D: Muestreo sistemático estratificado no alineado (Renfrew y Bahn, 2011: 80). 
Así el muestreo dirigido o no- probabilístico puede ser efectivo cuando se decide intencionadamente prospectar un determinado medio como por ejemplo las terrazas fluviales de un valle (Ruiz Zapatero et al., 1988: 48), como ocurre en nuestro caso.

Por último, pero no menos importante, hay que tener en cuenta la intensidad, es decir, "la cantidad de esfuerzo dedicado a la inspección del área de estudio o el grado de detalle con el que se analiza la superficie del área prospectada” (Schiffer et al., 1978: 13) así como la visibilidad y la perceptibilidad de los yacimientos.

\subsubsection{Estrategia de prospección en nuestro caso}

Ante la falta de excavaciones en la zona, la principal tarea era revisar los yacimientos ya conocidos, para ver la variabilidad o posibles alteraciones sufridas, así como prospectar nuevas zonas con hallazgos aislados que permitan, por medio de la prospección, localizar nuevos yacimientos. Parte fundamental del desarrollo de este trabajo era realizar prospecciones en zonas con terrazas colgadas, de las que se tienen constancia, y que están muy próximas a algunos yacimientos, como el caso de la Sima las Palomas (Teba) o de la Cueva de Ardales, a través de mapas geomorfológicos y litológicos. Todo ello, con la recogida de material para efectuar los pertinentes estudios y su comparación con los materiales de otras zonas limítrofes a nuestra área de estudio.

De este modo podríamos establecer la movilidad de este material lítico dentro de los diferentes yacimientos en el área del Guadalteba y Turón, en relación a sus áreas de captación, así como las características del material lítico que pueden diferenciar varios yacimientos.

La estrategia de prospección debe acondicionarse a las diferentes variables que presenta cada área de estudio, sin embargo, cuando se trata de establecer patrones de asentamiento de un territorio determinado, parece más conveniente la aplicación de sistemas de cobertura total (San Miguel Mate, 1992: 39), ya que es capaz de presentar datos globales sobre dichos patrones en un análisis macro-espacial, a su evolución demográfica y permitiendo que no se descarte ninguna información por muy pequeña que sea. En nuestro caso se llevó a cabo una prospección selectiva en aquellas áreas con yacimientos documentados y estudiados y una prospección intensiva en las zonas no prospectadas con anterioridad. 
La metodología a seguir ante una prospección como la que abordamos en el presente trabajo se inicia con un proceso de documentación previo al trabajo sobre el terreno propiamente dicho (fase pedestre). Para ello establecemos 3 pasos:

\section{Trabajo de gabinete:}

Recopilación de toda la información necesaria para el desarrollo de la prospección tales como la consulta de las cartografías de la zona a prospectar (topográficas, geológicas y geomorfológicas) y de la bibliografía existentes. Es un paso indispensable para la ejecución del estudio, que nos permita alcanzar un conocimiento previo de la zona y una planificación correcta. Además, el resultado más inmediato de cualquier intervención arqueológica de reconocimiento realizado sobre el territorio, es un mapa donde aparecerá reflejada de forma gráfica la distribución de los yacimientos o hallazgos en el espacio prospectado.

\section{Trabajo de campo}

Una cuestión básica en el desarrollo de la prospección sobre el terreno es la de la estrategia de cobertura y la batida o intensidad. Aunque existen una gran cantidad de alternativas en cuanto a la estrategia de cobertura, en mi caso, llevaré a cabo una prospección arqueológica superficial con recogida de materiales, desarrollando una prospección selectiva en los yacimientos descritos en los planeamientos urbanísticos, con el fin de constatar la adscripción cronológica de los enclaves prehistóricos. Así mismo, las zonas no prospectadas serán objetivo de una prospección intensiva, centrándonos en los entornos fluviales y en los hitos geográficos susceptibles de ocupación durante la Prehistoria en función de las estrategias de distribución territorial de las sociedades cazadoras-recolectoras.

En cuanto a la intensidad de prospección o batida, o intervalo que debe separar a los prospectores en el proceso de batida del territorio y en función de las características marcadas por el propio paisaje, se establece una distancia visual de $5 \mathrm{~m}$. Independientemente de la metodología que se siga, las estrategias de cobertura y batida del terreno, son en parte dependientes de una serie de parámetros relativos a las condiciones de perceptibilidad del registro arqueológico. Estas condiciones son de dos clases: por un lado las condiciones inherentes al propio registro arqueológico, y por otra parte las condiciones físicas imperantes a nivel de superficie.

En el caso de localizar un yacimiento arqueológico, se hará un rastreo exhaustivo del área, delimitando el yacimiento a través de coordenadas U.T.M, 
enumerándolo y situándolo posteriormente sobre un mapa, con recogida del material más representativo, conservándolo en bolsas con las pertinentes etiquetas para su clasificación, y con toma de fotografías del yacimiento y materiales. Los yacimientos localizados serán georreferenciados utilizando el GPS. Contaremos para nuestra prospección con una estación total de base y un GPS móvil para obtener una mejor precisión. En función de la legislación vigente, la información espacial tendrá como sistema de referencia espacial el ETRS89, y concretamente en nuestra zona de estudio por estar inserta en la provincia de Málaga utilizaremos el EPSG 25830.

\section{Trabajo de laboratorio}

Como última etapa de nuestro trabajo, realizaremos el análisis y estudios del material, para establecer una valoración e interpretación arqueológica, que exponga de forma objetiva los conocimientos obtenidos a lo largo del trabajo de prospección, y así dar a conocer los resultados para el conocimiento de las sociedades cazadorasrecolectoras de la zona del río Guadalteba y río Turón. Los análisis que he llevado a cabo con el material lítico incluyen no sólo el material recogido durante las tareas de muestreo y prospección, sino además el material almacenado en el Consorcio Guadalteba y en los diferentes centros de Interpretación donde se conservan los materiales arqueológicos.

Los medios utilizados para realizar este trabajo son todos de carácter individual, el equipo de trabajo para las prospecciones constaba de 4 personas. Los trabajos de prospección se iniciaron al final del verano, coincidiendo con el inicio de las campañas de excavación arqueológicas contempladas en el marco del P.G.I, por tanto, los resultados aquí expuestos sobre nuevas localizaciones o yacimientos arqueológicos son preliminares. Los instrumentos utilizados han sido un GPS para tomar las coordenadas de las localizaciones o hallazgos y las ortofotos y cartografías a escala 1:10000 y 1:40000 de la Junta de Andalucía. 


\subsubsection{Método de excavación}

Los datos aportados en este apartado constituyen una aproximación a los trabajos desarrollados dentro de las intervenciones arqueológicas puntuales realizadas en la Sima de Las Palomas (Teba) y la Cueva de Ardales, los cuales han consistido principalmente en la limpieza de un perfil ya existente, en el caso de la sima y varios sondeos en la Cueva de Ardales realizados entre los años 2011-2014 y que han culminado con dos publicaciones donde se exponen los resultados de ambas intervenciones (Ramos Muñoz et al., 2014 y Weniger et al., 2014).

En la Sima de Las Palomas, la actuación arqueológica realizada fue la regularización de un perfil arqueológico de unos 7 metros de profundidad, que había sufrido una alteración postdeposicional de carácter antrópico para extracción de sedimento arcilloso (figura 3). Se llevó a cabo un control microespacial de todos los restos arqueológicos localizados en el perfil tales como restos líticos, faunísticos, de malacofauna y carbones algunos de ellos con una alta concentración lo que hace pensar en posibles hogares.

Se han realizado diversas ortofotos con la estación total con la situación de todos los productos, posicionándose así todos los objetos controlando los niveles arqueológicos dentro del perfil, un total de 10, estableciendo las diferentes fase de ocupación y ratificando varias ocupaciones por grupos humanos del Paleolítico medio (Weniger et al., 2014: 36).

Junto a esta actuación se realizaron investigaciones geofísicas y perforaciones en el entorno de la misma, así como análisis sedimentológicos y geoquímicos, estudios polínicos, de traceología, paleontológicos o antropológicos de varios restos óseos como los realizados sobre un fragmento de mandíbula infantil de Homo sapiens de unos 3-4 años. 


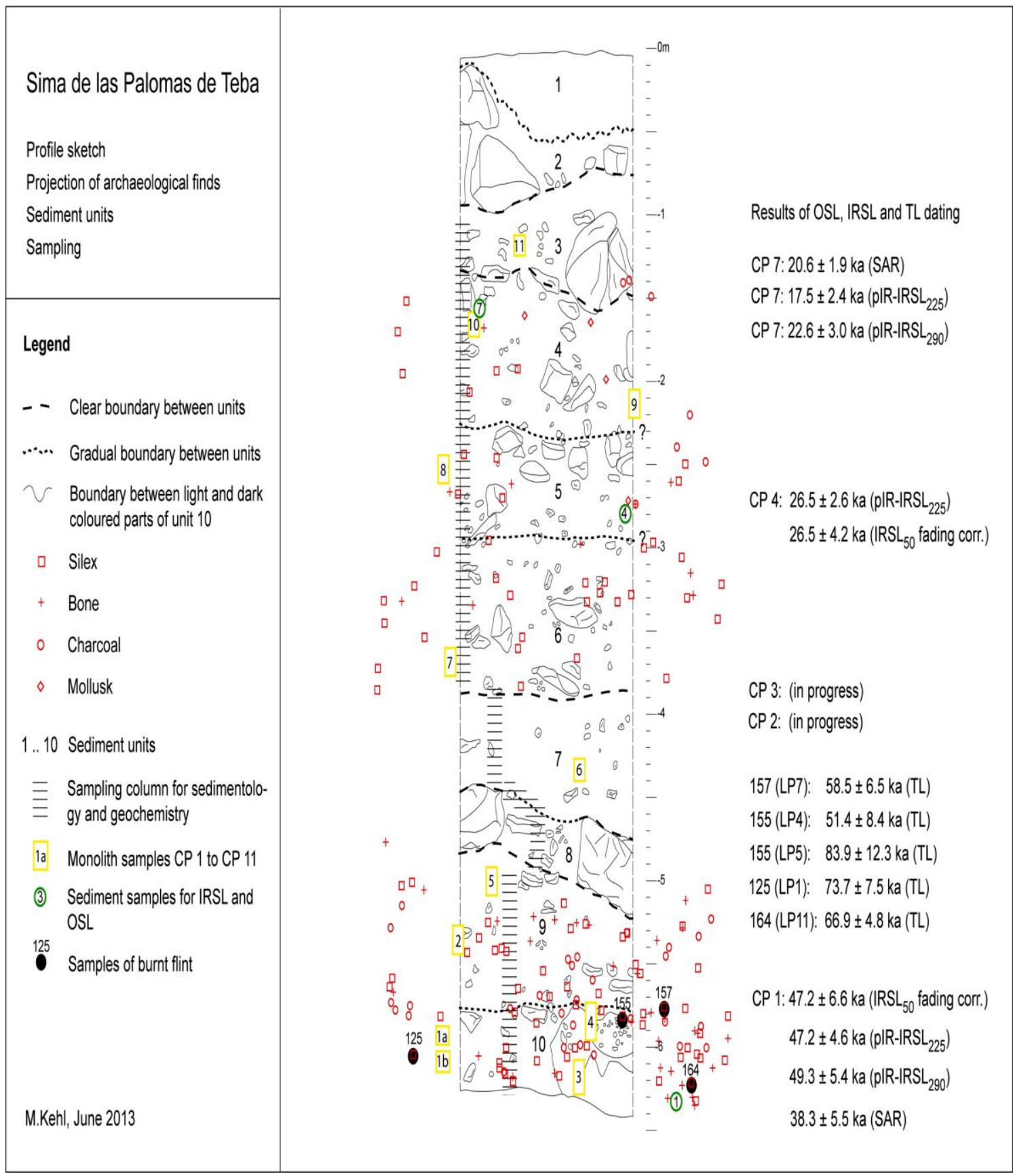

Figura 3. Perfil de la Sima de Las Palomas de Teba con las unidades sedimentarias, las ubicaciones de las muestras y los resultados de las dataciones estimadas por luminiscencia

(Kehl, 2014: 46).

En el caso de la Cueva de Ardales el método de excavación consistió en cuatro microactuaciones (figura 4) situadas junto al cono de sedimentos de la entrada de la cavidad, además de estos sondeos se han desarrollado varias actuaciones en el interior y el exterior de la cueva, a nivel interdisciplinar, consistentes en la aplicación de georradar, perforaciones mecánicas para obtención de sedimentos, escáner 3D en zonas 
con arte rupestre, escáner laser de barrido en el cono de entrada o trabajos con GPR en la pendiente de entrada, entre otras (Ramos Muñoz et al., 2014).

A continuación se describen brevemente las cuatro zonas donde se efectuaron los sondeos, no entraremos en más detalles de las mismas puesto que el trabajo completo se puede consultar en las publicaciones del año 2014 (Ramos Muñoz et al., 2014).

Sondeo Zona 1: Cercana a la boca de entrada junto a la escalera construida en el siglo XIX y que dejó a la luz un pequeño perfil donde se han documentado 6 niveles sedimentológicos y 3 arqueológicos.

Sondeo Zona 2 (figura 5): Situado a media altura del cono de sedimentos, se localizaron varios niveles de sedimentos, separados por 3 costras calcáreas, datadas por C14 y con material arqueológico. Bajo la costra superior, la más reciente del cono,

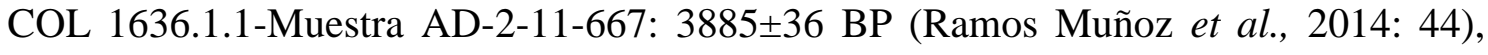
presenta un nivel de limo rojizo/marrón con piedras angulosas, donde se localizó un fragmento cerámico de cronología postneolítica, la costra intermedia con una datación

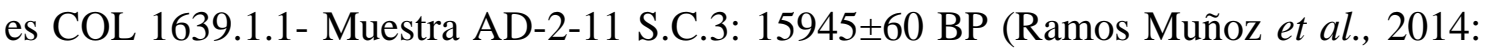
44), con varios niveles de sedimentos compuesta de limos rojos con restos de fauna, bajo este sedimento de limos y asociado a un nivel de gravilla apareció un buril (BN2G) de sílex blanco asociado al Paleolítico superior. Bajo este sedimento apareció la tercera y última costra la cual fue perforada y bajo la cual apareció un sedimento de limos rojos pero que aún no se ha sondeado.

Sondeo Zona 3: Situado en el otro extremo de la entrada de la cueva en el cono de sedimentos, bajo unos motivos rojos sobre el techo, se sondeó un metro cuadrado y $35 \mathrm{~cm}$ de profundidad. Se localizaron 5 niveles sedimentológicos, donde se tomaron muestras de fragmentos de huesos de fauna y carbones, junto con muestras de sedimentos y polen. Se han obtenido dos dataciones COL16343.1.1-Muestra AD-3-11-

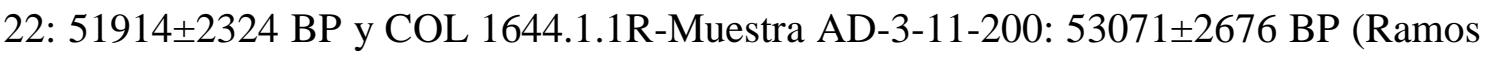
Muñoz, et al., 2014:45), en este sondeo también se han datado a través de U/Th la costra superior.

Sondeo Zona 4 (figura 6): Situado en la base del cono de sedimentos. El sondeo se realizó en una superficie de un metro por cincuenta centímetros, donde se localizaron 3 niveles sedimentológicos. El primero de ellos con arcillas amarillas, bajo esta otro nivel de limos de color rojizo/marrón donde aparecieron fragmentos de fauna y piezas de sílex como una gran lasca levallois (BP), bajo esta otro nivel de limos de color 
marrón con muchas piedras, han aparecido numerosos restos de carbones en los tres niveles y 19 restos arqueológicos (fauna y sílex). Destacar en este sondeo la existencia del sedimento quemado y con acumulación de carbones junto a los bloques ya que podría ser un indicio de restos de un hogar (Ramos Muñoz et al., 2014: 45).

Los resultados obtenidos, en las actividades arqueológicas plantea la necesidad de continuar con las investigaciones arqueológicas en ambas cuevas para ampliar el conocimiento de los grupos humanos paleolíticos del sur de la Península Ibérica, ofreciendo un gran potencial en la investigación prehistórica del Pleistoceno.

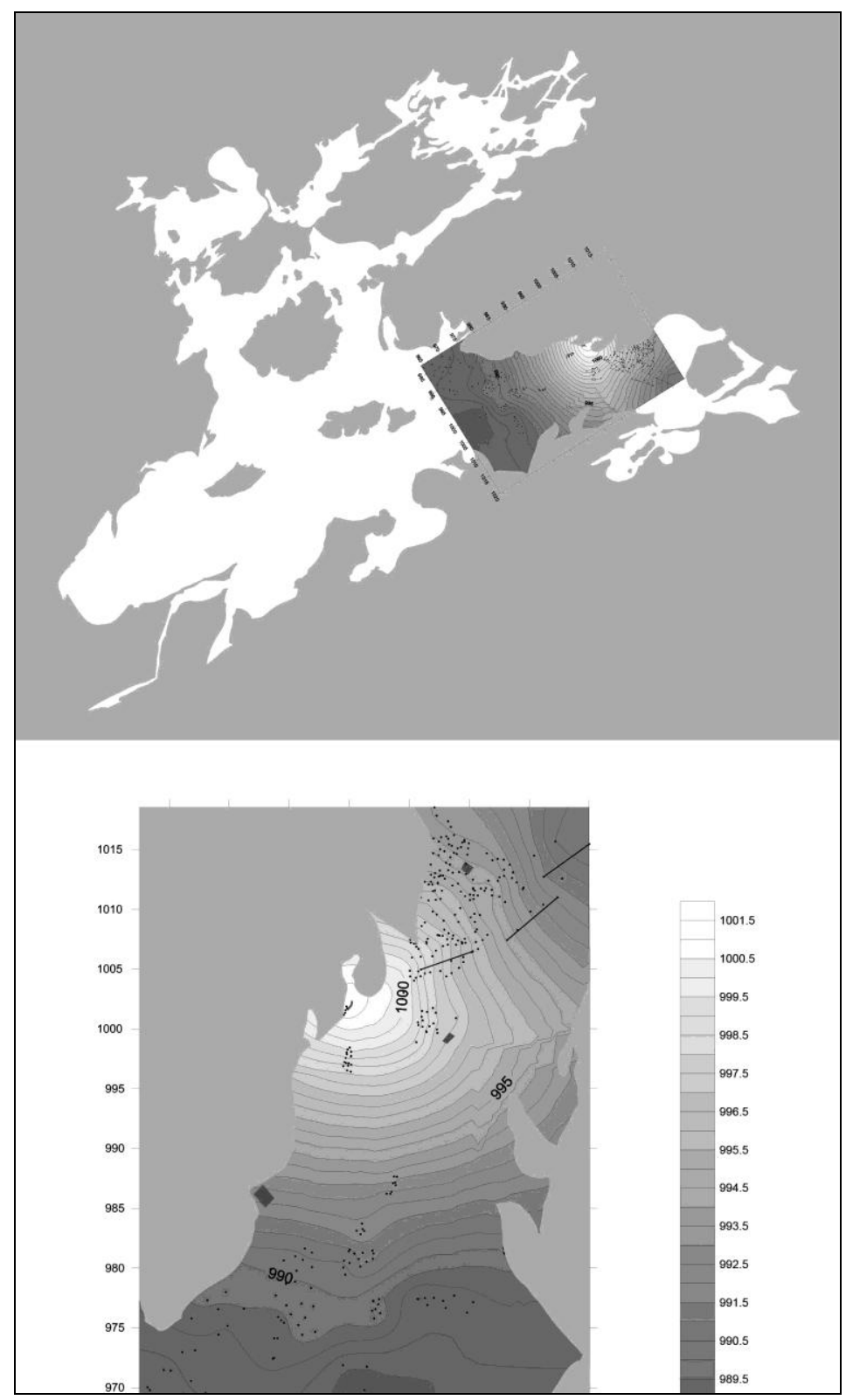

Figura 4. Topografía interior de la Cueva de Ardales con la localización de los sondeos (Ramos Muñoz et al., 2014: 43). 


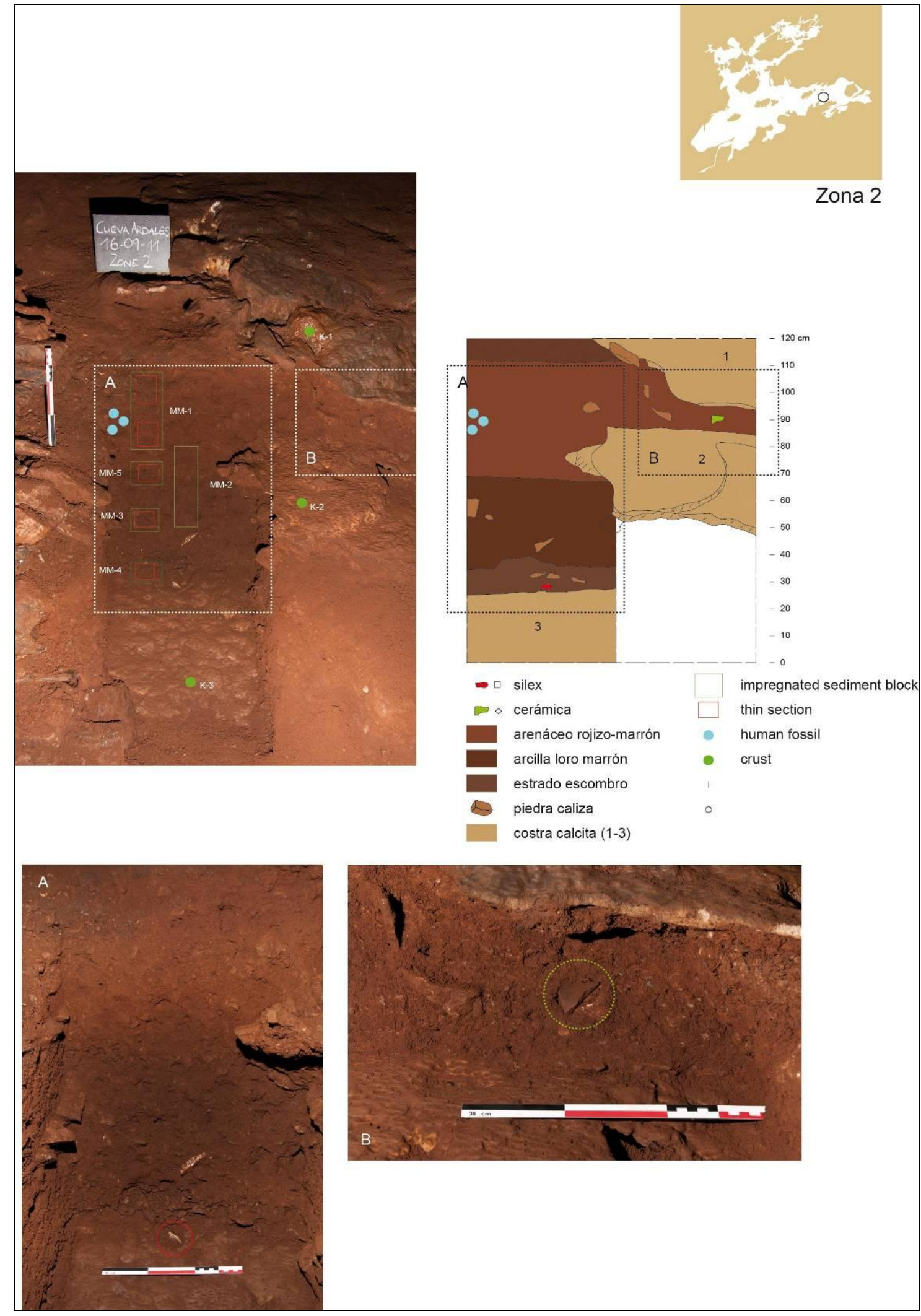

Figura 5. Cueva de Ardales. Sondeo zona 2 (Ramos Muñoz et al., 2014). 


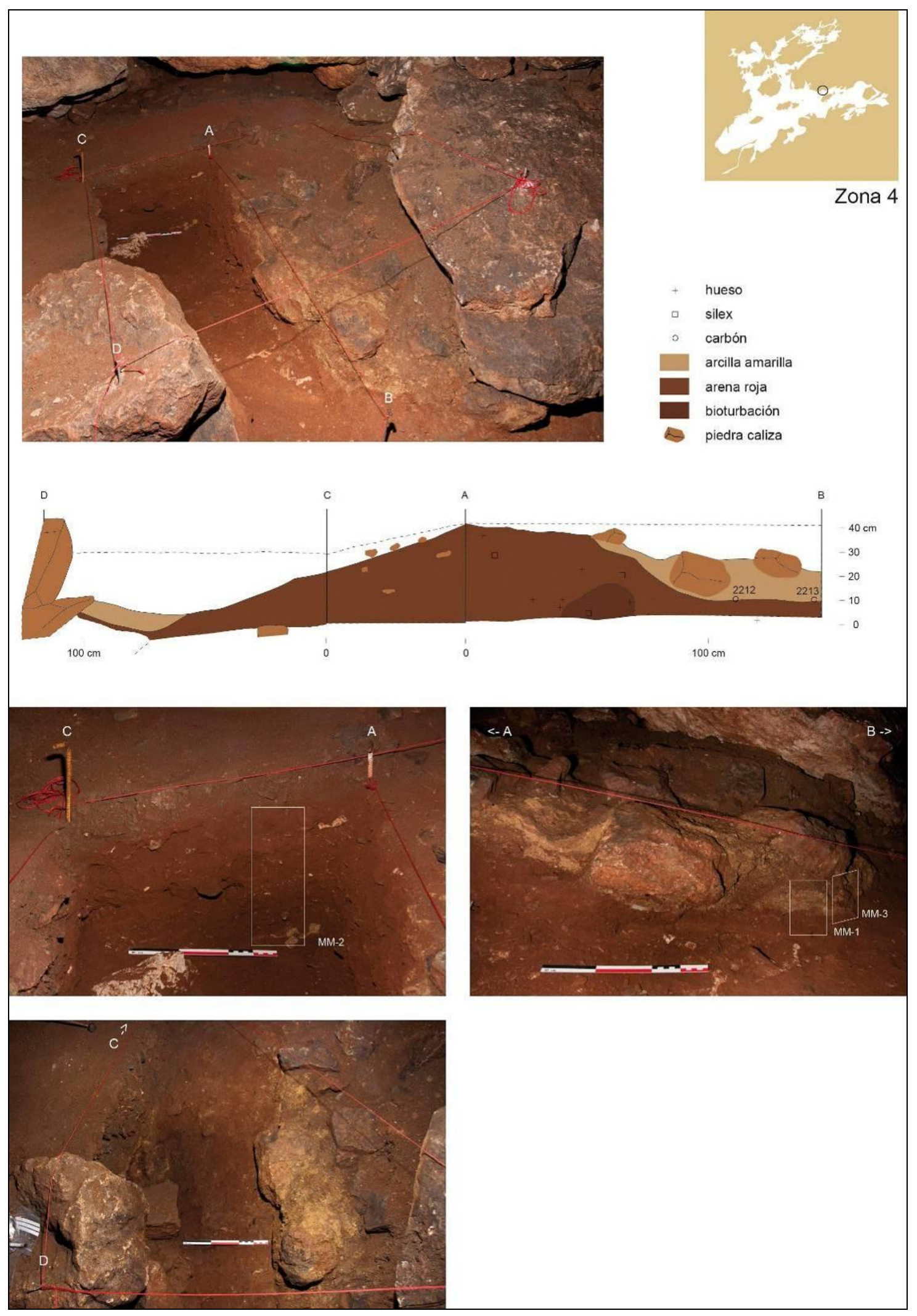

Figura 6. Cueva de Ardales. Sondeo zona 4 (Ramos Muñoz et al., 2014). 


\subsubsection{Aplicación de la Geoarqueología a la prospección}

La Geoarqueología, es una disciplina surgida en los años 70 del siglo XX, adquiriendo posteriormente un elevado protagonismo en el contexto de la investigación arqueológica (Jordá Pardo, 1994: 466). Con anterioridad, en 1958, Ian Cornwall, publica su libro titulado Soils for the Arqueologist, el cual ofrece el primer tratamiento sistemático de lo que se ha denominado Geoarqueología (Butzer, 2007: 64).

Tiene su punto de partida con los trabajos de Shackley (1975) y de Davidson y Shackley (1976) con aportaciones posteriores de diversos autores como Butzer, en la década de los ochenta (Jordá Pardo, 1994: 467, Jordá Pardo, 2006-2009).

A partir de sus primeros años, la Geoarqueología se divide en dos corrientes de influencia, por un lado la francesa, centrada en el estudio de cuevas y abrigos de cronología prehistórica, con el objetivo de definir su evolución paleoambiental, basándose en análisis sedimentológicos; y por otro la inglesa, orientada al estudio geomorfológico y la petrografía sedimentaria, con la finalidad de establecer "patrones de asentamientos, tanto a escala local como regional" (Polo Díaz, 2007-2008: 690).

Su objetivo es el estudio y la interpretación de las relaciones existentes entre el medio natural y el hombre plasmados en el registro arqueológico. La interacción entre la propia naturaleza y la acción antrópica del hombre, supone la formación de secuencias físico-naturales en las que queda reflejada el impacto humano en los procesos derivados de la actuación de los diferentes sistemas morfogenéticos, "constituyendo el elemento clave a la hora de estudiar el registro arqueológico desde la óptica de la Geoarqueología” (Jordá Pardo, 2006-2009: 47). Su metodología basada en la aplicación de métodos y técnicas de la investigación geológica, permite determinar "los procesos de formación y transformación del registro arqueológico en el contexto de los diferentes dominios y sistemas morfogenéticos” (Navazo Ruiz et al., 2005: 237).

En el estudio del registro arqueológico, sobre todo en los yacimientos del Paleolítico, existen factores como los procesos de formación y alteración de los depósitos que impiden en ocasiones ver con claridad las actividades que se realizaban en ellos, que no se puede explicar a través de la prospección y que son necesarios para comprender como se distribuyen los materiales en superficie. Dichos procesos, provocan en muchas ocasiones errores a la hora de interpretar el yacimiento, en ese intento de una correcta interpretación, se busca la ayuda de la Geoarqueología, "como instrumento por el cual proporcionar respuestas y soluciones al análisis arqueológico mediante la aplicación de métodos y técnicas de las Ciencias de la Tierra" (Polo Díaz, 
2007-2008: 690), seleccionando los procedimientos adecuados para que estos sean capaces de producir los resultados más esenciales para la correcta valoración de un contexto concreto (Butzer, 2007: 69).

Con la importancia que adquirió la prospección arqueológica en nuestro país a partir de los años 80 del siglo pasado, la aplicación de la Geoarqueología jugó un papel fundamental (Jordá Pardo, 2006-2009). Se convierte en una disciplina necesaria para las prospecciones arqueológicas superficiales, ya que las interpretaciones que se obtengan durante el desarrollo de la actividad arqueológica pueden inducir a error si no se contrastan los datos obtenidos con "la interpretación geoarqueológica del paisaje en el que se localizan los diferentes restos arqueológicos" (Jordá Pardo, 1994: 471). Su campo de estudio abarca aspectos que van más allá de la formación inicial del yacimiento y las transformaciones contemporáneas a su utilización, como su sepultamiento, la erosión, dispersión y mezcla de artefactos y otros restos culturales en el yacimiento o fuera de él (Butzer, 2007).

En el desarrollo de la prospección arqueológica superficial tanto la Geología como la Geomorfología inciden notablemente en las estrategias de prospección, limitando o favoreciendo el trabajo del prospector, a su vez se debe llevar a cabo una caracterización geológica y geomorfológica, una vez localizados los restos arqueológicos en superficie, y una interpretación geoarqueológica que determinará su posición primaria o secundaria, "evaluándose la intensidad de los procesos postdeposicionales, y se realizará un análisis territorial que permitirá la realización de un análisis sincrónico y diacrónico, espacial y secuencial, que conducirá a una interpretación en términos geoarqueológicos e históricos del área prospectada"(Jordá Pardo, 2006-2007: 49).

“En suma, la Geoarqueología debe incluirse en el desarrollo de la prospección arqueológica en tres fases, en el proceso de planificación previa, en el análisis de los restos descubiertos y en la interpretación global de los resultados" (Burillo Mozota, 1997: 121). Esta constituye una ayuda muy importante para interpretar los contextos arqueológicos e incluso para la evaluación de la visibilidad (Ruiz Zapatero et al., 1988: 51), permite además "evaluar el medioambiente al que se enfrentarían los habitantes de un yacimiento en distintos periodos" (Renfrew y Bahn, 2011: 274). 
Para el estudio de los depósitos secundarios, vinculados la mayor parte a terrazas fluviales, el sistema de muestreo que utilizaremos será el de superficie, sabemos que la mejor manera para muestrear este tipo de depósitos antiguos es el sondeo en profundidad, sin embargo el elevado coste del mismo y la imposibilidad de llevarlo a cabo nos inclina a utilizar el de superficie, a través del denominado pebble count, por el cual procederemos a un recuento aleatorio en vertical de los cantos de río en los niveles de terraza visibles y que será en torno a un $1 \mathrm{~m}^{2}$.

\subsubsection{Territorialidad, aprovisionamiento de recursos y movilidad}

Tanto a nivel arqueológico como antropológico, el concepto de territorialidad debe ser abordado más allá de una simple visión geográfica y debe vincularse al de cultura. La cultura supuso una ventaja evolutiva de los seres humanos dándole un sentido más amplio al concepto de territorio, aunque sabemos de las cargas políticas e ideológicas del mismo y de que aún no están muy claras las diferencias con otros conceptos como espacio o paisaje, los cuales ya hemos abordado anteriormente, la territorialidad "incluye dimensiones materiales (paisaje) y simbólicas (sus significados) a partir de las cuales construimos nuestro sentido de relación espacial y temporal" (Ardila, 2006: 61).

El estudio del territorio desde una perspectiva antropológica cuenta con datos etnográficos suficientes para decir que entre el ser humano y el medio ambiente existe una idea o una concepción determinada que es la de territorialidad (García, 1976: 22). Dentro de esta concepción de territorialidad, entendemos que el territorio constituye el espacio, donde los grupos humanos se mueven en función del aprovechamiento de los recursos existentes.

Desde el punto de vista de la Antropología la territorialidad está enfocada a los modelos de comportamiento humano y su evolución, según las distintas culturas, a lo largo del proceso histórico. El estudio de esos modelos de comportamiento conllevará una serie de teorías y estrategias enmarcadas dentro de las diferentes corrientes de pensamiento antropológico que existen desde principios del siglo $\mathrm{XX}$.

A nivel arqueológico la territorialidad y el uso del espacio constituyen una fuente de información sobre la vida de los grupos humanos (Navazo Ruíz, 2006: 97), unas formas de vida que serán diferentes en función de los recursos de los que dispongan. En el siguiente apartado revisaremos los modelos en el campo de la Antropología y la Arqueología en relación al territorio y uso del espacio. 


\subsubsection{Modelos existentes sobre territorio y uso del espacio desde la Antropología y desde la Arqueología}

Territorio y espacio son conceptos que aparecen relacionados de distinta manera en determinadas disciplinas (Ther Ríos, 2012: 3), a lo largo de este capítulo revisaremos los modelos existentes tanto en Antropología como en Arqueología.

Desde sus inicios la Antropología ha abordado la relación existente entre cultura, sociedad y espacio, en el caso de este último es "visto como parte de los esquemas que organizaban la cultura” (Belló, 2011: 42), el cual es posible estudiar a través de las analogías que se pueden establecer con otras culturas o sociedades a través de un enfoque antropológico y donde los usos tradicionales, costumbres, memoria, rituales y las diferentes formas de organización social constituyen lo que denominamos territorio (Barabás, 2010: 11). Se considera como "el sustrato espacial necesario de toda relación humana y su problemática estriba en que el hombre nunca accede a ese sustrato directamente, sino a través de una elaboración significativa que en ningún caso está determinada por las supuestas condiciones físicas del territorio” (García, 1976: 13).

Sin embargo, el término territorio en el análisis de los fenómenos antropológicos ha variado según las diversas perspectivas teóricas en uso (Belló, 2011:42). El principal problema del término se debe a su utilización por diferentes ciencias como, "la Ecología, la Etología, la Economía, la Psicología, la Sociología y finalmente la Antropología pasando desde la objetividad del paisaje humano propia de la Geografía Humana hasta las complicadas estructuras mentales y significativas que le sustentan y le hacen humano" (García, 1976: 13) lo que origina una definición poco precisa del concepto, teniendo en cuenta otros aspectos en su definición como es la como la percepción antrópica del mismo, por el contrario a nivel arqueológico y sobre todo desde la Prehistoria los investigadores "suelen tener en cuenta la localización geográfica de los recursos como elemento tangible fundamental para nuestra definición de territorio" (Mangado, 2006: 81). El territorio es por tanto una "realidad creada a partir de la apropiación y representación que las personas hacen del espacio” (Belló, 2011: 42) y como concepto antropológico debe entenderse como el espacio donde ocurren las relaciones socioculturales entendidas no sólo como el núcleo habitado sino el entorno donde transcurre la vida comunitaria (Ruíz Torres, 2004: 118). 
Numerosas son las corrientes o escuelas dentro del ámbito de la Antropología que desde sus inicios tratan el tema del uso del espacio y el territorio. Hay que retroceder hasta sus orígenes en el siglo XIX, con la escuela evolucionista, cuando autores como C. Darwin con su evolucionismo biológico o H. Spencer popularizaron el término evolución, y contribuyeron al auge que convirtió al esquema evolutivo en la base de explicación de los fenómenos sociales. La secuencia evolutiva de salvajismo, barbarie y civilización basado en el esquema de Montesquieu (Martín Casares, 2006: 120) fue retomada por los antropólogos para explicar la evolución de la cultura.

Los principales representantes de la escuela evolucionista son H. Spencer, E. Tylor, J. Frazer en Inglaterra y L. Morgan en Estados Unidos. L. Morgan distingue tres grandes fases en la historia: salvajismo, barbarie y civilización identificando dentro de cada una tres periodos, antiguo, medio y tardío (Restrepo, 2009: 11) y estableciendo la evolución cultural como progresión gradual desde la fase de salvajismo basada en la recolección, caza y domesticación de animales hasta la civilización iniciada con la invención de la escritura (Laguardia Martínez, 2008). Consideraban los evolucionistas que todas las culturas formaban parte de un mismo proceso evolutivo pero que no todos se encontraban en la misma fase de evolución, es decir, una trayectoria unilineal de la evolución. Utilizan el método comparativo para establecer analogías entre grupos humanos separados en tiempo y espacio.

Para Morgan, el territorio sobre todo en el último estadio, el de civilización, constituye el principio organizativo de lo que él denomina la civitas, donde las desigualdades sociales basadas en la propiedad aparecen (Martínez Veiga, 2008: 58).

A finales del siglo XIX y principios del XX surge el Historicismo Cultural, criticaron los postulados de la corriente evolucionista, ya que pensaban que los cambios tecnológicos, sociales o culturales eran propiciados por una influencia externa. Se asocia a tres escuelas de pensamiento, una británica cuyos máximos exponentes son E. Smith y W. J. Perry, para quienes Egipto constituía el foco de civilización a otras culturas que estuviesen en contacto con el país y consideraban la imposibilidad de que culturas distantes entre sí hubiesen llegado a inventar lo mismo si no era porque lo habían adoptado de otras. La corriente austroalemana con F. Graebner y W. Schmidt, mantenían que los rasgos culturales se difundían por medio de un grupo o de forma individual y que no todo procedía de Egipto, por último la escuela norteamericana, donde destaca C. Wissler, para quienes las características de un territorio concreto procedían de un centro cultural. El autor "planteó la teoría de épocas y áreas: si un 
rasgo concreto se difunde desde un centro cultural, resulta lógico que las características más extendidas sean también las más antiguas” (Barañano Cid, 2010: 66).

El Particularismo histórico, cuya figura más destacada es F. Boas, considerado por algunos como el fundador de la antropología moderna en EE.UU. Consideraba que era "indispensable reconstruir la historia particular de cada cultura y sólo a partir de esta reconstrucción era posible identificar trazos de difusión de algunos rasgos culturales en relación con los grupos humanos vecinos y en contextos geográficos definidos" (Restrepo, 2009: 21). Su método de trabajo consistía en comparar los fenómenos culturales dentro de un área cultural determinada, referida a unas zonas geográficas donde se puedan establecer una relativa similitud cultural (Restrepo, 2009: 25). Destacan también A. Kroeber y R. Lowie.

Otra de las corrientes es el Funcionalismo, su principales representantes fueron B. Malinowski, quien inicia el trabajo de campo etnográfico moderno, "señalaba la necesidad de comprender los fenómenos de la cultura a partir de un área geográfica perfectamente limitada” (Belló, 2011: 42) y A. R. Radcliffe-Brown, para quien los diferentes modos de comportamiento de una sociedad son la base de su estructura social y que es considerada como un sistema que hay que mantener de ahí que este modelo reciba el nombre de funcional-estructuralista (Barañano Cid, 2010: 66). A. R. Radcliffe-Brown sostenía que, "bajo todas o la mayoría de las condiciones ecológicas, el pautamiento óptimo de la organización espacial de los cazadores-recolectores sería alguna forma de banda territorial" (Dyson-Hudson et al., 1978: 21). La primera oposición que hacen al evolucionismo es negar esa idea de evolución unilineal y que los cambios no son producto de algo individual sino que se producen por medio de los contactos culturales.

En los años 30 del siglo XX, surge el Neo-evolucionismo heredado de la escuela evolucionista, sus principales representantes son L. White, para quién la cultura evoluciona según la cantidad de energía empleada por persona y la eficacia de los instrumentos usados (Barañano Cid, 2010: 66) y J. Steward, quien desarrolló la Ecología cultural fundamentada en el análisis comparativo de las relaciones existentes entre humanos y medio ambiente. Inspirado por los estudios de áreas de los años cincuenta, consideraba que las culturas tenían expresiones espaciales organizadas en diversos niveles de integración, local, regional o nacional (Belló, 2011: 42). Esta 
corriente "sostenía que las características y peculiaridades de una cultura dada y de su evolución dependen intrínsecamente de su adaptación a los recursos propios de sus entornos inmediatos" (Diez Martín, 2007: 4).

Otra de las corrientes es la Nueva Arqueología cuyo representante L. Binford consideraba que los prehistoriadores deben basar sus interpretaciones en las relaciones entre sus datos y los testimonios reales de las sociedades de cazadores-recolectores dando así una visión más completa (Delibes de Castro, 199: 163). Adoptó la postura de su maestro L. White quien definió la cultura como un medio extrasomático de adaptación y lo inserta en la arqueología dando lugar a la nueva arqueología americana, dependiente por completo de la antropología de los EE.UU. (Villafañez, 2011: 139), quienes pretendían buscar un punto de encuentro entre la cultura y el espacio (Belló, 2011: 42). L. Binford se ayudó de la Etnografía con pueblos de cazadores-recolectores para comprender el uso del territorio, desde el nivel macro al micro espacial, en los procesos de caza, talla las relaciones sociales del grupo y la disposición de los poblados en el medio (Ortíz Nieto-Márquez, 2009: 169).

A partir de los años 60, aparece la Antropología simbólica, cuyos máximos representantes son $\mathrm{V}$. Turner, quien estudiaba los rituales y la vida mental de las culturas, M. Douglas y M. Sahlins, quien consideraba que existía una evolución específica, entendida como una adaptación a un entorno y una evolución general que es la que se identifica con el progreso y por tanto el cambio de una sociedad a otra más avanzada (Laguardia Martínez, 2004).

Desde la Arqueología el espacio se puede entender como una "dimensión física innegable porque funciona como contenedor y sostén de los elementos y materiales arqueológico-culturales que en él se encuentran distribuidos y depositados" (Mendiola Galván, 2008: 24).

En el caso del término territorio, este surge con la aparición de la Nueva Arqueología a finales de los años 60, las técnicas de la Field Archaeology y las propuestas de la Nueva Geografía en Gran Bretaña sientan las bases de esta nueva corriente, la cual establece la definición de territorio "como un conjunto de recursos que han de estar en equilibrio con la comunidad" (Orejas, 1991: 202).

Para G. Ruiz Zapatero "el término constituye uno de esos conceptos polisemíticos, que por sí sólo, sin precisiones calificativas, se vacía a causa de su generalidad [...] este hace referencia a las características físicas y naturales de una 
extensa superficie de tierra, siendo sinónimo de región y por tanto de control humano del mismo" (Ruiz Zapatero et al., 1988: 46).

Los nuevos planteamientos surgidos propiciaron el interés por el estudio del espacio y del territorio dando lugar a la denominada Arqueología Espacial y al Site Catchment Analysis, enfocados al estudio de la distribución de los asentamientos así como la relación de estos y sus recursos (Orejas, 1991: 202).

Desde la Arqueología Espacial, influida por la Geografía cuantitativa y centrada en la relación hombre-hombre (Diez Martín, 2007), nos encontramos con modelos como el de la Teoría del Lugar Central, creada por el geógrafo alemán W. Christaller en los años 30 y que sostenía que en un "paisaje uniforme -sin montañas, ni ríos ni variaciones en la distribución de los suelos y recursos- el patrón espacial del asentamiento sería totalmente regular" (Renfrew y Bahn, 2011: 184), estableciendo un centro principal rodeado por un anillo de yacimientos dependientes del principal. Otro de los modelos en el estudio del territorio y el espacio son los polígonos Thiessen, estos constituyen formas geométricas simples que divide un área en varios territorios independientes centrados todos ellos en torno a un único yacimiento (Renfrew y Bahn, 2011: 184).

Los anteriores modelos obviaron la posibilidad de que los yacimientos que ocupan el mismo nivel en una jerarquía de asentamientos pueden tener diferentes tamaños (Renfrew y Bahn, 2011: 185), para solventar este problema se estableció el método de rango-tamaño, cuyo objetivo es establecer o asignar territorios a los centros según su escala. Donde se establecen un criterio de dominación según el cual un núcleo grande absorbe a uno pequeño, ello supone que la magnitud de cada centro es proporcional a su área de influencia.

En relación al análisis de las áreas de captación o Site Catchment Analysis, tiene su origen en los años 70, cuando C. Vita-Finzi y E. Higgs lo utilizaron como método para examinar las hipótesis relativas al empleo de los cereales en el Natufiense de Palestina (Davidson et al., 1984: 25) y del Paleolítico superior griego. A través del Site Catchment Analysis se puede analizar la evaluación teórica del espacio explotado habitualmente, rastrear los lugares de procedencia de las materias primas y los recursos que localizamos en los yacimientos, así como la creación de patrones de ocupación y explotación del territorio, estimando así las áreas de influencia de los asentamientos dentro de un territorio. Este análisis de áreas de captación intenta definir el tamaño de 
las áreas de las cuales proceden las materias primas (Davidson et al., 1984: 28), el tamaño no será igual para todos los yacimientos dependiendo de factores tales como la topografía, los cursos de agua, la disponibilidad de los recursos, etc..

La Teoría de Alcance Medio o middle-range theory constituye otro modelo procedente de la Etnoarqueología procesual. El concepto fue expuesto por primera vez en la década de los 50 por el sociólogo R.K. Merton, quien reconoció la importancia de la teoría general y consideró de igual importancia la capacidad de comprobarla empíricamente. Será utilizada por L. Binford, quien pretendía encontrar regularidades en contextos controlables actuales y que permitieran extrapolarlos al registro arqueológico (González Ruibal, 2003: 18). Se trata de una teoría del comportamiento humano en su contexto cultural y social, y tienen un efecto limitado ya que no explican el por qué cambian las culturas "sino que intentan explicar cómo se origina el registro arqueológico, cómo pervive y porqué, y como podemos interpretarlo" (Abad Mir, 2006: 12).

Otro de los modelos es la Teoría del Forrajeo Óptimo. Constituye un supuesto teórico procedente de la Biología y fue planteada por primera vez por McArthur y Pianka (1966) y Emlen (1966) argumentando que la importancia del éxito del forrajeo para la supervivencia de un determinado depredador debería permitir predecir su comportamiento en aras a maximizar los recursos alimentación obtenibles (Marín Arroyo, 2008: 50). Este modelo "asume que el objetivo las actividades cinegéticas de las comunidades humanas es la máxima rentabilización de la energía obtenida, en forma de alimento, en relación a la invertida en dichas actividades" (García Moreno, 2010: 25). Busca establecer una teoría general basada en parámetros concretos para cuantificar y racionalizar de algún modo estos comportamientos. A partir de este modelo comienzan a surgir otros como el de Modelo de Amplitud de Dieta o Diet Breadth Model, que buscar conocer en virtud de la disponibilidad de recursos que especies son las cazadas y las consumidas (Marín Arroyo, 2008: 51) o el de la selección de ruta o Path-Choice model, por el cual se asume que cuando en una zona determinada el rendimiento es menor, el grupo o el individuo se desplaza a otra zona donde existen más recursos (García Moreno, 2010: 32), ambos tienen en común la ratio entre la energía consumida durante el proceso de obtención de estos recursos y la energía obtenida con ellos. En el caso de que el coste de energía en obtener el recursos sea mayor que el beneficio esto conlleva un cambio en la actitud de los grupos humanos de 
cazadores-recolectores, ya sea mediante el cambio de las especies consumidas o del lugar de residencia (García Moreno, 2010: 27).

Un modelo basado en el enfoque regional es el planteado por K. Butzer, para el yacimiento de Torralba Ambrona (figura 7), donde los grupos de cazadores-recolectores compartirían con los grandes herbívoros su capacidad de explotar recursos concentrados y dispersos con estrategias adaptativas y ajustando sus desplazamientos estacionales a los altibajos de la productividad de los recursos durante el ciclo anual, estableciendo un foco de campamentos estacionales en las rutas migratorias de los herbívoros entre los pastos de invierno y los de verano (Butzer, 2007:277). Igualmente establece unos modelos sobre los patrones de asentamiento a nivel de macroescala (figura 8).

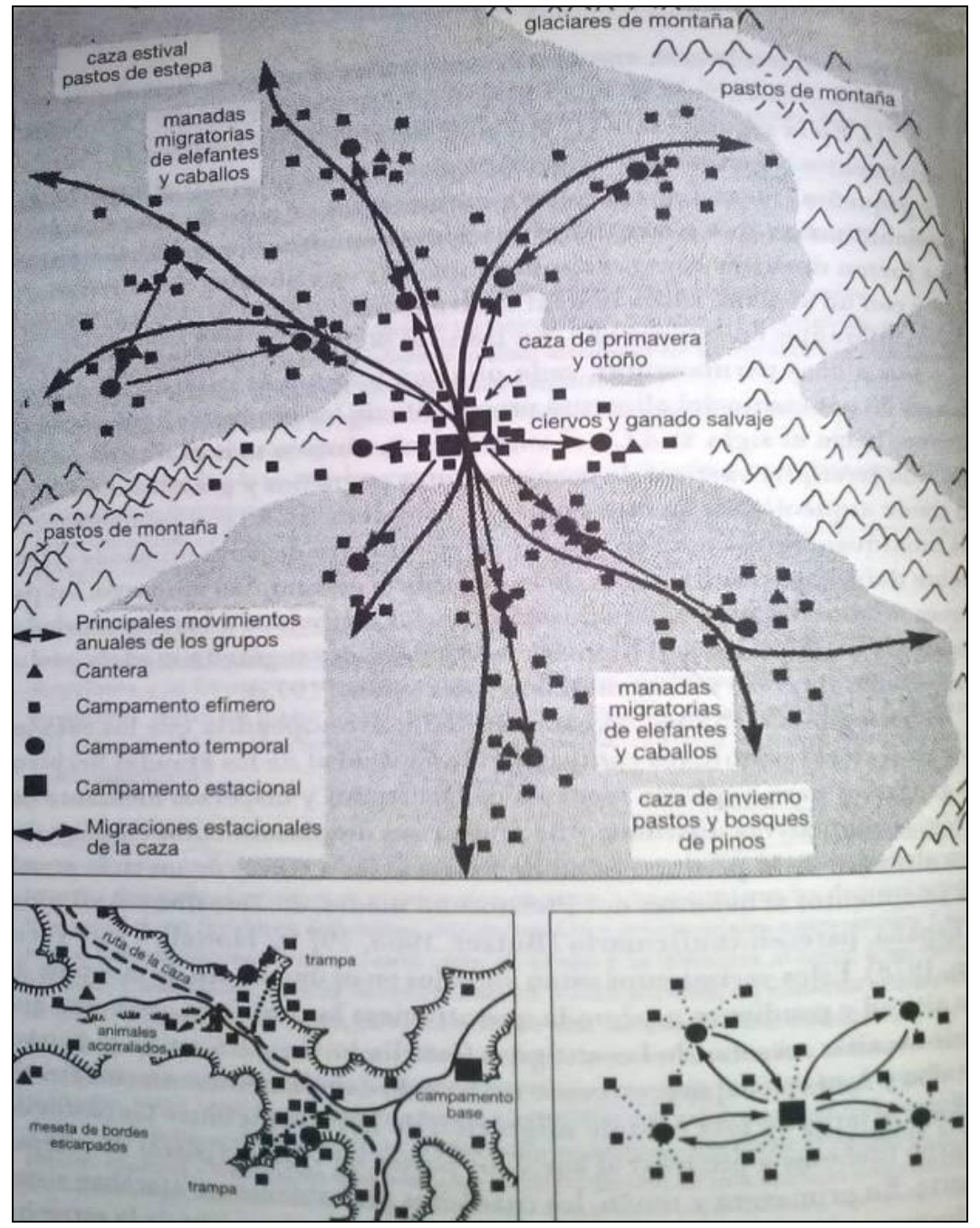

Figura 7. Modelo de movilidad en Torralba Ambrona según Butzer (Butzer, 2007: 278). 


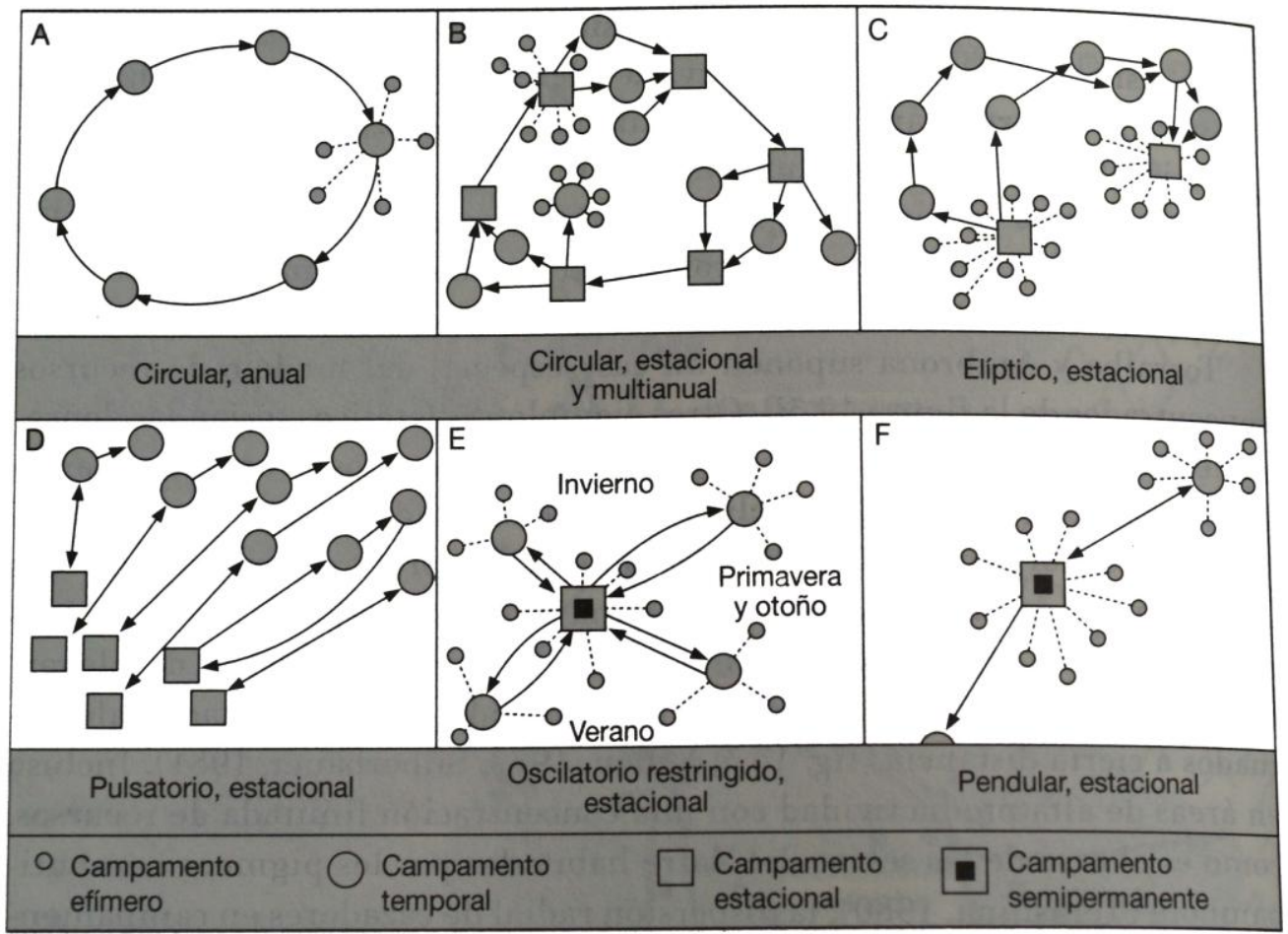

Figura 8. Modelo de movilidad a macroescala según Butzer (Butzer, 2007:280).

F. Bordes, establecería media docena de modelos diferentes de asentamiento estacionales, para el suroeste francés, con objetivos multiples, y de asentamientos temporales de actividad limitada, en relación a la concentración y variación estacional de los recursos (Butzer, 2007: 279)

Por último, citar el modelo de off-site procedente de la Arqueología Distribucional, iniciada en Inglaterra por investigadores como R. Foley, R. Dunnell o W. Dancey. Se basa en el reconocimiento espacial y territorial, que desde un enfoque regional pretende esclarecer la estructura a escala macro-espacial y las interconexiones de los vestigios, así como el uso del registro arqueológico reconocido en las superficies contemporáneas, teniendo en cuenta las secuencias estratigráficas disponibles (Diez Martín, 2007). La distribución de los artefactos en el paisaje y su posterior interpretación se evalúan a través de la relación que existe entre las "relaciones de concentración / dispersión y presencia/ausencia objetos arqueológicos en el espacio regional” (Villafañez, 2011: 141).

Este modelo supone la valoración de los registros arqueológicos de superficie, el estudio de los materiales asociados constituyen una fuente importante de información en algunos casos, donde el artefacto se convierte en la unidad básica de investigación (Diez Martín, 1997: 21). En el proceso de investigación de la arqueología distribucional el 
estudio de los procesos de formación y alteración de los yacimientos superficiales resulta de gran importancia para el análisis sobre la distribución territorial que nos permitirá la "reconstrucción de los sistemas de asentamiento” (Diez Martín, 1997: 22).

Interesante el modelo R. Foley (figura 9), para el África oriental, consistente en clarificar cuantitativamente la productividad de las plantas y la biomasa animal en bosque de montaña, de llanuras, de riberas, de la sabana y los márgenes lacustres y de praderas. Reconocía que el gasto de energía humana no sólo depende de la distancia, sino también de la tecnología, los recursos, el hábitat o la topografía (Butzer, 2007: 258). El registro de útiles líticos y puntos muestreados, al sur de Kenia en la región de Amboselia le permitió calcular el porcentaje de abandono de útiles en distintas zonas medioambientales y de vegetación e interpretar los patrones de distribución en función de la estrategia y movimiento de los grupos de cazadores-recolectores, reflejados en concentraciones significativas de industria lítica en los campamentos base y en campamentos temporales (Renfrew y Bahn, 2011: 197).
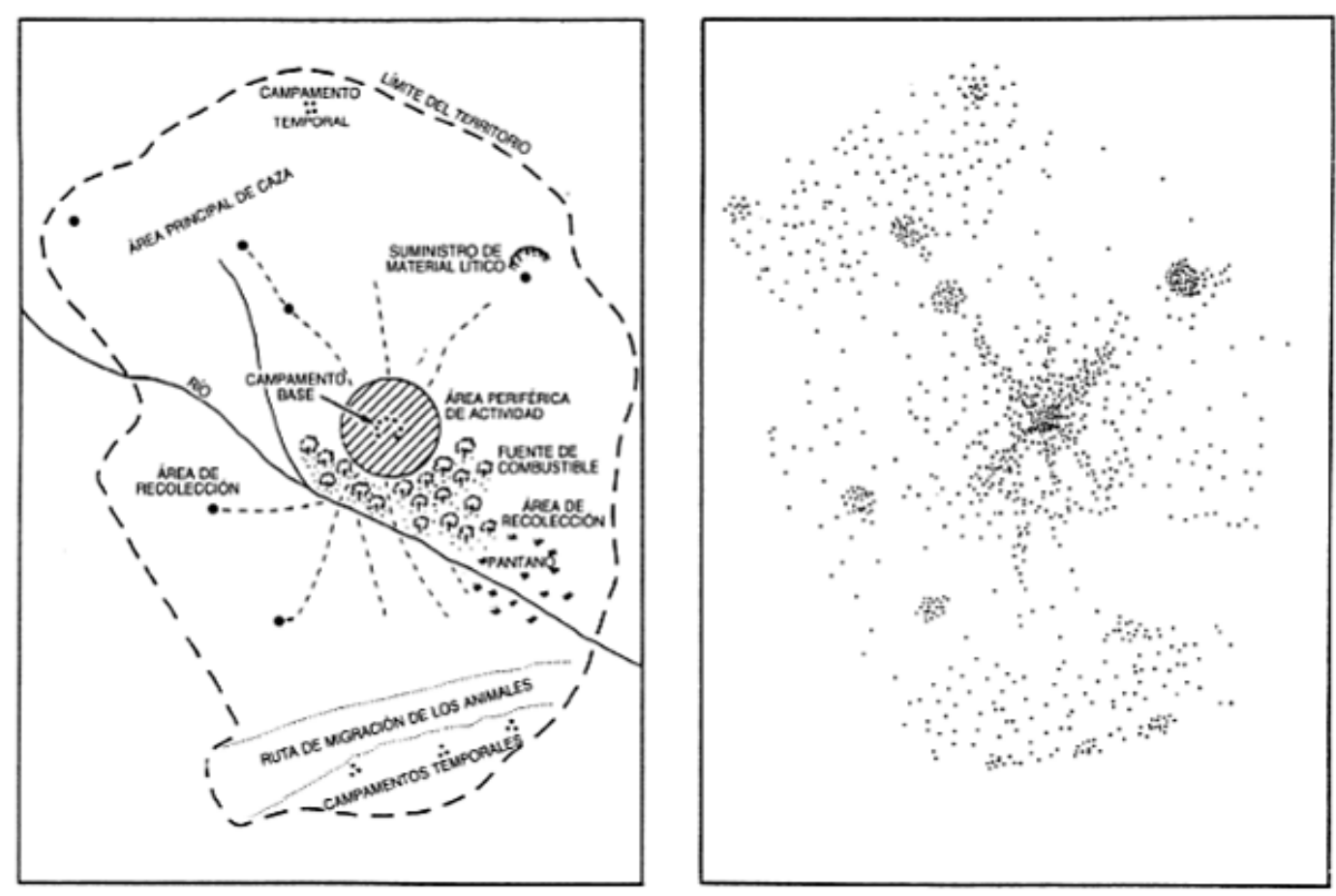

Figura 9. Modelo de Robert Foley para las actividades dentro del territorio anual de una banda de cazadores-recolectores y las dispersiones de artefactos

(Renfrew y Bahn, 2011: 197). 
Dentro de la arqueología distribucional otros trabajos se han centrado en interpretar los sistemas de adaptación y movilidad del territorio para diferentes grupos de cazadores recolectores y que se basan en plantear y resolver cuestiones sobre el carácter antropológico basadas en la movilidad, abastecimiento de materias primas y uso del territorio.

\subsubsection{Modelo asumido por nosotros}

La idea principal del estudio que aquí se presenta es establecer la relación entre los grupos humanos del Pleistoceno y los recursos existentes en este territorio, al referirnos a los recursos entendemos que es necesaria una visión de conjunto tanto de recursos líticos, como animales y vegetales. Si consideramos como territorio aquel espacio habitado y explotado por cazadores-recolectores, es imprescindible comprender la interacción de estos grupos humanos con el medio ambiente.

Nuestra investigación parte de los recursos localizados en los yacimientos existentes en el área de estudio y de estimar los posibles lugares de procedencia, sobre todo materias primas líticas, para ello resulta primordial el estudio y conocimiento de la zona, por lo que es necesario llevar a cabo una prospección arqueológica superficial que completará el registro arqueológico existente, si bien es cierto que pueden existir áreas donde existían recursos que actualmente están perdidos del registro arqueológico, es un riesgo que debemos correr, siendo necesario una exhaustiva valoración de los conjuntos líticos analizados para obtener datos serios en la investigación. Por ese motivo, es crucial establecer una metodología arqueológica apropiada para la prospección arqueológica, así como un estudio geológico y de los procesos postdeposicionales que afectan a los yacimientos.

En nuestro caso, para sociedades del Paleolítico consideramos poco oportuno utilizar la teoría del Lugar Central o los polígonos Thiessen, puesto que al ser grupos con cierta movilidad no se pueden establecer criterios como los que utilizan estos métodos, concebidos en el estudio de la territorialidad desde sociedades capitalistas y por tanto sólo se podrían aplicar en aquellas sociedades jerarquizadas espacialmente y con algún tipo de especialización (Diez Martín, 2007). Algo parecido ocurre con la teoría del forrajeo optimo, ya que no pueden representar la variabilidad en las actividades cinegéticas de los grupos humanos del Paleolítico y no tienen en cuenta implicaciones sociales o culturales que puedan tener las diferentes actividades que desarrollan (García Moreno, 2010: 26), como considerar a cada individuo igual a otros 
en la caza y obviar otro tipo de recursos como pueden ser la recolección o la caza de pequeños animales (García Moreno, 2010: 30)

Desde nuestra perspectiva seguimos la corriente de la Arqueología distribucional, puesto que creemos que el estudio de los materiales superficiales resulta de carácter primordial, ya que supone poder establecer investigaciones concluyentes en relación a lo que mencionábamos al principio de este apartado referida a la interacción entre el hombre y el medio. Para ello debe existir una clara metodología en el proceso de investigación que conlleve no sólo el estudio de los materiales sino de aquellos factores que inciden en el registro arqueológico, ya sean naturales o antrópicos, donde la Geoarqueología se convierte en una ciencia fundamental para comprender los procesos geológicos y geomorfológicos que afectan a los yacimientos arqueológicos. En el caso de nuestra área de estudio y existiendo dos yacimientos en cueva con materiales en posición estratigráfica, el estudio de los registros superficiales, la mayoría fluviales, que presentamos en este trabajo supone obtener una información complementaria en el análisis y la interpretación del poblamiento paleolítico desde el punto de vista regional.

\subsection{Metodología de trabajo}

\subsubsection{Trabajo de gabinete: de los planteamientos iniciales a la presentación de la} memoria. Uso de informática, de cartografía, de fotos aéreas y de satélite, de SIGs, etc...

En cualquier actividad arqueológica ya sean excavaciones, sondeos, prospecciones o estudio de materiales entre otras, es necesaria una planificación inicial al desarrollo del trabajo de campo, comenzando por la recopilación de las fuentes documentales existentes, ayudándose incluso de la toponimia. Los organismos públicos tales como los ayuntamientos o los consorcios disponen de información arqueológica de la zona de estudio, recogidos en los planes generales urbanísticos (PGOU), y los inventarios o cartas arqueológicas. Conjuntamente se han de revisar todos los trabajos publicados sobre el área de estudio para obtener la mayor información posible. Dichas fuentes documentales deben incluir mapas topográficos, cartográficos o fotografías aéreas tanto actuales como antiguas.

El uso de la cartografía y los mapas topográficos ha permitido conocer mejor nuestra zona de estudio, se ha consultado el Mapa Topográfico Nacional de Andalucía a escala 1:50.000, así como las cartografía de la comunidad autónoma de Andalucía a 
escala 1: 400.000, igualmente se ha consultado durante el proceso de trabajo la cartografía geológica disponible del Instituto Geológico y Minero de España a escala 1: 50.000. Otras cartografías de interés utilizadas han sido los mapas de suelos o recursos minerales como el Mapa de Suelos de Andalucía elaborado a partir del Atlas de Andalucía (tomo II), E. 1:400.000 junto con el Mapa Geotécnico General a escala $1: 200.000$.

En relación a la fotografía aérea, hay que decir que constituye un avance muy importante para la localización de yacimientos arqueológicos y sirve de apoyo para los trabajos de prospección arqueológica superficial constituyendo una información de base. La primera vez que se aplicó la fotografía aérea a la Arqueología fue en 1899, cuando Giacomo Boni realizó las primeras fotografías del foro romano (Orejas, 1995: 33). Pero será a finales de los cincuenta con las iniciativas de Bradford, Schmiedt o Chevallier, cuando se difunde su uso (Orejas, 1991: 217).

Las fotografías aéreas se realizan utilizando unas cámaras especiales instaladas en aviones. Para la toma de fotografías aéreas es importante la altura del avión, para la escala de las fotografías que se van a realizar y el intervalo de tiempo entre cada una de las fotos realizadas, que según la velocidad del avión garantiza el recubrimiento de las mismas (Jordá Pardo et al., 2012: 177-178).

Existen dos tipos de fotografía aérea, la oblicua y la vertical. En el caso de las oblicuas, son fotografías panorámicas que revelan contornos y proporcionan una mayor perspectiva. Este tipo de fotografías aéreas son las que más resultados proporcionan en cuanto a la detección de nuevos yacimientos, aunque su principal problema es la difícil combinación con otros mapas durante el proceso de rectificación (García SanJuan, 2004: 16). Las fotografías aéreas oblicuas deben realizarse a primera o última hora del día para poder captar las sombras que los rayos de sol rasante dibujan en las superficies del suelo, alterada por los cultivos (Cerrato Casado, 2011: 6), las verticales, son más idóneas para trazas planos y mapas (Renfrew y Bahn, 2011: 83), “estas presentan deformaciones angulares que al ser corregidas a una proyección ortoganal, constituyen las ortofotos" (Jordá Pardo et al., 2012: 178).

En nuestro caso, la fotografía aérea utilizada será la vertical que es la apropiada para la elaboración de planos cartográficos de grandes áreas de estudio, que es con el que trabajamos, las fotografías aéreas deben estar realizadas en diferentes estaciones del año y a horas distintas para comprobar la variabilidad del terreno. Para las excavaciones 
arqueológicas utilizamos fotografías aéreas verticales realizadas con globo que permiten obtener unas fotografías con más detalle.

En el desarrollo de ese trabajo, una vez seleccionadas las fotografías debemos identificar y seleccionar los elementos útiles para contrastarlos a través del trabajo de campo por medio de la prospección arqueológica y elaborar nosotros mismos nuestra propia cartografía indicando todos los elementos localizados y de interés, ello nos permitirá contextualizar los diferentes yacimientos en su marco ambiental y administrativo y de este modo interpretar sus territorios de captación de recursos y su influencia (Jordá Pardo et al., 2012: 181).

En el análisis de las fotografías aéreas hemos utilizado principalmente la ortofotografía digital en color de la provincia de Málaga a escala 1:10.000, las imágenes de satélite mediante Google Earth y la información geográfica del SIGPAC (sistema de información geográfica de parcelas agrícolas).

Además de la cartografía, los mapas topográficos y las fotografías aéreas contamos con otros instrumentos muy usados actualmente y de gran utilidad para el trabajo arqueológico como son los Sistemas de Información Geográfica (SIG). Tiene su inicio en la década de los 70 a partir de técnicas informáticas de diseño y mapeado (CAD/CAM) (Renfrew y Bahn, 2011: 91). Sus primeras aplicaciones arqueológicas se produjeron en EE.UU, en los años 80 del siglo XX, orientadas a la gestión de los recursos culturales y al desarrollo de modelos predictivos de localización de asentamientos, con posterioridad su objetivo era la reconstrucción paleoambiental y la relación de las sociedades con el medio ambiente de clara tendencia procesualista.

En el Reino Unido, y posteriormente en Países Bajos, Dinamarca y Francia su utilización se enfocó hacia la Arqueología espacial y la gestión del patrimonio arqueológico. En el caso de España, la utilización de los SIG en Arqueología también tuvo sus inicios en la década de los 80 del siglo XX, siendo el equipo de la universidad autónoma de Madrid pioneros en la utilización de los SIG en arqueología, bajo la dirección de J. Baena y C. Blasco.

Los SIG se pueden definir como herramientas informáticas, capaces de gestionar y analizar la información georreferenciada, con vistas a la resolución de problemas de base territorial y medioambiental (Jordá Pardo et al., 2012: 211). Su utilización para las prospecciones y su vinculación con la Arqueología de Paisaje es ya notoria desde principios de los 90 del siglo XX, no sólo por la concienciación de un marco conceptual 
parecido sino además por un abaratamiento de los elementos que componen los SIG (García Sánchez, 2012: 146)

La utilización de la información obtenida a través de la fotografía aérea como capa SIG en combinación con los datos topográficos y la información topográfica disponible pueden llevar a alcanzar resultados arqueológicos muy fructíferos (Renfrew y Bahn, 2011), ya que el volcado de los datos georreferenciados durante el transcurso de una prospección dará origen a un mapa de distribución arqueológica.

Para el desarrollo de nuestro trabajo optamos por la utilización de herramientas SIG, en este caso, empleamos el programa de software libre de gvSIG. La aplicación de los SIG en trabajos de prospección arqueológica han supuesto un autentico avance haciéndola más "eficiente, fiable y productiva" (García San Juan, 2004: 185), constituye además una excelente herramienta para gestionar las fotografías aéreas y la cartografía. Los yacimientos estudiados en nuestra zona de estudio se han georreferenciado dentro de un sistema de coordenadas U.T.M (Universal Tranversa Mercator). En función de la legislación vigente, la información espacial tendrá como sistema de referencia espacial el ETRS89, y concretamente en nuestra zona de estudio por estar inserta en la provincia de Málaga utilizaremos el EPSG 25830. Estas coordenadas serán tomadas a pie de campo por medio de un GPS (Global Positioning System), que nos permita visualizarlas y representarlas cartográficamente junto con otros elementos tales como ríos, embalses o zonas de captación de materias primas.

Las aplicaciones de los SIG en arqueología son variadas y de gran interés, en el caso de la prospección resulta de gran utilidad, como ya hemos visto, no sólo para facilitar el trabajo de campo permitiendo con posterioridad introducir todos los datos obtenidos de la prospección, sino que resulta muy útil para las investigaciones como las que nos ocupan en este trabajo centradas en el análisis espacial como es el de la captación de recursos, el análisis ecológico-cultual o el de la territorialidad teórica (Jordá Pardo et al., 2012: 214). También es importante su utilización en excavaciones permitiendo extrapolar los datos a un SIG permitiendo un mejor manejo de la información y de una forma más rápida.

En nuestro caso, la aplicación de los sistemas de información geográfica nos permitirá elaborar un mapa con la distribución de los yacimientos en el territorio objeto de este estudio y de la movilidad de las materias primas en relación a las áreas de captación en posición primaria y secundaria. 


\subsubsection{Trabajo de campo: Las campañas de campo y sus resultados}

Con anterioridad a las prospecciones arqueológicas, llevamos a cabo muestreos geoarqueológicos, tanto en los afloramientos geológicos como en los yacimientos arqueológicos. Estos muestreos que fueron realizados entre los años 2011-2014, con ayuda de mi codirector Salvador Domínguez y Serafín Becerra, han permitido obtener muestras de 30 lugares con presencia de materia prima y elaborar un total de 116 láminas delgadas.

En diciembre de 2013, junto a J. Durán y P. Robledo, realizamos una salida de campo a las terrazas fluviales del bajo Guadalteba para una valoración previa de las mismas. Al año siguiente y en el mismo mes, junto a mi director J. Jordá y P. Cantalejo visitamos las terrazas del río Turón, valorando y analizando cada una de ellas y los materiales arqueológicos localizados en dichas terrazas.

No será hasta finales del año 2015, con un año de retraso en los permisos, cuando se inician las campañas de prospección, en el marco del Proyecto General de Investigación: Las sociedades prehistóricas (del Paleolítico medio al Neolítico final) en la Cueva de Ardales y Sima de Las Palomas de Teba (Málaga). Estudio geoarqueológico, cronológico y medioambiental, aprobado por un periodo de estudio de cuatro años. En el marco del Proyecto, se enmarcan dos prospecciones arqueológicas vinculadas a los ríos Guadalteba y Turón, esta última bajo mi dirección y con una duración de dos meses cada una.

Una vez establecida el área de prospección, unos 106 km² para la cuenca del Turón y $200 \mathrm{~km}^{2}$ para la cuenca del Guadalteba, iniciamos los trabajos de campo, con 4 personas en total. Establecimos como sectores de prospección selectiva los yacimientos descritos en los planeamientos urbanísticos de dichos municipios, con el fin de constatar la adscripción cronológica de los enclaves prehistóricos. Así mismo, las zonas no prospectadas debían ser objeto de una prospección intensiva, centrándonos en los entornos fluviales y en aquellas zonas susceptibles de ocupación durante la Prehistoria, en función de las estrategias de distribución territorial de las sociedades cazadorasrecolectoras.

El equipo, bajo la supervisión de los dos directores, desarrolló la prospección con un recorrido lineal y en paralelo sobre el terreno, con trayectos que cubran los $10 \mathrm{~m}$ de anchura hasta ocupar toda la superficie de la zona en proceso de prospección. De este modo, cada técnico arqueólogo se encargará de visualizar $5 \mathrm{~m}$ a ambos lados de su 
persona durante cada recorrido lineal. En los casos en que la orografía del terreno es más complicada, debido a la presencia de cortados, promontorios acusados u otros accidentes, se estableció una visualización más detenida y exhaustiva de la superficie.

Igualmente, durante los trabajos de campo se realizó una documentación fotográfica donde quedará recogido cualquier resto arqueológico inmueble emergente, como también los nuevos yacimientos arqueológicos, que aunque no cuenten con restos estructurales, puedan identificarse a través de la concentración de cultura material mueble.

En la salida al campo, el equipo de prospección contaba con el material mínimo indispensable: cámara de fotos, bolsas de plástico, cintas métricas, brújula, lápices, mapas topográficos, cuaderno... Se han realizado unos modelos de fichas (figura 10) en las que se recogió el contexto ambiental del yacimiento documentado, su tamaño, el tipo de materiales que se encuentran, la posible función y cronología, el estado de conservación, el acceso, etc.

Los hallazgos fueron posicionados mediante GPS capaz de georreferenciar mediante coordenadas UTM ETRS89 ZONA 30 cualquier punto susceptible de interés arqueológico a través de lecturas tanto horizontales como verticales (cotas absolutas medidas sobre el nivel del mar), y los datos volcados en la cartografía del área de estudio. Se evaluaron además, los procesos post-deposicionales que pudieron alterar la distribución superficial de los artefactos: procesos naturales como la erosión y culturales como el movimiento y la destrucción del registro arqueológico provocado por las actividades agrícolas.

La recogida fue selectiva, no siendo posible recoger todos los productos arqueológicos de un yacimiento, tanto por cuestión de operatividad, como para permitir estudios posteriores. Estos se fueron recuperando con sumo cuidado y con metodología arqueológica, después de verificar su ubicación exacta, y su contexto microespacial, se procedió, a su documentación gráfica y fotográfica. Los objetos fueron recogidos y guardados en bolsas de plástico con sus respectivas etiquetas para proceder a su lavado y siglado en el laboratorio.

Aunque el inicio de las campañas de excavación coincidió con la finalización de mi tesis doctoral, pudimos localizar dos yacimientos arqueológicos, uno con industrias asociadas al Paleolítico inferior y otro al Paleolítico medio que han sido incorporados a este trabajo. 


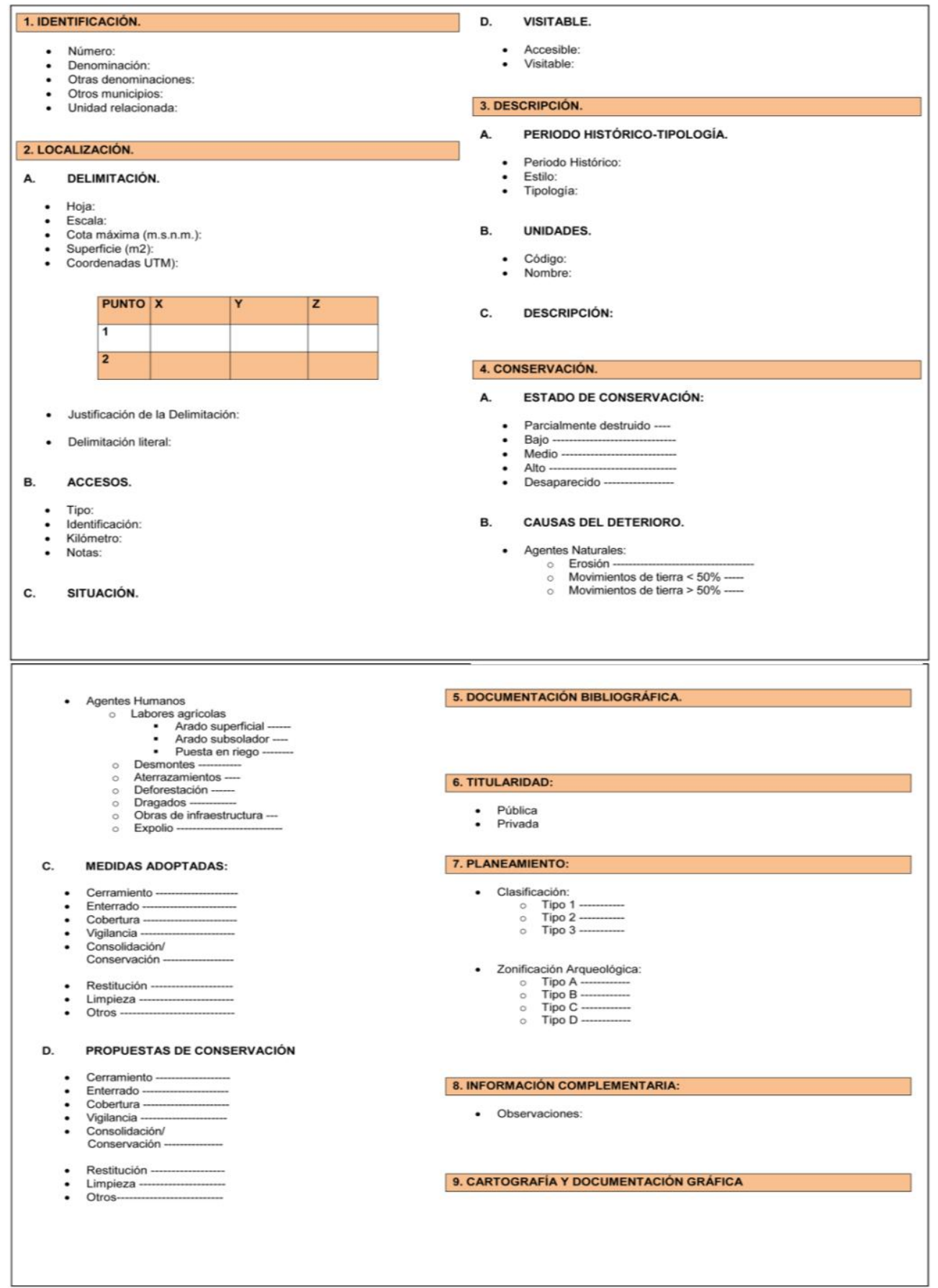

Figura 10. Modelo de ficha utilizado para los hallazgos arqueológicos. 


\subsubsection{Trabajo de laboratorio: estudio de las colecciones líticas}

El trabajo de laboratorio es ya la última etapa de los trabajos de prospección y se ha planteado en paralelo a las actividades arqueológicas dentro del P.G.I, donde el material recuperado será lavado y siglado y dibujado. Posteriormente procederemos al análisis de la tecnología y la tipología de cada uno de ellos para intentar establecer correctamente su adscripción cultural.

\subsubsection{Planteamientos teóricos y metodológicos para el estudio de las colecciones.}

Los estudios sobre industria lítica tienen su origen a finales del siglo XIX con los trabajos experimentales de Sir J. Evans, para demostrar que los objetos de piedra encontrados por J. Boucher de Perthes, en los yacimientos en terrazas, eran fruto del trabajo de la talla realizada por los hombres y no originados por procesos naturales (De la Peña Alonso, 2007: 2). Sin embargo, no será hasta los años 80 del siglo XX, cuando los estudios sobre los conjuntos líticos se desarrollen desde un punto de vista tecnológico, comportando un cambio conceptual, frente a las concepciones culturales y cronológicas de los estudios tipológicos anteriores se establece la importancia de la conducta social en la fabricación de esa tecnología.

Los primeros investigadores, sobre todo ingleses y franceses, “clasificaron el material lítico utilizando una nomenclatura basada tanto en prejuicios culturales, como en comparaciones etnográficas discutibles, o en otros factores subjetivos ligados a la preparación y al medio cultural de cada uno de ellos" (Querol Fernández et al.,1981: 113).

Se generará un interés por distinguir entre aquellos objetos producto de la naturaleza y los fabricados por el hombre, propiciando en los primeros momentos de la arqueología prehistórica, a principios del siglo XX, el desarrollo de dos corrientes teóricas, la evolucionista lineal y la historicista cultural, donde el material lítico se convierte en la principal fuente de estudio para las sociedades de la Prehistoria.

En estos primeros años de la Arqueología, la aproximación que se hacía al estudio de la lítica era desde el punto de vista tipológico (De la Peña Alonso, 2007: 2), donde el útil constituía la base principal de investigación. Estos útiles eran interpretados como marcadores culturales y se consideraban como el fósil-director, el "concepto procedente de la Paleontología, sustituyendo el papel de marcador cronológico de un fósil por una determinada herramienta" (Carbonell et al., 2011: 53), y con ello determinar la adscripción cultural a la que pertenecían dichos útiles. Se pensaba "que su 
sucesión indicaba una evolución tecnológica -que entonces se creía unilineal (Prous Poirier, 2004: 21). Los primeros investigadores de esta corriente evolucionista unilineal, como E. Lartet o G. de Mortillet, establecieron "tipologías de base morfológica" (Prous Poirier, 2004: 21) para los útiles en piedra y hueso.

Junto a esta corriente evolucionista unilineal, se desarrolló la historicistacultural. Sus máximos representantes H. Breuil y D. Peyrony, pasaron "de una visión de evolución única a un modelo basado en los mismos parámetros pero con diferentes culturas paralelas" (De la Peña Alonso, 2007: 2-3).

Desde mediados del siglo XX, se desarrollan dos nuevas corrientes europeas. Por un lado la cultural y empírica, cuyo máximo representante es F. Bordes. Se sustituye la noción de fósil-director y se inicia el uso de la estadística cuantitativa aplicada a la tipología para el estudio de las industrias (Muñoz Ibáñez, 2002: 303-302), surgiendo así “las verdaderas «tipologías»” (Querol Fernández et al., 1981: 114) como las listas-tipo de Bordes y Bourgon, para el Paleolítico inferior y medio o SonnevilleBordes y Perrot para el Paleolítico superior, aparece un interés por la tecnología y la talla experimental de manos del mismo F. Bordes, J. Tixier en Francia y D. Cratbree en Estados Unidos con posterioridad. A partir de los años 60 se asiste a una crítica de esas listas-tipo, "por una excesiva intuición, subjetivismo y falta de rigor al incluir en uno u otro tipo cada pieza retocada" (Muñoz Ibáñez, 2002: 303-302).

Frente a la concepción empirista de F. Bordes, surge la figura de G. Laplace, de corte estructuralista, que junto a A. Lamming-Emperaire pretenden establecer un sistema de clasificación "a partir de la descripción minuciosa de los objetos" (Prous Poirier, 2004: 21) es entonces cuando crea la "Tipología analítica y estructural influencia del estructuralismo y de los planteamientos y sistemas de ordenación derivados de la Paleontología" (Carbonell et al., 2011: 53).

Los cambios que acontecerán, en años posteriores, en la concepción de los estudios de industria lítica y que darán origen a nuevas corrientes metodológicas, hay que buscarlos en la influencia de la escuela anglosajona, con una visión procesualfuncionalista frente al empirismo de la escuela francesa, con la aparición de la New Archaeology, de manos del americano L. Binford y del británico D.L. Clarke, dicha influencia junto a la "introducción de enfoques sistémicos en la investigación [..] generarán un cambio en la valoración de los artefactos "(Terradas, 2001: 29-30), 
considerándolos como el resultado de uno o varios procesos cuyo estudio permitirá la reconstrucción de actividades tecnológicas desde diferentes puntos de vista.

Ante esta nueva situación surge la corriente paleoetnológica, de corte estructuralista, representada por A. Leroi-Gourhan. Este autor reintrodujo el término, de M. Mauss, de "chaîne opératoire” que supuso una de las principales herramientas conceptuales y metodológicas para el estudio de tecnología lítica (De la Peña Alonso, 2007: 2-3). A partir de sus trabajos el desarrollo y la aplicación de una perspectiva tecnológica adquirió especial relevancia, era más importante la dimensión social en las actividades técnicas (Mora Torcal et al., 2008: 5)

Estos nuevos "estudios tipológicos,.. que parten del concepto de cadena operativa, "estaban basados en un enfoque procesual de los sistemas técnicos ya que considera imprescindible estudiar las fases de la producción de los objetos, desde el aprovisionamiento de la materia prima hasta su utilización y abandono" (Carbonell et al., 2011: 54).

El desarrollo de este concepto también influyó en los años 80 del siglo XX en Francia, donde surge la escuela de tecnología cultural, "es decir, de los estudios etnográficos centrados en la actividad técnica" (Cortés Sánchez, 2007: 19), sus principales representantes son, B. Creswell, H. Balfet o P. Lemonnier y consideran el material lítico como resultado de un "proceso técnico" (De la Peña Alonso, 2007: 2-3).

En esta nueva corriente está el origen de los estudios tecnológicos frente a los tipológicos, surgidos a principios del siglo XX. La principal diferencia respecto a los anteriores estudios tipológicos se centra en dos aspectos: la morfología del útil aunque necesaria no es lo fundamental, ya que la importancia radica en la fabricación de los artefactos y no en el resultado final y "en la necesidad de estudiar el conjunto de materiales originados a lo largo del proceso de producción, siendo igual de importantes todos los desechos de fabricación que constituyen el grueso de los conjuntos arqueológicos" (Vaquero, 2011/2012: 233-234). Junto a los autores anteriormente citados, mencionar a J.M. Geneste y E. Boëda "por su aportación a través de las proposiciones nacidas de la práctica experimental" (Cortés Sánchez, 2007:19), todos ellos desde el punto de vista teórico, han contribuido a delimitar "un sistema analítico de profundo calado deductivo" (Cortés Sánchez, 2007:19). Ambos autores, se enmarcan dentro las tendencias actuales de estudio de la tecnología lítica, como son la perspectiva tecno-económica (Geneste), que tiene como objetivo analizar desde un punto de vista económico y social el comportamiento técnico humano 
influenciado a su vez por aspectos espacio-temporales (Terradas Batlle, 2001: 49) y la perspectiva tecno-psicológica (Boëda), cuyo objetivo es "determinar los conocimientos que participan en todo sistema técnico de producción lítica” (Terradas Batlle, 2001: 42), su objeto de conocimiento es el comportamiento técnico que abarca desde los componentes materiales de la cadena operativa y la selección y control de estos materiales.

En España, también en la década de los 80 del siglo XX, se asiste al desarrollo del Sistema Lógico Analítico (SLA), bajo la dirección de E. Carbonell, como crítica al carácter tipológico cultural de los sistemas de clasificación empíricos tradicionales. Desde el punto de vista teórico se fundamenta en tres líneas de pensamiento, la tipología analítica de G. Laplace, pero prescindiendo de su componente tipológico, la arqueología analítica y sistémica de L. Clarke y la lógica histórica de D. Thompson, en la búsqueda de información que permita realizar inferencias sobre los grupos humanos del Pleistoceno y recoge además la perspectiva procesual del estudio de las cadenas operativas (Carbonell et al., 2011: 54). Este sistema "ofrece un nuevo enfoque al estudio de los tecnocomplejos, analizando los aspectos tecnológicos y procesuales en la génesis del conjunto sin centrarse únicamente en las características morfológicas y estilísticas, ni en unos objetos determinados" (Lombera Hermida, 2005: 8).

El desarrollo de estas corrientes teóricas en el estudio de la industria lítica generaron a su vez diferentes modelos sobre el problema de "variabilidad" de los conjuntos líticos del Paleolítico, sobre todo en el Musteriense, cuyo debate después de 60 años aún sigue vigente. Se han puesto de manifiesto numerosos factores que pueden incidir en esta variabilidad, tales como las materias primas, problemas de continuidad en el entorno, o incluso grupos culturales distintos, entre otras muchas causas. Este intenso debate ha generado la creación de modelos explicativos en un intento de determinar las causas que originaron dichas variantes.

Es necesario establecer en primer lugar una visión general de los inicios al estudio del Musteriense, y la posterior evolución de los diferentes modelos propuestos.

El término Musteriense es utilizado por primera vez por G. de Mortillet en 1869 y definido con anterioridad por L. Lartet en 1865 como “L'époque du Moustier". En 1905, H. Bourgon en las excavaciones de la cueva de Le Moustier distingue varios niveles arqueológicos con "contenidos lo suficientemente parecidos como para mantener el término Musteriense” (Leroi-Gourhan, 2002: 295-297), con posterioridad 
en 1930, D. Peyrony propone denominar Musteriense de tradición Achelense al Musteriense arcaico con bifaces, en 1951, el abate H. Breuil establece una nueva división no cronológica del Musteriense distinguiendo entre Achelense, Tayaciense o Levalloisiense (Leroi-Gourhan, 2002: 295-297), entre los años 1947 y 1955, F. Bordes y H. Bourgon desarrollan un sistema de análisis para el estudio de las industrias del Paleolítico medio e inferior y en 1966, L. Binford discute las teorías de F. Bordes y plantea la hipótesis de una diferente funcionalidad y no de grupos étnicos (Carbonell et al., 1983: 77).

Debemos centrarnos ahora en explicar los diferentes modelos surgidos desde la primera ordenación de F. Bordes, quién abrió el debate en cuanto a las causas de la variabilidad de las industrias líticas del Paleolítico, con anterioridad a este modelo las primeras referencias que existen sobre la variabilidad musteriense se remontan a principios del siglo XX, cuando D. Peyrony tras excavar varias cuevas francesas (Le Moustier, la Ferrassie..etc.,) estableció la secuencia Musteriense regional. Entendía que la variabilidad musteriense debía situarse en relación con la cronología y con pueblos diferentes dentro de un mismo territorio que aprovechaban los mismos abrigos (Turq, 2007: 120), sin embargo, hasta la tipología de Bordes, en el estudio de la secuencia musteriense únicamente eran válidos los artefactos retocados (Carbonell et al., 2011: $518)$.

En los años 50, destaca la figura de F. Bordes quién establece los "criterios de clasificación técnica y tipológica de las industrias musterienses" (Leroi-Gourhan, 2002: 295) y las del Paleolítico inferior. En su clasificación tipológica describe las facies del utillaje sobre lascas (lascas, puntas, raederas, raspadores, buriles,...), del utillaje bifacial y los núcleos y con su clasificación técnica estudia los tipos de talla existentes (Merino, 1994: 249). Pretendía con ello organizar el paleolítico inferior y medio, a través de la morfología de los bifaces y la evolución del método levallois, teniendo en cuenta los útiles sobre lascas y su facetado. Distinguió cinco grupos de musteriense: Musteriense de tradición Achelense, Musteriense típico, Musteriense de denticulados, Musteriense tipo Ferrassie y Musteriense tipo Quina. Al comprobar que la variabilidad técnica no se explicaba a través de la cronología, el medio o la tecnología, ni siquiera con los cambios climáticos o geográficos los interpretó como cambios culturales (Leroi-Gourhan, 2002: 296), en clara concordancia con la corriente de pensamiento de F. Bordes, imperante en esa época, el historicismo-cultural, donde las facies estudiadas eran un indicador de la identidad étnica de los grupos. 
La principal crítica a la interpretación de F. Bordes partió de dos investigadores dentro de una nueva corriente de la Nueva Arqueología, el funcionalismo. Se trata de L. y S. Binford. Aunque esta corriente no se cuestiono los presupuestos empíricos sobre la definición de las facies ni la concepción de los artefactos establecida por Bordes (Carbonell et al., 2011: 520), si consideraba que las diferentes facies no era producto de grupos étnicos o diferentes culturas sino que la variabilidad era funcional, asociados a actividades específicas. Sin embargo, este modelo sufre un fuerte revés al iniciarse los estudios sobre las huellas de uso que demostrarían que diferentes útiles han sido utilizados para las mismas actividades. Todo ello "contribuye a que la variabilidad deje de ser leída de forma exclusiva en clave cultural" (Sánchez Yustos, 2012: 31).

Otra de las alternativas a este debate ha sido la de P. Mellars, conocido esencialmente por su vertiente cronológica. Critica el concepto de funcionalidad de los Binford por considerar que la variabilidad musteriense no responde a una causa única. Opina que las facies del Musteriense tipo Ferrassie, tipo Quina, y el Musteriense de tradición Achelense se solapan en este orden cronológicamente y de forma independiente, basándose sobre todo en el yacimiento de Combe Grenal. Su hipótesis fue corroborada con posterioridad por nuevas dataciones en varios yacimientos de Francia (Leroi-Gourhan, 2002:296). En cuanto al Musteriense típico, lo considera un cúmulo de útiles mal caracterizados, mientras que el Musteriense de denticulados ocupa una posición marginal. Sin embargo, el problema de este planteamiento se debe a que no es extensible a otros territorios donde existen tecnocomplejos musteriense, limitándose exclusivamente a yacimientos del Perigord (Francia) que habían sido los estudiados por P. Mellars (Carbonell et al., 1983: 82).

Los modelos vistos anteriormente responden a una explicación meramente tipológica, a posteriori con el surgimiento de los nuevos estudios tecnológicos surgen nuevos modelos para explicar esa variabilidad técnica.

Uno de estos nuevos modelos es el de la reducción lítica de H. L. Dibble, según este autor y en palabras de E. Carbonell, "los distintos tipos de raederas diferenciados en la lista de Bordes eran en realidad el resultado del grado de reconfiguración diferencial de los soportes, de tal manera que, a medida que un artefacto se iba reconfigurando, pasaba de un tipo a otro" (Carbonell et al, 2011: 520), siendo el fenómeno menos acusado dependiendo de la cantidad de materia prima que exista. La premisa de Dibble, iba enfocada a tener en cuenta varios aspectos, por un lado el grado 
de reducción de la pieza y por otro que la reducción afecta a la superficie de la lasca y no al plano de percusión. Este autor junto con A. Jelinek defendieron la relación entre raederas y denticulados, donde los últimos se encontraban en un momento anterior respecto a las raederas en la cadena operativa (Colino Polo, 2007:5).

H. Dibble junto a N. Rolland, opinan que dentro de los muchos factores que influyen en la variabilidad musteriense, "la disponibilidad de materias primas y el patrón de asentamiento, definido por las pautas de movilidad y la intensidad/duración de las ocupaciones" (Carbonell et al., 2011: 522) eran un punto clave para comprender dicha variabilidad. N. Rolland por su parte relaciona los cambios climáticos con las variaciones dentro de la industria musteriense (Rolland et al., 1990:488). H. Laville también es partidario del factor climático para la variabilidad Musteriense, quien en los años 70, en sus trabajos en el Perigord, mostró por medio de análisis geológicos la existencia continuada de las distintas facies dentro desde los inicios de Würm.

Para S. Kuhn, tras estudiar varios yacimientos italianos, la variabilidad musteriense está en función de las modalidades de aprovisionamientos de las materias primas en el marco de los procesos de transporte (Carbonell et al., 2011:522). Las ideas de S. Khun son seguidas por otros autores como J.M Geneste, L. Meignen, A. Delagnes o A. Turq cuyos trabajos establecen que algunos útiles, como las raederas, sufren un proceso de transporte mayor entre los lugares de ocupación a diferencia de otros menos móviles, ocurre lo mismo con el proceso de selección de las materias primas, transportándose aquellos materiales más aptos para la talla y los que necesitan “estrategias más exigentes, como la talla levallois" (Carbonell et al., 2011: 522) sugiriendo un fuerte componente contextual y por tanto no pueden reducirse a un único aspecto para explicar la variabilidad musteriense, basándose en una variabilidad diacrónica y una correlación funcional y ecológica (De la Torre et al., 2013).

El resto de industrias del Paleolítico presentan una enorme variabilidad, pero en el caso de las industrias del Paleolítico superior las pautas de variación están mejor definidas lo que permiten una mejor caracterización de las entidades culturales (Carbonell et al., 2011: 542). La aparición de los estudios tecnológicos generó un nuevo punto de vista donde "la variabilidad tecnológica se enmarcaba dentro de los procesos económicos y medioambientales en que se activan las estrategias de gestión de los recursos líticos” (Sánchez Yustos, 2012: 28).

F. Bordes fue el que sistematizó la tipología del Achelense, configurándose como un fenómeno de gran variabilidad tanto a nivel geográfico como temporal (Colino 
Polo, 2007: 2). Para el Paleolítico superior D. de Sonneville-Bordes y J. Perrot, establecen un sistema tipológico cerrado. Sonneville-Bordes lo hace por medio del método estadístico y opina que el paso al Paleolítico superior se debe al Musteriense de tradición Achelense.

Con anterioridad a los años 70 los estudios que se realizaban sobre los conjuntos líticos del Auriñaciense y del Gravetiense, seguían los modelos de clasificación franceses, en su mayoría. Autores como H. Breuil que discutió y argumentó la posición del Auriñaciense en las secuencias francesas definiendo tres momentos en función de fósiles directores, H. Obermaier que "consideraba que todo el área sur y mediterránea peninsular había estado influida y ocupada por el Capsiense inferior, una especie de Auriñaciense africano con abundante utillaje de dorso" (De la Peña,2009: 30-31). M. Almagro Basch siguiendo D. Peyrony o L. Pericot y F. Jordá identificaban a los conjuntos auriñacienses y gravetienses como culturas o étnias paralelas explicando los sucesivos cambios a través de las migraciones. En el caso del Solutrense "su variabilidad era interpretada de manera unifocal como fases evolutivas" (Strauss, 2012: 28). Para autores como L.G. Strauss, la variabilidad del Solutrense no estaba relacionada con la etnicidad o la evolución tecnológica en abstracto, sino que se debía a varios factores tales como el clima, el medio ambiente, la litología y la función del yacimiento (Strauss, 2012: 30). Las industrias del Magdaleniense superior presenta una diversidad cultural, la cual no se explica por la cronología sino que debe estar más en función de variaciones regionales, locales o incluso funcionales (Olaria Puyoles, 1999: 25).

\subsubsection{Planteamiento teórico y metodológico aplicado al estudio de nuestras colecciones líticas}

En el estudio de las sociedades cazadoras-recolectoras del Pleistoceno, el análisis de las colecciones líticas constituye un elemento clave para comprender la interactuación de estos grupos dentro de un espacio y un territorio determinado, las características de los distintos territorios marcarán unas pautas de comportamiento técnico y social que explicarían la variabilidad técnica de las industrias líticas.

El objetivo principal de esta tesis es reconocer e interpretar la movilidad de estos grupos humanos dentro del territorio que constituye el curso bajo del río Guadalteba y del río Turón, en función de los yacimientos conocidos y las nuevas localizaciones 
obtenidas a través de la prospección arqueológica y los diferentes muestreos de los afloramientos con materiales primarios y secundarios. La comparación de los datos obtenidos de las diferentes localizaciones permitirá establecer una visión general sobre la movilidad de las materias primas desde el lugar de captación hasta su lugar de transformación, utilización y posterior abandono en relación con los asentamientos estudiados, desde una perspectiva tecno-económica, no centrándome exclusivamente en el estudio tecnológico sino en datos arqueológicos exteriores, ya que considero tal y como expone $\mathrm{X}$. Terradas, que la combinación de "parámetros tecnológicos con aspectos espacio-temporales ofrecen una perspectiva más global, dinámica $e$ integradora" (Terradas, 2001: 49), puesto que si nos basamos exclusivamente en los aspectos tecnológicos de los complejos industriales obtendríamos una visión sesgada del proceso de transformación de la materia prima desde su obtención hasta la elaboración del artefacto y los restos resultantes del proceso de talla.

Los estudios tipológicos, desarrollados en el apartado anterior, agrupaban los artefactos morfológicamente en tipos según sus atributos morfológicos, el principal problema radica en la importancia que se le otorgaba a los objetos retocados, con una gran carga de subjetividad a la hora de estudiar los conjuntos al agruparlos en categorías o tipos fijos (Lombera Hermida, 2005: 8), olvidando los procesos que dan lugar a estos artefactos y los factores que pueden incidir en ellos.

El sistema de clasificación utilizado para el estudio de nuestras colecciones líticas será el Sistema Lógico Analítico (SLA), el cual organiza y clasifica los objetos líticos y a su vez contextualiza el conjunto industrial, distinguiendo categorías estructurales y no tipos, donde los objetos líticos son estudiados desde tres modos de análisis (Carbonell et al.,2011: 55):

- morfotécnico: estudio analítico de los rasgos de cada objeto.

- morfopotencial: capacidad teórica de intervención sobre la materia de una determinada estructura morfotécnica.

- morfofuncional: experimentación y observación mediante microscopio de los filos de los objetos.

Este tipo de análisis nos permite superar las tipologías y avanzar en el conocimiento de las técnicas, de las herramientas, de las funciones e incluso de los procesos de trabajo y modos de vida de estas sociedades del Pleistoceno (Ramos Muñoz et al., 2014: 156). 
Para el estudio de los conjuntos líticos se han utilizado unas tablas descriptivas que sirvieron para el estudio analítico de los materiales estudiados en las actividades arqueológicas puntuales realizadas entre 2011-2014 en la Cueva de Ardales y Sima de Las Palomas (Teba), con algunas modificaciones, las cuales serán explicadas en el capítulo 5 (tabla 1, 2, 3). En el estudio analítico de la industria lítica se consideran los datos relativos a la materia prima, rodamiento, color, pátina, termoalteración, tipo de núcleo, tipo de base negativa, el carácter facial, centrípeto, el de oblicuidad y el de profundidad, así como el carácter de la arista frontal y sagital y los temas operativos técnicos.

\begin{tabular}{|c|c|c|c|c|c|c|c|c|c|c|c|c|c|}
\hline \multicolumn{14}{|c|}{ YACIMIENTOS ARDALES. ESTUDIO ANALÍTICO DE LAS BN1G } \\
\hline \multicolumn{2}{|r|}{ Nombre } & \multicolumn{4}{|c|}{ Materias primas y morfología } & \multicolumn{2}{|c|}{ Tipos de bases negativas } & \multicolumn{5}{|c|}{ Criterios analíticos de las BN1G } & \multirow[t]{2}{*}{ Tema operativo técnico } \\
\hline \multicolumn{2}{|c|}{ T. Grajeras } & M & $R$ & \begin{tabular}{|l|l|}
$C$ & $P$ \\
\end{tabular} & $T$ & TN & $\mathrm{BN}$ & $\mathrm{CF}$ & $\mathrm{CC}$ & $\mathrm{CO}$ & $\mathrm{CP}$ & \begin{tabular}{|l|l|} 
CAF & CAS \\
\end{tabular} & \\
\hline \multicolumn{14}{|c|}{ LEYENDA DEL ESTUDIO ANALÍTICO DE LAS BN1G } \\
\hline \multirow[t]{25}{*}{ № SIGLA } & \multirow{6}{*}{$\begin{array}{l}\text { M: MATERIA PRIMA } \\
\text { S:Silex } \\
\text { A:Arenisca compacta } \\
\text { R: Radiolarita } \\
\text { CU:Cuarcita } \\
\text { O: Otros } \\
\end{array}$} & & \multirow{4}{*}{\multicolumn{2}{|c|}{$\begin{array}{l}\text { CF: CARÁCTER FACIAL } \\
\text { U: Unifacial } \\
\text { B: Bifacial } \\
\text { T: Trifacial } \\
\end{array}$}} & \multirow{6}{*}{\multicolumn{4}{|c|}{$\begin{array}{l}\text { CP: CARÁCTER DE PROFUNDIDAD } \\
\text { mm: muy marginal } \\
\text { m: marginal } \\
\text { p: profundo } \\
\text { mp: muy profundo } \\
\text { t: total } \\
\end{array}$}} & \multirow{3}{*}{\multicolumn{2}{|c|}{$\begin{array}{l}\text { TOT:TEMA OPERATIVO TÉCNICO } \\
\text { T.O.T.I: TEMA OPERATIVO TÉCNICO INDIRECTO } \\
\text { T.O.T.D: TEMA OPERATIVO TÉCNICO DIRECTO }\end{array}$}} \\
\hline & & & :Inicio & talla & & & & & & & & & \\
\hline & & & & & & & & & & \\
\hline & & & :Bipola & & & & & & & & & & \\
\hline & & \multicolumn{4}{|c|}{ L:Levallois } & \multirow{2}{*}{\multicolumn{2}{|c|}{ CC: CARÁCTER CENTRÍPETO }} & & & & & & \\
\hline & & & Centri & & & & & & & & & & \\
\hline & R: RODAMIENTO & \multicolumn{4}{|c|}{ POL: Multipolar poliedrico } & \multicolumn{2}{|c|}{ C: $1 / 8$ a $3 / 8$} & \multirow{2}{*}{\multicolumn{4}{|c|}{ CAF: CARACTER ARISTA FRONTAL }} & & \\
\hline & P:Poco & & :Prism & & & $2 \mathrm{C}: 3 /$ & & & & & & & \\
\hline & M:Medio & \multicolumn{4}{|c|}{ SL: Sobre lasca } & \multicolumn{2}{|c|}{ 3C: $5 / 8$ a $7 / 8$} & \multicolumn{4}{|c|}{ cc: concavo } & & \\
\hline & B:Bastante & \multicolumn{4}{|c|}{ DIV: Diverso } & \multirow{2}{*}{\multicolumn{2}{|c|}{$\begin{array}{l}\text { 4C: zona tallada ocupa } \\
\text { todo el borde }\end{array}$}} & \multicolumn{4}{|c|}{ rt: recto } & & \\
\hline & C: COLOR & & N: BAS & EGATIVA & & & & CAS: & ARÁCTE & ISTA & GITAL & & \\
\hline & R:Rojo & & N1GC: & se negativa de & & $\mathrm{CO}: \mathrm{C}$ & OBLICUIDAD & inc: $i$ & urvada & & & & \\
\hline & B: Beige & & agener & ión de & & P:Plar & & $\sin : s$ & uosa & & & & \\
\hline & G:Gris & & onfigur & & & SP: Se & & rt: re & & & & & \\
\hline & N: Negro & & N1GE: & enegativa de & & s:Sim & & & & & & & \\
\hline & 0: Otros & & gener & ión de & & SA:Se & & & & & & & \\
\hline & P: PÁTINA & & xplotac & & & A: Abr & & & & & & & \\
\hline & B:Blanca & & & & & & & & & & & & \\
\hline & A: Amarilla & & & & & & & & & & & & \\
\hline & R:Roja & & & & & & & & & & & & \\
\hline & G:Gris & & & & & & & & & & & & \\
\hline & 0: Otros & & & & & & & & & & & & \\
\hline & T:TERMOALTERADA & & & & & & & & & & & & \\
\hline & $\mathrm{Si}$ & & & & & & & & & & & & \\
\hline & No & & & & & & & & & & & & \\
\hline
\end{tabular}

Tabla 1. Modelo de presentación de los datos de las BN1G. Tabla y leyenda. 


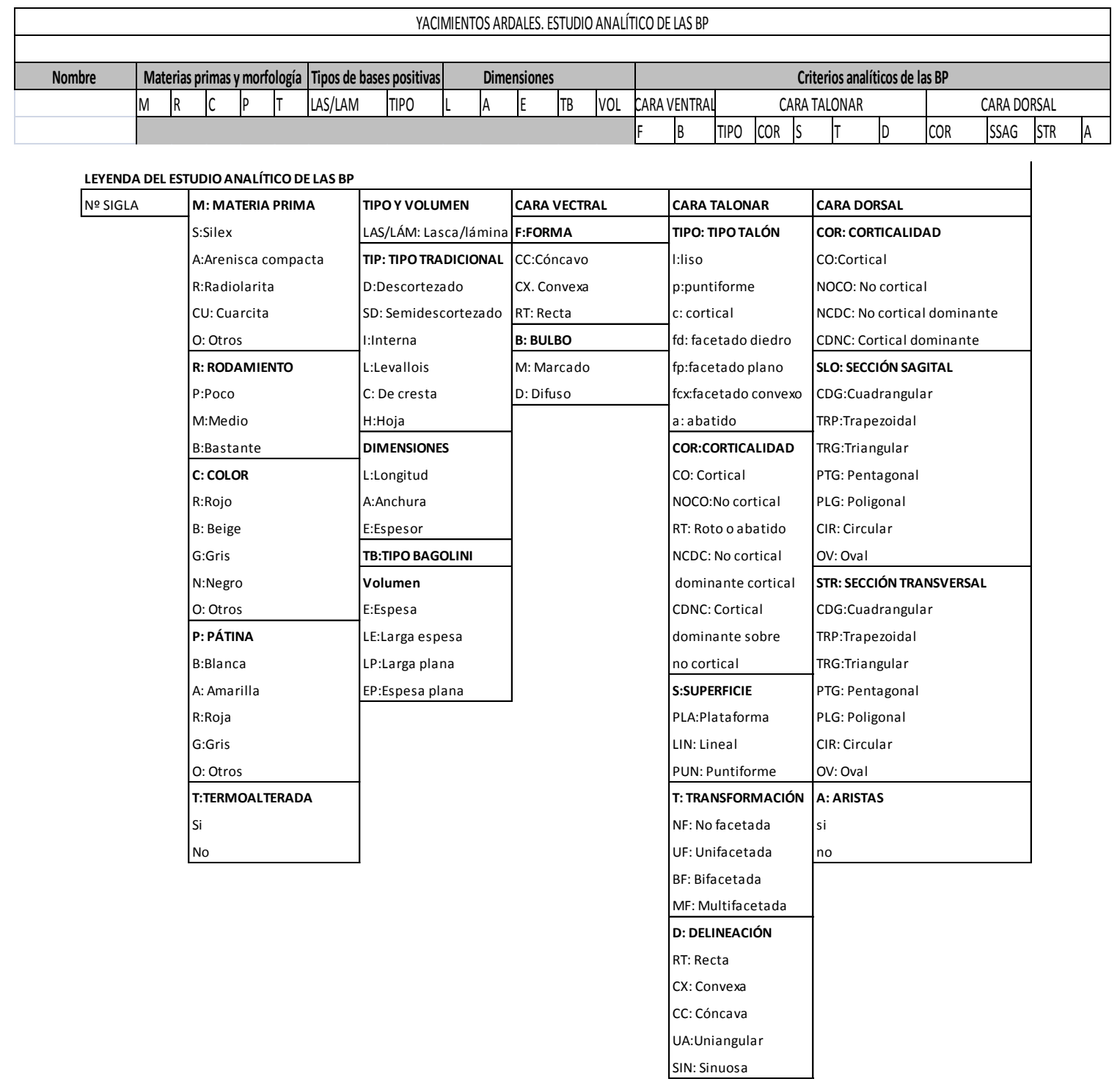

Tabla 2. Modelo de presentación de los datos de las BP. Tabla y leyenda

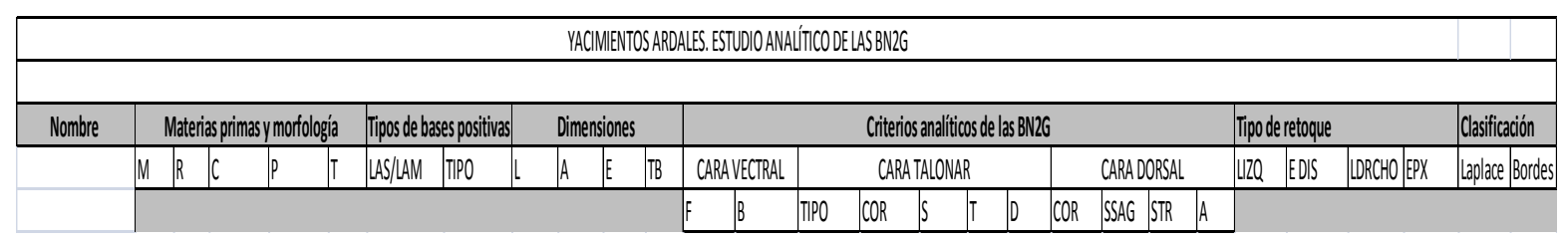

\begin{tabular}{|c|c|c|c|}
\hline \multicolumn{4}{|c|}{ LEYENDA DEL ESTUDIO ANALITICO DE LOS MODOS DE RETOQUE DE LAS BN2G } \\
\hline $\begin{array}{l}\text { Modos } \\
\mathrm{s}=\text { Simple } \\
\mathrm{a}=\text { Abrupto }\end{array}$ & $\begin{array}{l}\text { Amplitud } \\
m=\text { Marginal } \\
p=\text { Profundo }\end{array}$ & \multirow{2}{*}{$\begin{array}{l}\text { Dirección } \\
\text { d= Directo } \\
\text { i= Inverso } \\
\text { a = Alterno } \\
\text { b= Bifaz }\end{array}$} & \multirow{2}{*}{$\begin{array}{l}\text { Delineación } \\
\text { c= Continua } \\
\text { e= Con muesca } \\
\text { d = Denticulado }\end{array}$} \\
\hline $\begin{array}{l}\mathrm{p}=\text { Plano } \\
\text { se= Sobreelvado }\end{array}$ & & & \\
\hline
\end{tabular}

$\mathrm{e}=$ Ecaille

Tabla 3. Modelo de presentación de los datos de las BN2G. Tabla y leyenda 


\subsection{Aprovisionamiento de materias líticas, técnicas de identificación de materias primas}

El inicio de este tipo estudios no está del todo claro y parece ser que los trabajos de A. F. Stukeley en 1740 en Stonehenge fueron los primeros, así en Gran Bretaña surge en el siglo XVII la investigación geológica y en el siglo XIX, las bases de la petrología moderna (Terradas Batlle, 2001: 29), ya en 1982 destaca la figura de P. Y. Demars que tras la publicación de sus tesis en Francia dio origen en nuestro país al desarrollo de los primeros estudios para la caracterización de materias primas en base a criterios de orden macroscópico, en la actualidad se está asistiendo a una aproximación prehistórica a la disciplina geológica (Mangado Llach, 2000: 12-13).

En el desarrollo de los procesos de gestión de los recursos minerales por parte de los grupos humanos del Pleistoceno, las distintas actuaciones desarrolladas en el medio ambiente donde se articulan, reflejan una serie de estrategias cuya reconstrucción nos permitirá caracterizar (Terradas Batlle, 2001: 96), entre otras actividades el aprovisionamiento de materias líticas, comprendiendo la articulación de estos grupos en el territorio en función de la mayor o menor disponibilidad de materias primas, de su calidad y los patrones de selección de estos materiales según estén en posición primaria (afloramientos rocosos y sus depósitos) o en posición secundaria (terrazas fluviales). A nivel general, podemos decir que el aprovisionamiento de material lítico durante el Paleolítico inferior aparece en base a una materia prima principalmente local, influenciadas por la movilidad y duración de la ocupación y será en momentos del Paleolítico medio y superior cuando se asiste a una movilidad mayor para la obtención de ciertos materiales (Conde Ruiz et al., 2000: 148), siendo mayoritarios en todas las fases "los mecanismos de captación [..] de fuentes de aprovisionamiento de tipo secundario" (Mangado Llach, 2000: 13).

Para determinar la movilidad de estos grupos en relación a sus áreas de captación, utilizaremos una serie de técnicas analíticas propias de la Arqueometría adecuadas para la consecución de nuestros objetivos, aunque existen más técnicas explicaremos únicamente las que se han utilizado en el desarrollo de nuestra investigación.

\section{Macroscopía u observación de visu}

La primera observación de materias primas e industria lítica se realiza de visu normalmente a pie de campo y posteriormente en el laboratorio, este examen de sílex 
constituye la forma más rápida y sencilla para una primera clasificación, que posteriormente será corroborada en el laboratorio.

Varios son los elementos que pueden ayudar en la diferenciación y clasificación de los sílex.

- Aspecto externo del nódulo: forma, tamaño, córtex, fósiles

- Aspecto interno del sílex: transparencia, textura, color, microfósiles

Lo primero que distinguimos son los colores de las distintas litologías basándonos en la carta de colores Munsell (Munsell @ Soil Color Charts, 1994), utilizaremos igualmente una lupa binocular para observar texturas visibles o fósiles, lo que permitirá distinguir los diferentes tipos de sílex, como masivos, bandeados $\mathrm{u}$ oolíticos, también para las cuarcitas, areniscas o radiolaritas y de ese modo establecer una discriminación preliminar entre el conjunto de materiales arqueológicos objeto de estudio.

En el caso de los fósiles, son un indicador del medio de formación y pueden informar sobre la formación geológica de origen y su edad jurásica, cretácica, terciaria, etc..,

\section{Microscopía óptica lámina delgada}

Esta técnica tiene como base las propiedades ópticas de los minerales que configuran las rocas, para aquellas que tienen la propiedad de que la luz pueda pasar a través de ellos. Se emplea la microscopía de luz transmitida a las láminas delgadas con el fin de obtener datos sobre la materia prima que es, su textura, su composición mineralógica, especialmente en las fases minoritarias, y que no se pueden detectar por medio de otras técnicas analíticas, su formación, o su contenido en fósiles, entre otros aspectos.

Las muestras analizadas corresponden a sílex, cuarcitas o areniscas compactas. Dentro de los sílex nos encontramos con variedades minerales como el cuarzo que aparece de diferentes modalidades.

- Cuarzo de pequeño tamaño: Son cristales entre 20 y 200 micras, se originan en medios donde las soluciones silíceas son diluidas y tienen pocas impurezas, los cuarzos de crecimiento libre con forma de romboedros se encuentran en los huecos donde pueden desarrollarse terminando el relleno después la calcedonia. Pueden aparecer orientados de forma paralela, son angulosos, dispersos, sin orientación, de talla regular. Visto al macroscopio óptico conforma un mosaico homogéneo. 
- Cuarzo microcristalino: Su formación se produce por soluciones menos puras y con un alto índice de sílice, con granos que van de 3 a 20 micras unidos unos con otros de extensión irregular y arbitraria con contornos mal definidos. Este tipo de cuarzo son frecuentes en los sílex Cenozoicos y cretácicos, formando el fondo de la roca.

- Cuarzo detrítico: Son cristales de cuarzo de talla grande, con formas que van desde las irregulares hasta las subangular y por contener inclusiones de rutilo, circonio o turmalina

- Calcedonia: Son formas fibrosas del sílice. Formada por las soluciones saturadas en sílice, donde las impurezas desorganiza el crecimiento de los cuarzos. Al microscopio puede aparecer en esferolitos o formando la matriz de sílex Cenozoicos, en otras ocasiones lo vemos rellenando grietas y en el interior de organismos fosilizados como pueden ser los radiolarios.

- Ópalo: Presenta una apariencia amorfa al microscopio.

Se han aplicado determinaciones de las características mineralógicas con microscopía óptica (estereomicroscopía y microscopía de luz transmitida) (entre x10 y x200 aumentos) con un microscopio Olympus BH de luz polarizada y sobre láminas delgadas del material lítico

Hemos realizado multitud de láminas delgadas (116), de muestras geológicas y de material arqueológico de la zona de estudio, de las recogidas durante los muestreos geoarqueológicos entre los años 2011-2014 y las prospecciones realizadas en 2015, así como las muestras recogidas con anterioridad por Salvador Domínguez-Bella en estudios geológicos de la zona de estudio.

Tras la selección de las piezas geológicas y arqueológicas, se procedió a cortarlas con una cortadora de disco diamantado y refrigerada con agua, con lo que se obtienen unos tacos rectangulares, en el caso de que la muestra sea muy porosa o poco cementada el tratamiento será distinto se realizará un impregnación al vacio con resinas que consolidará el material y evitara su disgregación. Posteriormente se desbastan por una de sus caras, la que ha quedado lisa, con polvo de carburo de silício con diferentes grosores, en nuestro caso hemos utilizado 320, 600, 1000 unidades, para obtener una superficie lisa y sin rugosidades que eviten la formación de burbujas que podría provocar una pérdida de calidad en la imagen de la lámina delgada al observarla a través del microscopio. 
Una vez pulida una de las caras se pega a un portaobjeto de vidrio mediante una resina termofusible para pasarlo a la máquina cortadora (figura 11) y obtener una lámina de $1 \mathrm{~mm}$ de espesor aproximadamente.

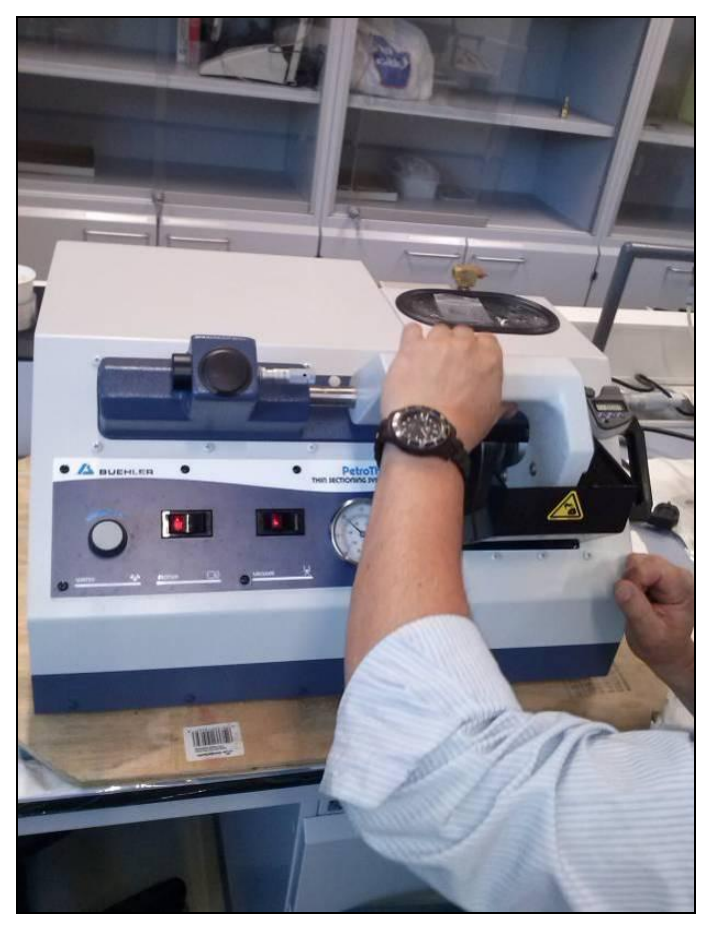

Figura 11. Máquina cortadora y preparadora de láminas delgadas (SCCYT, UCA).

Con posterioridad desbastamos la lámina con el carburo de silicio, controlando el espesor, aproximadamente $30 \mu \mathrm{m}$. a través de la inferencia de color de los minerales observándolos a través del microscopio óptico de luz trasmitida, usando condiciones de luz polarizada y luz doblemente polarizada, lo que permite obtener una gran información acerca de la textura, el grano, la porosidad o la presencia de fósiles. En ocasiones, es necesario llevar a cabo una tinción, con el fin de poder diferenciar minerales de una roca, (calcita, dolomita, yeso) o fases minerales muy similares (feldespato potásico, plagioclasa). Por último se cubre con un cubreobjetos de vidrio muy fino o bien se barniza la lámina delgada para protegerla y se sigla la muestra.

Una vez preparada la lámina delgada se procedió a su caracterización geológica para poder establecer la relación entre el material arqueológico y el geológico. 


\subsection{Explotación y configuración de las industrias líticas: tipología, sistema} lógico analítico, utilización, abandono y procesos postdeposicionales

Tradicionalmente los artefactos $\mathrm{u}$ objetos de un conjunto industrial eran analizados, en su mayoría, desde un punto de vista tipológico, sin prestar atención a los procesos técnicos de elaboración de dichos artefactos y centrándose exclusivamente en los artefactos acabados, "entendiéndolos como el único fin de las cadenas operativas técnicas, ofreciendo una visión parcial de los conjuntos” (Lombera Hermida, 2005: 8).

A pesar de las restricciones que presentan las tipologías, estas pueden ser un complemento al estudio de la industria lítica dentro del proceso de producción de los artefactos líticos, desde la selección y captación de la materia prima, hasta su transformación, uso y abandono (figura 12).

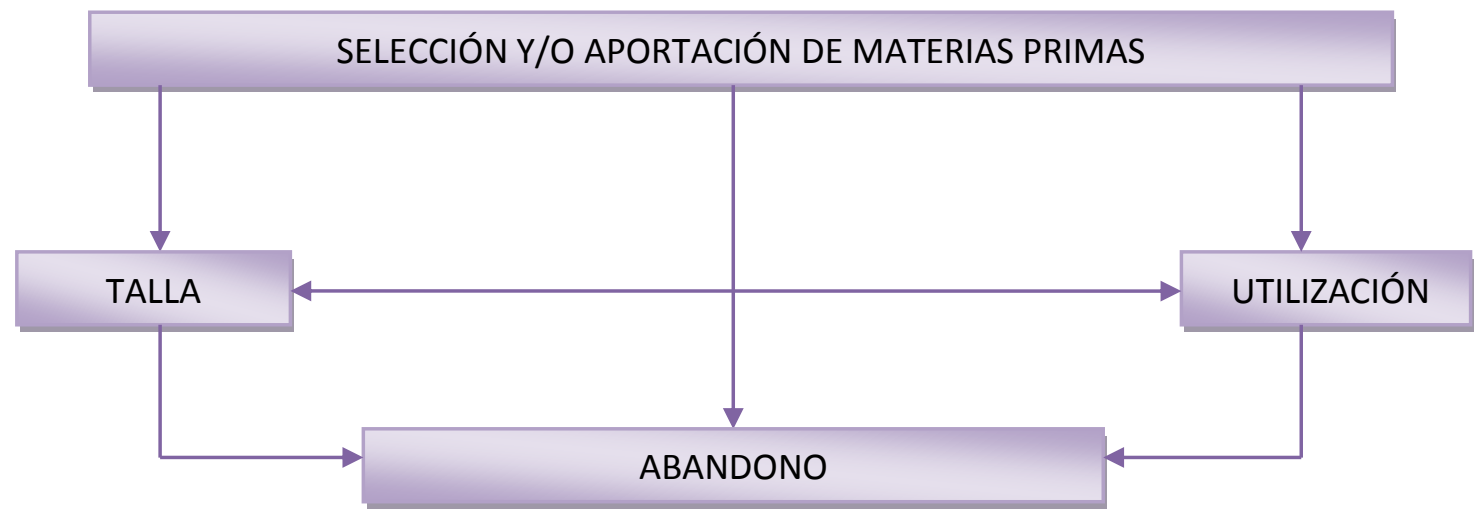

Figura 12. Proceso de producción (Mora Torcal et al., 1991: 176).

\section{Sistema Lógico Analitico (SLA)}

En nuestro caso aplicaremos el Sistema Lógico Analítico (SLA) al estudio de la industria lítica objeto de este trabajo, "analizando los aspectos tecnológicos y procesuales presentes en la génesis del conjunto" (Lombera Hermida et al., 2005: 8) alejándonos del encasillamiento que constituían las tipologías, "agrupando series de objetos que presentan atributos morfológicos similares" (Rodríguez Álvarez et al., 1999: 40), obviando los factores presentes en la cadena operativa desde el momento de la selección y que por medio de los procesos técnicos dan lugar a ese objeto u artefacto.

Para el SLA el objeto es un "instrumento de acción sobre el medio, por tanto resultado de un proceso de selección e interacción" (Carbonell et al., 2011: 55) y lo 
“considera una estructura jerarquizada por tres elementos básicos: morfotécnico, morfopotencial y morfofuncional" (Lombera Hermida, 2005: 14).

Este sistema establece un esquema teórico, dentro del cual existen unas categorías de conceptos relacionadas con las diferentes fases del proceso técnico: constructiva, descriptiva y explicativa.

\section{- Fase constructiva:}

Entendida como "la clasificación del artefacto dentro del proceso de producción, donde las sucesivas fases del proceso de talla dan lugar a diferentes categorías estructurales" (Carbonell et al., 2011: 55). Estas categorías estructurales (figura 13) comienzan con la selección previa de dos bases naturales (Bn), una como percutor y otra como matriz, mediante la interacción de ambas da lugar a la fragmentación de la base utilizada como matriz conservando el negativo de la extracción, del proceso aparecen dos nuevas categorías denominadas, Base Negativa de Primera Generación (BN1G) y Base Positiva (BP), también denominadas Bases Positivas de Primera Generación (BP1G). El proceso de talla puede continuar con la percusión de una de las Bases Positivas extraídas, dando lugar a la aparición de un nuevo objeto desprendido de la antigua BP y que presentará el negativo de la extracción, así esta BP se convertirá en una Base Negativa de Segunda Generación (BN2G), mientras que el nuevo objeto será una Base Positiva de Segunda Generación (BP2G), si continuamos el proceso y percutimos sobre esta Base Positiva de Segunda Generación (BP2G) la convertiríamos en una BN3G y obtendríamos una BP3G y así sucesivamente (Carbonell et al., 2011: 55).

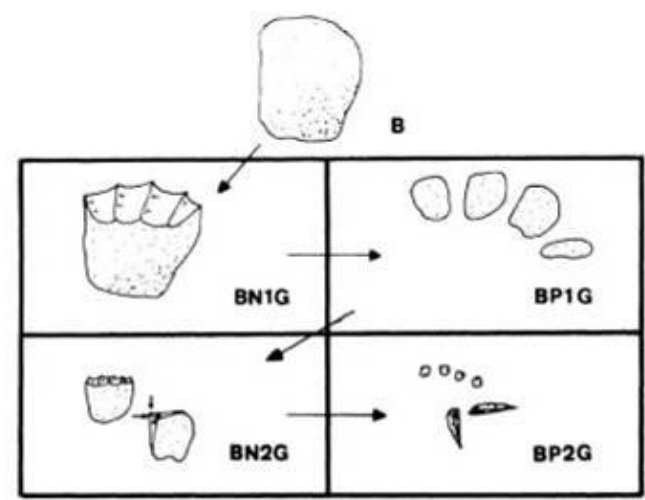

Figura 13. Cadena de producción y formación de las principales categorías estructurales (Mosquera Martínez et al., 1992: 136). 
Dentro de las consideradas como Bases naturales existen varios tipos. Se entiende por Base natural el objeto sometido a dinámica antrópica, en un contexto arqueológico, dentro de la esfera de transporte y selección y utilizados como percutor a estas se les denominan Bases naturales (Bna), cuando una de estas bases se selecciona para tallar e interactuar con otra base y los estigmas son identificables se les llama (Bnb), cuando se trata de un percutor fracturado o un fragmento de una base es una (Bnc) (Lombera Hermida, 2005: 10).

Estas categorías estructurales permiten situar cada objeto dentro de una secuencia de producción, utilizando unos conceptos situados a nivel de la sistemática, sin embargo, para pasar del nivel constructivo al nivel de la sistemática es necesario desarrollar un esquema conceptual que nos permita organizar los distintos niveles de la acción antrópica (Carbonell et al., 2002: 110).

\section{Esquema conceptual de la sistemática}

Dicho esquema (figura 14) parte de la selección e interacción, es decir, la selección (S) es entendida como la captación de materia prima y la interacción (I) como la talla lítica en sí. La interacción de dos bases constituye una Unidad Operativa Técnica (UOT), así el conjunto de las diferentes unidades con la misma finalidad de producción forman los Temas Operativos Técnicos (TOT) (Lombera Hermida, 2005: 13) utilizados para la fabricación de los objetos y necesarios de identificar una vez clarificadas las categorías estructurales.

Estos Temas Operativos Técnicos se clasifican en directos o indirectos. Los directos (TOTD) son aquellos donde el proceso tiene como objetivo configurar una Base Negativa de Primera Generación, son las estrategias de configuración de útiles sobre cantos y por tanto se trata de una Base Negativa de Primera Generación de Configuración o BN1GC (Carbonell et al., 2002: 110). Los indirectos (TOTI), son aquellos en los que el proceso está dirigido a la obtención y producción de los otros productos de talla (BP y BN2G), son las estrategias de explotación de los núcleos, producción de soportes y configuración de útiles sobre lasca. Las bases negativas utilizadas como núcleos son Bases Negativas de Primera Generación de Explotación o 


\section{BN1GE.}

En un nivel superior al Tema Operativo Técnico o TOT, se encuentra el concepto de Cadena Operativa Técnica (COT), este incluye la selección de la materia, su transformación en artefacto, así como su utilización y posterior abandono (Carbonell et al., 2002: 110).

En un segundo nivel conceptual están los Sistemas Operativos Técnicos (SOT), definidos como el "conjunto de actividades humanas psicomateriales dirigidas a la selección, interacción y transformación del medio mediante modelos prácticos que son la plasmación de los esquemas mentales" (Carbonell et al., 2002: 110).

A un nivel superior de este esquema conceptual, nos encontramos con el término Unidad Eco-social o conjunto de relaciones entre el sistema productivo de una comunidad y su medio ambiente, toda la realidad productiva y reproductiva de un ser vivo (Carbonell et al., 2002: 110).

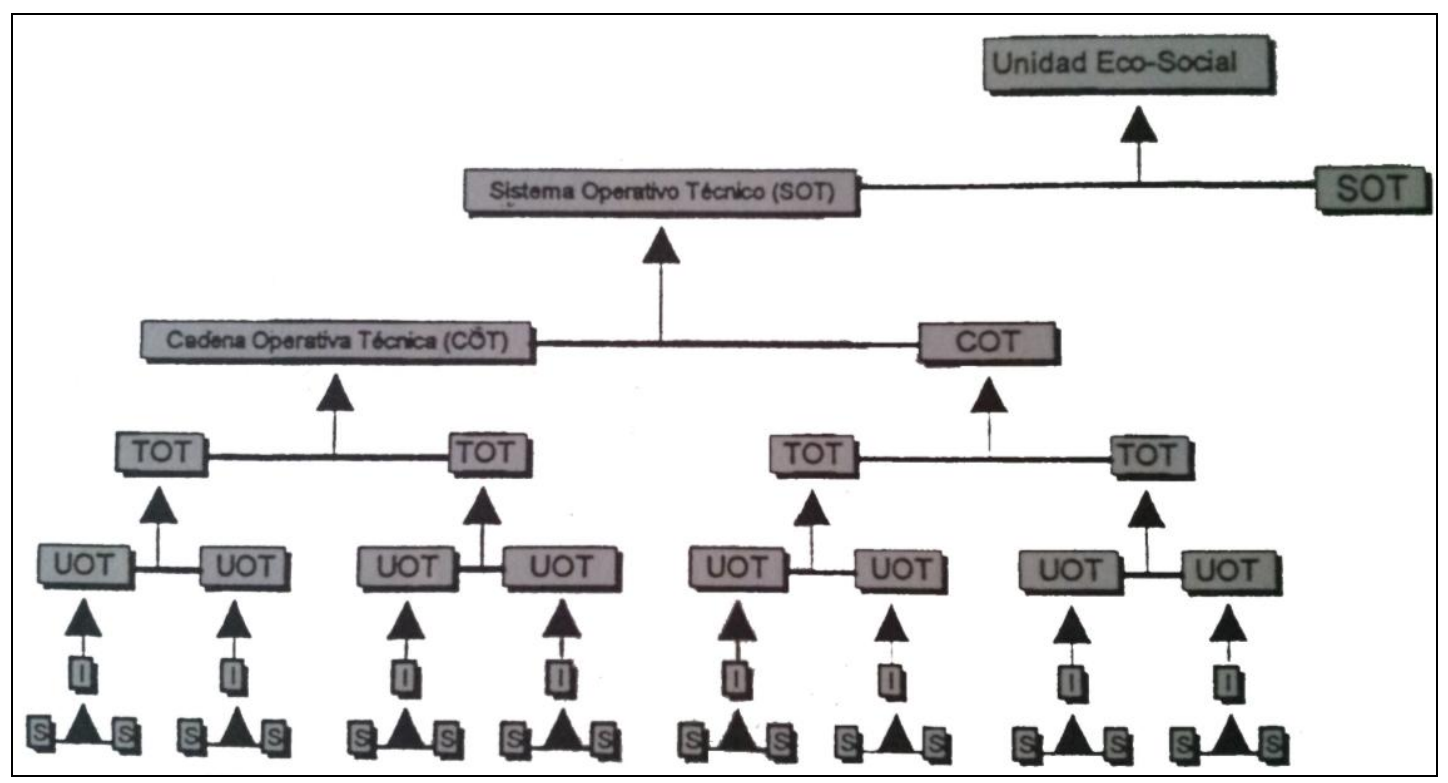

Figura 14. Esquema conceptual del Sistema Lógico Analítico (Carbonell et al., 1992).

\section{- Fase descriptiva:}

El estudio de los objetos y su análisis se establece en base a tres niveles el morfotécnico, morfopotencial y morfofuncional.

- Morfotécnico:

Consiste en el "estudio analítico de los rasgos fundamentales de cada objeto" (Carbonell et al., 2011: 55-56), generados en su proceso de elaboración y que quedan reflejados en su forma final. 
Algunas de las categorías estructurales contienen mayor información que otras es el caso de las Bases Negativas de Primera Generación o BN1G, las Bases Positivas o BP y las Bases Negativas de Segunda Generación o BN2G. Tanto las Bases Negativas de Primera Generación como las Bases Positivas son las más representativas en el proceso de Selección/Interacción mientras que las Bases Negativas de Segunda Generación suponen un segundo nivel de interacción realizada a partir de los soportes obtenidos durante la primera fase (Terradas Batlle, 1995: 38).

Bases naturales $(\mathrm{Bn})$ :

Se entiende como Base natural "aquel objeto que ha sido sometido a una dinámica antrópica, y por tanto presenta contradicciones, sin que ello implique su transformación o utilización” (Mora Torcal et al., 1991: 177). Son las categorías que se generan bajo las esferas de selección y transporte, las cuales son sometidas a un proceso de transformación, ya sea mediante la utilización directa o bien por talla, y se inicia la dinámica de selección/interacción que dará lugar a un conjunto de categorías: Base Negativa (Bne), Base Negativa de Primera Generación (BN1G), Base Positiva (BP), Base Positiva de Segunda Generación (BP2G) (Mora Torcal, 1994: 371).

Bases Negativas de Primera Generación (BN1G):

Son bases modificadas. Pueden ser núcleos o grandes útiles como los triedos, los choppers o los chopping-tools (Mosquera Martínez et al., 1992: 137).

Como ya indicamos anteriormente las Bases Negativas de Primera Generación pueden ser de Explotación o de Configuración (BN1GE/BN1GC). Las BN1GC son bases cuyo objetivo es su utilización como instrumento y forman parte de los sistemas operativos directos (TOTD)

El primer paso a realizar en el análisis de la industria lítica es buscar e identificar las plataformas y superficies de talla, entendidas como la parte de la base natural sobre la que se golpea o presiona y los negativos de los productos de talla que se han desprendido. Este debe ser orientado según el rectángulo minimal establecido por G. Laplace (Laplace, 1972) (figura 15). Para describir volumétricamente un objeto se distinguen tres planos: horizontal $(\mathrm{H})$, sagital $(\mathrm{S})$ y transversal $(\mathrm{T})$. 


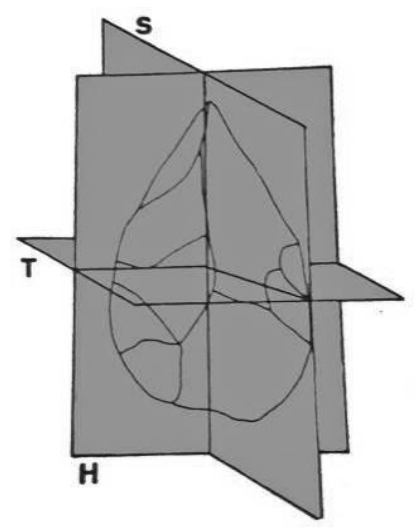

Figura 15. Planos para la descripción volumétrica de los objetos.

Una vez realizada la descripción volumétrica, se establecen seis criterios analíticos aplicados al estudio de estas BN1GC:

1. Carácter facial: Nos indica el número de planos afectados por la transformación, “y refleja, en cierta medida, el grado de complejidad de la talla" (Mora Torcal, 1994: 373). Puede ser Unifacial (U), Bifacial (B), Trifacial (T) o Multifacial (M) (figura 16).
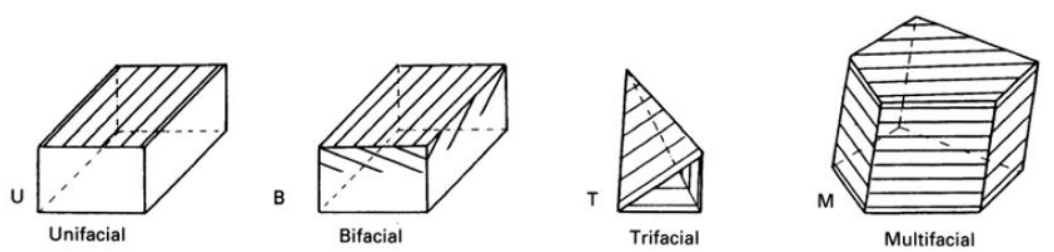

Figura 16. Esquema de las categorias de carácter facial (Mora Torcal, 1994: 373).

2. Carácter centrípeto: Definido en base a la superficie que ocupan las extracciones en referencia a la totalidad del plano en que se desarrollan (Mora Torcal, 1994: 373), es decir, "indican la proporción entre las zonas talladas y no talladas" (Navazo Ruiz, 2006: 83).

Existen cinco modalidades (figura 17): No centrípeto (NC), Centrípeto (C), Debilmente Centrípeto (2C), Fuertemente Centrípeto (3C), Centrípeto Total (4C). 


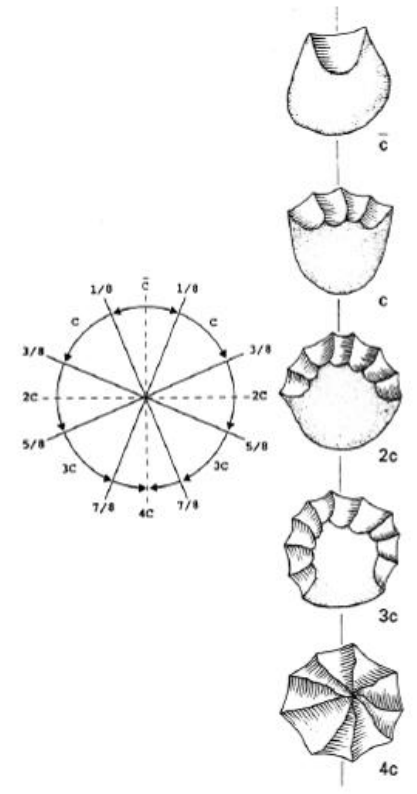

Figura 17. Categorías del carácter centrípeto (Mora Torcal, 1994: 373).

3. Carácter de oblicuidad: Se refiere al ángulo de inclinación de las extracciones respecto al plano de orientación. Existen cinco tipos (figura 18), Plano (P), Semiplano (SP), Simple (S), Semiabrupto (SA) y Abrupto (A).
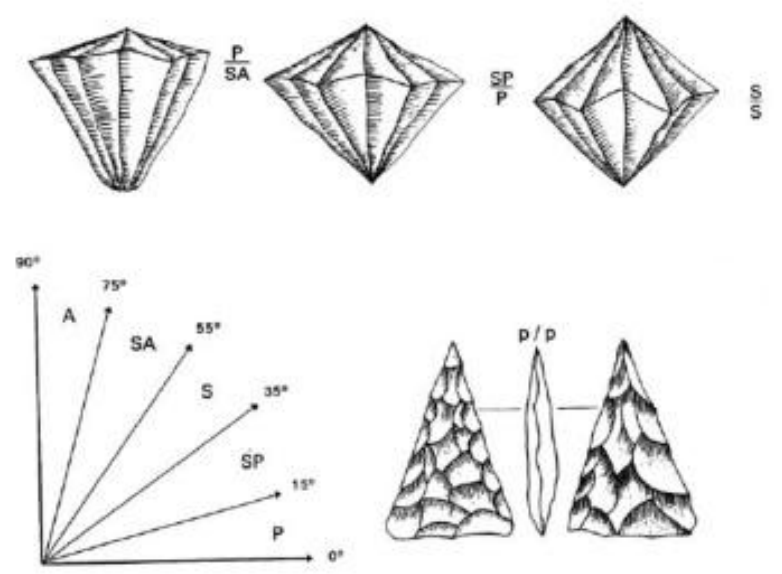

Figura 18. Esquema de las categorías del carácter de oblicuidad (Mora Torcal, 1994: 374).

4. Carácter de profundidad: Definido por la longitud relativa de las extracciones en relación a la totalidad del plano (Mora Torcal, 1994:373). Existen cinco tipos (figura 19), muy marginal (mm), marginal (m), profundo (p), muy profundo (mp) y total (t). 

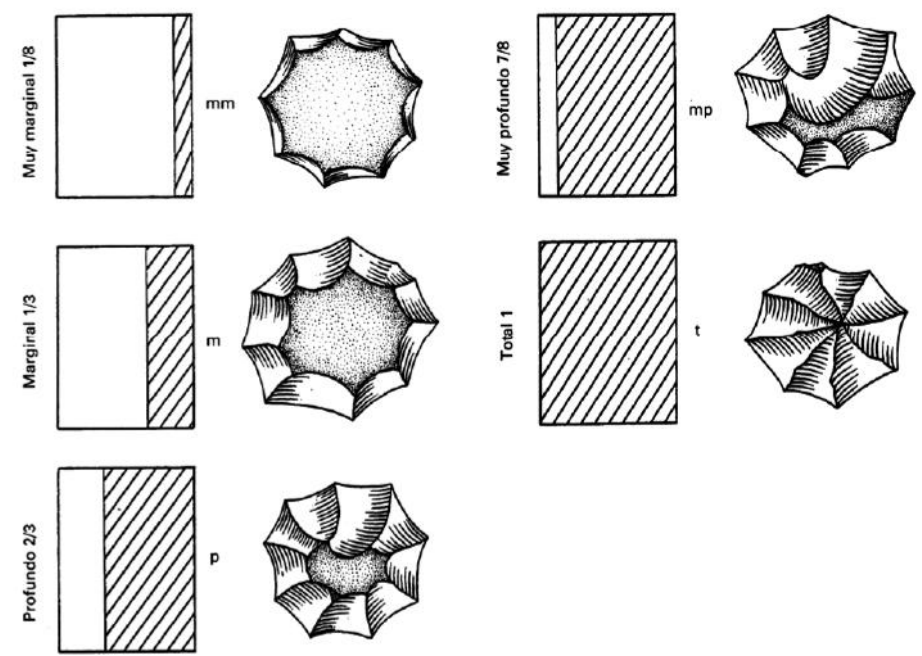

Figura 19. Categorias del carácter de profundidad (Mora Torcal, 1994: 375).

5. Carácter de la arista frontal: Pretende determinar la forma del filo desde una visión superior de la cara horizontal (Navazo Ruiz, 2006: 85), combinada con el carácter centrípeto dá lugar a numerosas modalidades: Convexo (cx), Circular o Semicircular (c), Oval (o), uniangular (1a), biangular (2a), triangular (3a), cuadrangular (4a), recta (r), concava (cc) (figura 20).

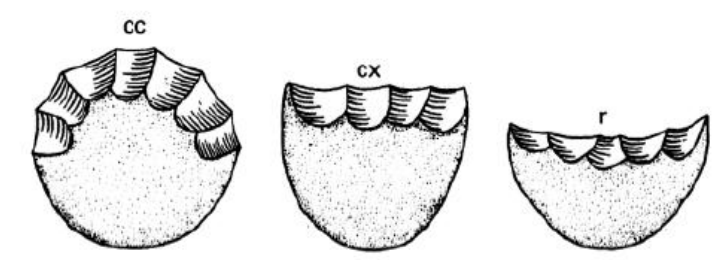

Figura 20. Categorías de la arista frontal (Mora Torcal, 1994: 376).

6. Carácter de la arista sagital: Determina la forma y la simetria de la arista sagital de la pieza (Navazo Ruiz, 2006: 85). Existen tres modalidades, encorvado (enc), sinuoso (sin) y recto (r). "La simetría viene dada por el volumen de materia que se desplaza a ambos lados en función de la arista sagital" (Mora Torcal, 1994: 375) y existen dos modalidades, simétrica (s) y asimétrica (Nsi) (figura 21). 

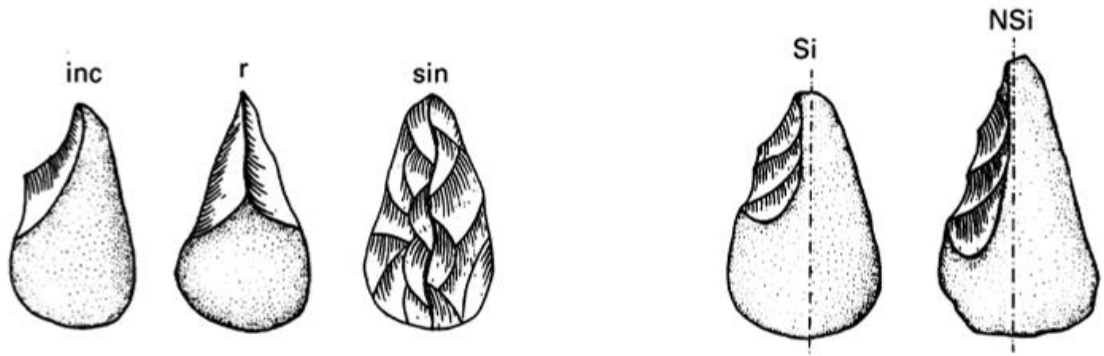

Figura 21. Categorías de la arista sagital (Mora Torcal, 1994: 376).

Las BN1GE, forman parte de los sistemas operativos indirectos o TOTI, los criterios que se utilizan para definir estos temas operativos en función de las características de los Bases Negativas de Primera Generación son dos:

A) Facialidad o carácter facial de los retoques, que son los mismos que para las BN1GC: unifacial, bifacial, trifacial y multifacial.

B) Dirección de las extracciones: Unipolar lineal, bipolar opuesta, bipolar ortogonal, multipolar ortogonal y multipolar centrípeto.

Bases Positivas (BP):

Son los positivos o las lascas obtenidos durante la talla de las Bases Negativas de Primera Generación o BN1G. "Presentan tres planos o caras, el superior o dorsal, el inferior o ventral y el talonar o plataforma de percusión" (Mora Torcal et al., 1991: 180), en su estudio se analiza las estructuras técnicas de los planos anteriormente citados, y posteriormente buscar relaciones entre ellos, de ese modo conocer las unidades técnicas que nos permitirán caracterizar una parte del proceso de talla (Mora Torcal, 1994:376)

Dentro de las estructuras técnicas que utilizaremos para su estudio se encuentran, la plataforma de percusión o cara talonar, la cara dorsal y presenciaausencia de aristas, cara ventral o inferior y la sección sagital y transversal.

Los caracteres morfotécnicos, que debemos considerar "dentro de la plataforma de percusión o cara talonar son, su grado de corticalidad, el tipo de superficie, el estado de transformación y su delineación” (Terradas Batlle, 1995: 45) (figura 22).

Para la cara dorsal se tendrán en cuenta el grado de corticalidad, permitiendo diferenciar en qué fase del proceso de talla se obtuvo la base positiva y la presencia o ausencia de aristas. 
Para la cara ventral, se considerará su delineación general de la cara ventral, "el carácter del bulbo y el ángulo de percusión, que corresponde a la medida en grados del ángulo existente entre el plano inferior y el plano de interacción” (Terradas Batlle, 1995: 45).

Para la sección sagital y transversal se establecen los tipos en función de la combinación de los ángulos que forman las facetas de los tres planos de la Base Positiva en función de la sección sagital y transversal.
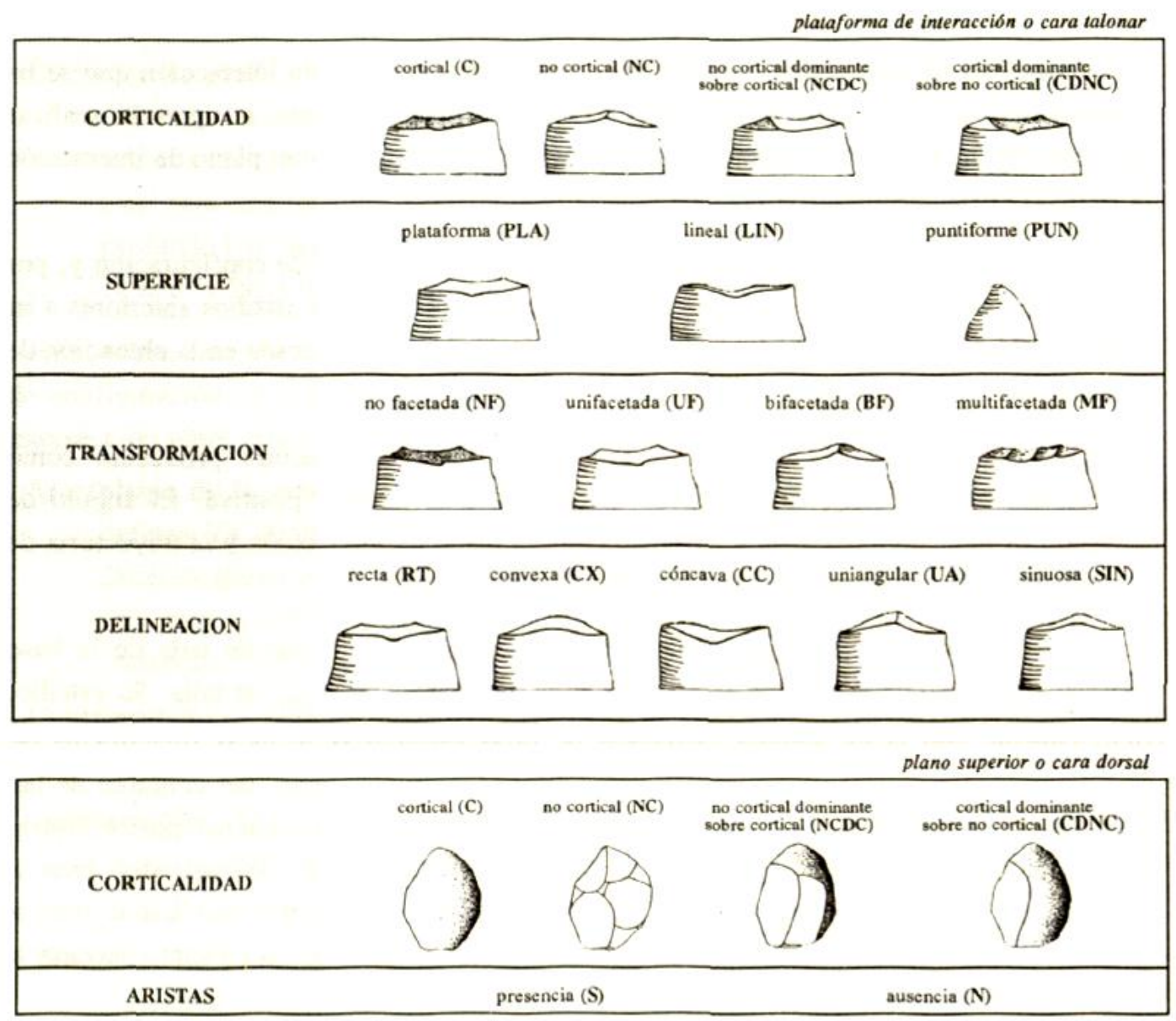

Figura 22. Algunos de los caracteres morfotécnicos considerados en el análisis de las BP (Terradas Batlle, 1995: 46).

BN2G:

Son Bases Positivas o las Bases Negativas de Primera Generación retocadas y que dan lugar a estas Bases Negativas de Segunda Generación (raederas, raspadores, buriles, etc.,). 
Las BN2G, se analizan en primer lugar como las BP, estableciendo los criterios de medidas según el sistema tipométrico de Bagolini, que nos permitirá conocer como se distribuye la muestra en función de las variables de longitud y anchura y Laplace para definir los objetos retocados, con posterioridad describir caracteres relativos al retoque y que tendremos en cuenta a la hora de analizar el objeto, tales como: su localización, el modo, la amplitud, su dirección y su delineación (figura 23).

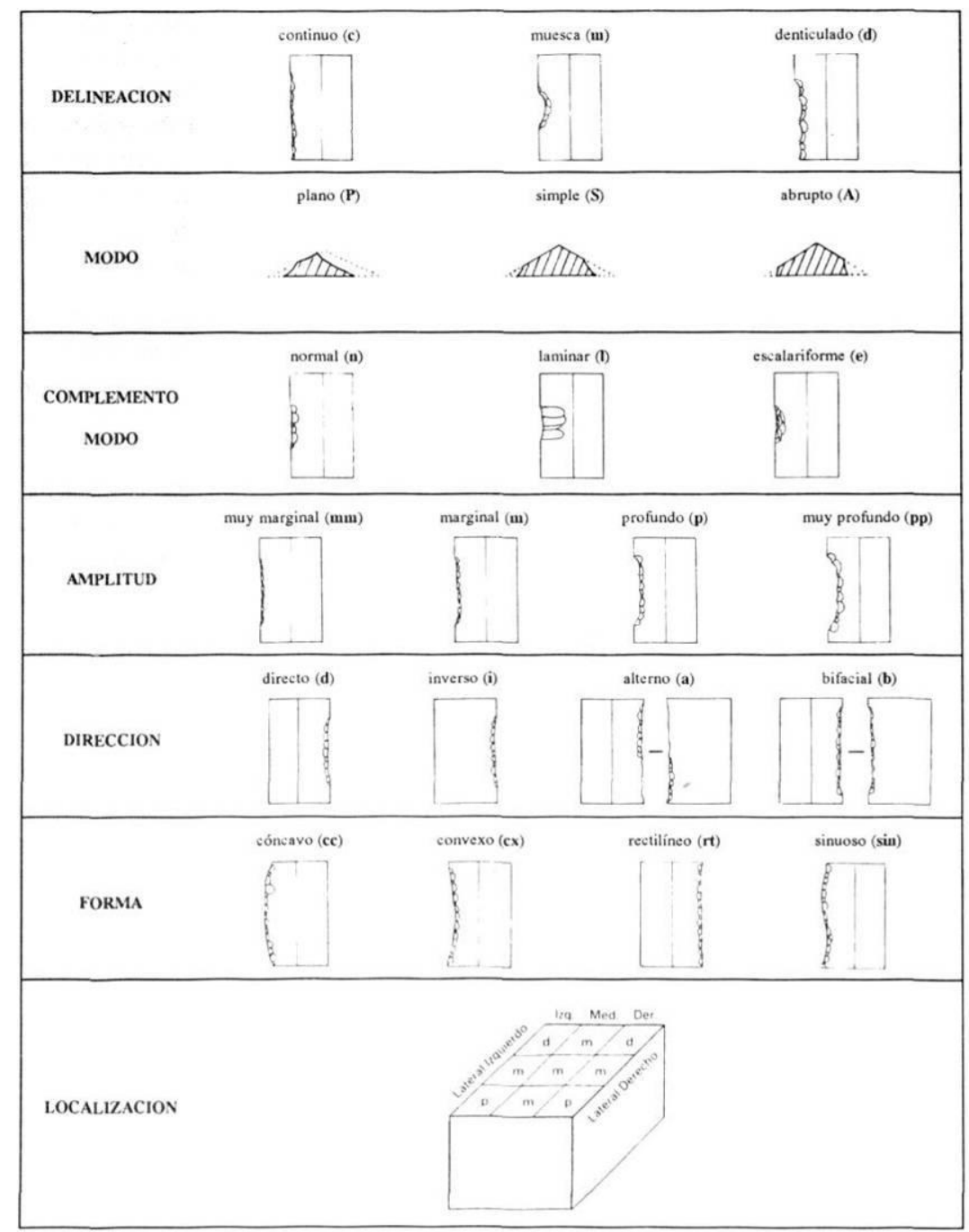

Figura 23. Caracteres morfotécnicos para las BN2G

(Terradas Batllé, 1995: 48).

- Morfopotencial:

Entendido como "la capacidad teórica de intervención sobre la materia de una determinada estructura morfotécnica" (Carbonell et al., 2011: 56).

Los objetos son analizados y agrupados según las asociaciones de morfopotencialidades presentes y no según la forma general de la pieza (Lombera 
Hermida, 2005: 14) para evaluar las diferentes potencialidades se han establecido unos modelos geométricos (driedro, triedro, semitriedro y pirámide) a los que se asocia la estructura de las aristas de los objetos, los ángulos que forman estas aristas calibran y cuantifican la potencialidad de los objetos (Carbonell et al., 2011: 56) (figura 24).
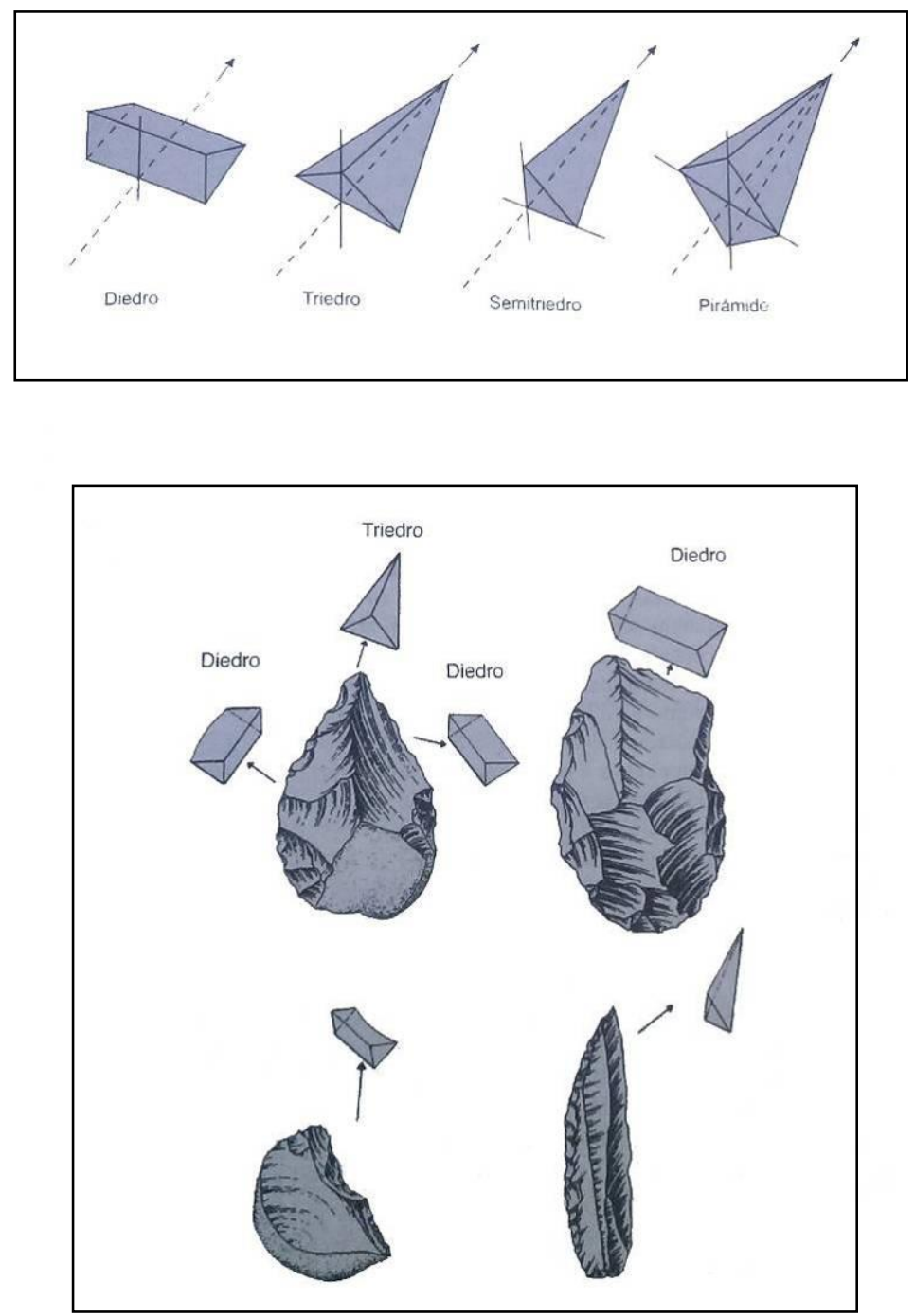

Figura 24. Modelos morfopotenciales aplicados a los filos de los artefactos líticos (Carbonell et al., 2011:57).

- Morfofuncional:

Se apoya en la experimentación y la observación mediante microscopio de los filos de los objetos, permitiendo determinar qué tipo de tareas se realizaron y sobre que materiales (Carbonell et al., 2011: 58), "dada la complejidad y escasez de los estudios traceológicos, тиy pocas veces son analizadas las industrias bajo este enfoque" (Lombera Hermida, 2005: 14). En nuestro caso no analizaremos nuestro material a nivel 
morfofuncional debido al elevado grado de rodamiento y alteración que ha sufrido gran parte el material estudiado, puesto que son principalmente piezas procedentes del registro arqueológico de superficie. El único material al que se le ha realizado el estudio morfofuncional para saber la utilización de los objetos ha sido el material recogido de la Sima de Las Palomas (Teba), cuyo resultado expondremos en el apartado del estudio de las colecciones líticas.

\section{○ Fase explicativa:}

Los conceptos de esta fase son establecidos para definir y valorar cuantitativamente los conjuntos. Los datos obtenidos mediante el análisis morfotécnico son sintetizados en la matriz morfogenética. Esta matriz morfogenética es un instrumento analítico procesual donde se representa de forma gráfica el registro arqueológico, aporta información sobre la generación del objeto durante el proceso de talla, e indica la presencia o ausencia de de una determinada fase del proceso de talla en los tema operativos presentes en el yacimiento (Lombera Hermida, 2005: 14).

\section{Procesos postdeposicionales}

Después de su uso y abandono, el material lítico vinculado a cualquier yacimiento arqueológico, ya sea de superficie o bajo esta, sufre unos procesos postdeposicionales que influirán de manera determinante en la transformación y/o destrucción de un yacimiento, se distinguen varios procesos postdeposicionales los cuales se pueden enmarcar en naturales y culturales.

Dentro de los procesos postdeposicionales naturales, considerados como los acontecimientos naturales que determinan el enterramiento de los objetos y la supervivencia del registro arqueológico (Renfrew y Bahn, 2011: 54) nos encontramos con los procesos geodinámicos, tales como deslizamientos, desplazamientos o arroyadas (Jordá Pardo et al., 2012: 167-168), donde la dispersión previa definida como "un movimiento horizontal primario de los agregados de superficie que afecta en diferente medida a partículas de masa y formas distintas y que produce la distorsión o eliminación de las relaciones microespaciales originales" (Butzer, 2007: 135), constituye un factor importante en la alteración cultural de los restos arqueológicos, ya que la mayor parte de las industrias líticas tienen tendencia a desplazarse en respuesta a procesos geomorfológicos (Butzer, 2007: 136). Uno de los principales agentes de dispersión de estos materiales y que incluso los afecta de manera directa a lo largo del 
tiempo son las corrientes de aguas superficiales, que en lugares con una cierta pendiente pueden ocasionar su dispersión e incluso su sepultamiento. En nuestro caso, la dispersión se produce principalmente en las terrazas y yacimientos localizados en los márgenes de los ríos Guadalteba y Turón, así como en algunos arroyos próximos, ocurre igual con los embalses donde el oleaje afecta directamente a las terrazas y a los yacimientos existentes en los cursos bajos de estos ríos (Guadalteba, Turón). Otros factores de dispersión son la gravedad, que provoca el desplazamiento de los materiales más pesados o las heladas, muy frecuentes en nuestra zona de estudio, y que al helarse el suelo empujaría el material lítico hacia arriba y una vez que se derrite este se desliza antes de volver a asentarse.

Otra de las alteraciones postdeposicionales naturales más frecuentes es la perturbación, se trata de un "movimiento vertical de los agregados sepultados que afecta a partículas de masa, forma y material distintos, y que introduce cambios de inclinación, orientación y de posición horizontal o vertical” (Butzer, 2011: 142). Puede ser fisiogénica, a modo de inundaciones, movimientos masivos en pendientes, o el desplazamiento lateral de sedimentos superficiales sobre arcillas, entre otras 0 biogénica, como la bioturbación provocada por la acción de lombrices, conejos, ratas o la propia vegetación cambiando la posición horizontal por vertical.

Aunque los yacimientos con estratigrafía se han visto como una mayor fuente de información en contraposición a los de superficie, lo cierto es que ambos sufren en mayor o menor medida perturbaciones tanto naturales como antrópicas, por lo que el estudio exhaustivo este tipo de perturbaciones será indispensable para detectar el contexto original de los materiales arqueológicos.

Los procesos postdeposicionales culturales, serían aquellas actividades humanas deliberadas o accidentales, en la medida en que fabrican o usan artefactos, construyen o abandonan sitios o edificaciones, el pastoreo y aran sus campos, etc. (Renfrew y Bahn, 2011: 54), siendo esta última actividad una de las que más afección provoca en los yacimientos arqueológicos superficiales.

De hecho desde la década de los 70 existe una disciplina arqueológica dedicada a las zonas de arados sobre los yacimientos arqueológicos, denominadas ploughzone. Estos estudios están circunscritos exclusivamente a EE.UU y el Reino Unido, sin embargo "en España a pesar del papel que han jugado los análisis de superficie dentro de la investigación paleolitica, los procesos de alteración cultural han sido obviados" (Diez Martín, 2003: 50) y los primeros estudios realizados sobre esta temática y 
vinculados a la arqueología del paisaje fueron realizados en 1996 en los páramos del Duero por F. Diez Martín (Diez Martín, 2009: 24; Navazo Ruiz, 2006; Navazo Ruiz y Díez, 2008).

La alteración mecánica producida por el arado suele afectar a los 20-40 cm del suelo, pudiendo alcanzar en algunos casos hasta los $70 \mathrm{~cm}$ (Diez Martín, 2010: 27) dependiendo del tipo de maquinaria utilizada, provocando una mezcla y distribución de los materiales arqueológicos, donde los cultivos producen un número de cambios horizontales y verticales en la forma y contenido de la distribución de los artefactos (Boismier, 1989: 133). Es importante diferenciar dentro de un mismo yacimiento la zona afectada por el laboreo agrícola y la zona no afectada, ya que en el caso de esta última la alteración postdeposicional cultural no le afectaría.

La mayor parte de los estudios realizados sobre este tipo de afección coinciden en señalar varios aspectos en la trasformación del registro arqueológico a consecuencia de la utilización del arado (Diez Martín, 2003: 51-52; Diez Martín, 2010: 51-52):

\section{Desplazamiento horizontal}

Se trata del desplazamiento lateral de los materiales ante el paso del arado, este desplazamiento es proporcional a las dimensiones y el peso de los materiales, así con el paso de tiempo y el sucesivo laboreo agrícola la superficie de dispersión de los materiales aumentará mientras que la densidad de la superficie tenderá a disminuir.

\section{Desplazamiento vertical}

Se trata de un cambio en la estructura vertical del yacimiento por el que se modifica la estratigrafía original del mismo generando un movimiento tanto ascendente como descendente de los materiales en función de su peso, así los objetos más grandes y pesados se acumulan en la superficie, mientras que los objetos más pequeños y menos pesados se quedan escondidos dentro del paquete de arada a causa del desplazamiento vertical de las partículas sólidas que origina el arado, este fenómeno se denomina size effect o efecto dimensional.

\section{Representatividad de las muestras superficiales}

Las fuerzas horizontales y verticales originan una acumulación de materiales en superficie. Desde un punto de vista cuantitativo esta acumulación no es representativa del total de la población arqueológica, ya que la superficie sólo supone una pequeña porción del terreno arado, y "la mayor parte de los estudios están de acuerdo en señalar que las muestras superficiales nunca representan más del 10\% de la población 
real total" (Diez Martín, 2010: 51). Desde el punto de vista cualitativo, se pretende establecer si las muestras obtenidas son lo suficientemente representativas del total d ela población, algunos estudios consideran que únicamente los grupos de objetos que representen un $1 \%$ en el total de la población, se verán sometidos a fluctuaciones significativas en el total de las muestras.

4. Alteración de las pautas espaciales de agregación

Los desplazamientos horizontales y verticales junto a otros factores postdeposicionales naturales, anteriormente mencionados, originan el cambio o la destrucción de los yacimientos.

5. Cambios en las condiciones de preservación de los conjuntos

La acción continuada del arado o incluso del pastoreo, provocan en muchas ocasiones la roturas de la industria lítica, un elevado rodamiento afectado además por las condiciones climáticas y las características de los suelos que generan cambios en su morfología. Según J.F. Jordá Pardo y M. Zarzalejos Prieto (Jordá Pardo et al., 2012 : 168), se pueden establecer cuatro categorías de yacimientos en función de la intensidad de los procesos postdeposicionales que les afectan: yacimientos en posición original sin alterar su contexto; yacimientos que conservan su posición original con modificaciones internas; yacimientos formados por materiales desplazados pero cuyo emplazamiento original es identificable y por último, aquellos hallazgos aislados sin un contexto arqueológico con el que poder relacionarlo. 


\section{El medio natural de la zona de estudio}

Las condiciones geológicas y geográficas de nuestra zona de estudio, generan una amplia diversidad de ambientes que abarcan desde zonas de media montaña hasta humedales. A nivel general, nos encontramos con un predominio de arcillas, calizas y dolomías, junto con zonas de areniscas que aparecen muy localizadas y en menor cantidad que las anteriores. El relieve es suave con predominio de zonas llanas y con la presencia de zonas montañosas con cotas superiores a los $800 \mathrm{~m}$.

A nivel hidrológico nos encontramos con varios cursos de agua como son el río Turón y el río Guadalteba, con multitud de arroyos con cauces de régimen temporal y que vierten sus aguas a los embalses del Guadalteba y del Conde del Guadalhorce.

El clima es de tipo meso a termomediterráneo, donde las especies vegetales y animales están bien adaptadas a las condiciones geológicas y climáticas existiendo una gran diversidad de las mismas.

\subsection{Encuadre geológico general en Iberia y en las Cordilleras Béticas}

Las Cordilleras Béticas representan el extremo más occidental del conjunto de cadenas alpinas europeas. Se trata, junto a la parte norte de la zona africana, de una región inestable afectada durante una parte del Mesozoico y parte del Cenozoico de fenómenos tectónicos mayores, situadas entre los grandes cratones europeo y africano (AA.VV 1990 a y b). Se extiende por el sur de la Península Ibérica, donde ocupan la mayor parte de Andalucía, Murcia, Albacete y la parte meridional de la Comunidad Valenciana. Al este, emerge en Ibiza y Mallorca. En la parte occidental tiene continuidad al norte de África a través del estrecho de Gibraltar (Serrano Lozano et al., 2004: 6-7).

Pueden distinguirse cuatro unidades geológicas con subdivisiones internas que están conformadas de la siguiente manera (figuras 25 y 26): 


\begin{tabular}{|c|}
\hline Zona Externa \\
Dominio Prebético \\
Dominio Subbético \\
Dominio Penibético \\
Complejo del Campo de Gibraltar \\
Zona Interna \\
Complejo Nevado-Filábride \\
Complejo Alpujárride \\
Complejo Maláguide \\
Unidades Frontales (Rondaides y Dorsal) \\
Materiales postorogénicos \\
\hline
\end{tabular}

Figura 25. Esquema geológico de la Cordillera Bética (Serrano Lozano et al., 2004: 13).

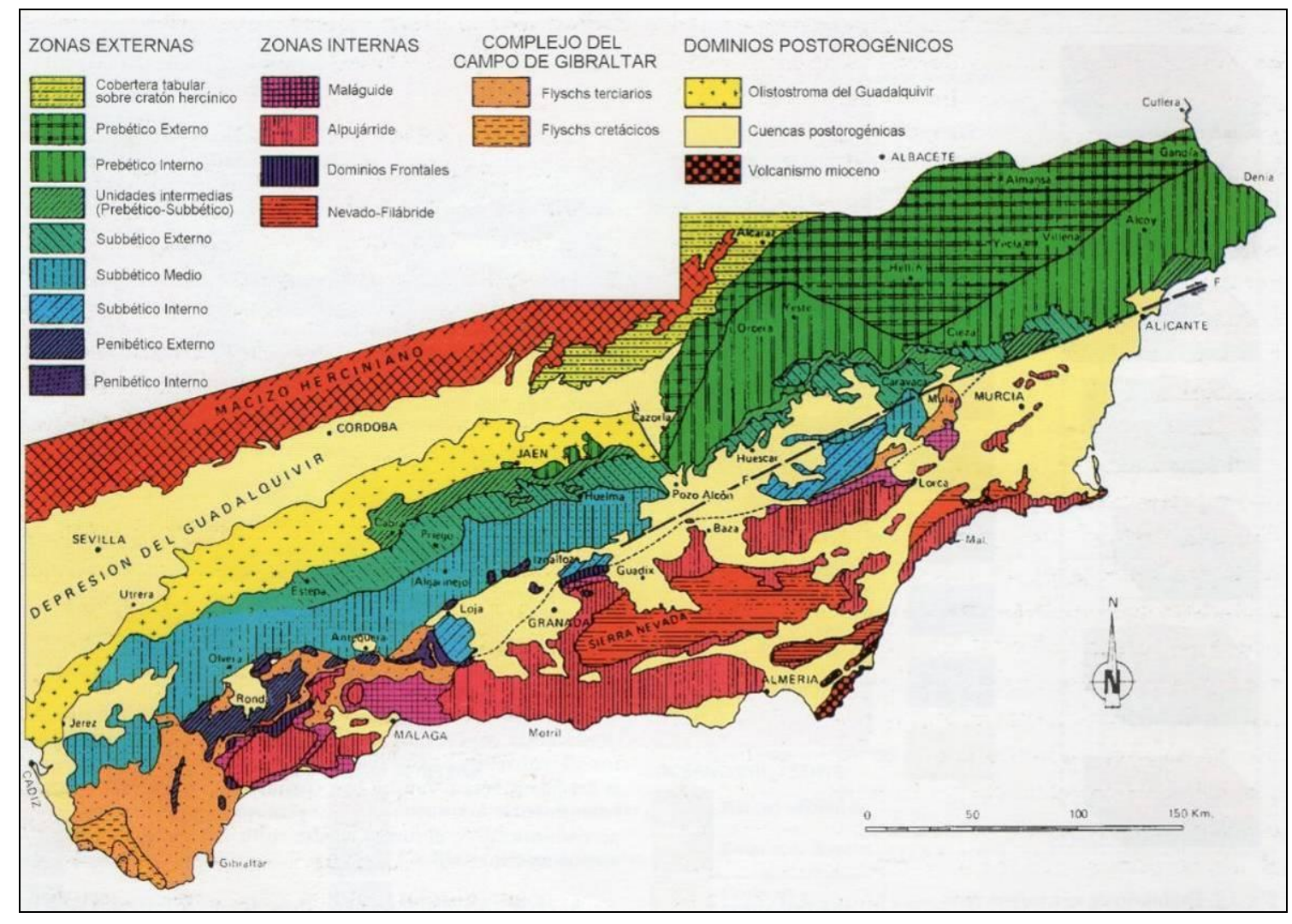

Figura 26. Mapa geológico de la Cordillera Bética (Serrano Lozano et al., 2004: 13). 
Zona Externa. Formada por materiales depositados en el margen continental meridional del bloque Ibérico durante el Mesozoico y el Cenozoico. Se pueden diferenciar tres dominios paleogeográficos como son el Prebético, Subbético y Penibético.

El Prebético, corresponde con la parte de la cordillera más próxima al continente. Sus sedimentos son propios de medios marinos costeros o someros con ciertos episodios de carácter continental (AA.VV. 1990 a y b). Aparece representado en la parte nororiental abarcando entre las ciudades de Alicante y Jaén, prolongándose hacia el oeste quedando en la actualidad cubierto por los sedimentos de la depresión del Guadalquivir (Serrano Lozano et al., 2004: 12). Dentro del Prebético se distingue un Prebético externo, la zona de la sierra de Cazorla, y un Prebético interno, sierra de Segura.

El dominio Subbético corresponde a la parte más interna a partir del Lías superior con predominio de facies pelágicas, con margas, calizas nodulosas, radiolaritas y hasta facies turbídicas a partir del Jurásico terminal (AA.VV. 1990 a y b). Aparece representado en un amplia franja de dirección ENE-WSW, que abarca desde Alicante hasta Cádiz en el área peninsular emergida y con una anchura de 50-100 km hacia el oeste y más reducida al este (Serrano Lozano et al., 2004: 14).

Dentro del Subbético se han distinguido dos áreas por un lado el Subbético externo al norte y el Subbético interno, al sur. Entre ambos se encuentra el Subbético medio que corresponde a un área de sedimentación más profunda y con frecuentes episodios de margas durante el Jurásico (Serrano Lozano et al., 2004: 14).

El dominio Penibético, se localiza en el sector occidental de las cordilleras Béticas, en el se puede diferenciar un dominio septentrional con características de umbral pelágico durante el Jurásico, denominado Penibético externo y un dominio meridional más profundo o Penibético interno (Serrano Lozano et al., 2004: 14).

En el caso de Málaga, ocupa la franja septentrional, donde alternan grandes elevaciones y terrenos deprimidos. Formando parte de estas zonas aparecen materiales del Subbético y del Penibético (Serrano Lozano et al., 2004: 16).

Complejo del Campo de Gibraltar. Ocupa una franja central a lo largo de toda la provincia de Málaga, en la zona de contacto entre las Zonas Externas y las Internas. Presenta facies detríticas de carácter tectosedimentario. Las más importantes son las areniscas del Aljibe o Numídico, el Neonumídico o Numinoide, la Unidad de Algeciras, las arcillas escamosas y las denominadas Unidades Predorsalinas (Durán Valsero, 1996: 
51-52). Las unidades del campo de Gibraltar afloran de manera extensa en la provincia de Cádiz y en Málaga donde ocupa la franja central, coincidiendo con terrenos alomados relativamente deprimidos, pero en los que con frecuencia resaltan cerros o pequeñas sierras y de forma local en algunos puntos de Granada y Almería.

Zona Interna. Reúne dominios ajenos al bloque Ibérico (Serrano Lozano et al., 2004: 15), situadas al sur de la Zona Externa. Presentan materiales metamórficos de manera generalizada, aunque existen rocas no metamórficas y con materiales más antiguos que en las Zonas Externas con amplia representación del Paleozoico (Durán Valsero, 1996: 49).

La zona interna presenta cuatro dominios el Nevado-Filábride en una posición tectónica inferior, el Alpujárride en posición intermedia y el Maláguide en la parte más alta del plegamiento tectónico y, por último, las unidades frontales (Serrano Lozano et al., 2004: 15). En la provincia de Málaga ocupa la franja meridional y está formada por las alineaciones montañosas más próximas a la costa.

El Nevado-Filábride, representado en el núcleo de Sierra Nevada y los Filabres, constituido por rocas metamórficos agrupados por dos grandes mantos de corrimiento superpuestos, donde abundan micaesquistos grafitosos y los micaesquistos feldespáticos.

El Alpujárride, que aparece al este de Málaga capital, con mantos similares a los del tercio central de la cordillera, y al oeste de Málaga (Durán Valsero, 1996: 49), donde destacan los materiales peridotíticos.

El complejo Maláguide situado sobre el anterior y representado fundamentalmente en la región de los Montes de Málaga, separando en superficie los dos dominios alpujárrides anteriores.

Y por último, la Dorsal Bética (Complejo Rondaide), conjunto de unidades a caballo entre las Zonas Internas y Externas, con características intermedias entre ambas, aunque asimilables a las primeras y especialmente desarrolladas en la región de Ronda (Durán Valsero, 1996: 51)

Materiales postorogénicos. Corresponde con materiales originados con posterioridad a la fase inicial de plegamiento de la Cordillera Bética provocada por la colisión entre la Zona Externa y la Zona Interna durante el Mioceno inferior. Suelen aparecer algunas deformaciones originadas a posteriori sobre todo en el Mioceno medio y superior, en las áreas más próximas a las cuencas (Serrano Lozano et al., 2004: 15). Los materiales al ser más modernos se sitúan indistintamente sobre los más antiguos, 
rellenando las cuencas que surgieron con el paroxismo de las deformaciones. Entre estas cuencas se encuentran las depresiones del Guadalquivir, Ronda, Guadalhorce, Granada, Guadix-Baza, Almería, Níjar, Sorbas, Vera, Huércal-Overa, Lorca, Murcia y Campo de Cartagena y a las que hay que incluir las rocas resultantes de la importante actividad volcánica neógena, centrada especialmente en sierra de Gata (Almería) y en la región de Cartagena (Serrano Lozano et al., 2004: 16). En Málaga se encuentra distribuida por el interior y a lo largo de la franja costera (Serrano Lozano et al., 2004: 16).

\subsubsection{Geología: estratigrafía, litología, tectónica}

La descripción del marco geológico, en el cual se desarrolla este trabajo, se extrae del Mapa Geológico de España hoja no 1038 (16-43) Ardales y nº 1037 (15-43) Teba, escala 1:50.000, segunda serie primera edición del Instituto Tecnológico Geominero de España (AA.VV. 1990 a y b) (figura 27).

La zona de estudio, "constituye un territorio de frontera entre el altiplano de Antequera, al noroeste de la provincia de Málaga y las sierras de Ronda y Cádiz, en un espacio intermedio, que a lo largo del Pleistoceno ha permitido la comunicación entre la parte del interior andaluz y las vertientes mediterránea y atlántica del sur de la Península Ibérica” (Medianero Soto et al., 2012: 60).

Situada dentro de las Cordilleras Béticas, presenta una compleja litología reflejada en la existencia de materiales pertenecientes a unidades geológicas diferentes, como son las Zonas Externas, los Flyschs del Campo de Gibraltar, el Complejo Maláguide, el Complejo Alpujárride, las Unidades Frontales y los materiales postorogénicos, con presencia de calizas, dolomías, margas, margocalizas, arcillas, conglomerados, calcarenitas, grauvacas, pizarras, mármoles, esquistos y peridotitas (Becerra Parra, 2006: 126).

En cuanto a su estratigrafía y, teniendo en cuenta que el área de estudio abarca dos términos municipales (Teba y Ardales), la complejidad de los materiales geológicos hace que cada término municipal presente diferencias geológicas.

Zona Externa. La mayor parte de los materiales que aparecen en esta área presentan una secuencia constituida por un Jurásico calizo, un Cretácico inferior ausente o escaso y un Cretácico superior de capas rojas.

- Dominio Subbético: Los materiales presentes pertenecen todos al Subbético medio, ocupando una franja en sentido este-oeste al norte de la comarca del Guadalteba, 
en ella se incluye la unidad del Triásico de Antequera, con presencia de calizas y dolomías de color negro o muy oscuro, areniscas, margas y arcillas verdes y rojos con presencia de yesos intercalados entre los niveles de areniscas. Afloran ampliamente al norte del río de la Venta, en una franja que discurre entre la depresión de Antequera y la zona de unión entre las provincias de Sevilla, Cádiz y Málaga.

- Dominio Penibético: Los materiales que componen esta unidad la podemos diferenciar en dos facies. Por un lado una potente secuencia jurásica enteramente caliza, con presencia de calizas dolomíticas del Trias, dolomías brechoides y micríticas del Lías inferior, calizas oolíticas y pisolíticas del Lías medio al Dogger. Por otro, una fase del Jurásico superior de calizas nodulosas y brechoides de color rojo, amarillentas y grisácesas, que aparecen en casi todos los relieves presentes en Teba como son la sierras de Teba/Peñarrubia, Ortegicar o la Lentejuela, y a un Cretácico-Paleógeno denominado "Capas rojas", compuesto por materiales margosos y margocalizos que rellenan las zonas deprimidas y que están en contacto con las calizas del Jurásico superior, con presencia de nódulos y bandas de sílex. Aparece en el río de la Venta (Teba), al sur del cerro Colorado o Llanos de Carrasco.

Zonas Internas. Incluyen varias unidades:

- Unidad de Nieves, compuesta por dolomías negras y grises bien estratificadas atribuidas a la formación del Triásico superior y en cuya base alternan con calizas margosas, en ocasiones con sílex y margocalizas rojizas, y es visible en la sierra de Alcaparaín y en la sierra de las Nieves, junto a estos materiales aparece una brecha calizo-dolomítica masiva y presencia de materiales epimetamórficos.

- Unidad de Capellán, con dolomías a veces esquistosas en la base de la secuencia y calizas, en ocasiones con sílex y calízas dolomíticas por encima aparecen representadas en un pequeño afloramiento en la sierra de Alcaparaín.

- Alpujárrides: Unidad de Casares, donde aparecen representadas dos unidades, por un lado la formación basal compuesta por filitas negras, azul violáceo y grises con intercalaciones de cuarcitas y cuarzoesquistos y calco-esquistos y por el otro dolomías grises amarillenteas que pertenecen al Triásico medio superior, junto con gneis bandeados al norte y oeste de la sierra de Aguas (Carratraca). Afloran al sureste y suroeste de Ardales y del río Turón.

- Maláguides, con presencia de dolomías y calizas, entre las que aparecen las oolíticas como las que aparecen entre la carretera de Ardales-El Burgo y calizas 
estratificadas con nódulos de sílex como los relieves calcáreos del Veredón, sierra Blanquilla y en el castillo del Turón (Ardales) y que se encuadran dentro del Jurásico, junto a areniscas calcáreas y conglomerados, margas, margo-calizas, calizas margosas y detríticas del Cenozoico. Las areniscas y margas rojas afloran al suroeste de Ardales y en las proximidades de la loma de la Galeota y en el puerto de Azulejo.

Unidades del Flysch del Campo de Gibraltar. Afloran materiales que se incluyen dentro de las denominadas:

- Unidades Numídicas o del Aljibe, compuestas por areniscas cuarzosas del Oligoceno y Aquitaniense, denominadas Areniscas del Aljibe. Se localizan en el sector de Cámara Alta, al sur de la sierra de Teba/Peñarrubia, en las inmediaciones del cerro de Las Grajeras y en la margen izquierda de la cola del embalse del Conde del Guadalhorce. Estas areniscas se sitúan sobre arcillas y margas con intercalaciones de calizas detríticas y areniscas.

- Unidades Infranumídicas, con predominio de arcillas y arcillas margosas intercaladas con calizas detríticas y conglomerados junto con areniscas localizados al suroeste de Ortegícar, en cortijo Nuevo, en un pequeño talud del arroyo del Alforzo, en la ladera suroccidental del cerro de la Higuera intercaladas con arcillas rojas y verdes y calizas detríticas, también en el cerro del Conde.

- La formación olistostromica o Neonumídico, es una formación arcillosoarenisca color ocre y marrón oscuro que presenta klippes sedimentarios u olistolitos de distinta naturaleza y edad. Aparece en el entorno de Cerro de la Torre, la margen noroeste del río Turón, o la franja que va desde las laderas de la Sierra del Padrastro a la zona de Nina Alta.

- La unidad de tipo Algeciras, con margas y arcillas de colores rojizos y marrón ladrillo con gran cantidad de niveles finos de areniscas de grano fino y niveles calcareníticos. Aflora en ambas márgenes de la cola del embalse del Conde del Guadalhorce y al norte de los embalses del Guadalteba y Turón.

Formaciones post-mantos. Se trata de materiales no afectados por la tectónica de mantos, se incluyen depósitos cuaternarios y materiales del Mioceno superior.

- Mioceno: con tres tramos litológicos compuesto por areniscas, limos, margas y arenas y conglomerados. Los de mayor extensión se encuentran en la zona de El Chorro al norte de Ardales, donde se alcanzan potencias de más de 300 m. En la zona de Teba está representado por areníscas calcáreas bioclásticas, conglomerados y margas cuyos 
materiales pueden observarse en el sector de Cañete la Real, al oeste de la sierra de la Lentejuela y, al noreste y noroeste de la Teba, varios puntos dentro de la cuenca del río Guadalteba.

- Cuaternario:

- Terrazas aluviales antiguas: que incluyen las formaciones aluviales colgadas sobre la red actual. Están constituidas en su mayoría por cantos de rocas metamórficas peridotitas aflorantes en sierra de Aguas (Carratraca) y rocas metamórficas encajantes. Se localizan en el castillo del Turón, y el curso bajo del río Turón, también en la zona de Teba existen varias terrazas colgadas a más de un veintena de metros sobre el cauce actual.

- Travertinos: son formaciones vinculadas a la surgencias de aguas subterráneas, la mayoría se encuentra en los bordes de la sierra de Cañete, también se localizan en la plataforma de Cuevas del Becerro o en el tajo del Molino de Teba.

- Conos de deyección: son acumulaciones de cantos angulosos o subredondeados, de materiales heterogéneos y de muy diversa granulometría, con matriz arcilloarenosa, en los bordes de los relieves importantes relacionados con la actividad torrencial. Aparecen al norte de la sierra de Cañete la Real y en la ladera noroccidental de la sierra de Alcaparaín.

- Derrubios de ladera: representados por acumulaciones a pie de campo, constituida por cantos angulosos, de diversa naturaleza y tamaño, poco o nada cementados por una matriz arcillo-arenosa. Al sur de la sierra de Ortegícar, predominan los bloques de tamaño métrico resultantes de los desplazamientos en losa.

- Depositos aluviales: se trata de formaciones aluviales relacionadas con el cauce actual, donde pueden estar incluidas pequeñas superficies correspondientes a terrazas antiguas más bajas (2-3 m). Están compuestas por depósitos detríticos que incluyen desde arcillas a gravas, en el caso de los últimos están los cantos están bien redondeados. Se localizan en los cauces del Guadalteba, el río de la Venta (Teba) y el cauce del Turón.

- Depósitos coluviales y suelos: afloran ampliamente en zonas de materiales blandos como arcillas, margas. Los suelos son predominantemente arcillosos e incluyen fragmentos calizos y areniscas intercalados con las secuencias de las que proceden. 
Desde el punto de vista tectónico, en Ardales ( $\left.\mathrm{n}^{\circ} 1038\right)$, se localizan dos de las grandes divisiones de la Cordillera Bética. Dentro de las Zonas Internas contamos con materiales correspondientes al Complejo Alpujárride, que constituyen materiales más bajos tectónicamente, y del Complejo Maláguide, que constituye la unidad más alta y está superpuesta al Alpujárride mediante una superficie de corrimiento de primer orden (AA.VV.1990 b). En las Zonas Externas, aparecen unidades encuadradas dentro de la Unidad de Algeciras y la Unidad del Aljibe, y su complejidad aumenta al quedar las unidades anteriormente citadas cubiertas por formaciones del tipo Flysch.

En el caso del Teba $\left(\mathrm{n}^{\circ} 1037\right)$, se encuentran las unidades pertenecientes a las Zonas Internas, de nuevo las unidades con Flysch y las Zonas Externas. En el caso de las Zonas Internas, con una reducida extensión, presentan una naturaleza alóctona sobre la formación olistostrómica, la cual incluye bloques de las unidades del Flysch. 


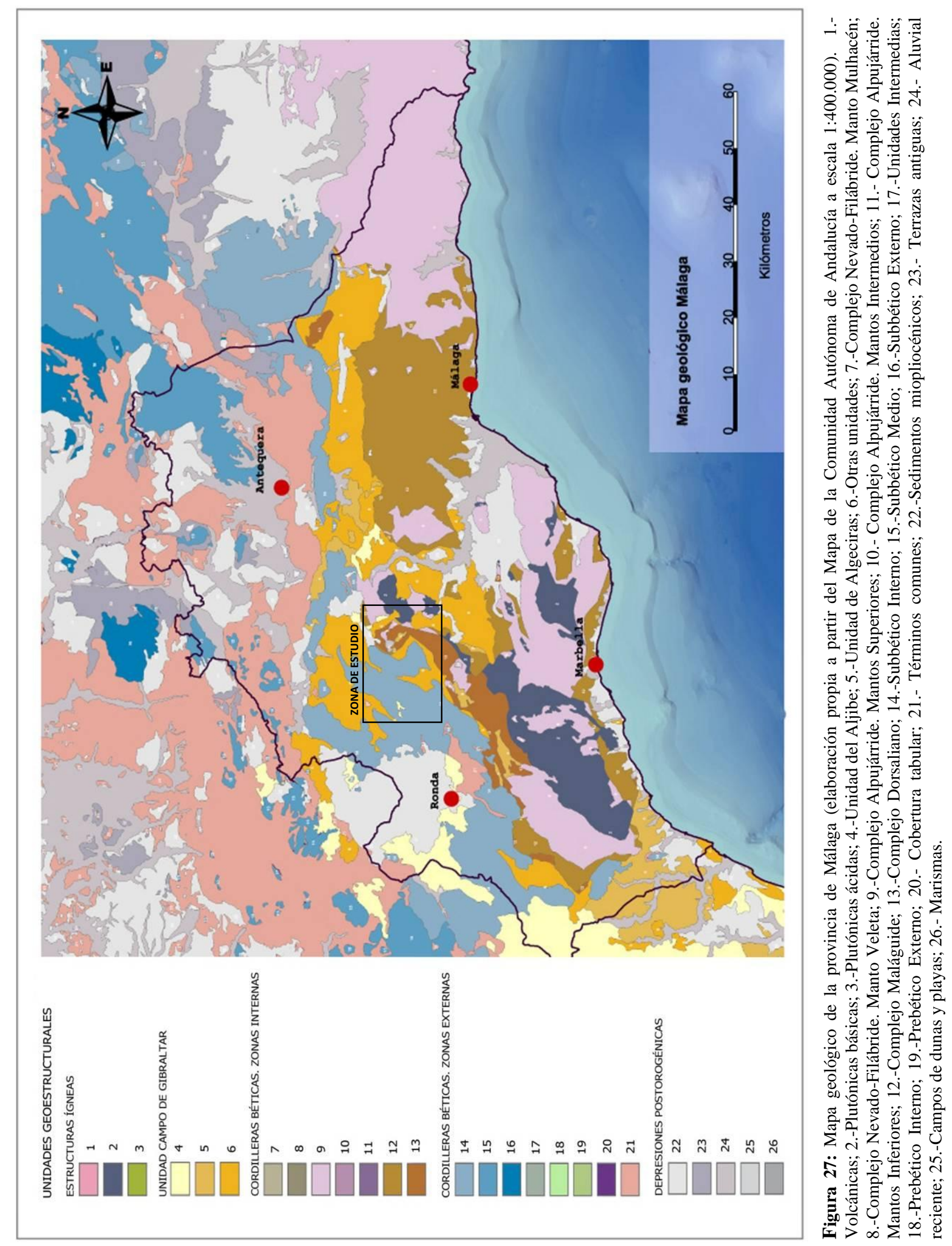




\subsubsection{Geología de detalle de la zona de estudio}

El área de estudio se ubica en el tercio occidental de las Cordilleras Béticas, próximos a la separación entre la Zona Interna y Externa, caracterizándose por la variedad de materiales aflorantes pertenecientes a diversas unidades y complejos geológicos (Martín González et al., 2004: 35), lo que genera unas características a nivel geológico singulares (figura 28).

Dentro de la Zona Externa, en el área de estudio se localiza el Penibético con una potente secuencia jurásica, enteramente caliza que da lugar a los fuertes relieves de la zona, como la sierra de Peñarrubia, la de Teba u Ortegicar entre otras, y un CretácicoPaleógeno margocalizo muy característico ("Capas rojas"). Además hay presencia de calizas nodulosas y brechoides rojas, amarillas y grises, calizas, calizas oolíticas, calizas margosas, margocalizas y margas de capas rojas del Cretácico y del Cenozoico. Destaca un paquete de margas oscuras y verdosas con niveles de margocalizas del Albiense, con una potencia muy reducida en algunos tramos. En otra zona aparece un tramo más compacto compuesto por margocalizas amarillentas con gran cantidad de sílex gris y negro de edad Cenomaniense y una facies de margocalizas rosadas pertenecientes a las "Capas rojas", en cuyos términos más bajos aparece gran cantidad de sílex gris y rojo dentro de los niveles margocalcáreos, estos últimos localizados en la margen derecha del bajo Turón.

En cuanto al Complejo del Campo de Gibraltar, formado por materiales sedimentarios, en su mayor parte de edad cenozoica aparecen en la zona del bajo Guadalteba y bajo Turón donde se presenta con materiales alóctonos. Están presentes en gran parte de la cuenca del río Guadalteba y se pueden incluir entre las Unidades Numídicas. Estas unidades están caracterizadas por una potente formación de areniscas cuarzosas del Oligoceno y Aquitaniense, que en algunos puntos descansan sobre materiales arcillosos o margoarcillosos con intercalaciones de calizas detríticas o microconglomerados y areniscas propias de las denominadas Unidades Infranumídicas.

De las Unidades Infranumídicas, los materiales presentes son arcillas, calizas detríticas, areniscas, conglomerados, margas y margas calcáreas en zonas como el suroeste de Ortegicar, en el sector del Conde, en el sector cortijo Nuevo, sector cerro de la Higuera, en la vertiente septentrional de Colorado entre otras.

De las Unidades Numídicas aparecen en la zona areníscas cuarzosas “Areníscas del Aljibe", de espesor variable, llegando en algunas zonas hasta 10 y 15 m., donde el 
cuarzo es el elemento predominante, con un $75 \%$ del total de la roca, arcillas y margas arcillosas, limos arcillosos con presencia de klippes sedimentarios u olistolitos de distinta naturaleza y edad y areníscas de colores blanquecinos a amarillentos algunos de los cuales pueden presentar pátinas parduzcas o rojizas. Afloran en las inmediaciones del cerro de Las Grajeras, en el sector de Cámara Alta, al sur de la sierra de PeñarrubiaTeba o en el cauce del arroyo de las Arenas próximo a Cañete la Real así como en la margen izquierda de la cola del embalse del Conde de Guadalhorce, junto a calizas nodulosas y brechoides rojas, amarillas y grises, calizas y calizas oolíticas del Jurásico. Brechas olistostrómicas y arcillas, ocasionalmente areniscosas y margas arcillosas con klippes.

El Neonumídico, con materiales de matriz arcilloso-areniscosa de color ocre y marrón oscuro que presenta klippes sedimentarios u olistolitos de distinta naturaleza y edad, aparece en la zona central del valle Guadalteba, en torno al cerro de la Torre, la margen noroeste del río Turón y en zonas de Cañete la Real.

La unidad de tipo Algeciras, que presenta margas de color ladrillo y arcillas de colores rojizos y marrón ladrillo con gran cantidad de niveles finos de areniscas y niveles calcareníticos con fauna de ortofragminas y Nummulites, con una potencia superior a los $150 \mathrm{~m}$, localizados sobre todo en la parte norte del embalse del Guadalteba.

El Complejo de Águila, compuesto de margas, margo calizas claras y capas rojas cretácicas, removilizadas tecto sedimentariamente durante el Mioceno inferior "Capas rojas" (AA.VV. 1990 a).

Dentro de las Zonas Internas, el Complejo Alpujárride aflora extensamente al sur de la línea Ardales-Valle de Abdalajís (López Martínez et al., 1995: 11). El Complejo Maláguide está presente con calizas alabeadas y calcofilítas al oeste de Carratraca y en la sierra de Alcaparaín, donde este tramo está claramente diferenciado de las calizas alabeadas, y con areniscas y margas rojas localizadas al este de Ardales, así como calizas blancas y calizas con sílex, margo calizas blancas y rojas esquistosas al norte de Ardales.

En relación a los materiales postorogénicos las litologías dominantes son las calcarenitas y conglomerados con intercalaciones de margas y desarrollo de bancos de ostras, estos materiales aparecen en al norte de Ardales en la zona del Almorchon y Mesas de Villaverde. 


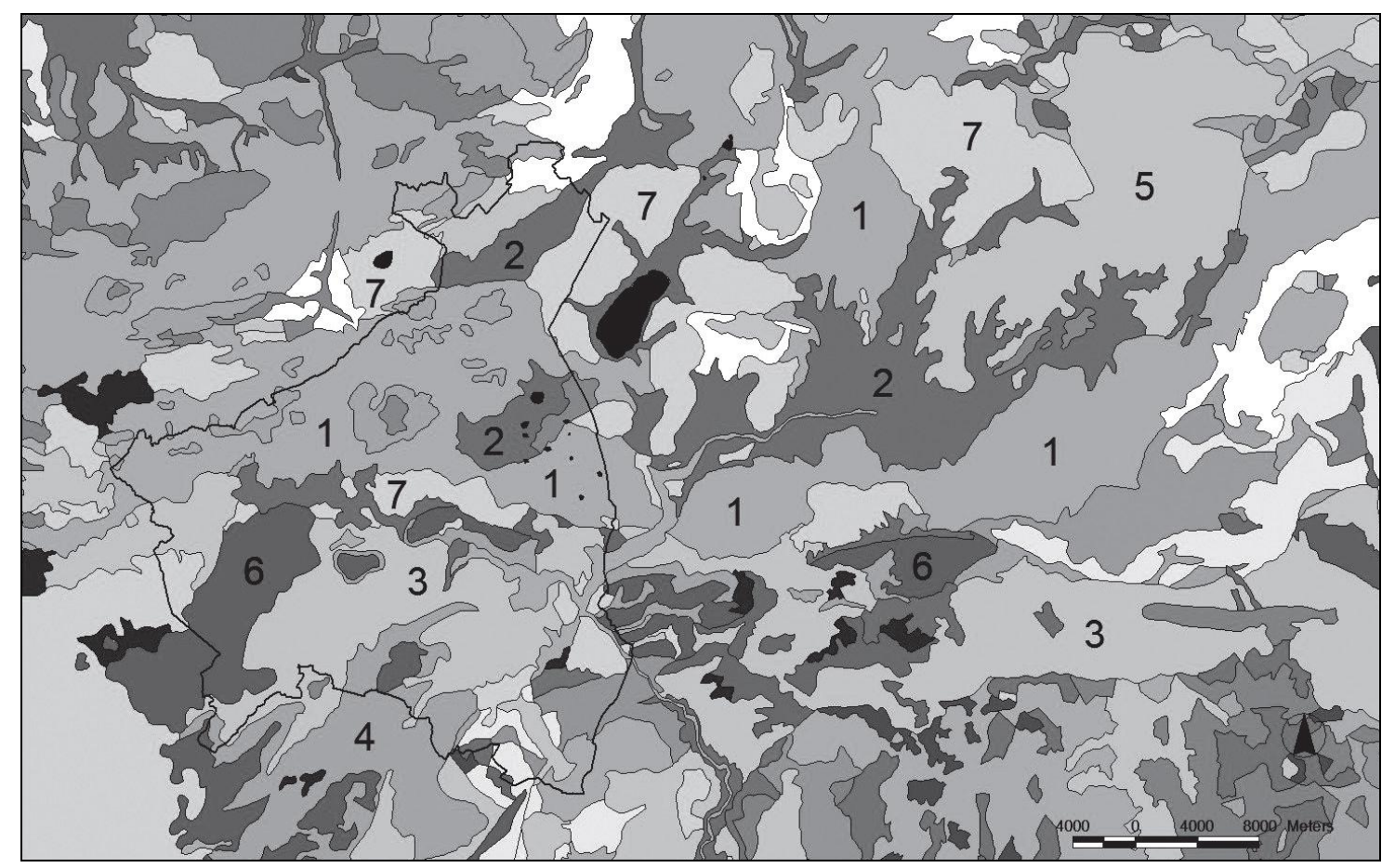

Figura 28. Geología del área de estudio (la línea negra delimita la comarca del Guadalteba):

1. Triásico: arcillas abigarradas, areniscas rojas, yesos y calizas; 2. Cuaternario: conglomerados, arenas y arcillas; 3. Paleógeno-Mioceno Inferior: arcillas y margas; 4. Cretácico: calizas y margas; 5. Jurásico: calizas y margas; 6. Jurásico: dolomías y calizas y 7. Mioceno SuperiorPlioceno: calcarenitas, margas, yesos y calizas (Durán Valsero, 2014: 28).

\subsection{Geomorfología}

\subsubsection{Encuadre geomorfológico general en Iberia y en las Cordilleras Béticas}

Las Cordilleras Béticas constituyen un conjunto montañoso que se extiende desde el estrecho de Gibraltar (provincia de Cádiz) al Cabo de la Nao (provincia de Alicante) continuando hasta las Islas Baleares. Por la parte noreste están unidas a la cobertera del zócalo de la Meseta y la terminación oriental de la Cadena Ibérica; por el tramo central y occidental, la depresión occidental del Guadalquivir se interpone entre la Meseta (Goy et al., 1994: 123).

El área de estudio se encuentra dentro del Surco Intrabético. Surge a finales del Mioceno e instalado en sinclinales y fosas tectónicas, con predominio de sedimentos pelágicos (margas y calizas) sobre los continentales (conglomerados y areniscas), separa las Zonas Internas y Externas de las Cordilleras Béticas. Las cordilleras Béticas presentan unas características y una estructuración, a nivel geomorfológico, complejas condicionadas por los procesos tectónicos y morfogenéticos, cuyos aspectos más 
destacados se explican a continuación, según el estudio de J. Rodríguez Vidal y J. Gracia Prieto (Rodríguez Vidal y Gracia Prieto, 2004).

Dentro de la Cordillera Bética existen dos grandes dominios geológicos con una posición paleogeográfica en origen distinta a la actual. Por un lado, las Zonas Externas que corresponden a la cobertera mesozoica-terciaria y por otro, las Zonas Internas con restos de un dominio, el mar de Alborán, con una posición más oriental en un principio y que con posterioridad se desplazó hacia el oeste durante el Mioceno inferior. La estructuración cortical y el empuje radial fueron la consecuencia del choque entre las placas africana y euroasiática con un régimen tectónico no homogéneo. Al final del Mioceno medio se produce la última fase de compresión, entre el denominado Tortoniense y Plioceno, responsables de la formación de los relieves elevados, de fosas, surcos y semifosas y de la creación de la cuenca del Mar de Alborán.

En el Mioceno Superior, se producen las elevaciones de grandes relieves como Sierra Nevada. Se generan grandes depresiones por los movimientos verticales de hundimiento, que en zonas marinas ocasionaron la inmersión de amplios sectores rodeados por relieves de diferentes pendientes. Durante el Messiniense se cierra la depresión del Guadalquivir por el este y se amplía la extensión de las tierras emergidas y la génesis de amplias estructuras sinclinales. Se produjo un desceso del nivel del mar que ocasionó que las cuencas se rellenaran con depósitos fluviales y calizas lacustres con caliches, los cuales enlazan lateralmente con suaves piedemontes con morfología de glacis generando paisajes regularizados.

Durante el Plioceno continúa el descenso del nivel del mar de la etapa anterior ocasionando la fosilización de relieves continentales. La actividad tectónica de este momento configuró grandes desniveles topográficos en las costas, mientras que en el interior de los continentes se produjo una independencia de las cuencas fluviales, con abanícos aluviales en los piedemontes y una gran acumulación de sedimentos lacustres en las depresiones. La actividad de las fallas que generaban un sistema de erosión y deposición ocasionaron la erosión de las montañas, la jerarquización de los valles fluviales, desarrollando en ocasiones grandes cañones, se produce un retroceso de las laderas y se generan pedimentos y aplanamientos erosivos que enlazan con sediplanos de relleno de las cuencas.

En el Pleistoceno, continúan en los bordes de las cuencas los depósitos de abanícos aluviales que se inician durante el Plioceno, mientras que en el centro se produce una sedimentación fluvial y lacustre. Durante el Cuaternario se produjo un 
cambio en la dirección de la compresión provocando una elevación de la Cordillera en el Cuaternario inferior con un máximo de elevación a mediados del Cuaternario. Se produjo a su vez una actividad tectónica de bloques que modificó la geometría y la localización de muchas cuencas y generó el desarrollo de nuevas áreas deprimidas tectónicamente, sufriendo un relleno sedimentario a lo largo de este periodo mediante la deposición de abanícos aluviales y playas-lakes.

En las Zonas Internas, se desarrolló un sistema de glaciares con morfología de circo y carentes de lengua, en las sierras más altas mientras que en las más bajas que evidencian tres episodios glaciares: "Tardiglacial, con un límite de nieves perpetuas entre 2.800 y 2.900 m; Würm, con límite hacia los 2.300 m; y Riss, éste más dudoso, con límite unos 200 m más bajo" (Rodríguez Vidal y Gracia Prieto, 2004: 129). En el resto de las sierras se conservan formas formas periglaciares heredadas.

La evolución paleoclimática del Pleistoceno favoreció el desarrollo de amplia y abundantes morfologías kársticas, como por ejemplo el polje de Zafarraya.

Los periodos fríos del Holoceno que propiciaron los procesos de aluviones fluviales y la formación de terrazas, se mantienen hoy en día, únicamente interrumpidos por algunas pulsaciones tectónicas. Las altiplanicies y las vertientes tuvieron una gran actividad peniglaciar, con diferentes formas unas veces con glaciares y otras con la retirada de los hielos, como ocurre en Sierra Nevada.

\subsubsection{Geomorfología de detalle de la zona de estudio}

Destaca la presencia de calizas oolíticas y nodulosas homogéneas separadas entre sí, en la mayoría de los casos por encajonamientos fluviales donde afloran los materiales más deleznables, ambas aunque forman parte del mismo conjunto aparecen individualizadas por el cauce del río de la Venta, sobre afloramientos de margocalizas (AA.VV. 2008).

En la zona de Teba aparecen materiales pertenecientes al Tortoniense superiorMessiniense posteriores a una etapa distensiva, de tal modo que fosilizan un paleorelieve donde destacan elevaciones en las calizas jurásicas.

Existen superficies de aplanamiento modeladas en materiales calizo-dolomítico y truncando las estructuras correspondientes. Las más significativas que encontramos en nuestra zona de estudio aparecen en la de Teba-Peñarrubia que, tanto al noreste del vértice la Camorra, como al este el tajo del Molino, se extiende a una cota de $600 \mathrm{~m}$ o la 
cumbre de la sierra de Alcaparaín a 1190 m (AA.VV.1990 a). El actual encajamiento del río de la Venta en materiales miocénicos y el no aparecer nivelados por los aplanamientos antes citados permiten descartar que sean Post-Messiniense, de modo que estas superficies están relacionadas con el mar Messiniense, coherente con la distribución que aparece en Cañete la Real y Llanos de Carrasco.

Si bien la escasa diferencia de cotas de las superficies hace razonable atribuir a una misma generación las superficies antes citadas (Cañete la Real, Llanos de Carrasco, Ortegícar y Mesa Juan), las características y los materiales presentes en las proximidades de Teba hacen pensar que también tuvieron su origen con el nivel de colmatación del Messiniense. De igual modo que se admite la existencia de deformaciones en estos materiales con posterioridad.

Un ejemplo de estas deformaciones se encuentra en el río de la Venta, subsidiario del Guadalteba. Su curso es epigénico corta transversalmente la sierra TebaPeñarrubia en el encajamiento del tajo del Molino. La sobre imposición de materiales del Miocéno debío ocurrir en consonancia con una estructuración de los mismos basculando hacia el sur, hacia el actual curso del río Guadalteba (AA.VV. 1990 a).

Además de estas estructuras antiguas, existe una evolución geomorfológica reciente con presencia de terrazas y diferentes formaciones travertínicas y que abordaremos en el capítulo 3.2.2.2.

En relación a las terrazas aluviales debemos decir que existen numerosas terrazas colgadas sobre el curso actual de los ríos, entre Ortegícar y Lentejuela, al sur de la sierra de Teba, entre Teba y Ardales al noroeste del cerro del Conde y a lo largo del río Turón. En cuanto a las formaciones travertínicas la que presenta una mayor amplitud es la localizada en el río de la Venta, en las demás la superficie está próxima a un kilómetro cuadrado, los otros se localizan en la cabecera del río Guadalteba a la altura de la sierra de Cañete y en la zona de Cuevas del Becerro.

\subsubsection{Las superficies antiguas}

Existen pocas superficies antiguas, únicamente localizamos una en el área de estudio denominada Olivar de Currito, en el término municipal de Ardales. Esta superficie antigua presenta una altitud de $485 \mathrm{~m}$ sobre el nivel del mar y una extensión de $208.636 \mathrm{~m}^{2}$. Desde el punto de vista geomorfológica se trata de una superficie de mayor antiguedad que las terrazas fluviales asociadas a los ríos Turón y Guadalteba, que culmina en la parte más alta del cerro próximo al arroyo del Alforzo, subsidiario del 
Turón. Es una superficie erosiva, posiblemente anterior al encajamiento fluvial del sistema Turón-Guadalteba. En superficie aparecen fragmentos de la roca del sustrato, arenisca y caliza y algún clasto de sílex, sin ningún tipo de redondeamiento.

\subsubsection{Los valles fluviales y las terrazas: el valle del Guadalteba y el valle del Turón}

Los valles fluviales del Guadalteba y del Turón constituyen una parte importante en la configuración de nuestra zona de estudio, la cual ha de remontarse a finales del Mioceno cuando los cauces de ambos ríos van excavando su recorrido en la cara norte y oeste de la Serranía de Ronda, en el caso del Guadalteba, y en los rebordes montañosos al norte de la sierra de las Nieves, en el caso del Turón (Cantalejo Duarte, 2007). Al no ser ríos con caudales muy grandes, presentan una tendencia a unas aguas más tranquilas en los cursos bajos, que en épocas de verano incluso llegan a secarse, lo que propicia el sedimento de materiales y el bajo transporte de los mismos quedándose los sedimentos en estas zonas casi llanas conformando grandes espacios abiertos.

En relación a las terrazas, existen varios afloramientos a lo largo del río Guadalteba y de uno de sus afluentes, el río de la Venta. Algunas de ellas presentan una notable desconexión con el cauce actual del río, otras por el contrario bordean el río y presentan una extensión considerable, con cotas entre 60-80 m, 40-35 m, hasta 30 m, en relación al cauce actual. Las litologías presentes son similares en todas estas terrazas, con presencia de cantos decimétricos a centimétricos y algunos de mayor tamaño, con rocas principalmente calizas, otras de naturaleza silícea (areniscas, radiolaritas y sílex), y también aparecen aunque en menor cantidad rocas básicas o metamórficas (Medianero Soto et al., 2013).

Las terrazas más bajas están colgadas sobre el cauce actual unos 20 m, al sur de la población de Teba (Málaga), con matriz arcillo-arenosa predominando los cantos centimétricos a decimétricos y en la zona de Peñarrubia (Campillos), donde se encuentran las más bajas entre 15 y $2 \mathrm{~m}$.

El estudio de los travertinos del curso alto de río Guadalteba y de su curso bajo, en concreto en la zona del río de la Venta, establece su formación en momentos anteriores al Holoceno, de modo que podría establecerse que el conjunto pertenece al Pleistoceno (AA.VV. 1990). 
En cuanto al río Turón, las terrazas fluviales aparecen localizadas en ambas márgenes constituidas por cantos de rocas metamórficas y calcáreas en general englobados en matriz arcillo-arenosa, con cotas de entre +7-10 m al norte de Ardales y + 20 m localizadas al noroeste de Ardales y en la zona del castillo Turón, en el caso de estas últimas la formación aluvial está muy cementada.

\subsubsection{Las formas kársticas}

Desde un punto de vista general la provincia de Málaga destaca por un elevado número de formaciones kársticas. Son conocidas más de 1.000 cavidades, entre ellas la Cueva de Ardales objeto de estudio, y otras cavidades muy conocidas como cueva de Nerja, cueva de La Pileta, o cueva del Hundidero-Gato. En cuanto al exokarst, la provincia presenta una amplia variedad de formas con presencia de dolinas, poljes, torcales, cañones fluviokársticos o valles ciegos (Durán Valsero, 1996: 99), a las que se les unen otras formas como los depósitos travertinicos del río de la Venta, en la zona del tajo del Molino (Teba), presentes en el área de estudio.

La ubicación de nuestra zona de estudio dentro de las Cordilleras Béticas propicia la existencia de numerosas formas exokársticas y endokásticas, con presencia de fuentes termales y nacimientos de agua vinculados a ellas, ya que presentan numerosos macizos carbonatados susceptibles de kárstificación (Durán Valsero et al., 1999: 14).

La evolución kárstica de las sierras calizas localizadas en la zona, produjo numerosos desfiladeros, como el del tajo del Molino (Teba) o el desfiladero de Los Gaitanes, así como cavidades kársticas.

En la sierra de Teba-Peñarrubia, una formación caliza con pliegues y estratos inclinados y con una fase posterior de distensión y reajuste que provocó la aparición de fallas y diaclasas en los materiales rígidos, se localiza la cueva de Las Palomas (Teba). Esta sierra junto a otras próximas como la del Chorro o el Valle de Abdalajís presentan unos ejes de plegamiento con una orientación hacia el este incluso puntualmente hacia el este-sureste (Durán Valsero, 1996: 81).

El complejo kárstico de la cueva de Las Palomas "se desarrolla desde los 470 hasta los 430 m, con una gran caída hacia el río de la Venta. Su cauce rompe el macizo calizo de la Sierra de Teba-Peñarrubia y une, a través de un corredor natural, las cuencas atlántica y mediterránea en la comarca de Guadalteba" (Medianero Soto, et 
al., 2014: 22), presenta además una sima que incluye una dolina de hundimiento y varias galerías, no siendo especialmente rica en espeleotemas.

En el sector septentrional de la Serrezuela (Carratraca), se encuentra la Cueva de Ardales, que con una altitud de 565 m s.n.m y un desarrollo de $1500 \mathrm{~m}$, se abre en materiales carbonáticos del Triásico.

Una de las formas kársticas más importante de la zona, es el desfiladero de Los Gaitanes. Las calizas procedentes de los depósitos de lodo marino del Jurásico, aparecen en estratos verticales, abiertos primero por la erosión marina del Cenozoico y posteriormente por la acción fluvial de los ríos Guadalteba, Turón y Guadalhorce. Estos depósitos fueron comprimidos y deformados en pliegues por el empuje de las placas ibéricas y africanas.

\subsection{Marco cronológico general y escalas cronoestratigráficas utilizadas}

La evolución humana tiene su culminación en el periodo geológico denominado Cuaternario con la aparición de nuestra especie en el Pleistoceno superior.

Las tres principales características del Cuaternario son (Fernández Fernández et al, 2006):

- Variación climática con alternancia de periodos glaciares e interglaciares, aunque esta variabilidad no es exclusiva del Cuaternario su conocimiento es mayor.

- Variabilidad climática en influencia en el paisaje.

- Aparición del genero Homo.

Se define como una unidad cronoestratigráfica que "constituye el techo de la secuencia geológica con depósitos y materiales actuales” (Jordá Pardo, 1995: 53). Dicha definición, ha sido objeto de un intenso debate desde el siglo XVIII. El término fue creado a finales del siglo XVIII por el geólogo Giovanni Arduino quién elaboró la que se considera la primera clasificación del tiempo geológico en cuatro órdenes dispuestos unos sobre otros correlativamente, Primario, Secundario, Terciario y Cuaternario (Bardají et al., 2009: 38). Pero la primera vez que se aplicó el término fue en 1829 por J. Desnoyers para describir unos depósitos marinos más recientes que el Cenozoico en la cuenca del Sena (París). Entre los años 1830-1832, M. de Serres y H. Reboul restringieron su uso para los depósitos relacionados con el Diluvio bíblico (Jordá Pardo, 2014:22). Con posterioridad autores como Bronn, Lyell, Moritz Hörnes o 
Forbes, entre otros, emplearon términos como Mioceno, Plioceno o Neógeno. En 1835 Lyell usa el término de Pleistoceno para asignar depósitos post-pliocenos y en 1840 Forbes utiliza el término Pleistoceno como sinónimo de periodo glacial (Carbonell et al.,2011: 388). Todo ello sin crear un consenso para unificar criterios a la hora de definir el término, ya que aunque reconocido a nivel geológico, su categoría dentro de la escala cronoestratigráfica internacional nunca tuvo reconocimiento explicito, hasta que en el año 2008, la International Union for Geological Sciences (IUGS), le otorgó la categoría de sistema dentro del eratema Cenozoico y por encima del Neogeno. De modo que la categoría de esta unidad dentro de la escala cronoestratigráfica (figura 28), es la de sistema, mientras que en la escala geocronológica es la de periodo (Jordá Pardo, 2014: 24). Sin embargo, no será hasta junio de 2009, tras el XVIII congreso Internacional de INQUA, cuando fue aceptado por la Comisión Internacional de Estratigrafía (ICS), se define como un GSSP (Global Stratotype Section and Point) y es ratificado por la IUGS (International Union of Geological Sciences). Con ello se le reconoce como el periodo geológico más reciente que se extiende desde hace 2,588 hasta la actualidad (Bardají et al., 2009: 37). Su límite inferior se establece en el estratotipo del monte de San Nicola, coincidiendo con la base del Gelasiense y del Pleistoceno; el Gelasiense se integra formalmente como la base del Pleistoceno y el límite inferior se fija en 2, 588 Ma (Jordá Pardo, 2014: 24-25).

El Cuaternario se divide en dos series en la escala cronoestratigrafica, el Pleistoceno y el Holoceno, y a su vez el Pleistoceno se divide en inferior, medio y superior y se caracteriza por la alternancia de periodos fríos con otros cálidos o templados. La escala cronoestratigráfica utilizada a lo largo de todo este trabajo será la de Pleistoceno (figura 29). 


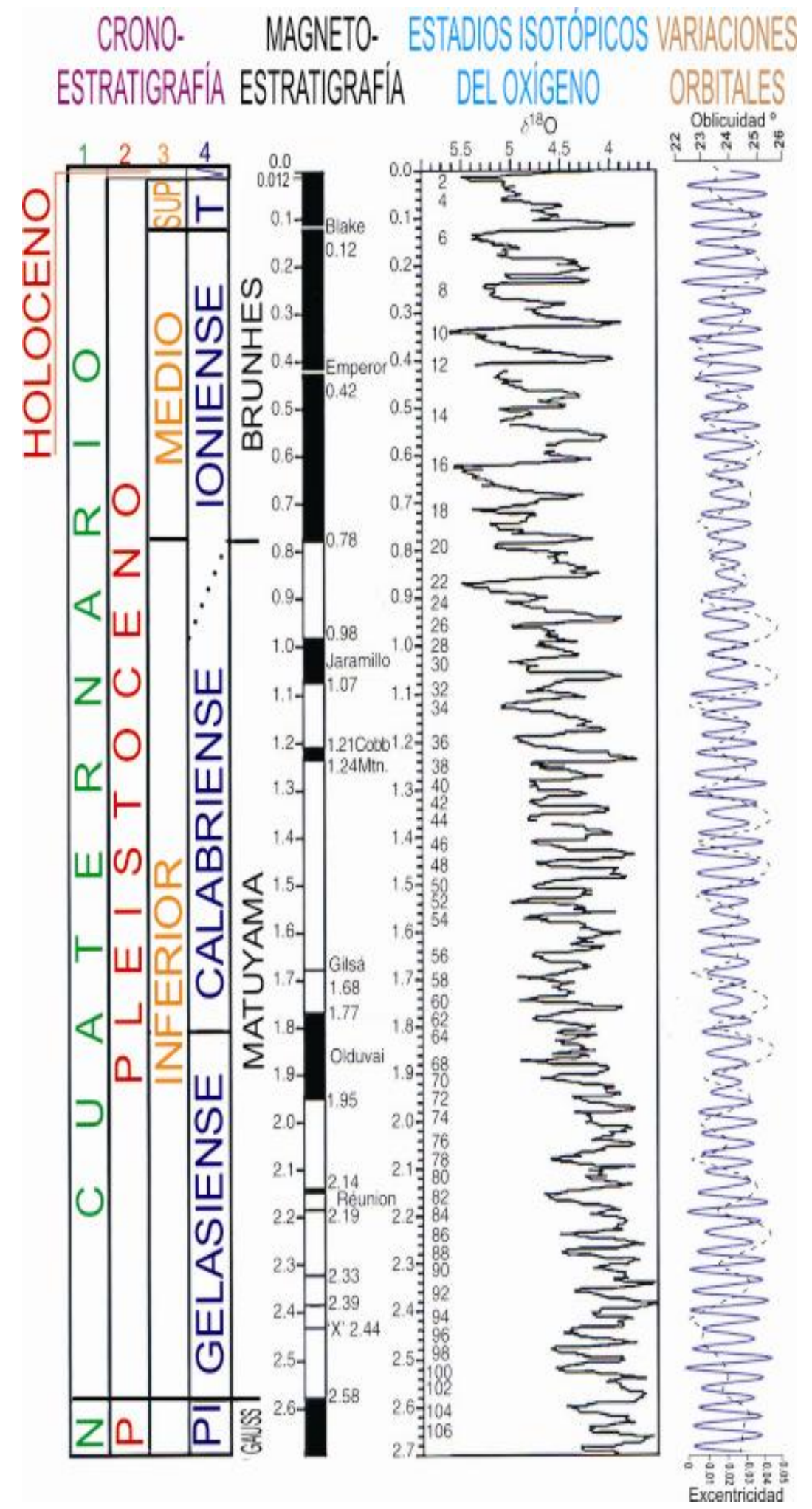

Figura 29. Tabla cronoestratigráfica del Cuaternario (Jordá Pardo, 2014: 23). 


\subsection{Edafología}

En los estudios de edafología, el suelo se convierte en objeto de investigación en sus aspectos físicos, químicos, biológicos y geográficos (Sunyer Martín, 1994: 87). $\mathrm{Su}$ formación y evolución viene determinada por una serie de factores como el clima, la topografía, la naturaleza de la roca madre, los organismos, el tiempo o la actividad humana (Barrios, 1985: 99).

En el término municipal de Campillos, Ardales y Teba, predominan los suelos entisoles formados sobre el Triásico de textura arcillosa, con contenido calizo alrededor del $15 \%$ y $\mathrm{pH}$ inferior a 8 . Son de mediana a baja calidad agrícola.

Según el Mapa Geológico de España, escala 1:50.000, Teba. Hoja 1037, 15-43 y Ardales. Hoja 1038, 16-43 y los datos aportados por el P.G.O.U de Campillos y Teba, se establece la siguiente clasificación general de los suelos donde se ubica la zona de estudio (figura 29):

- Cuaternarios: salvo afloramientos locales dispersos, se disponen alrededor del núcleo urbano en sentido noreste-suroeste, exceptuando el cerro de la Silleta y cerro de Las Aguilillas.

- Margas y margocalizas al noreste y noroeste y pequeñas manchas. De textura arcillosa y buena calidad agrícola para cultivos que toleran su alto contenido calizo.

- Margas y areniscas al sur del término de Campillos, enmarcando la zona del embalse del Guadalteba. Contenido bajo en materia orgánica, textura arcillosa y calidad agrícola de mediana a buena.

- Los entisoles, formados sobre materiales como arcillas, margas, yesos y dolomías.

Las unidades de suelo identificadas en la cuenca del bajo Guadalteba y del bajo Turón se dividen en tres tipos (figura 30), según los datos del Mapa de Suelos de Andalucía, E. 1:400.000 de 1989. Los suelos aparecen en unidades cartográficas agrupadas a nivel de segundo orden de los criterios de la clasificación de la F.A.O. (1974) y del Mapa de Suelos de la Unión Europea de 1985:

- Litosoles, luvisoles crómicos y rendsinas con cambisoles cálcicos.

- Cambisoles cálcicos, regosoles calcáreos y litosoles con rendsinas.

- Cambisoles vérticos, regasoles calcáreos y vertisóles crómicos con cambisoles cálcicos. 


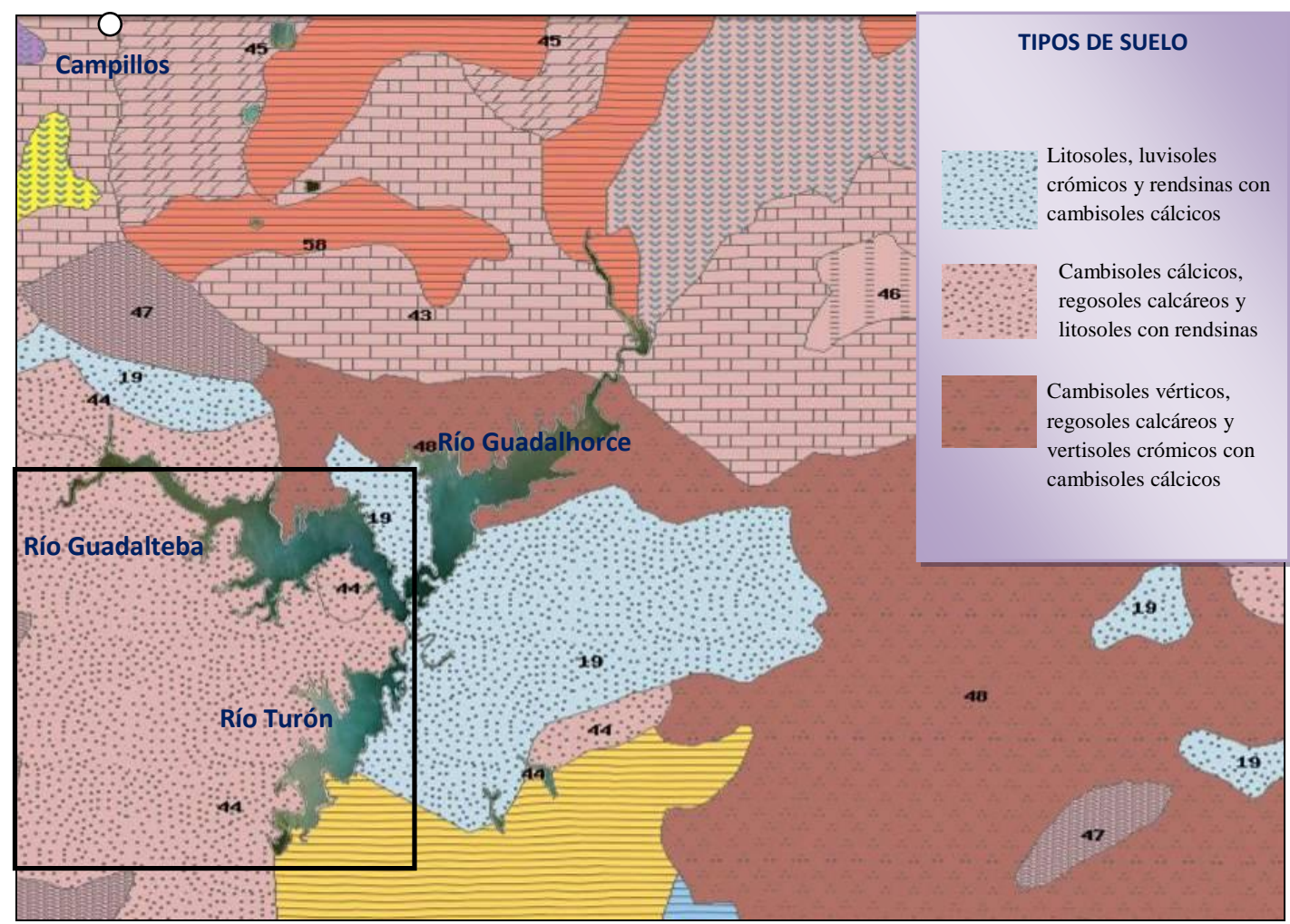

Figura 30. Edafológia del área de estudio, modificado a partir del mapa de suelos de

Andalucía, escala E: 1:400000.

\subsection{Geografía}

El área de estudio que abarca este trabajo corresponde al valle del bajo Guadalteba y bajo Turón, localizados en la zona noroeste de la provincia de Málaga. Afecta a varios términos municipales, Almargen, Ardales, Cañete la Real, Carratraca, Cuevas del Becerro, Sierra de Yeguas, Teba y Campillos. Su superficie es de 722,58 $\mathrm{km}^{2}$ y linda con los términos municipales de Ronda, Álora y Antequera.

Sus límites naturales son:

- Al norte, la campiña sevillana.

- Al sur, el valle del Guadalhorce.

- Al oeste, la Serranía de Ronda y la sierra de Cádiz

- Al este, la vega de Antequera.

"Altitudinalmente, el espacio se extiende entre altitudes extremas de $240 \mathrm{~m}$ y $1191 \mathrm{~m}$ s.n.m. lo que supone un alto gradiente $(951 \mathrm{~m})$, que se refleja en la estructura y la tipología de los recursos, a través de una gran diversidad" (Romero González et al., 2004: 22). Sus principales alineaciones montañosas son las sierras del Viján (Viján, 905 m), Cañete la Real (Padastro, 999 m), Teba (La Camorra, 743 m) y Peñarrubia 
(Castillón, $729 \mathrm{~m}$ ), que limitan el valle del Guadalteba por el oeste y por el norte, la sierra de Ortegicar (Ortegícar, 963 m) que separa los valles del Guadalteba y Turón, y la sierra de la Cabrilla (Tajo Cabrilla, 1503 m), Prieta (sierra Prieta, 1518 m), Alcaparaín (Grajo, 1293 m), Serrezuela (Serrezuela, 729 m) y de la Pizarra (Almorchón, 665 m) que constituyen la divisoria de aguas con el valle del Guadalhorce (Becerra Parra, 2006: 126).

\subsubsection{Orografía}

A la disposición de los materiales geológicos se le une un relieve muy acusado, con presencia de tajos, escarpes y laderas empinadas, entre los que se abren paso los ríos y barrancos de menor entidad (Romero González et al., 2004: 77).

El relieve montañoso de la zona delimita un territorio con presencia de valles y campiñas, y algunos pasos naturales, por cañones y desfiladeros como el Tajo del Molino (Teba), través de los cuales discurre uno de los afluentes del río Guadalteba, denominado río de la Venta.

La orografía influye en las condiciones climáticas y en las comunicaciones entre la zona de estudio y el sur de la provincia canalizadas a través de pasos naturales. En el interior de la nuestra zona de estudio aparecen pequeñas sierras como las de Cañete la Real, Peñarrubia o sierra de los Caballos. Los relieves más importantes aparecen en el sur de este a oeste nos encontramos con la sierra del Valle de Abdalajís, sierra de Pizarra, sierra de Aguas, sierra de Baños, sierra de Alcaparaín y sierra de Ortegícar. Estas ejerce de un fuerte barrera frente a los efectos del mar lo que influye en las condiciones climáticas de la zona Las alturas oscilan entre los $370 \mathrm{~m}$ en las zonas inundables de los embalses a los $720 \mathrm{~m}$ del cerro del Castillón (sierra de Peñarrubia).

En cuanto a las pendientes, oscilan entre el 3 y el 15\%, en el curso bajo del Guadalteba y Turón. En la unión con el río Guadalhorce se aprecian pendiente en torno a un $30 \%$, siendo la sierra de Peñarrubia y algunos puntos cercanos al curso alto y medio de ambos ríos donde aparecen pendientes superiores a un 45\% (AA.VV., 2008). 


\subsubsection{Hidrografía}

El río Guadalhorce es el río de mayor longitud de la provincia de Málaga (154 $\mathrm{km})$. Su cuenca vertiente ocupa parte de la zona septentrional y centro meridional de la provincia de Málaga. Desde el punto de vista ambiental, se encuadra en el marco biogeográfico mediterráneo, caracterizado por un caudal irregular y acusados estiajes (AA.VV., 2007).

La red hidrográfica de la zona de estudio está compuesta por dos ríos principales, Guadalteba y Turón, una multitud de arroyos y cauces con aporte variable de agua según el año hídrico, y varias lagunas temporales en el término municipal de Campillos, "que constituyen uno de los más interesantes humedales endorreicos andaluces" (Romero González, 2006: 99), junto a una amplia red de aguas subterráneas que manifiesta la riqueza hidrológica de la zona (Marín, 2006: 113). Además existen dos embalses el del Guadalteba y el del Conde del Guadalhorce.

En el tramo medio del Guadalhorce y como afluentes del mismo se encuentran los ríos Guadalteba y Turón. Presentan una cuenca relativamente extensa, con materiales muy erosionables, que permiten la formación de abundantes terrazas aluviales (Medianero Soto et al., 2012: 62). Se trata de ríos de mineralización de baja montaña mediterránea, con una cierta altitud, que impone un clima menos templado, y por la mayor aportación específica. Con una mineralización alta, aunque variable y con la existencia de tramos puntuales de conductividad muy elevados, asociados principalmente a lavados de terrenos yesíferos (AA.VV., 2007). Durante su recorrido el Guadalteba recoge las aguas de los arroyos Cerezo, de las Cobatillas, del Barbero, de Castilla, Salado, del Término y del río de la Venta. El Turón lo hace del arroyo del Alforzo y de Cantarranas.

En su desembocadura, el cambio de ambiente motivado por las aguas del embalse, provoca la sedimentación de las tierras y con ello la radiación de una importante masa de tarajes (Taramix africana), en un bosquete de gran interés biológico. Uno de los afluentes del Guadalteba, el río de la Venta, más reducido en cuenca y caudal, drena toda la zona norte de Peñarrubia, a la que atraviesa a través del Tajo de la Venta (Romero González et al., 2004: 71). 
Las características hidrológicas de nuestra zona de estudio permiten distinguir tres áreas (AA.VV., 1977):

- Zona permeable por la gran fisuración existente, el drenaje trascurre por escorrentía superficial, con algunos casos de infiltración debido a la fisuración que existe en algunos puntos. La hidrología subterránea vinculada a fenómenos kársticos con posibilidad de acumulación de grandes cantidades de agua. En zonas próximas a la Sima de Sílex del Complejo de Las Palomas (Teba) y en la zona del pueblo de Ardales.

- Zona en su mayoría impermeable, con presencia en algunos puntos de zonas permeables o semipermeables. En las zonas llanas, debido a la topografía, presenta un drenaje deficiente con encharcamientos después de las lluvias, en las zonas de pendiente el drenaje es bueno efectuándose con escorrentía superficial. El agua subterránea puede aparecer en pequeñas cantidades a poca profundidad. Próximo a la zona de contacto del río Guadalteba y el Gualdalhorce.

- Zona con materiales semipermeables, presentando en algunos puntos niveles más o menos permeables dependiendo de la litología y el grado de cementación. El drenaje es aceptable por porosidad intergranular en las llanuras, y favorable por escorrentía y percolación en áreas con pendientes. Están localizadas en el extremo izquierdo del río Turón y en el derecho del río Guadalteba.

A partir del Atlas hidrogeológico de Andalucía del Instituto Tecnológico Geominero de España se detalla el comportamiento hidrogeológico en función de la litología de la zona (AA.VV, 1998):

- Conjunto del Jurásico: Calizas y dolomías con una alta permeabilidad.

- Conjunto del Neógeno - Cretácico - Jurásico superior: Compuesto por margocalizas, margas y Flysch que generan baja permeabilidad

- Conjunto del Mioceno-Plioceno: Compuesto por gravas, arenas, areniscas y arcillas con una permeabilidad media presentando algunas zonas localmente permeables

- Conjunto del Cuaternario: Compuesto por gravas, arenas y arcillas (aluvial y pie de monte) con una permeabilidad media. 


\subsection{Climatología}

La configuración natural de la provincia de Málaga genera unas condiciones climáticas variadas que origina una amplia diversidad de paisajes.

Su situación entre dos cuencas; la Mediterránea y la Atlántica, permite una interacción entre un clima húmedo medio atlántico y un clima medio mediterráneo a lo largo de toda la provincia (AA.VV., 2007). A escala microclimática, presenta una influencia termorreguladora del agua recogida en los diversos pantanos del Complejo Hidrológico de El Chorro, así como la derivada de la altitud de los terrenos y su orientación (Romero González et al., 2004: 30).

En relación a las precipitaciones y las temperaturas, a nivel general, existe un contraste pluviométrico, debido a la orografía de la provincia y a la influencia atlántica y mediterráneo, que en mm oscila entre los 400 y 1.500 al año, ante esta situación nos encontramos que el área de estudio se encuentra en una zona seca-semiárida, con valores anuales de precipitación en torno a los $500 \mathrm{~mm}$ (AA.VV., 2007). Su régimen pluviométrico es muy irregular, con vientos de componente norte, aire frío de origen polar y presencia de vientos de poniente, de origen Atlántico, más frecuentes en invierno, que favorecen la entrada de frentes y precipitaciones.

Las temperaturas, en cuanto a valores medios anuales, marcan un régimen típicamente mediterráneo, con veranos secos y cálidos e inviernos con periodos cortos de mayor frío. Se sitúan en torno a los $17^{\circ} \mathrm{C}$, con mínimos de $9-10^{\circ} \mathrm{C}$ y máximos de 25 $26^{\circ} \mathrm{C}$. Los valores extremos se sitúan en torno a los $0^{\circ} \mathrm{C}$ en enero y máximos de hasta $38^{\circ} \mathrm{C}$ en julio y agosto (figura 31 ). 


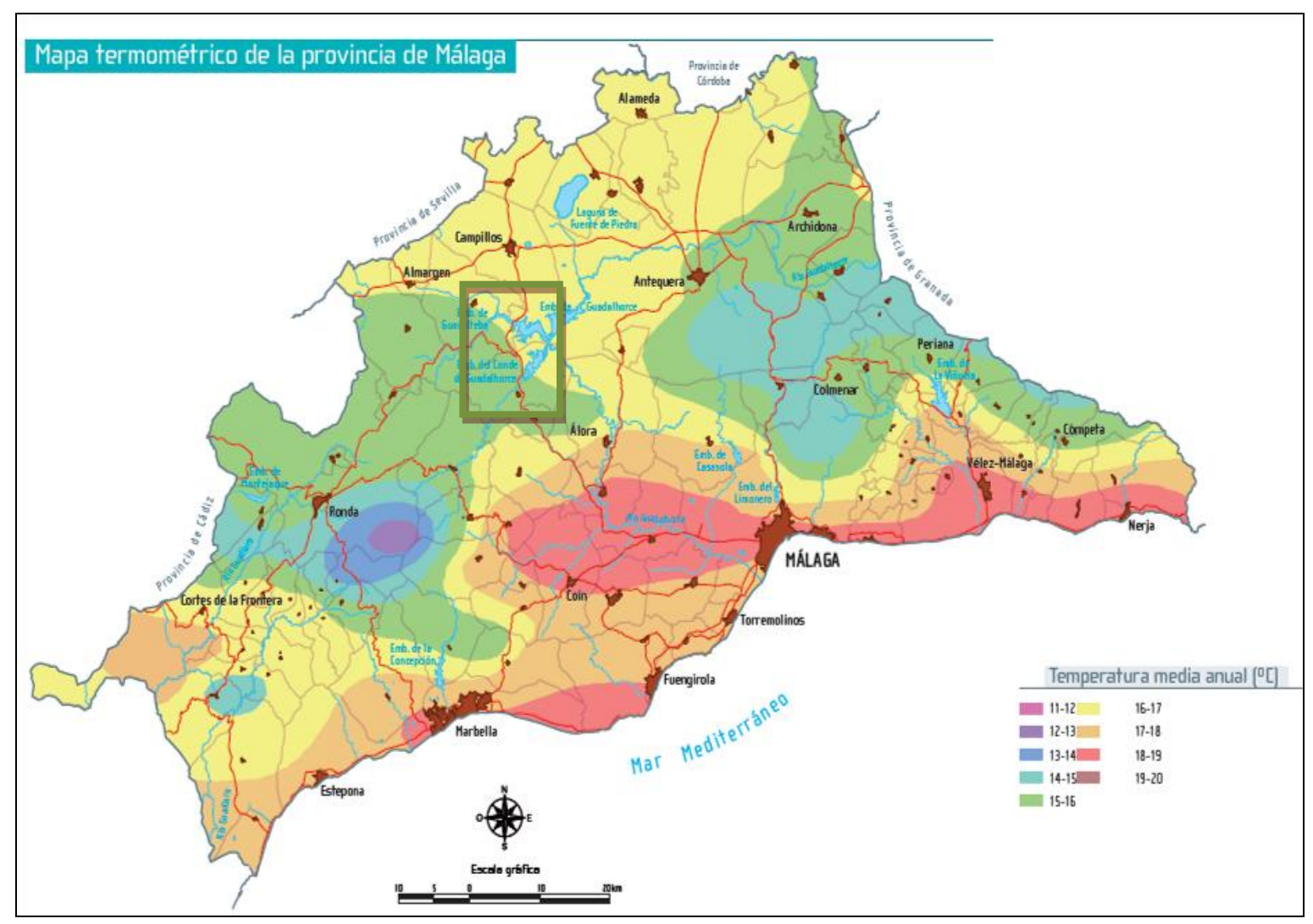

Figura 31. Temperatura media anual de la provincia de Málaga (AA.VV., 2007).

El régimen de vientos, es similar a la zona central de la provincia. Los vientos fríos de norte y noroeste, inciden en la zona central y la vertiente norte, de igual forma que los vientos cálidos del verano. Durante el resto del año, vientos del este y del sur afectan de manera más directa a las vertientes orientadas en dicha dirección. La influencia del mar, es patente en la zona meridional, mientras que la fractura del desfiladero de Los Gaitanes, emboca en ocasiones fuertes corrientes de aire en sentido norte-sur, o viceversa, al igual que ocurre en el cañón del Granado o en el tajo de la Venta (Teba) (Romero González et al., 2004: 34).

En resumen, podemos decir que el clima presente en el área de nuestro estudio, podría encuadrarse como un clima de transición termo a mesomediterráneo, caracterizado por temperaturas altas en verano y bajas en invierno, con frecuentes heladas y nevadas ocasionales, con temperaturas suaves en otoño e invierno, según los siguientes parámetros (AA.VV, 2008):

- Temperatura media anual: $16,7^{\circ} \mathrm{C}$ (Mesomediterráneo).

- Temperatura mínima mes más fío: 4,9 $9^{\circ} \mathrm{C}$ (Mesomediterráneo).

- Temperatura media máximas mes más frío: $13,9^{\circ} \mathrm{C}$ (Termomediterráneo). 
- Meses con heladas (diciembre a febrero): Termomediterráneo.

La ubicación de las montañas y la distribución del relieve (dirección E-O), definen una variación tajante entre solanas y sombrías, con diferencias de hasta varios grados centígrados (Romero González et al., 2004: 31).

En función de su índice de humedad y eficacia térmica, según la clasificación de Thornthwite (AA.VV., 2007-2008), correspondería a la categoría D, se enmarcaría dentro del tipo Semiárida, Mesotérmico, "con un pequeño exceso de agua de Enero a Marzo, o templado cálido Mediterraneo según Koppen, tipología que pasa a secosubhúmedo mesotérmico en determinadas situaciones concretas del territorio" (Romero González et al., 2004: 30).

\subsection{Vegetación y fauna}

La vegetación y la fauna presentes en la actualidad son características del ambiente de tipo mediterráneo, propias de terrenos abiertos, con árboles y bosques dispersos, abundancia de monte bajo y matorral.

La comunidad vegetal está compuesta por una gran cantidad de especies bien adaptadas a las condiciones climáticas, entre la que destacan gran cantidad de especies acuáticas (Marín, 2006: 113). “Corresponden a dos pisos bioclimáticos: termomediterráneo superior y mesomediterráneo” (Romero González, 2006: 101), que condiciona la riqueza de flora y, en general, de la vegetación.

Dentro de las comunidades vegetales nos encontramos con:

- Encinas (Quercus rotundifolia)

- Comunidades ripícolas, que se encuentran en las zonas de los ríos y arroyos, destacan las saucedas (Sailicetum), los chopos (Populus alba), fresnedas (Ficario-fraxineto angustifoliae) o adelfares (Nerio oleandri-Populetum albae), entre otras.

- Sabinares (Juniperus turbinata), destacando algunas zonas en la desembocadura del río Guadalteba y Turón, y en la sierra de Pizarra.

- Carrizales (Phragmites australis) y juncos (Juncus acutus, Articulatus, Bufonius)

- Pino carrasco (Pinus halepensis, P. pinea y P. pinaster)

- Acebuchal (Olea europea var. sylvestris) 
- Matorrales de degradación, como coscojas (Quercus coccifera), majoletos (Crataegus monogyna), lentiscos (Pistacia lentiscus), érguenes (Calicotome villosa), espino prieto (Rhamnus lycioides), retama (Retametum sphaerocarpae), etc.

- Matorrales bajos, como romero (Rosmarinus officinalis), matagallos (Phlomis purpuerea), aulagas (Ulex parviflorus), etc.

En cuanto a la fauna, dentro del grupo de los mamíferos predominan las propias de los ámbitos antropogeneizados y las de matorral y bosque mediterráneo, lo más relevante es la presencia de especies protegidas, como por ejemplo, el murciélago común (Pipistrellus pipistrellus), el gato montés (Felix silvestres) o la cabra montés (Capra pyrenaica hispanica), en número abundante aparecen los reptiles, entre los que destaca el lagarto ocelado (Lacerta lepida) y varios tipos de culebra como la de escalera (Elaphe scalaris) o la bastarda (Malpolon monspessulanus). Entre los anfibios, destaca la presencia de gallipato (Pleurodeles waltl), salamandra (Salamandra salamandra) y sapillo pintojo meridional (Discoglossus jeanneae). El grupo de las aves constituye el más numeroso, debido a las condiciones ecológicas de la zona, su situación geográfica y ser un área de invernada de estas especies, destacan las rapaces como el alimoche (Neophron percnopterus) o el buitre leonado (Gyps fulvus), las especies de estepas cerealista como el alcaraván (Burhinus oedicnemus), aguilucho cenizo (Circus pygargus) o las grullas (Grus grus); y ya dentro de las especie acuáticas se encuentran el águila pescadora (Pandion haliaetus), el flamenco (Phoenicopterus roseus), el somormujo (Podiceps major), el zampullín (Tachybaptus ruficollis), el cormoran (Phalacrocorax auritus) o la cigüeñuela (Himantopus himantopus) (Romero González, 2006: 101).

\subsection{Poblamiento humano y redes de comunicaciones. El impacto humano en el paisaje}

El uso humano del territorio, ha generado cambios que rompen con la naturaleza original del mismo. Como ejemplos destacan las actividades agrícolas o las grandes infraestructuras de los embalses.

La geomorfología, la geología, la vegetación y los usos humanos definen las unidades del paisaje presentes en el área de estudio, distinguibles por sus características y usos humanos (Romero González et al., 2004: 78): 
- Una zona norte y occidental: cultivos herbáceos y arbustivos, con algunos enclaves naturales y la sierra de Peñarrubia-Teba

- Una zona central: cultivos herbáceos intensivos con huertas locales y olivar disperso y arbustivos, definida en la zona de los embalses

- Una zona meridional: pequeñas áreas agrícolas de montaña.

De ello se desprende la utilización mayoritaria del territorio para usos agrícolas y ganaderos, viéndose en la expansión de los mismos un retroceso de los bosques primitivos (encinas, alcornoques o sabinas), objeto de un intenso aprovechamiento, como fuente de leña, madera o taninos para curtidos, entre otros, que marcaron la distribución de los asentamientos humanos en el territorio.

La ubicación de este marco geográfico y la existencia de una amplia infraestructura para regulación y abastecimiento del agua de los embalses del Conde del Guadalhorce y del Guadalteba, ha generado la proliferación de una amplia red de comunicaciones, que lo unen con la práctica totalidad de la provincia por carretera o incluso ferrocarril en la zona de los embalses. 


\section{Presentación de los datos}

\subsection{Los afloramientos de materias primas}

En la localización de los afloramientos de las materias primas ha jugado un papel muy importante la bibliografía geológica existente, fundamentalmente la del IGME (AA.VV. (1990 a y b), así como los muestreos realizados con anterioridad por mi codirector de tesis S. Domíngez-Bella en el área de estudio. Con ayuda de las técnicas arqueométricas realizadas en los laboratorios de la Universidad de Cádiz, hemos podido establecer una aproximación a la vinculación entre los materiales líticos arqueológicos y los afloramientos geológicos, que ha permitido desarrollar una interpretación de la movilidad de los grupos humanos paleolíticos de la zona en función de las necesidades y disponibilidades líticas, proporcionando además una lista de materias primas explotadas y la localización de las áreas fuente.

Hemos establecido dos categorías principales de áreas fuente que cuentan con las siguientes localizaciones:

- Zona de afloramientos primarios o semi-primarios: El Azulejo (Ardales), La Atalaya (Cañete la Real), herriza de La Lapa (Cañete la Real), Valle de Abdalajís, sierra de Humilladero, herriza del Carnero (Casarabonela), Los Madroñales (Almargen), parque eólico PEMA4 (Almargen), los Canchos (Cuevas del Becerro), la Mogea (Cuevas del Becerro), la Galeota (Ardales) y castillo Turón (Ardales).

- Zona de afloramientos en posición secundaria: terraza de Las Grajeras (Ardales), terraza de Peñarrubia (Campillos), terraza Casilla Vallejo (Teba).

\subsubsection{Los afloramientos con materiales en posición primaria o semi-primaria}

La caracterización geológica se ha realizado sobre el material recogido en 12 puntos de muestreo semiprimarios (figura 32) y un total de 46 láminas delgadas. Los puntos de muestreo están asociados a zonas de derrubios de ladera próximos a los afloramientos geológicos primarios. La caracterización de visu con lupa (Triplet 10x-21 mm) nos permitió establecer una primera clasificación de los materiales geológicos, que posteriormente fue corroborada o no a partir de la descripción microscópica de las láminas delgadas. A su vez la caracterización de las láminas delgadas se ha realizado con microscopía óptica utilizando objetivos de 25, 100 y 400 aumentos, tanto con luz polarizada (LP) como con luz doblemente polarizada (LDP). 
Para las descripciones de las unidades geológicas a las que pertenece cada afloramiento se han utilizado los mapas geológicos del IGME elaborados por diferentes autores (AA.VV., 1990 a y b y AA.VV., 1986 a y b).
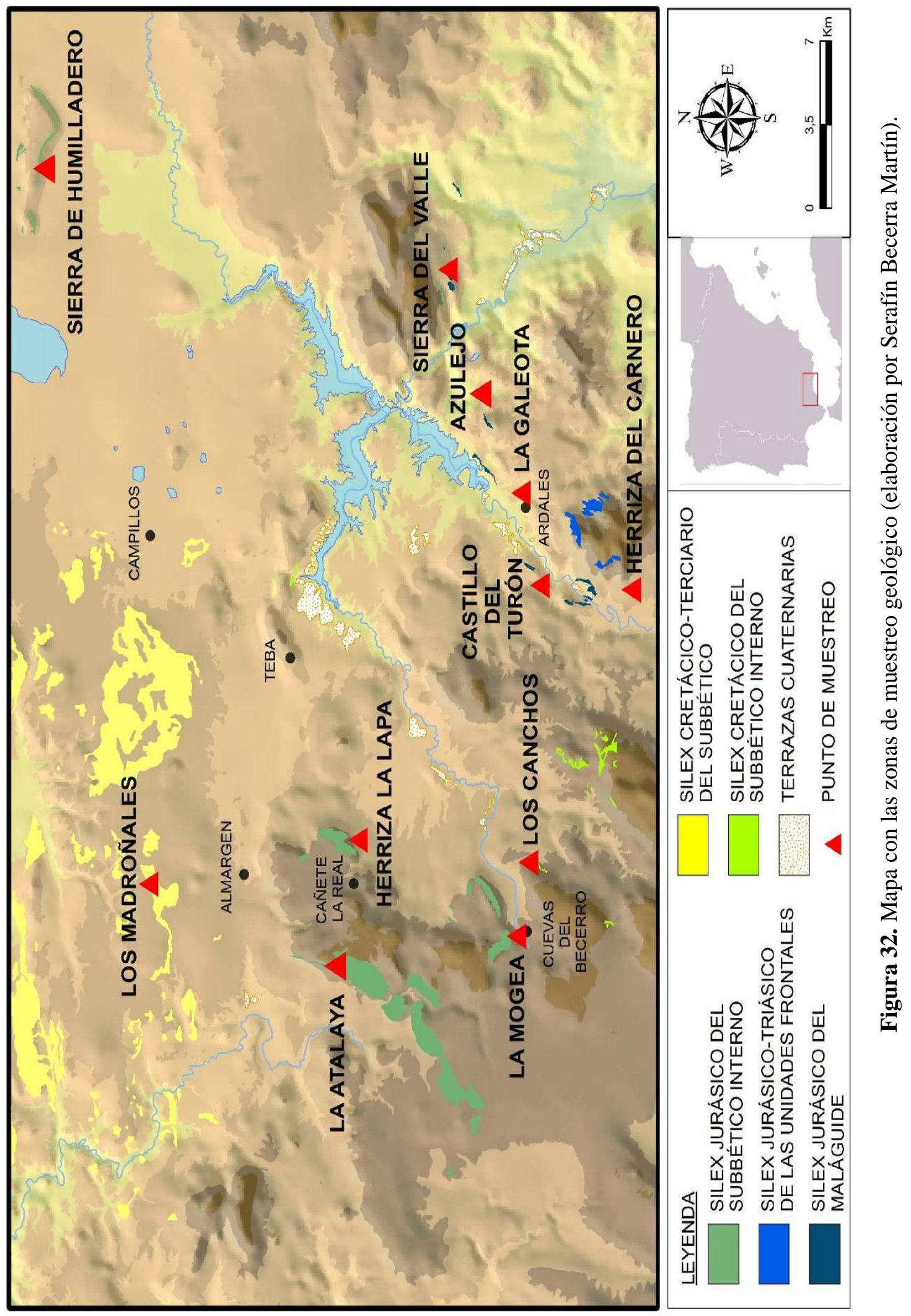


\subsubsection{La Atalaya (Cañete la Real)}

Coordenadas UTM ETRS89 30 del punto de muestreo:

\begin{tabular}{|c|c|}
\hline $\mathbf{X}$ & $\mathbf{Y}$ \\
\hline 303161 & 4093893 \\
\hline
\end{tabular}

Ubicación y características del afloramiento

El afloramiento geológico se localiza en el borde occidental de la sierra de Cañete la Real, que constituye la divisoria entre la vertiente atlántica y mediterránea. La parte oriental es drenada por el río Guadalteba y Turón, la parte occidental drena al río Corbones y la más meridional y el borde occidental forman parte del río Guadalete. El muestreo geológico fue realizado en superficie, el material aparece en forma de tabletas en posición secundaria y forman parte de los derrubios de ladera, sin embargo en además de estos tableados en calizas también aparecía posición primaria como inclusiones en la roca.

Descripción de la unidad geológica

Los materiales geológicos de la sierra de Cañete la Real se encuadran dentro del Subbético interno, en una secuencia del Jurásico enteramente caliza, con niveles margosos y radiolaríticos. Aunque la mayor parte del relieve de la sierra está formado por un potente paquete dolomítico, en la Atalaya, afloran materiales del Lías medio y superior y Dogger inferior, con calizas dolomíticas, calizas oolíticas y calizas margosas con sílex sobre el paquete dolomítico. Existe una presencia importante de microfauna, identificándose especies como Nautiloculina oolithica, Involutina liasica, Thaumatoporella parvovesiculifera y Palaeodasycladus (AA.VV., 1990 a). El Dogger superior aparece representado en el borde occidental de la sierra y al este-noreste. Está formado por calizas margosas y margocalizas con sílex, con intercalaciones de radiolaritas predominando hacia las zonas más altas radiolaritas oscuras con intercalaciones de margo-calizas tableadas con sílex en abundancia.

Características del sílex

La caracterización de visu muestra la presencia de sílex masivo en tonalidades grises oscuros y claros, beige, bandeados, sílex oolítico y radiolarita roja. El afloramiento primario aparece como inclusiones dentro del paquete calizo, en las zonas más altas de la sierra. 
Caracterización de las láminas delgadas

. CÑAT-1 (figura 33): Posible sílex masivo. Presenta una textura llena de pellets, con trazas de carbonato con calcita esparítica y restos de fósiles, posiblemente conchas en calcita y otros restos en calcita monocristalina, los intrapellets con calcedonia fibrosa y presencia de óxidos de hierro. También aparece alguna fisura rellena de calcedonia. El tamaño de los nódulos tiene aproximadamente $0,2 \mathrm{~mm}$ de promedio.
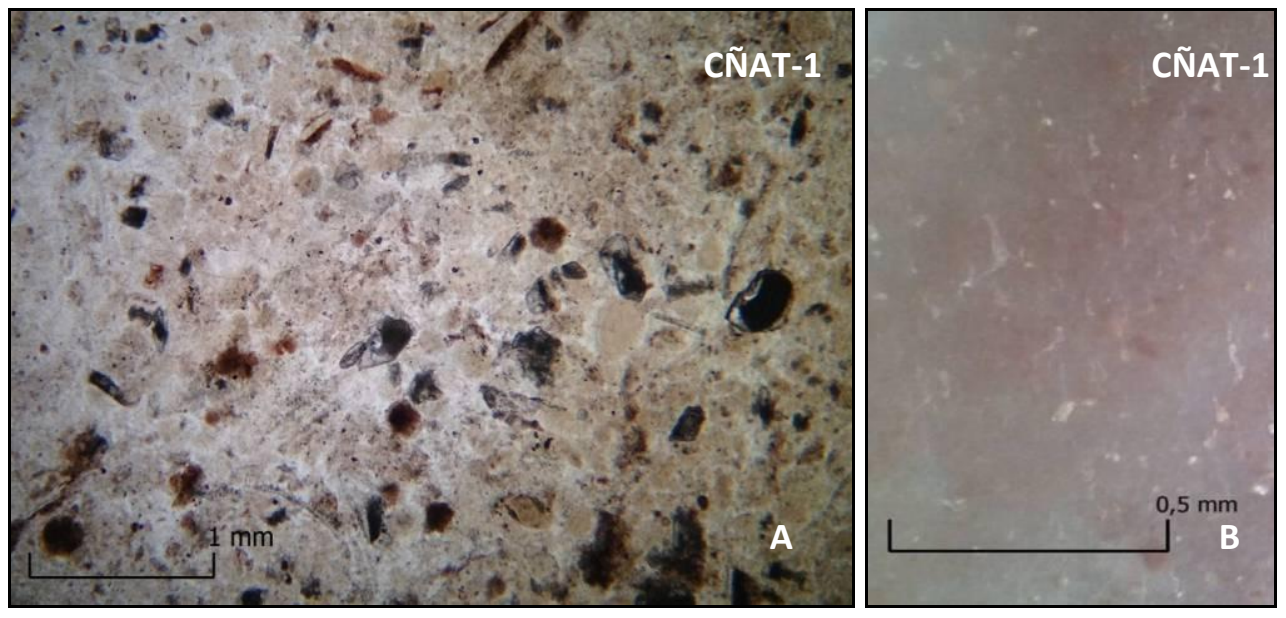

Figura 33. A: Lámina delgada CÑAT-1. Textura llena de pellets. Foto con LDP x25 aumentos. B: Sílex masivo. Foto con lupa tipo triplete10X.

. CÑAT-3 (figura 34): Radiolarita con fragmentos de concha orientados, espículas y radiolarios. Una parte carbonatada con calcita y la otra con radiolarios. El tamaño máximo es de 0,3 y 0,1 mm. Muchos radiolarios están rellenos de calcedonia fibrosa.
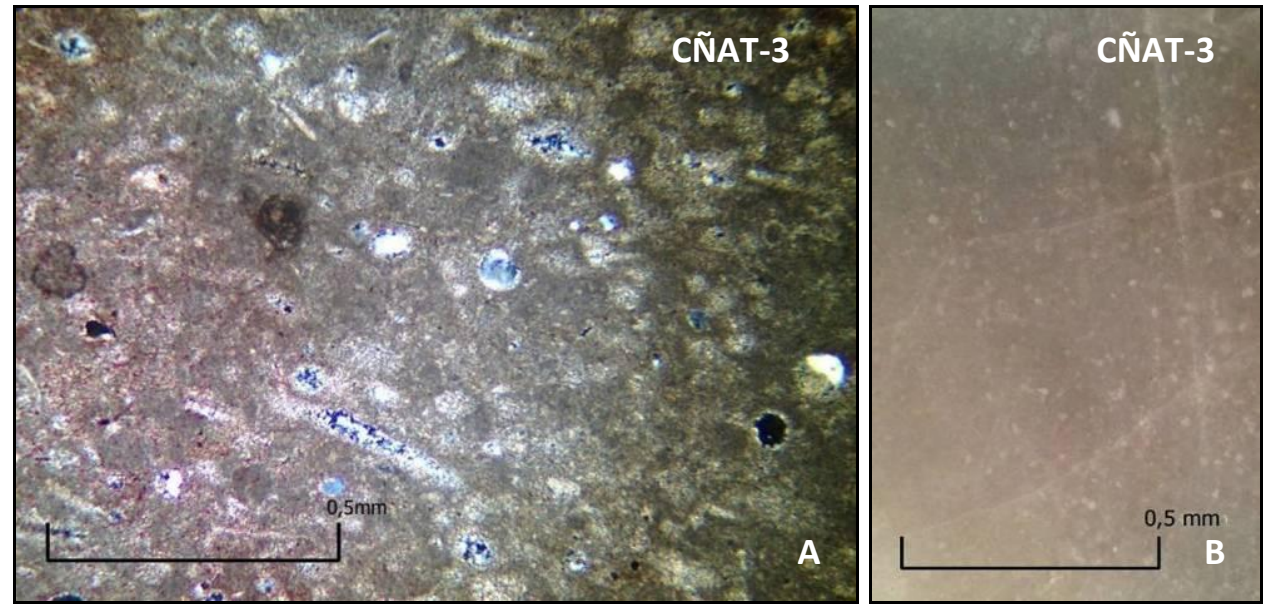

Figura 34. A: Lámina delgada CÑAT-3. Zona de contacto entre muestra teñida y no teñida con espículas y radiolarios. Foto con LDP x100 aumentos. B:

Radiolarita. Foto con lupa tipo triplete 10X. 
. CÑAT-4 (figura 35): Sílex masivo con estructura en pellets y restos de carbonato en calcita. Aparecen muchas inclusiones, algunos restos de fósiles y fragmentos de ooides, algunos de los espacios aparecen rellenos de calcedonia. Presencia de algún cuarzo monocristalino y mucha calcita en parches. Casi todos los fósiles están en las calcitas. Relleno intraporos en calcedonia fibrosa con algún pisolito en calcita esparítica y un fósil de tipo molusco.
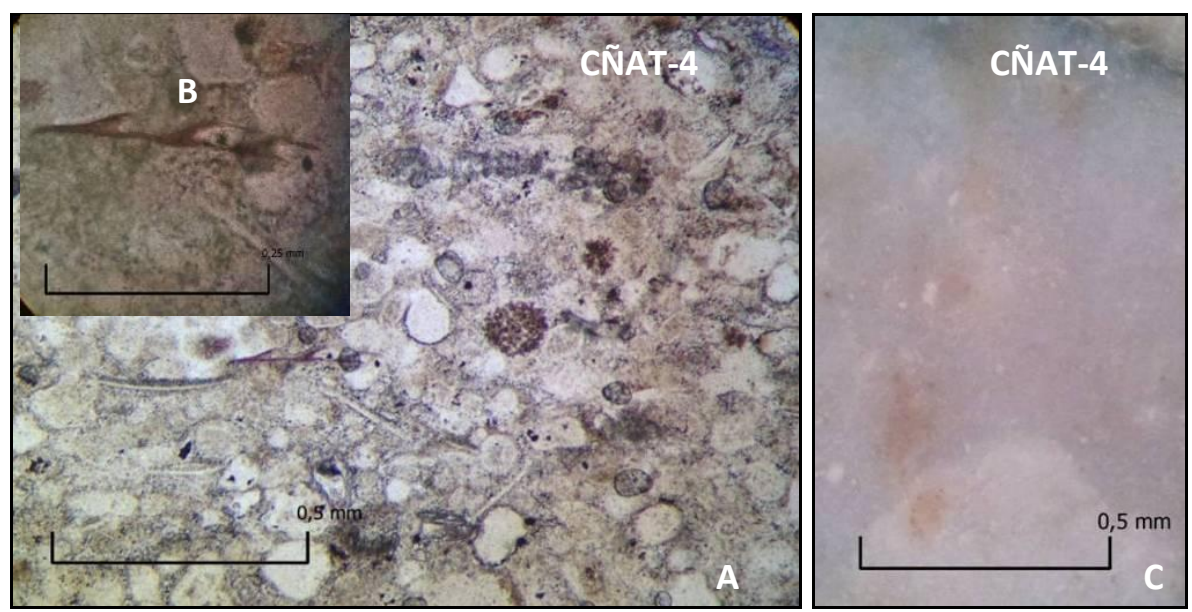

Figura 35. A: Lámina delgada CÑAT-4. Estructura en pellets y restos de fósiles. Foto con LP x100 aumentos. B: Detalle microfósil no clasificado.

Foto con LP x400 aumentos. C: Sílex masivo. Foto con lupa tipo triplete10X.

. CÑAT-6 (figura 36): Sílex masivo con pellets y rellenos de calcedonia. Multitud de inclusiones, restos fósiles de filamentos, hay opacos pequeños y puntos de óxidos y restos de posibles radiolarios.
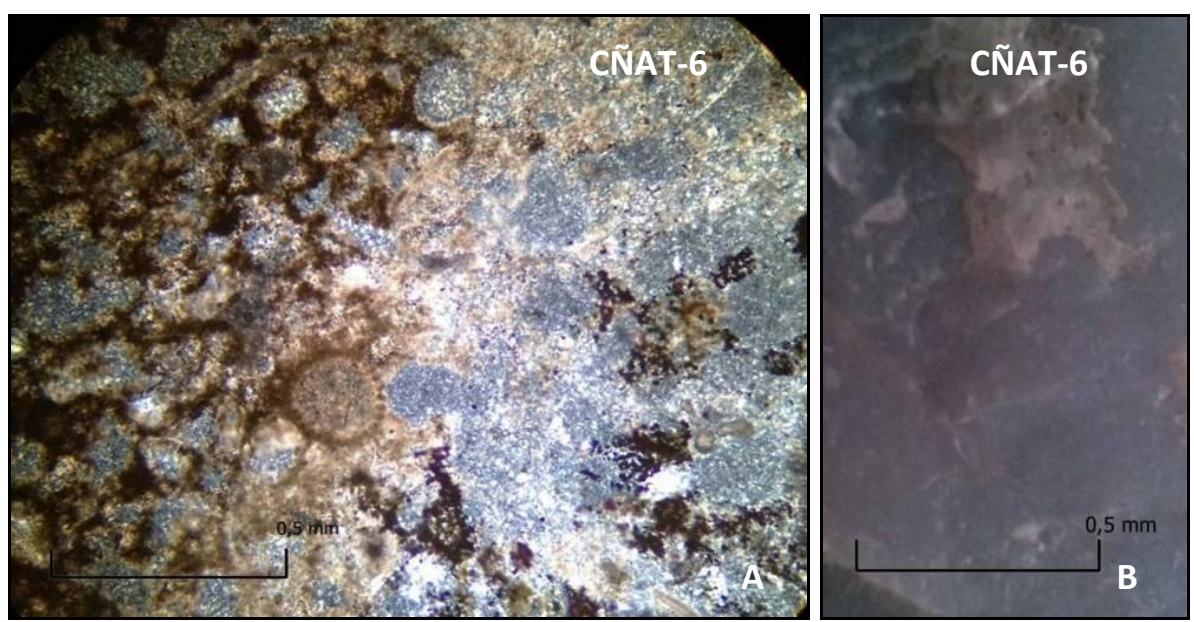

Figura 36. A: Lámina delgada CÑAT-6. Aspecto general con radiolario en el centro y presencia de óxidos y carbonatos. Foto con LDP x100 aumentos. B: Sílex masivo. Foto con lupa tipo triplete 10X. 
. CÑAT-7 (figura 37): Sílex masivo con multitud de microinclusiones con calcita, hay aparentemente radiolarios recristalizados en calcedonia. Muestra en parte craquelada sobre todo en los bordes por choque térmico. Presencia de fisuras rellenas de calcedonia fibrosa y zonas brechificadas rellenas también de calcedonia fibrosa. En el relleno, cristales de calcita esparítica. Aparecen dos generaciones de fisuras rellenas todas de calcedonia y muchos micropuntos opacos negros de óxidos.
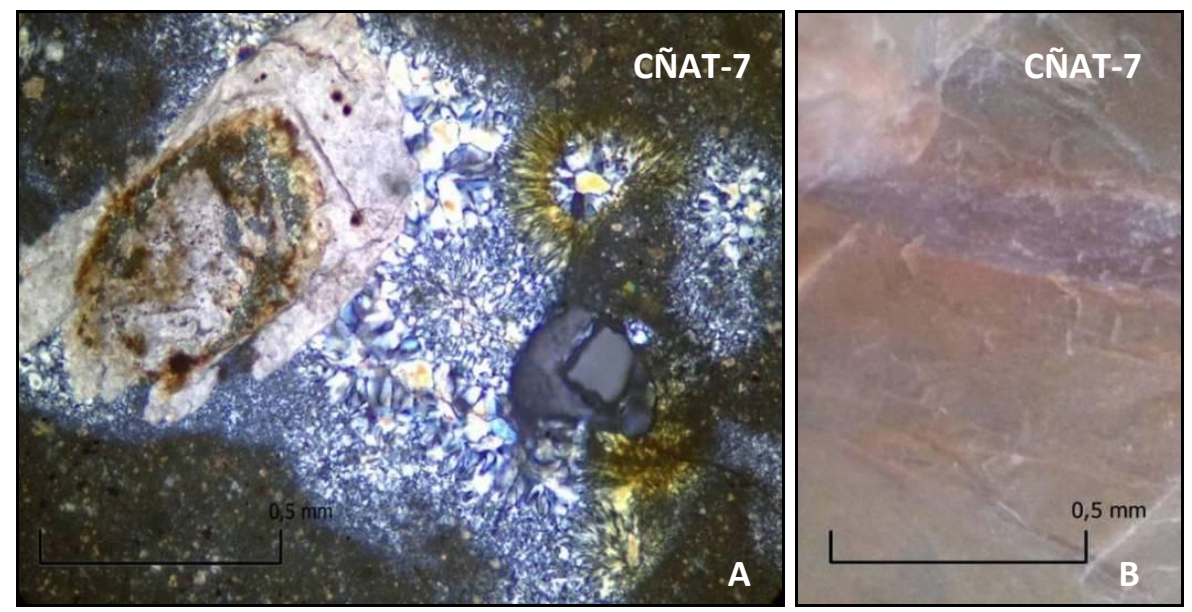

Figura 37. A: Lámina delgada CÑAT-7. Cristal de calcita y relleno de calcedonia y cuarzo. Foto con LDP x 100 aumentos. B: Sílex masivo. Foto con lupa tipo triplete 10X.

. CÑAT9 (figura 38): Sílex masivo relleno de inclusiones, minerales opacos, restos de moluscos con espículas. Parches rellenos de calcita, poros rellenos con cuarzo monocristalino y calcedonia. Grumos de pellets, óxidos y carbonatos.
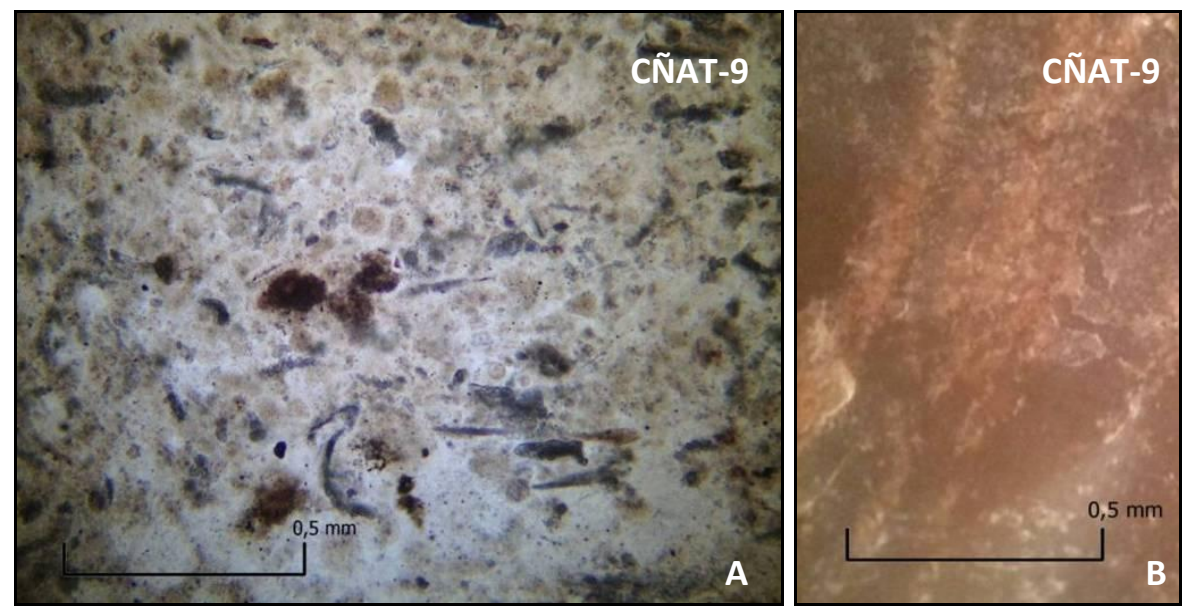

Figura 38. A: Lámina delgada CÑAT-9. Foto general de parches con restos de fósiles y calcedonia. Foto con LDP x 100 aumentos. B: Sílex masivo.

Foto con lupa 10X-21mm. 


\subsubsection{Herriza ${ }^{1}$ de La Lapa (Cañete la Real):}

Coordenadas UTM ETRS89 30 del punto de muestreo:

\begin{tabular}{|c|c|}
\hline $\mathbf{X}$ & $\mathbf{Y}$ \\
\hline 321530 & 4091360 \\
\hline
\end{tabular}

Ubicación y características del afloramiento

El afloramiento se localiza al sureste de la sierra de Cañete la Real, a la altura del cortijo de La Lapa (sierra de Malandrejo) que vierte hacia el río Guadalteba. El material recogido en superficie aparece tableado y sobre los derrubios de ladera.

Descripción de la unidad geológica

Los materiales geológicos de la zona de muestreo se encuadran dentro del Subbético interno. La mayor parte del relieve de la sierra está formado por dolomías, siendo predominante frente a otros materiales como las arcillas areniscosas y margas arcillosas del Flysch del campo de Gibraltar. En la herriza de La Lapa sobre el paquete dolomítico aparecen calizas, calizas oolíticas y calizas con sílex del Dogger.

Características del sílex

Una primera caracterización de visu muestra la presencia de sílex masivos en tonalidades grises y beige oscuro, sílex oolítico, poroso y radiolarita roja.

Caracterización de las láminas delgadas:

. CÑHL1 (figura 39): Radiolarita roja con bordes termoalterados, fisuras rellenas de calcedonia. Los radiolarios también aparecen rellenos de calcedonia fibrosa y con multitud de microimpurezas así como restos de fósiles. También aparecen óxidos de hierro.

\footnotetext{
${ }^{1}$ Herriza: Terreno pedregoso, por lo general en la cumbre de un cerro, que permanece inculto por su resistencia a la reja y escasa productividad. Real Academia Española ( Todos los derechos reservados
} 

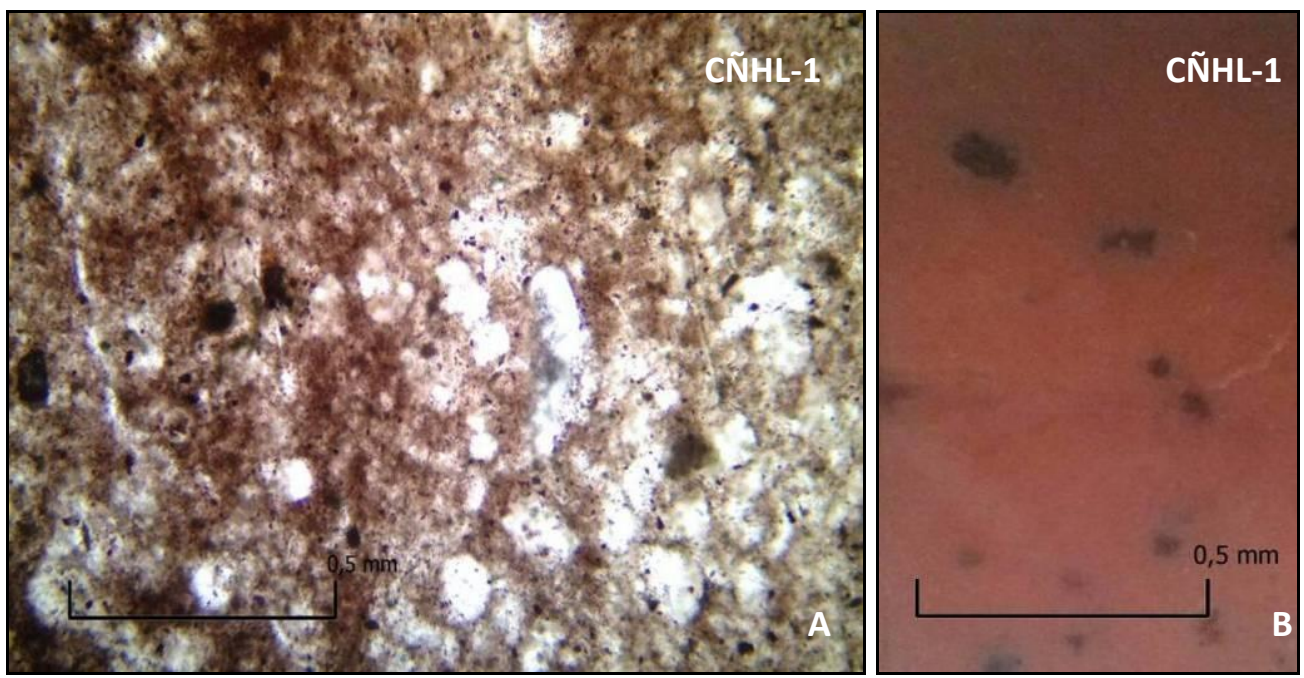

Figura 39. A: Lámina delgada CÑHL-1. Aspecto general de parches y radiolarios con los óxidos de hierro. Foto con LP x 100 aumentos. B: Radiolarita. Foto con lupa tipo triplete10X.

. CÑHL2 (figura 40): Sílex oolítico, aparecen oolitos muy pegados y partes en los que apenas están presentes.
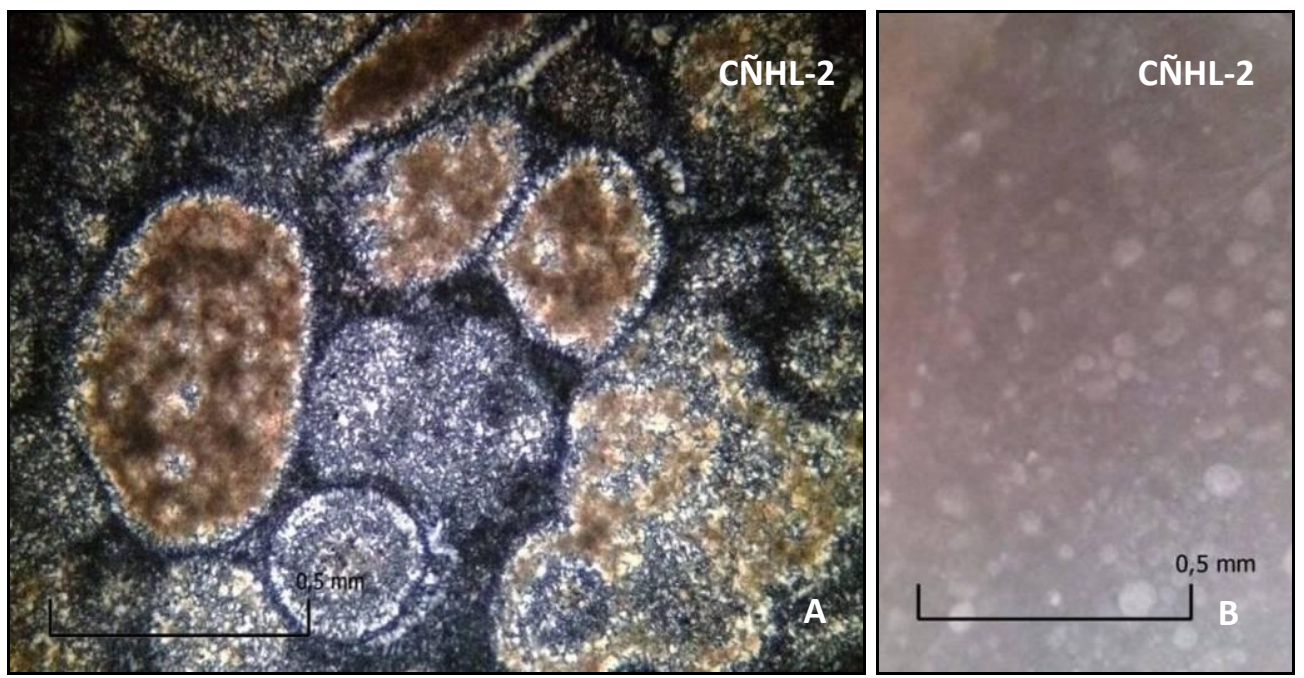

Figura 40. A: Lámina delgada CÑHL-2. Foto de los oolitos muy pegados. Foto con LDP x 100 aumentos. B: Sílex oolítico. Foto con lupa tipo triplete 10X. 
- CÑHL3 (figura 41): Sílex masivo con algo de carbonato, muchas inclusiones, posiblemente radiolarios fracturados y rellenos de calcedonia fibrosa. Hay geodas de cuarzo cristalino.
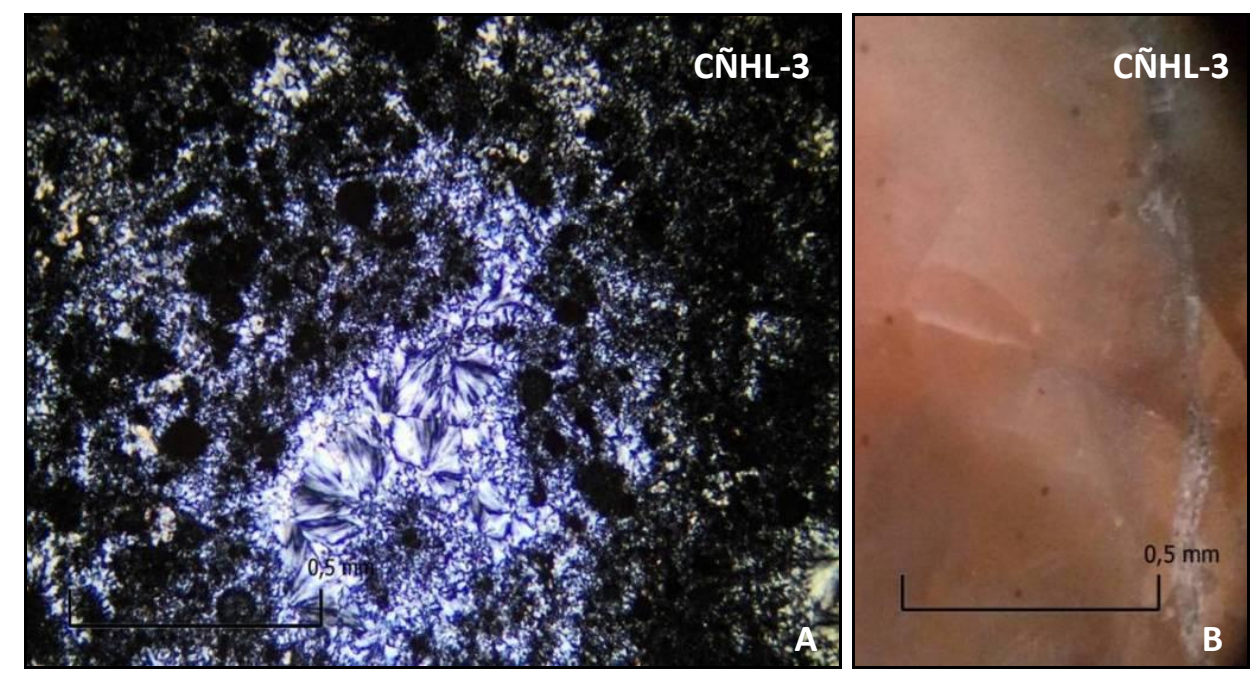

Figura 41. A: Lámina delgada CÑHL-3. Aspecto general con inclusiones rellenas de calcedonia fibrosa. Foto con LDP x 100 aumentos. B: Sílex masivo.

Foto con lupa tipo triplete10X.

- CÑHL4 (figura 42): Sílex masivo con oolitos y parches en calcita, los espacios intraporos están rellenos de calcedonia. Hay algún clasto anguloso de minerales pesados, inclusiones oscuras de opacos, inclusiones planas y en paralelo posible presencia de granos de estaurolita y fisuras rellenas de calcita esparítica.
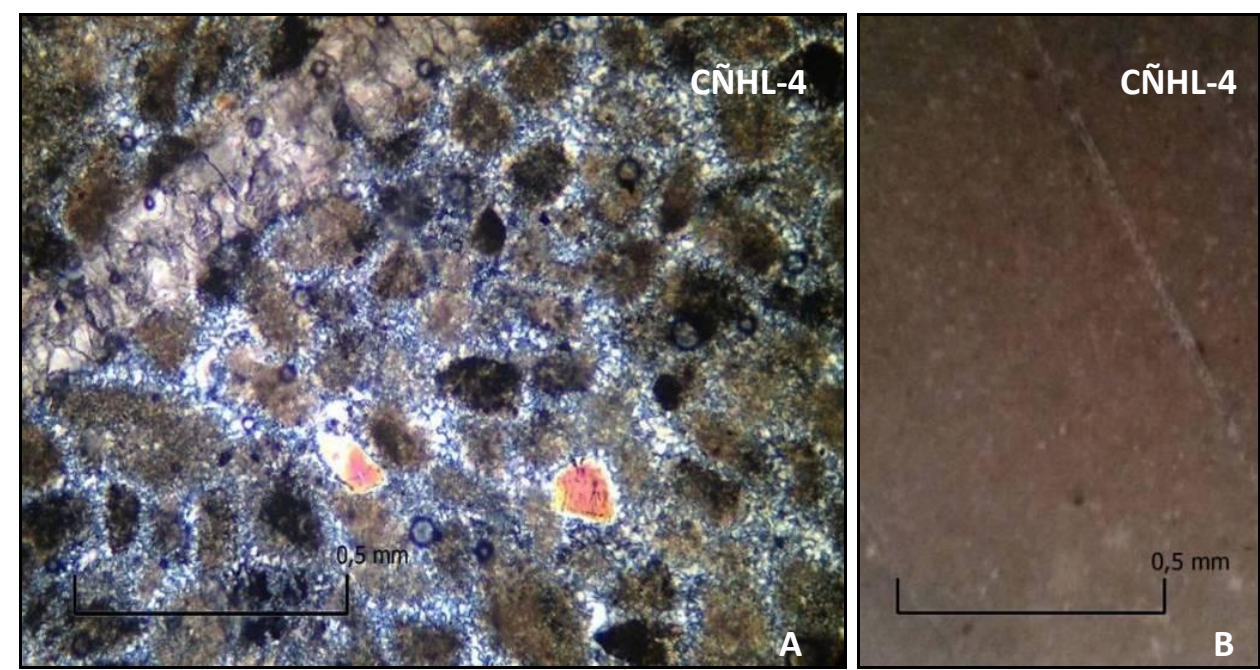

Figura 42. A: Lámina delgada CÑHL-4. Aspecto general con filón de calcita, con inclusiones oscuras carbonatadas y posible grano de estaurolita. Foto con LDP x100 aumentos. B: Sílex masivo. Foto con lupa tipo triplete 10X. 


\subsubsection{La Mogea (Cuevas del Becerro)}

Coordenadas UTM ETRS89 30 del punto de muestreo:

\begin{tabular}{|c|c|}
\hline $\mathbf{X}$ & $\mathbf{Y}$ \\
\hline 317474 & 4083431 \\
\hline
\end{tabular}

Ubicación y características del afloramiento

Las muestras recogidas de este afloramiento geológico se tomaron en los derrubios de ladera de la sierra de la Mogea, también denominada en la cartografía como Pilón del Zorro. Se ubica al norte-noroeste del casco urbano de Cuevas del Becerro, sobre la carretera que une Ronda con Campillos. Es un crestón calizo de 1,5 $\mathrm{km}$ de longitud, bajo el cual se configuran importantes derrubios de ladera, en los cuales se aprecia la presencia de sílex tableado. Con una altura de unos $850 \mathrm{~m}$, esta formación es un apéndice de la sierra de Cañete, separando los términos municipales de Cuevas del Becerro y Cañete la Real.

Descripción de la unidad geológica

Este afloramiento se enmarca dentro de la secuencia de la sierra de Cañete, perteneciente al Penibético. Las silicificaciones aparecen tras un tramo de dolomías, concretamente en una secuencia de edad jurásica que se inicia con niveles de calizas y calizas dolomíticas, seguidas de calizas oolíticas de colores crema y blanco, intercaladas hacia el techo con calizas margosas con sílex. Hacia el techo, los niveles con sílex son más abundantes. La parte terminal de este tramo cuenta con calizas recristalizadas. En estos niveles, datados en el Lías superior-Dogger inferior, se encuentra microfauna de este período, como la Nautiloculina oolithica (AA.VV., 1990 a).

Características del sílex

Los materiales que aparecen en el afloramiento y las muestras recogidas, de visu podemos diferenciarlos entre las radiolaritas verdes y rojas por un lado, y los sílex de tonalidades grisáceas y oscuras por otro. También hemos constatado la presencia de sílex oolítico. Todos estos materiales silíceos aparecen en forma de tabletas, que en los derrubios de ladera aparecen muy alteradas debido a la erosión y la acción mecánica de los arados. 
Caracterización de las láminas delgadas:

- LM (A)-1 (figura 43): Sílex, posiblemente oolítico. La muestra analizada tiene multitud de esferas y bastante cantidad de carbonato cálcico. Las zonas intersticiales están recristalizadas en calcedonia, apareciendo también óxidos. Las esferas son restos de fósiles fantasma, parece tratarse de oolitos recristalizados en calcedonia.
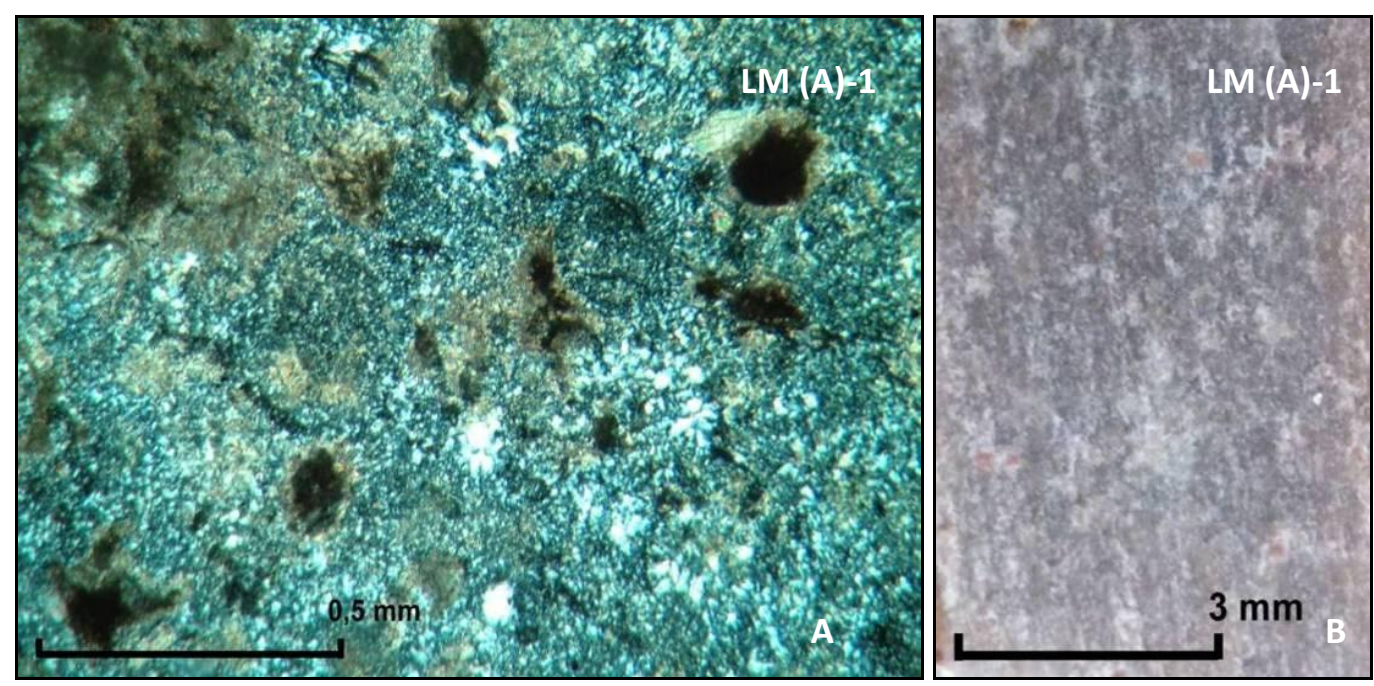

Figura 43. A: Lámina delgada LM (A)-1. Zona con presencia de posibles oolitos recristalizados y de carbonatos de calcedonia. Foto con LDP x100 aumentos.

B: Sílex oolítico. Foto con lupa tipo triplete 10X.

\subsubsection{Los Canchos (Serrato-Ronda)}

Coordenadas UTM ETRS89 30 del punto de muestreo:

\begin{tabular}{|c|c|}
\hline $\mathbf{X}$ & $\mathbf{Y}$ \\
\hline 320587 & 4082846 \\
\hline
\end{tabular}

Ubicación y características del afloramiento

El afloramiento que hemos denominado como Los Canchos se ubica en la falda oriental del cerro de los Tercios (Colorado, 1055 m s.n.m.), a los pies del paraje conocido como Piedra de Molino. Los materiales silíceos se distribuyen a lo largo de una franja de algo más de $0,5 \mathrm{Km}$ de longitud y unos $100 \mathrm{~m}$ de ancho; donde aparece sílex tableado muy alterado por la acción mecánica de los arados en dichos terrenos. Descripción de la unidad geológica

Las silicificaciones se encajan en materiales pertenecientes al contacto entre el Cretácico inferior y el Cretácico superior dentro del Penibético de la zona. Concretamente en margo-calizas con abundantes niveles de sílex, en bandas de edad 
albiense-cenomaniense. Las margas y margo-calizas blanquecinas son del Albiense superior, y contienen Rotalipora ticinensis y Biticinella beggiensis. Por su parte, las margas pizarrosas grises y verdosas del Cenomaniense tienen Planomalina buxtorfi, Rotalipora appenninica, Rotalipora cushumani y Praeglobotruncana stephani (CruzSanjulián, 1990: 25).

Características del sílex

De visu, las características de las muestras recogidas nos evidencia una gran presencia de radiolaritas de diferentes tonalidades, que van del negro-grisáceo al rojo. Las radiolaritas y los sílex del afloramiento están muy deshidratados, presentando un aspecto fracturado. Como ya hemos mencionado, todos estos materiales aparecen en grandes tabletas, las cuales están muy alteradas por el laboreo agrícola.

Caracterización de las láminas delgadas

- LC (A)-1 (figura 44): Radiolarita. Aparecen los radiolarios en bandas, en las cuales también aparecen algunos romboedros de dolomita. Toda la muestra cuenta con manchones de gran tamaño de calcita. La superficie está muy silicificada, y los radiolarios están rellenos de calcedonia, documentándose minerales opacos.
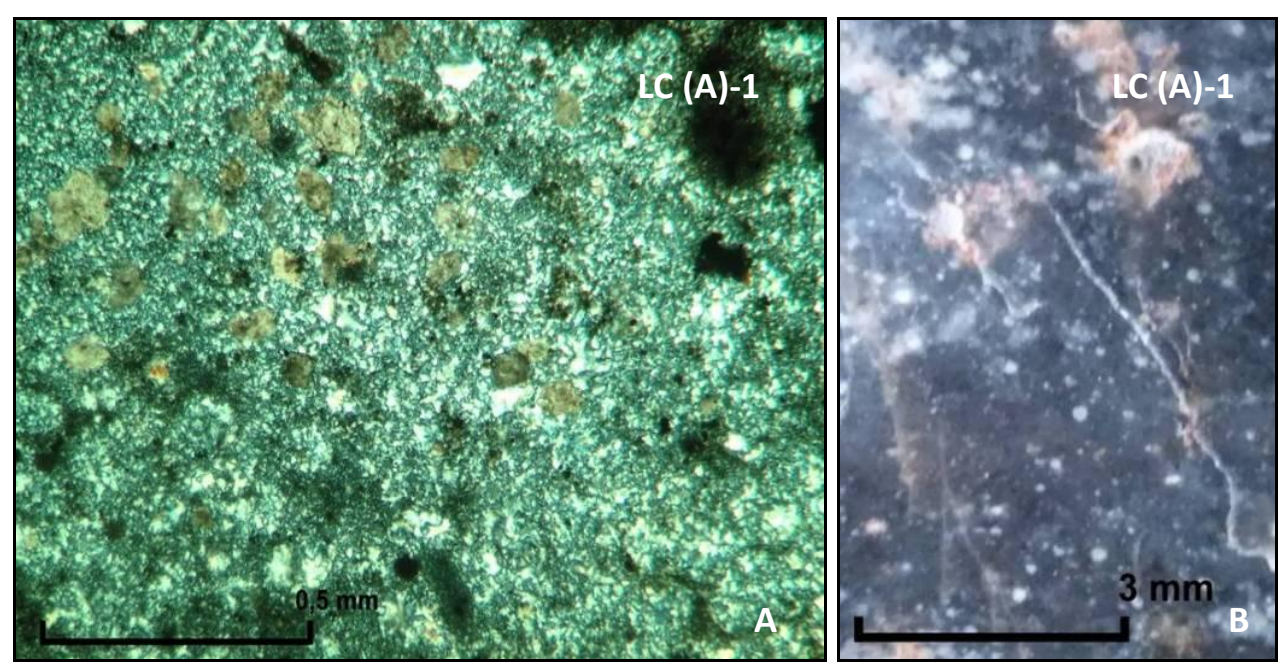

Figura 44. A: Lámina delgada LC (A)-1. Detalle de romboedros de dolomita muy alterados y radiolarios rellenos de calcedonia. Foto con LDP x100 aumentos. B:

Radiolarita bandeada. Foto con lupa tipo triplete 10X. 
- LC (A)-2 (figura 45): Sílex masivo. Este sílex presenta microfracturas rellenas de calcita esparítica. La gran cantidad de radiolarios que tiene nos induce a considerarla como una radiolarita.
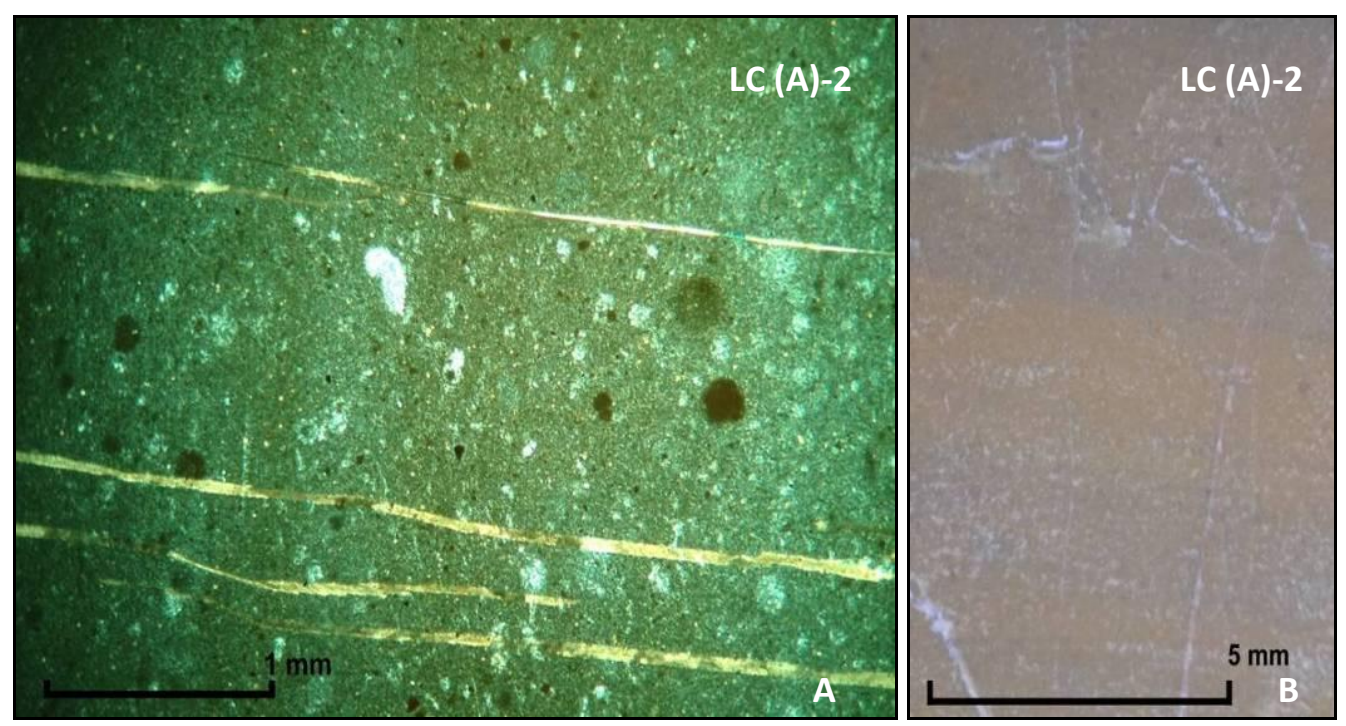

Figura 45. A: Lámina delgada LC(A)-2. Detalle de los radiolarios y vetas de calcita.

Foto con LDP x40 aumentos. B: Sílex masivo. Foto con lupa tipo triplete 10X.

- LC (A)-3 (figura 46): Radiolarita. Los radiolarios aparecen rellenos de calcedonia; junto a ellos aparecen manchas de óxidos de mayor tamaño en nódulos y también en los huecos intersticiales. La muestra presenta algunas venillas rellenas de calcedonia.
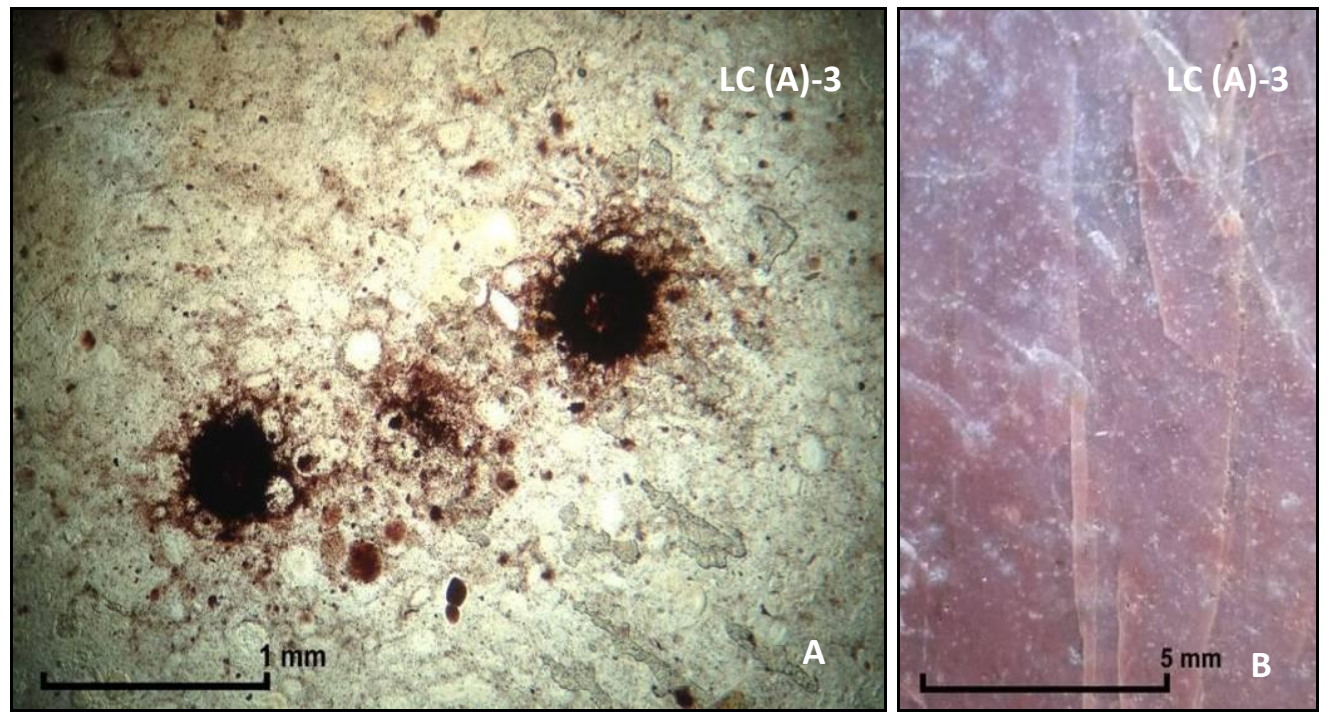

Figura 46. A: Lámina delgada LC(A)-3. Detalle de nódulos de óxido y radiolarios.

Foto con LP x40 aumentos. B: Radiolarita roja. Foto con lupa tipo triplete10X. 
- LC (A)-4 (figura 47): Radiolarita. La muestra presenta unas bandas con radiolarios rellenos de calcedonia. También, al igual que alguna de las anteriores, contiene manchitas escasas de calcita. Presencia anecdótica de romboedros de dolomita.
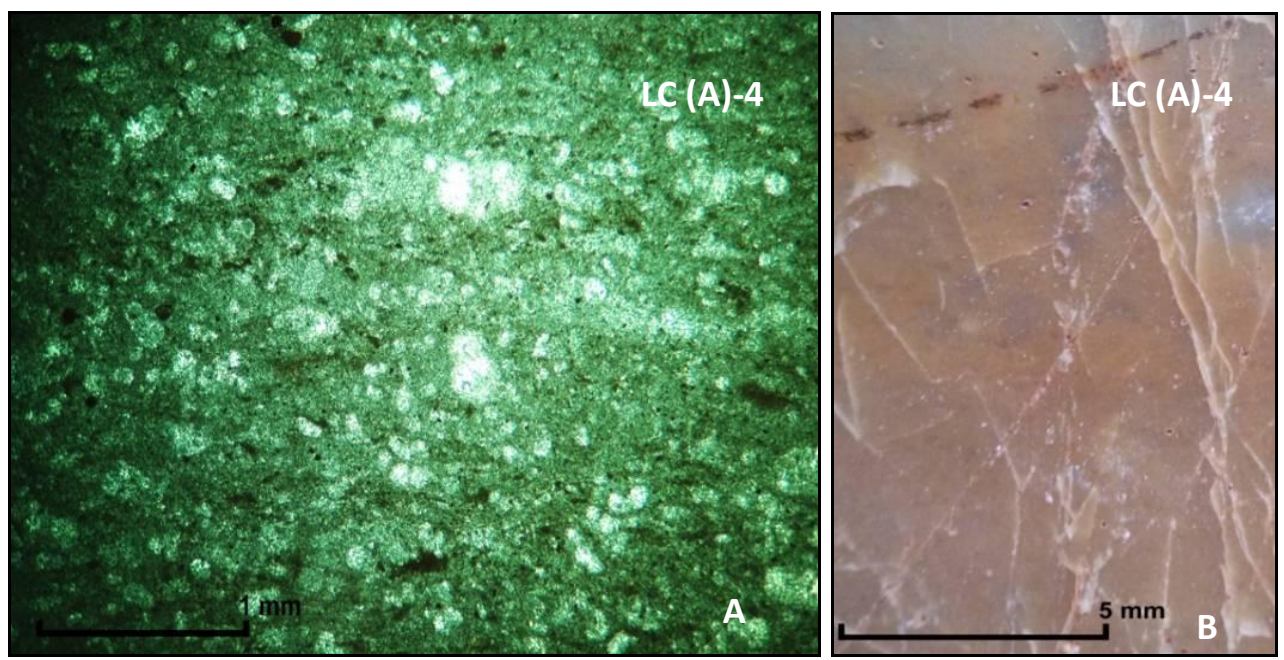

Figura 47. A: Lámina delgada LC(A)-4. Detalle de las bandas con los radiolarios.

Foto con LDP x100 aumentos. B: Radiolarita. Foto con lupa tipo triplete 10X.

- LC (A)-6 (figura 48): Sílex masivo. La muestra posee grandes parches de calcita micrítica y calcita esparítica. Aparecen microfisuras rellenas de calcedonia, y en una segunda generación, estas están rellenas de esparita. Contiene radiolarios rellenos de calcedonia.
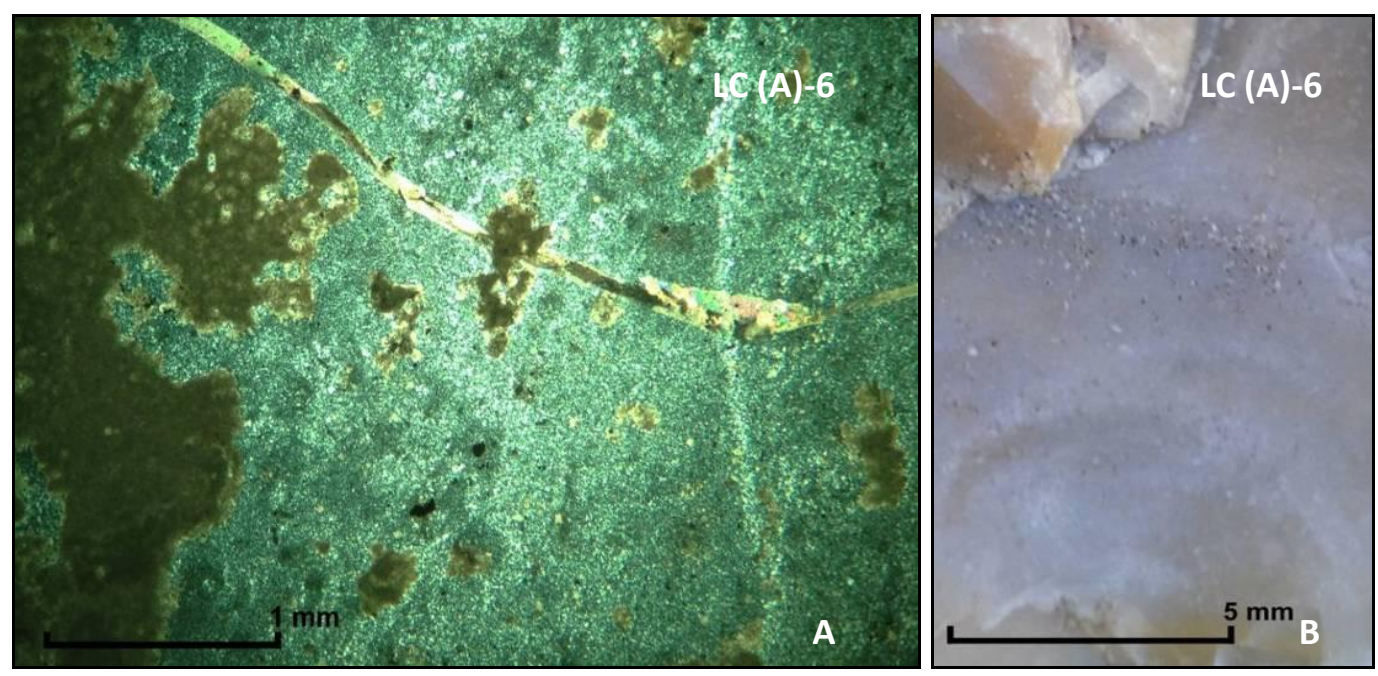

Figura 48. A: Lámina delgada LC(A)-6. Detalle mancha de calcita micrítica con relleno de fantasmas de radiolarios y filón de esparita. Foto con LDP x40 aumentos. B: Sílex masivo. Foto con lupa tipo triplete 10X. 


\subsubsection{Los Madroñales (Almargen)}

Coordenadas UTM ETRS89 30 del punto de muestreo:

\begin{tabular}{|c|c|}
\hline $\mathbf{X}$ & $\mathbf{Y}$ \\
\hline 319669 & 4101825 \\
\hline
\end{tabular}

Ubicación y características del afloramiento

Este afloramiento se ubica a caballo de los términos municipales de Campillos, Los Corrales, Almargen y El Saucejo, con una topografía formada por colinas alomadas con pendientes en torno al $8 \%$ y $16 \%$. Diferentes escorrentías y arroyos surcan estas suaves lomas formando algunos barrancos. El sílex aflora en abundancia, apareciendo en forma de cantos y tabletas, muy alterado por la acción mecánica de los arados y por las obras de construcción de la carretera que une Campillos con el Saucejo, y de varios parques eólicos.

Descripción de la unidad geológica

Los cantos y tabletas de sílex se engloban en margo calizas, calizas margosas y margas de color asalmonado y blanco del Cretácico superior-Luteciense medio pertenecientes al Subbético triásico de facies Keuper. Son materiales que descansan encima del Triásico, como afloramientos se encuentran principalmente en Los Barrancos y en el sector de Roman-Cerro de Quebrantaencinas.

Características del sílex

El sílex de esta zona aparece en tabletas y nódulos mezclados con guijarros y cantos de calizas, todo muy alterado por la plantación del un olivar y por el laboreo agrícola. De visu, los materiales silíceos que hemos reconocido son radiolaritas rojas y verdes, más frecuentes las primeras; también sílex porosos, bandeados, oolíticos y masivos. Sus coloraciones van desde tonos grises y rosáceos a tonos melados, e incluso aunque menos comunes, aparecen sílex de color negro.

Caracterización de las láminas delgadas:

- ALM1-1 (figura 49): Sílex bandeado. Presenta gran cantidad de inclusiones de óxido de hierro, así como otras de color grisáceo de entre 0,1 y 0,2 mm. La muestra tiene un contenido alto en carbonatos de grano muy fino, con alguna que otra fractura rellena de calcedonia. 

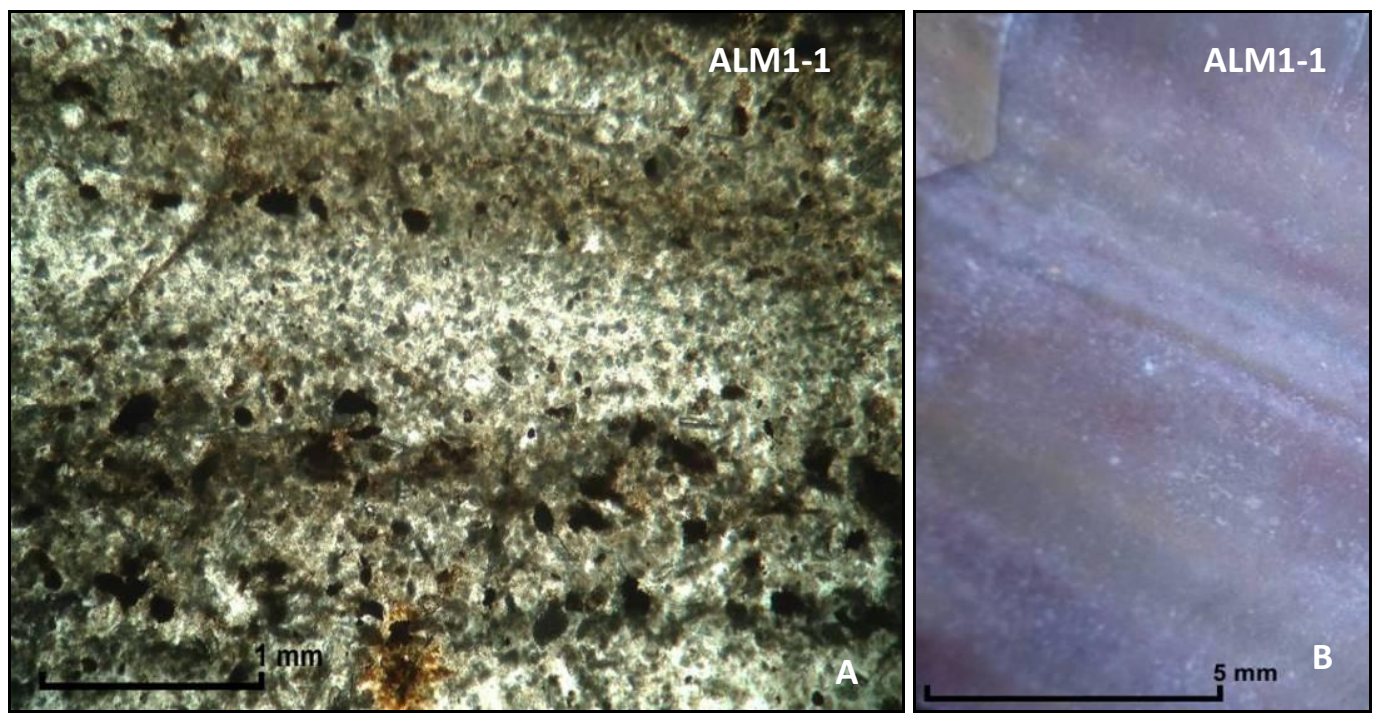

Figura 49. A: Lámina delgada ALM1-1. Bandas de diferentes tonalidades con multitud de inclusiones. Foto con LP x40 aumentos. B: Sílex bandeado. Foto con lupa tipo triplete 10X.

- ALM1-2 (figura 50): Sílex con radiolarios, posible radiolarita. La muestra es rica en sílice, con óxidos de hierro y esferas de calcedonia en la parte del cortex. Algunas zonas presentan una gran acumulación de radiolarios, con venillas y esferas rellenas de calcedonia.
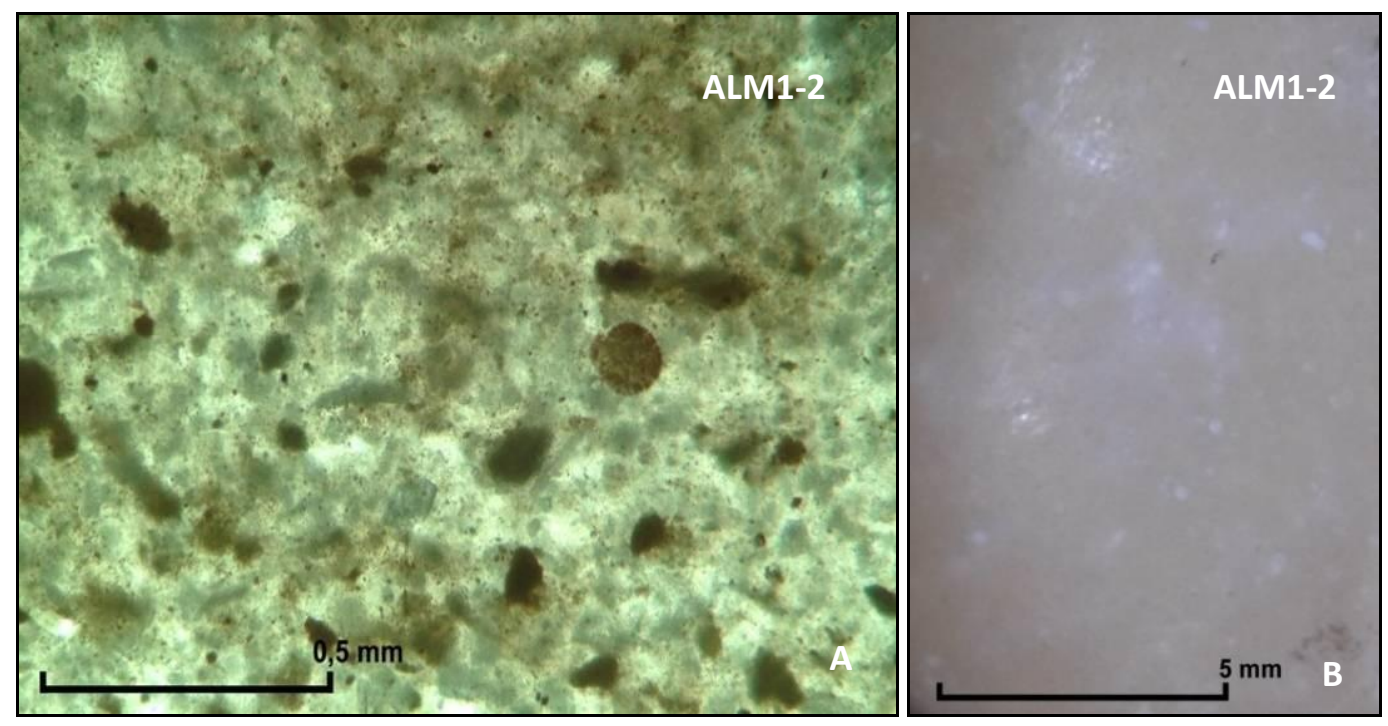

Figura 50. A: Lámina delgada ALM1-2. Detalle de una zona con acumulación de radiolarios y óxidos. Foto con LP x100 aumentos. B: Radiolarita. Foto con lupa tipo triplete10X. 
. ALM1-3 (figura 51): Sílex masivo con radiolarios. Esta muestra contiene multitud de microfósiles, como radiolarios, espículas y algunos fragmentos de concha en calcita. Es un sílex algo bandeado con microláminas de sedimentación.
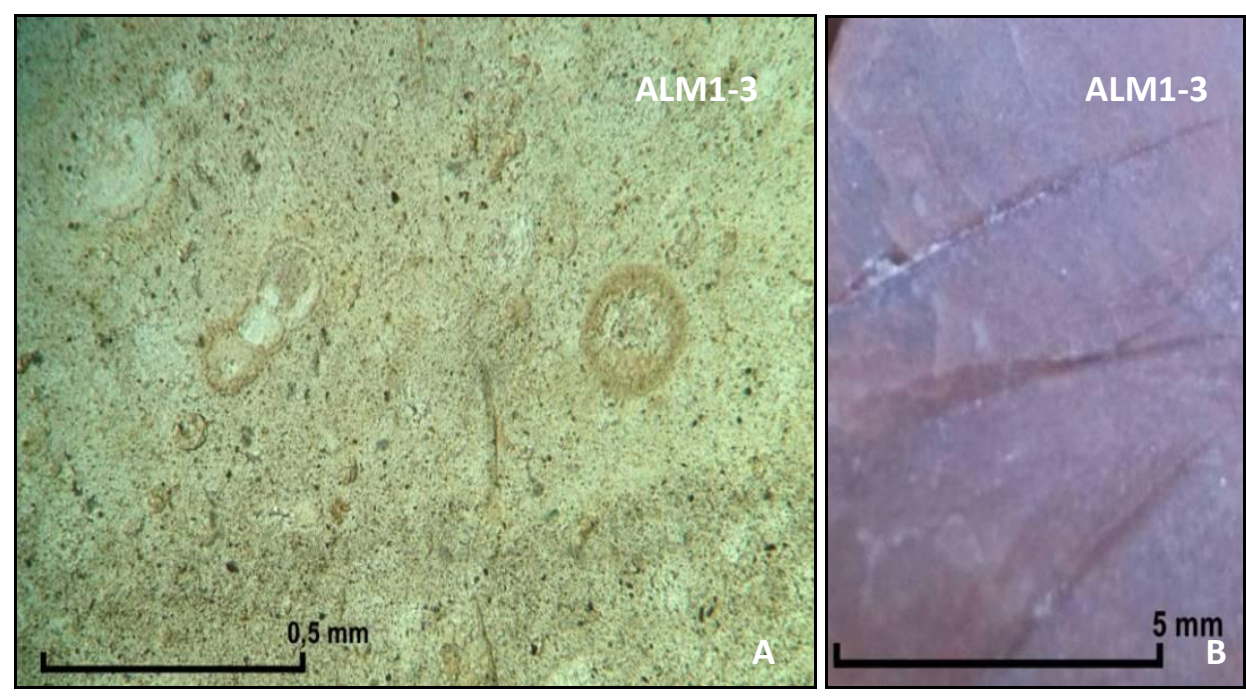

Figura 51. A: Lámina delgada ALM1-3. Detalle de la matriz con multitud de restos fósiles. Foto con LP x100 aumentos. B: Sílex masivo con radiolarios.

Foto con lupa tipo triplete $10 \mathrm{X}$.

- ALM1-4 (figura 52): Sílex oolítico. Es una muestra que posee gran cantidad de microfósiles. Los rellenos entre poros son de calcedonia fibrosa, con algunas inclusiones de granos de óxido. Los fósiles están rellenos de calcita monocristalina y de calcita micrítica. Aparece algún que otro cristal de sección hexagonal.
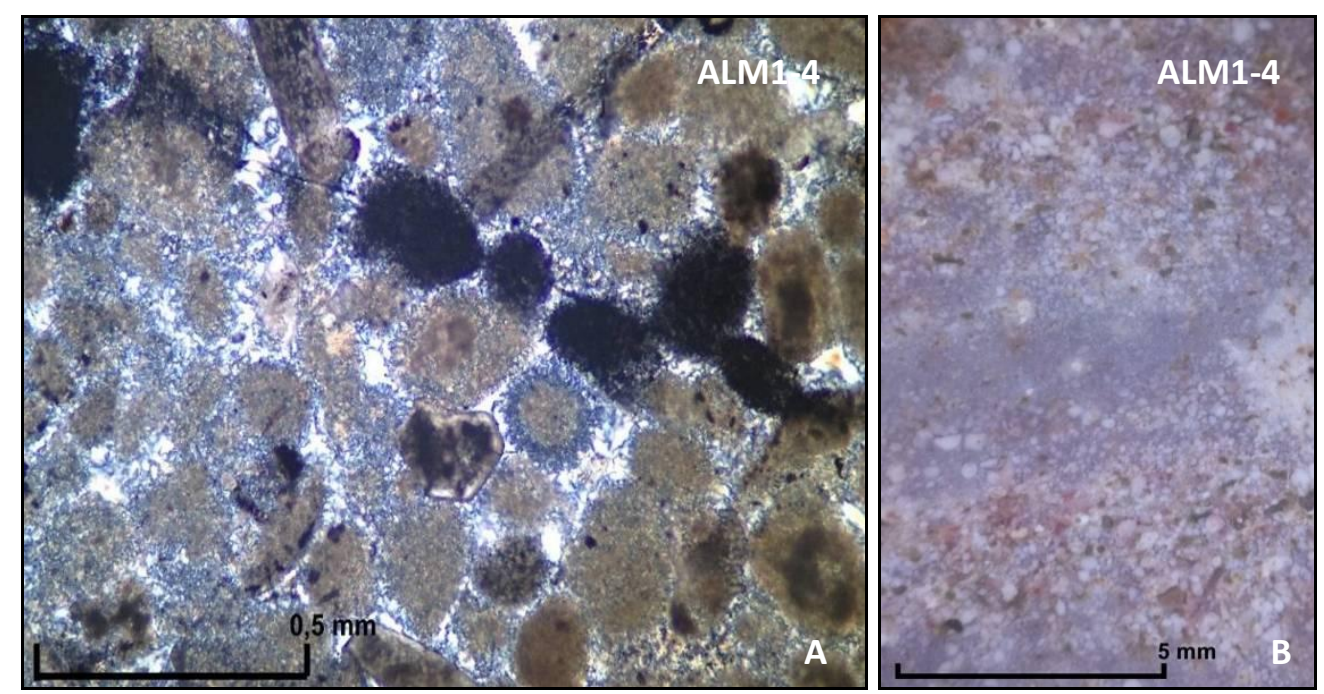

Figura 52. A: Lámina delgada ALM1-5. A: Detalle de los microfósiles y de los rellenos de calcedonia. Foto con LDP x100 aumentos. B: Sílex oolítico. Foto con lupa tipo triplete $10 \mathrm{X}$. 


\subsubsection{Parque eólico Los Madroñales (Almargen)}

Coordenadas UTM ETRS89 30 del punto de muestreo:

\begin{tabular}{|c|c|}
\hline $\mathbf{X}$ & $\mathbf{Y}$ \\
\hline 321502 & 4101959 \\
\hline
\end{tabular}

Ubicación y características del afloramiento

Se localiza en la zona baja de una ladera. Se accede desde el pueblo de Almargen a través de la cañada real de Ronda a Sevilla hasta enlazar con la carretera MA-6407 (carretera del Saucejo a Campillos), una vez allí coger dirección Campillos y recorrer un kilómetro y a la derecha de la carretera se encuentra el yacimiento. El material aparece sobre la superficie, generalmente en forma de tabletas, presentando una gran variedad de tonalidades desde grises hasta beige claros y oscuros o marrones, son abundantes también las radiolaritas en tonos verdosos y rojos y una gran cantidad de sílex oolíticos.

Descripción de la unidad geológica

Está compuesto por margas y margo-calizas blancas y rosadas. Margo-calizas con sílex. Arcillas margosas, con algunos tramos, aunque muy escasos, con presencia de margas, calizas biodetríticas turbidíticas del Subbético dentro del manto AntequeraOsuna del Cenozoico

Características del sílex

La caracterización de visu muestra presencia de sílex oolítico, radiolaritas rojas y verdes y sílex masivo en tonalidades grises y beige.

Caracterización de las láminas delgadas:

- PEMA4 (I) (figura 53): Sílex oolítico con la matriz intraporos rellenos de carbonatos, en algunos el relleno es de calcedonia, restos de pequeños nódulos de impurezas como óxidos de hierro y carbonato. Parece que en algunas partes está termoalterada. 

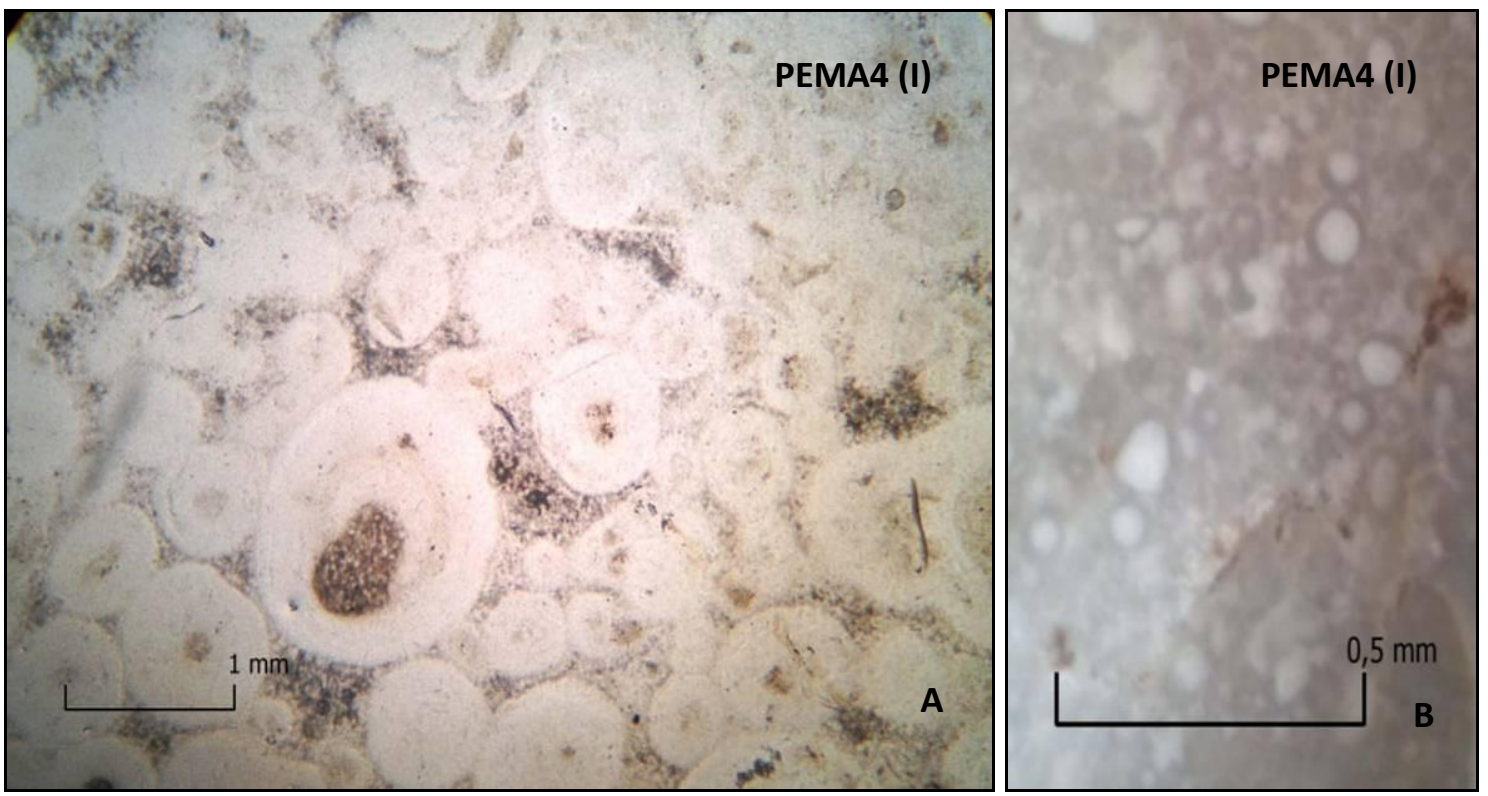

Figura 53. A: Lámina delgada PEMA4 (I). Detalle de los oolitos. Foto con LP x 25 aumentos. B: Sílex oolítico. Foto con lupa tipo triplete 10X.

. PEMA4 (II) (figura 54): Radiolarita con bandeados, con bastante carbonato. Multitud de inclusiones de calcita esparítica, microfósiles rellenos de calcedonia.
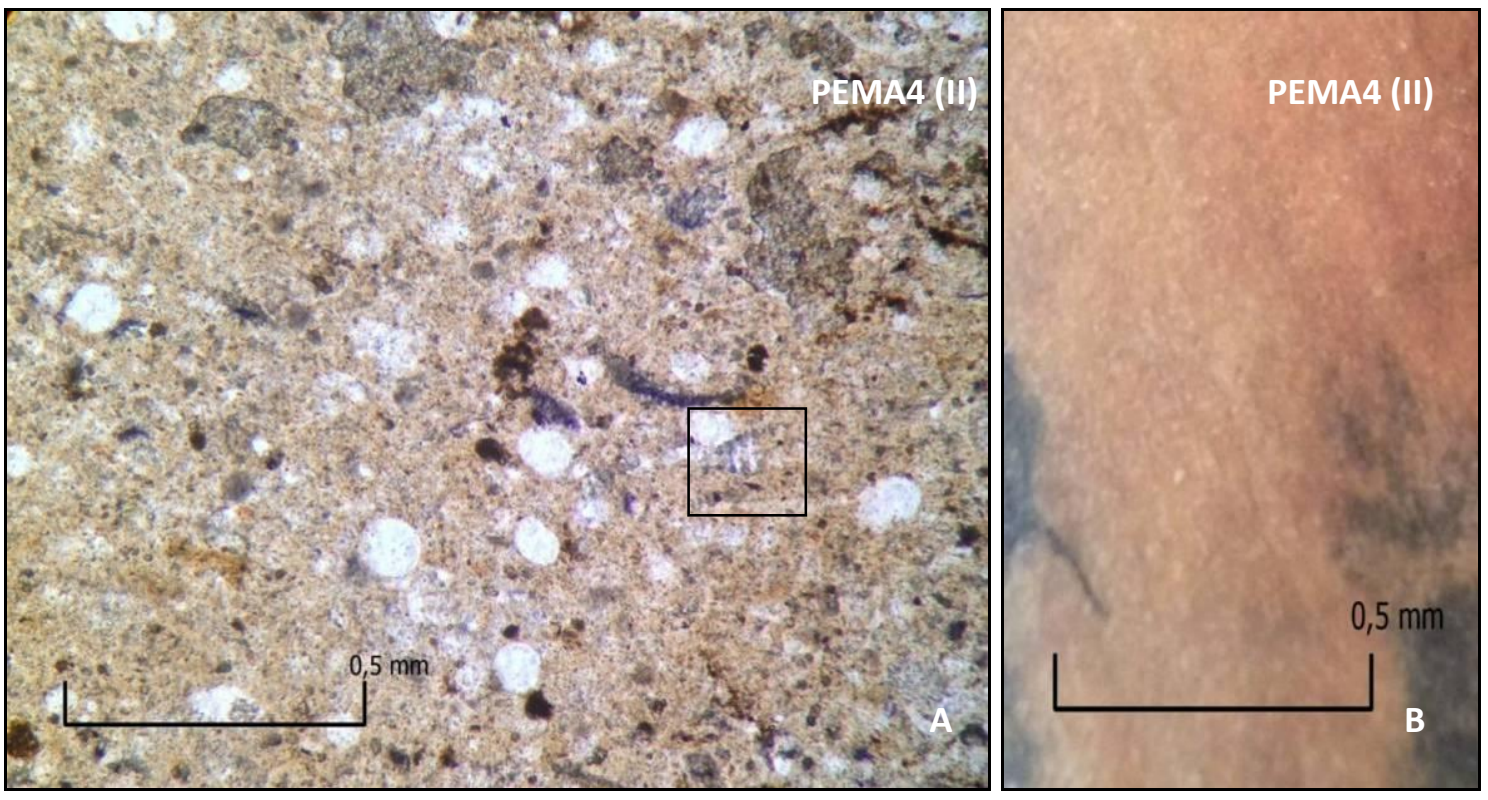

Figura 54. A: Lámina delgada PEMA4 (II). Detalle de inclusiones y microfósiles, uno de ellos en forma de cono. Foto con LDP x100 aumentos. B: Radiolarita. Foto con lupa tipo triplete $10 \mathrm{X}$. 
. PEMA4 (III) (figura 55): Sílex masivo con oolítos o radiolarios aproximadamente de $0,6 \mathrm{~mm}$, restos de caparazones de radiolarios.
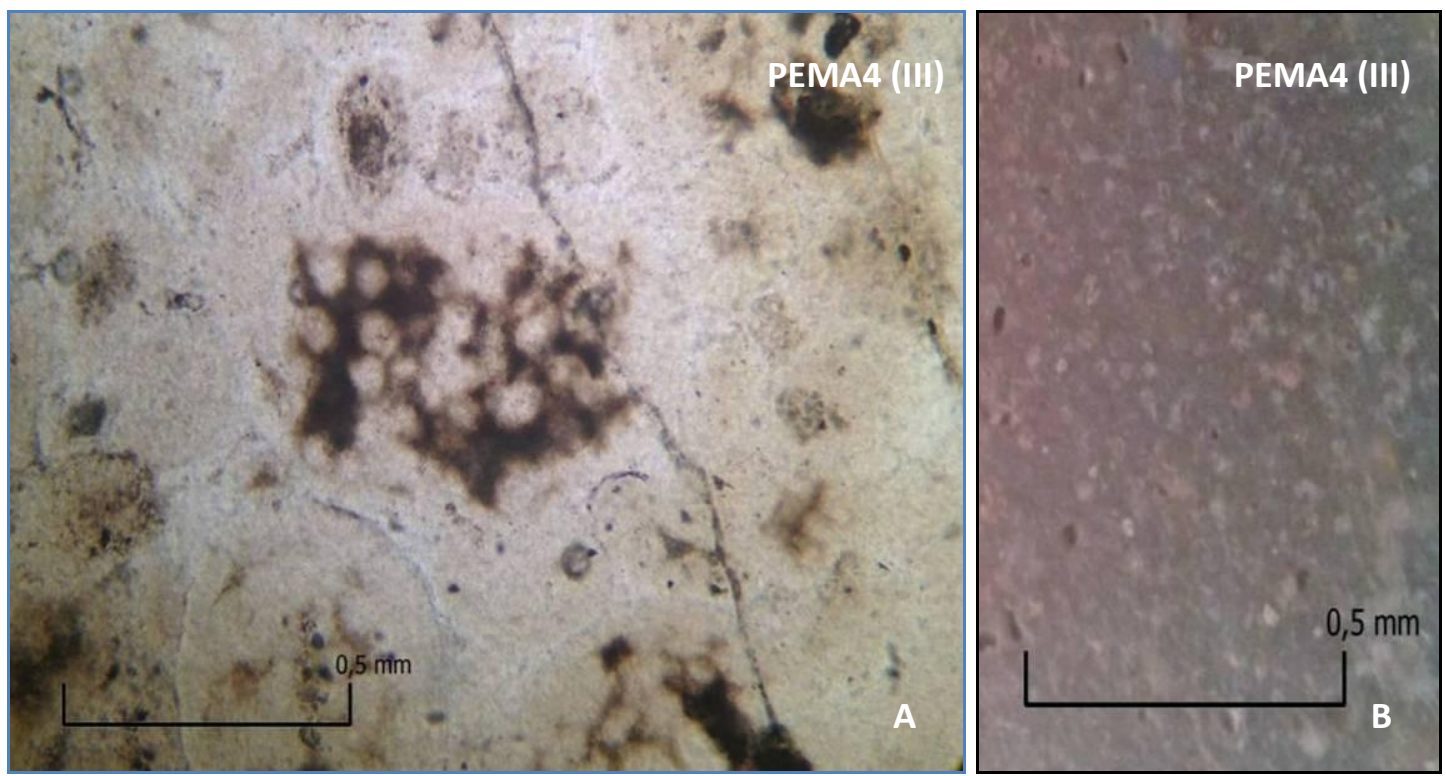

Figura 55. A: Lámina delgada PEMA4 (III). Detalle de un posible resto de caparazón de radiolario. Foto con LP x100 aumentos. B: Sílex masivo. Foto con lupa tipo triplete10X.

. PEMA4 (IV) (figura 56): Sílex oolítico con muchos microfósiles, con grumos oscuros de óxidos opacos y oolitos u ooides. Los radiolarios aparecen rellenos de calcedonia.
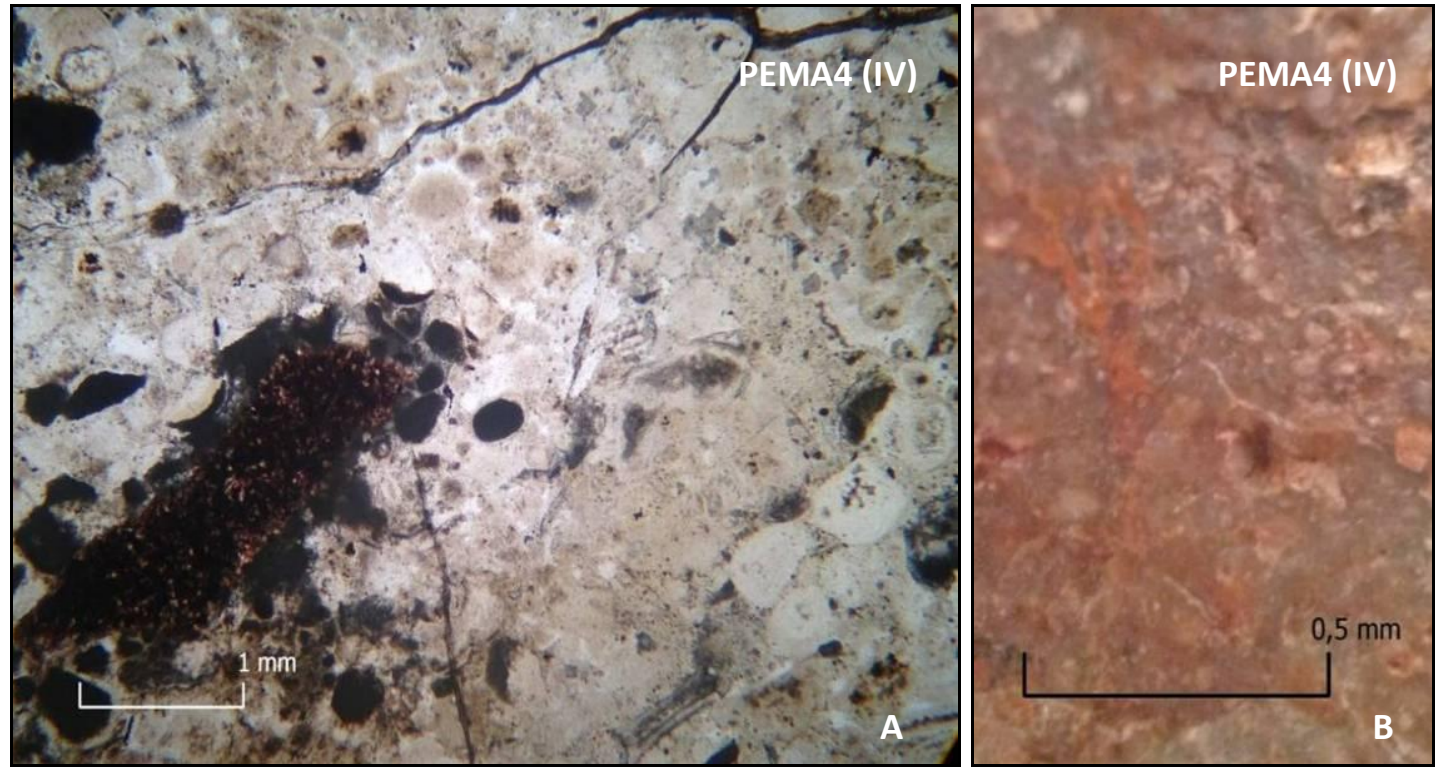

Figura 56. A: Lámina delgada PEMA4 (IV). Estructura con grumo rico en óxido con ooides y restos de fósiles. Foto con LP x25 aumentos. B: Sílex oolítico. Foto con lupa tipo triplete10X. 
- PEMA4 (V) (figura 57): Sílex masivo con inclusiones y formas ooides, restos de fósiles y radiolarios, con ciertos bandeados y una banda más carbonatada entre la sílice. Casi toda la matriz es sílice microcristalino.
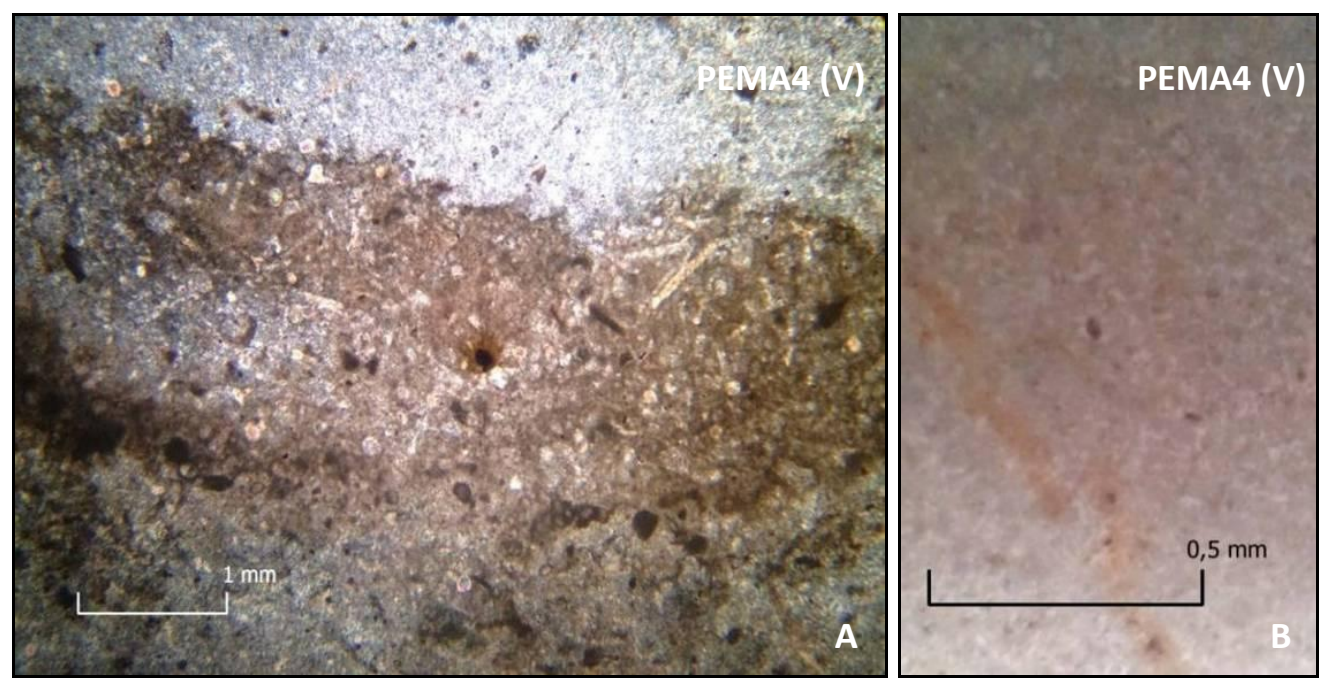

Figura 57. A: Lámina delgada PEMA4 (V). Inclusiones de formas esféricas, restos de fósiles con cierto bandeado. Foto con LP x25 aumentos. B: Sílex masivo. Foto con lupa tipo triplete $10 \mathrm{X}$.

. PEMA4 (VI) (figura 58): Sílex masivo con inclusiones de minerales con formas en barritas. Es un sílex bastante traslúcido y restos de radiolarios, con algún romboedro de dolomita. Posible grano de glauconita.
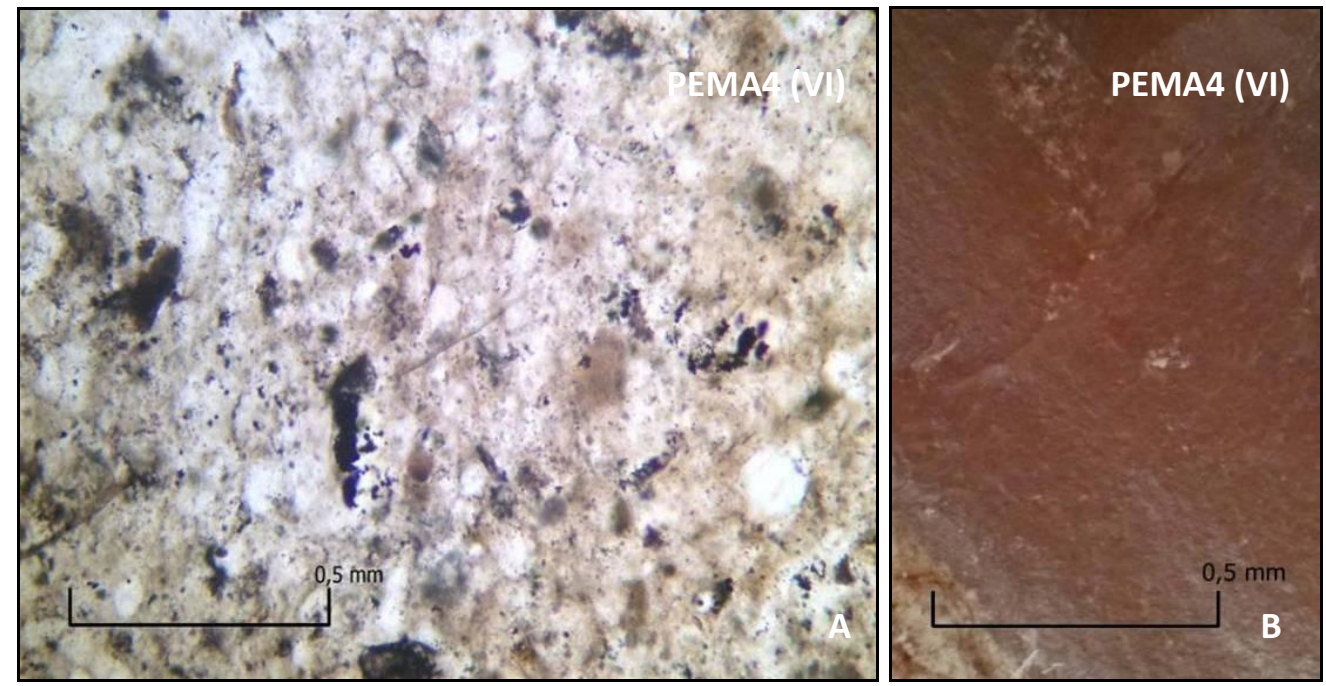

Figura 58. A: Lámina delgada PEMA4 (VI). Estructura con parches de carbonatos y radiolarios. Foto con LP x100 aumentos. B: Sílex masivo. Foto con lupa tipo triplete $10 \mathrm{X}$. 


\subsubsection{El Azulejo (Ardales)}

Sus coordenadas UTM ETRS89 30 son:

\begin{tabular}{|c|c|}
\hline $\mathbf{X}$ & $\mathbf{Y}$ \\
\hline 339656 & 4086067 \\
\hline
\end{tabular}

Ubicación y características del afloramiento

El afloramiento se ubica al noreste del casco urbano de Ardales, concretamente en las inmediaciones del puerto del Azulejo. Los materiales aparecen en dos segmentos: uno en un crestón calcáreo que discurre sudeste-noreste, donde se encuentra el pico del Azulejo (684 m s.n.m.); y otro, de menor tamaño, ubicado al noreste del primero. Hemos tomado las muestras de cantos y tabletas situados en posición secundaria, concretamente en el derrubio de ladera, por lo que aparecen rodados y alterados. El arroyo Granado atraviesa uno de los segmentos de esta unidad geológica con sílex, aportando probablemente material al cauce del río Guadalhorce, tras salir este último del desfiladero de los Gaitanes.

Descripción de la unidad geológica

Estos afloramientos pertenecen al Complejo Maláguide de las Béticas, concretamente a materiales de época jurásica. Las silicificaciones se insertan en un paquete de dolomías y calizas datadas en el Dogger, de unos $30 \mathrm{~m}$ de espesor, situadas bajo los niveles cretácicos. Se correlacionan con los niveles calcáreos de la zona del Veredón a través de la sierra de Huma (Valle de Abdalajís).

Características del sílex

De visu, los materiales silíceos que aparecen no presentan una gran variedad, siendo en su mayoría sílex masivos de tonalidades que van de los pardos claros con inclusiones minerales a las grisáceas. También aparecen sílex bandeados blancos y grises y, ocasionalmente, aparecen otros en tonos rojizos o rosáceos. Las láminas delgadas nos evidencian la presencia de sílex oolíticos y radiolaritas.

Caracterización de las láminas delgadas:

- AZ1-1 (figura 59): Sílex oolítico con bandas de tonalidades más oscuras. Toda la superficie está llena de inclusiones, localizándose granos recristalizados en cuarzo monocristalino con extinción ondulante. La muestra presenta fósiles rellenos en calcita orientados según la laminación. 

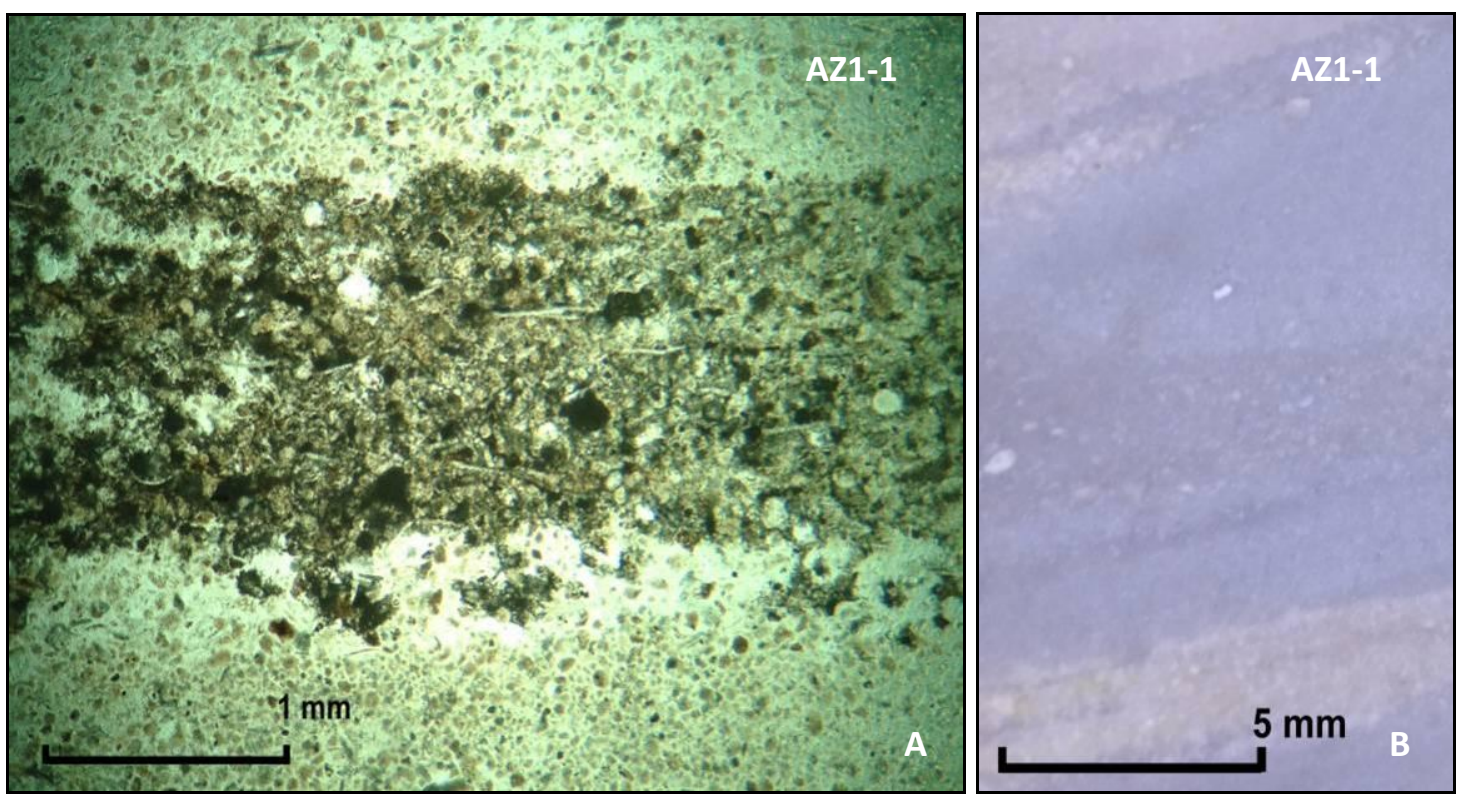

Figura 59. A: Lámina delgada AZ1-1. Banda más oscura con inclusiones de fósiles y zonas más clara con presencia de oolitos. Foto con LDP x40 aumentos. B: Sílex bandeado. Foto con lupa tipo triplete $10 \mathrm{X}$..

- AZ1-2 (figura 60): Sílex masivo muy carbonatado. Contiene cristales de calcita esparítica y recristalizaciones en cuarzo poligonal. Presenta romboedros de dolomita.
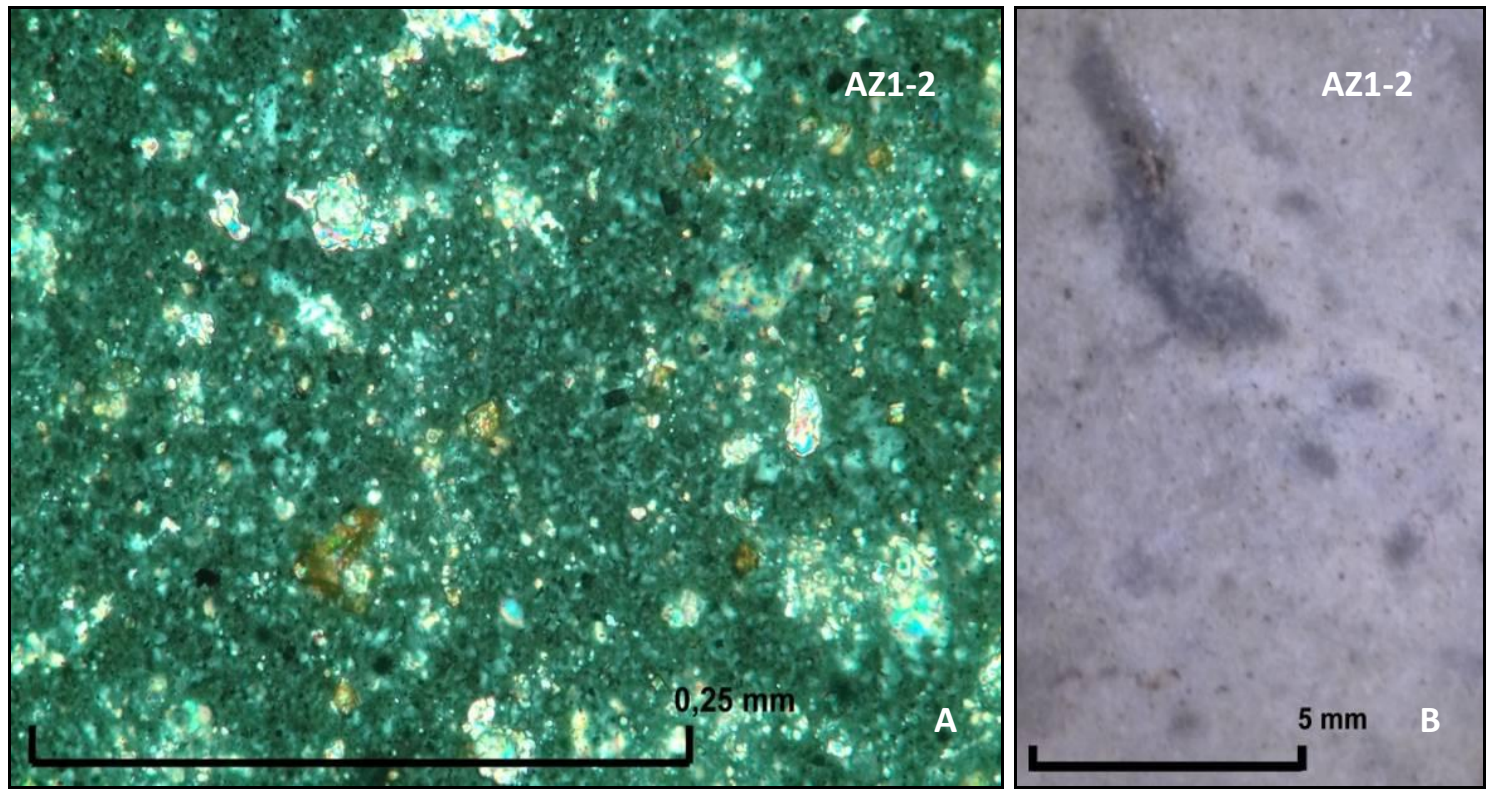

Figura 60. A: Lámina delgada AZ1-2. Detalle de romboedros de dolomita y cristales de esparita. Foto con LP x400 aumentos. B: Sílex masivo. Foto con lupa tipo triplete 10X. 
- AZ2-46 (figura 61): Sílex masivo con escasa presencia de inclusiones en calcita. Es un sílex bastante homogéneo, con una gran cantidad de romboedros de dolomita, también se aprecian algunos minerales opacos.
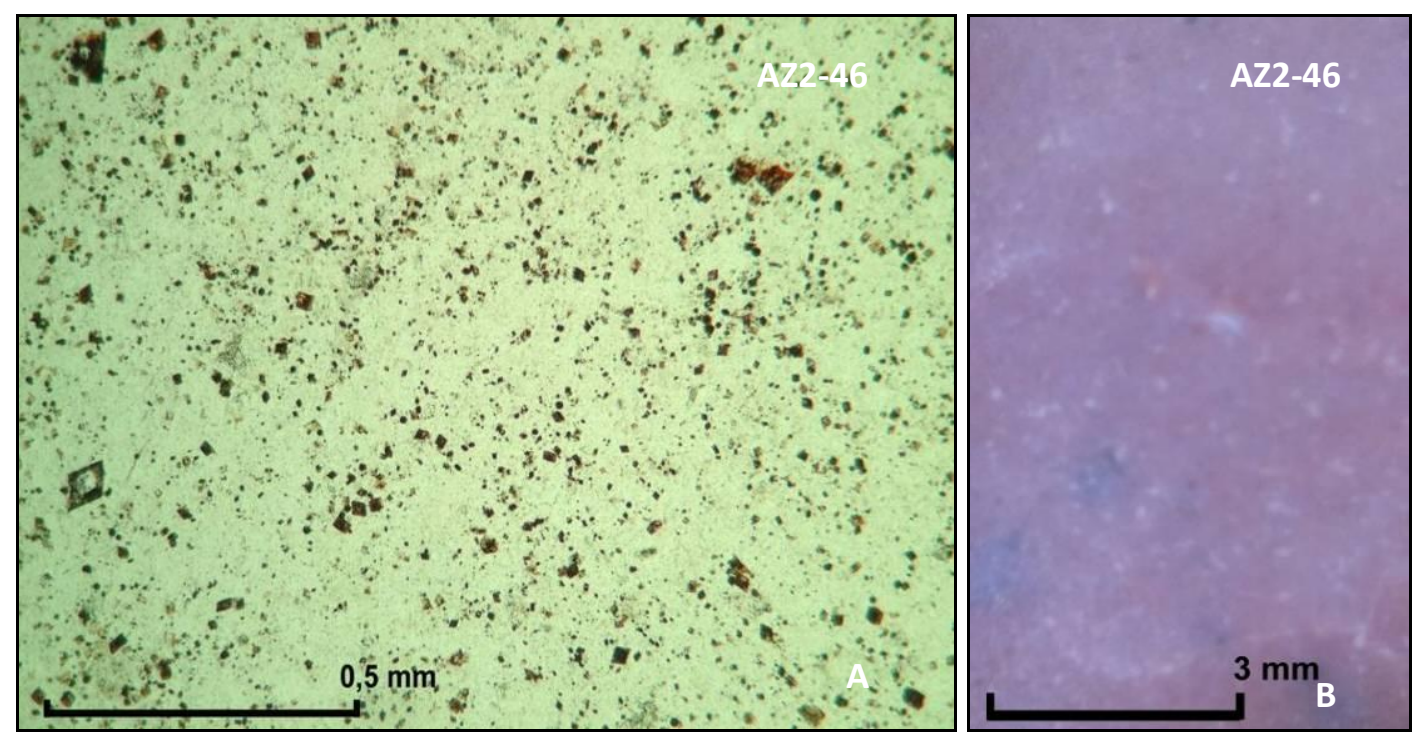

Figura 61. A: Lámina delgada AZ2-46. Detalle de la matriz homogénea con romboedros de dolomita. Foto con LP x100 aumentos. B: Sílex masivo. Foto con lupa tipo triplete 10X.

- AZ2-235 (figura 62): Sílex masivo. La muestra contiene unas manchas alargadas, una de ellas de 0,5 mm, rellenas de calcedonia. También, al igual que las anteriores presenta romboedros de dolomita. Posee inclusiones de calcita esparítica.
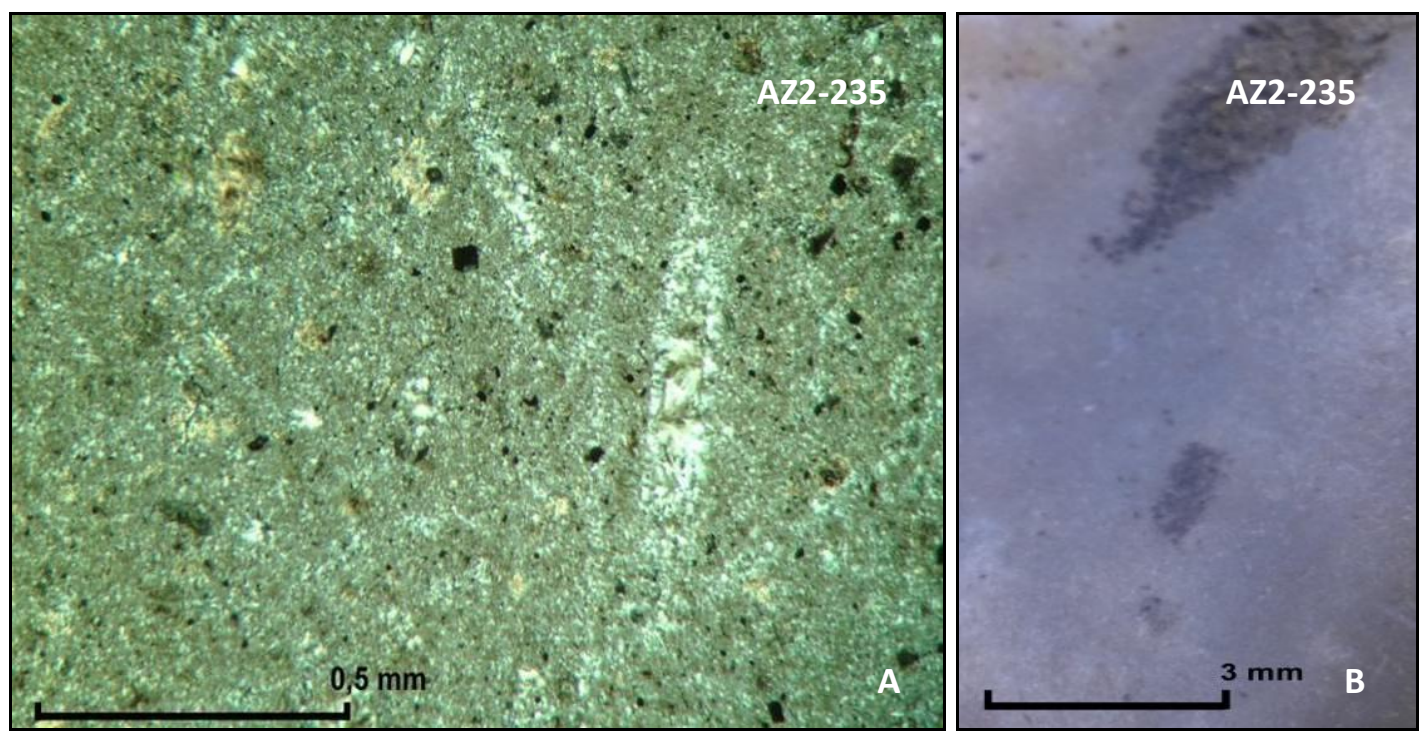

Figura 62. A: Lámina delgada AZ2-235. Detalle de la mancha alargada rellena de calcedonia y de romboedros de dolomita. Foto con LDP x100 aumentos. B: Sílex masivo. Foto con lupa tipo triplete10X. 
- AZ2-352 (figura 63): Sílex masivo. La muestra posee gran cantidad de romboedros de dolomita. Aparecen manchas rellenas de calcedonia e inclusiones de minerales opacos. Se aprecian de visu formas ramiformes o arborescentes de óxidos.
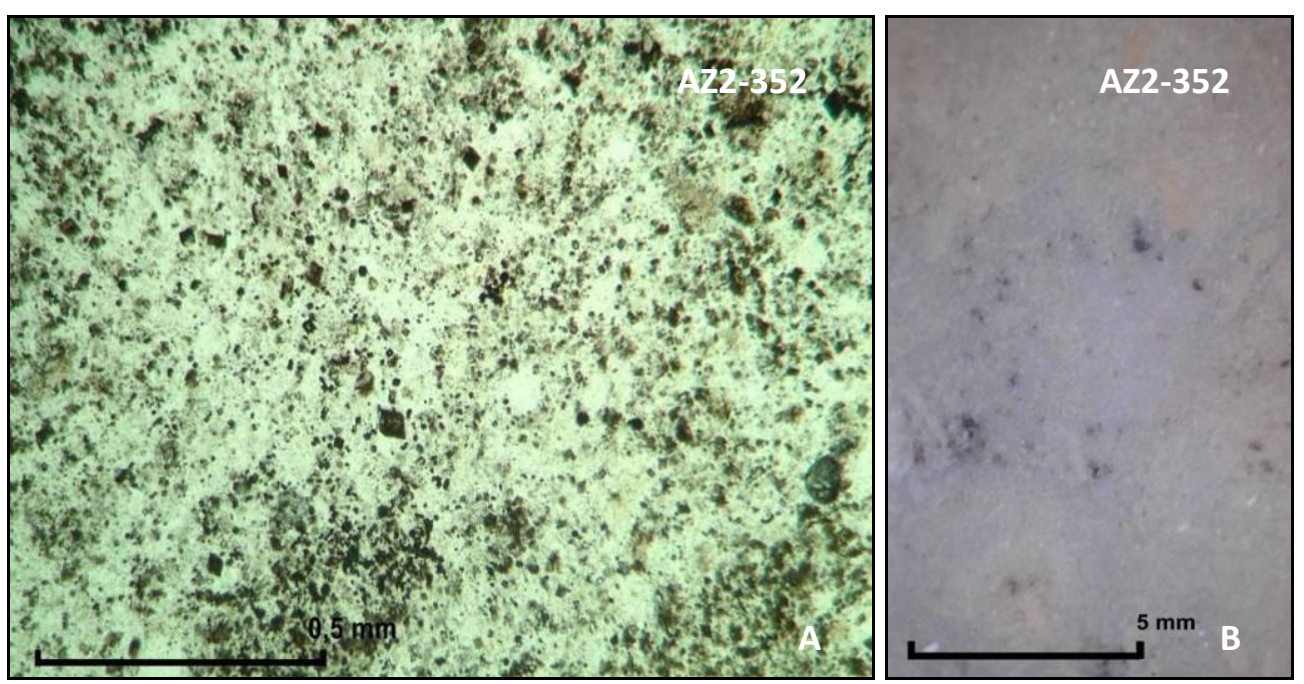

Figura 63. A: Lámina delgada AZ2-352. Detalle romboedros de dolomita e inclusiones de minerales opacos. Foto con LDP x100 aumentos. B: Sílex masivo.

Foto con lupa tipo triplete10X.

- AZ2-374 (figura 64): Sílex masivo con nódulos de pequeño tamaño, posiblemente sean radiolarios. El tono rosado de las zonas exteriores que percibimos de visu concuerda con las radiolaritas de la zona. Aparece en la muestra cristales de cuarzo rellenando el interior de los fantasmas de los radiolarios.
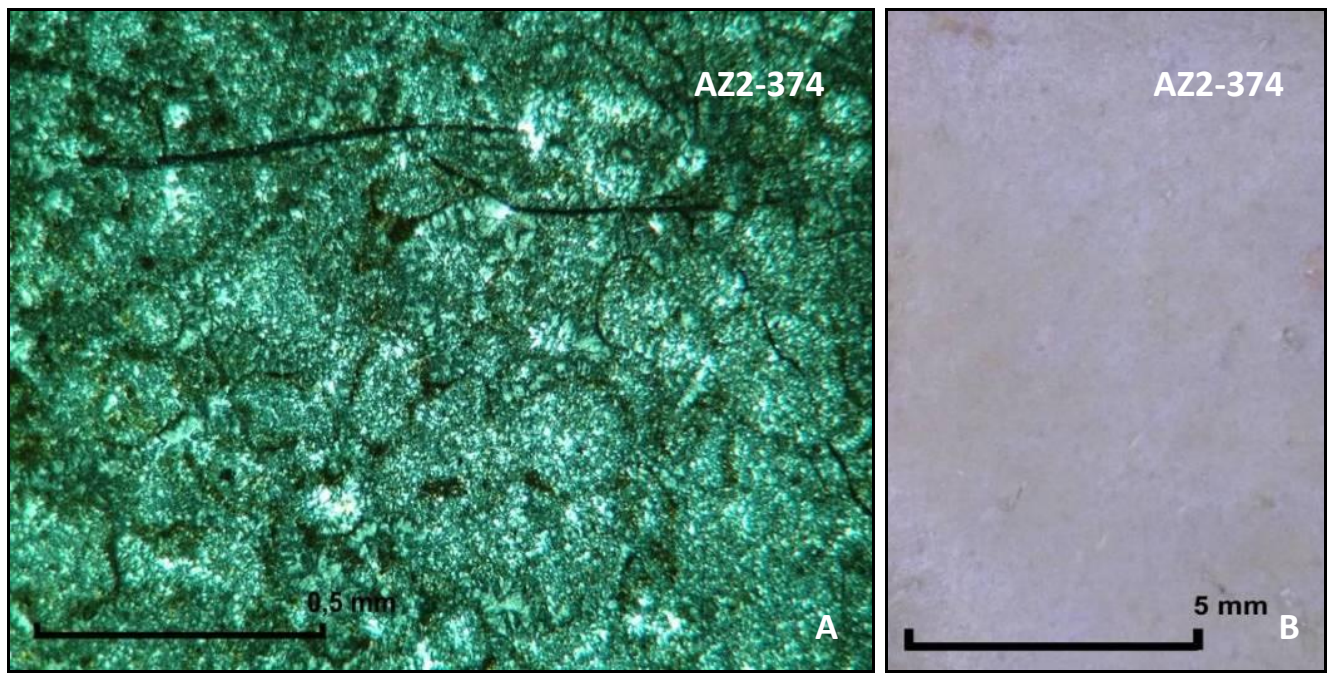

Figura 64. A: Lámina delgada AZ2-374. Detalle de los fantasmas de radiolarios rellenos de cuarzo. Foto con LDP x100 aumentos. B: Sílex con radiolarios. Foto con lupa tipo triplete $10 \mathrm{X}$. 
- AZ2-376 (figura 65): Sílex masivo. La muestra presenta manchas alargadas rellenas de calcedonia y algunos romboedros de dolomita. También se constata al microscópio las oxidaciones arborescentes que se aprecian de visu.
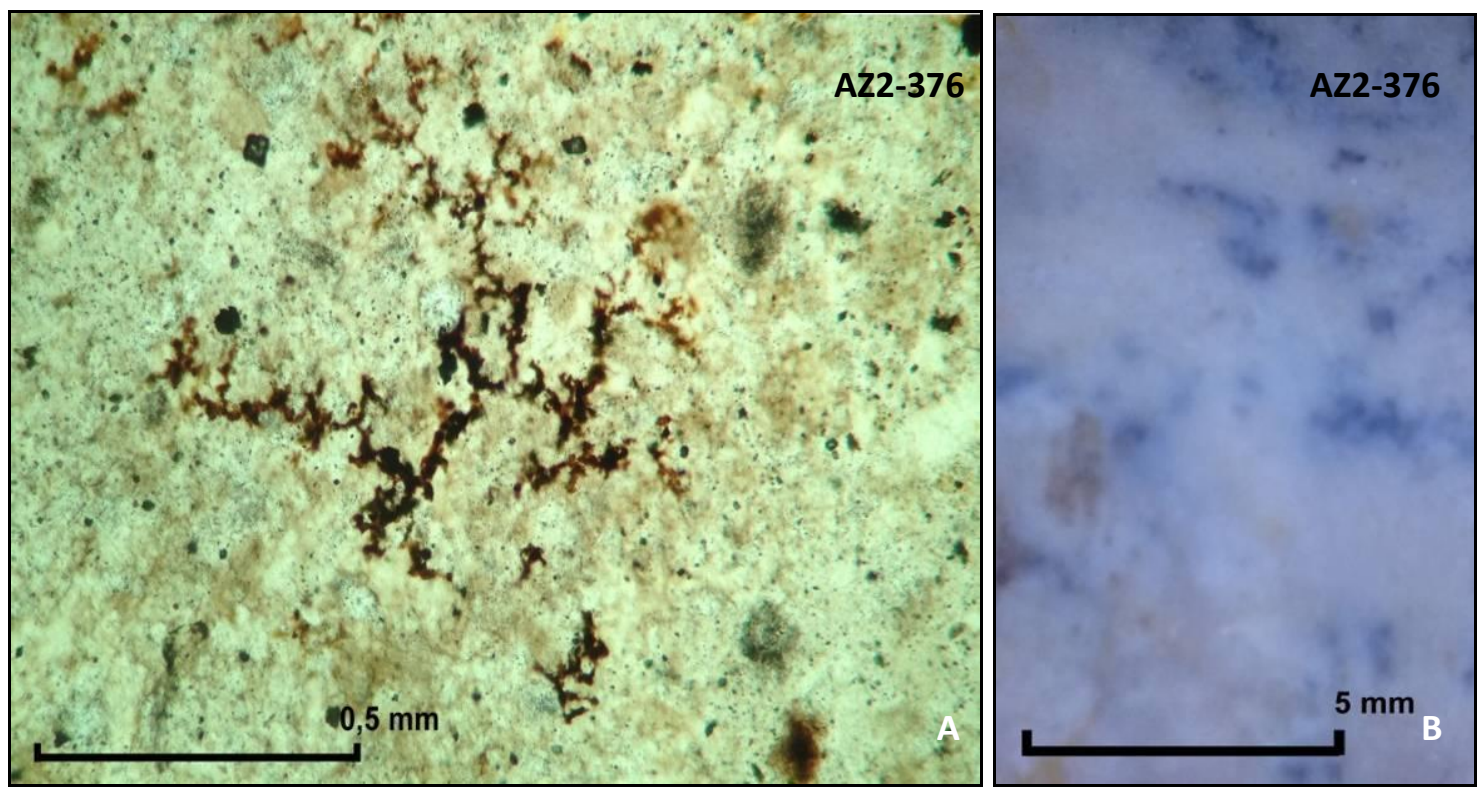

Figura 65. A: Lámina delgada AZ2-376. Detalle de oxidación arborescente. Foto con LP x100 aumentos. B: Sílex masivo con oxidaciones. Foto con lupa tipo triplete 10X.

\subsubsection{La Galeota (Ardales, Málaga)}

Coordenadas UTM ETRS89 30 del punto de muestreo:

\begin{tabular}{|c|c|}
\hline $\mathbf{X}$ & $\mathbf{Y}$ \\
\hline 335878 & 4083514 \\
\hline
\end{tabular}

Ubicación y características del afloramiento

La Galeota se sitúa en la ladera del cerro homónimo, sobre la actual carretera que une Ardales con Campillos (A-357), a $1 \mathrm{~km}$ escaso de distancia del casco urbano de Ardales. Se trata de un afloramiento donde los nódulos de sílex se dispersan en abundancia por una superficie de más de $1.000 \mathrm{~m}^{2}$, insertos en una matriz poco compacta.

Descripción de la unidad geológica

El afloramiento es una de las mélanges pertenecientes a la formación Numidoide, de edad Aquitano-Burdigaliense, del Complejo del Campo de Gibraltar, en el valle del Turón, las cuales contienen bloques de sílex de buena calidad. Estos conglomerados contienen rocas del Mesozoico y del Cenozoico originarias de la sucesión tipo Pereila y en ellos destaca la presencia de calizas grises con sílex del 
Jurásico. La construcción de la carretera A-357 nos permite observar una estratigrafía donde se aprecia el nivel de cantos de microbrechas, en el cual se encuentran los nódulos de sílex, entre una masa de arcillas marrones y otra de margas azuladas.

Características del sílex

El sílex del afloramiento de La Galeota es el denominado tipo Turón. Es un sílex de grano fino y textura homogénea, las tonalidades van desde el color beige, pasando del gris oscuro al negro, presenta buenas condiciones para la talla. Aparece en nódulos de gran tamaño y poco alterados.

Caracterización de las láminas delgadas:

- GA-580 (figura 66): Sílex masivo. Presenta inclusiones de calcedonia formando nódulos, así como una gran cantidad de cristales de dolomita por toda la muestra.
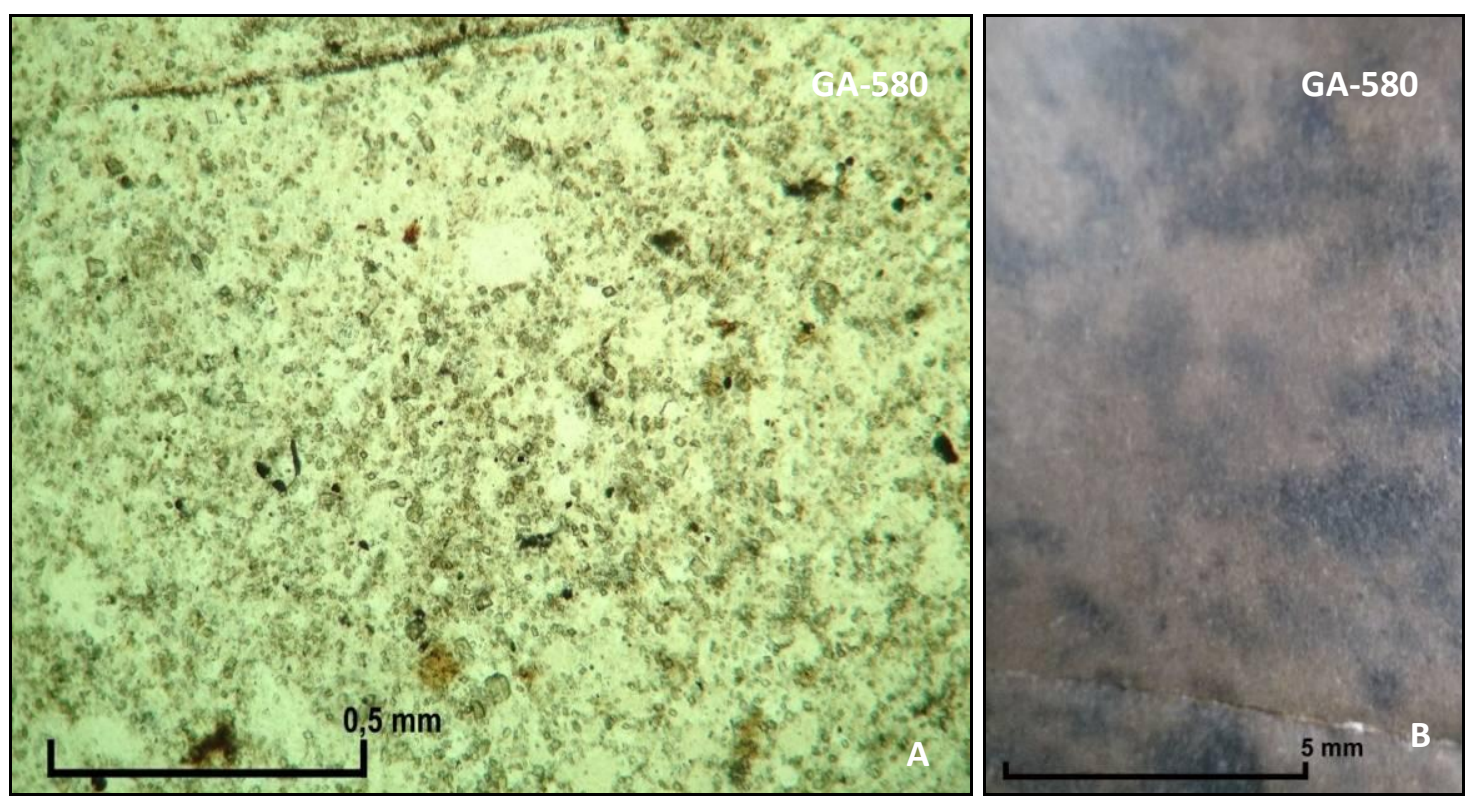

Figura 66. A: Lámina delgada GA-580. Detalle de la multitud de cristales de dolomita por toda la muestra. Foto con LP x100 aumentos. B: Sílex masivo. Foto con lupa tipo triplete 10X.

. LAGAL-ARD-1 (figura 67): Sílex masivo. En toda la muestra se aprecian manchas de carbonatos y abundancia de espículas y restos de fósiles rellenos de calcedonia. Al igual que en la descrita anteriormente, en este se aprecian multitud de romboedros de dolomita. 

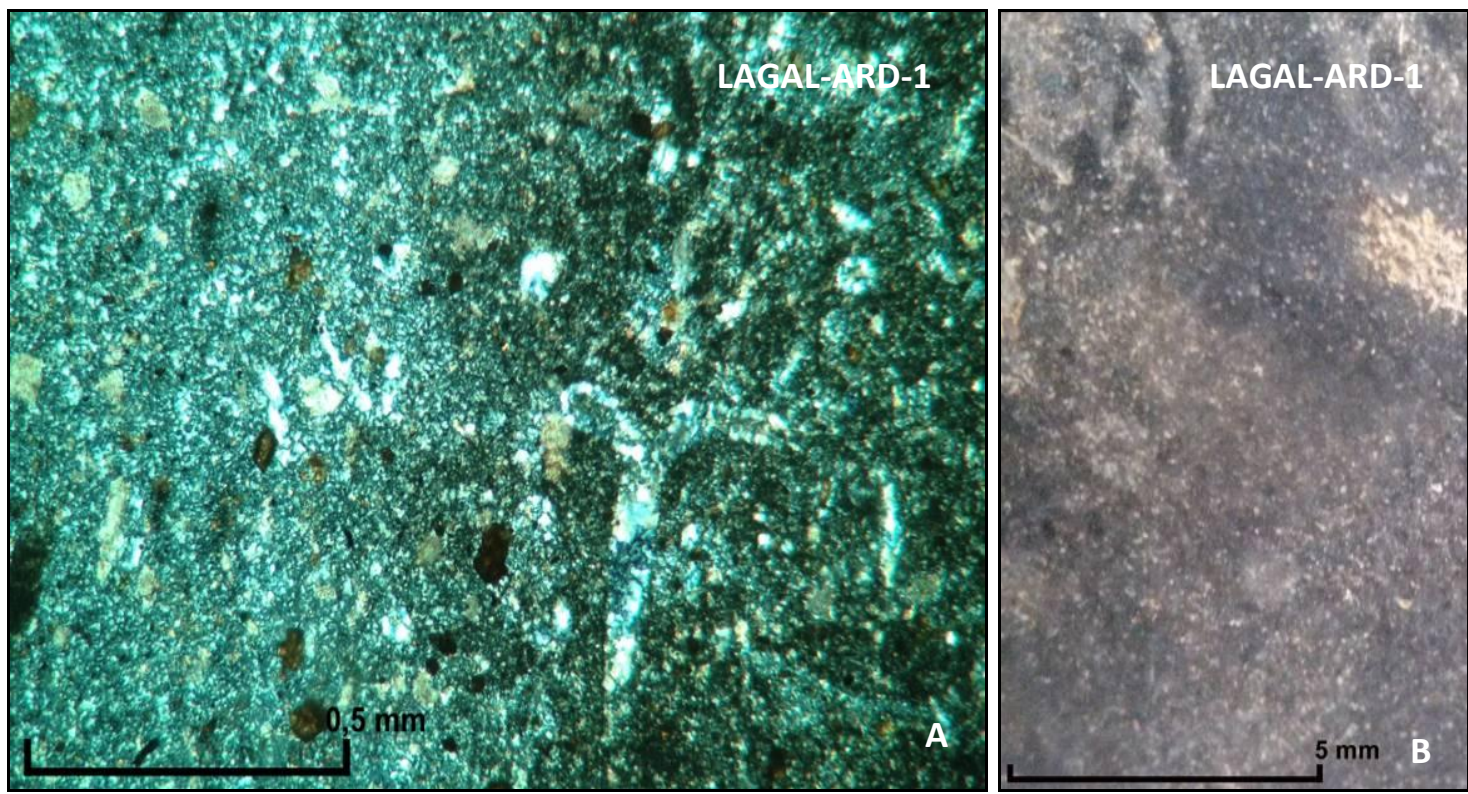

Figura 67. Lámina delgada LAGAL-ARD-1. Detalle de romboedros de dolomita y espícula rellena de calcedonia. Foto con LP x100 aumentos. B: Sílex masivo. Foto con lupa tipo triplete $10 \mathrm{X}$.

- LAGAL-ARD-2 (Figura 68): Sílex masivo. Recristalizado en sílice con clastos de cuarzo monocristalino. Aparecen gran cantidad de manchas de calcita esparítica, así como venillas de calcita esparítica recristalizada. Presencia de romboedros de dolomita $\mathrm{y}$ algunos minerales opacos.
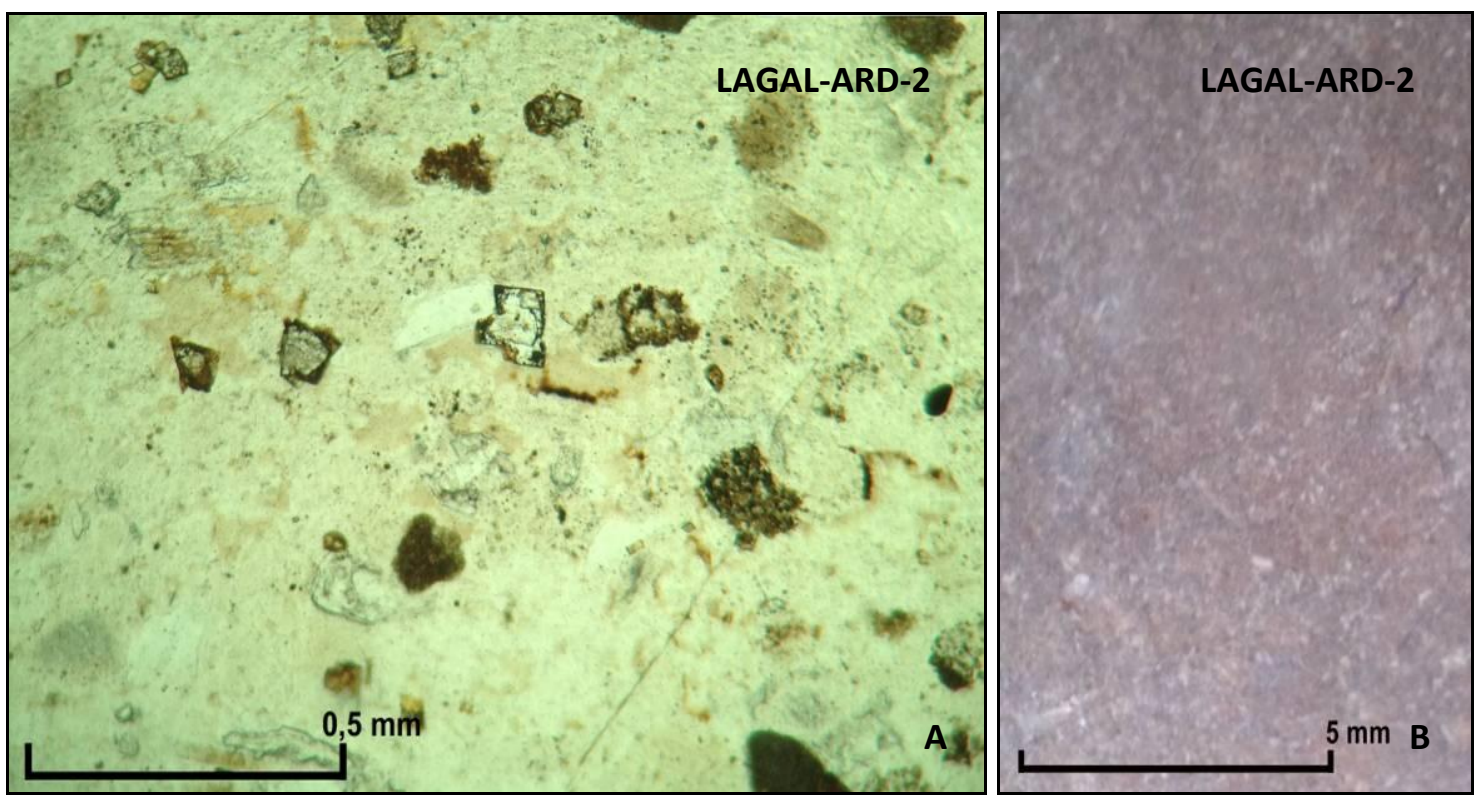

Figura 68. A: Lámina delgada LAGAL-ARD-2. Detalle de romboedros de dolomita. Foto con LP x100 aumentos. B: Sílex masivo. Foto con lupa tipo triplete 10X. 
. LAGAL-ARD-3 (figura 69): Sílex masivo. La muestra está completamente llena de espículas y restos fósiles rellenos de calcedonia. Hay venas de calcita esparítica, y abundantes romboedros de dolomita.
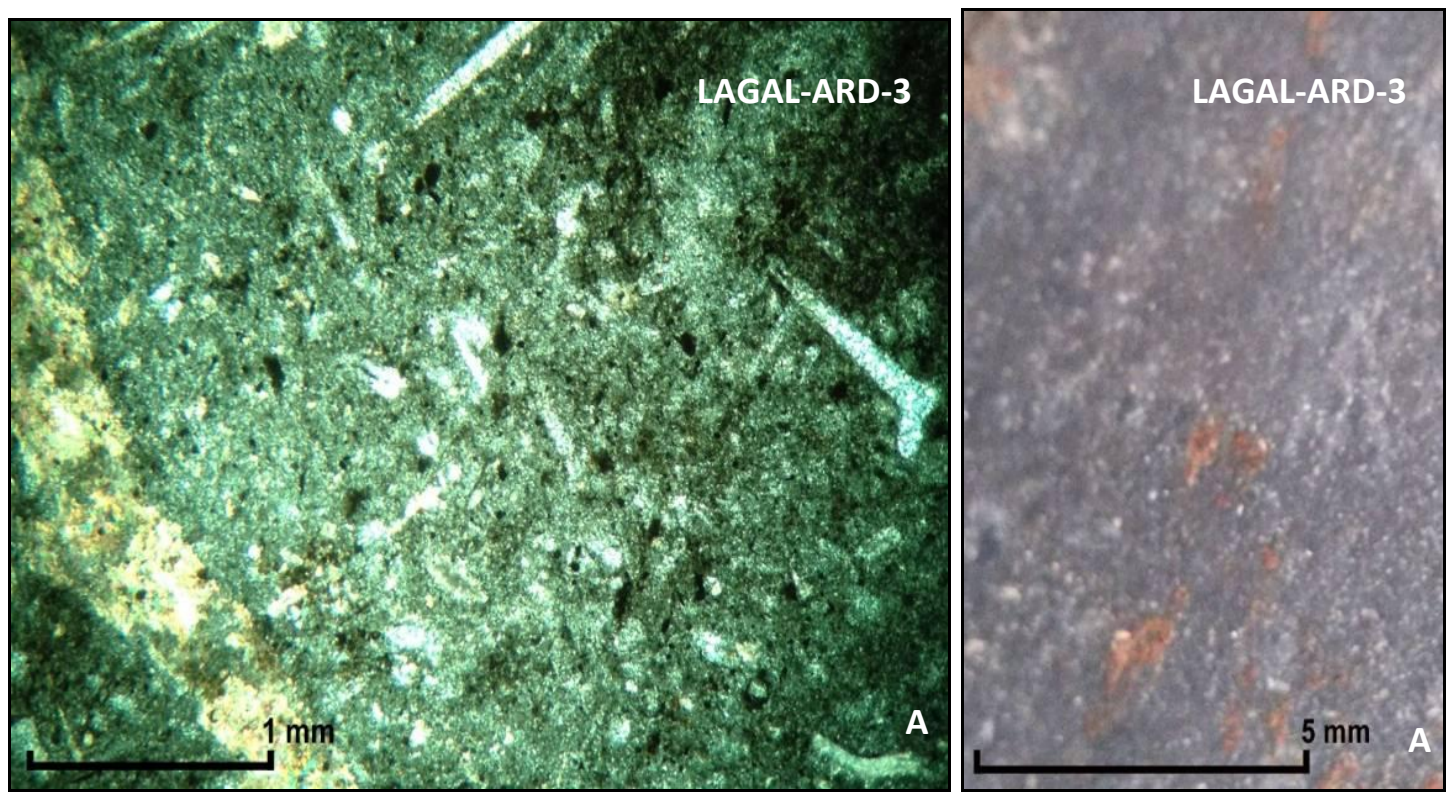

Figura 69. A: Lámina delgada LAGAL-ARD-3. Detalle espículas rellenas de calcedonia, de romboedros de dolomita y de una vena de calcita. Foto con LDP x100 aumentos. B: Sílex masivo. Foto con lupa tipo triplete10X.

\subsubsection{Castillo del Turón (Ardales, Málaga)}

Coordenadas UTM ETRS89 30 del punto de muestreo:

\begin{tabular}{|c|c|}
\hline $\mathbf{X}$ & $\mathbf{Y}$ \\
\hline 332276 & 4082396 \\
\hline
\end{tabular}

Ubicación y características del afloramiento

El afloramiento se ubica en el paraje conocido como loma del Castillo, al sudoeste del casco urbano de Ardales. Los materiales se distribuyen en forma de nódulos y tabletas fracturadas por la parte inferior de la ladera noroeste que baja de la fortaleza del Turón, a una cota de 510 ms.n.m.

Descripción de la unidad geológica

En términos geológicos, el afloramiento aparece como una intercalación de conglomerados dentro de arcillas, ocasionalmente areniscosas y margas arcillosas con klippers pertenecientes a la formación Olistostromica del Complejo del Campo de 
Gibraltar. En contacto con estos materiales se encuentra una alineación de calizas jurásicas estratificadas con presencia de nódulos de sílex, perteneciente al Complejo Maláguide.

Características del sílex

Macroscópicamente son sílex de grano fino, con tonalidades que van desde gris claro a gris azulado, en depósitos tabulares formando tabletas de 1-12 cm de espesor, intercalados en la caliza. Presentan buenas condiciones para los procesos de talla.

Caracterización de las láminas delgadas:

. CT-ARD-1 (figura 70): Sílex masivo. La muestra, de sílex tallado, contiene una fuerte presencia de dolomita, con multitud de espículas rellenas en calcedonia. También abunda el carbonato cálcico. Inclusiones de óxidos de hierro y minerales opacos de morfología alargadas.
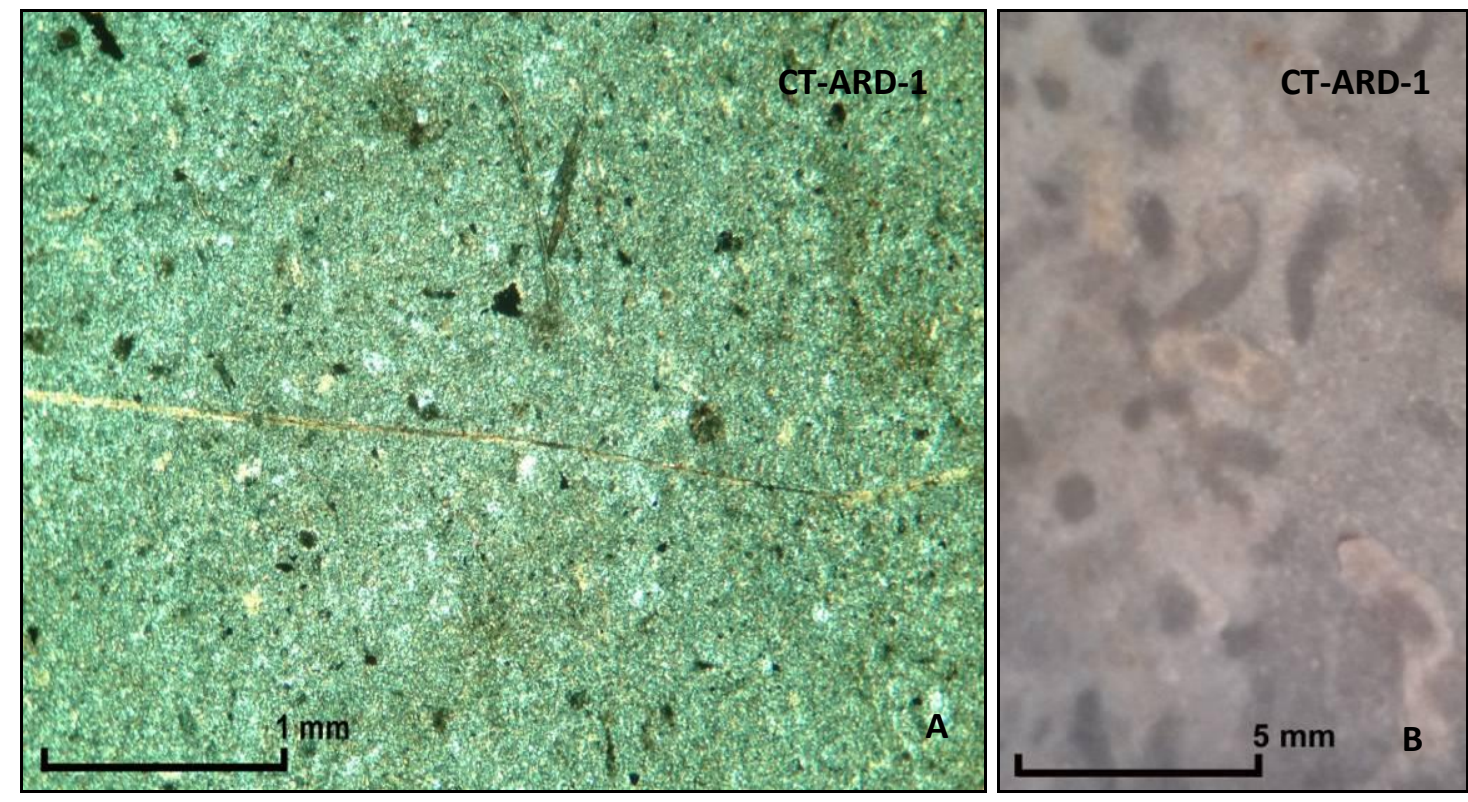

Figura 70. A: Lámina delgada CT-ARD-1. Filón de calcita, minerales opacos y romboedros de dolomita. Foto con LDP x40 aumentos. B: Sílex masivo con huellas de Phycosiphon. Foto con lupa tipo triplete 10X.

- CT-ARD-2 (figura 71): Sílex masivo. La muestra, de sílex tallado, tiene una abundante presencia de romboedros de dolomita y de microinclusiones. Aparecen microfisuras rellenas de calcita esparítica y restos de fósiles rellenos de calcedonia. 

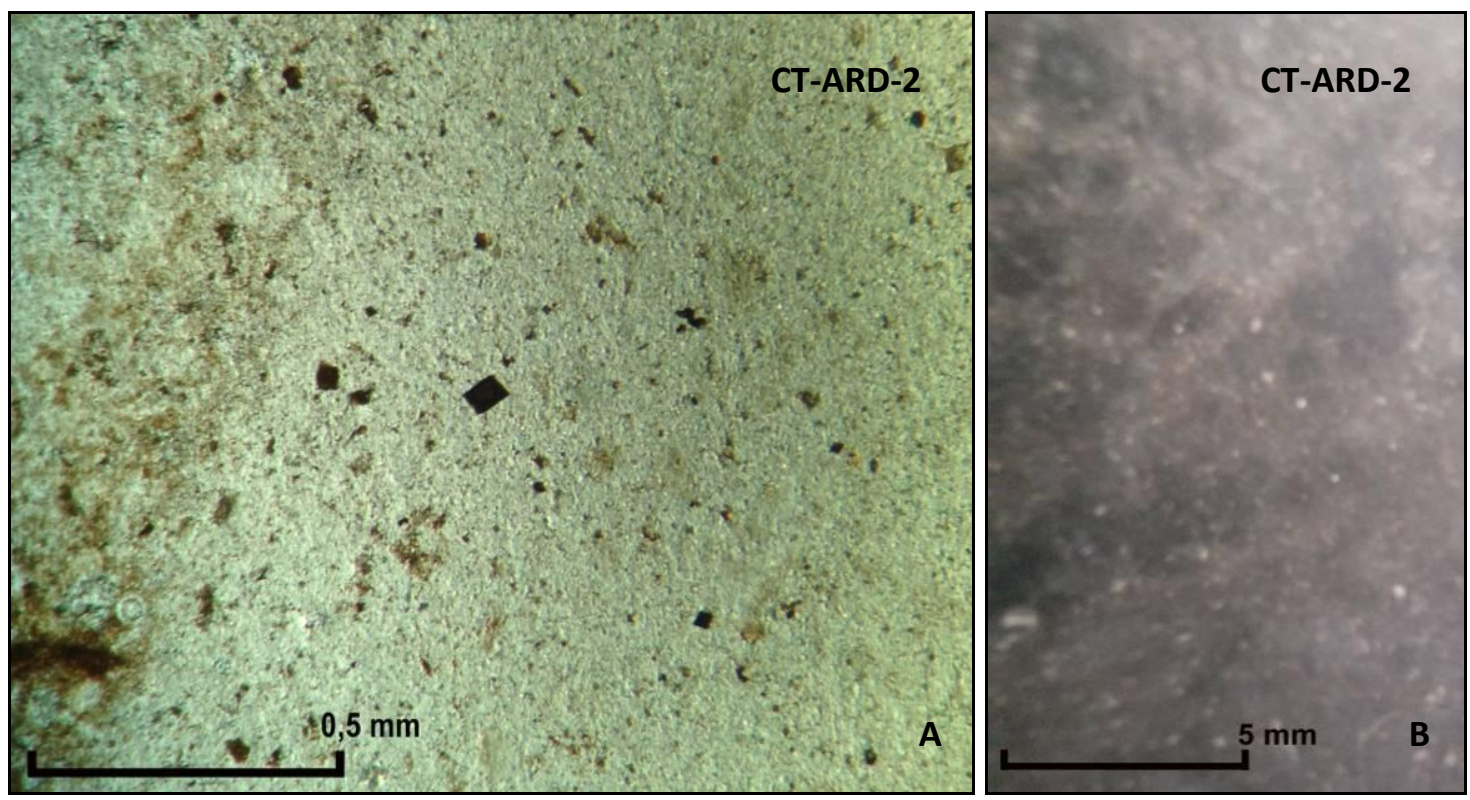

Figura 71. A: Lámina delgada CT-ARD-2. Detalle de romboedros de dolomita. Foto con LDP x100 aumentos. B: Sílex masivo. Foto con lupa tipo triplete 10X.

. CT-ARD-3 (figura 72): Sílex masivo muy carbonatado. En las partes silicificadas en calcedonia se ven restos de antiguas espículas. Aparecen cristales de calcita, alguno de ellos de esparita, de pequeño tamaño y color pardo.

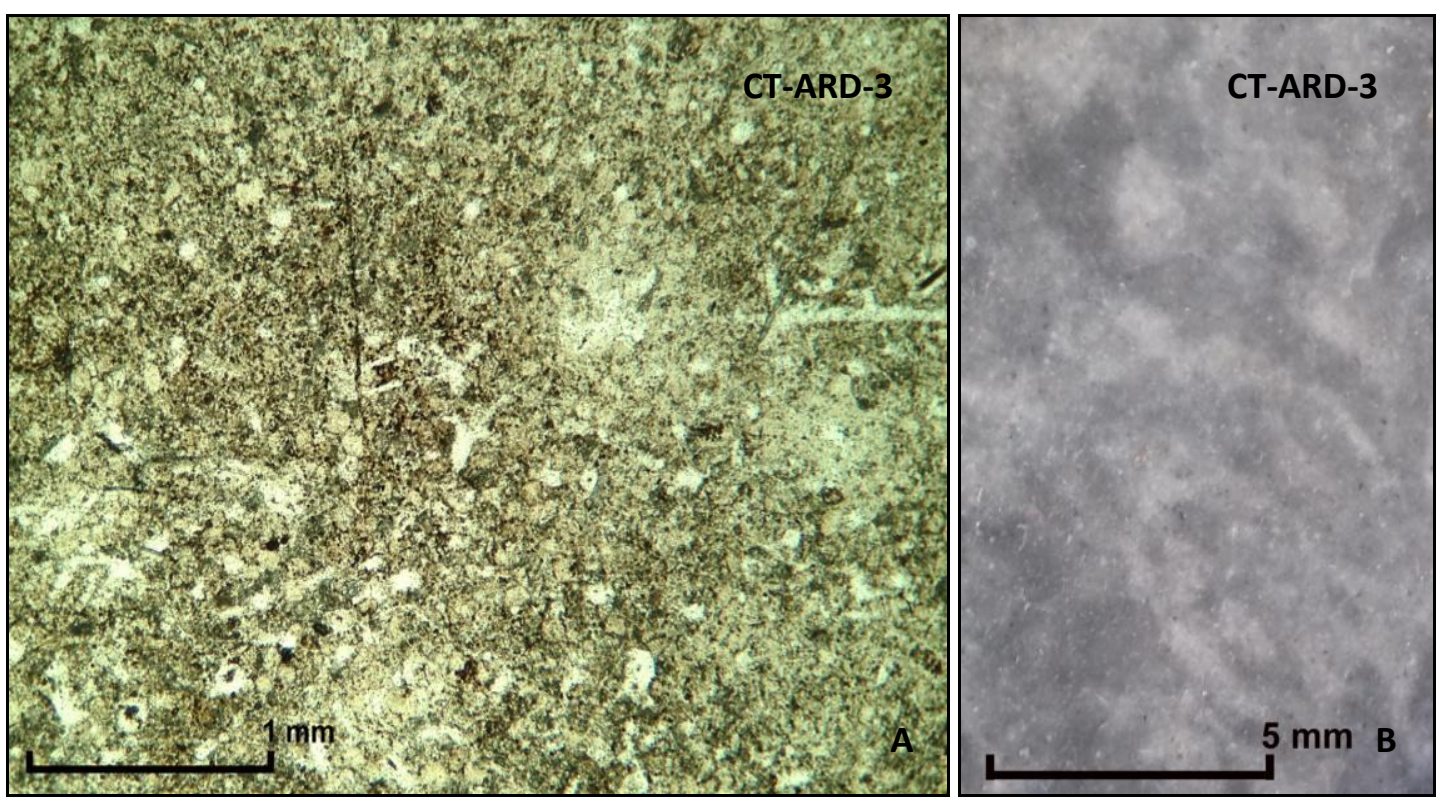

Figura 72. A: Lámina delgada CT-ARD-3. Detalle de la abundancia de fósiles. Foto con LP x40 aumentos. B: Sílex masivo. Foto con lupa tipo triplete 10X. 
- CT-ARD-4 (figura 73): Sílex masivo. La muestra, de sílex tallado, contiene muchas inclusiones de carbonatos, y microparches de calcita esparítica; así como granos de cuarzo detrítico y recristalizaciones en calcedonia. También posee minerales opacos de morfología triangulares, espículas rellenas de calcedonia, y abundantes cristales de dolomita.
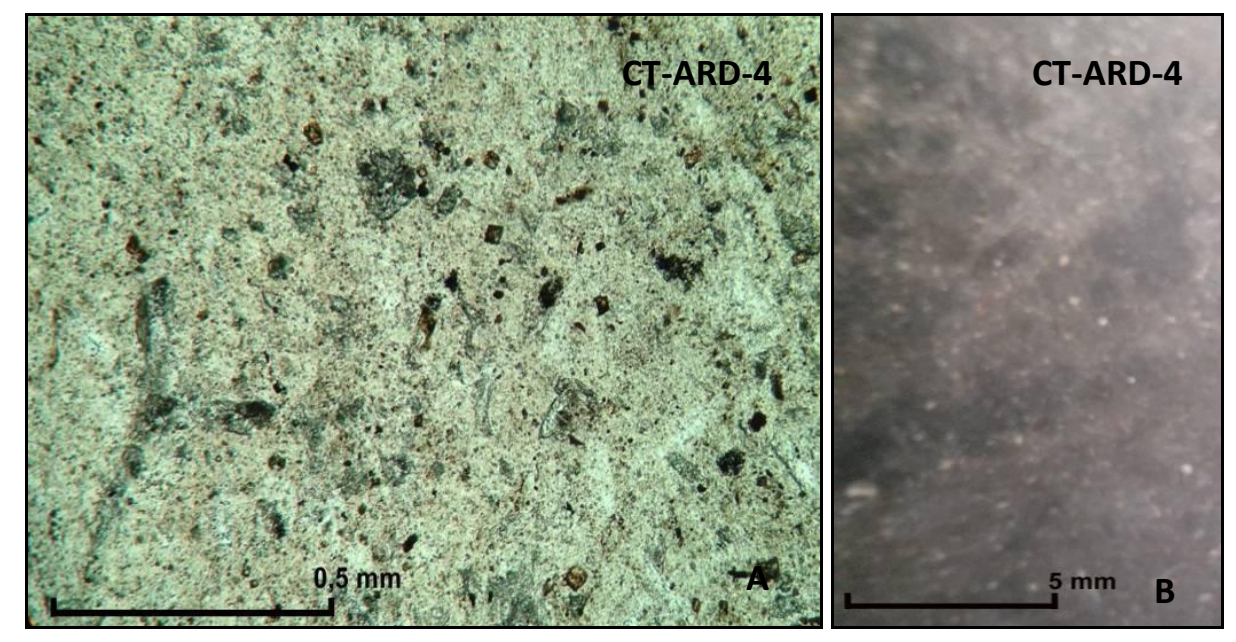

Figura 73. A: Lámina delgada CT-ARD-4. Detalle de espícula rellena de calcedonia y de romboedros de dolomita. Foto con LDP x100 aumentos. B:

Sílex masivo. Foto con lupa tipo triplete 10X.

\subsubsection{Herriza del Carnero (Casarabonela).}

Coordenadas UTM ETRS89 30 del punto de muestreo:

\begin{tabular}{|c|c|}
\hline $\mathbf{X}$ & $\mathbf{Y}$ \\
\hline 332235 & 4078201 \\
\hline
\end{tabular}

Ubicación y características del afloramiento

El afloramiento se ubica en una zona elevada, con el mismo nombre y dominando el paisaje abierto del río Turón (Morgado Rodríguez, 2002: 346), y en las estribaciones de la sierra de Alcaparaín. El material silíceo aparece en forma de nódulos de sílex.

Descripción de la unidad geológica

El afloramiento aparece como una intercalación de conglomerados dentro de arcillas, ocasionalmente areniscosas y margas arcillosas con klippes pertenecientes a la formación Olistostromica del Complejo del Campo de Gibraltar. 
Características del sílex

Macroscópicamente son sílex con tonalidades que van desde el gris oscuro a negro, del denominado tipo Turón. Aparecen en forma de bolos y presentan buenas condiciones para la talla.

Caracterización de la lámina delgada:

. HC-1 (figura 74): Sílex masivo. Contiene gran cantidad de romboedros de dolomita. Algún parche de calcita e inclusiones de minerales opacos.
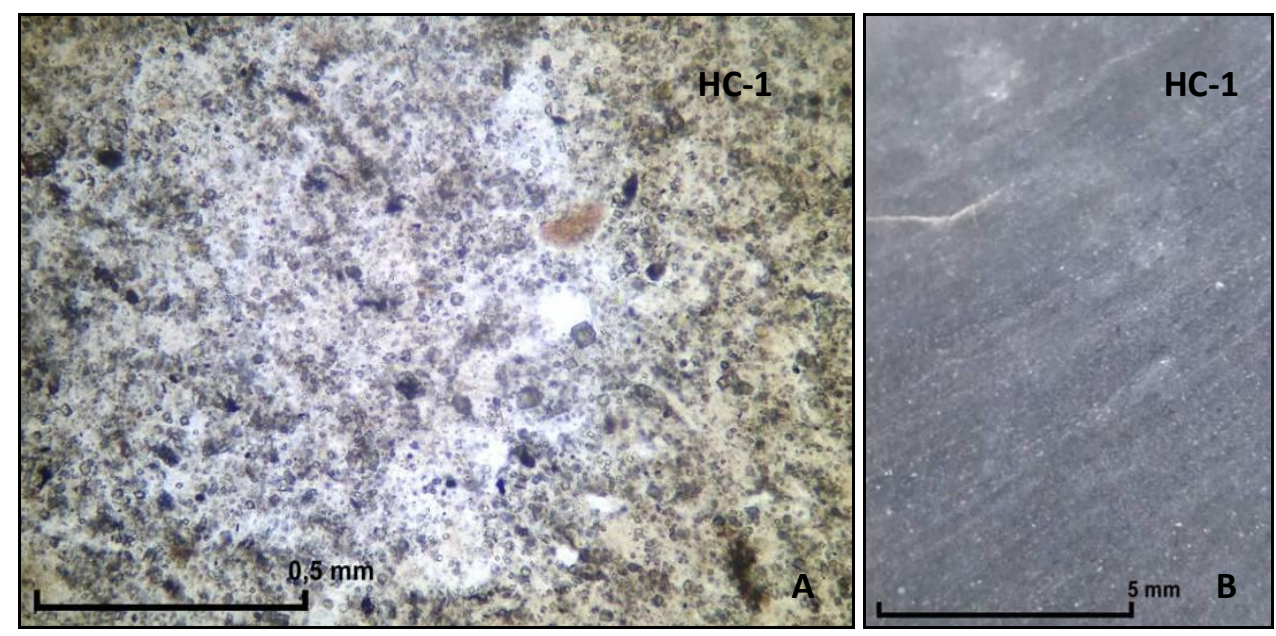

Figura 74. A: Lámina delgada HC-1. Detalle romboedros de dolomita e inclusiones de minerales opacos. Foto con LP x100 aumentos. B: Sílex masivo. Foto con lupa tipo triplete 10X.

\subsubsection{Sierra del Valle de Abdalajís}

Coordenadas UTM ETRS89 30 del punto de muestreo:

\begin{tabular}{|c|c|}
\hline $\mathbf{X}$ & $\mathbf{Y}$ \\
\hline 345541 & 4086864 \\
\hline
\end{tabular}

Ubicación y características del afloramiento

La zona de recogida de material se localiza al suroeste de la sierra del Valle de Abdalajís. El muestreo se realizó recogiendo materiales en posición semiprimaria procedentes de los derrubios de ladera y aparecen en forma de tabletas muy fracturadas. Descripción de la unidad geológica

Los materiales geológicos de la zona de muestreo se encuadran dentro del Complejo Maláguide de la formación de las Millanas-Viñuelas, intercalándose con las formas tectosedimentarias del Complejo del Águila. Dentro de la formación Millanas- 
Viñuelas nos encontramos con silexitas de color blanco en bancos de 10 a $15 \mathrm{~m}$ de espesor, dentro de los que aparecen niveles centimetricos de sílex en tonalidades oscuras y verdosas. Aparecen igualmente pequeños afloramientos que representan breves secciones estratigráficas del Jurásico y que se sitúan al oeste de la sierra, en la zona del Veredón, donde el sílex aparece dentro de las calizas en bloques y con un aspecto craquelado muy similar a las recogidas en el muestreo.

Características del sílex

Una primera caracterización de visu realizada con la lupa mostraba sílex masivos en tonalidades negras o grises oscuros y radiolaritas rojas.

Caracterización de las láminas delgadas:

- VAAB-1 (figura 75): Sílex masivo con microinclusiones negras de minerales opacos. Aparecen fisuras rellenas de calcita esparítica y espículas en forma de V.
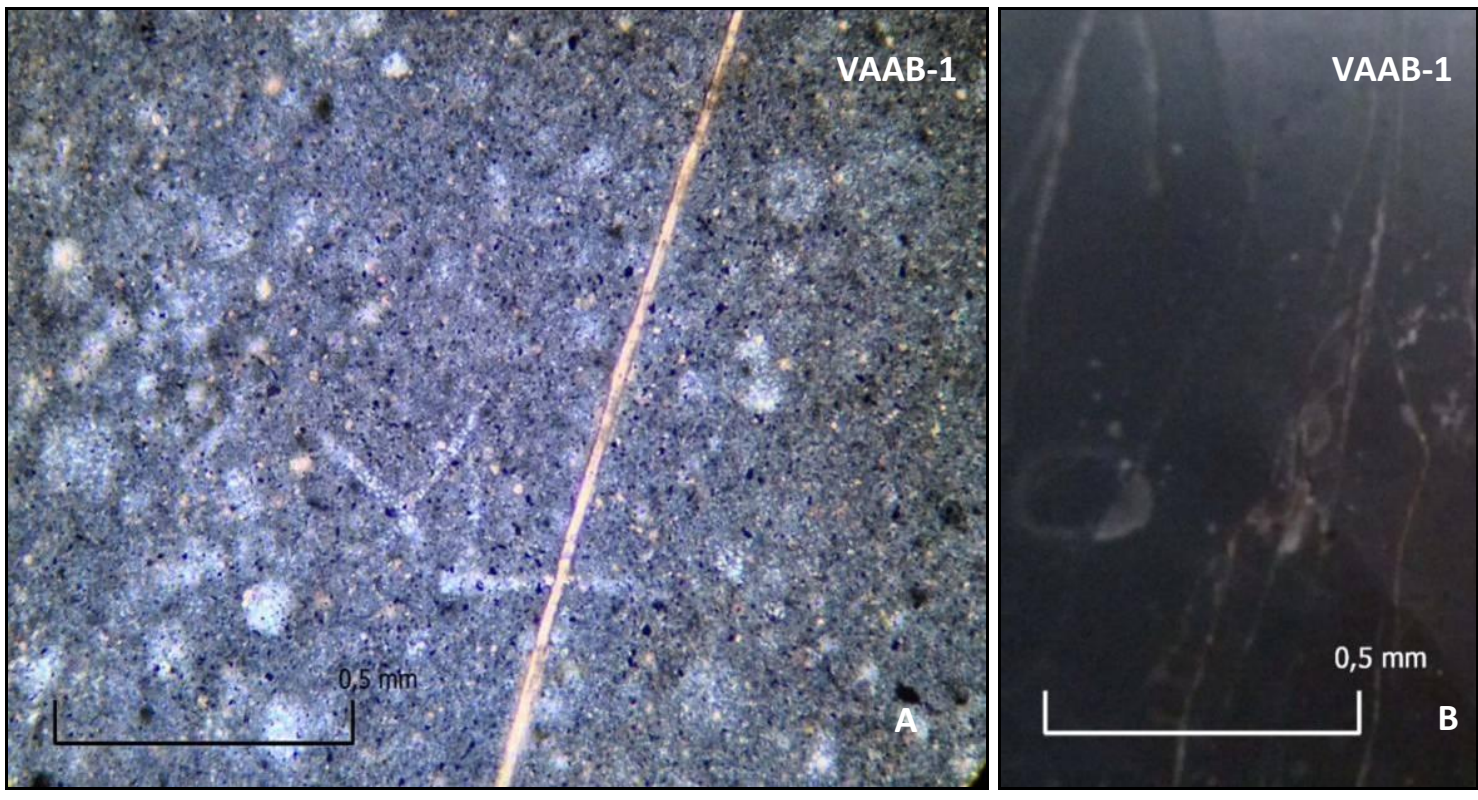

Figura 75. A: Lámina delgada VAAB-1. Aspecto general con microinclusiones, fisura llena de calcita esparítica y espículas en forma de V. Foto con LDP x100 aumentos. B: Sílex masivo. Foto con lupa tipo triplete $10 \mathrm{X}$.

- VAAB-2 (figura 76): Radiolarita fracturada rellena de calcita esparítica todo en color rojizo. Las fisuras aparecen rellenas de calcedonia y son anteriores al relleno de la calcita, también aparecen restos de óxidos de hierro. 

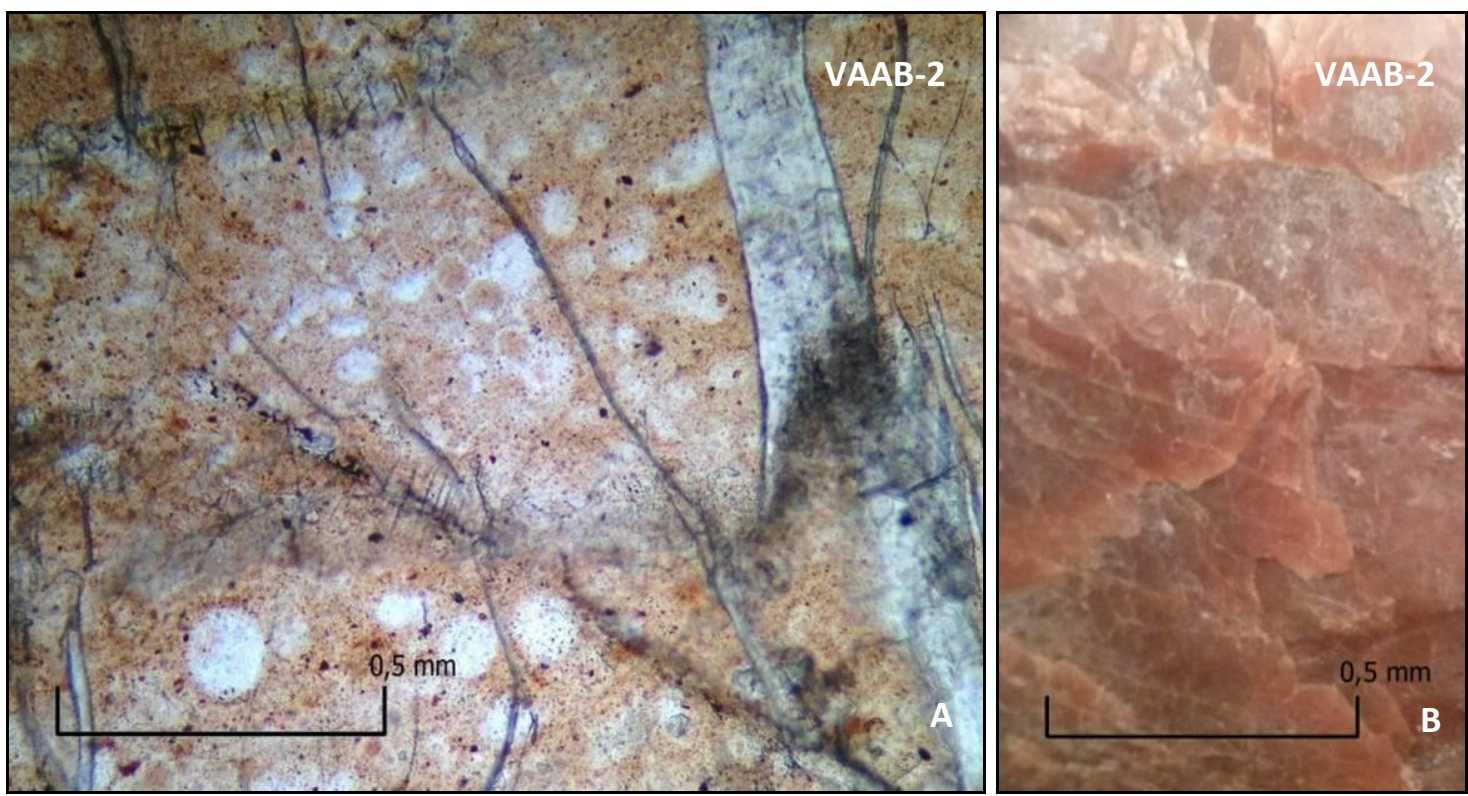

Figura 76. A: Lámina delgada VAAB-2. Radiolarios, fracturas rellenas de calcita y óxidos de hierro. Foto con LP x100 aumentos. B: Radiolarita roja. Foto con lupa tipo triplete 10X.

- VAAB-3 (figura 77): Radiolarita totalmente brechificada con fisuras rellenas de calcita esparítica.
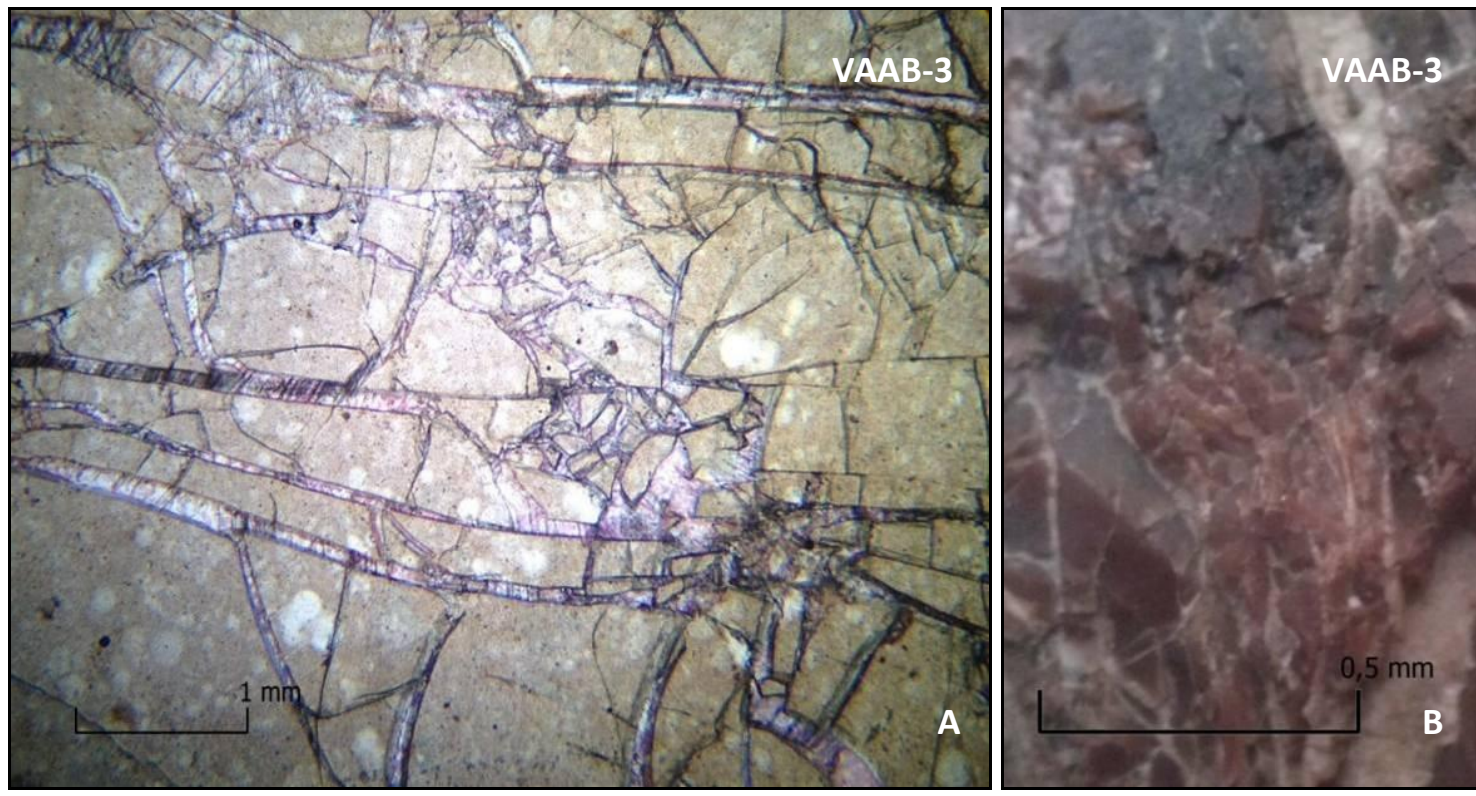

Figura 77. A: Lámina delgada VAAB-3. Estructura brechificada con fisuras rellenas de calcita. Foto con LP x25 aumentos. B: Radiolarita roja. Foto con lupa tipo triplete10X. 


\subsubsection{Sierra de Humilladero}

Coordenadas UTM ETRS89 30 del punto de muestreo:

\begin{tabular}{|c|c|}
\hline $\mathbf{X}$ & $\mathbf{Y}$ \\
\hline 345403 & 3996705 \\
\hline
\end{tabular}

Ubicación y características del afloramiento

Se localiza en la zona sur de la sierra de Humilladero. Aparecen en forma de tabletas dispersas por los derrubios de ladera de la sierra.

Descripción unidad geológica

Los materiales geológicos de la zona de muestreo se encuadran dentro del Subbético medio. La mayor parte del relieve de la sierra está formado por calizas y dolomías, con una potencia de 100 a $250 \mathrm{~m}$ en el caso de las últimas. Junto a las calizas y dolomías aparecen margocalizas con sílex y margas verdes. Estas calizas con sílex aparecen con organismos silíceos como espículas y radiolarios.

Características del sílex

De visu el material muestreado es un sílex en tonalidades grises oscuros y claros.

Caracterización de las láminas delgadas:

- SHU (figura 78): Sílex masivo con formas elipsoidales de 0,3 mm de diámetro.

Calcitas, restos de fósiles en calcita esparítica con inclusiones de todo tipo.
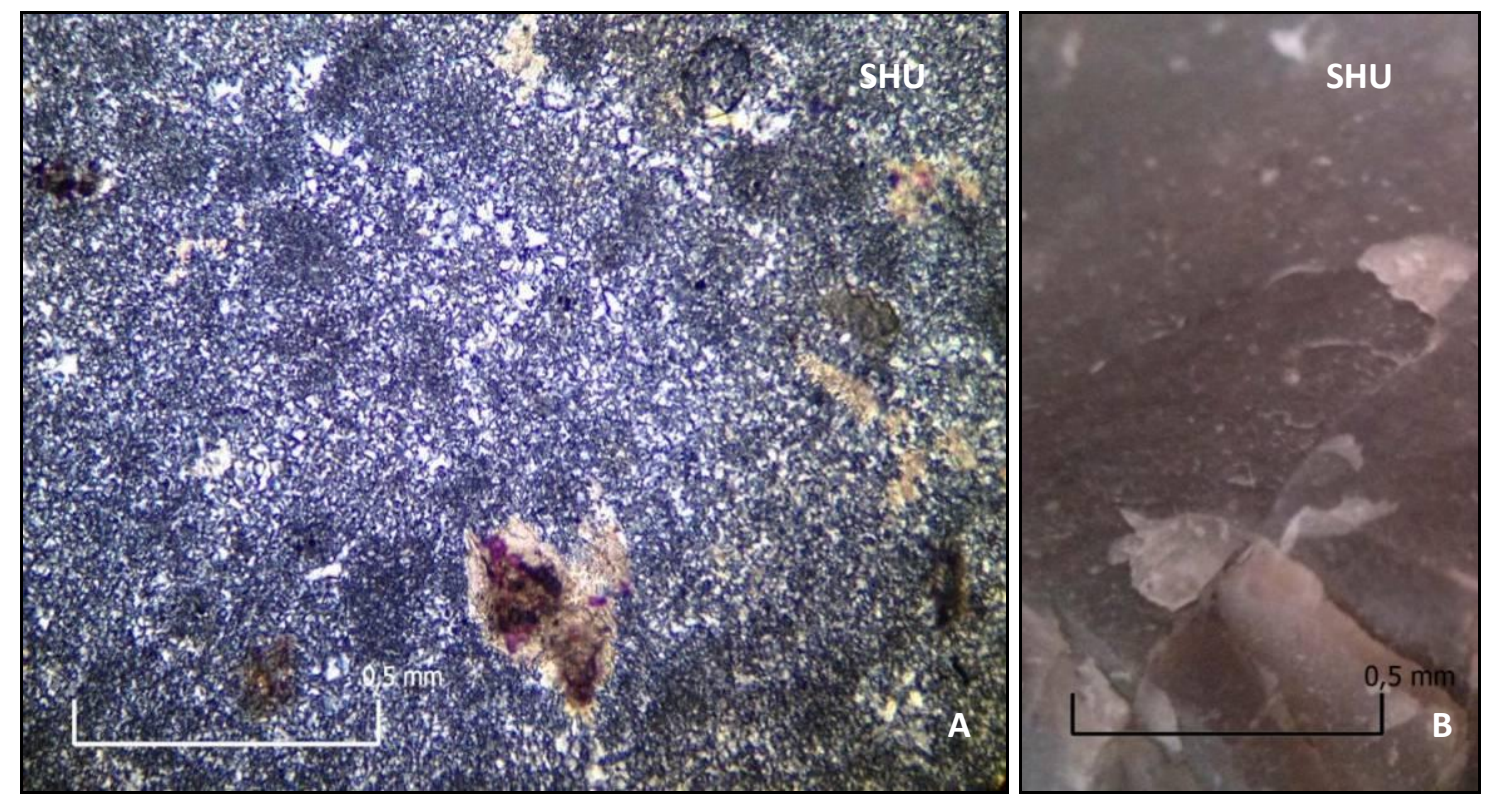

Figura 78. A: Lámina delgada SHU. Estructura de calcita esparítica con parche de calcita teñido. Foto con LDP x100 aumentos. B: Sílex masivo. Foto con lupa tipo triplete 10X. 


\subsubsection{Los afloramientos con materiales en posición secundaria (terrazas fluviales)}

Las muestras recogidas pertenecen a 3 localizaciones vinculadas a zonas de terrazas fluviales, analizando un total de 10 láminas delgadas. Para su caracterización se han utilizado las mismas técnicas que para los afloramientos en posición primaria o semiprimaria.

\subsubsection{Terraza de Las Grajeras (Ardales)}

Coordenadas UTM ETRS89 30 del punto de muestreo:

\begin{tabular}{|c|c|}
\hline $\mathbf{X}$ & $\mathbf{Y}$ \\
\hline 337252 & 408601 \\
\hline
\end{tabular}

Ubicación y características del afloramiento

Se localiza sobre una ladera, al norte del pueblo de Ardales, en la margen izquierda del río Turón, a unos $4 \mathrm{~km}$ del pueblo. El material fue recogido en superficie de los desmontes de la terraza.

Descripción de la unidad geológica

Con presencia de materiales compuestos por margas y arcillas marrones con presencia de klippes sedimentarios u olistolitos de distinta naturaleza y edad, de las formaciones tecto-sedimentarias, junto con algunos sectores con presencia de areniscas masivas y margas de color ladrillo con niveles detríticos y calcarenitas del Mesozoico. Características del sílex

En muestras a mano nos encontramos ante calizas, areniscas compactas, posibles cuarcitas, sílex y radiolarita.

Caracterización de las láminas delgadas:

- TG12-TL (figura 79): Arenisca compacta con granos de hasta $3 \mathrm{~mm}$. Hay granos de plagioclasas. Los clastos son angulosos, con presencia de moscovita y circones. Aparecen unos minerales en tonalidades verdosas, rellenando los huecos en los granos de cuarzo. Presencia de agujas de rutilo con algunos clastos de cuarzo. La morfología de los granos es subredondeada a angulosa. Aparecen granos de cuarzo con inclusiones fluidas y algún apatito. 

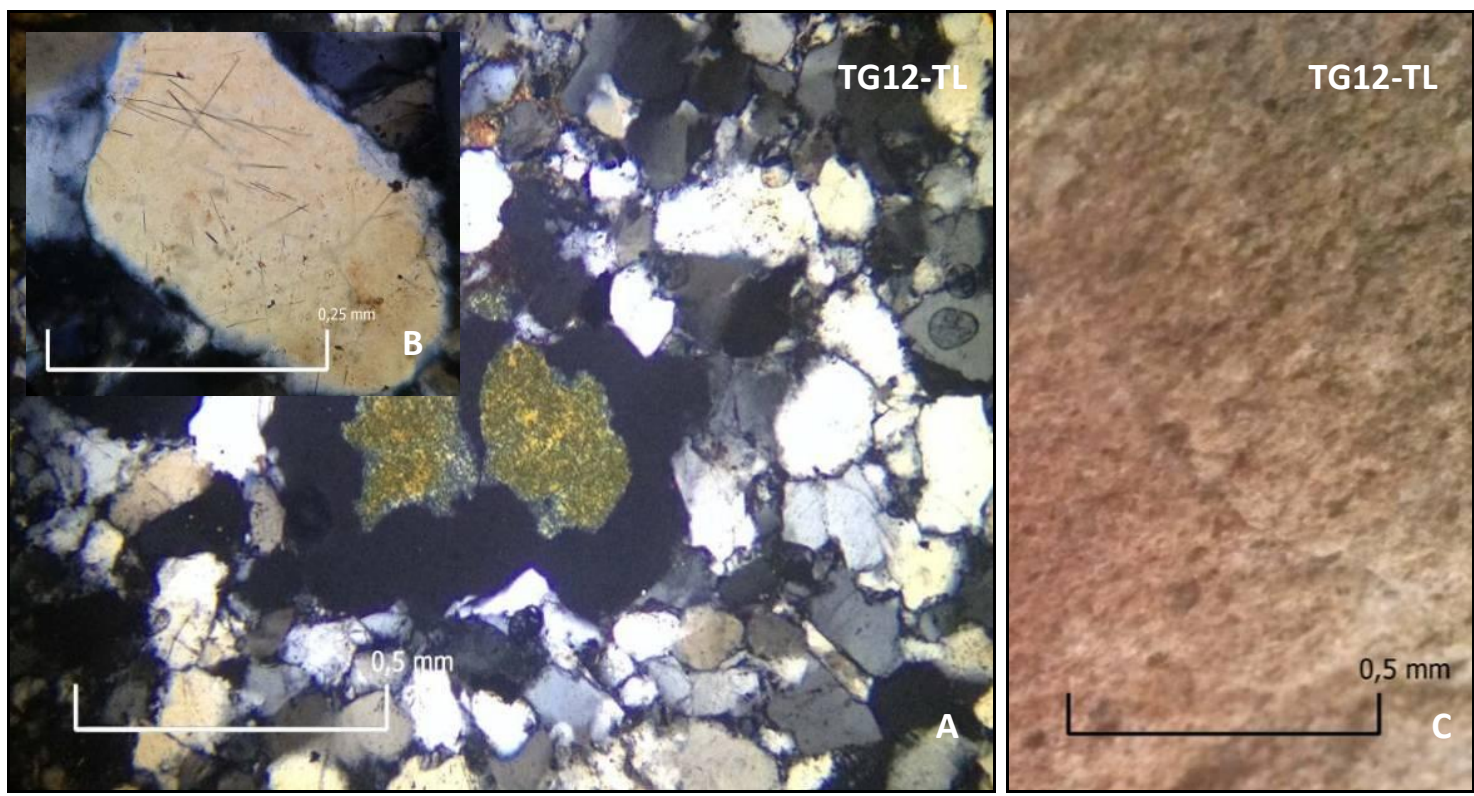

Figura 79. A: Lámina delgada TG12-TL. Granos con glauconita con cuarzo y calcita. Foto con

LDP x100 aumentos. B: Detalle de las agujas de rutilo en un cuarzo. Foto con LDP x400 aumentos. C: Arenisca compacta. Foto con lupa tipo triplete 10X.

- TG13-TL (figura 80): Protocuarcita, con moscovita, clorita y posibles circones. El cuarzo es anguloso, con un promedio de grano de 0,8 a $1 \mathrm{~mm}$, algunos son muy pequeños, llegando a 0,3 $\mathrm{mm}$. Hay presencia de plagioclasas. Los clastos aparecen inbrincados unos con otros. Se observa algún opaco y minerales de alteración como minerales micáceos, quizás feldespato alterado y algún óxido de hierro dentro de los opacos.
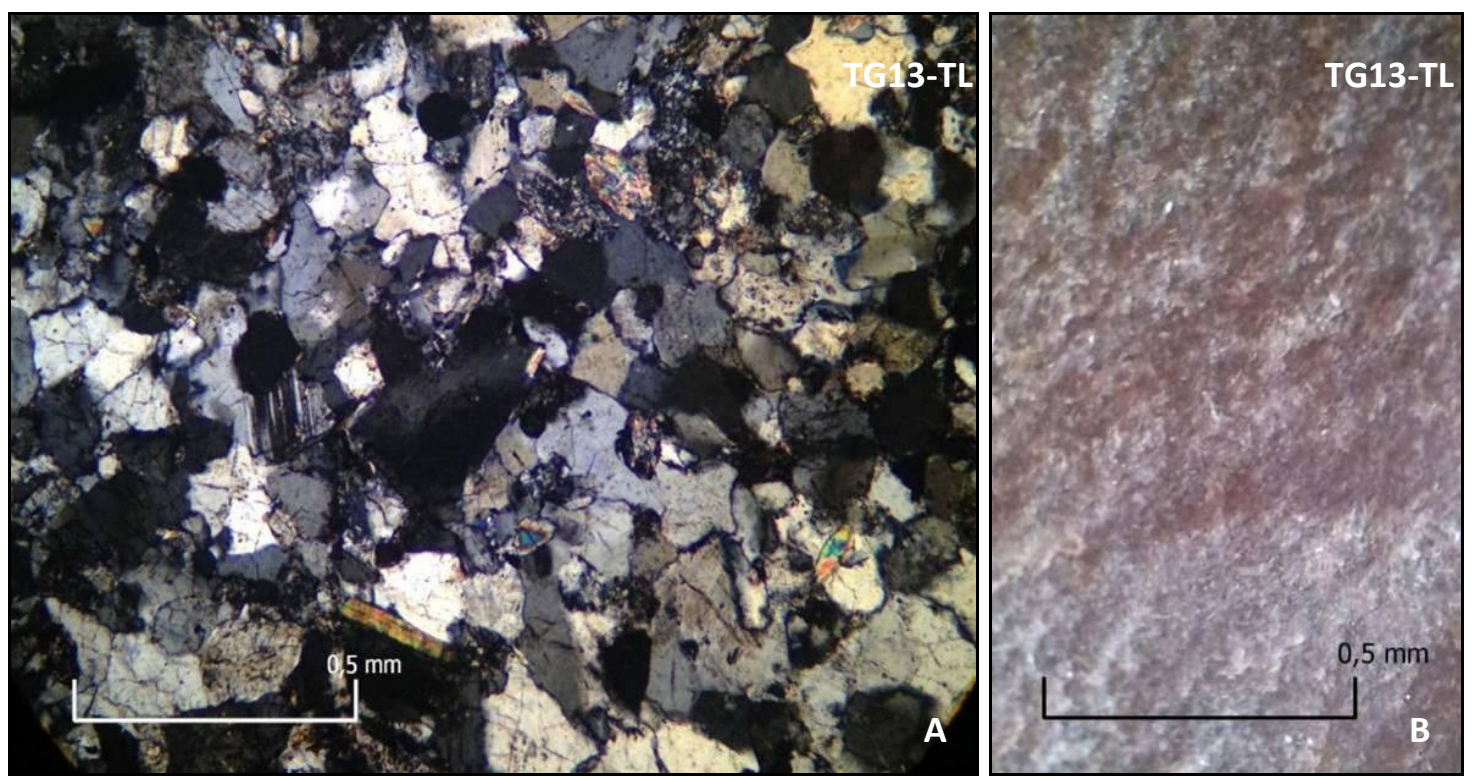

Figura 80. A: Lámina delgada TG13-TL. Textura con grano de cuarzos plagioclasa, moscovita y clorita. Foto con LDP x100 aumentos. B: Protocuarcita. Foto con lupa tipo triplete 10X. 


\subsubsection{Terraza de Peñarrubia (Campillos)}

Coordenadas UTM ETRS89 30 del punto de muestreo:

\begin{tabular}{|c|c|}
\hline $\mathbf{X}$ & $\mathbf{Y}$ \\
\hline 335388 & 4092474 \\
\hline
\end{tabular}

Ubicación y características del afloramiento

La zona de muestreo se localiza a unos 2/3 m de la orilla del río Guadalteba, al oeste del antiguo pueblo de Peñarrubia. Es una zona de terrazas con diferentes niveles, desmanteladas por la acción del oleaje del embalse, siendo la más próxima al río la que aporta más material arqueológico.

Descripción de la unidad geológica

Los materiales que afloran en la zona aparecen en el borde de los relieves del Subbético interno y son principalmente cantos, arenas y arcillas de la formación postmantos, estos materiales están constituidos por una masa arcillosa con una serie de cantos caóticos. Junto a estos materiales aparecen bloques y cantos calcáreos, arenas y arcillas (piedemonte muy cementado) junto a margocalizas rosadas "Capas rojas” de las unidades del Subbético interno.

Características del sílex

Una primera caracterización de visu de las rocas mostraba una presencia de sílex masivo en varias tonalidades grises, radiolaritas y areniscas compactas, también algún sílex oolítico.

Caracterización de las láminas delgadas:

- A1-A0 1 (figura 81): Sílex masivo con microfacturas y microinclusiones opacas muy pequeñas de tipo pellets, posibles restos de caparazones de radiolarios. Algunas fisuras están rellenas de calcedonia fibrosa y otras de óxidos. 

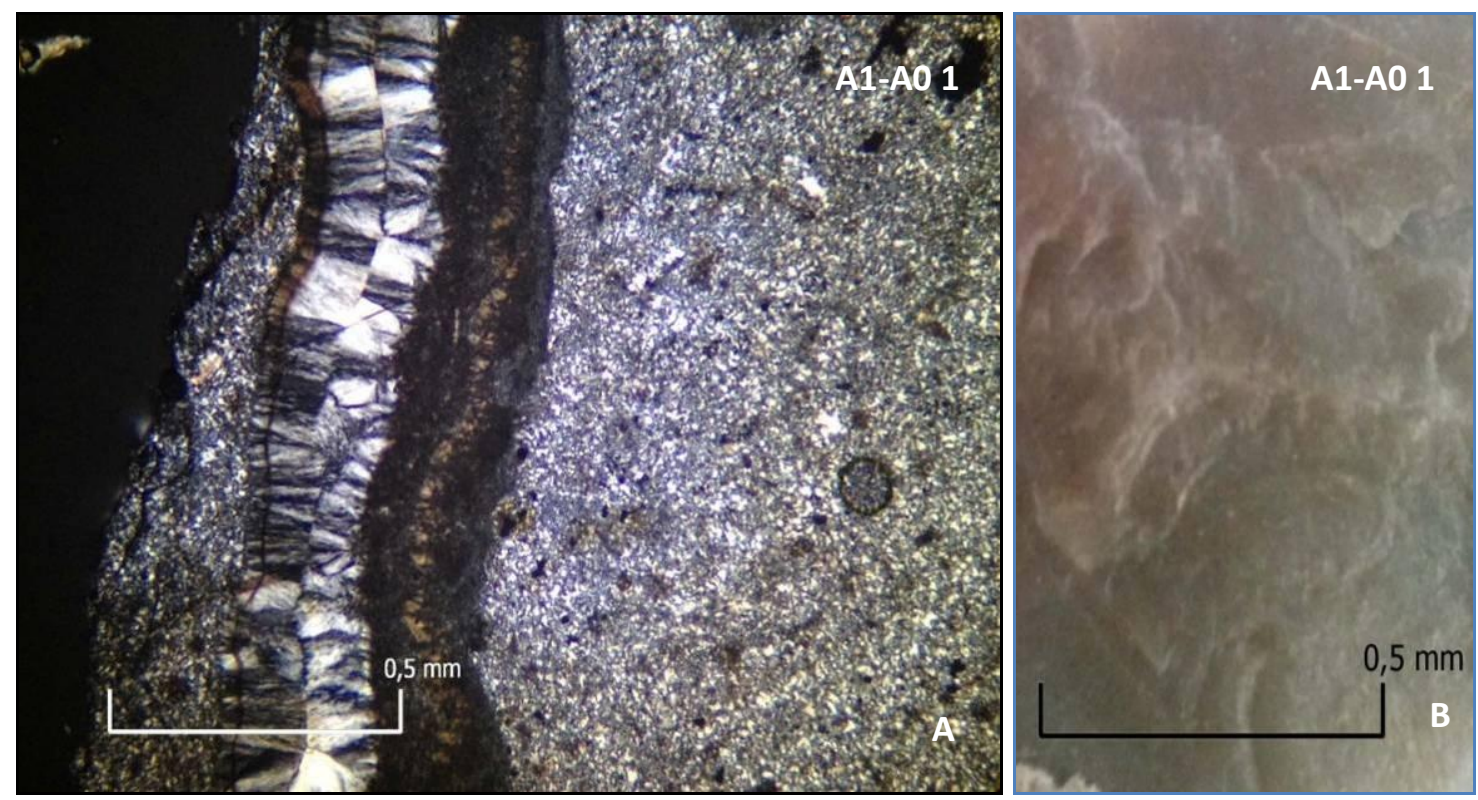

Figura 81. A: Lámina delgada A1-A01. Fisura rellena de calcedonia fibrosa y óxidos. Foto con LDP x100 aumentos. B: Sílex masivo. Foto con lupa tipo triplete 10X.

- A1-A0 3 (figura 82): Sílex masivo muy carbonatado con parches de calcita esparítica y rellena de calcedonia fibrosa. Tiene muchas inclusiones con abundantes microfósiles de tipo esférico (espículas y foraminíferos), aunque los radiolarios no se ven de forma clara.
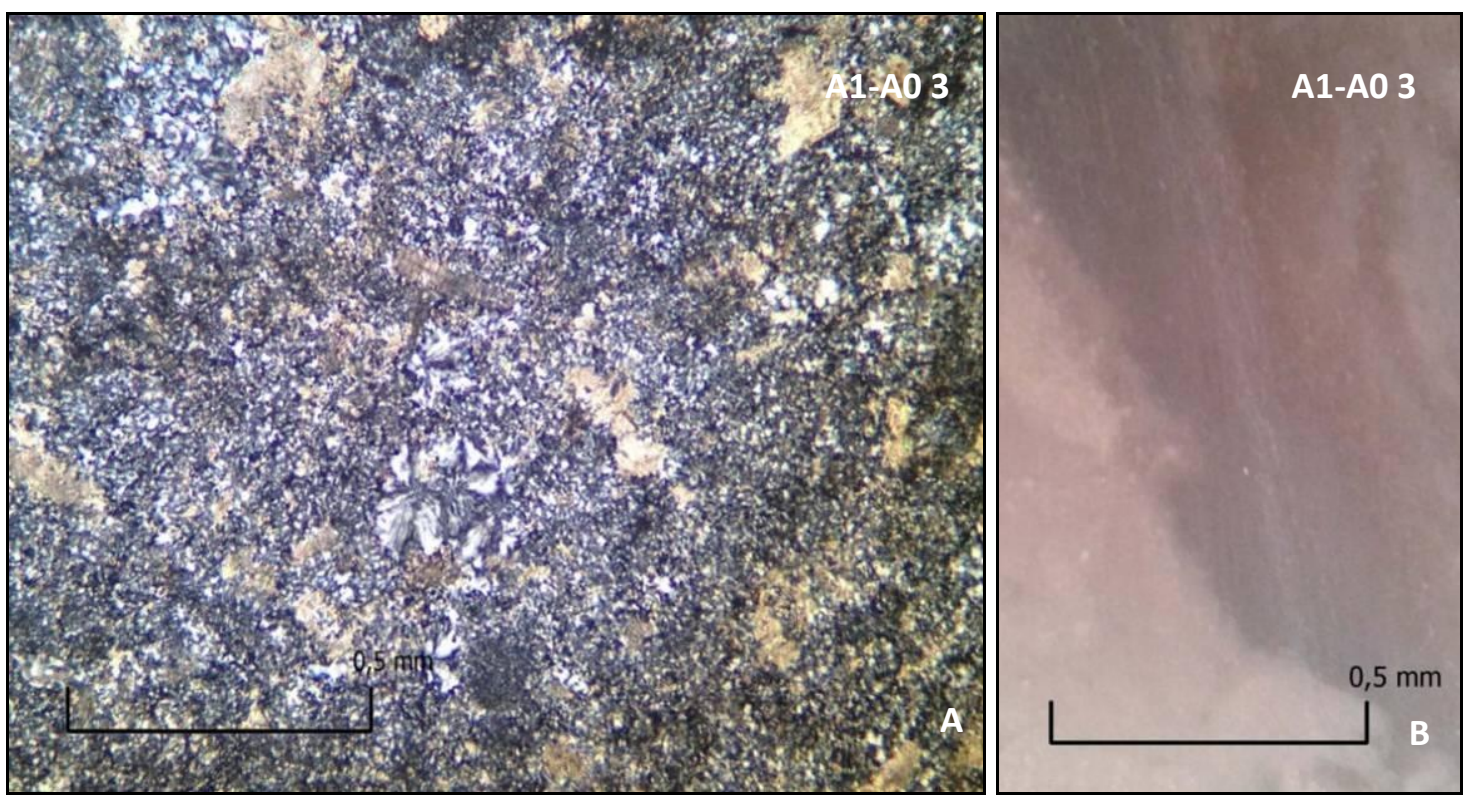

Figura 82. A: Lámina delgada A1-A03. Estructura carbonatada con parches de calcedonia, microfósil esférico. Foto con LDP x100 aumentos. B: Sílex masivo. Foto con lupa tipo triplete $10 X$.

- A1-A04 (figura 83): Sílex masivo muy carbonatado, con radiolarios rellenos de calcedonia fibrosa, carbonatos (calcita) y restos de fósiles (filamentos de fragmentos de 
moluscos). Hay algún mineral opaco y óxidos. También hay un posible foraminífero con corona de calcedonia.
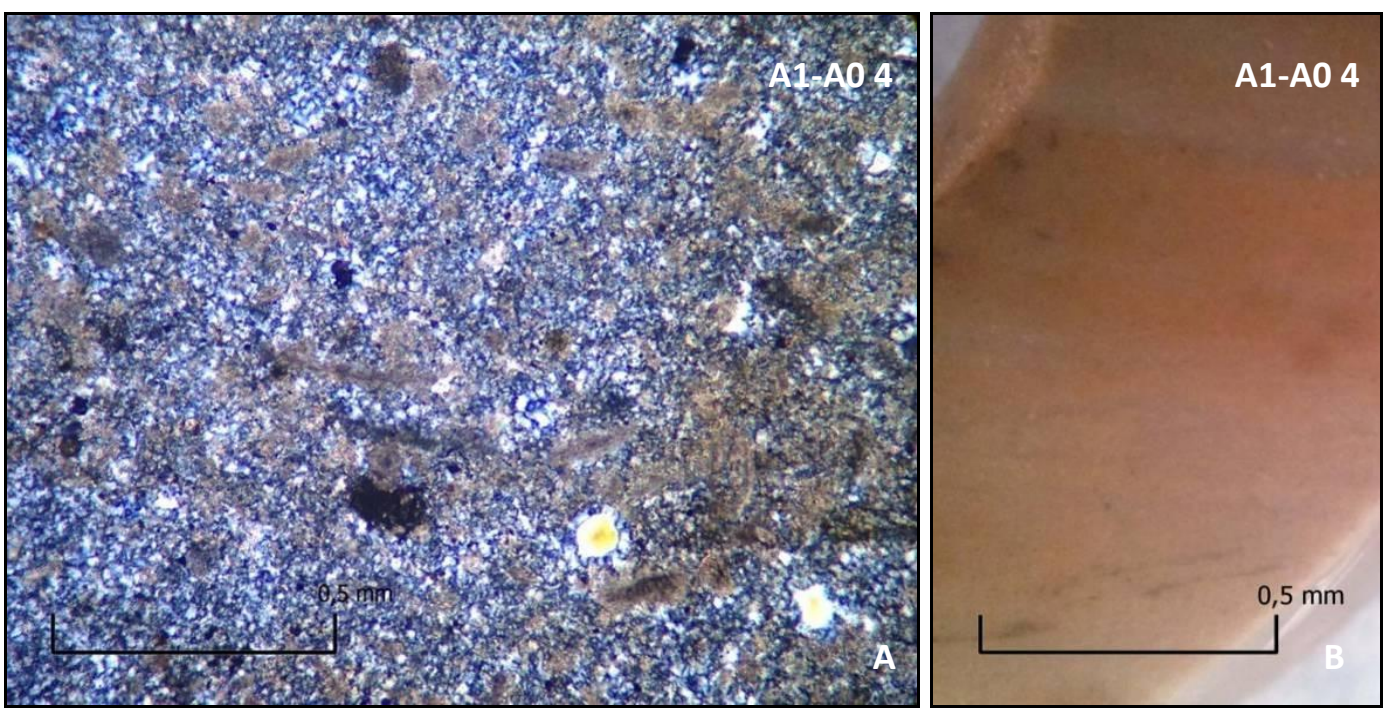

Figura 83. A: Lámina delgada A1-A04. Estructura carbonatada con un posible foraminífero con corona de calcedonia. Foto con LDP x100 aumentos. B: Sílex masivo. Foto con lupa tipo triplete 10X.

.TPÑ28-TL (figura 84): Arenisca compacta con clastos de cuarzo redondeados y subangulares, con mucha variedad de tamaños de granos (hasta $5 \mathrm{~mm}$ ). Algunos granos son policristalinos y los más pequeños de $0,3 \mathrm{~mm}$. Cuarzos con extinción ondulante en abundancia. Presencia de cuarzo monocristalino alterado en los bordes, con cemento enriquecido en óxidos amarillentos.
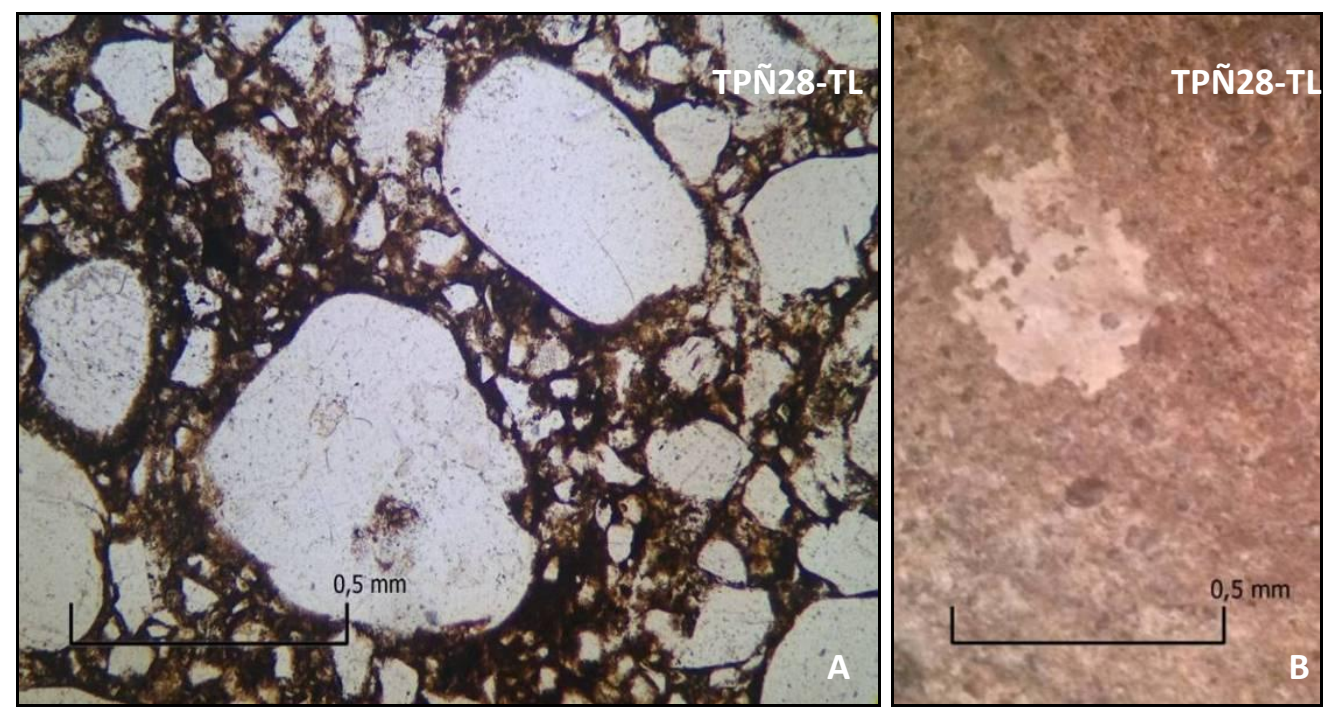

Figura 84. A: Lámina delgada TPÑ28-TL. Clastos de cuarzo redondeados y óxidos de hierro en la matriz. Foto con LDP x100 aumentos. B: Arenisca. Foto con lupa tipo triplete $10 \mathrm{X}$. 
. TPÑ2 (figura 85): Sílex masivo, con gran cantidad de pequeñas inclusiones y algunos radiolarios. Aparecen pequeños puntos de posibles óxidos, alguna presencia de caparazones de radiolarios de color ocre. Hay inclusiones en forma de pellets y otras alargadas negras y opacas, posiblemente agujas de hematites. Posible presencia anecdótica de minerales pesados.
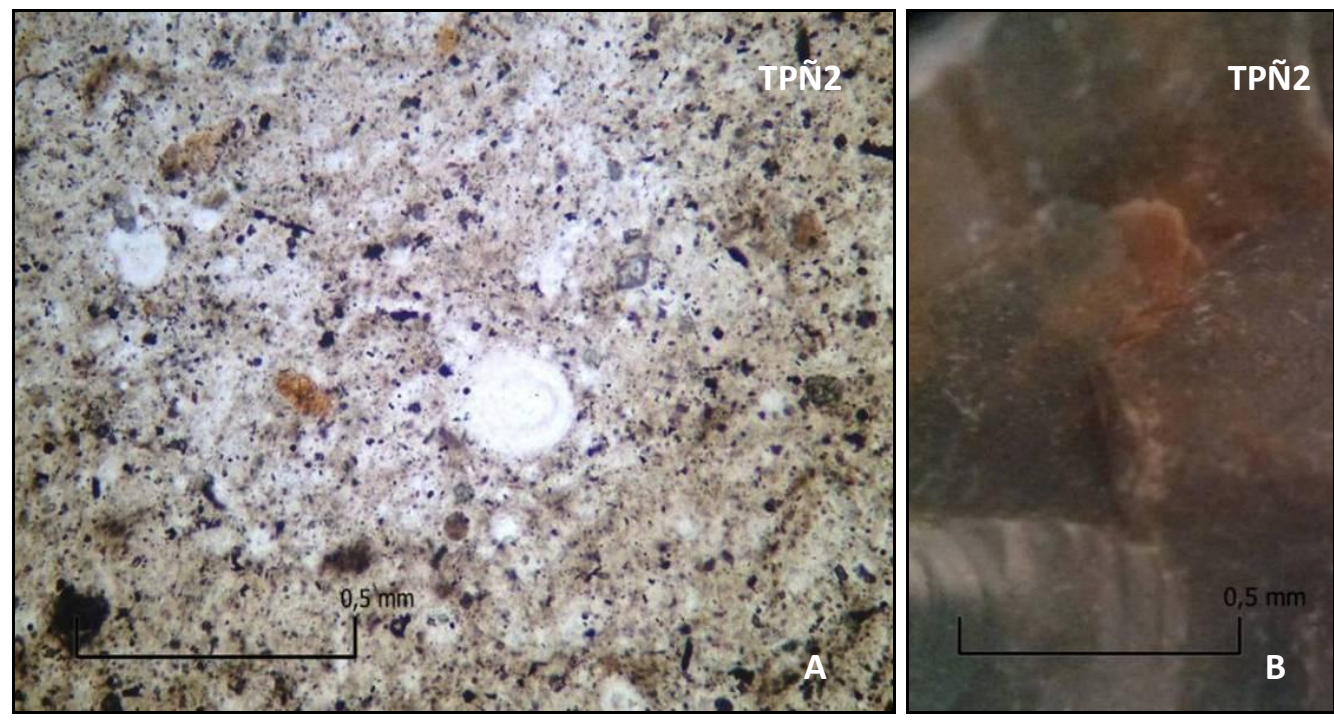

Figura 85. A: Lámina delgada TPÑ2. Inclusiones y puntos negros y radiolario. Foto con LP x100 aumentos. B: Sílex masivo. Foto con lupa tipo triplete 10X.

\subsubsection{Terraza Casilla Vallejo (Teba)}

Coordenadas UTM ETRS89 30 del punto de muestreo:

\begin{tabular}{|c|c|}
\hline $\mathbf{X}$ & $\mathbf{Y}$ \\
\hline 332227 & 4093487 \\
\hline
\end{tabular}

Ubicación y características del afloramiento

La zona de muestreo se localiza en un olivar, a una veintena de metros del cauce actual del río Guadalteba. Es la parte más elevada de una terraza aluvial antigua donde aparecen numerosos cantos y tabletas de sílex de tonalidades diferentes.

Descripción de la unidad geológica

Se trata de una terraza aluvial del Cuaternario, que pertenece a la formación Post-mantos y donde abunda la matriz arcilloso-arenoso. En las terrazas más bajas se localizan cantos centrimétricos a decimétricos. Estas terrazas aluviales aparecen rodeadas por calizas margosas, margo calizas y margas "Capas rojas"del Subbético 
interno y por arcillas, calizas detríticas, areniscas, conglomerados, margas y margas calcáreas de las unidades infranumídicas del Flysch campo de Gibraltar.

Características del sílex

La caracterización de visu muestra presencia de sílex masivo en tonalidades grises oscuros y claros, beige, bandeados, sílex oolítico y radiolaritas.

Caracterización de las láminas delgadas:

- TT3-1 (figura 86): Cuarcita con granos de cuarzo imbricados, sin espacios intergranulares y cuarzo policristalino. Hay silicatos, probablemente micas. El relleno de cuarzo policristalino con posible moscovita o sillimanita. Posible presencia de feldespato potásico, cuarzo cristalino, silicatos y margenes termoalterados.
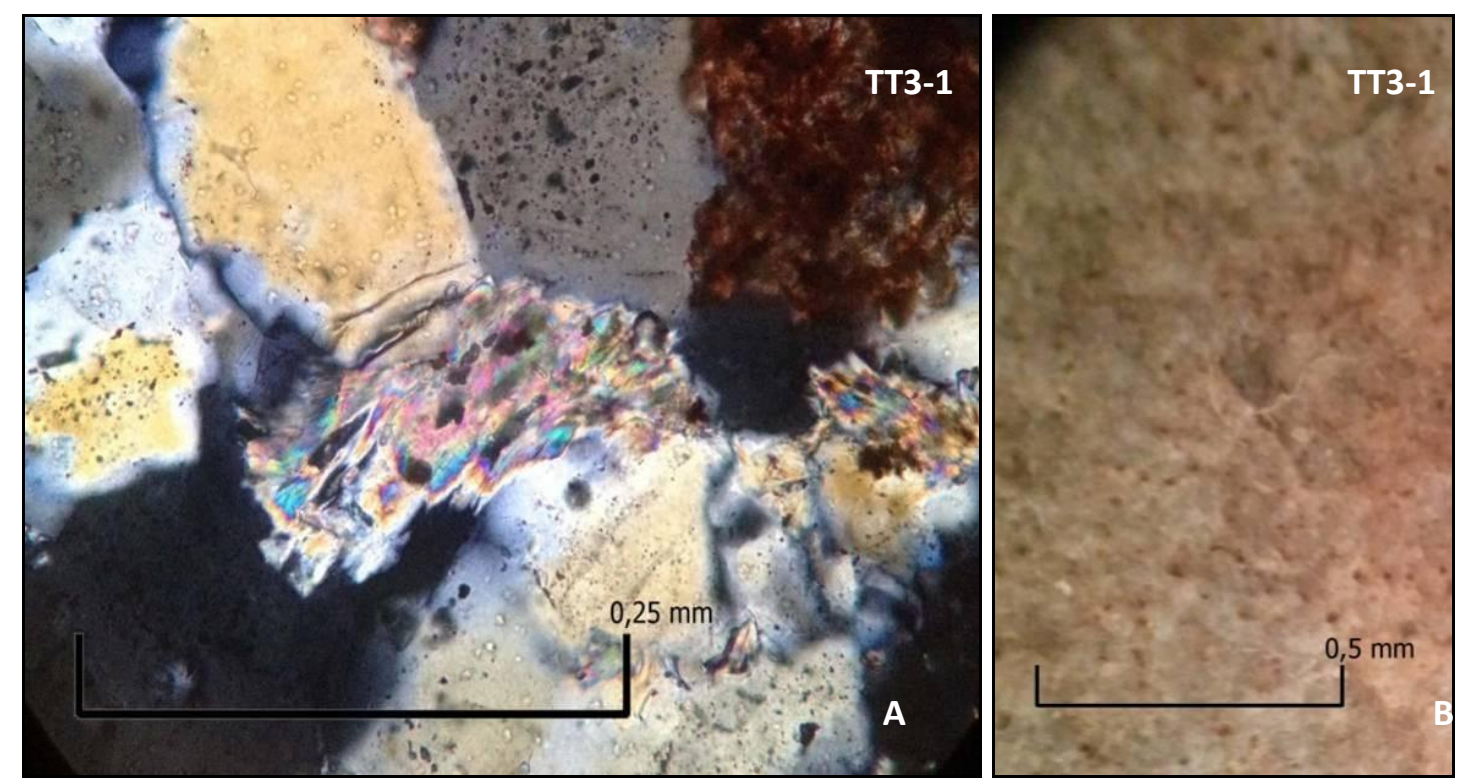

Figura 86. A: Lámina delgada TT3-1. Estructura de relleno de cuarzo policristalino con posible moscovita o sillimanita. Foto con LDP x400 aumentos. B: Cuarcita. Foto con lupa tipo triplete $10 X$.

- TT3-2 (figura 87): Arenisca de grano grueso. Cuarzo monocristalino y policristalino, con cemento de cuarzo. Inclusiones fluidas con cuarzos redondeados y subredondeados. Parte del cemento es calcedonia fibrosa. Presencia de pequeños granos de óxido rodeando los granos de cuarzo. Los contactos entre granos se han realizado por presión y presentan disolución. 

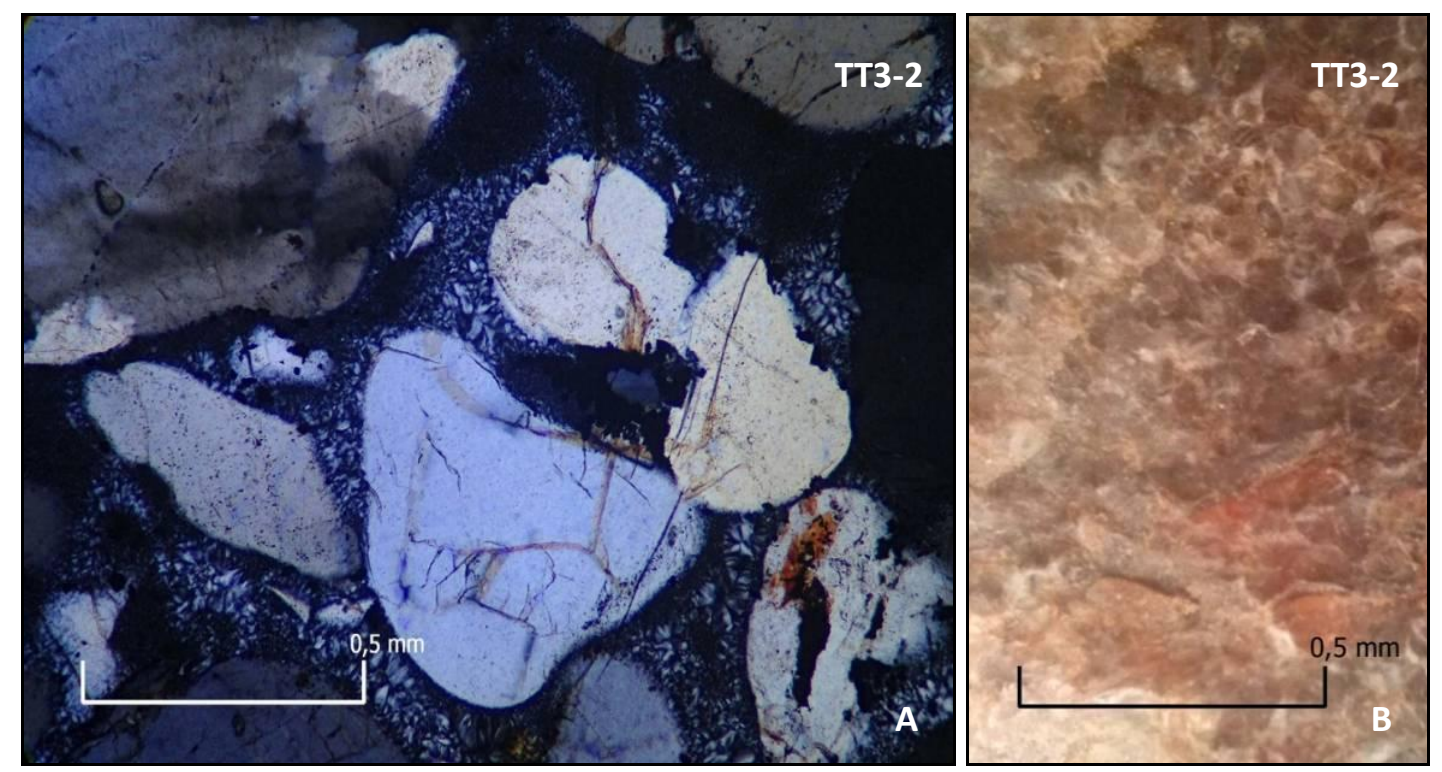

Figura 87. A: Lámina delgada TT3-2. Cuarzos mono y policristalinos y feldespato potásico, con relleno de calcedonia. Foto con LDP x100 aumentos. B: Arenisca. Foto con lupa tipo triplete 10X.

- TT3-3 (figura 88): Arenisca compacta, con cantos redondeados a subangulares, cuarzos monocristalinos y policristalinos, en torno a los $4 \mathrm{~mm}$. El espacio intraporos relleno de calcita esparítica, clastos de cuarzo intercalados con óxidos de hierro. Los clastos presentan bordes que parecen parcialmente disueltos. Cuarzo con inclusiones de circón, redondeado policristalino.
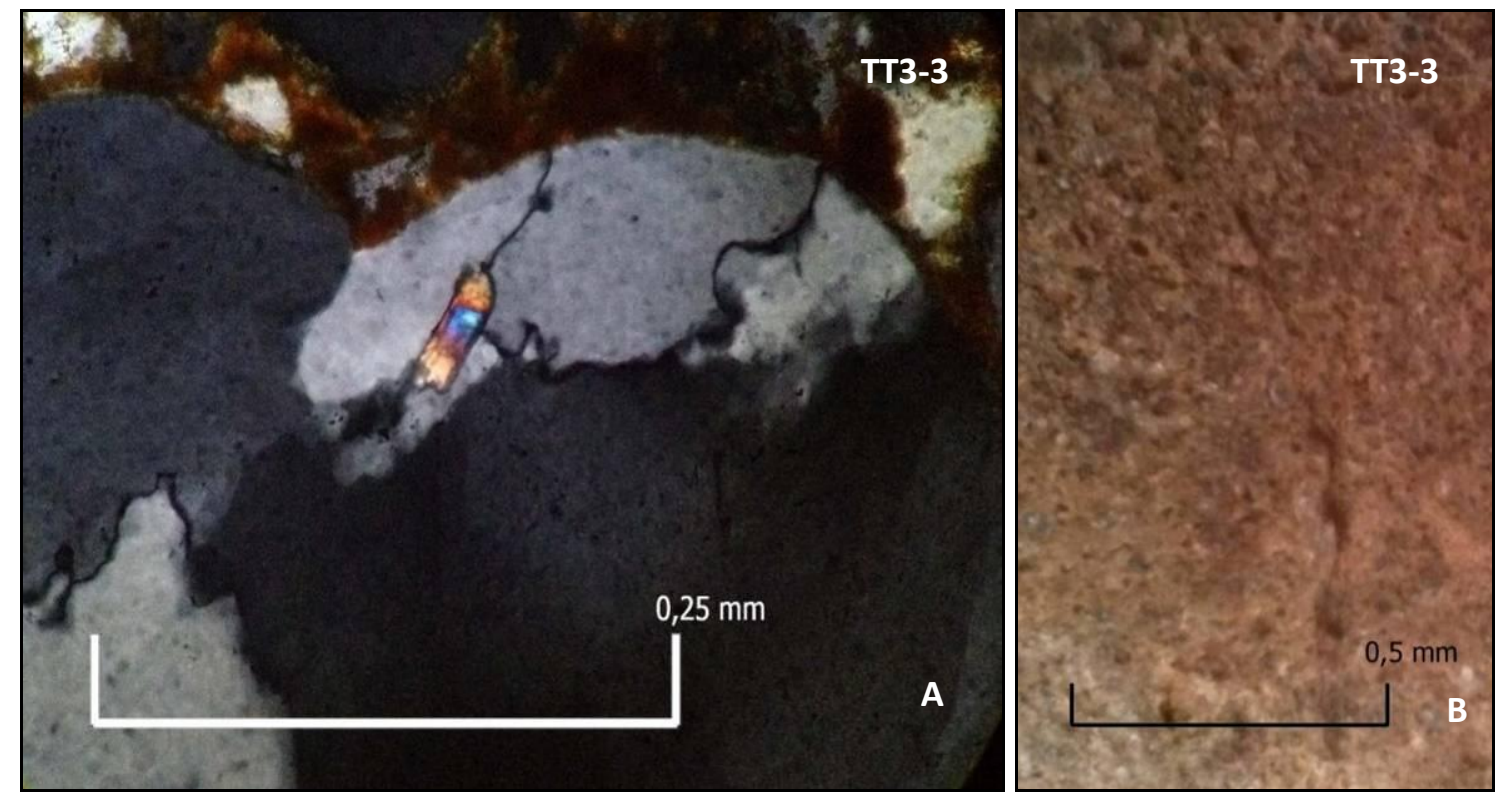

Figura 88. A: Lámina delgada TT3-3. Estructura de cuarzo redondeado policristalino con inclusiones de circón. Foto con LDP x400 aumentos. B: Arenisca. Foto con lupa tipo triplete $10 \mathrm{X}$. 


\subsection{Los yacimientos}

Se han estudiado un total de 15 yacimientos en ambas cuencas, algunos asociados a terrazas fluviales, otros a depósitos antiguos y dos de ellos en cuevas.

\subsubsection{Cuenca del Turón.}

En la cuenca del Turón se han estudiado 10 yacimientos arqueológicos con industrias asociados al Paleolítico inferior, medio y superior. Aunque no se han encontrado, por el momento, nuevos hallazgos arqueológicos, si se ha localizado un depósito cuaternario con materiales arqueológicos, dentro de la estratigrafía, asociados al Paleolítico medio. Ha sido muy importante la revisión de materiales arqueológicos de los yacimientos localizados en los márgenes del río Turón y que están depositados en el Centro de Interpretación de la Prehistoria de Ardales, pues ha permitido un nuevo encuadre cronológico de algunos de estos materiales adscritos a la Prehistoria reciente.

Los yacimientos presentan en su mayoría una vinculación estrecha con la red fluvial, dado que se encuentran situados a escasos metros de la misma. Si comparamos los mapas topográficos antiguos, como el de la figura 89, con el estado actual del río Turón, convertido en embalse, vemos que algunos de los yacimientos estudiados en esta tesis se encuentran, en parte, bajo las aguas del embalse del conde del Guadalhorce, siendo visibles en épocas de descenso del nivel del pantano. Sin embargo, el contar con estos mapas topográficos antiguos nos permite comprender mejor la ubicación de cada uno de estos yacimientos y como se articulan dentro del territorio.

En los siguientes apartados nos centraremos en las características de cada uno de ellos. Los yacimientos que analizaremos son: Cueva de Ardales, Cucarra, depósito Hoyos de Barbú, terraza arroyo Cantarranas, depósito del Hundilón, terraza Morenito, Llanos de Belén, terraza de Las Grajeras, Raja del Boquerón y Lomas del Infierno. 


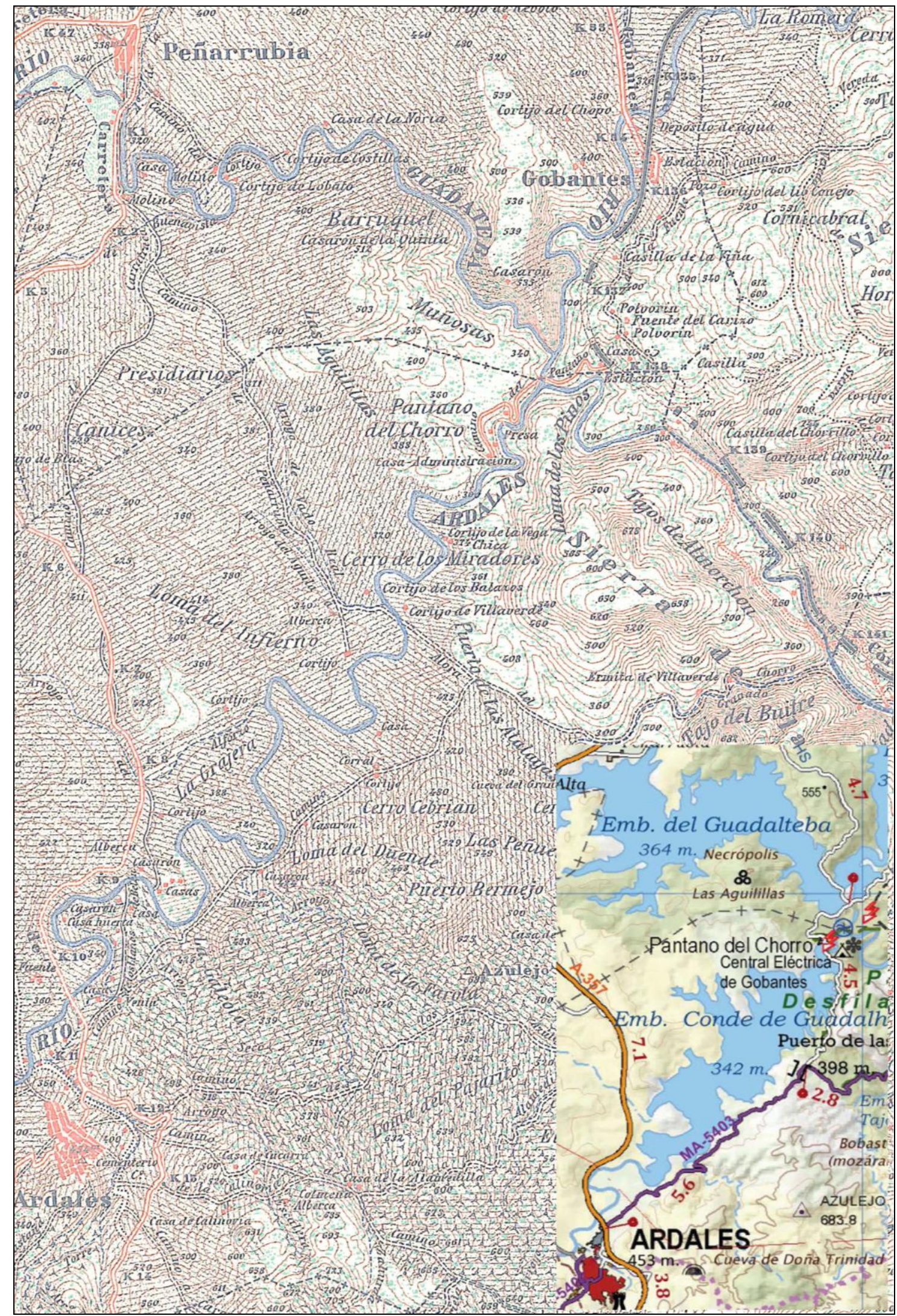

Figura 89. Mapa Topográfico Nacional de 1911-1920, con la cuenca original del río Turón.

Escala 1:50.000 (MTN50) y embalse del Guadalhorce en la actualidad. 


\subsubsection{Cueva de Ardales}

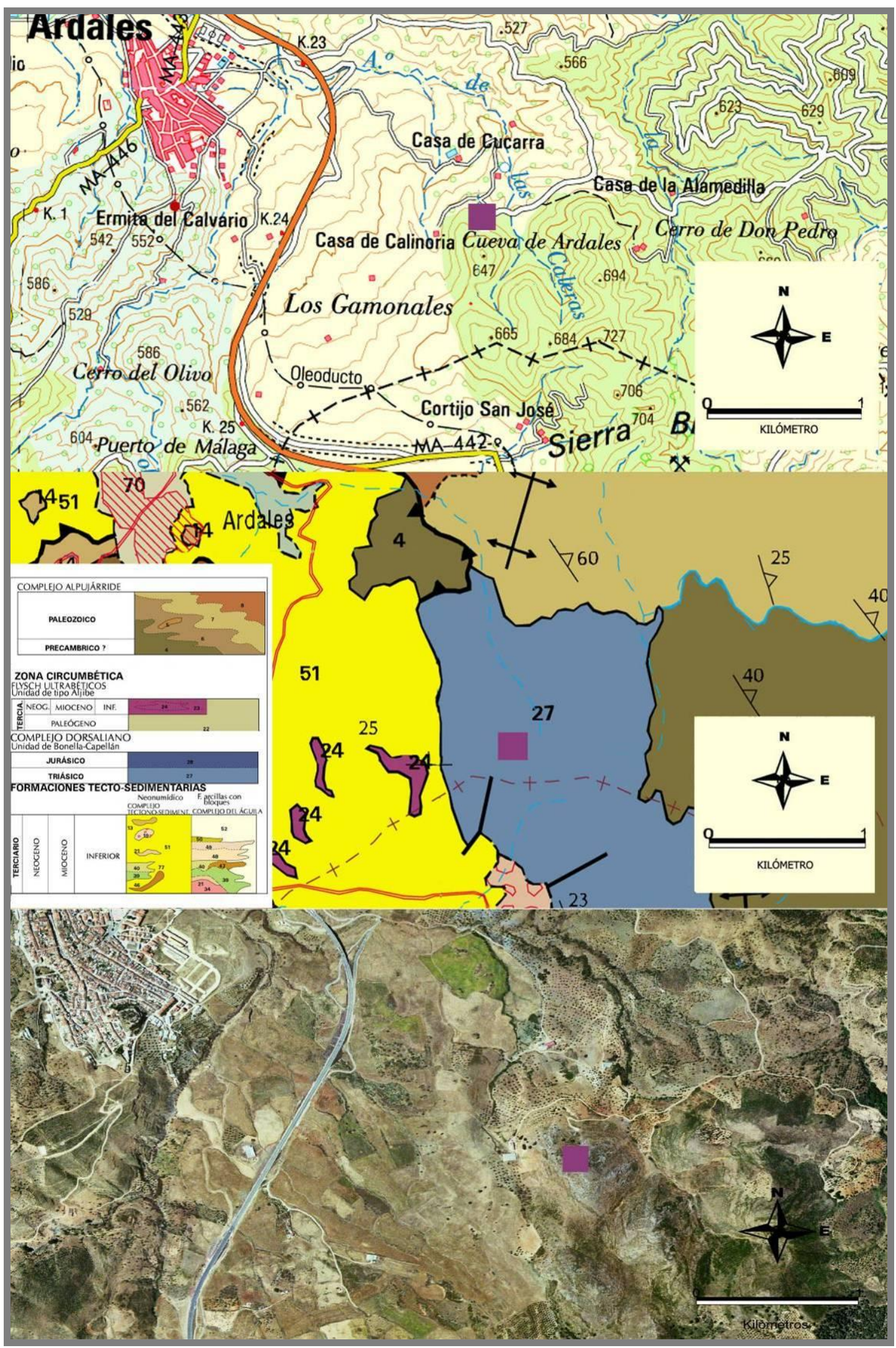


La Cueva de Ardales está situada en el cerro de la Calinoria. Es una cavidad con un recorrido completo de $1.577 \mathrm{~m}$ y con una distancia horizontal y proyectada en planta de $1.394 \mathrm{~m}$. Se accede desde la localidad de Ardales por la carretera A-357, desde donde se coge la carretera local de subida a la cueva.

Las coordenadas UTM ETRS89 30 son:

\begin{tabular}{|c|c|}
\hline $\mathbf{X}$ & $\mathbf{Y}$ \\
\hline 337110 & 4082540 \\
\hline
\end{tabular}

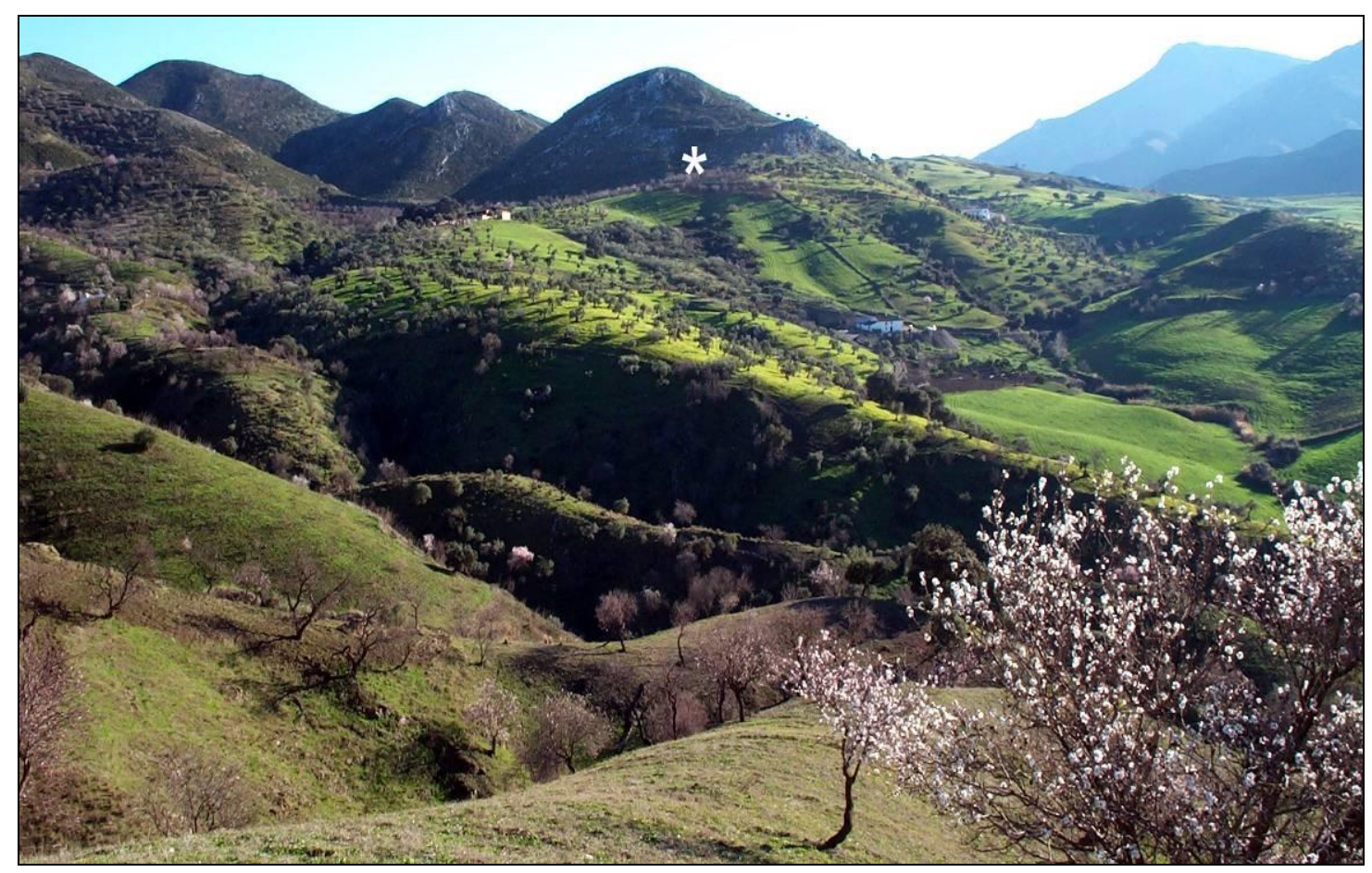

Figura 90. Situación Cueva de Ardales.

Altitud m s.n.m.: $646 \mathrm{~m}$

Extensión: 123.992,42 $\mathrm{m}^{2}$

. Contexto geológico y geomorfológico

A nivel geológico la cavidad se desarrolla en materiales pertenecientes a las Zonas Internas de las Cordilleras Béticas, estando muy cerca del límite de la Zona Externa (Durán Valsero et al., 2014: 27). Se sitúa dentro del afloramiento de materiales carbonáticos que se localiza entre las localidades de Ardales y Carratraca (la Serrezuela), encuadrándose en la Unidad de Yunquera, dentro del complejo Alpujárride. Estos materiales alpujárrides están constituidos por dolomías, calizas-dolomíticas e intercalaciones de rocas metapelíticas que aparecen en algunos puntos del interior de la cavidad (Durán Valsero et al., 2014: 27). 
. Relación con red fluvial

El cerro de la Calinoria es una divisoria hidrográfica, con un drenaje centrífugo de aguas superficiales, el cual vierte sus aguas directamente al río Turón por el norte y oeste, al arroyo de las Cañas por el sur y por el este al río Guadalhorce (Durán Valsero et al., 2014: 27).

. Procesos sedimentarios y procesos postdeposicionales

La sala de entrada se rellenó en parte con los sedimentos de un cono aluvial y presenta diferentes ambientes deposicionales, que dan lugar a varias capas separadas por costras de carbonatos intercalados y/o fuertes cambios verticales en la composición granulométrica (Kehl, 2014: 59). Algo similar ocurre en la zona alta, conocida como Galerías Altas, donde los accesos primitivos se colmataron con sedimentos hasta su taponamiento final, posiblemente durante la segunda mitad del Pleistoceno medio, como demuestra la microfauna existente en los sedimentos detríticos de la Sala del Lago que representa un ambiente cálido (Durán Valsero et al., 2014: 32)

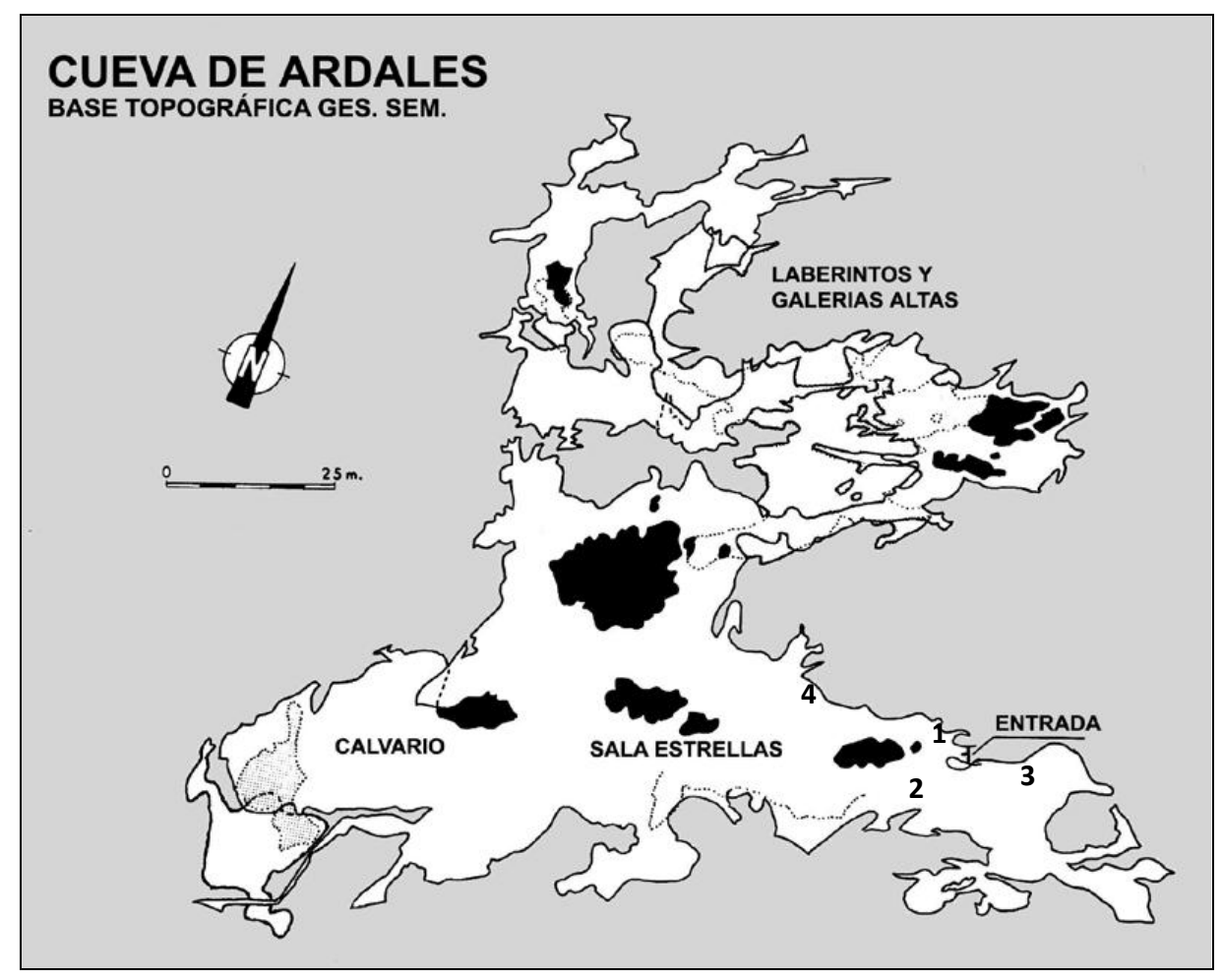

Figura 91.Cueva de Ardales. Zonas de sondeos arqueológicos (Ramos Muñoz et al., 2014: 40). 
Los procesos postdeposicionales observados en la cueva representan ambientes diferentes. Las zonas más cercanas al cono de entrada muestran una removilización del sedimento originado por la entrada de agua en el interior de la cueva, así como por la bioturbación, con presencias de madrigueras y canales. Además hay que tener presente la acción antrópica donde el pisoteo en algunas zonas de los sondeos de la zona 4 o zona 3 provocaron una compactación del sedimento. Junto a esto es importante mencionar una alteración postdeposicional muy fuerte a principios del siglo XIX, cuando se desmontó parte del cono de sedimentos de la entrada para construir unas escaleras de acceso a la cueva.

\section{. Interpretación geoarqueológica}

Los materiales arqueológicos se encuentran en su mayor parte en la zona de la entrada y han sido localizados en su mayoría dentro de los sedimentos del cono aluvial que rellenó la entrada de la cueva, separadas por costras carbonatadas. La industria lítica recuperada presenta unos filos poco rodados.

\section{. Análisis de la industria lítica}

El estudio sobre el material lítico que aquí presentamos se realiza sobre el material recogido en el marco de los sondeos realizados en las intervenciones puntuales de los años 2011-2012 que se encuentran en el Centro de Interpretación de la Prehistoria de Ardales. Así mismo, se han analizado dos piezas localizadas con anterioridad a dichas intervenciones, pero que resultan de interés para nuestro estudio.

Los materiales estudiados son 6 piezas, correspondientes a momentos del Paleolítico superior y una lasca levallois Musteriense. El resto de material lítico analizado se encuadra en momentos neolíticos y por tanto fuera de este trabajo. Los resultados estratigráficos obtenidos de las costras calcáreas que contenían industria lítica indican, hasta el momento, una cronología asociada al Paleolítico superior.

La materia prima es de naturaleza silícea, con ejemplares de sílex masivos beige o gris y un ejemplar en sílex poroso beige. Tan sólo aparece un ejemplar con pátina.

En cuanto al estudio morfotécnico se documentan Bases Positivas (BP) y Bases Negativas de Segunda Generación (BN2G).

Las BP (tabla 4) corresponden a 2 ejemplares del sondeo del sector 2 y 1 ejemplar del sector 5, este último en superficie. La primera es una lasca levallois en sílex gris, poco rodada, que tipométricamente corresponde a una microlasca laminar. 
Presenta la cara ventral recta, con volumen LP (largo plano) y talón liso cortical. El segundo ejemplar es una lámina-hoja en sílex gris, poco rodada, que tipométricamente corresponde a una microlaminilla estrecha. La cara ventral es recta con un volumen LP (largo plano) y talón liso puntiforme. La lasca levallois en sílex beige está poco rodada, con un volumen espeso plano, un bulbo marcado y un talón facetado cóncavo.

\begin{tabular}{|c|c|c|c|c|c|c|c|c|c|c|c|c|c|c|c|c|c|c|c|c|c|}
\hline \multicolumn{22}{|c|}{ YACIMIENTOS ARDALES. ESTUDIO ANALÍTICO DE LAS BP } \\
\hline \multirow{2}{*}{ Nombre } & \multicolumn{5}{|c|}{ Materias primas y morfología } & \multicolumn{2}{|c|}{ Tipos de bases positivas } & \multicolumn{4}{|c|}{ Dimensiones } & \multicolumn{10}{|c|}{ Criterios analíticos de las BP } \\
\hline & M & R & c & $\mathrm{P}$ & $T$ & LASS/LAM & TIPO & A & E & TB & \begin{tabular}{l|l} 
TB & VOL \\
\end{tabular} & CARA & VENTRA & & CARA TA & LLNAR & & & CARADC & ORSAL & \\
\hline Cueva de Ardales & & & & & & & & & & & & $\mathrm{F}$ & $B$ & TIPO & \begin{tabular}{|l|l|} 
COR & $S$ \\
\end{tabular} & $T$ & $D$ & COR & SSAG & STR & A \\
\hline AD-2-11-1137 & s & p & G & NO & NO & LASCA & L & 2,2 & 1 & 0,3 & $16 \mathrm{LP}$ & RT & D & c & NOCO PUN & UF & RT & NOCO & TRP & TRP & SI \\
\hline AD-2-11-1334 & s & p & G & NO & NO & LÁMINA & H & 3,5 & 0,9 & 0,2 & $7 \mathrm{LP}$ & RT & D & $p$ & NOCO PUN & UF & RT & NOCO & TRP & TRP & Sl \\
\hline AD15-55-1 & s & $p$ & B & NO & NO & LASCA & L & 6,4 & 7,1 & 1,2 & 21 EP & CC & M & $\mathrm{fcc}$ & NOCO PLA & MF & CC & NOCO & TRP & TRP & $\mathrm{SI}$ \\
\hline
\end{tabular}

Tabla 4. Estudio analítico de las BP de Cueva de Ardales.

Para las BN2G (tabla 5) utilizamos la nomenclatura del sistema tipológico de Laplace (Laplace, 1972) y los de la Lista-Tipo Bordes (Bordes, 1961). Se documenta un ejemplar de buril realizado sobre una lasca de sílex gris con pátina blanca. Tiene un volumen de tipo LP (largo plano), la delineación del talón desde la cara ventral es cóncava, sin bulbo y no cortical. La cara dorsal es no cortical. El retoque es profundo, inverso y continuo en el lateral izquierdo, mientras que en el lado derecho es plano, inverso y continuo. Se trataría de un buril de paño lateral según Laplace (B31) y un buril según Bordes (32).

Aparece un raspador frontal simple según Laplace (G11) o raspador típico según Bordes (30) y una hoja de laurel o foliáceo según Laplace (F3) o una punta foliácea bifacial según Bordes (63) con una fractura proximal.

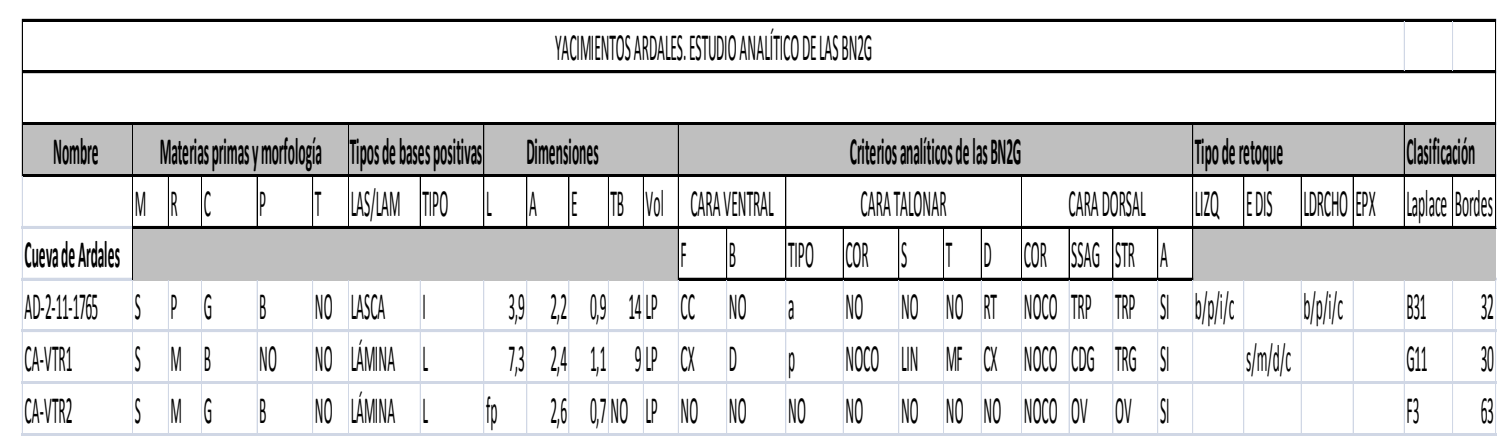

Tabla 5. Estudio analítico de las BN2G de Cueva de Ardales. 
- Valoración y conclusiones

Los resultados obtenidos de las diferentes actuaciones en la Cueva de Ardales y el estudio del material arqueológico certifican la ocupación de la cueva desde el Pleistoceno medio hasta el Holoceno. La localización de industria lítica bajo las costras calcáreas del cono de depósitos de la entrada de la cueva favoreció su protección y la posibilidad de estar en contexto estratigráfico y por tanto datable. Estas costras a su vez han evitado procesos postdeposicionales de origen antrópico al quedar totalmente sellados los sedimentos y el material arqueológico en su interior.

Los procesos postdeposicionales, tanto naturales como antrópicos que afectaron a la cavidad han ocasionado en la zona de acceso actual la mezcla de materiales arqueológicos. Los procesos naturales corresponden principalmente a la entrada de sedimentos en la cueva sobre todo arcillosos, desde el exterior y a la bioturbación. La actividad antrópica se produjo en época moderna con la construcción de unas escaleras a principios del siglo XIX, cuando la cueva es comprada por $\mathrm{D}^{\mathrm{a}}$. Trinidad Grund (Espejo Herrerías et al., 1988).

En cuanto a la tecnología, hay presencia de una lasca y una lámina, ambas de pequeño tamaño. Dentro del grupo de los productos retocados o BN2G nos encontramos con un ejemplar correspondiente a un buril realizado sobre una lasca interna.

La muestra arqueológica analizada es escasa, en comparación con otros yacimientos. Esto se debe principalmente a que nunca se han acometido excavaciones en el interior de la cueva, realizándose únicamente pequeños sondeos y microactuaciones. Las próximas intervenciones arqueológicas que se desarrollarán en el marco del Proyecto General de Investigaciones ampliarán los datos disponibles hasta el momento.

Destacamos la escasa presencia sílex pardos o negruzcos denominados de tipo Turón muy abundantes en zonas cercanas a la Cueva de Ardales y de los cuales hay evidencias de su explotación prehistórica en afloramientos próximos, como La Galeota.

Las dataciones de las 3 costras calcáreas del cono de entrada evidencian cronologías asociadas a momentos pleistocenos y holocenos. Para el Pleistoceno la

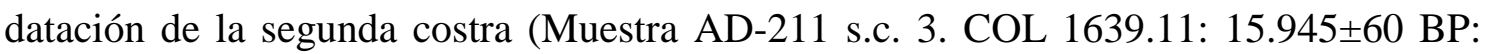
19.030 calBP) establece una correlación con el Paleolítico superior y aparece asociada a industria lítica y a restos antropológicos de Homo sapiens. Las dataciones de varios carbones localizados en la tercera costra (Muestra AD-3-11-22. COL16343.1.1: 51.914 \pm 2.324 BP, 54.760 \pm 3.540 cal BP, MuestraAD-3-11-200.COL1644.1.1R: 
$53.071 \pm 2.676,54.950 \pm 3.510$ cal BP), la más baja, indican una cronología de Pleistoceno superior medio, aunque la datación de un hueso de Felix silvestris del mismo perfil ofrece una cronología más reciente (Muestra AD-3-2252. COL2011.1.1: $5562 \pm 48$ BP). Por tanto, las nuevas intervenciones arqueológicas son imprescindibles para corroborar las dataciones y la posibilidad de una ocupación humana de la cavidad durante el Paleolítico medio y su relación con Cucarra, un yacimiento ubicado en el exterior de la cavidad y con industria lítica del Paleolítico medio o modo III.

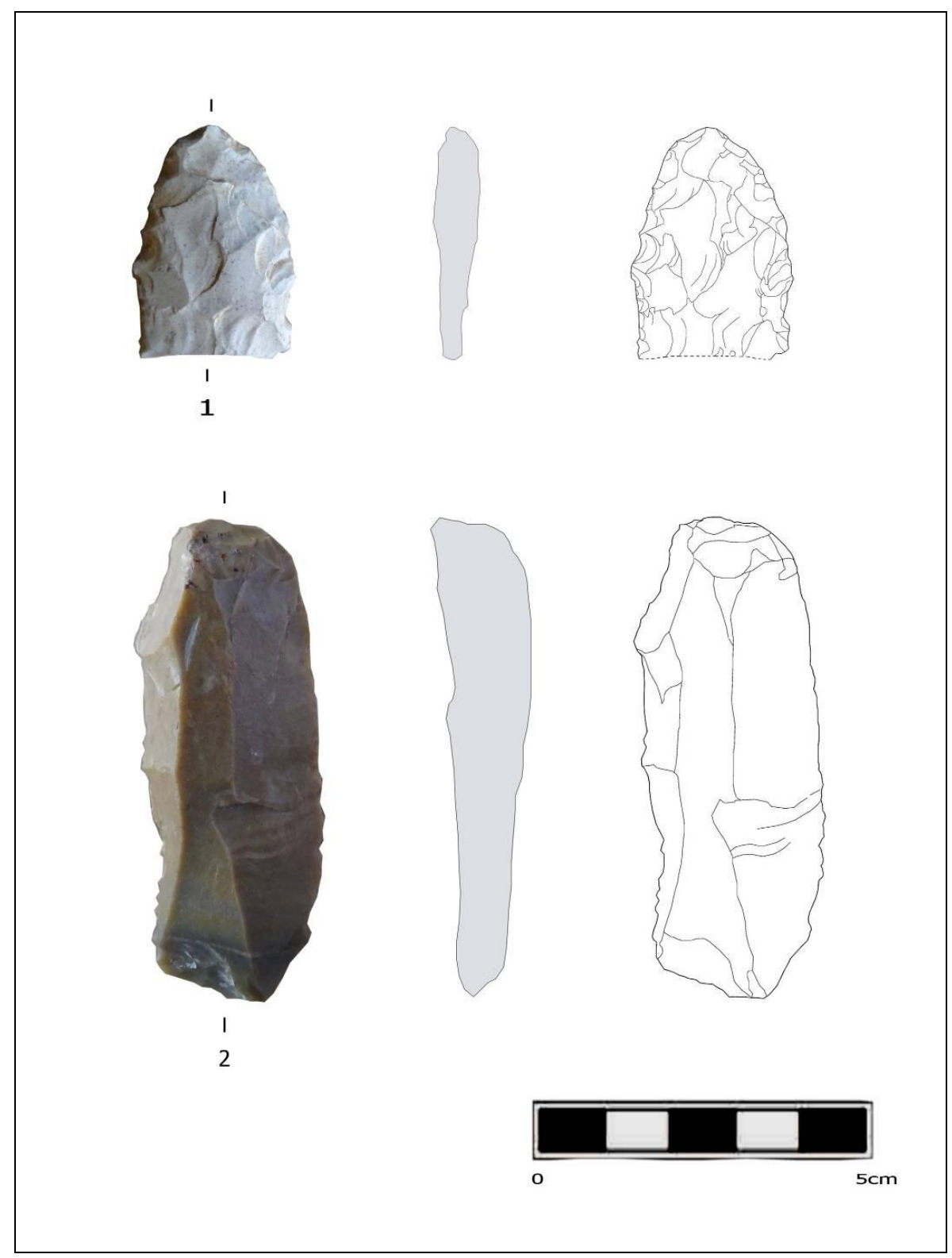

Figura 92. Cueva de Ardales (Ardales): 1: BN2G-Foliaceo; 2: BN2G-Raspador simple. 


\subsubsection{Cucarra (Ardales)}

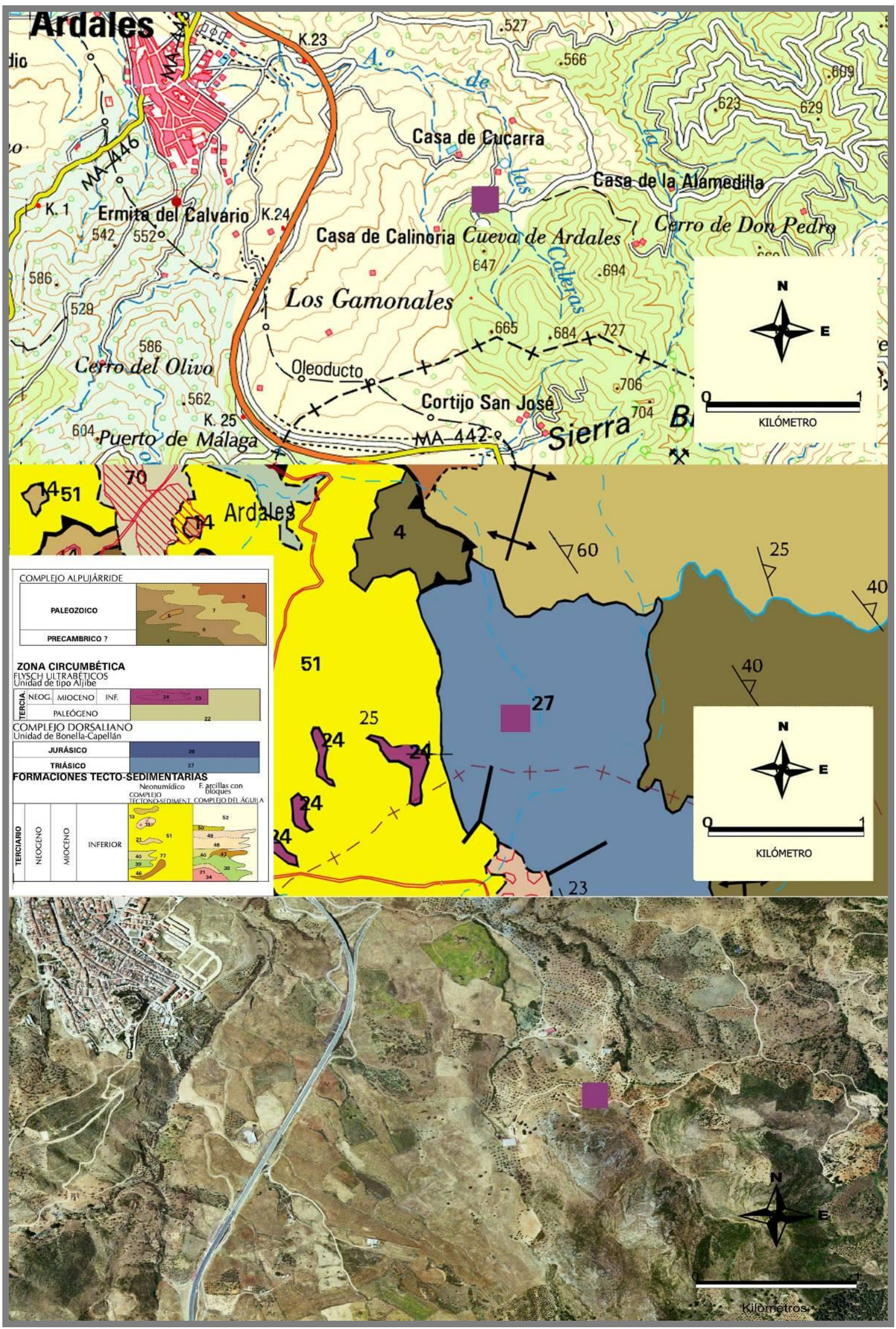


El yacimiento está ubicado en una ladera junto a la Cueva de Ardales. Se accede cruzando la carretera A-357 desde la localidad de Ardales en dirección a la Cueva de Ardales, por un camino de tierra.

Las coordenadas UTM ETRS89 30 se establecen en base al polígono de máxima protección, ya que se encuentra dentro de la delimitación de la Cueva de Ardales como BIC

\begin{tabular}{|c|c|}
\hline $\mathbf{X}$ & $\mathbf{Y}$ \\
\hline 337200 & 4082691 \\
\hline 337338 & 4082657 \\
\hline 337319 & 4082593 \\
\hline 337242 & 4082569 \\
\hline 337314 & 4082624 \\
\hline
\end{tabular}

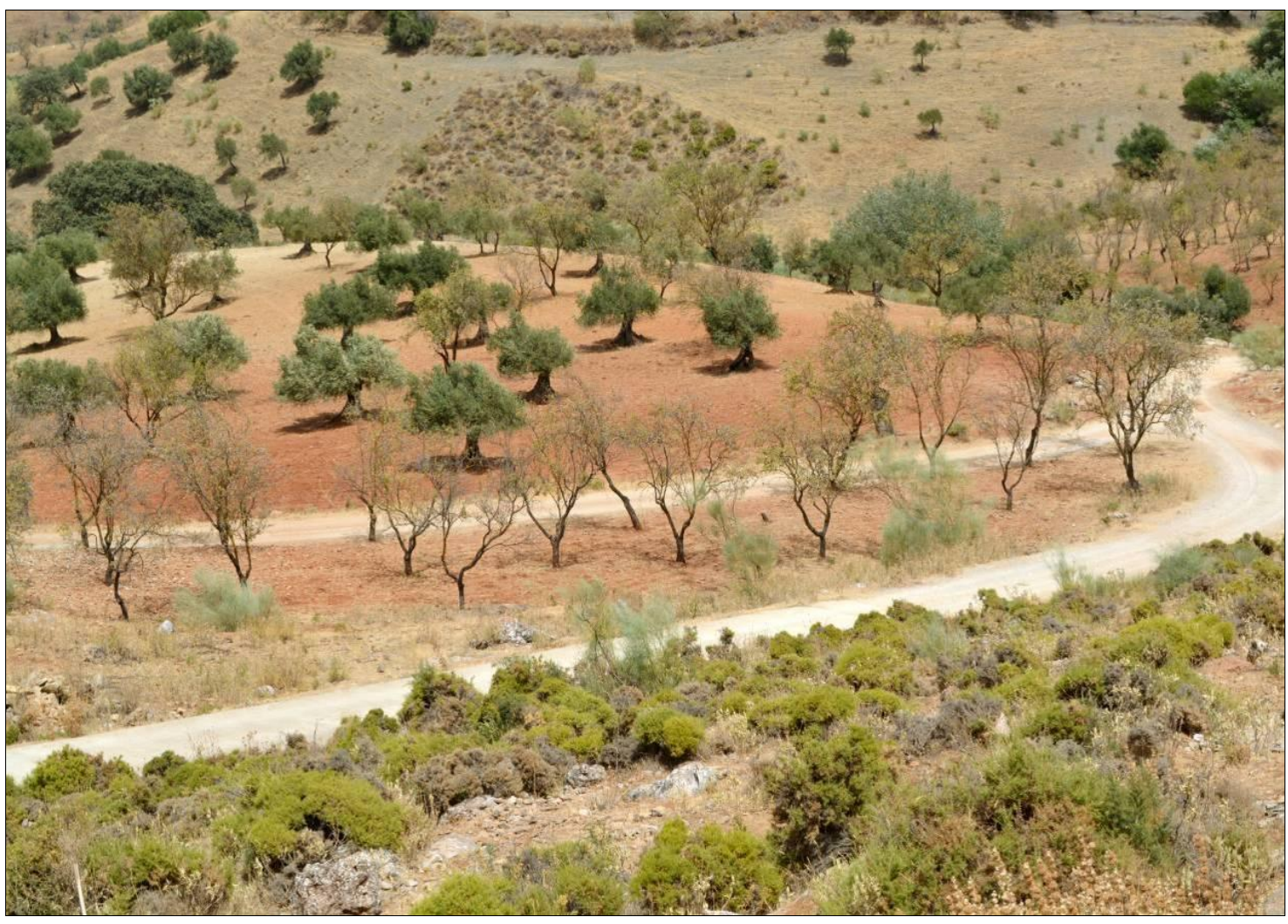

Figura 93. Vista general de Cucarra.

Altitud m s.n.m.: $550 \mathrm{~m}$

Extension: $14.540,91 \mathrm{~m}^{2}$

. Contexto geológico y geomorfológico

Presenta el mismo contexto geológico y geomorfológico de la Cueva de Ardales ya que está a escasos metros. La zona donde se localiza el yacimiento presenta materiales pertenecientes a las Zonas Internas de las Cordilleras Béticas, estando muy 
cerca del límite de la Zona Externa. Se sitúa dentro del afloramiento de materiales carbonáticos que se localiza entre las localidades de Ardales y Carratraca (la Serrezuela), encuadrándose en la Unidad de Yunquera, dentro del Complejo Alpujárride, con presencia de dolomías y calizas-dolomíticas.

. Procesos sedimentarios y procesos postdeposicionales

Al tratarse de un yacimiento en superficie y sobre una ladera bajo el sistema calizo del cerro de la Calinoria, los procesos sedimentarios corresponden principalmente a la escorrentía superficial y a desplazamientos de sedimentos de las zonas más altas. En cuanto a los procesos postdeposicionales, estos son principalmente los de gravedadvertientes y los de origen antrópico ocasionados por el arado que remueve el material arqueológico.

\section{. Interpretación geoarqueológica}

Es un yacimiento arqueológico que tiene como origen un abandono antrópico de los materiales líticos sobre la superficie siendo incorporados por los desplazamientos verticales y horizontales a los depósitos arcillosos sobre parte de la ladera situada bajo la entrada de la Cueva de Ardales. En la actualidad la superficie ha sido transformada por el arado y la plantación de almendros y olivos generando una removilización de los materiales arqueológicos, visible sobre todo en el nivel de rodamiento de los materiales arqueológicos.

\section{. Análisis de la industria lítica}

El estudio lítico que presentamos se realiza sobre el material recogido durante las prospecciones de los años 80 y los muestreos geoarqueológicos llevados a cabo en el marco de las intervenciones arqueológicas entre 2011-2014 y que se encuentran en la actualidad en el Centro de Interpretación de la Prehistoria de Ardales. Corresponden a un total de 51 piezas que han sido seleccionadas en función de varios caracteres, tales como la pátina y el rodamiento principalmente. Mientras se realizó la selección de las piezas se observó como en algunas de ellas existían retoques modernos, que afectaban a las pátinas y que indicaba una reutilización posterior.

La materia prima (figura 94) predominante es el sílex masivo gris o beige con pátina amarillenta o blanca y algunos ejemplares de sílex poroso de tonalidades grises y 
con pátinas amarillentas y blancas, 5 ejemplares de radiolarita y 2 cuarcitas, 1 roja y otra blanca.

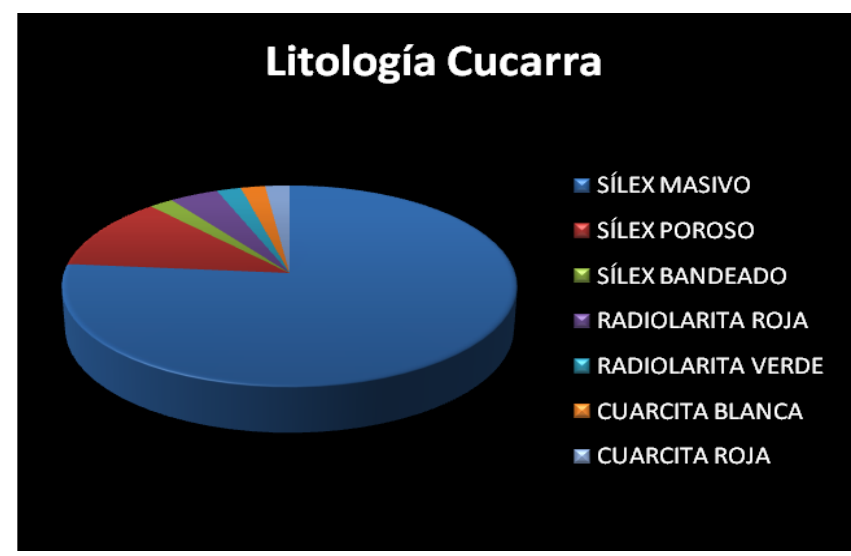

Figura 94. Materias primas de las piezas líticas recuperadas en el yacimiento de Cucarra.

En relación al estudio morfotécnico, se documentan Bases Negativas de Primera Generación (BN1G), Bases Positivas (BP) y Bases Negativas de Segunda Generación (BN2G).

Las BN1G (tabla 6) corresponden a 12 ejemplares entre los que destaca la presencia mayoritaria de núcleos con explotación centrípeta, con 10 ejemplares de sílex masivo gris/negro de tipo Turón. Con un carácter facial de tipo unifacial y con un carácter centrípeto casi completo de tipo 4C en 10 ejemplares y $3 \mathrm{C}$ en 2 , las extracciones son variadas y están presentes las de tipo plano, simple, semiabrupto y abrupto. El carácter de profundidad es total en la mayoría, salvo en un ejemplar que es muy profundo y en otro profundo. La arista frontal es convexa mientras que la sagital es sinuosa.

\begin{tabular}{|c|c|c|c|c|c|c|c|c|c|c|c|c|c|c|}
\hline \multicolumn{15}{|c|}{ YACIMIENTOS ARDALES. ESTUDIO ANALÍTICO DE LAS BN1G } \\
\hline \multirow{2}{*}{\begin{tabular}{|l|}
\multicolumn{1}{|c|}{ Nombre } \\
Cucarra \\
\end{tabular}} & \multicolumn{5}{|c|}{ Materias primas y morfología } & \multicolumn{2}{|c|}{ Tipos de bases negativas } & \multicolumn{6}{|c|}{ Criterios analíticos de las BN1G } & \multirow[t]{2}{*}{ Tema operativo técnicc } \\
\hline & M & $\mathrm{R}$ & C & $\mathrm{P}$ & $T$ & TN & BN & CF & CC & $\mathrm{CO}$ & CP & CAF & CAS & \\
\hline CU-S-47 & $S$ & M & G & A & NO & C & BN1GE & $U$ & $4 \mathrm{C}$ & $\mathrm{S}$ & $\mathrm{t}$ & $\mathrm{CX}$ & $\sin$ & T.O.T.I \\
\hline CU-S-76 & $S$ & M & G & 0 & NO & C & BN1GE & $\mathrm{U}$ & $3 C$ & SA/A & $\mathrm{mp}$ & $\mathrm{CX}$ & $\sin$ & T.O.T.I \\
\hline CU-S-112 & S & M & G & B & NO & C & BN1GE & $U$ & $4 C$ & $\mathrm{~A} / \mathrm{SA}$ & $\mathrm{t}$ & $C X$ & $\sin$ & T.O.T.I \\
\hline CU-S-179 & S & M & B & B & NO & C & BN1GE & $U$ & $4 C$ & S & $\mathrm{t}$ & $C X$ & $\sin$ & T.O.T.I \\
\hline CU-S-187 & $S$ & M & B & A & NO & POL & BN1GE & B & $4 C$ & SA/A & $\mathrm{t}$ & $C X$ & $\sin$ & T.O.T.I \\
\hline CU-S-221 & $S$ & M & G & B & NO & $U$ & BN1GE & $U$ & $3 C$ & $S$ & $p$ & $C X$ & $\sin$ & T.O.T.I \\
\hline CERRO CALINORIA & $S$ & M & G & 0 & NO & C & BN1GE & $U$ & $4 C$ & $\mathrm{SA} / \mathrm{S}$ & $\mathrm{t}$ & $\mathrm{CX}$ & $\sin$ & T.O.T.I \\
\hline CU-S-TL1 & $S$ & M & G & B & NO & C & BN1GE & B & $4 C$ & $A / P$ & $\mathrm{t}$ & $C X$ & $\sin$ & T.O.T.I \\
\hline CU-S-TL2 & S & M & G & A & NO & C & BN1GE & B & $4 C$ & $S / P$ & $\mathrm{t}$ & $C X$ & $\sin$ & T.O.T.I \\
\hline CU-S-TL3 & $S$ & M & G & A & NO & C & BN1GE & B & $4 C$ & $S / A$ & $t$ & $C X$ & $\sin$ & T.O.T.I \\
\hline CU-S-TL4 & $S$ & $M$ & G & B & NO & C & BN1GE & $\mathrm{T}$ & $4 C$ & $A / P$ & $t$ & $C X$ & $\sin$ & T.O.T.I \\
\hline CU-S-TL5 & $\mathrm{R}$ & $\mathrm{M}$ & $\mathrm{R}$ & 0 & SI & C & BN1GE & B & 4C & S/SA & $\mathrm{t}$ & $C X$ & $\sin$ & T.O.T.I \\
\hline
\end{tabular}

Tabla 6. Estudio analítico de las BN1G de Cucarra. 
Las BP (tabla 7) analizadas son 24 ejemplares, de las cuales 23 son lascas y una es una lámina. Todas presentan una pátina de color amarillo, con un rodamiento medio y con presencia de cúpulas de termoalteración en algunos ejemplares. Se ha documentado 1 ejemplar de BP-D (descortezado) y 2 BP-SD (semidescortezado), 10 BP-I (internas) y 11 BP-L (levallois). En cuanto al volumen hay un predominio de LP (largo plano) frente a EP (espeso plano). La delineación desde la cara ventral muestra talones variados siendo predominantes los convexos frente a los rectos, con un bulbo marcado en la mayoría. Los talones son facetados en casi todas las lascas, aunque también están presentes los lisos y 1 ejemplar con talón puntiforme, son no corticales en todos los casos menos en uno y con presentan superficies en plataforma y lineales, con una transformación donde predominan los unifacetados, frente a bifacetados $\mathrm{y}$ multifacetados. Las caras dorsales son no corticales predominantemente.

\begin{tabular}{|c|c|c|c|c|c|c|c|c|c|c|c|c|c|c|c|c|c|c|c|c|c|}
\hline \multicolumn{22}{|c|}{ YACIMIENTOS ARDALES. ESTUDIO ANALITICOO DE LAS BP } \\
\hline \multirow[t]{3}{*}{ Nombre } & \multicolumn{5}{|c|}{ Materias primas y morfología } & \multicolumn{2}{|c|}{ Tipos de bases positivas } & \multicolumn{4}{|c|}{ Dimensiones } & \multicolumn{10}{|c|}{ Criterios analíticos de las BP } \\
\hline & $\mathrm{M}$ & R & c & 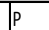 & $T$ & LAS/LAM & TIPO & L & A & TB & VOL & \multicolumn{2}{|c|}{ CARA VENTRAL } & \multicolumn{4}{|c|}{ CARA TALONAR } & \multicolumn{4}{|c|}{ CARA DORSAL } \\
\hline & & & & & & & & & & & & $\mathrm{F}$ & $B$ & TIPO & \begin{tabular}{|l|l|} 
COR & $S$ \\
\end{tabular} & $T$ & $\mathrm{D}$ & COR & SSAG & STR & A \\
\hline CU-S-155 & s & M & G & A & NO & LASCA & D & 4 & 3,7 & 0,9 & $18 \mathrm{LP}$ & $c x$ & M & a & NOCO LIN & UF & $C X$ & $\operatorname{CDNC}$ & CDG & TRG & NO \\
\hline CU-S-104 & s & M & G & A & NO & LASCA & SD & 3,4 & 4,2 & 1,1 & 22 EP & RT & M & I & CO LIN & UF & RT & NCDC & CDG & TRP & $\mathrm{SI}$ \\
\hline CU-S-46 & $\mathrm{R}$ & M & 0 & NO & NO & LASCA & SD & 3,8 & 3 & 0,8 & $18 \mathrm{LP}$ & $c x$ & M & $\mathrm{fp}$ & NOCO LIN & MF & $c x$ & NCDC & OV & TRG & NO \\
\hline CU-S-14 & s & M & G & B & SI & LASCA & 1 & 3,3 & 2,5 & 0,6 & $19 \mathrm{LP}$ & RT & M & $\mathrm{fp}$ & NOCO PLA & MF & RT & NCDC & CDG & TRG & $\mathrm{SI}$ \\
\hline CU-S-49 & $\mathrm{s}$ & M & B & A & NO & LASCA & 1 & 3,8 & 4,6 & 0,9 & $21 \mathrm{EP}$ & RT & M & 1/a & NOCO PLA & UF & RT & NOCO & TRP & TRP & $\mathrm{SI}$ \\
\hline CU-S-53 & S & M & NO & A & NO & LASCA & 1 & $\mathrm{fd}$ & 3,7 & 0,9 NO & $0 \quad L P$ & $C X$ & D & $\mathrm{a} / \mathrm{l}$ & NOCO PLA & UF & $C x$ & NOCO & CDG & TRG & SI \\
\hline CU-S-80 & s & M & G & 0 & SI & LASCA & I & $\mathrm{fd}$ & 2,4 & $0,7 \mathrm{NO}$ & $0 \quad L P$ & $C X$ & M & fc & NOCO LIN & MF & $C X$ & NOCO & CDG & TRG & $\mathrm{SI}$ \\
\hline CU-S-116 & S & M & G & A & $\mathrm{SI}$ & LASCA & 1 & $\mathrm{fd}$ & 3,2 & $0,7 \mathrm{NO}$ & $0 \quad E P$ & CC & M & 1 & NOCO LIN & UF & $\mathrm{CC}$ & NOCO & OV & OV & NO \\
\hline CU-S-132 & CU & M & 0 & A & NO & LASCA & 1 & 4,4 & 3 & 1,2 & $18 \mathrm{LP}$ & $c x$ & D & $\mathrm{fp}$ & NOCO LIN & MF & $c x$ & NOCO & TRP & TRG & $\mathrm{SI}$ \\
\hline CU-S-174 & S & M & G & B & NO & LASCA & 1 & $\mathrm{fd}$ & 2,9 & $0,8 \mathrm{NO}$ & $0 \quad L P$ & $C x$ & M & $\mathrm{fd}$ & NOCO PLA & $\mathrm{BF}$ & $C x$ & NOCO & TRP & TRP & $\mathrm{SI}$ \\
\hline CU-S-200 & CU & $M$ & $R$ & NO & NO & LASCA & 1 & 4,6 & 4,6 & 1,3 & $21 \mathrm{EP}$ & RT & M & I & NOCO PLA & UF & RT & NOCO & TRP & TRG & $\mathrm{SI}$ \\
\hline CU-S-223 & $S$ & $M$ & G & $R$ & NO & LASCA & 1 & 3,9 & 3 & 0,6 & $18 \mathrm{LP}$ & RT & $M$ & I & NOCO PLA & UF & RT & NOCO & CDG & TRP & $\mathrm{SI}$ \\
\hline CU-S-TL6 & $S$ & M & NO & B & SI & LASCA & I & 3,8 & 3,9 & 0,6 & $18 \mathrm{LP}$ & $C X$ & M & $\mathrm{fc}$ & NOCO LIN & MF & $C X$ & NOCO & TRP & TRG & $\mathrm{SI}$ \\
\hline CU-S-TL7 & S & M & B & A & NO & LASCA & L & 3,9 & 3,5 & 0,9 & $18 \mathrm{LP}$ & RT & M & $\mathrm{fc}$ & NOCO LIN & MF & $C x$ & NOCO & TRP & TRG & $\mathrm{SI}$ \\
\hline CU-S-TL8 & $S$ & $M$ & B & A & NO & LASCA & L & 4,9 & 3,2 & 0,8 & $13 L P$ & $c x$ & M & $\mathrm{fd}$ & NOCO PLA & $\mathrm{BF}$ & $c x$ & NOCO & TRP & TRP & $\mathrm{SI}$ \\
\hline CU-S-TL9 & S & $M$ & G & 0 & NO & LASCA & L & 4,9 & 4,3 & 1,1 & $17 \mathrm{LP}$ & $c x$ & $M$ & $\mathrm{fc}$ & NOCO PLA & MF & $c x$ & NOCO & CDG & TRG & $\mathrm{SI}$ \\
\hline CU-S-12 & s & M & G & A & NO & LASCA & L & 4 & 3,2 & 0,7 & $18 \mathrm{LP}$ & RT & M & 1 & NOCO LIN & UF & RT & NOCO & TRP & TRG & $\mathrm{SI}$ \\
\hline CU-S-33 & $S$ & $M$ & G & A & NO & LASCA & L & $\mathrm{fd} / \mathrm{fp}$ & 3,1 & $0,6 \mathrm{NO}$ & $0 \quad L P$ & NO & NO & NO & NO NO & NO & NO & NOCO & TRP & TRG & $\mathrm{SI}$ \\
\hline CU-S-57 & $S$ & M & G & $B / A$ & NO & LASCA & L & 2,7 & 4,8 & 0,6 & $26 \mathrm{EP}$ & $C X$ & M & 1 & NOCO PLA & UF & RT & NOCO & TRP & TRG & $\mathrm{SI}$ \\
\hline CU-S-72 & $S$ & M & N & A & SI & LASCA & L & 4,1 & 2,7 & 0,9 & $18 \mathrm{LP}$ & $C X$ & D & a & NOCO NO & NO & NO & NOCO & TRP & TRG & $\mathrm{SI}$ \\
\hline CU-S-113 & $S$ & M & G & A & NO & LASCA & L & 5,3 & 3,5 & 0,8 & $17 L P$ & $C X$ & M & $\mathrm{fd}$ & NOCO LIN & $\mathrm{BF}$ & UA & NOCO & TRP & TRP & $\mathrm{SI}$ \\
\hline CU-S-129/198 & $R$ & $M$ & $R / 0$ & A & NO & LASCA & L & 5,4 & 3,8 & 0,6 & $17 \mathrm{LP}$ & $c x$ & $M$ & $\mathrm{fd}$ & NOCO LIN & $\mathrm{BF}$ & UA & NOCO & TRP & TRP & $\mathrm{SI}$ \\
\hline CU-S-193 & S & $M$ & G & B & NO & LASCA & L & 3 & 4 & 1,1 & 22 EP & RT & D & $p$ & NOCO PLA & UF & RT & NOCO & TRG & TRG & $\mathrm{SI}$ \\
\hline CU-01-VTR & S & M & G & B & NO & LÁMINA & L & 6,6 & 2,7 & 0,8 & $9 L P$ & $c x$ & D & a & NOCO LIN & UF & $c x$ & NOCO & CDG & TRG & $\mathrm{SI}$ \\
\hline
\end{tabular}

Tabla 7. Estudio analítico de las BP de Cucarra.

Los productos retocados o $\mathrm{BN} 2 \mathrm{G}$ (tabla 8) corresponden a 15 ejemplares. Nosotros utilizamos la nomenclatura del sistema tipológico de Laplace (Laplace, 1972) y los de la Lista-Tipo Bordes (Bordes, 1961). Hay un predominio de sílex masivo en tonalidades grises o beige y con pátina, también hay 3 ejemplares en sílex poroso y 2 ejemplares en radiolarita roja. Tenemos 4 muescas realizadas sobre lascas de sílex beige y gris, 3 de ellas sobre lascas levallois y una interna que corresponden a un denticulado 
en la tipología de Laplace (D21) y a una muesca según Bordes (42). Todas tienen un volumen de tipo LP (largo plano), un ejemplar no presenta talón ni bulbo, el resto tienen una delineación del talón desde la cara ventral recta y convexa en una de ellas y el bulbo marcado en todas. La cara talonar presenta un talón abatido, en plataforma y unifacetado en uno de los ejemplares y facetado diedro en plataforma y lineal, y multifacetado en los otros dos. La cara dorsal es no cortical.

En relación al tipo de retoque, hay 1 ejemplar que tiene retoque abrupto, marginal, directo y con muesca en el lateral izquierdo. Otro presenta el retoque abrupto, profundo, directo y con muesca, en el lateral derecho. El tercer ejemplar presenta el retoque abrupto, profundo, directo y con muesca en el extremo distal y el cuarto presenta un retoque abrupto, profundo, directo y con muesca en el extremo proximal.

Hay 9 ejemplares que corresponden a raederas realizadas sobre 6 lascas internas y 3 levallois, en sílex masivo 4 de ellas, 4 en sílex poroso y 1 en radiolarita.

Las raederas de sílex masivo sobre lasca levallois presentan un volumen LP (largo plano), con una fractura en el extremo próximal en 2 ejemplares y distal en otra. La cara dorsal es no cortical. Una presenta el retoque en el lateral derecho que es simple, marginal, directo y continuo. Corresponde a una raedera lateral según Laplace (R21) o a una raedera lateral cóncava según Bordes (11). Mientras que las otras dos tienen el retoque en el lateral izquierdo de tipo simple, marginal, directo y continuo y corresponden a una raedera lateral según Laplace (R21) o raedera simple derecha según Bordes (9), y a una raedera latero- trasversal (R23) o raedera trasversal convexa según Bordes (23) respectivamente.

El ejemplar en radiolarita y en una lasca interna tiene un volumen LP (largo plano), con una fractura en el extremo proximal. La cara dorsal es no cortical. Presenta un retoque simple, profundo, inverso y continuo en el lateral izquierdo. Corresponde a una raedera lateral (R21) y una raedera con retoque alterno (29).

Las raederas sobre lascas internas presentan un volumen LP (largo plano), salvo en una de ellas que es EP (espeso plano), la delineación de la cara ventral es convexa en 3 de ellas y una cóncava. Con un bulbo marcado en la mayoría y difuso en una, la cara talonar con talón facetado, no cortical, con superficies en plataforma y lineal, bifacetado y una delineación convexa y uniangular. La cara dorsal es no cortical. Tres ejemplares corresponden a raederas laterales en la tipología de Laplace (R21) y a raederas simples convexas (10) y raedera simple derecha (9) según Bordes. 
El último ejemplar está realizado sobre una lasca interna de sílex poroso, con un volumen EP (espeso plano). La delineación de la cara ventral es recta y con bulbo marcado, la cara talonar con talón liso, no cortical, en plataforma y unifacetada. Su cara dorsal es no cortical. Con retoque simple, profundo, directo y con muesca en el extremo distal, corresponde a una raedera de denticulado (D23) o raedera transversal convexa según Bordes (23).

Un denticulado de sílex masivo sobre una lasca de descortezado, con un volumen LP (largo plano), y con una fractura en el extremo proximal que impide el análisis de su cara ventral y talonar. La cara dorsal es cortical. El retoque es abrupto, profundo, inverso y denticulado y se localiza en el lateral izquierdo. Se trata de un denticulado en espina (D22) y un denticulado según Bordes (43).

El último de los ejemplares corresponde a un raspador en radiolarita. Con un volumen LP (largo plano) y una delineación desde la cara ventral recta y bulbo marcado. Su cara talonar presenta un talón liso, no cortical, en plataforma y unifacetado. $\mathrm{Su}$ cara dorsal es no cortical. Presenta un retoque simple, marginal, directo y continuo en el extremo. Se trata de un raspador carenado según Laplace (G3) y un raspador según Bordes (30).

\begin{tabular}{|c|c|c|c|c|c|c|c|c|c|c|c|c|c|c|c|c|c|c|c|c|c|c|c|c|c|c|c|}
\hline \multicolumn{26}{|c|}{ YACIMENTOS ARDALES. ESTUDIO ANALIITICO DELAS BN2G } & \multirow{2}{*}{\multicolumn{2}{|c|}{ Clasificación }} \\
\hline Nombre & \multicolumn{5}{|c|}{ Materias primas y morfología } & \multicolumn{2}{|c|}{ Tipos de bases positivas } & \multicolumn{3}{|c|}{ Dimensiones } & \multicolumn{11}{|c|}{ Criterios analiticos de las BN2G } & \multicolumn{4}{|c|}{ Tipo de retoque } & & \\
\hline & M & R & c & p & $\mathrm{T}$ & LAS/LAM & TIPO & L & \begin{tabular}{|l|l|l}
$A$ & $E$ \\
\end{tabular} & \begin{tabular}{l|l|l|} 
E & TB & Vol \\
\end{tabular} & & RAVENTRAL & & & A TALON & & & & CARA & DORSAL & & LIZQ & EDIS & LDRCHO & & \multicolumn{2}{|c|}{ Laplace Bordes } \\
\hline Cucarra & & & & & & & & & & & $F$ & $B$ & TIPO & COR & s & $\mathrm{T}$ & $D$ & COR & SSAG & STR & A & & & & & & \\
\hline CUS-50 & s & M & G & 0 & No & LASCA & L & 5,3 & 2,7 & $0,7 \quad 13$ LP & RT & M & a & NOCO & PLA & UF & RT & NOCO & CDG & TRP & SI & $\mathrm{a} / \mathrm{m} / \mathrm{d} / \mathrm{e}$ & & & & 021 & 42 \\
\hline CU.S-51 & s & M & G & B & NO & LASCA & L & $\mathrm{fd} / \mathrm{fp}$ & 3,7 & 0,9 NO LP & NO & NO & NO & NOCO & NO & NO & NO & NOCO & TRP & TRG & SI & & & $s / m / d / c$ & & R21 & 11 \\
\hline CU.S-70 & s & M & B & A & NO & LASCA & I & no & NO & $0,7 \mathrm{NO} \quad L P$ & NO & NO & NO & NOCO & NO & NO & NO & NOCO & TRG & TRG & SI & & & $a / p / d / e$ & & 021 & 42 \\
\hline CU-S.79 & s & M & B & A & $S I$ & LASCA & 1 & 4,8 & 4,2 & $0,7 \quad 17$ LP & $c x$ & M & $\mathrm{fc}$ & NOCO & UN & MF & $C X$ & NOCO & CDG & CDG & SI & & & $s / m / d / c$ & & R21 & 10 \\
\hline CU.S-110 & s & M & B & G & NO & LASCA & L & 5,9 & 2,9 & $0,6 \quad 13 L P$ & $c x$ & M & $\mathrm{fd}$ & NOCO & PLA & $B F$ & $C x$ & NOCO & CDG & OV & SI & $s / m / d / c$ & & & & R21 & 9 \\
\hline CUS-S-120 & s & M & B & A & NO & LASCA & L & $f p$ & 3,8 & $0,8 \mathrm{NO} \quad L P$ & NO & NO & NO & NO & NO & NO & NO & NOCO & TRP & TRG & SI & $\mathrm{s} / \mathrm{m} / \mathrm{d} / \mathrm{c}$ & & & & R23 & 23 \\
\hline CUS-S-123 & s & M & G & 0 & NO & LASCA & D & $\mathrm{fp}$ & 2,5 & 0,7 NO LP & NO & NO & NO & NO & NO & NO & NO & CO & OV & OV & NO & $\mathrm{a} / \mathrm{pl} / \mathrm{d}$ & & & & D22 & 43 \\
\hline CU.S-149 & s & M & B & A & NO & LASCA & 1 & 3,1 & 3,9 & 122 EP & $c x$ & M & $\mathrm{fd}$ & NOCO & PLA & $B F$ & $C x$ & NOCO & OV & TRG & SI & & & & $s / p / d / c$ & R22 & 22 \\
\hline CUS-S-172 & R & M & R & R & NO & LASCA & I & $\mathrm{fp}$ & 3,1 & $0,6 \mathrm{NO} \quad L P$ & NO & NO & NO & NO & NO & NO & NO & NOCO & TRP & TRG & SI & $s / p l i / c$ & & & & R21 & 29 \\
\hline CUS-208 & $R$ & M & R & B & NO & LASCA & I & 6,7 & 3 & $1,9 \quad 19 \mathrm{LP}$ & RT & M & I & NOCO & PLA & UF & RT & NOCO & PTG & TRG & SI & & $s / m / d / c$ & & & G3 & 30 \\
\hline CUS-S210 & s & M & B & A & NO & LASCA & L & 3,4 & 3,5 & $0,6 \quad 22 L P$ & RT & M & $\mathrm{fd}$ & NOCO & LN & $B F$ & UA & NOCO & TRP & TRP & SI & & $a / p / d / e$ & & & D21 & 42 \\
\hline CU.S-220 & s & M & $G$ & B & NO & LASCA & L & $\mathrm{fd}$ & 3,5 & $0,8 \mathrm{NO} \quad L P$ & $c x$ & M & $\mathrm{fd}$ & NOCO & PLA & BF & UA & NOCO & CDG & TRP & SI & & & & $\mathrm{a} / \mathrm{p} / \mathrm{d} / \mathrm{e}$ & & 42 \\
\hline CU.S & s & M & $G$ & A & NO & LASCA & I & 6,3 & 3,1 & $1,1 \quad 13 L P$ & $C C$ & $D$ & $\mathrm{fd}$ & NOCO & PLA & BF & UA & NOCO & CDG & TRP & SI & & & $s / p / d / c$ & & R21 & 10 \\
\hline CU-S-TL1O & s & M & $G$ & B & NO & LASCA & I & 8,3 & 9,6 & $2,5 \quad 21 \mathrm{EP}$ & RT & M & I & NOCO & PLA & UF & RT & NOCO & TRP & TRP & SI & & $s / p / d / e$ & & & 023 & 23 \\
\hline CU-O2-VTR & s & M & $G$ & B & NO & LASCA & 1 & NO & 4,1 & $0,8 \mathrm{NO} \quad L P$ & $c x$ & NO & NO & NO & NO & NO & NO & NOCO & CDG & TRG & SI & & $\mathrm{a} / \mathrm{m} / \mathrm{d} / \mathrm{c}$ & & & R22 & 22 \\
\hline
\end{tabular}

Tabla 8. Estudio analítico de las BN2G de Cucarra. 
. Valoración y conclusiones

Su localización sobre una ladera, cercana a la Cueva de Ardales y con una ocupación atestiguada desde el Pleistoceno medio hasta el Holoceno, hace pensar en una utilización de este yacimiento al aire libre en periodos de tiempo estable y la utilización de la caverna en momentos de clima más inestables.

Los procesos postdeposicionales, tanto naturales como antrópicos, han ocasionado la mezcla de materiales arqueológicos desplazándolos de su lugar originario y ocasionando incluso roturas posteriores en algunos de los ejemplares.

En cuanto a la tecnología destacamos una presencia mayoritaria de lascas, con una escasa representación de BP-D y BP-SD, que sería indicadores del inicio de talla, si hay BP internas vinculadas a la continuidad de talla y BP levallois de mediano y pequeño tamaño, dentro del grupo de los productos retocados o BN2G, nos encontramos con 10 ejemplares correspondientes a muescas, raederas, un denticulado y un raspador.

La muestra arqueológica analizada evidencia la ocupación de este espacio durante del Paleolítico medio, aparece además algún ejemplar como el raspador carenado que evidencian el inicio de los primeros momentos del Paleolítico superior. La utilización de la Cueva de Ardales desde el Paleolítico superior y su continuidad en el Neolítico y Calcolítico, así como su proximidad al yacimiento quizás expliquen la reutilización de la industria lítica, marcada por retoques que rompen las pátinas.

La materia prima predominante es el sílex masivo gris, beige localizado en su mayoría en zonas cercanas al río Turón y en afloramientos cercanos como el Azulejo. 


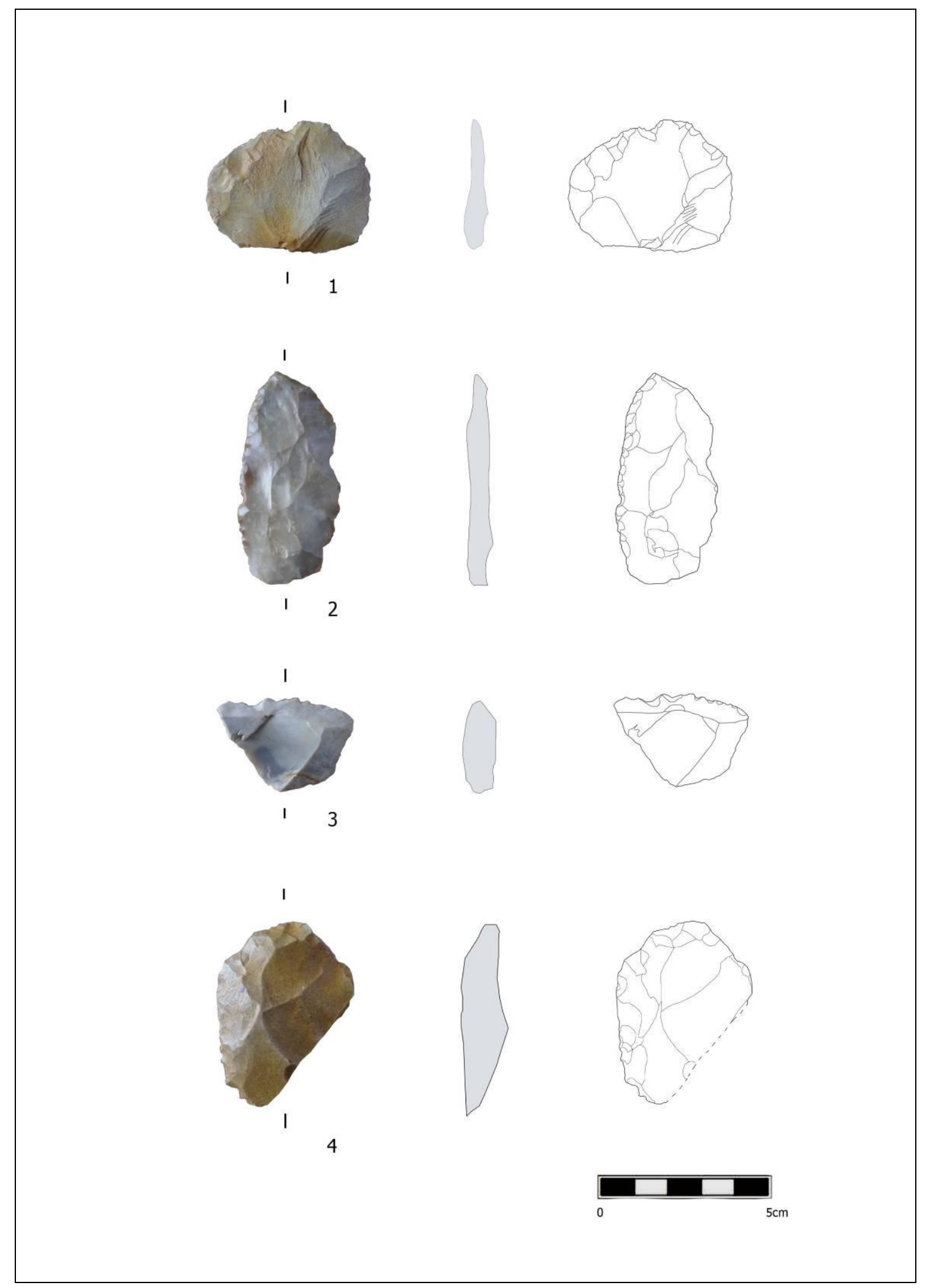

Figura 95. Cucarra (Ardales): 1, 2, 3, 4: BN2G-Raederas. 


\subsubsection{Depósitos de Hoyos de Barbú (Ardales)}

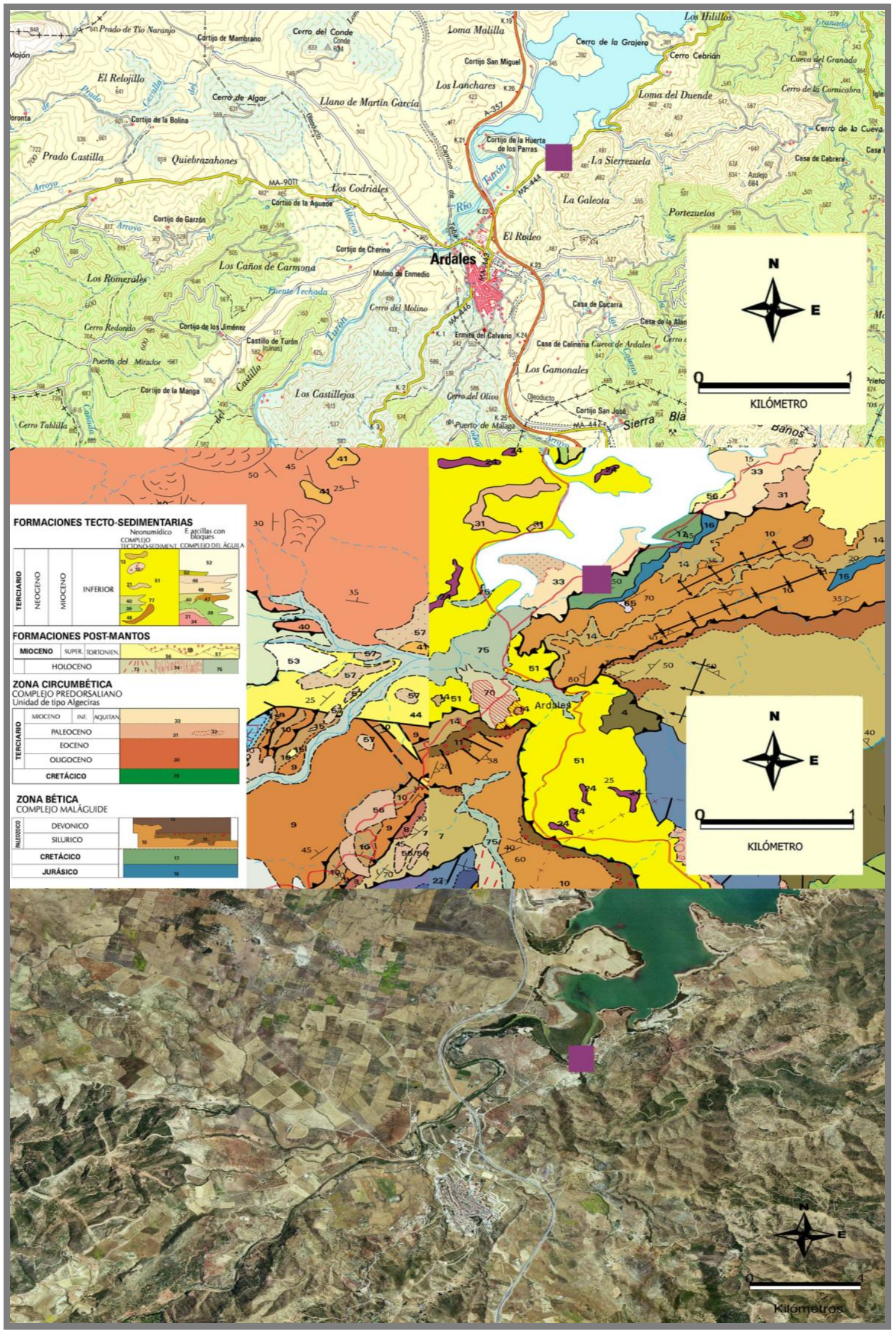


Es un depósito localizado en una ladera en la margen izquierda del río Turón, con presencia de cantos y lascas talladas. El acceso se realiza por la carretera entre Ardales y los embalses (MA-444), situándose a ambas márgenes de dicha carretera. Es también conocido como Lomas del Duende 2 o lomas de la Galeota.

Sus coordenadas UTM ETRS89 30 son:

\begin{tabular}{|c|c|}
\hline $\mathbf{X}$ & $\mathbf{Y}$ \\
\hline 336794 & 4084906 \\
\hline
\end{tabular}

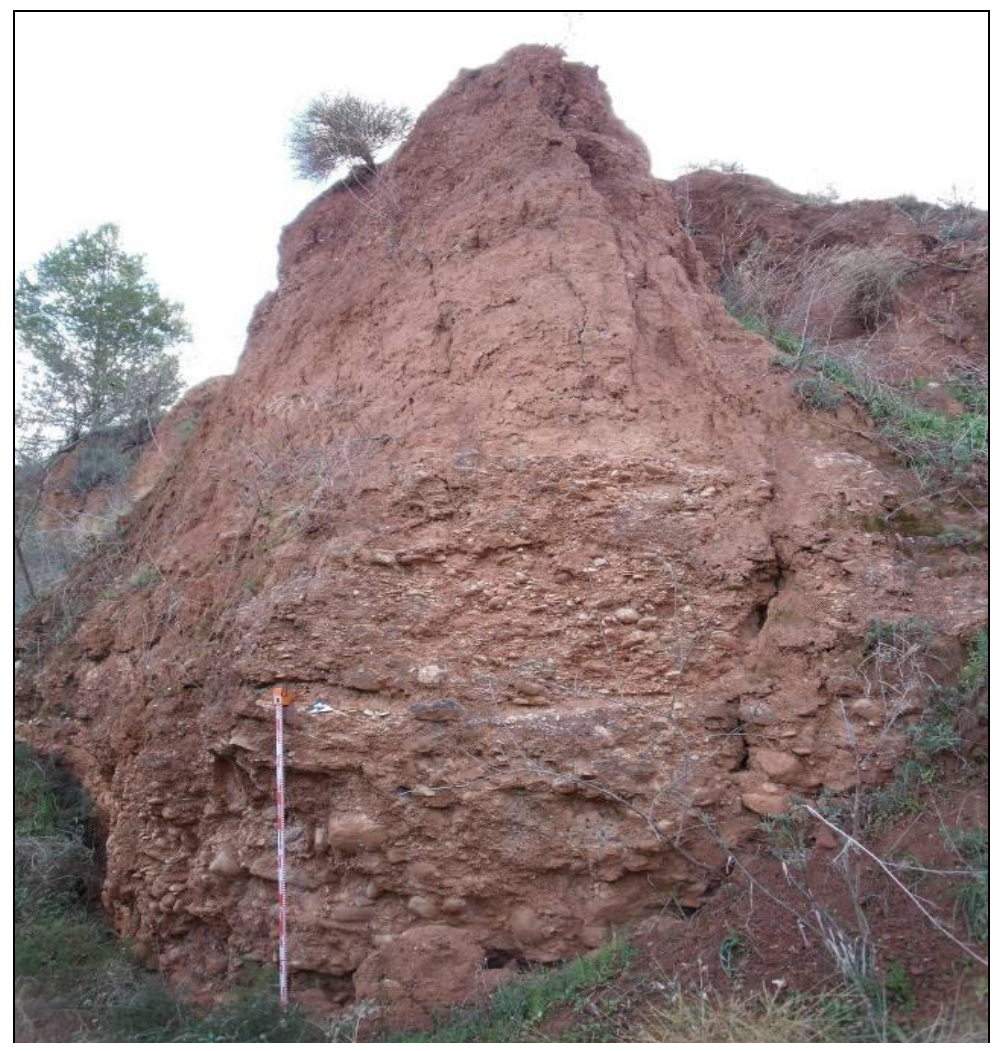

Figura 96. Depósito Hoyos de Barbú

Altitud m s.n.m: $\pm 424 \mathrm{~m}$

Extensión: $17.504,13 \mathrm{~m}^{2}$

. Contexto geológico y geomorfológico

A nivel geológico existe una presencia de margocalizas blancas y rojas esquistosas del Cretácico y pertenecientes de Complejo Maláguide dentro de la Zona Bética, bajo estos niveles Cretácicos aparece un paquete de dolomías y calizas blancas y 
calizas con sílex del Jurásico y areniscas, margas marrones y verdes de la unidad de tipo de Algeciras de la Zona Circumbética.

En la zona aflora un importante depósito del Mioceno superior, formado por una potente sucesión de conglomerados cementados de color rojo, con cantos y bloques bien redondeados, mayoritariamente de calizas y areniscas, que hacia el techo pasan a arcillas rojas con niveles de cantos para culminar con niveles de gravas. Se trata de un depósito granodecreciente que corresponde a una sedimentación de abanicos aluviales que se apoyan en los relieves que rodean la cuenca sedimentaria cenozoica a partir de cuya desmantelación se han generado.

El yacimiento se encuentra en superficie sobre pequeños conos aluviales y depósitos de vertiente cuaternarios que configuran las laderas. Los relieves han sido labrados en estos materiales miocenos por la erosión producida durante el encajamiento fluvial cuaternario. Estos conos de deyección se formaron a expensas del desmantelamiento de los materiales conglomeráticos y arcillosos miocenos. Estos depósitos aluviales generados por pequeños cursos efímeros durante épocas con precipitaciones son los que alimentan el arroyo que desemboca en el río Turón.

. Procesos sedimentarios, procesos postdeposicionales

Los procesos sedimentarios que dieron lugar al yacimiento están asociados a la formación de los conos de deyección cuaternarios y al posterior desmantelamiento de estos con arrastre gravitacional e hídrico de materiales Los principales procesos postdeposicionales por los que se ve afectado el yacimiento son tanto de carácter natural, la erosión y los movimientos de gravedad-vertientes, como antrópico, el arado superficial y la construcción de la carretera que da acceso al mismo y que dividió y destruyó parte del depósito.

\section{. Interpretación geoarqueológica}

Se trata de depósitos de vertiente y conos aluviales producto del desmantelamiento de un depósito mioceno. Los materiales arqueológicos aparecen todos en superficie, en la ladera desarrollada sobre el depósito y en la parte baja de este. Se encuentran en posición secundaria debido a la naturaleza de los depósitos donde se han recuperado. Los filos presentan un rodamiento medio indicativo de que no han sufrido un largo proceso de transporte. 
. Análisis de la industria lítica

El análisis de la industria lítica se ha realizado sobre el material recogido durante las prospecciones de los años 80, que se encuentran en el Centro de Interpretación de la Prehistoria de Ardales y los muestreos geoarqueológicos llevados a cabo en el marco de las intervenciones arqueológicas entre 2011-2014. Corresponden a un total de 18 piezas.

La materia prima (figura 97) predominante es la arenisca compacta con 10 ejemplares, 4 sílex masivos en tonalidades claras beige/gris y marrón, 2 sílex porosos y 2 cuarcitas una de ellas blanca.

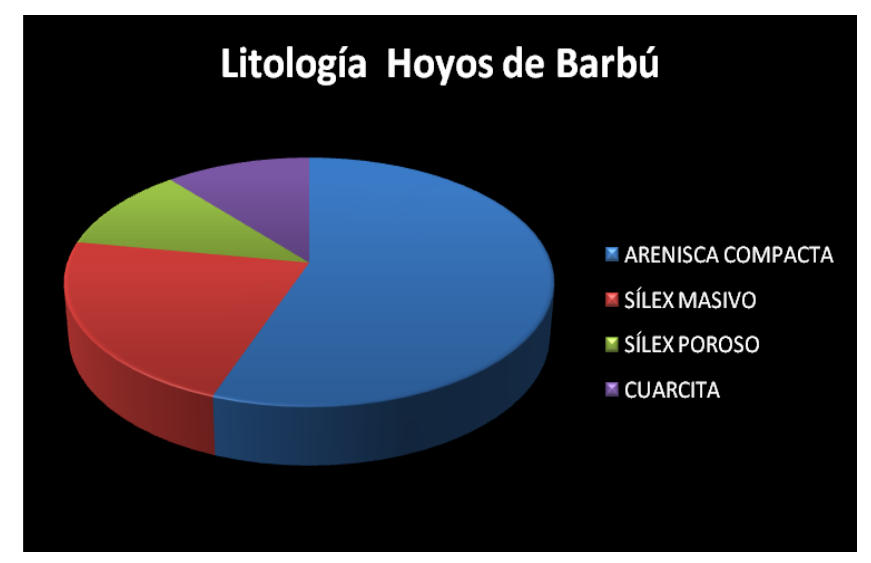

Figura 97. Materias primas de las piezas líticas recuperadas del yacimiento Hoyos de Barbú.

El estudio morfotécnico realizado sobre la industria lítica muestra un predominio de Bases Negativas de Primera Generación de Configuración (BN1GC) frente a las de Explotación (BN1GE), con presencia de Bases Positivas Internas y Levallois (BP-I/L) y con Bases Negativas de Segunda Generación (BN2G).

Las BN1GC (tabla 9) corresponden a cantos tallados, hendedores, picos triedros y un bifaz. Son un total de 10 ejemplares, todos ellos en arenisca compacta salvo el bifaz que está elaborado sobre un sílex masivo en tonalidades beige. Los 10 ejemplares menos dos de ellos presentan una talla unifacial. Tienen un carácter centrípeto casi completo de tipo 3C y 4C, salvo uno de los cantos tallados, que tiene un ángulo de inclinación de las extracciones variables (simples, semiabruptosy abruptos). El carácter de profundidad es total en la mayoría, con algún ejemplar marginal y muy profundo. La arista frontal es convexa en 9 ejemplares mientras que la sagital es sinuosa en la mayoría. 
Los hendedores se clasifican dentro del tipo 2 de Tixier, mientras que el bifaz lo encuadramos dentro del grupo IV u ovalados según la tipología de Bordes.

En relación a las BN1GE hay 2 ejemplares, uno en sílex y otro en arenisca que corresponden a núcleos poliédricos, de tipo bifacial con un carácter centrípeto completo de 4C y unas extracciones de tipo semiabrupto/abrupto, con una profundidad total. La arista frontal es convexa y la sagital es sinuosa en ambos.

\begin{tabular}{|c|c|c|c|c|c|c|c|c|c|c|c|c|c|c|}
\hline \multicolumn{15}{|c|}{ YACIMIENTOS ARDALES. ESTUDIO ANALÍTICO DE LAS BN1G } \\
\hline \multirow{2}{*}{\begin{tabular}{|c|} 
Nombre \\
Terrz. Hoyos de Barbú \\
\end{tabular}} & \multicolumn{5}{|c|}{ Materias primas y morfología } & \multicolumn{2}{|c|}{ Tipos de bases negativas } & \multicolumn{6}{|c|}{ Criterios analíticos de las BN1G } & \multirow[t]{2}{*}{ Tema operativo técnicc } \\
\hline & $M$ & $\mathrm{R}$ & C & $\mathrm{P}$ & $\mathrm{T}$ & TN & $\mathrm{BN}$ & CF & CC & $\mathrm{CO}$ & $\mathrm{CP}$ & CAF & CAS & \\
\hline T.H.B 05 (1) & A & $\mathrm{M}$ & 0 & 0 & NO & Canto tallado & BN1GC & $\mathrm{U}$ & $\bar{C}$ & $\mathrm{~S}$ & $\mathrm{~m}$ & CC & inc & T.O.T.D \\
\hline T.H.B 1-TL & A & $\mathrm{M}$ & 0 & A & NO & Canto tallado & BN1GC & U & $4 C$ & SP & $\mathrm{t}$ & $c x$ & $\sin$ & T.O.T.D \\
\hline T.H.B 2-TL & A & $M$ & G & 0 & NO & Triedro & BN1GC & U & $3 C$ & $S$ & $\mathrm{t}$ & $c x$ & $\sin$ & T.O.T.D \\
\hline T.H.B 3-TL & A & $\mathrm{M}$ & G & NO & NO & Triedro & BN1GC & U & $3 C$ & $S$ & $\mathrm{mp}$ & $c x$ & inc & T.O.T.D \\
\hline T.H.B 4-TL & A & $M$ & G & 0 & NO & Hendedor & BN1GC & B & $2 C$ & $S$ & $\mathrm{~m}$ & $c x$ & $\sin$ & T.O.T.D \\
\hline T.H.B 5-TL & A & $M$ & G & 0 & NO & Hendedor & BN1GC & B & $4 C$ & S/SA & $\mathrm{t}$ & $c x$ & $\sin$ & T.O.T.D \\
\hline T.H.B 6-TL & $S$ & $M$ & B & A & NO & Bifaz & BN1GC & U & $4 C$ & $S / P$ & $\mathrm{t}$ & $c x$ & $\sin$ & T.O.T.D \\
\hline T.H.B 7-TL & A & $M$ & G & NO & NO & POL & BN1GE & B & $4 C$ & $\mathrm{SA} / \mathrm{A}$ & $\mathrm{t}$ & $c x$ & $\sin$ & T.O.T.I \\
\hline T.H.B 11-TL & $S$ & $M$ & G & B & NO & POL & BN1GE & B & $4 C$ & SA/A & $\mathrm{t}$ & $c x$ & $\sin$ & T.O.T.I \\
\hline
\end{tabular}

Tabla 9. Estudio analítico de las BN1G de Hoyos de Barbú.

Las BP (tabla 10) analizadas son 6 ejemplares elaborados sobre arenisca, sílex o cuarcita. Se han documentado 4 ejemplares de BP-I (internas) y 2 BP-L (levallois). En cuanto al volumen, hay un predominio de LP (largo plano) frente a EP (espeso plano) o LE (larga espesa) también presentes. La delineación desde la cara ventral muestra talones convexos en casi todos los ejemplares, con un bulbo difuso en la mayoría. Los talones son lisos y facetados, no corticales y superficies en plataforma, con una transformación de los mismos de tipo unifacetado y multifacetado. Las caras dorsales son no corticales.

\begin{tabular}{|c|c|c|c|c|c|c|c|c|c|c|c|c|c|c|c|c|c|c|}
\hline \multicolumn{19}{|c|}{ YACIMENTOS ARDALES. ESTUDOOANALIITCODELLSBP } \\
\hline Nombre & \multicolumn{5}{|c|}{ Materias primasy morfologia Tipos de bases positivas } & \multicolumn{3}{|c|}{ Dimensiones } & \multicolumn{10}{|c|}{ Criterios analiticios de las BP } \\
\hline & M & R & $c$ & \begin{tabular}{|l|l|l|} 
P & $T$ & LAS/LAM \\
\end{tabular} & TPO & \begin{tabular}{|l|l} 
& $A$ \\
\end{tabular} & \begin{tabular}{|l|l|l}
$E$ & TT \\
\end{tabular} & \begin{tabular}{|l|l|} 
TB & VOL \\
\end{tabular} & & AVENRA & & CARATA & FILNAR & & & CARADORS & & \\
\hline Tern. Hoyos de Barbi & & & & & & & & & F & $B$ & TIPO & COR $S$ & $T$ & D & COR & SSAG SS & STR & A \\
\hline T.H.BOA & A & M & 0 & NO NO LASCA & । & $10,5 \quad 7,4$ & $7,4 \quad 1,9$ & $9 \quad 13 L \mathrm{~L}$ & $d x$ & M & I & NOCO PLA & Uf & $C x$ & NOCO & $\operatorname{cog} 0$ & OV & $\mathrm{SI}$ \\
\hline T.H.BO6 & s & M & 0 & A NO LASCA & L & fp & $6,6 \quad 2,7 \mathrm{~N}$ & 7NO LP & NO & NO & NO & NOCO NO & NO & NO & NOCO & $\operatorname{TRP} \quad T$ & TRP & SI \\
\hline T.H.BOT & s & B & $B$ & A/C NO LASCA & I & $6,8 \quad 6,4$ & $6,4 \quad 2,5$ & $5 \quad 17 / \mathrm{LP}$ & RT & 0 & I & NOCO PLA & Uf & RT & NOCO & TRP T & TRG & SI \\
\hline T.H.B8-TL & $\mathrm{CU}$ & B & 0 & A NO LASCA & I & $10,1 \quad 6,5$ & $6,5 \quad 3,8$ & $8 \quad 13 L P$ & $d x$ & 0 & I & NOCO PLA & UF & $\alpha x$ & NOCO & TRP T & TRG & SI \\
\hline T.H.BQ-TL & $A$ & B & 0 & A NO LASCA & I & $6,2 \quad 8,4$ & $8,4 \quad 3,6$ & $25 E \mathrm{EP}$ & dx & 0 & fp & NOCO PLA & MF & $d x$ & NOCO & TRP 0 & OV & SI \\
\hline T.H.B10-TL & $A$ & M & $G$ & NO NO LASCA & L & $\begin{array}{ll}5 & 5,2\end{array}$ & $5,2 \quad 1,9$ & 21LE & $d x$ & 0 & fo & NOCO PLA & MF & $d x$ & NOCO & PTG T & TRP & SI \\
\hline
\end{tabular}

Tabla 10. Estudio analítico de las BP de Hoyos de Barbú. 
En el estudio de las BN2G (tabla 11) utilizamos la nomenclatura del sistema tipológico de Laplace (Laplace, 1972) y los de la Lista-Tipo Bordes (Bordes, 1961). Corresponden a 3 ejemplares en sílex y 1 en cuarcita. Presentan un volumen de tipo LP (largo plano), una delineación del talón desde la cara ventral convexa en uno de ellos y recta en los otros 2 ejemplares. Todos con bulbo marcado y un talón liso en dos y facetado diedro en uno. La cara dorsal es no cortical. Dos de los ejemplares corresponden a raederas, ambas presentan un retoque simple, marginal, directo y continuo en el lateral derecho, la primera corresponde a una raedera lateral en la tipología de Laplace (R21) o una raedera lateral cóncava según Bordes (11), mientras que la segunda es una raedera carenada (R3) según Laplace o una raedera lateral convexa según Bordes (10). El último de los ejemplares corresponde a un raspador denticulado sobre cuarcita roja (D25) y a un raspador según Bordes (30)

\begin{tabular}{|c|c|c|c|c|c|c|c|c|c|c|c|c|}
\hline \multicolumn{11}{|c|}{ 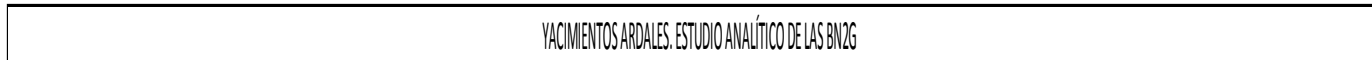 } & \multirow{2}{*}{\multicolumn{2}{|c|}{ Casifilaxion }} \\
\hline Nombre & Materispp & asymorio & logia Tiposche basespositivas & Dimensiones & & & 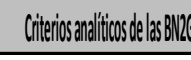 & & Tipoderetoque & & & \\
\hline & $\begin{array}{lll}M & R & C \\
\end{array}$ & $p$ & 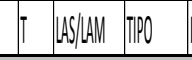 & A $A$ E & CARANENPAL. & & CARATHLONAR & CARADOSSA. & LLO EDS & IDRCHC) EPX & lappece & Borcles \\
\hline Terta Hovosce bart. & & & & & $B$ & TPP & 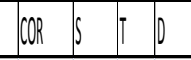 & COR SSAG STR A & & & & \\
\hline THBOL & $5 B G$ & $A$ & NO LASCA L & 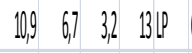 & a N & 1 & NOCO PLA UF Q Q & NOCO COG TRP SI & $\mathrm{s} m \mathrm{~m} / \mathrm{d}$ & & R21 & 11 \\
\hline THABDS & C $M O$ & $\mathbb{M}$ & NO LSSCA I & $\begin{array}{llll}8 & 5,5 & 2,5 & 17 / .\end{array}$ & RT M & if & NOCO PlA BF RT & NOCO COG TRG SI & $a / m|d| d$ & & 055 & 30 \\
\hline THBBD & $S M B$ & $B A$ & NO LSSCA I & $\begin{array}{lll}6,6,2 & 2,4 & \text { glp }\end{array}$ & RT M & | & NOCO PlA UF RT & NOC TRG TRG SI & $s \mathrm{~m} d \mathrm{~d}$ & & R3 & 10 \\
\hline
\end{tabular}

Tabla 11. Estudio analítico de las BN2G de Hoyos de Barbú.

. Valoración y conclusiones

Su localización sobre una ladera y próximo al río Turón, sobre un depósito con materias primas, como las areniscas de las mismas características geológicas que la industria, así como el rodamiento medio nos indica un escaso desplazamiento del material y plantea la posibilidad de que el material localizado esté sobre el propio yacimiento de materia prima, pudiendo ser utilizado como una zona de oteo tanto de montaña como de valle fluvial.

Aunque los procesos postdeposicionales, tanto naturales como antrópicos, han ocasionado la alteración original del depósito y la zona de derrubios, los materiales aparecen relativamente cerca unos de otros.

En cuanto a la tecnología destacamos una presencia mayoritaria de BN1GC, una presencia de BP internas vinculadas a la continuidad de talla y BP levallois de gran 
tamaño, dentro del grupo de los productos retocados o BN2G, nos encontramos con 3 ejemplares correspondientes a raederas y un raspador de gran tamaño.

La muestra arqueológica analizada evidencia una industria caracterizada por una macroindustria con presencia mayoritaria de útiles o productos típicos del Paleolítico inferior o del modo II, como hendedores, triedros y un bifaz, así como lascas y productos retocados de gran tamaño. Esto nos hace plantear el uso de este espacio con un aprovechamiento de la materia prima existente en el mismo, en este caso la arenisca compacta, aunque también se documentan algunos sílex de tonalidades claras que presentan las mismas características que los localizados en los afloramientos cercanos como el Azulejo o castillos Turón. 


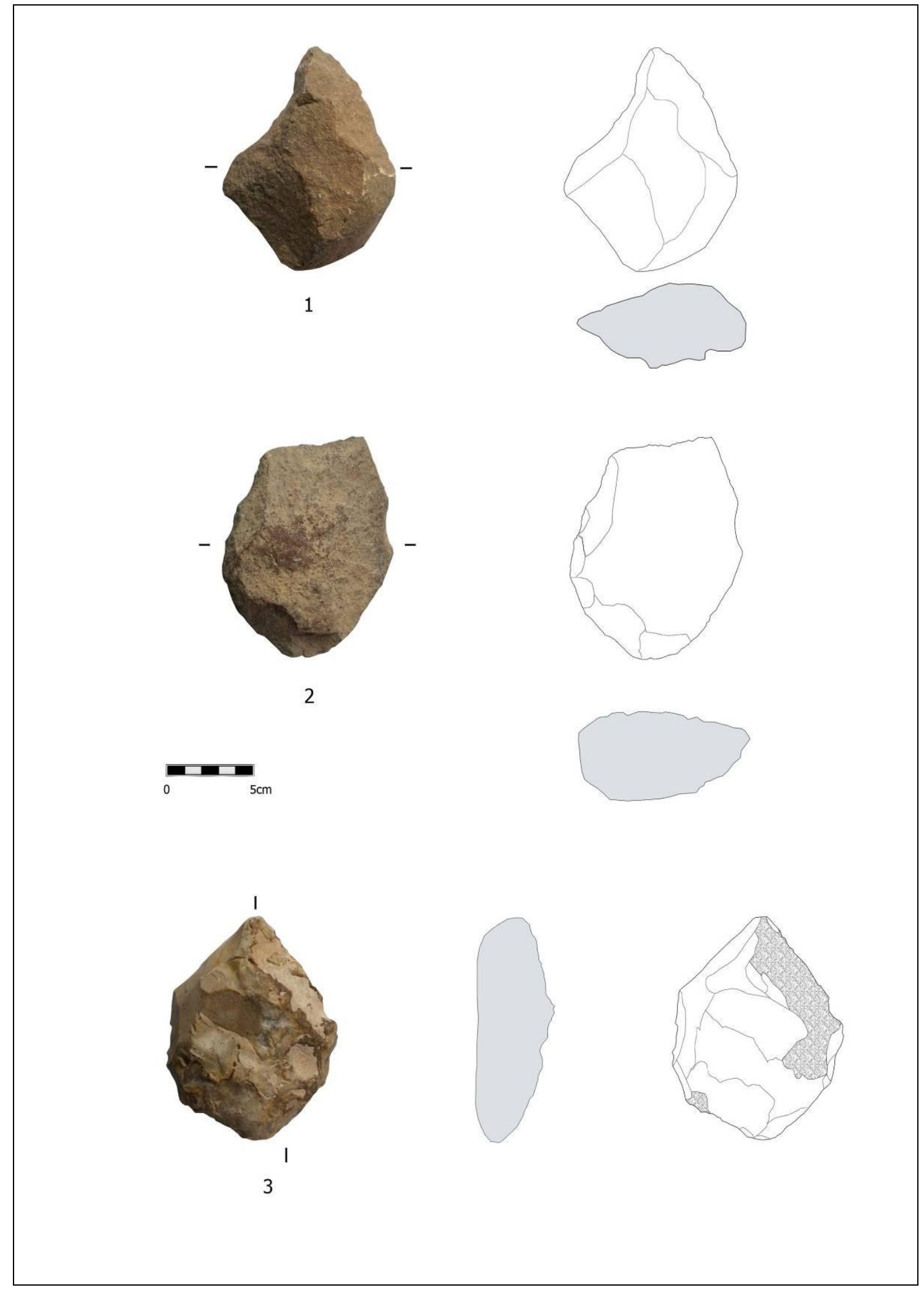

Figura 98. Hoyos de Barbú (Ardales): BN1GC-1: Triedro, 2: hendedor, 3: bifaz. 


\subsubsection{Terraza arroyo Cantarranas (Ardales)}

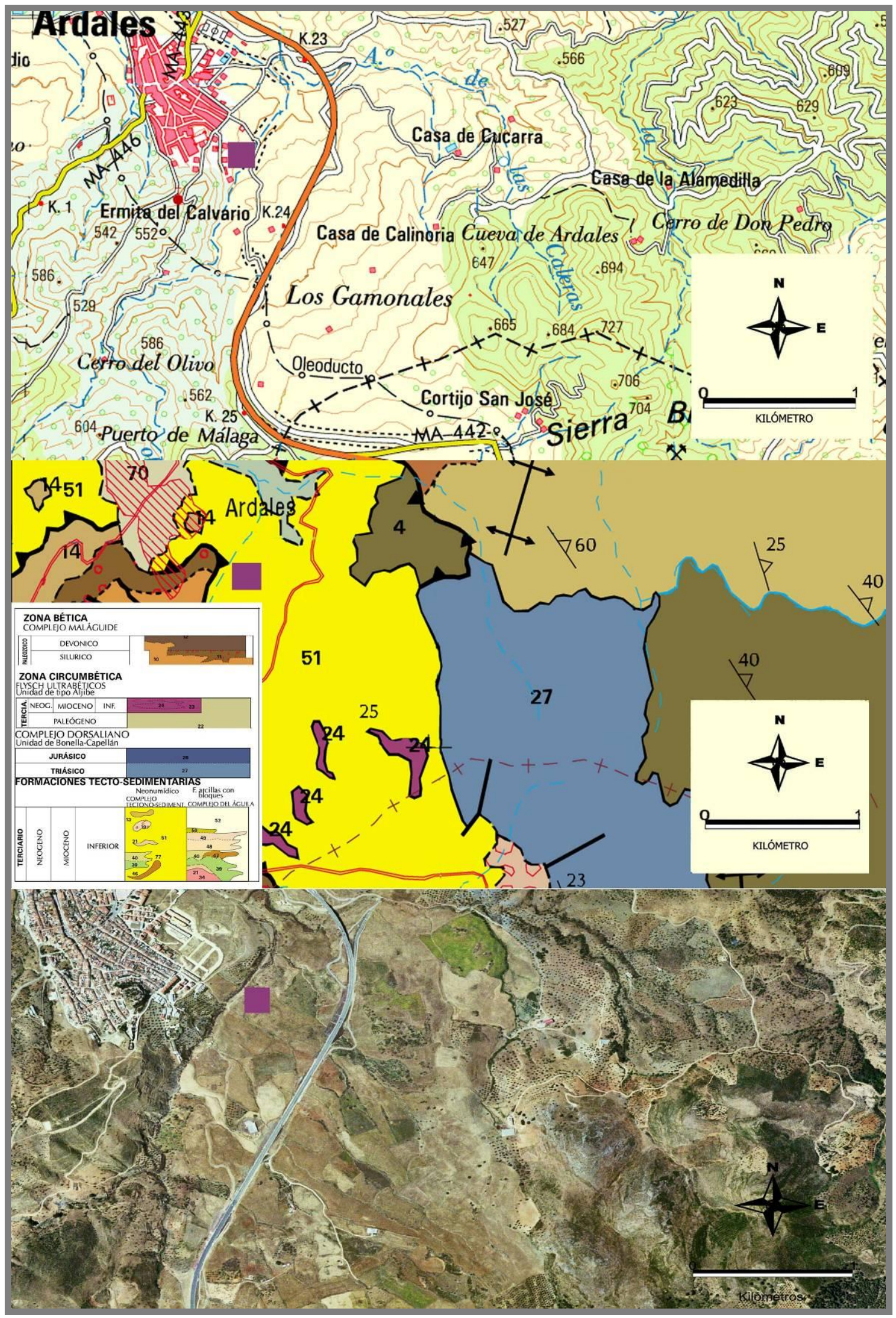


Es una terraza situada al este del pueblo de Ardales en un cortado del arroyo denominado Cantarranas. Su acceso se hace directamente desde el pueblo de Ardales. Sus coordenadas U.T.M ETRS89 30 son:

\begin{tabular}{|c|c|}
\hline $\mathbf{X}$ & $\mathbf{Y}$ \\
\hline 336060 & 4082922 \\
\hline
\end{tabular}

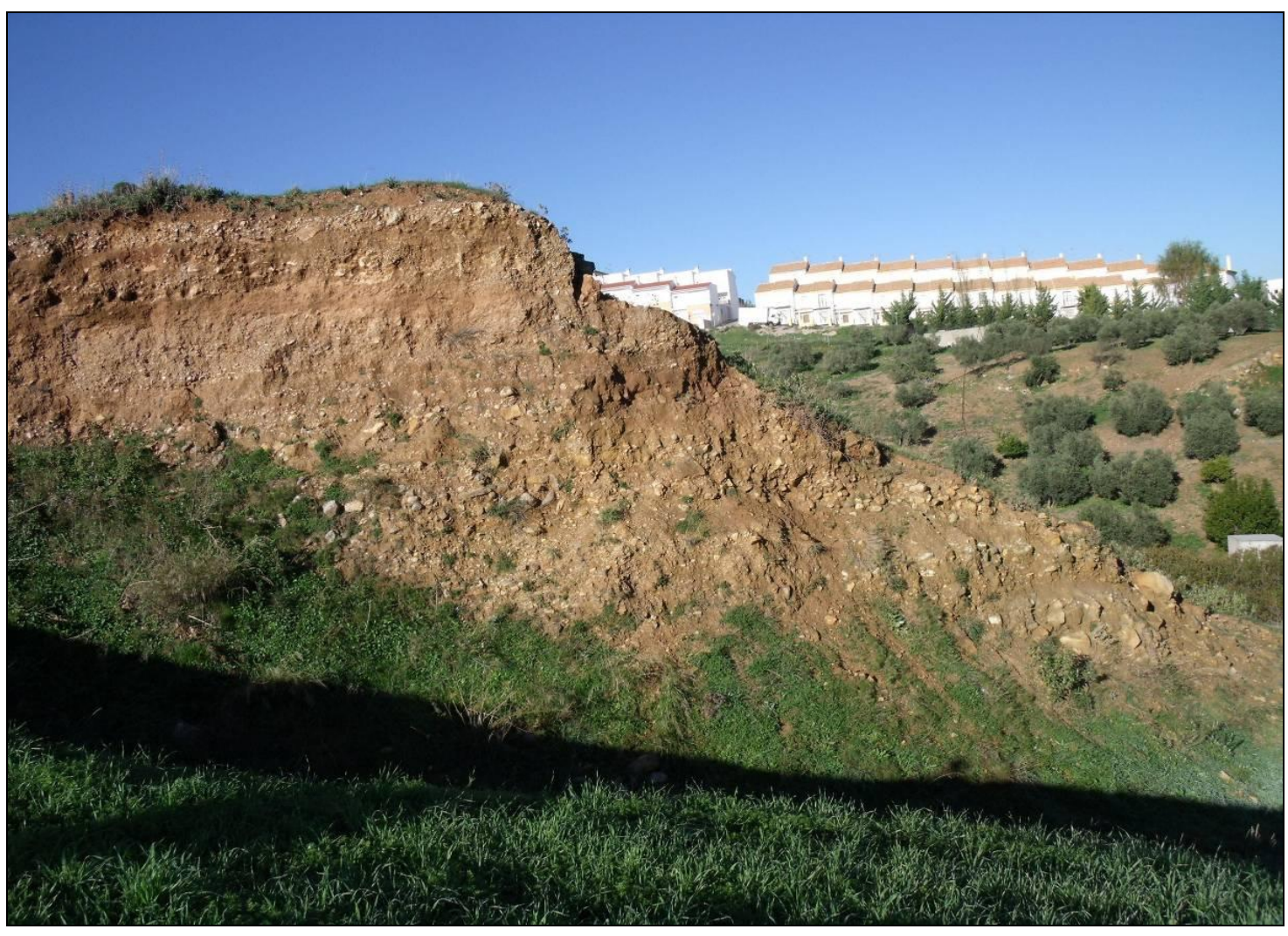

Figura 99. Vista general de la terraza del arroyo Cantarranas.

Altitud m s.n.m: el techo del depósito está a 390 m.

Extensión: 1.848,364 m²

. Contexto geológico y geomorfológico

Es una gran terraza generada por los aportes del arroyo Cantarranas, tributario del río Turón, que a su vez es el responsable de la disección del depósito producida por el encajamiento posterior del citado arroyo, de tal forma que aflora en sus dos orillas. Alcanza una potencia aproximada de unos $10 \mathrm{~m}$ y descansa sobre las areniscas del sustrato. En general, se trata de una secuencia granodecreciente, formada por paquetes horizontales formados por bloques y cantos de diferentes litologías (pizarra, esquisto, arenisca, cuarzo y caliza), poco rodados, con una matriz arcilloso - limosa, que alternan con paquetes de limos y arcillas de color rojo. Se observan grandes bloques dispersos. 
En la base del depósito y en su parte media los depósitos corresponden a una sedimentación de flujos densos o debris flow. A techo hay un nivel de cantos, bien estratificado. Se pueden distinguir varias capas de muro a techo:

- $6 \mathrm{~m}$ de bloques y cantos de litologías variadas y poco redondeados.

- 0,5 a 1 m de arcillas y limos, donde se localiza, dentro del depósito, una lasca levallois de sílex beige/gris poco rodada y muy fresca.

- $1 \mathrm{~m}$ de gravas de litología variada.

- $1 \mathrm{~m}$ de arcillas con bloques y cantos de tamaño mediano.

- 1m de bloques y cantos de tamaño mediano que se encuentran culminados por una capa fina de arcillas rojas.

En general, se trata de un depósito inmaduro, que ha sufrido un breve transporte a lo largo de un corto recorrido, lo que hace que contenga una gran variedad de litologías y que los clastos estén poco rodados. Se trata de una sedimentación de tipo abanico aluvial distal en la que alternan flujos densos, tanto de tipo debris flow como de tipo mud flow, con flujos canalizados.

. Procesos sedimentarios y postdeposicionales

Desde el punto de vista sedimentario, los procesos principales corresponden a los aportes del arroyo, donde las arcillas, arenas y gravas de diferentes tamaños se van depositando por diferentes mecanismos (mud flow, debris flow, flujos canalizadores). Los procesos postdeposicionales corresponden sobre todo al desmantelamiento natural de la propia terraza a ambos lados del arroyo, a lo que se le une la acción antrópica de los trabajos agrícolas en el caso del lado izquierdo del arroyo.

\section{. Interpretación geoarqueológica}

El hallazgo de una lasca muy fresca en el interior del paquete arcilloso permite pensar en el desmantelamiento de un asentamiento de superficie situado aguas arriba y, por el poco rodamiento de la pieza se puede pensar en un desplazamiento de poco recorrido. 


\section{. Análisis de la industria lítica}

Durante el desarrollo de los trabajos de campo únicamente se localizó una lasca muy fresca en el interior del paquete arcilloso. Se trata de una lasca levallois o BP-L de sílex masivo beige con algunas inclusiones negras (tabla 12). La pieza no presenta pátina y está poco rodada, la delineación desde la cara ventral es cóncava y un bulbo difuso. Su talón es liso, no cortical, lineal, unifacial y cóncavo. Su cara dorsal es no cortical y con presencia de aristas.

\begin{tabular}{|c|c|c|c|c|c|c|c|c|c|c|c|c|c|c|c|c|c|c|}
\hline \multicolumn{19}{|c|}{ YACIMIENTOS ARDALES. ESTUDIO ANALIITICO DE LAS BP } \\
\hline \multirow[t]{2}{*}{ Nombre } & \multicolumn{4}{|c|}{ Materias primas y morfologia } & \multicolumn{2}{|c|}{ Tipos de bases positivas } & \multicolumn{4}{|c|}{ Dimensiones } & \multicolumn{8}{|c|}{ Criterios analíticos de las BP } \\
\hline & $M$ & \begin{tabular}{|l|l|}
$R$ & $C$ \\
\end{tabular} & \begin{tabular}{l|l|}
$C$ & $P$ \\
\end{tabular} & $\mathrm{~T}$ & LAS/LAM & TIPO & $\mathrm{L}$ & $E$ & TB & VOL & CARA VENTRAL & & CARAT & ALONAR & & & CARA DORSAL & \\
\hline T. Arroyo Cantarranas & & & & & & & & & & & \begin{tabular}{|l|l|}
$F$ & $B$ \\
\end{tabular} & TIPO & \begin{tabular}{l|l} 
COR & $S$ \\
\end{tabular} & $T$ & $D$ & COR & \begin{tabular}{|l|l|} 
SSAG & STR \\
\end{tabular} & A \\
\hline TAC1-TL & S & $\begin{array}{ll}P & 0\end{array}$ & 0 NO & NO & LASCA & L & fdistal & 4 & $1 \mathrm{NO}$ & LE & $C C \quad D$ & I & NOCO LIN & UF & $\mathrm{CC}$ & NOCO & $\begin{array}{ll}\text { TRP } & \text { TRP }\end{array}$ & $\mathrm{SI}$ \\
\hline
\end{tabular}

Tabla 12. Estudio analítico de las BP de la terraza del arroyo Cantarranas.

. Valoración y conclusiones

La localización de una pequeña lasca (figura 100), poco rodada, dentro del paquete sedimentario de la terraza, hace imposible establecer el origen de la misma y de si procede de algún yacimiento desmantelado aguas arriba o de si es una lasca arrastrada de forma accidental.

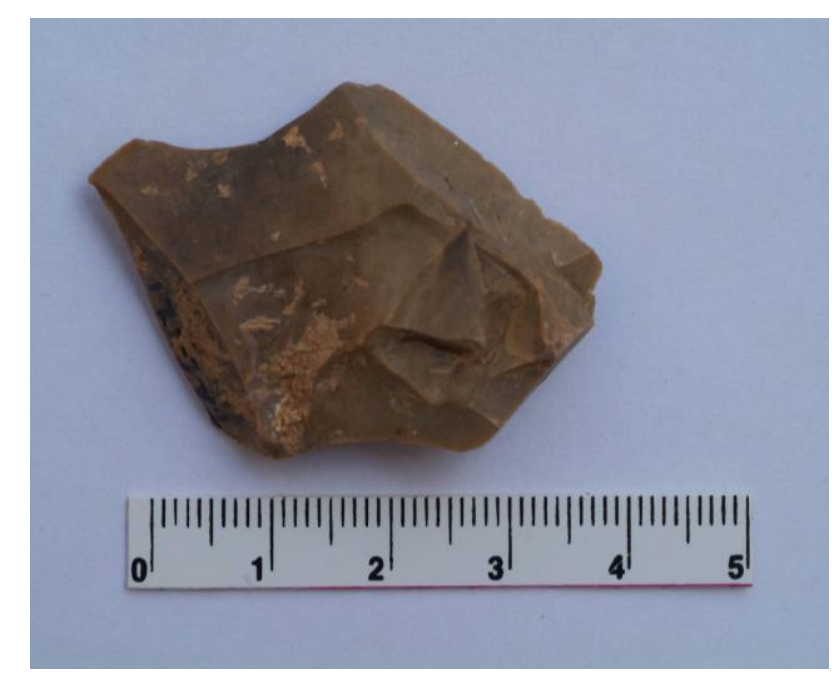

Figura 100. BP- Levallois de la terraza del arroyo

Cantarranas. 


\subsubsection{Depósito del Hundilón (Ardales)}

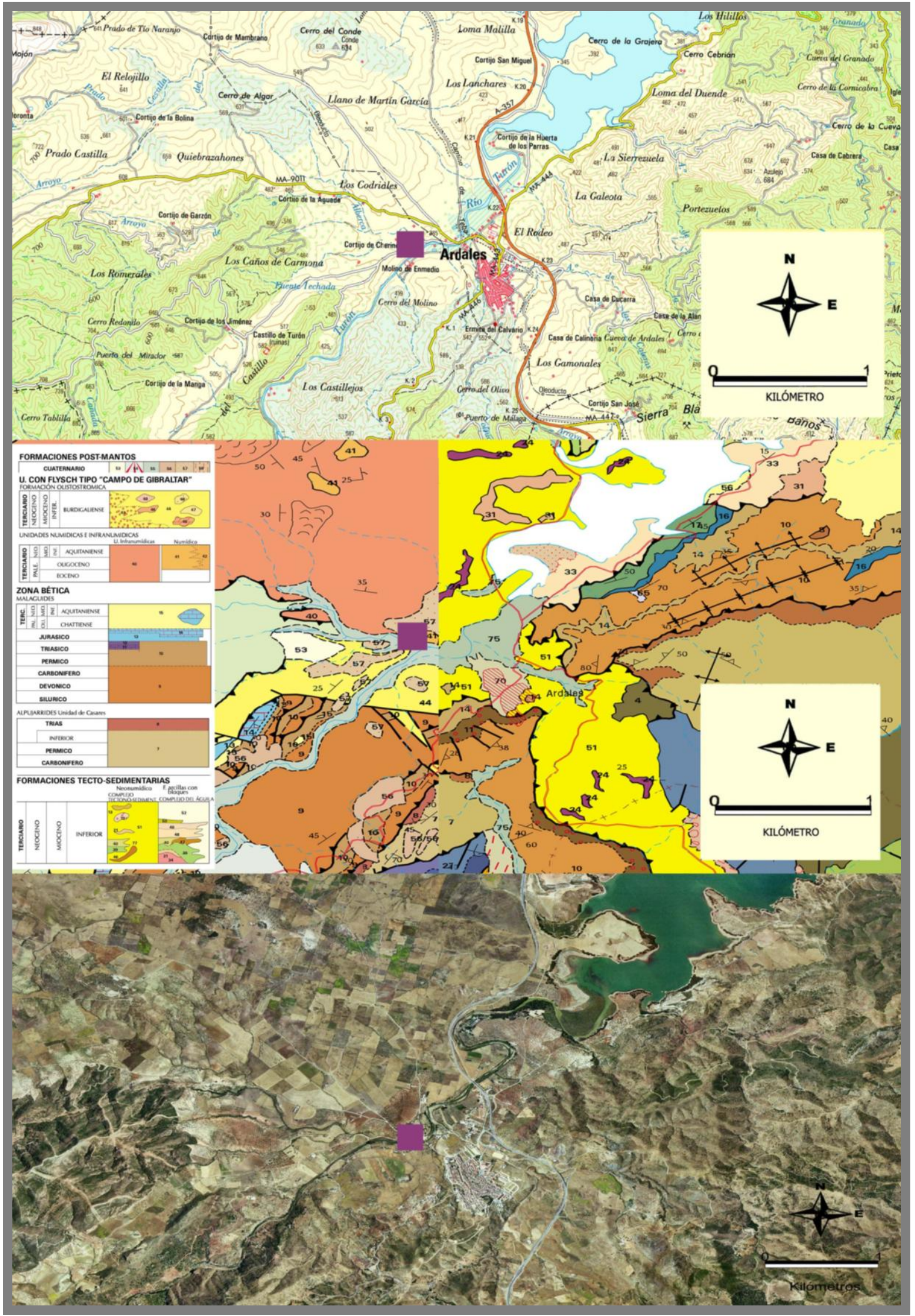


Se localiza al oeste del pueblo de Ardales, en la margen izquierda del río Turón. $\mathrm{Su}$ acceso se realiza desde el propio pueblo de Ardales.

Sus coordenadas en UTM ETRS89 30 son:

\begin{tabular}{|c|c|}
\hline $\mathbf{X}$ & $\mathbf{Y}$ \\
\hline 334706 & 4083572 \\
\hline
\end{tabular}

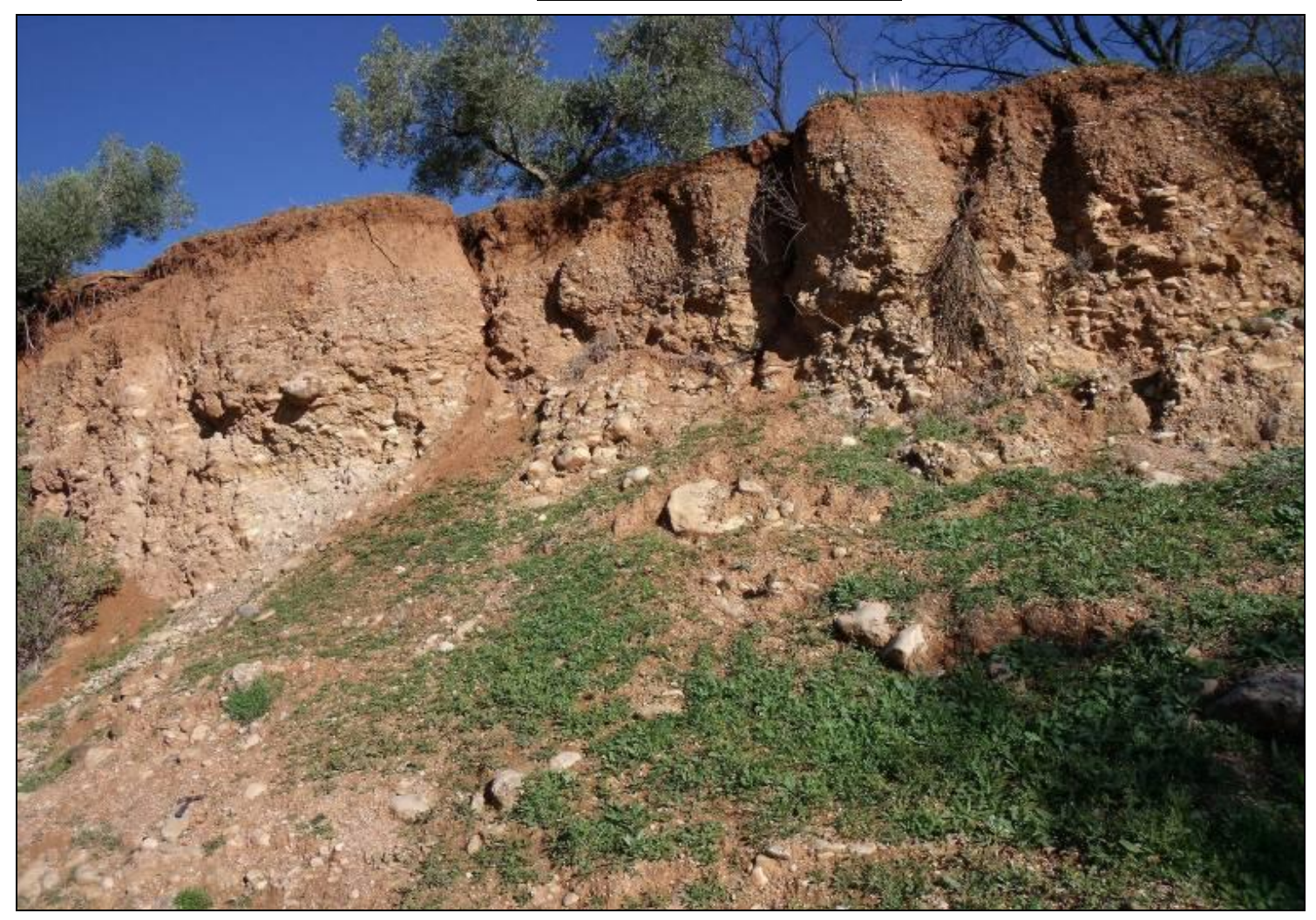

Figura 101. Vista general del depósito del Hundilón.

Altitud m s.n.m: 345/339 m

Extensión: 438, $92 \mathrm{~m}^{2}$

. Contexto geológico y geomorfológico

Se trata de un abanico aluvial que pasa lateralmente aguas abajo a un glacisterraza. En la parte proximal, su techo se encuentra a $345 \mathrm{~m}$ s.n.m. en su punto más alto, mientras que en su extremo distal su techo está a 339 m s.n.m., lo que da lugar a una superficie inclinada con una suave pendiente aguas abajo del río y a + 9/10 m sobre el nivel del río actual. En la parte proximal se caracteriza por una fuerte presencia de cantos, gravas y arenas, mientras que en la parte distal predominan los limos y las arcillas. En la parte proximal el depósito es granodecreciente, con bloques, cantos y gravas con apenas matriz en la base, que hacia el techo pasan a gravas y gravas finas, culminando con un paquete de limos y arcillas. Tanto los paquetes de cantos como los 
de gravas están bien organizados, con disposición paralela a la superficie deposicional. En la parte distal, el depósito está más desorganizado y los niveles de cantos y gravas aparecen entre paquetes de limos y arcillas.

Las principales litologías que encontramos son arcillas, calizas detríticas, areniscas, conglomerados, margas y margas calcáreas (puede incluir materiales Cenozoicos subbéticos internos) de las Unidades Infranumídicas y arcillas, ocasionalmente areniscosas y margas arcillosas con klippes de la formación Olistostromica del Flysch del Campo de Gibraltar.

. Procesos sedimentarios y postdeposicionales

Los procesos sedimentarios que afectan al depósito son principalmente de tipo aluvial, donde los materiales tanto geológicos como arqueológicos han sido arrastrados y depositados por la corriente fluvial del río Turón. Los postdeposicionales están relacionados con las escorrentías posteriores al momento del depósito procedentes de la parte superior de la ladera sobre la que se localiza el abanico que desplazan sobre todo arcillas y limos. Otro de los procesos postdeposicionales que afectan al abanico es la acción antrópica por efecto del arado y la plantación de almendros que ha desmantelado la parte alta del propio depósito.

El muestreo se ha realizado sobre un total de 100 clastos aproximadamente, en una superficie de $1 \mathrm{~m}^{2}$ (figura 102). El nivel inferior de unos $30 \mathrm{~cm}$, presenta cantos de mediano y gran tamaño y gravas, mezclados con limos y arcillas, hay presencia de areniscas compactas, calizas, cuarzos y esquistos. El nivel intermedio de unos $80 \mathrm{~cm}$ tiene bloques y cantos de mediano y gran tamaño, mezclado con arcillas y limos, entre las litologías hay una presencia mayoritaria de calizas y areniscas compactas, junto con cuarzos y esquistos. El nivel superior, con unos $40 \mathrm{~cm}$, tiene cantos de pequeño tamaño, gravas y arenas, con intercalaciones dentro del nivel intermedio de la zona muestreada. 


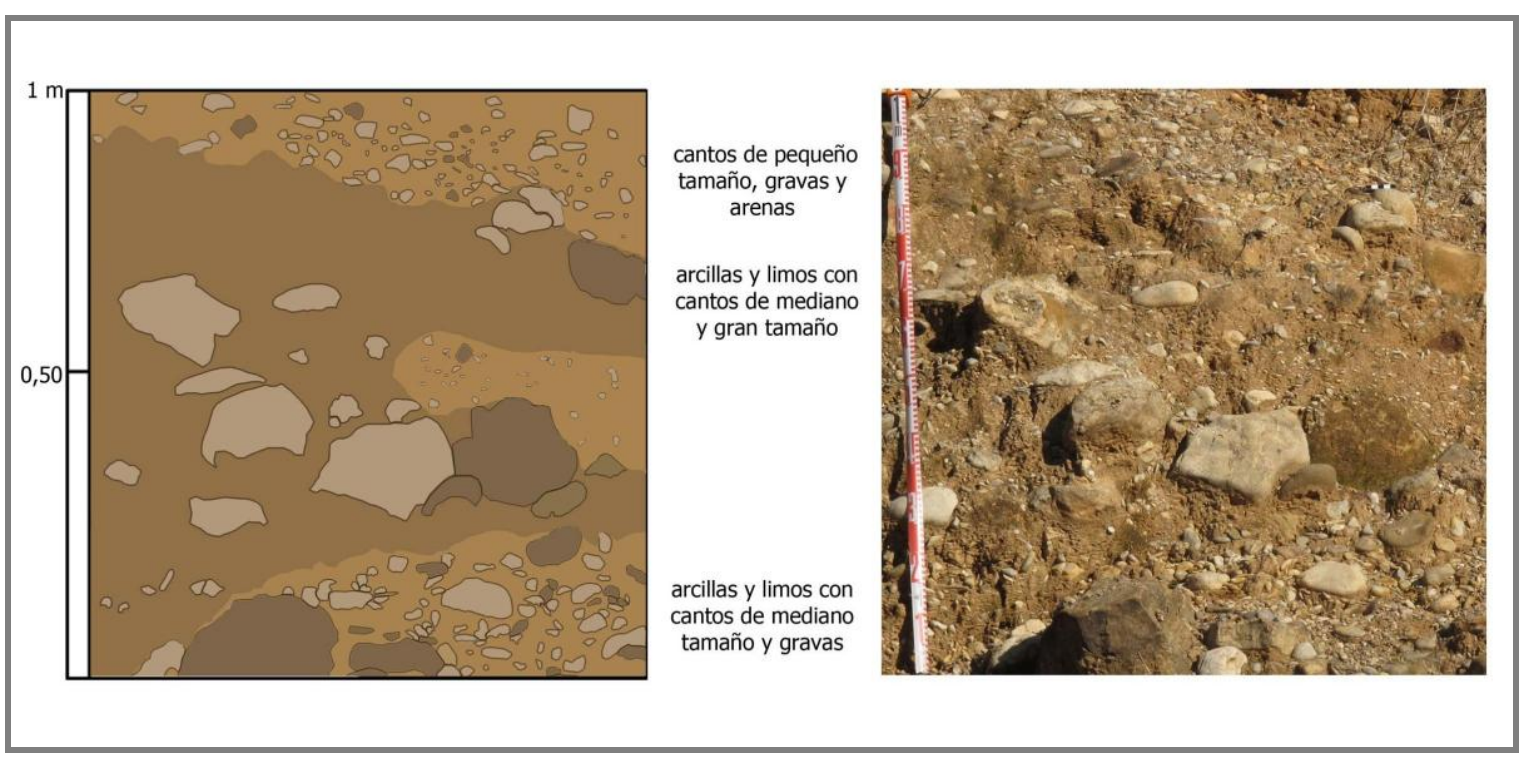

Figura 102. Muestreo $1 \mathrm{~m}^{2}$.

. Interpretación geoarqueológica

Los restos de industria lítica recuperados en el corte del depósito se encuentran en posición secundaria, y presentan los filos con un rodamiento medio/alto, por lo que han sido sometidos a un largo proceso de transporte desde su emplazamiento original.

\section{. Análisis de la industria lítica}

Se localizaron 10 piezas líticas durante los trabajos de prospección arqueológica iniciados a finales del verano de 2015. Los materiales aparecen en posición estratigráfica dentro del depósito de abanico colgado sobre el río Turón y se encuentran asociadas a un nivel de gravillas.

En cuanto a la materia prima todas las piezas líticas, salvo un ejemplar en sílex beige, son de sílex masivo negro tipo Turón. De las 10 se han analizado 6 ejemplares, ya que los otros 4 pertenecen a desechos de talla, todas en sílex masivo en tonalidades gris/negro

En su estudio morfotécnico comprobamos la presencia de Bases Naturales de Primera Generación (BN1G) de Bases Positivas (BP) y Bases Negativas de Segunda Generación (BN2G).

Las BN1G (tabla 13), corresponden a tres ejemplares de sílex negro tipo Turón. Presentan un sistema de explotación unipolar en uno de los ejemplares y diverso en los otros dos, de tipo bifacial y trifacial. Tienen un carácter centrípeto de tipo 4C y 3C, las extracciones son variadas en los tres ejemplares, son de tipo plano, simple, semiabrupto 
y abrupto, con un carácter de profundidad marginal en uno de ellos y muy profundo en los otros dos. La arista frontal es convexa mientras que la sagital es incurvada.

\begin{tabular}{|c|c|c|c|c|c|c|c|c|c|c|c|c|c|c|}
\hline \multicolumn{15}{|c|}{ YACIMIENTOS ARDALES. ESTUDIO ANALÍTICO DE LAS BN1G } \\
\hline \multirow{2}{*}{\begin{tabular}{|c|} 
Nombre \\
Terraza Hundilón \\
\end{tabular}} & \multicolumn{5}{|c|}{ Materias primas y morfología } & \multicolumn{2}{|c|}{ Tipos de bases negativas } & \multicolumn{6}{|c|}{ Criterios analíticos de las BN1G } & \multirow[t]{2}{*}{ Tema operativo técnico } \\
\hline & M & $R$ & C & $\mathrm{P}$ & $T$ & TN & $\mathrm{BN}$ & CF & CC & $\mathrm{CO}$ & CP & CAF & CAS & \\
\hline TH4-TL & $\mathrm{s}$ & B & $\mathrm{N}$ & NO & NO & U & BN1GE & B & 4C & SA & $\mathrm{mp}$ & CX & inc & T.O.T.I \\
\hline TH5-TL & $\mathrm{s}$ & B & $\mathrm{N}$ & B & NO & DIV & BN1GE & B & $3 C$ & $\mathrm{~s}$ & $\mathrm{~m}$ & $C X$ & inc & T.O.T.I \\
\hline TH6-TL & $\mathrm{s}$ & B & $\mathrm{N}$ & NO & NO & DIV & BN1GE & $T$ & 4C & $A / P$ & $\mathrm{mp}$ & $\mathrm{CX}$ & inc & T.O.T.I \\
\hline
\end{tabular}

Tabla 13. Estudio analítico de las BN1G del Hundilón.

Las BP (tabla 14) analizadas corresponden a lascas, ambas en sílex negro tipo Turón. Aparecen rodadas y una de ellas con pátina amarillenta. Se han documentado un ejemplar de BP-SD (semidescortezado) y uno de BP-I (interna). En cuanto al volumen las dos son LP (largo plano). La delineación desde la cara ventral muestra un talón recto en uno de los ejemplares y convexo en el otro, con un bulbo marcado en uno y difuso en otro. La cara talonar presenta un talón liso en uno de ellos y un talón facetado diedro en el otro, son no corticales y la superficie es en plataforma, la transformación es unifacetada y bifacetada. Las caras dorsales son no cortical dominante cortical y no cortical.

\begin{tabular}{|c|c|c|c|c|c|c|c|c|c|c|c|c|c|c|c|c|c|c|c|c|c|}
\hline \multicolumn{22}{|c|}{ YACIMIENTOS ARDALES. ESTUDIO ANALIITICO DE LAS BP } \\
\hline \multirow[t]{2}{*}{ Nombre } & \multicolumn{5}{|c|}{ Materias primas y morfología } & \multicolumn{3}{|c|}{ Tipos de bases positivas } & \multicolumn{4}{|c|}{ Dimensiones } & \multicolumn{9}{|c|}{ Criterios analíticos de las BP } \\
\hline & M & R & c & p & $\mathrm{T}$ & LAS/LAM & TIPO & $\mathrm{L}$ & A & E & TB & \begin{tabular}{l|l}
$B$ & VOL \\
\end{tabular} & & AVENTRAL & & CARATA & ALONAR & & & CARA DORSAL & \\
\hline Terraza Hundilón & & & & & & & & & & & & & $F$ & $B$ & TIPO & COR $S$ & $\mathrm{~T}$ & $D$ & COR & \begin{tabular}{l|l|} 
SSAG & STR \\
\end{tabular} & A \\
\hline TH8-TL & S & M & G & NC & NO & LASCA & SD & & 3,2 & 1,9 & 0,8 & $15 L P$ & RT & D & I & NOCO PLA & UF & RT & NCDC & TRP TRG & $\mathrm{SI}$ \\
\hline TH9-TL & S & B & N & A & NO & LASCA & । & & 3,7 & 3,1 & 1,2 & $18 \mathrm{LP}$ & $C x$ & M & $\mathrm{fd}$ & NOCO PLA & $B F$ & UA & NOCO & CDG CDG & $\mathrm{SI}$ \\
\hline
\end{tabular}

Tabla 14. Estudio analítico de las BP del Hundilón.

Se documenta 1 ejemplar de BN2G en sílex negro (tabla 15) y utilizamos para su clasificación la nomenclatura del sistema tipológico de Laplace (Laplace, 1972) y los de la Lista-Tipo Bordes (Bordes, 1961). Corresponde a una raedera realizada sobre una lasca levallois. Con un volumen de tipo LP (largo plano), la delineación del talón desde la cara ventral es convexa y con un bulbo difuso, de talón liso abatido, no cortical, lineal y unifacetado. La cara dorsal es no cortical. El retoque, es simple, marginal, alterno y continuo y se encuentra en el lateral derecho. Se trataría de una raedera lateral según Laplace (R21) y una raedera alterna según Bordes (29). 


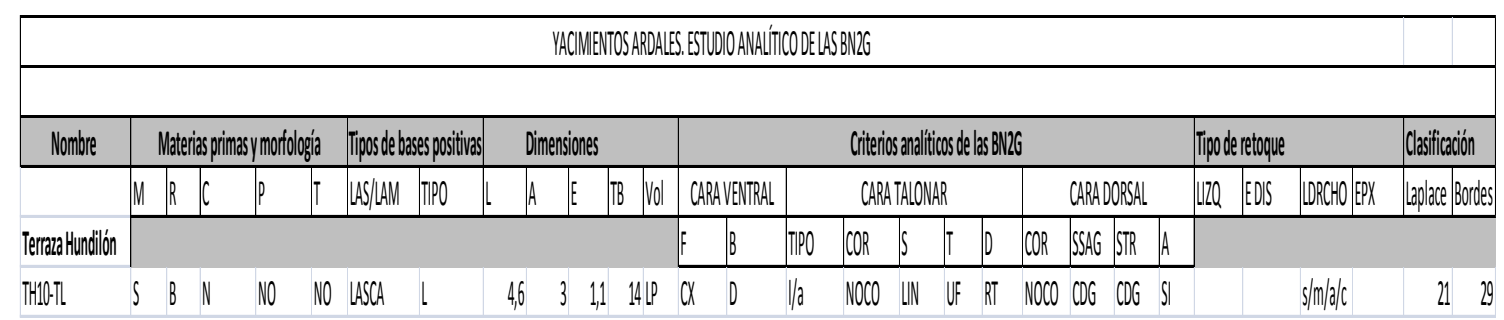

Tabla 15. Estudio analítico de las BN2G del Hundilón.

. Valoración y conclusiones

Corresponde a un abanico aluvial cuyos materiales proceden principalmente del río Turón y del arroyo de la Alberca. Su localización a pocos metros del cauce actual del río, conformando un abanico aluvial, el rodamiento medio de la industria lítica recuperada y la existencia aguas arriba de un afloramiento de sílex negro de tipo Turón, nos hace pensar en la posibilidad de que el arrastre se produjo desde una corta distancia, sobre todo por la localización de la mayoría de las piezas dentro del paquete sedimentario de gravillas del abanico.

En cuanto a la tecnología, aunque el número de ejemplares es pequeño para establecer conclusiones definidas, es importante por su situación dentro de la estratigrafía del depósito aluvial y para las comparativas con los demás hallazgos. Hay una presencia de núcleos casi agotados y de lascas, dentro de las lascas hay un ejemplar de BP de semidescortezado indicador del inicio de talla, BP internas vinculadas a la continuidad de talla, todas ellas retocadas, de pequeño y mediano tamaño, en el grupo de los productos retocados o $\mathrm{BN} 2 \mathrm{G}$, nos encontramos únicamente con un ejemplar correspondiente a una raedera. 


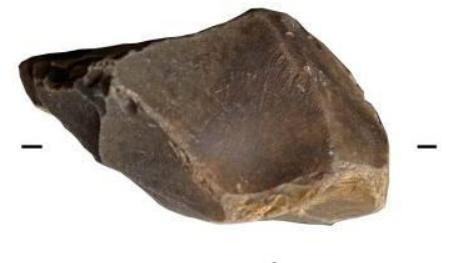

1
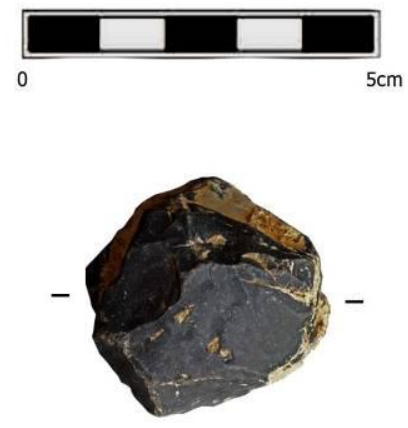

2

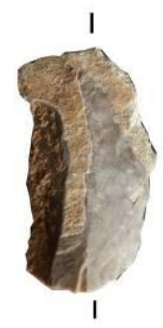

3

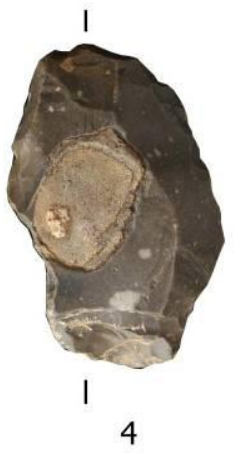

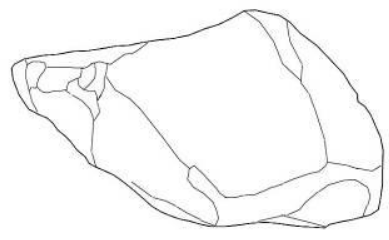
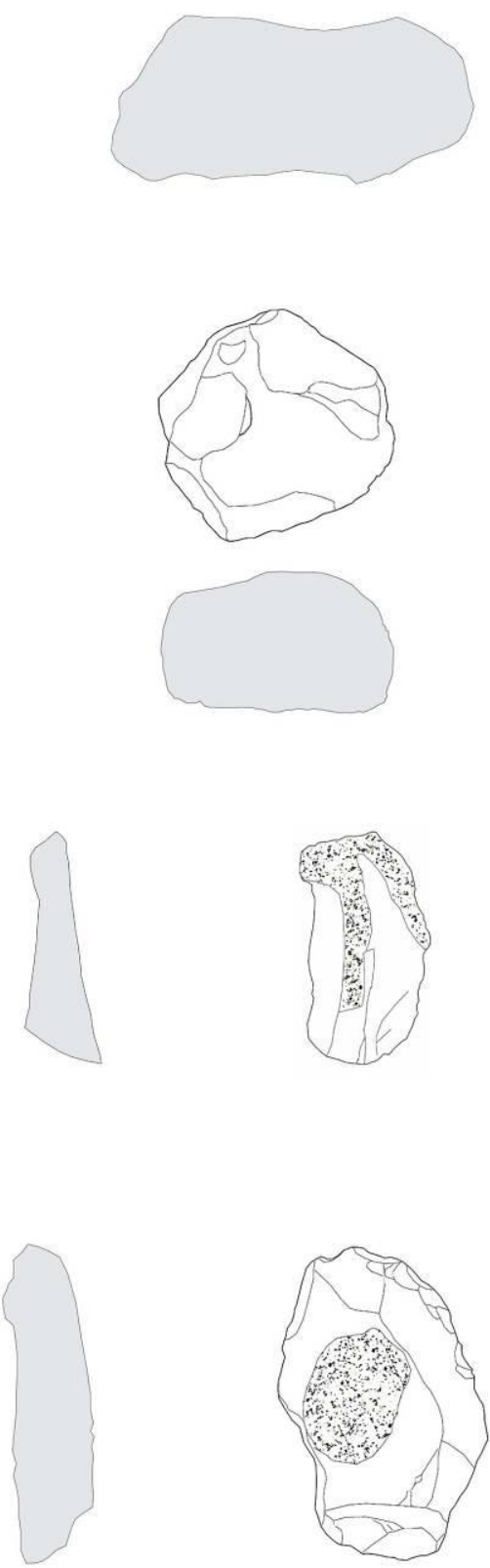

Figura 103. Depósito del Hundilón (Ardales): 1, 2:BN1G-Núcleo diverso y unipolar; 3: BPLasca de semidescortezado; 4: BN2G-Raedera lateral. 


\subsubsection{Terraza de Morenito (Ardales)}

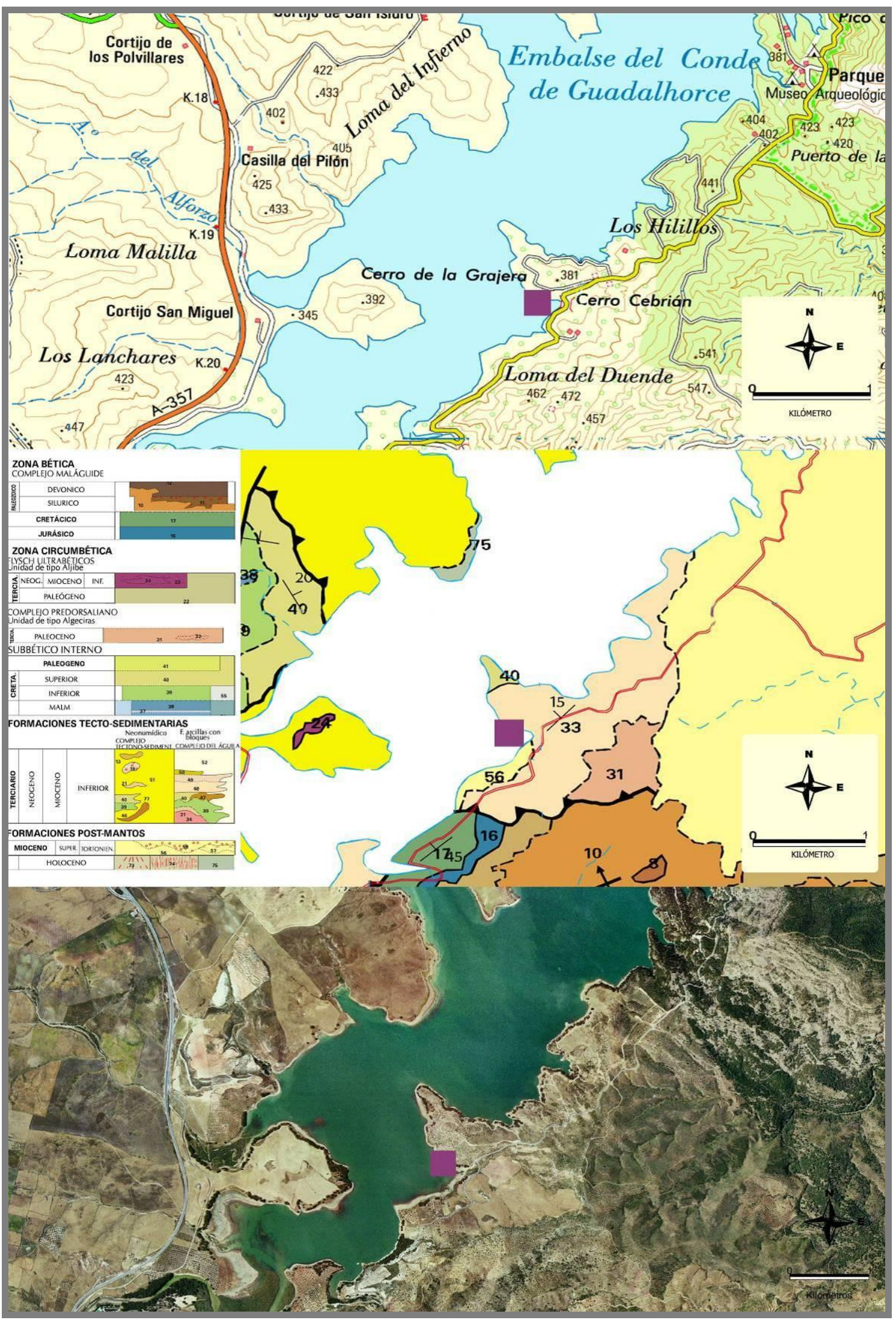


El yacimiento se encuentra situado en la ladera de un promontorio sobre el río Turón y forma parte de una terraza fluvial. Su acceso se realiza por la carretera entre Ardales y los embalses (MA-444).

Sus coordenadas UTM ETRS89 30 son:

\begin{tabular}{|c|c|}
\hline $\mathbf{X}$ & $\mathbf{Y}$ \\
\hline 337643 & 4086720 \\
\hline 338244 & 4086392 \\
\hline 337880 & 4086016 \\
\hline 337560 & 4086481 \\
\hline
\end{tabular}

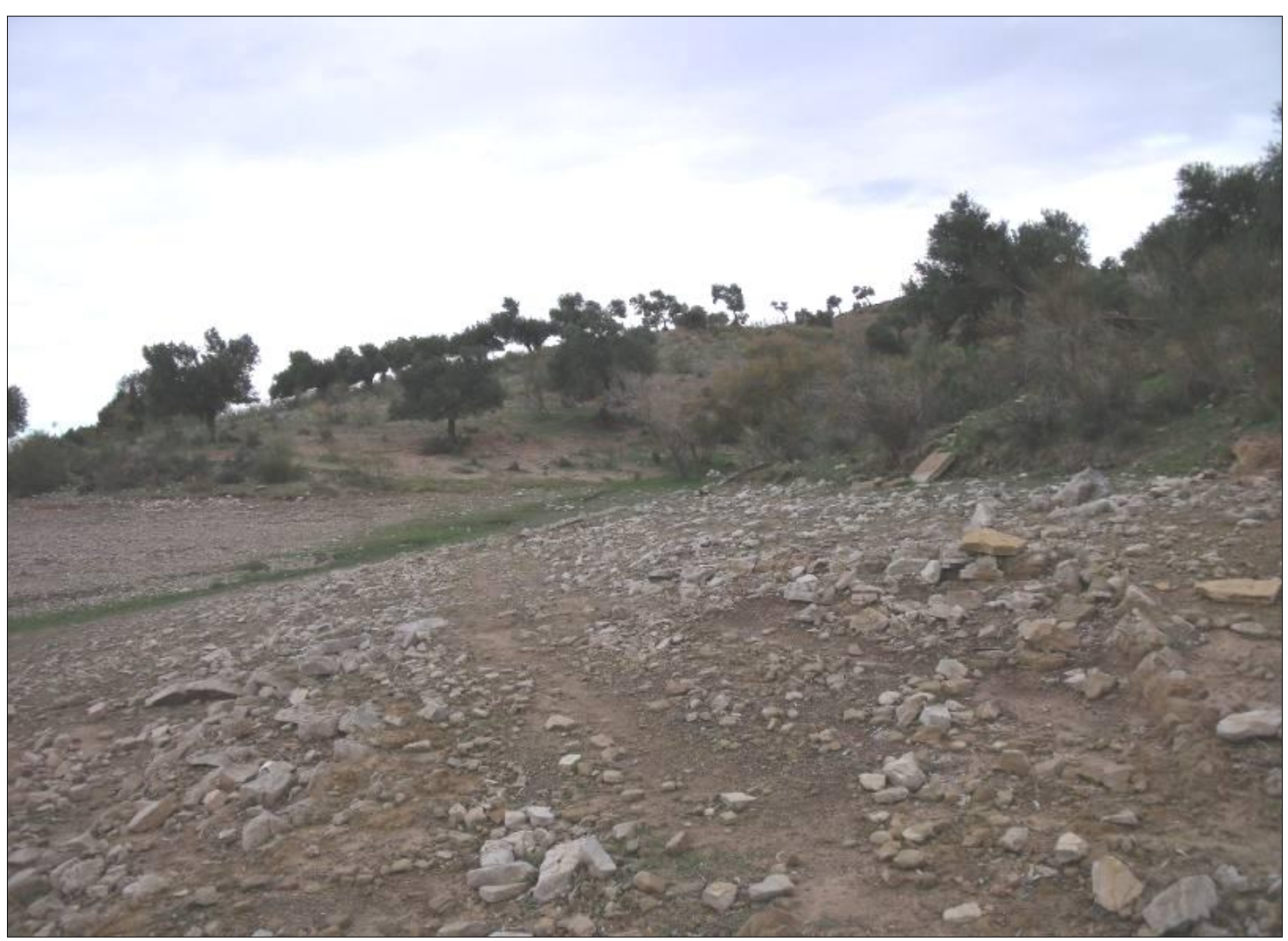

Figura 104. Vista general de la terraza de Morenito.

Altitud m s.n.m.: 335 m (base del depósito de la terraza baja) y 350 m (base de la terraza alta)

Extensión: $230.061 \mathrm{~m}^{2}$

. Contexto geológico y geomorfológico

La zona se encuentra sobre materiales del Cenozoico, compuestos por areniscas, margas marrones y verdosas de la unidad de Algeciras, perteneciente a la zona Circumbética, afloran junto a margocalizas rosadas "Capas rojas" cuyos tramos más 
bajos presentan gran cantidad de sílex gris y rojo dentro de los niveles margocalcáreos del Subbético interno y calcarenitas y conglomerados de la Formación Post-mantos.

Son dos terrazas desmanteladas del río Turón. La primera es una terraza desmantelada producida por el encajamiento del río Turón que se encuentra a una altura aproximada de +15 m sobre el nivel original del río. La base de este depósito se encuentra a $335 \mathrm{~m}$ s.n.m. El depósito fluvial original, de $1 \mathrm{~m}$ de espesor conservado, se apoya sobre un sustrato de calizas tableadas verticales que alternan con margas y está formado por un primer nivel de 5 a $10 \mathrm{~cm}$ de gravas y cantos (centil $5 \mathrm{~cm}$ ) sobre el que aparecen cantos y bloques rodados de mayor tamaño, mayoritariamente de caliza autóctona, bien redondeados, a los que se unen otras litologías como cuarzo, arenisca compacta y cantos de sílex negro/gris claro en plaquetas. El depósito original apenas se conserva en unos pequeños afloramientos por debajo de los cuales se extiende por la ladera un derrame de la terraza hacia el río formado por dos poblaciones, una que corresponde a las gravas y cantos de la terraza desmantelada y otra generada por el desmantelamiento del sustrato calizo sobre el que se apoya esta, que genera grandes cantos y bloques ligeramente redondeados y sin redondear.

Sobre los escasos restos de la superficie de la terraza y por ladera que se extiende en sentido ascendente, se dispone un coluvión formado arcillas con cantos y bloques, algunos de ellos bien redondeados. Este coluvión procede del desmantelamiento de una terraza antigua situada en posición superior, a la cota de 350 m s.n.m. y a + 30 m sobre el nivel original del río (antes del embalse), de la que apenas quedan restos y cuya potencia visible en la actualidad es de $1 \mathrm{~m}$.

\section{. Procesos sedimentarios y procesos postdeposicionales}

El principal agente sedimentario que configuró a la terraza fué el aporte de materiales del río Turón. Su ubicación en la margen del embalse ocasiona numerosos procesos postdeposicionales por las subidas y bajadas del nivel de agua, levantando y desplazando los materiales arqueológicos procedentes de la terraza (figura 105). 


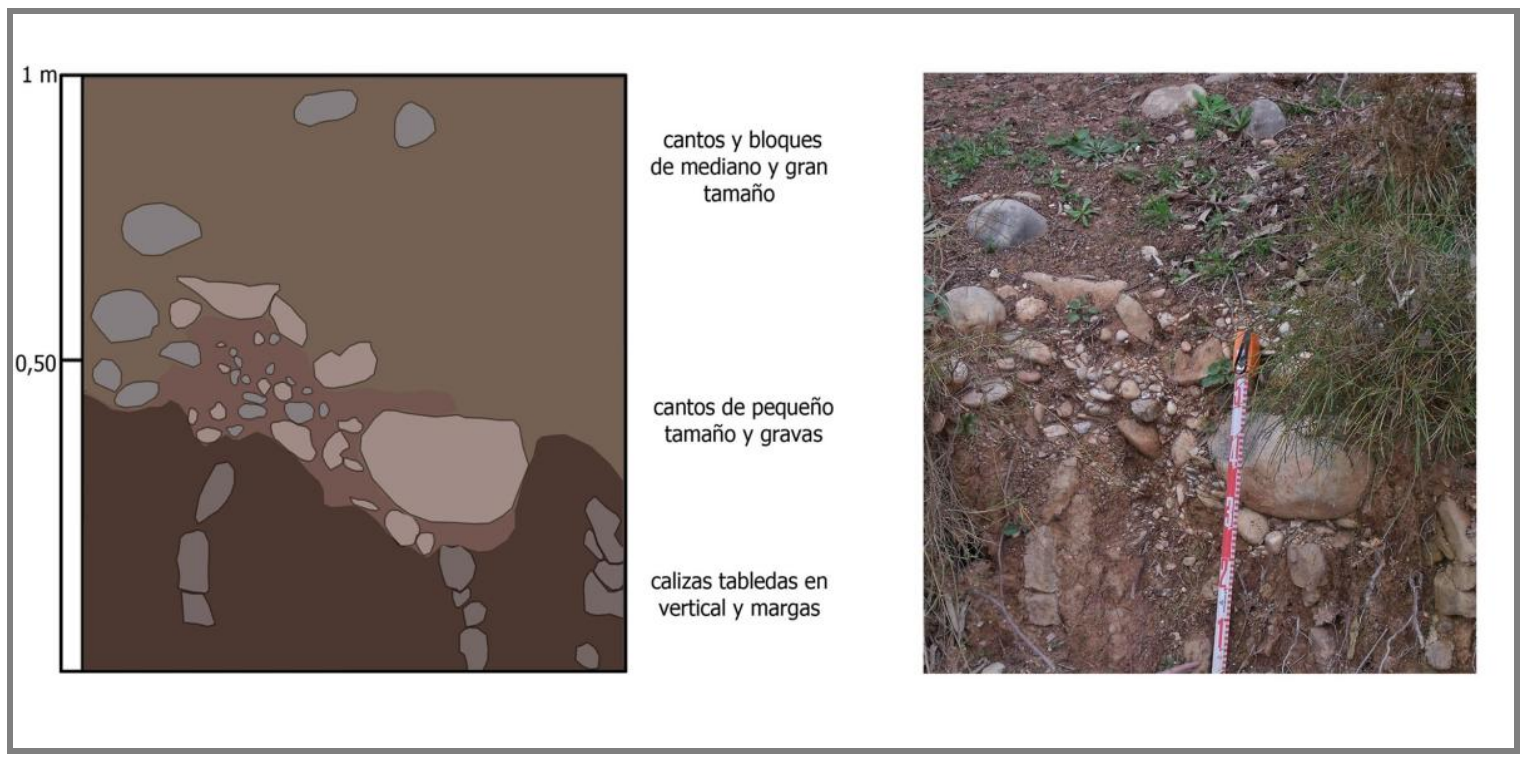

Figura 105. Muestreo de $1 \mathrm{~m}^{2}$

El muestreo se ha realizado en $1 \mathrm{~m}^{2}$, muestreando aproximadamente un total de 100 clastos. El nivel inferior de unos $30 \mathrm{~cm}$, aproximadamente, es un sustrato de calizas tabledas alternando con margas. Sobre este sustrato se apoya un primer nivel, de unos 5-10 $\mathrm{cm}$ con presencia de gravillas y pequeños guijarros poco redondeados, mezclados con limos y arcillas, entre las litologías hay una presencia mayoritaria de calizas, seguidos de algunos cuarzos, areniscas compactas y algunos cantos de sílex en plaquetas, muy pequeños. El nivel superior de unos $60 \mathrm{~cm}$ tiene bloques y cantos de tamaño mediano y grande, predominando las calizas frente a los bloques de arenisca, también de gran tamaño, con limos y arcillas.

\section{. Interpretación geoarqueológica}

Se trata de un depósito de terraza fluvial parcialmente desmanteladoLos materiales arqueológicos se localizan en posición secundaria en superficie, con filos que presentan un rodamiento medio.

\section{. Análisis de la industria lítica}

El análisis de la industria lítica se ha realizado sobre el material recogido entre los años 85-90, tanto de las prospecciónes arqueológicas desarrolladas durante esos años en Ardales, como de la intervención arqueológica del yacimiento realizada por el equipo de Ardales también en los años 90 (Ramos Muñoz et al., 1987). Parte de los materiales obtenidos se encuadraban en los momentos del Bronce final y en fases 
posteriores, sin embargo, con la revisión de los materiales del Centro de Interpretación de Ardales hemos comprobado la existencia de material arqueológico del Pleistoceno. Este material del Pleistoceno muestra diferencias respecto a los materiales de la Prehistoria reciente sobre todo por las pátinas, los rodamientos y la materia prima utilizada. Se han analizado un total de 13 ejemplares que han sido seleccionadas en función de varios caracteres tales como la pátina o el rodamiento principalmente.

La materia prima (figura 106) predominante es el sílex masivo beige oscuro y gris, con pátinas amarillentas en su mayoría. Uno de los sílex masivos aparece con posibles huellas de Phycosiphon presentes en los sílex denominados tipo Turón aflorantes en las zonas próximas y aguas arriba del río. También aparecen dos ejemplares de arenisca compacta de grano variable.

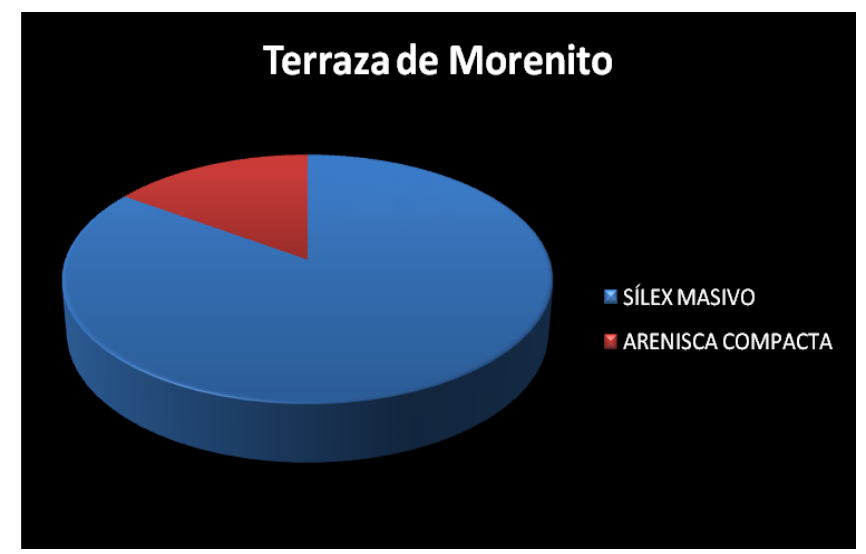

Figura 106. Materias primas de las piezas líticas recuperadas en el yacimiento de Morenito.

En su estudio morfotécnico comprobamos la presencia de Bases Naturales de Primera Generación (BN1G) de Bases Positivas (BP) y Bases Negativas de Segunda Generación (BN2G).

Hay un solo ejemplar de BN1GE (tabla 16) de sílex masivo gris y pátina blanca. Presenta un sistema de explotación unipolar de tipo unifacial, con un carácter centrípeto casi completo de tipo 3C, las extracciones son de tipo semiabrupto, con un carácter de profundidad muy profundo. La arista frontal es convexa mientras que la sagital es sinuosa. 


\begin{tabular}{|c|c|c|c|c|c|c|c|c|c|c|c|c|c|c|}
\hline Nombre & $\mathrm{Ma}$ & rias & ma & & ogía & Tipo & negativas & & iter & anal & $\cos d$ & as $\mathrm{BN}$ & & Tema operativo técnico \\
\hline errz. Morenito & $M$ & $\mathrm{R}$ & C & $\mathrm{P}$ & $T$ & $\mathrm{TN}$ & $\mathrm{BN}$ & CF & CC & $\mathrm{CO}$ & $\mathrm{CP}$ & CAF & CAS & \\
\hline 10-58 & S & M & G & B & NO & U & BN1GE & U & $3 C$ & SA & $\mathrm{mp}$ & $c x$ & $\sin$ & .O.T.I \\
\hline
\end{tabular}

Tabla 16. Estudio analítico de las BN1G de la terraza de Morenito.

Las BP (tabla 17) corresponden a lascas, casi todas en sílex masivo beige o gris. Ambas aparecen con un rodamiento medio y con pátinas amarillentas. Se han documentado 1 ejemplar de BP-SD (semidescortezado), 2 BP-I (interna) y 7 BP-L (levallois). En cuanto al volumen hay un predominio de las LP (largo plano) frente a las EP (espesas planas) y LE (larga espesa). La delineación desde la cara ventral muestra talónes rectos, convexos y cóncavos. La cara talonar presenta un talón liso en la mayoría, con presencia de algunos facetados y abatidos, predominantemente con talones no corticales y superficie en plataforma. Las caras dorsales son sobre todo no corticales.

\begin{tabular}{|c|c|c|c|c|c|c|c|c|c|c|c|c|c|c|c|c|c|c|c|c|c|}
\hline \multicolumn{22}{|c|}{ YACIMIENTOS ARDALES. ESTUDIO ANALIITICO DE LAS BP } \\
\hline \multirow{3}{*}{$\begin{array}{r}\text { Nombre } \\
\text { Terrz. Morenito }\end{array}$} & \multicolumn{5}{|c|}{ Materias primas y morfología } & \multicolumn{2}{|c|}{ Tipos de bases positivas } & \multicolumn{4}{|c|}{ Dimensiones } & \multicolumn{10}{|c|}{ Criterios analíticos de las BP } \\
\hline & \multirow[t]{2}{*}{ M } & \multirow[t]{2}{*}{$R$} & \multirow[t]{2}{*}{ c } & \multirow[t]{2}{*}{ P } & \multirow[t]{2}{*}{ T } & \multirow[t]{2}{*}{ LAS/LAM } & \multirow[t]{2}{*}{ TIPO } & \multirow[t]{2}{*}{ L } & \multirow[t]{2}{*}{ E } & \multirow[t]{2}{*}{ TB } & \multirow[t]{2}{*}{ VOL } & \multicolumn{2}{|c|}{ CARA VENTRAL } & \multicolumn{4}{|c|}{ CARA TALONAR } & \multicolumn{4}{|c|}{ CARA DORSAL } \\
\hline & & & & & & & & & & & & $\mathrm{F}$ & $B$ & TIPO & \begin{tabular}{|l|l|} 
COR & $S$ \\
\end{tabular} & $\mathrm{~T}$ & $\mathrm{D}$ & COR & SSAG & STR & A \\
\hline T.MOR1 & $S$ & M & G & A & NO & LASCA & 1 & 7,7 & 8,7 & 2,4 & $21 \mathrm{LE}$ & RT & M & $a$ & NOCO PLA & UF & RT & NOCO & TRP & TRG & $\mathrm{SI}$ \\
\hline MO-342 & $S$ & B & G & A & NO & LASCA & L & 5,4 & 3 & 0,8 & $13 \mathrm{LP}$ & $c x$ & M & $\mathrm{fc}$ & NOCO PLA & MF & $c x$ & NOCO & TRG & TRG & $\mathrm{SI}$ \\
\hline MO-470 & A & M & 0 & NO & NO & LASCA & 1 & 5,3 & 8,9 & 2,1 & $25 \mathrm{LP}$ & $c x$ & D & c & CO PLA & NF & $c x$ & NOCO & OV & OV & $\mathrm{SI}$ \\
\hline MO-594 & A & M & G & NO & NO & LASCA & $S D$ & 4,8 & 6,6 & 1,4 & $25 \mathrm{EP}$ & $C C$ & M & 1 & NOCO LIN & UF & $C C$ & CDNC & OV & OV & $\mathrm{SI}$ \\
\hline T. MORENITO & $S$ & M & G & A & NO & LASCA & L & 8 & 4,8 & 3,2 & $13 \mathrm{LP}$ & $c X$ & M & $\mathrm{fd}$ & NOCO PLA & BF & $c x$ & NCDC & PTG & TRG & $\mathrm{SI}$ \\
\hline MO-43 & $S$ & M & G & NO & NO & LASCA & L & 7 & 5 & 1,3 & $17 \mathrm{LP}$ & RT & NO & NO & NO NO & NO & NO & NCDC & TRP & TRG & SI \\
\hline MO-100 & $S$ & M & G & A & NO & LASCA & L & 5,5 & 3,8 & 1,2 & $13 \mathrm{LP}$ & $C C$ & M & 1 & NOCO PLA & UF & $C C$ & NOCO & TRG & TRG & SI \\
\hline MO-350 & $S$ & M & B & A & NO & LASCA & L & 2,9 & 2,7 & 0,9 & $19 \mathrm{LP}$ & $c x$ & D & $1 / a$ & NOCO PLA & UF & $c x$ & NOCO & TRG & TRG & $\mathrm{SI}$ \\
\hline MO-400 & $S$ & M & G & A & NO & LASCA & L & 4,3 & 3,4 & 1 & $18 \mathrm{LP}$ & RT & M & 1 & NOCO PLA & UF & RT & NOCO & TRP & TRG & SI \\
\hline M0-183 & $S$ & $M$ & B & $A$ & NO & LASCA & L & 8,5 & 4,2 & 3 & $13 \mathrm{LP}$ & $c X$ & NO & c & CO PLA & NF & $c x$ & NOCO & PTG & TRP & SI \\
\hline
\end{tabular}

Tabla17. Estudio analítico de las BP de la terraza de Morenito.

En relación a las $\mathrm{BN} 2 \mathrm{G}$ (tabla 18) utilizamos la nomenclatura del sistema tipológico de Laplace (Laplace, 1972) y los de la Lista-Tipo Bordes (Bordes, 1961). Aparecen 2 ejemplares, uno en sílex masivo marrón con pátina amarillenta y otro en sílex masivo beige con pátina anaranjada. Ambos ejemplares corresponden a raederas realizadas sobre lascas internas. Con un volumen de tipo LP (largo plano), una delineación del talón desde la cara ventral convexa y recta y con bulbo difuso en una de ellas ya que el otro ejemplar carece de bulbo. En relación al tipo de retoque, ambas presentan un retoque simple, marginal, directo y continuo Se trataría de una raedera lateral según Laplace (R21) y una raedera simple convexa según Bordes (10). Y de un raedera trasversal (R22) o una raedera lateral convexa (22). 


\begin{tabular}{|c|c|c|c|c|c|c|c|c|c|c|c|c|c|c|c|c|}
\hline \multicolumn{15}{|c|}{ 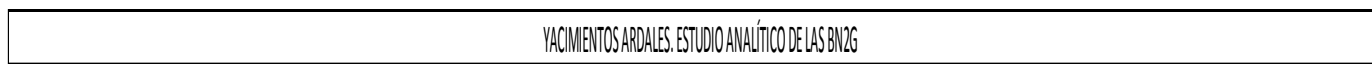 } & & \\
\hline Nonbe & Nateisppin & symoro & gía Tiposde basesspositivas & & mensiones & & & & & 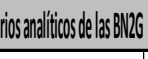 & & & Tipoderetoque & & \multicolumn{2}{|c|}{ Casifilicacion } \\
\hline & IN $R$ & p & IT $\quad$ LAS/LAM & & E & & CARA YENTA & & & RATAONARR & & ARDORSSAL. & LLO EOS & IDCECD EPX & applace & ebordes \\
\hline Term. Morenitio & & & & & & & $F$ & TPP & COR & \begin{tabular}{|l|l|l|}
$S$ & $\mathrm{~T}$ & 0 \\
\end{tabular} & COR SSA & SAG STR $A$ & & & & \\
\hline TMOOOL & S M O & A & NO LSSA I & 1,7 & $5,1,2,1.3$ & & $\alpha \quad 0$ & 1 & NOCO & PlA UF $\quad$ QX & NOCO TRG & AG TRG SI & & $\mathrm{s} m \mathrm{~m} d \mathrm{de}$ & R2I & 10 \\
\hline T.MOR2 & $\begin{array}{l}S \\
B\end{array}$ & A & NO LSSA I & 10,4 & $9,2 \quad 2,8 \quad 17$ & $17 / \mathrm{P} R$ & RT $\quad 10$ & 10 & NO & NO NO NO & NOC TRG & $20 \mathrm{TRG} S \mathrm{SI}$ & $s|m| d||$ & & R2I & 21 \\
\hline
\end{tabular}

Tabla 18. Estudio analítico de las BN2G de la terraza de Morenito.

. Valoración y conclusiones

El yacimiento se encuentra directamente sobre una terraza fluvial, donde los materiales asociados a las industrias del Paleolítico destacan por unas pátinas amarillentas con un rodamiento medio y generalmente en sílex beige/marrones o en tonalidades claras, areniscas o cuarcitas, frente a los sílex negros brillantes tipo Turón con escaso rodamiento y filos muy frescos asociados en su mayoría a industrias de la Prehistoria reciente. Su localización a pocos metros del cauce actual del río, conformando un especie de recodo y que genera la acumulación de materiales desde la cabecera del río, el rodamiento medio de la industria lítica recuperada y la existencia aguas arriba de un afloramiento de sílex en la zona del castillo Turón nos hace pensar en la posibilidad del arrastre de parte de material geológico siendo aprovechado y recogido en la zona de la terraza. La procedencia de la materia prima se establece en virtud de la presencia Phycosiphon en el sílex beige/negro, que es propia del sílex tipo Turón para las fases de la Prehistoria reciente.

En cuanto a la tecnología, hay una escasa presencia de núcleos, donde las BP representan al grupo más numeroso sobre todo las BP- L (levallois) y con una escasa representación de ejemplares de BP-D (descortezado) y BP-SD (semidescortezado), indicadores del inicio de talla. Las BP-I (internas) vinculadas a la continuidad de talla de mediano tamaño, al igual que las levallois. En el grupo de los productos retocados o BN2G, nos encontramos únicamente con 2 ejemplares de raederas.

El análisis de la industria lítica establece una vinculación con la tecnología propia del Paleolítico medio o Modo II, con presencia de lascas levallois mayoritariamente de sílex como materia prima. El yacimiento presenta una buena visibilidad y proximidad con otros yacimientos, que presentan materiales similares, situados en la margen opuesta como terraza de Las Grajeras, Raja del Boquerón o Lomas del Infierno. 

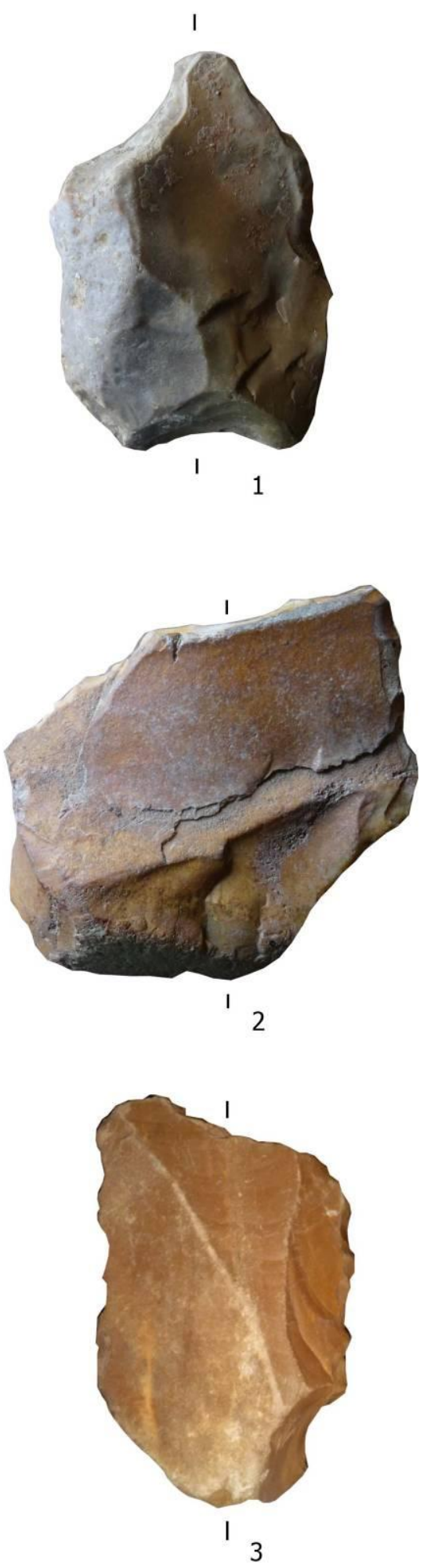
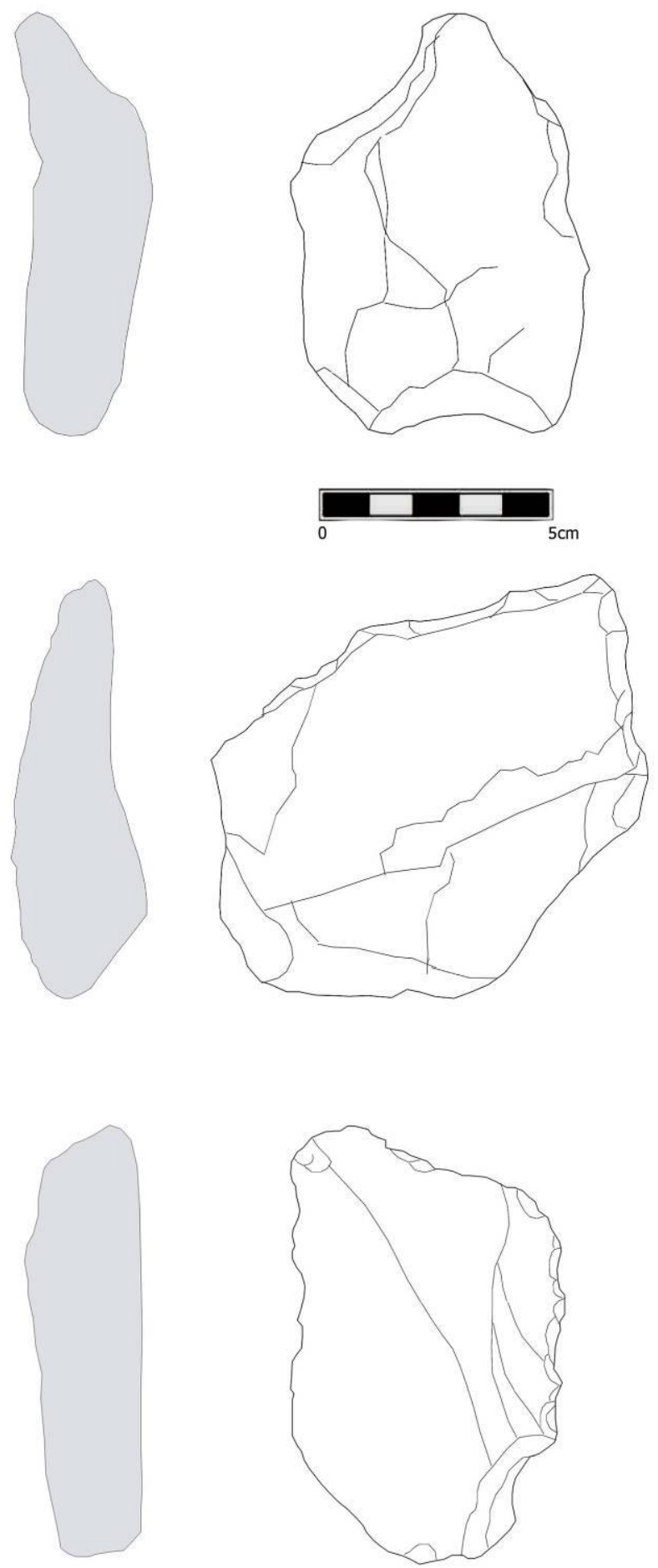

Figura 107. Terraza de Morenito (Ardales): 1: BP-Lasca levallois; 2, 3: BN2G-Raederas. 


\subsubsection{Llanos de Belén (Ardales)}

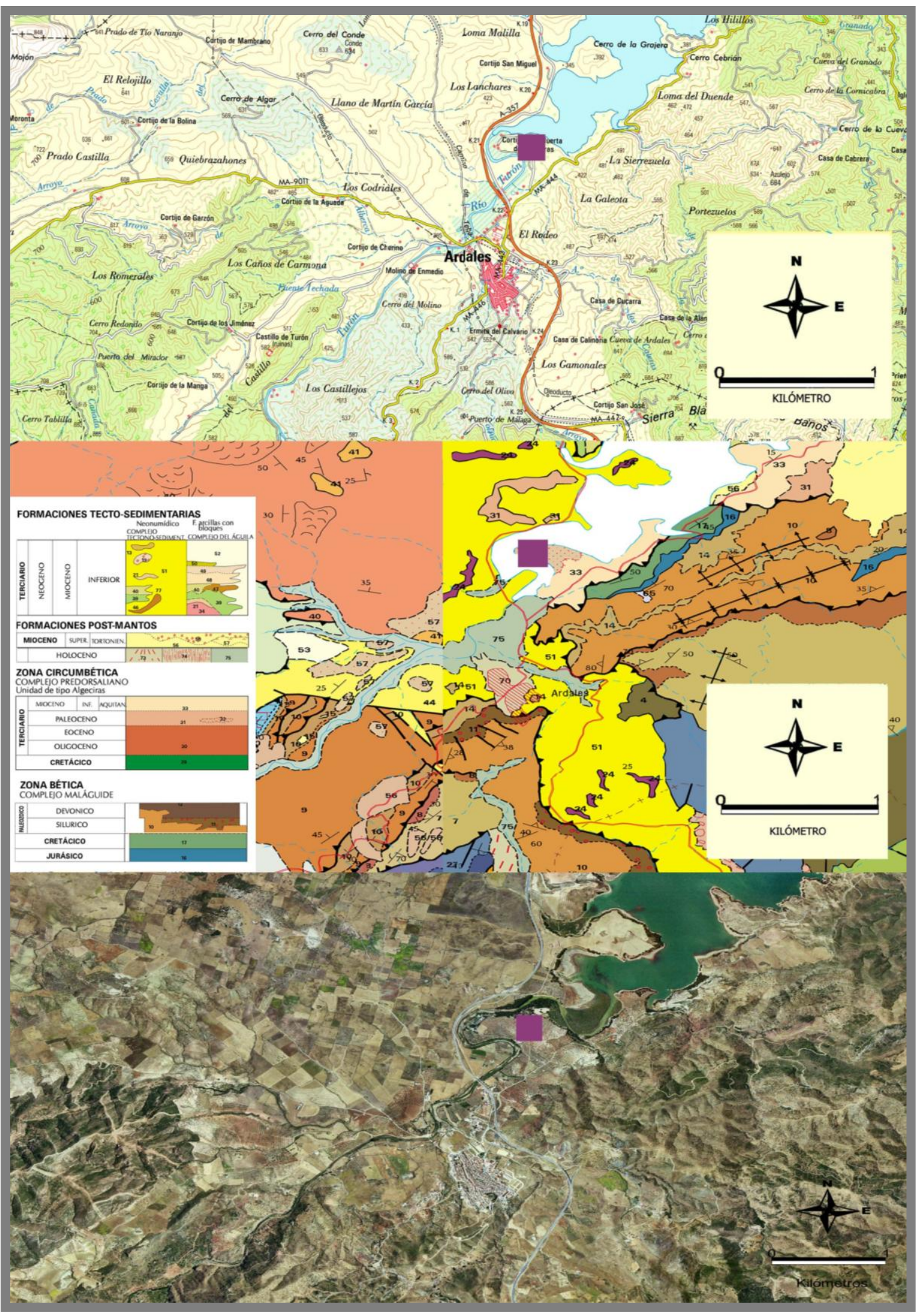


El yacimiento se ubica en una ladera al norte del pueblo de Ardales, en la orilla derecha del río Turón. Su acceso se realiza por la carretera A-357 desde Ardales dirección a los embalses.

Sus coordenadas UTM ETRS89 30 son:

\begin{tabular}{|c|c|}
\hline $\mathbf{X}$ & $\mathbf{Y}$ \\
\hline 335881 & 4084896 \\
\hline
\end{tabular}

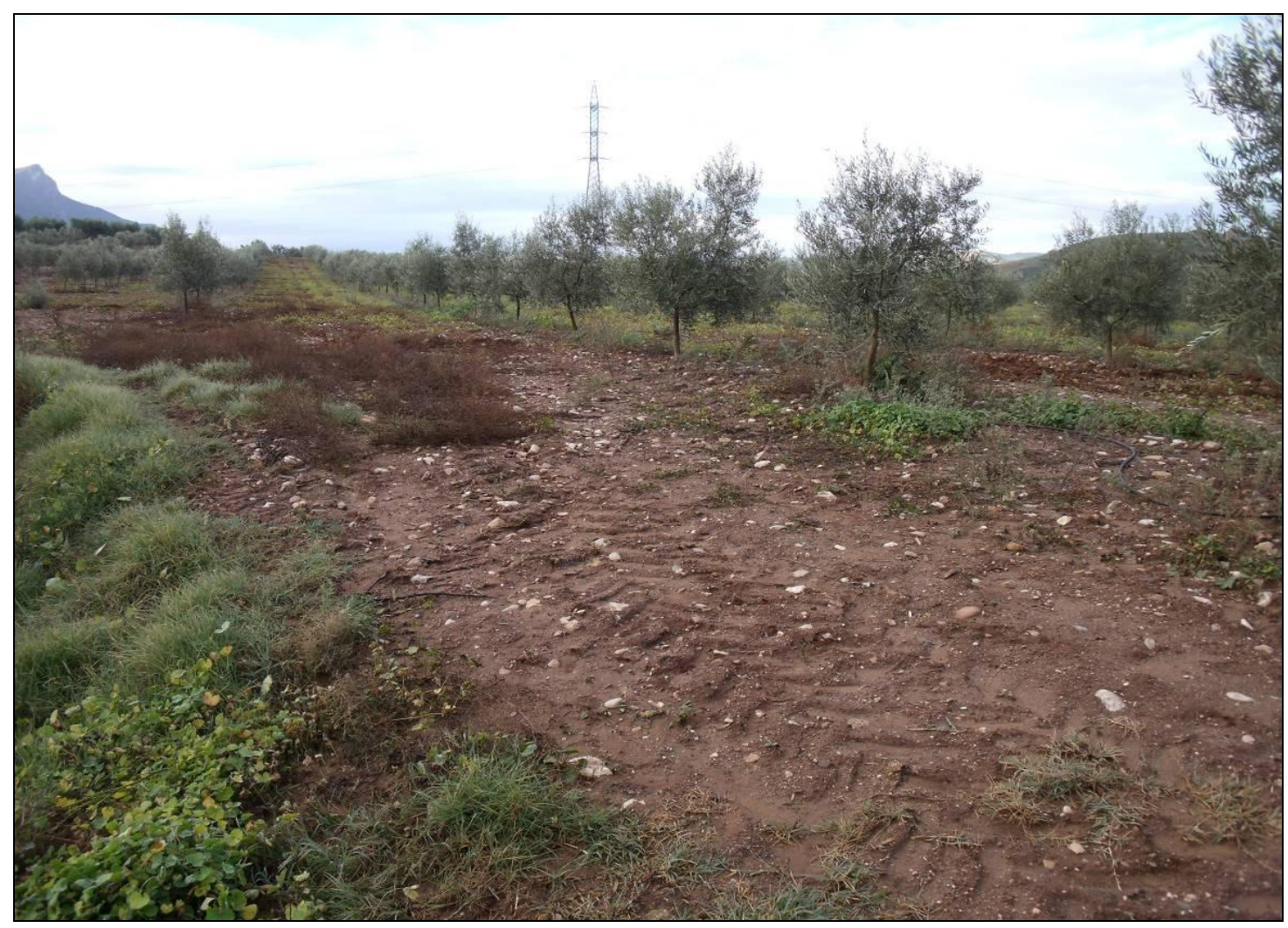

Figura 108. Vista general de Llanos de Belén.

Altitud m s.n.m: techo del depósito entre 345 y 330 m.

Extensión: 44.601,50 $\mathrm{m}^{2}$

. Contexto geológico y geomorfológico

Los materiales del yacimiento se encuentran en un cpntexto geológico dominado por la Formación Post-mantos, con areniscas y margas de la unidad de Algeciras correspondientes a la Zona Circumbética del Cenozoico. El yacimiento de superficie conocido como Llanos de Belén se localiza sobre dos terrazas del río Turón cuyas superficies están situadas a las cotas de +25 m (345 m s.n.m.) y +7/10 m (330 m s.n.m.) (IGME, 1990). La terraza más alta configura una zona más o menos llana con una ligera pendiente hacia el río, en la que aparecen en superficie cantos rodados de mediano 
tamaño y redondeados. La terraza más baja, también con una topografía llana con ligera pendiente hacia el río, está constituida por arcillas y limos rojos y en superficie presenta cantos de pequeño tamaño de litología variada con predominio de los cantos de caliza sobre los de cuarzo, arenisca compacta, cuarcita, sílex negro tipo Turón y gris azulado procedentes de la zona alta del río Turón, a los que hay que unir cantos de mayor tamaño procedentes del desmantelamiento de la terraza superior. La conexión entre ambas terrazas se produce mediante un derrame de terraza con una superficie muy tendida en la que aparecen cantos rodados procedentes de la terraza alta.

\section{. Procesos sedimentarios y procesos postdeposicionales}

Los procesos sedimentarios responsables de estos depósitos son de tipo fluvial debido a la actividad del río Turón. Las alteraciones postdeposicionales ocurridas en la yacimiento son las ocasionadas por la acción del arado y la plantación de olivos que han provocado un movimiento de materiales de la vertical y la horizontal.

Además se constata arrastre postdeposicional de la tierra superior a la inferior por procesos de gravedad-vertiente.

\section{. Interpretación geoarqueológica}

Los restos líticos recogidos muestran una utilización de areniscas compactas y sílex como materia prima, que presentan unos filos con rodamiento medio en casi todos los casos salvo las areniscas que presentan un rodamiento mayor, hecho este que puede interpretarse por un abandono antrópico de los materiales sobre la superficie de la terraza que posteriormente fue parcialmente desmantelada, sometiendo a los artefactos a un arrastre hasta las posiciones que ahora ocupan en algunas zonas. La superficie se encuentra afectada por intensas labores agrícolas del paso de los arados y la plantación de olivos.

\section{. Análisis de la industria lítica}

El material arqueológico que analizamos procede en parte de los materiales recogidos en superficie durante las prospecciones de los años 80 y que se encuentra en el Centro de Interpretación de la Prehistoria y también de los muestreos realizados en el marco de las actividades arqueológicas puntuales realizadas en la zona entre los años 2011-2014. 
Se han analizado un total de 16 ejemplares. Donde la materia prima predominante es el sílex masivo en tonalidades oscuras de gris/negro y la arenisca compacta (figura 109).

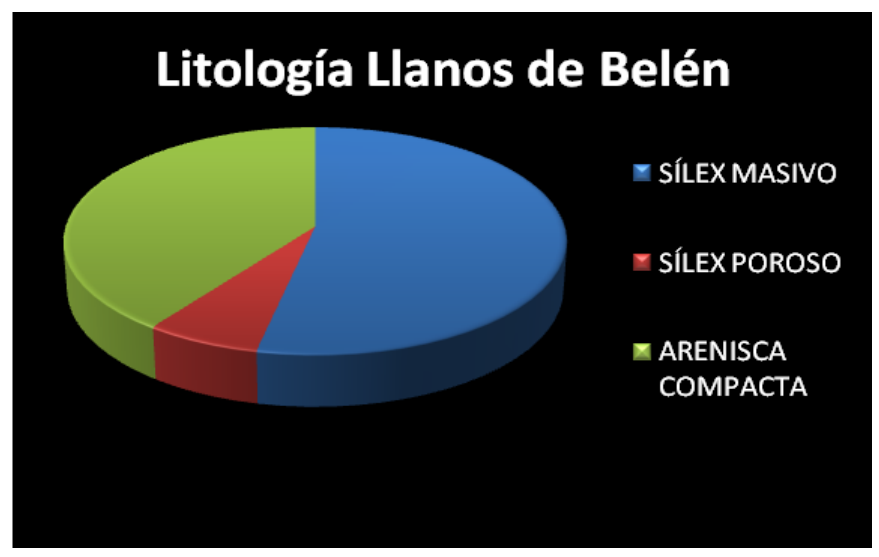

Figura 109. Materias primas de las piezas líticas recuperadas en el yacimiento Llanos de Belén.

El estudio morfotécnico realizado muestra una presencia de Bases Naturales de Primera Generación de Configuración y de Explotación (BN1GC/BN1GE) de Bases Positivas (BP) y Bases Negativas de Segunda Generación (BN2G).

Hay 7 ejemplares de BN1G (tabla 19) de sílex masivo gris/negro. Se documentan 2 ejemplares de BN1GC que corresponden a bifaces. Todos los ejemplares presentan un sistema de explotación unipolar, diverso y centrípeto de tipo bifacial en la mayoría, con un carácter centrípeto de tipo 3C y 4C, las extracciones son simples con un carácter de profundidad variable. La arista frontal es convexa mientras que la sagital es sinuosa.

\begin{tabular}{|c|c|c|c|c|c|c|c|c|c|c|c|c|c|c|}
\hline \multicolumn{15}{|c|}{ YACIMIENTOS ARDALES. ESTUDIO ANALÍTICO DE LAS BN1G } \\
\hline \multirow{2}{*}{\begin{tabular}{|c|} 
Nombre \\
Llanos de Belén \\
\end{tabular}} & \multicolumn{5}{|c|}{ Materias primas y morfología } & \multicolumn{2}{|c|}{ Tipos de bases negativas } & \multicolumn{6}{|c|}{ Criterios analíticos de las BN1G } & \multirow[t]{2}{*}{ Tema operativo técnicc } \\
\hline & $M$ & $\mathrm{R}$ & C & $\mathrm{P}$ & $\mathrm{T}$ & $\mathrm{TN}$ & $\mathrm{BN}$ & CF & CC & $\mathrm{CO}$ & $\mathrm{CP}$ & CAF & CAS & \\
\hline LLABE3 & A & B & 0 & NO & NO & C & BN1GE & $\mathrm{U}$ & $3 C$ & $\mathrm{SA} / \mathrm{A}$ & $\mathrm{mp}$ & $c x$ & $\sin$ & T.O.T.I \\
\hline LLANOS DE BELÉN & $\mathrm{S}$ & M & G & A & NO & Bifaz & BN1GC & B & $4 C$ & $S$ & $\mathrm{t}$ & $c x$ & $\sin$ & T.O.T.D \\
\hline LLABE1-TL & A & B & 0 & A & NO & Bifaz & BN1GC & B & $4 C$ & $S$ & $t$ & $c x$ & $\sin$ & T.O.T.D \\
\hline LLABE2-TL & A & B & G & A & NO & $U$ & BN1GE & B & $2 C$ & $S$ & $p$ & $c x$ & $\sin$ & T.O.T.I \\
\hline LLABE4-TL & $S$ & $M$ & $\mathrm{~N}$ & NO & NO & U & BN1GE & U & C & $S$ & $\mathrm{~m}$ & $c x$ & $\sin$ & T.O.T.I \\
\hline LLABE5-TL & $S$ & $M$ & $\mathrm{~N}$ & NO & NO & DIV & BN1GE & B & $3 C$ & $S$ & $\mathrm{mp}$ & $c x$ & $\sin$ & T.O.T.I \\
\hline LLABE6-TL & $S$ & $M$ & $\mathrm{~N}$ & NO & NO & DIV & BN1GE & $\mathrm{T}$ & $3 C$ & $S$ & $\mathrm{mp}$ & $c x$ & $\sin$ & T.O.T.I \\
\hline
\end{tabular}

Tabla 19. Estudio analítico de las BN1G de Llanos de Belén. 
Las BP (tabla 20) corresponden a 4 lascas y a una lámina levallois en sílex masivo beige o gris y arenisca. Presentan un volumen LP (largo plano). La delineación desde la cara ventral muestra talones convexos en la mayoría, no corticales, con una superficie en plataforma en tres ejemplares y lineales en los otros dos. Las caras dorsales son sobre todo no corticales.

\begin{tabular}{|c|c|c|c|c|c|c|c|c|c|c|c|c|c|c|c|c|c|c|c|c|c|}
\hline \multicolumn{22}{|c|}{ YACIMIENTOS ARDALES. ESTUDIO ANALITITCO DE LAS BP } \\
\hline Nombre & \multicolumn{5}{|c|}{ Materias primas y morfología } & \multicolumn{2}{|c|}{ Tipos de bases positivas } & & \multicolumn{3}{|c|}{ Dimensiones } & \multicolumn{10}{|c|}{ Criterios analíticos de las BP } \\
\hline & M & $R$ & c & $P$ & $T$ & LAS/LAM & TIPO & $\mathrm{L}$ & $E$ & TB & VOL & CARA & VENTRAL & & CARA TA & LONAR & & & CARA DO & RSAL & \\
\hline Llanos de Belén & & & & & & & & & & & & F & $B$ & TIPO & \begin{tabular}{|l|l|} 
COR & $S$ \\
\end{tabular} & $T$ & $D$ & COR & SSAG & STR & A \\
\hline LLABE2 & s & M & G & $B$ & NO & LASCA & L & 6,4 & 3,1 & 0,9 & $22 \mathrm{LP}$ & $c X$ & M & I & NOCO LIN & UF & $c X$ & NCDC & CDG & TRP & $\mathrm{SI}$ \\
\hline ARD-117 & s & M & B & A & NO & LASCA & L & 5,5 & 3,1 & 1,2 & $13 \mathrm{LP}$ & $c x$ & M & fo & NOCO PLA & MF & $c x$ & NOCO & CDG & TRG & $\mathrm{SI}$ \\
\hline LLABE8-TL & A & M & G & NO & NO & LASCA & L & 3,7 & 3,5 & 1,2 & $22 \mathrm{LP}$ & $c x$ & D & c & COR LIN & $\mathrm{NF}$ & $c x$ & NOCO & TRP & TRG & $\mathrm{SI}$ \\
\hline LLABE10-TL & s & p & G & NO & NO & LÁMINA & L & 5,6 & 1,6 & 0,6 & $6 \mathrm{LP}$ & RT & D & a & NOCO PLA & UF & $c X$ & NOCO & TRP & TRG & SI \\
\hline LLABE13-TL & $s$ & M & B & $R$ & NO & LASCA & I & $\mathrm{fd}$ & 4,2 & 1 NO & ) $L P$ & $c X$ & M & fo & NOCO PLA & MF & $c X$ & NOCO & CDG & TRG & SI \\
\hline
\end{tabular}

Tabla 20. Estudio analítico de las BP de Llanos de Belén.

Las BN2G (tabla 21) corresponden a 4 ejemplares. Utilizamos para su clasificación la nomenclatura del sistema tipológico de Laplace (Laplace, 1972) y los de la Lista-Tipo Bordes (Bordes, 1961).

Tres de ellas son raederas y una es una muesca. Tienen un volumen de tipo LP (largo plano), la delineación del talón desde la cara ventral es convexa y concava y con un bulbo difuso en dos de ellas, un ejemplar carece de bulbo y otro lo tiene marcado. Los retoques son simples, marginales, inversos/directos y continuos. Se trata de dos raederas trasversales (R22) según Laplace o raedera trasversal derecha según Bordes (22), hay una raedera lateral (R21) según Laplace o una raedera simple convexa según Bordes (10). La muesca sobre una lasca interna en sílex poroso, tiene una delineación desde la cara ventral convexa, el talón liso y en plataforma. El retoque es simple, marginal, directo y con muesca. Corresponde a un denticulado según Laplace (D21) y una muesca según Bordes (42).

\begin{tabular}{|c|c|c|c|c|c|c|c|c|c|c|c|c|c|c|c|c|c|c|c|c|c|c|c|c|c|}
\hline \multicolumn{24}{|c|}{ 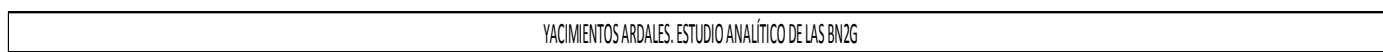 } & \multirow{2}{*}{\multicolumn{2}{|c|}{ Clasificación }} \\
\hline Nombre & \multicolumn{5}{|c|}{ Materias primas y moriología } & \multicolumn{2}{|c|}{ Tipos de bases positivas } & \multicolumn{4}{|c|}{ Dimensiones } & \multicolumn{10}{|c|}{ Citerios anal'ticos de las BN2G } & \multicolumn{2}{|l|}{ Tipoderetoque } & & \\
\hline & M & R & c & P & $T$ & LAS/LAM & TTPO & & \begin{tabular}{|l|l|}
$A$ & $E$ \\
\end{tabular} & $\mathrm{TT}$ & \begin{tabular}{l|l|}
$B$ & Vol \\
\end{tabular} & & ARAVENTRALL & & & ATALONA & & & & CARA DORSAL & & \begin{tabular}{|l|l|} 
LLZQ & EDIS \\
\end{tabular} & LDRCHO EPX & & \\
\hline Uanos se Belén & & & & & & & & & & & & E & $B$ & TIPO & COR & $s$ & Ti & D & COR & \begin{tabular}{|l|l|} 
SSAG & STR \\
\end{tabular} & $A$ & & & & \\
\hline LABEI & A & B & 0 & A & NO & LASCA & D & 6,2 & 7 & 2,5 & $17 / \mathrm{P}$ & $c x$ & No & c & co & LN & NF & $c x$ & CONC & OV OV & SI & $\mathrm{s} / \mathrm{m} / \mathrm{d} / \mathrm{c}$ & & R22 & 22 \\
\hline LABEG-TL & A & B & G & NO & NO & CANTO & SD & 9,8 & 6,8 & 4,6 & $17 L$ & $c x$ & 0 & c & co & PLA & NF & $\alpha$ & CONC & OV OV & Sl & $\mathrm{a} / \mathrm{m} / \mathrm{l} / \mathrm{c}$ & & R22 & 22 \\
\hline LABEI1-TL & s & M & $B / G$ & NO & NO & LASCA & I & 3,6 & 3,1 & 1,3 & $18[P$ & CX & 0 & I & NOCO & PLA & UF & $\alpha x$ & NOCO & CDG TRG & $\mathrm{Sl}$ & $\mathrm{s} / \mathrm{m} / \mathrm{d} / \mathrm{e}$ & & 021 & 42 \\
\hline LABEL1:TL & s & M & N & No & NO & LSSCA & L & 5,3 & 3,3 & 1,8 & $13 L P$ & Cl & M & $\mathrm{fcc}$ & NOCO & PIA & MF & $\alpha x$ & NOCO & TRG TRP & $\mathrm{SI}$ & & $\mathrm{s} / \mathrm{m} / \mathrm{ilc}$ & R21 & 9 \\
\hline
\end{tabular}

Tabla 21. Estudio analítico de las BN2G de Llanos de Belén. 
. Valoración y conclusiones

$\mathrm{Su}$ localización a pocos metros del río, permite el aprovisionamiento de materiales litológicos como las areniscas de las mismas características geológicas que la industria, en el caso del sílex no vemos una abundancia de bloques o cantos de sílex y los localizados son de tamaño mediano y pequeño quizás arrastrados por el río desde las zonas más altas donde se encuentran los afloramientos del sílex. El rodamiento medio de la industria lítica nos indica un desplazamiento relativo del material y plantea la posibilidad de que el material localizado esté sobre el propio yacimiento, aprovechando los materiales que aparecen en la propia terraza.

En cuanto a la tecnología destacamos una presencia mayoritaria de $\mathrm{BN} 1 \mathrm{G}$, una presencia de BP-L (levallois) de mediano tamaño, dentro del grupo de los productos retocados o $\mathrm{BN} 2 \mathrm{G}$, nos encontramos con 3 ejemplares correspondientes a raederas y una muesca.

La muestra arqueológica analizada evidencia una industria caracterizada por una presencia mayoritaria de sílex negro/gris con un rodamiento medio así como las arenisca. Aparecen BN1GC como bifaces, así como lascas sobre todo de técnica levallois y productos retocados. Podemos encuadrarla a nivel genérico dentro de un Paleolítico medio o modo III. 


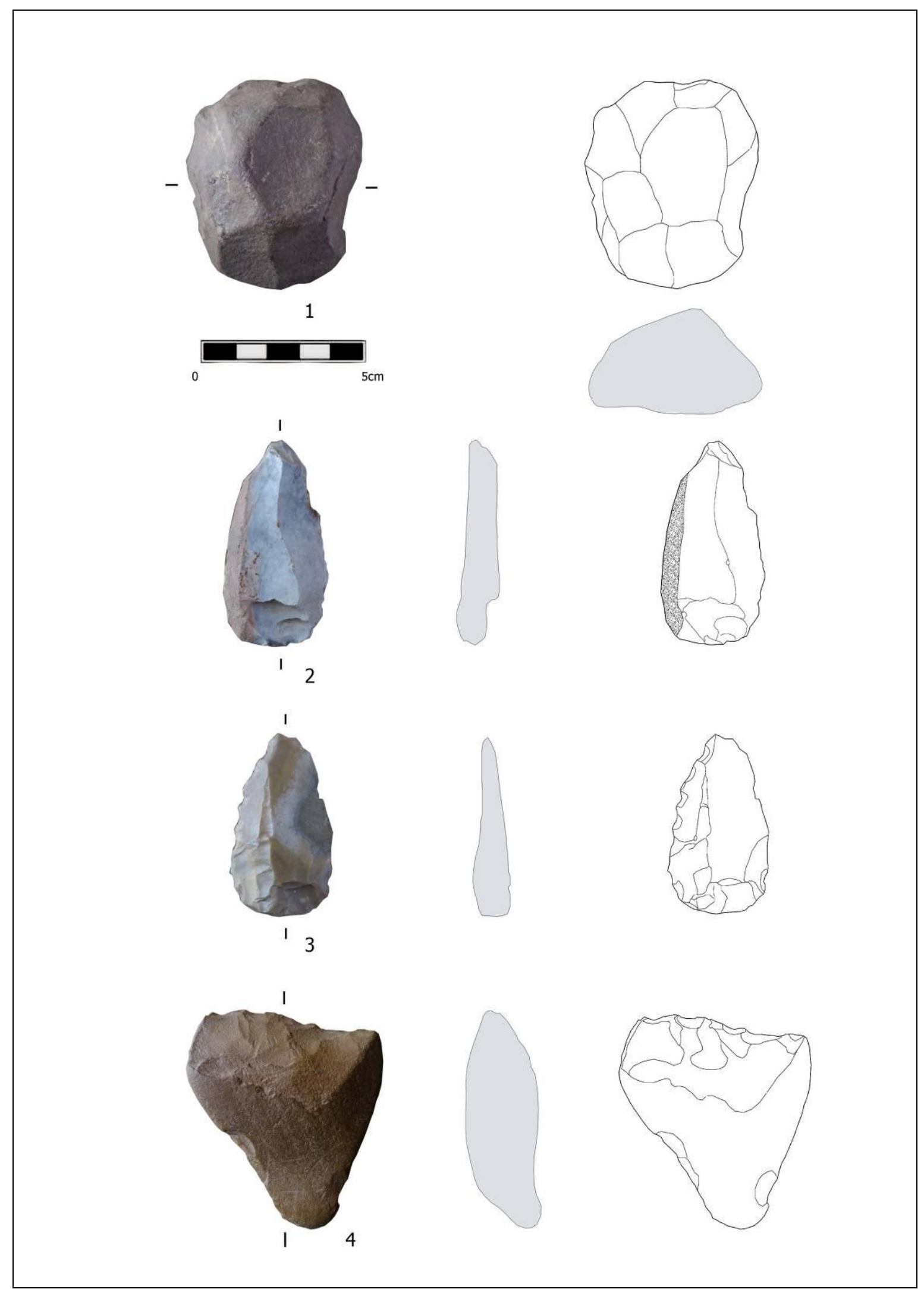

Figura 110. Llanos de Belén (Ardales): 1: BN1G-Núcleo centrípeto; 2,3: BP-Lascas levallois; 4: BN2GRaedera trasversal. 


\subsubsection{Terraza de Las Grajeras (Ardales)}

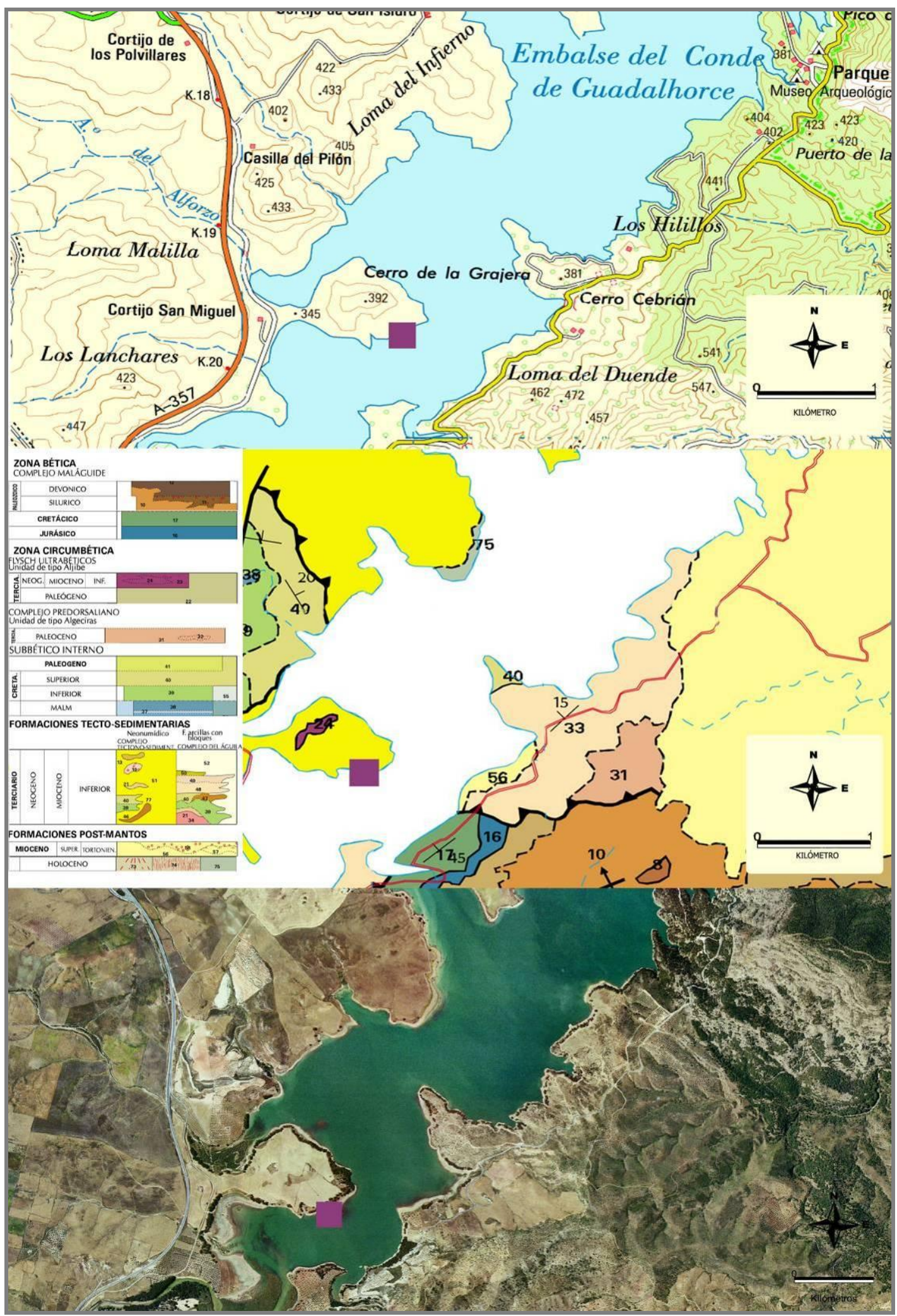


Es una terraza situada sobre una ladera al norte del pueblo de Ardales en la margen izquierda del río Turón, su acceso se realiza a través de la carretera entre Ardales y Teba (MA-443) a unos 4 kilómetros del pueblo.

Sus coordenadas UTM ETRS89 30 son:

\begin{tabular}{|c|c|}
\hline $\mathbf{X}$ & $\mathbf{Y}$ \\
\hline 337120 & 4086147 \\
\hline 337252 & 408601 \\
\hline 337785 & 4085766 \\
\hline 336576 & 4085948 \\
\hline 336907 & 4085960 \\
\hline
\end{tabular}

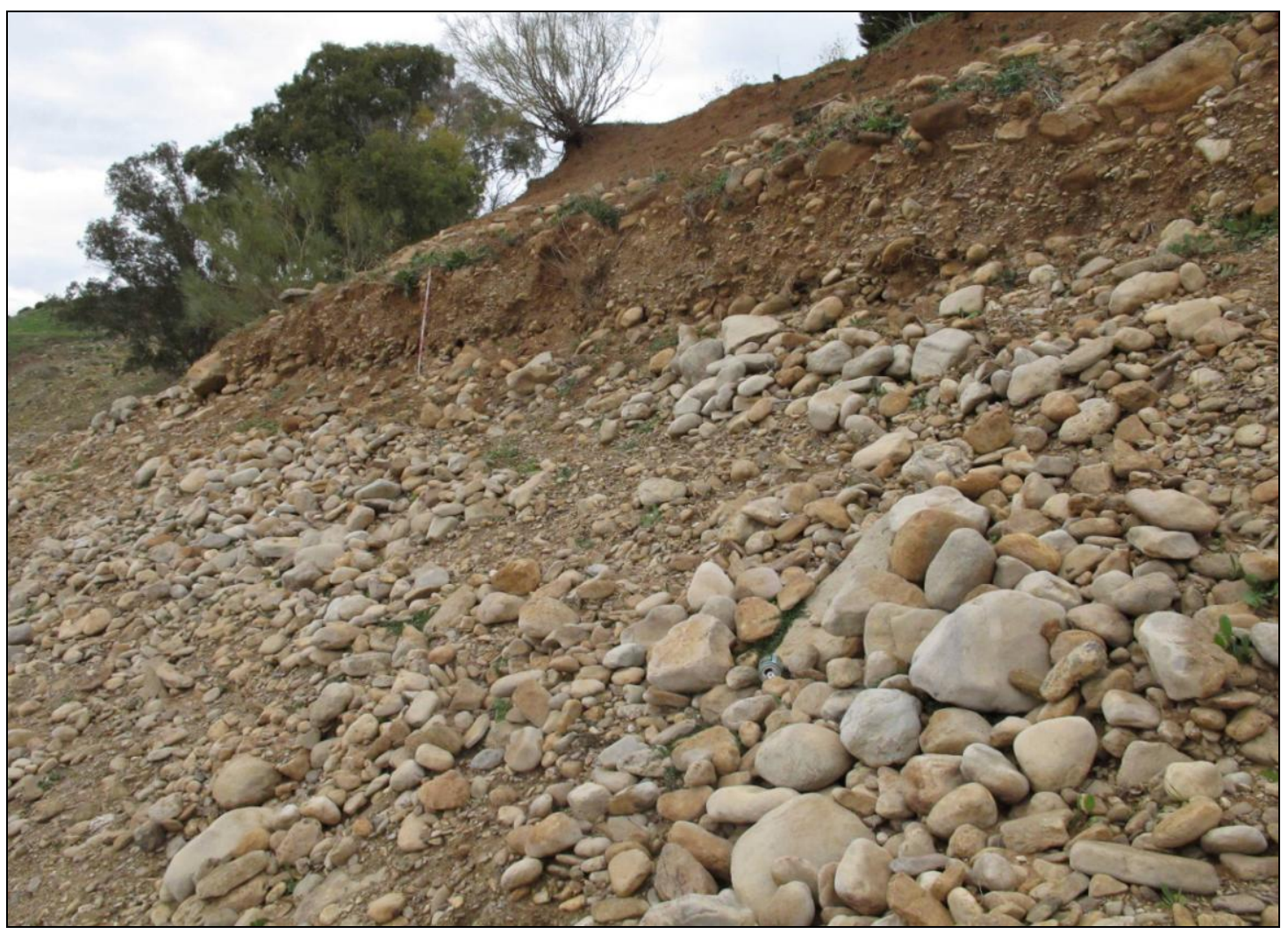

Figura 111. Vista general terraza de Las Grajeras.

Altitud m s.n.m: techos de las terrazas a $338 \mathrm{~m}$ y $355 \mathrm{~m}$

Extensión: 86.924,33 $\mathrm{m}^{2}$

. Contex to geológico y geomorfológico

El yacimiento, situado en una amplia terraza, presenta varios niveles de graveras, con cantos de mediano y gran tamaño. La terraza está emplazada sobre materiales compuestos por margas y arcillas marrones con presencia de klippes 
sedimentarios u olistolitos de distinta naturaleza y edad pertenecientes al Neonumídico y en concreto de de las formaciones Tecto-sedimentarias del Cenozoico.

Corresponden a dos terrazas desmanteladas del río Turón. La terraza inferior, cuya base visible está situada a 335 m s.n.m, se encuentra parcialmente desmantelada y sus materiales se dispersan por la ladera hacia el río, fundamentalmente por la acción del oleaje del embalse actual. Se apoya sobre la roca del sustrato, aunque el embalse impide ver su potencia total, y está formada por cantos y bloques de mediano y gran tamaño, redondeados a bien redondeados, predominantemente de calizas, y otras litologías variadas como sílex beige, gris claro, areniscas compactas. El depósito visible se articula en una primera secuencia granodecreciente, una capa intermedia con bloques medianos y pequeños y finalmente, un depósito de arcillas con gravas. En la base los cantos son de mayor tamaño y están redondeados a bien redondeados, mientras que en el tramo central los cantos son de mediano y pequeño tamaño, con fragmentos de roca apenas redondeados. Se observan dos poblaciones, una más rodada y otras menos lo que implica un transporte diferencial de los clastos. La superficie de la terraza, a $338 \mathrm{~m}$ s.n.m., está cubierta por un coluvión arcilloso que procede de la ladera del cerro de la Grajera.

La terraza más alta, situada a 355 m s.n.m., forma un ligero replano a media ladera del cerro y está desmantelada, pues de ella sólo queda la presencia de cantos y bloques de mediano y pequeño tamaño, que se dispersan por la ladera.

Ambas terrazas se sitúan en las mismas cotas que las dos terrazas de Morenito, por lo que tienen una estrecha relación con estas.

. Procesos sedimentarios y procesos postdeposicionales

Los procesos sedimentarios son los ocasionados por la propia acción fluvial configuradora del depósito de la terraza, como el transporte y la sedimentación de los clastos. Los procesos postdeposicionales principales son ocasionados por la acción erosiva del embalse debido a los repetidos ascensos y descensos de las aguas del pantano que provocan la dispersión de los materiales o el sepultamiento de los mismos. 
. Interpretación geoarqueológica

El material arqueológico se encuentra en superficie sobre la terraza desmantelada, la más baja de las dos localizadas. Sus filos presentan un nivel medio de rodamiento y se localizaron fuera del paquete sedimentario, por lo tanto en posición secundaria.

\section{. Análisis de la industria lítica}

Se han analizado un total de 24 ejemplares recogidos durante los muestreos geoarqueológicos realizados en las intervenciones arqueológicas de Ardales y Sima de Las Palomas (Teba) entre los años 2011-2014.

La materia prima (figura 112) dominante es el sílex seguido por las calizas y las areniscas compactas y una escasa presencia de radiolarita. Por el material recuperado observamos la utilización de la caliza y la arenisca compacta para los productos líticos más antiguos como son los cantos tallados en su mayoría y la utilización de sílex para productos más elaborados, como las lascas.

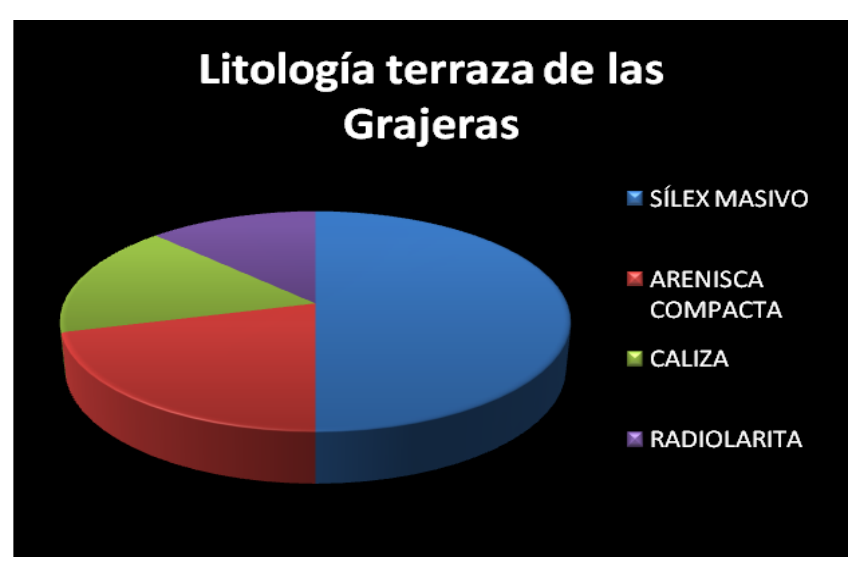

Figura 112. Materias primas de las piezas líticas recuperadas en el yacimiento de terraza de Las Grajeras.

El estudio morfotécnico muestra, a nivel general, una presencia de Bases Negativas de Primera Generación de Configuración (BN1GC) y de Bases Negativas de Primera Generación de Explotación (BN1GE), identificativo de los primeros momentos del proceso de talla lítica asociados en este caso a depósitos secundarios frente a Bases Positivas y Bases Negativas de Segunda Generación. 
Las BN1GC (tabla 22) suman un total de 2 piezas, con un carácter bifacial en ambos casos. En relación a las BN1GE constituyen la categoría más representativa del conjunto. Se han recogido 13 piezas, 6 unipolares, 2 bipolares, 1 diverso, 2 multipolares poliedricos y 2 centrípetos. En la mayoría de los casos presentan un carácter centrípeto variado aunque con predominio del tipo 3C, con un angulo de inclinación de las extracciones variables que van desde los simples a los abruptos.

\begin{tabular}{|c|c|c|c|c|c|c|c|c|c|c|c|c|c|c|}
\hline \multicolumn{15}{|c|}{ YACIMIENTOS ARDALES. ESTUDIO ANALÍTICO DE LAS BN1G } \\
\hline \multirow{2}{*}{\begin{tabular}{|c|}
\multicolumn{1}{|c|}{ Nombre } \\
T. Grajeras
\end{tabular}} & \multicolumn{5}{|c|}{ Materias primas y morfología } & \multicolumn{2}{|c|}{ Tipos de bases negativas } & \multicolumn{6}{|c|}{ Criterios analíticos de las BN1G } & \multirow[t]{2}{*}{ Tema operativo técnicc } \\
\hline & $M$ & $\mathrm{R}$ & C & P & $T$ & TN & BN & CF & CC & $\mathrm{CO}$ & CP & CAF & CAS & \\
\hline TG1-TL & 0 & B & G & 0 & NO & B & BN1GC & B & $\bar{C}$ & $\mathrm{~S}$ & $\mathrm{mp}$ & $\mathrm{rt}$ & inc & T.O.T.D \\
\hline TG4-TL & 0 & B & G & B & NO & $u$ & BN1GE & $U$ & NOC & $\mathrm{S}$ & $\mathrm{m}$ & cc & inc & T.O.T.I \\
\hline TG5-TL & A & B & B & NO & NO & B & BN1GC & B & $3 C$ & $S$ & $\mathrm{~m}$ & $\sin$ & $\sin$ & T.O.T.D \\
\hline TG8-TL & $S$ & B & B & NO & NO & U & BN1GE & $U$ & $3 C$ & SA/A & $\mathrm{m}$ & $\mathrm{rt}$ & $\sin$ & T.O.T.I \\
\hline TG12-TL & A & B & B & A & NO & $\mathrm{POL}$ & BN1GE & B & $3 C$ & SA & $p$ & $c x$ & $\sin$ & T.O.T.I \\
\hline TG19-TL & $S$ & B & B & A & NO & U & BN1GE & U & C & SA & $\mathrm{m}$ & $\mathrm{cc}$ & $\sin$ & T.O.T.I \\
\hline TG20-TL & 0 & B & G & A & NO & U & BN1GE & B & C & $S$ & $\mathrm{~m}$ & $\mathrm{rt}$ & $\mathrm{rt}$ & T.O.T.I \\
\hline TG22-TL & $S$ & B & 0 & NO & NO & DIV & BN1GE & U & $3 C$ & A & $p$ & $\mathrm{rt}$ & rt & T.O.T.I \\
\hline TG23-TL & A & B & B & NO & NO & U & BN1GE & U & $2 C$ & A & $p$ & $c x$ & $\sin$ & T.O.T.I \\
\hline TG25-TL & $\mathrm{R}$ & $M$ & $\mathrm{R}$ & NO & NO & $\mathrm{CM}$ & BN1GE & B & $4 C$ & $\mathrm{P} / \mathrm{SA}$ & $\mathrm{t}$ & $c x$ & $\sin$ & T.O.T.I \\
\hline TG32-TL & $S$ & $M$ & B & A & NO & $\mathrm{POL}$ & BN1GE & B & $3 C$ & SA/A & $\mathrm{t}$ & $c x$ & $\sin$ & T.O.T.I \\
\hline TG33-TL & $S$ & $M$ & G & A & NO & U & BN1GE & B & $3 C$ & $A / P$ & $\mathrm{t}$ & $\mathrm{rt}$ & $\sin$ & T.O.T.I \\
\hline TG34-TL & S & $M$ & $\mathrm{~N}$ & NO & NO & $\mathrm{CM}$ & BN1GE & U & $4 C$ & S/SA & $\mathrm{t}$ & $c x$ & $\sin$ & T.O.T.I \\
\hline
\end{tabular}

Tabla 22. Estudio analítico de las BN1G de la terraza de Las Grajeras.

Las BP (tabla 23) recuperadas son un total de 8 piezas realizadas en sílex con volúmenes EP (espeso plano) y LP (largo plano). Los talones son no corticales en todos los ejemplares, con un predominando de los tipos lisos. Hay 4 ejemplares que tienen una superficie en plataforma y 3 lineales, otro presenta fractura próximal. En cuanto a la cara dorsal 2 son corticales, 5 son no corticales y 1 cortical dominante sobre no cortical.

\begin{tabular}{|c|c|c|c|c|c|c|c|c|c|c|c|c|c|c|c|c|c|c|c|c|}
\hline \multicolumn{21}{|c|}{ YACIMIENTOS ARDALES. ESTUDIO ANALIITICO DE LAS BP } \\
\hline \multirow[t]{2}{*}{ Nombre } & \multicolumn{5}{|c|}{ Materias primas y morfología } & \multicolumn{3}{|c|}{ Tipos de bases positivas } & \multicolumn{2}{|c|}{ Dimensiones } & \multicolumn{10}{|c|}{ Criterios analíticos de las BP } \\
\hline & M & $R$ & c & P & $T$ & LAS/LAM & TIPO & L & \begin{tabular}{|l|l|}
$A$ & $E$ \\
\end{tabular} & \begin{tabular}{|l|l|} 
TB & VOL \\
\end{tabular} & & VENTRAL & & CARA TAL & LONAR & & & CARA DO & RSAL & \\
\hline T. Grajeras & & & & & & & & & & & $\mathrm{F}$ & $B$ & TIPO & COR $S$ & $\mathrm{~T}$ & D & COR & SSAG & STR & $\mathrm{A}$ \\
\hline TGg-TL & s & M & N & NO & NO & LASCA & SD & 5 & 5,4 & $1,4 \quad 21 \mathrm{EP}$ & $\mathrm{CC}$ & M & I & NOCO PLA & UF & $\mathrm{CC}$ & CDNC & CDG & TRG & $\mathrm{Sl}$ \\
\hline TG11-TL & R & M & 0 & NO & NO & LASCA & L & 3,5 & 3,1 & $1,5 \quad 18 \mathrm{EP}$ & RT & NO & I & CO PLA & NF & RT & NOCO & CDG & PLG & SI \\
\hline TG24-TL & s & B & B & A & NO & LASCA & D & 5,5 & 8,9 & $1,7 \quad 25 \mathrm{EP}$ & CC & M & I & NOCO LIN & UF & $C C$ & $\mathrm{CO}$ & TRP & OV & SI \\
\hline TG27-TL & A & B & 0 & NO & NO & LASCA & $D$ & 3,6 & 3,5 & $1,8 \quad 18 \mathrm{EP}$ & $C C$ & $D$ & I & NOCO LIN & UF & $C C$ & $\mathrm{CO}$ & CDG & OV & NO \\
\hline TG28-TL & $S$ & M & B & NO & NO & LASCA & L & f. dis & 2,3 & $0,5 \mathrm{NO} \quad L P$ & RT & M & $\mathrm{fd}$ & NOCO PLA & $B F$ & UA & NOCO & $C D G$ & TRG & $S \mid$ \\
\hline TG29-TL & $S$ & M & G & costr & aNO & LASCA & L & 3,4 & 2,6 & $0,9 \quad 19 L P$ & RT & M & a & NOCO LIN & NF & $C C$ & NOCO & TRP & TRG & $S \mid$ \\
\hline TG35-TL & A & M & 0 & costr & aNO & LASCA & I & 8,1 & 10 & $2,6 \quad 21 \mathrm{EP}$ & $c x$ & $D$ & 1 & NOCO PLA & UF & $C X$ & NOCO & TRP & OV & $S \mid$ \\
\hline TG36-TL & $R$ & M & R & NO & SI & LASCA & L & $f p$ & $\mathrm{fd}$ & 2,2 NO LP & NO & NO & NO & NO NO & NO & NO & NOCO & CDG & TRG & $\mathrm{Sl}$ \\
\hline
\end{tabular}

Tabla 23. Estudio analítico de las BP de la terraza de Las Grajeras. 
Las BN2G corresponden a 3 ejemplares (tabla 24). Utilizamos la nomenclatura del sistema tipológico de Laplace (Laplace, 1972) y los de la Lista-Tipo Bordes (Bordes, 1961). Uno con talón liso no cortical dominante cortical, uno sin talón y el otro con una fractura proximal. Con relación a la cara dorsal, un ejemplar es no cortical dominante cortical, otro es cortical dominante no cortical y el tercero es no cortical. El análisis del retoque indica que ambos presentan retoques simples, uno profundo y el otro marginal. En cuanto a la dirección del retoque los hay directos e inversos. Desde el punto de vista tipológico, se corresponden con una raedera lateral según Laplace (R21) o raedera simple convexa según Bordes (10), a una raedera lateral (R21) o raedera de retoque alterno (29) y a un denticulado marginal (D1) o muesca (42).

\begin{tabular}{|c|c|c|c|c|c|c|c|c|c|c|c|c|c|c|c|c|c|c|c|c|c|c|c|c|}
\hline \multicolumn{25}{|c|}{ YACIMIENTOS ARDALES. ESTUDIO ANALLITICO DE LAS BN2G } \\
\hline \multirow[t]{2}{*}{ Nombre } & \multicolumn{5}{|c|}{ Materias primas y morfología } & \multicolumn{2}{|c|}{ Tipos de bases positivas } & \multicolumn{3}{|c|}{ Dimensiones } & \multicolumn{10}{|c|}{ Criterios analiticos de las BN2G } & \multicolumn{2}{|l|}{ Tipo de retoque } & \multicolumn{2}{|c|}{ Clasificación } \\
\hline & M & $R$ & c & P & T & LAS/LAM & TIPO & L & A & \begin{tabular}{l|l|l|} 
& TB & Vol \\
\end{tabular} & & RAVENTRAL & & & TALON & & & & CARA DORSAL & & \begin{tabular}{l|l} 
LLZO & EDIS \\
\end{tabular} & LDRCHO EPX & Laplac & \\
\hline T.Grajeras & & & & & & & & & & & E & B & TIPO & COR & s & T & D & COR & \begin{tabular}{|l|l|}
$S S A G$ & STR \\
\end{tabular} & A & & & & \\
\hline TG2-TL & S & $B$ & B & & & LASCA & 1 & 9,5 & $5 \quad 11$ & $2,5 \quad 21 \mathrm{EP}$ & $c x$ & D & 1 & NCDC & LN & UF & RT & NCDC & CDG TRG & SI & $s / p l i / c$ & & R21 & 10 \\
\hline TG14TL & 0 & $B$ & G & A & NO & LASCA & 1 & 7,1 & $1 \quad 9,2$ & $1,4 \quad 21 \mathrm{EP}$ & NO & NO & NO & NO & NO & NO & NO & CDNC & CDG CDG & SI & $s / \mathrm{m} / \mathrm{d} / \mathrm{e}$ & & D1 & 42 \\
\hline TG37-TL & s & $B$ & G & A & NO & LASCA & 1 & fp & 3,5 & 1,4 NO LP & NO & NO & NO & NO & NO & NO & NO & NOCO & CDG TRG & SI & $\mathrm{s} / \mathrm{m} / \mathrm{l} / \mathrm{c}$ & $s / m / d / c$ & R21 & 29 \\
\hline
\end{tabular}

Tabla 24. Estudio analítico de las BN2G de la terraza de Las Grajeras.

. Valoración y conclusiones

El conjunto de materiales recuperados han sido removidos por las tareas agrícolas y por la acción erosiva del oleaje del embalse, que provoca el desmantelamiento del perfil de la terraza. El análisis de la industria evidencia un predominio del sílex masivo negro/ gris tipo Turón y beige, con posibilidad de que sea un aporte el propio río y el arroyo Alforzo, así como cantos de caliza y areniscas compactas estas afloran en el propio cerro de Las Grajeras. También hay un único ejemplar de radiolarita roja con huellas de termoalteración. Los esquemas operativos predominantes son los diversos, y presencia de núcleos unipolar, levallois y poliédrico

En cuanto a la tecnología, a pesar del reducido número de ejemplares podemos establecer unas características generales que en unión de los otros yacimientos nos dará una visión de conjunto más completa. Están presentes todos los procesos de la cadena operativa desde las bases naturales hasta los núcleos, lascas y productos. Se aprecia como aparecen algunos cantos tallados y núcleos en calizas y areniscas de gran tamaño propias de las fases más antiguas del Paleolítico y como los sílex se utilizan para 
núcleos centrípetos, poliédricos y unifaciales, pudiendo encuadrase a nivel genérico dentro del Paleolítico medio o Modo III.

El yacimiento presenta una buena visibilidad con otros yacimientos cercanos y están situados en ambos márgenes del río Turón y con materiales similares, como terraza de Las Grajeras, Raja del Boquerón o Lomas del Infierno. 

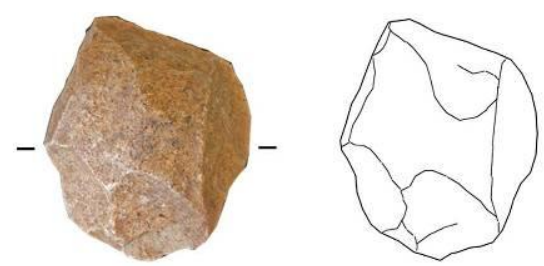

1
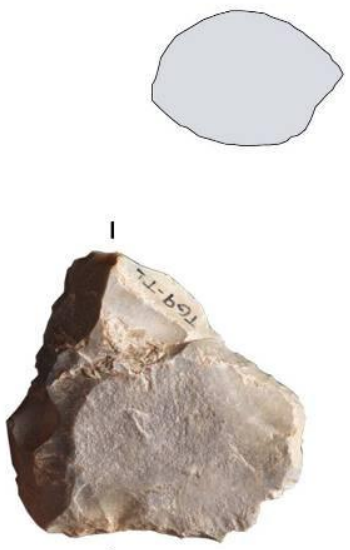

3

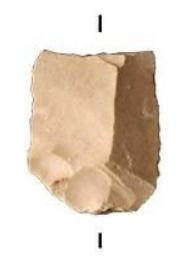

4
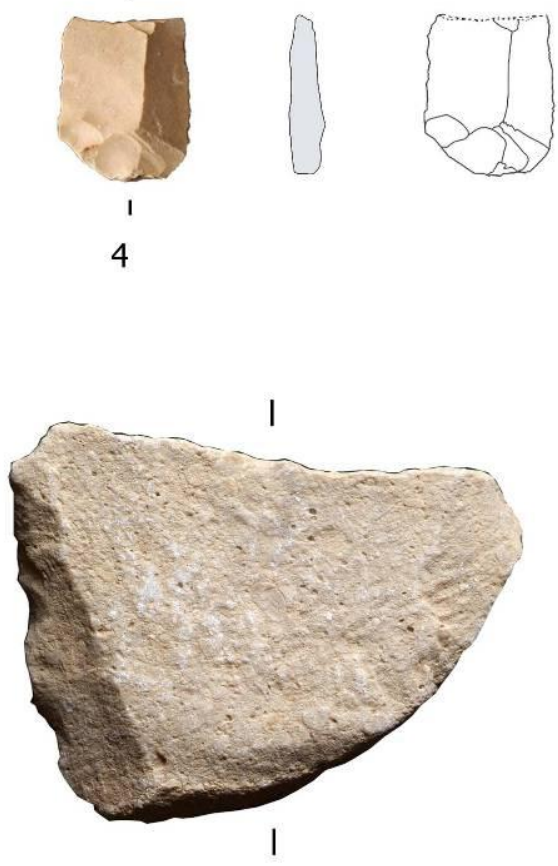

6
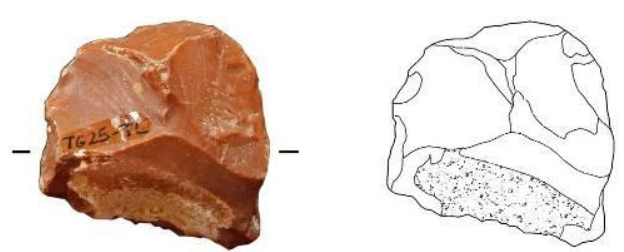

2
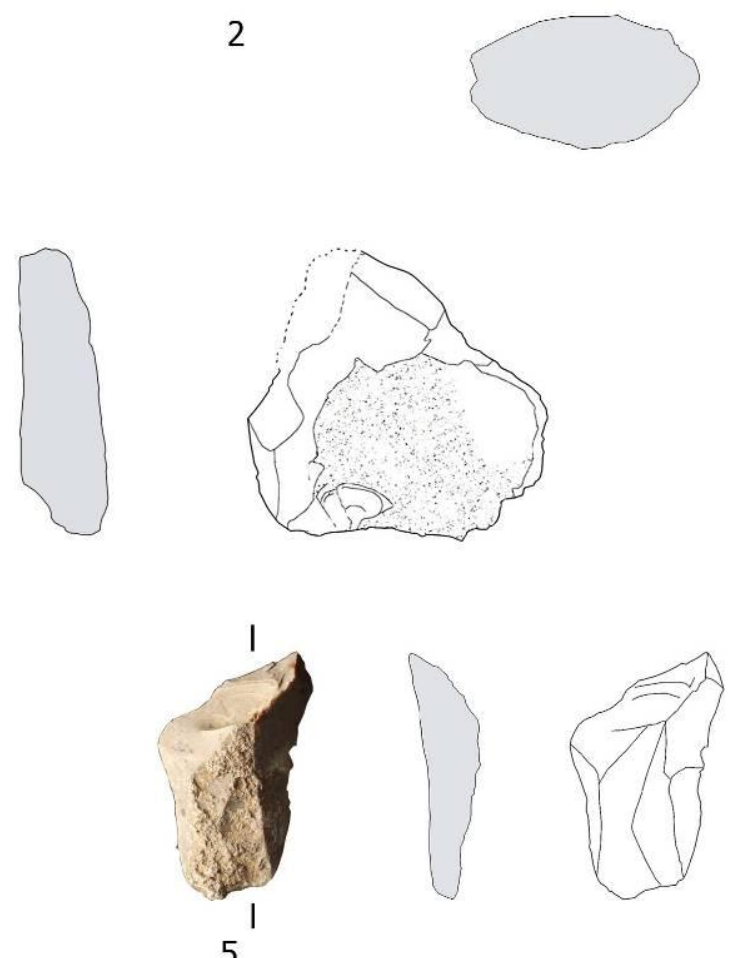

5
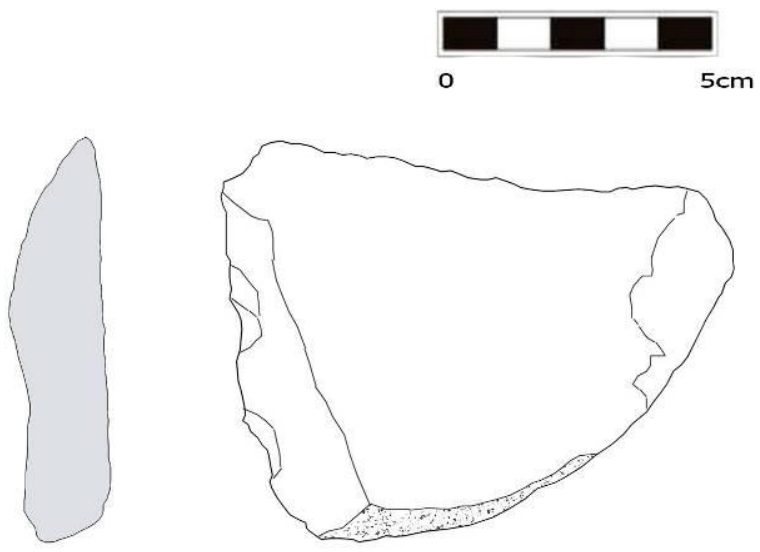

Figura 113. Terraza de Las Grajeras (Ardales): 1, 2:BN1G-Núcleo poliédrico y centrípeto multipolar; 3, 4, 5: BP-Lasca de semidescortezado y lascas levallois; 6: BN2G-Muesca. 


\subsubsection{Raja del Boquerón (Ardales).}

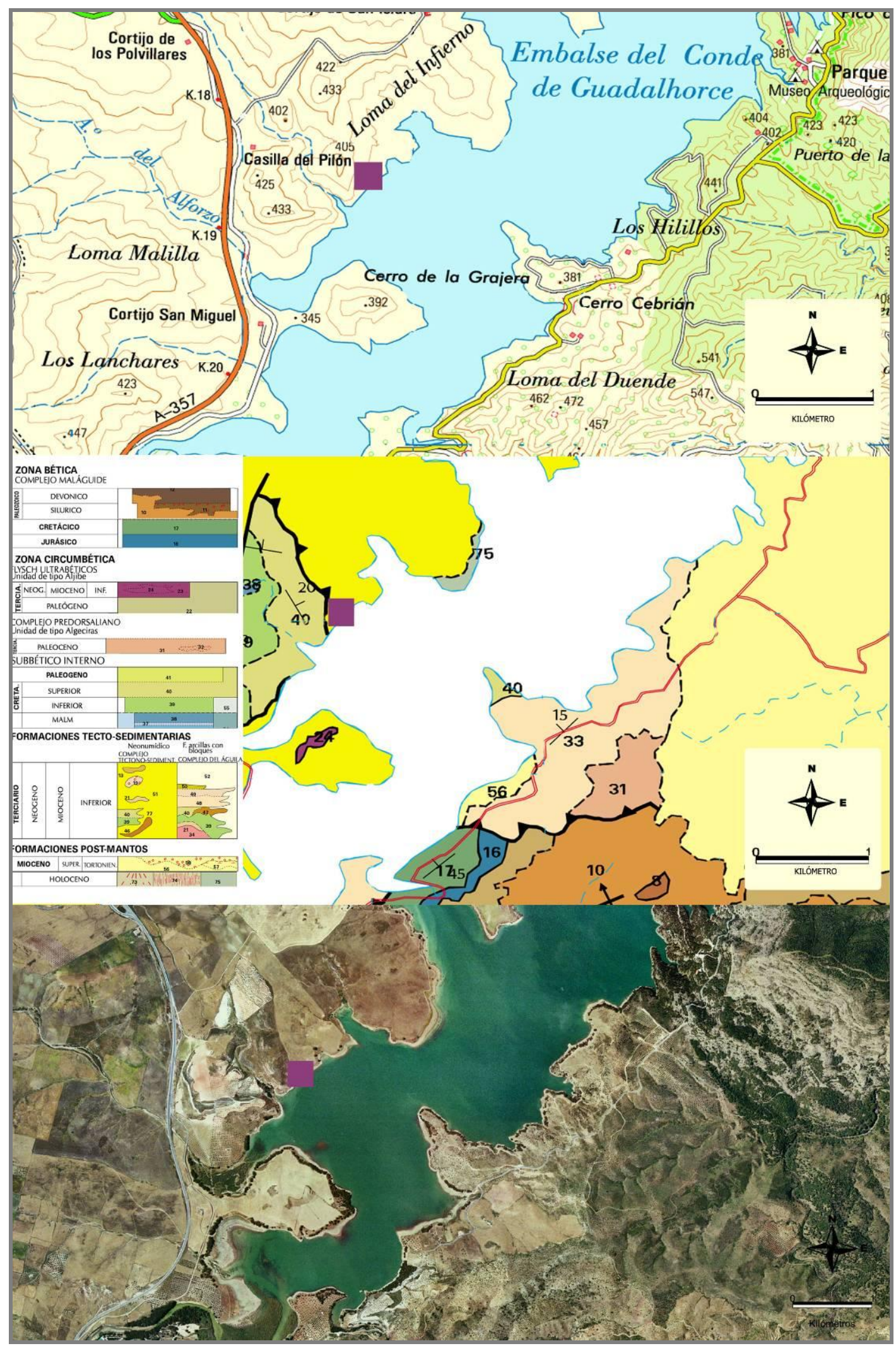


El yacimiento se localiza en una ladera sobre la margen izquierda del río Turón, al norte del pueblo de Ardales. Su acceso se realiza a través de la carretera MA-443 entre Ardales y Teba.

Sus coordenadas UTM ETRS89 30 son:

\begin{tabular}{|c|c|}
\hline $\mathbf{X}$ & $\mathbf{Y}$ \\
\hline 336950 & 4087051 \\
\hline 337037 & 4086945 \\
\hline 336807 & 4086736 \\
\hline 336687 & 4086827 \\
\hline
\end{tabular}

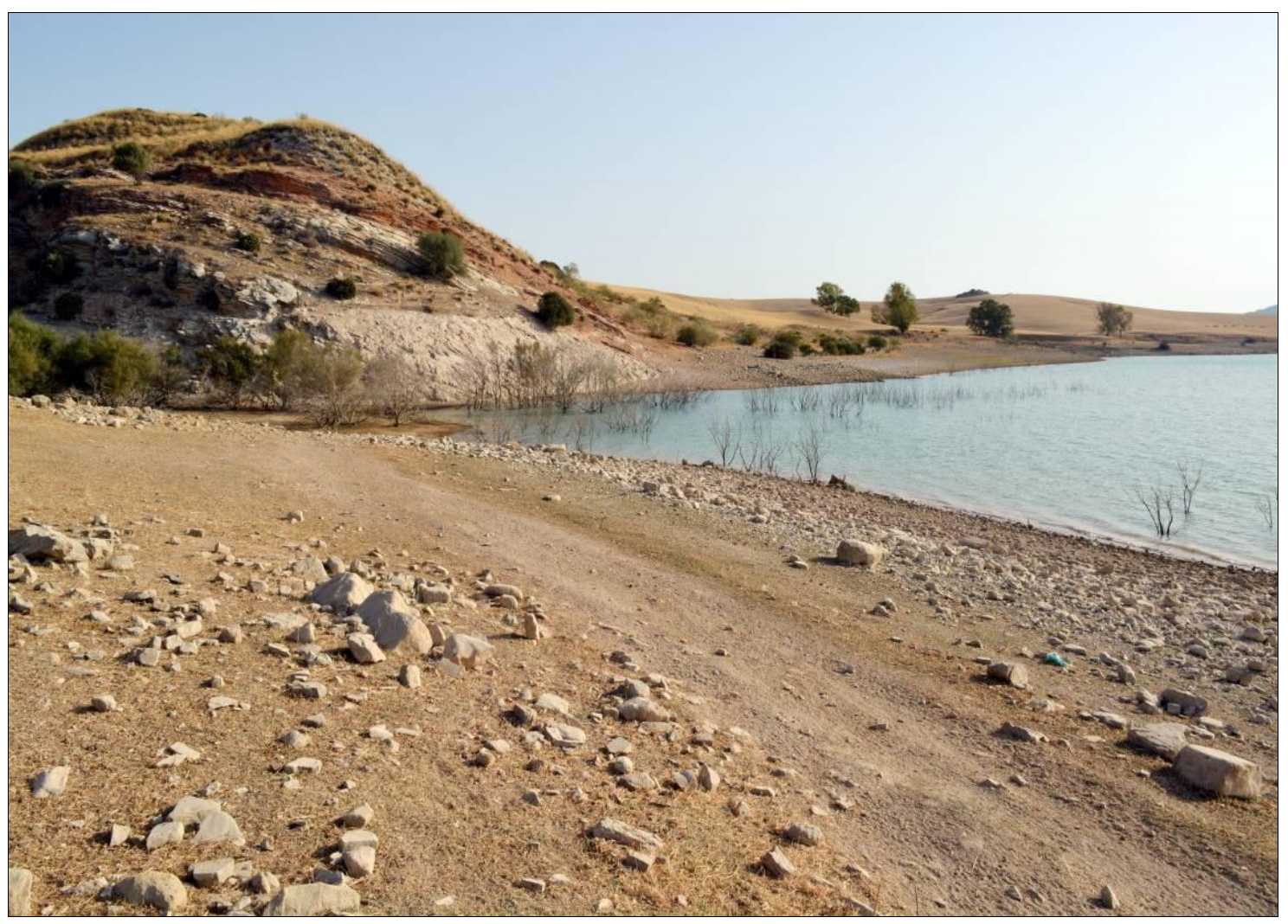

Figura 114. Vista general del yacimiento Raja del Boquerón.

Altitud de m s.n.m: 325 m

Extensión: $46.630 \mathrm{~m}^{2}$

. Contexto geológico y geomorfológico

Los materiales geológicos sobre los que se situa el yacimiento pertenecen al Neonumídico y más concretamente a las formaciones tecto-sedimentarias del Cenozoico. Se trata de margas y arcillas marrones con presencia de klippes sedimentarios u olistolitos de distinta naturaleza y edad. En las proximidades del mismo 
afloran margocalizas rosadas "Capas rojas" cuyos tramos más bajos presentan gran cantidad de sílex gris y rojo dentro de los niveles margocalcáreos, afloran además margas verdosas y blancas y margocalizas blancas del Albiense en cuyos tramos más compactados pueden aparecer junto a sílex gris o negro de edad Cenomaniense (Cretácico) y pertenecientes al Subbético interno.

\section{. Relación con la red fluvial}

Estrechamente vinculado a la red fluvial situándose a pocos metros del mismo viéndose afectado por las crecidas del río, que inunda la mayor parte del yacimiento.

. Procesos sedimentarios y procesos postdeposicionales

Los procesos sedimentarios del yacimiento son la deposición de limos y arenas por escorrentía superficial, así como movimientos de ladera en la zona noroeste del yacimiento donde los materiales geológicos presentes son margo-calizas. El material recuperado aparece sobre una ladera con una suave pendiente hasta llegar al río, hoy en día cabecera del embalse del Conde del Guadalhorce, motivo por el cual gran parte del yacimiento se encuentra bajo las aguas de dicho embalse. Debido a los procesos erosivos ocasionados por acción del oleaje, se produce el desplazamiento y la pérdida de gran cantidad de material, ocasionando a su vez una alteración postdeposicional que origina la mezcla de los materiales que se localizan en este yacimiento con diferentes adscripciónes cronológicas.

\section{. Interpretación geoarqueológica}

Es un yacimiento arqueológico que tiene como origen un abandono antrópico de los materiales líticos sobre la superficie de una ladera. La utilización del arado y la acción erosiva de las aguas del embalse, provoca movimientos verticales y superficiales de los materiales arqueológicos, lo que ocasiona la mezcla de la industria lítica más antigua, asociada al Paleolítico con las de la Prehistoria reciente.

\section{. Análisis de la industria lítica}

El estudio del material lítico que aquí presentamos se realiza sobre el material recogido entre los años 85-90, tanto en las prospecciónes arqueológicas desarrolladas durante esos años en Ardales, como en la intervención arqueológica del yacimiento 
realizada por el equipo de Ardales, también realizada en los años 90 (Espejo Herrerías et al., 1990). Parte de los materiales obtenidos se encuadraban en los momentos del Bronce final, sin embargo, con la revisión de los materiales del Centro de Interpretación de Ardales hemos comprobado la existencia de material arqueológico del Pleistoceno. El yacimiento no se pudo muestrear en el curso de este estudio debido a que se encontraba bajo las aguas del embalse y aunque visitamos el yacimiento no pudimos recuperar ningún material.

Del conjunto de materiales se han analizado 7 piezas, las cuales corresponden a industrias del Paleolítico medio, para su selección se han tenido en cuenta diferentes aspectos, tales como la pátina, la técnica levallois, o el rodamiento para diferenciar las industrias líticas del Paleolítico de las industrias asociadas a la Prehistoria reciente.

La materia prima (figura 115) predominante es la radiolarita roja/rosa con pátinas amarillentas y un ejemplar con pátina blanca, dos ejemplares de sílex masivo en tonalidades beige y gris y un ejemplar de sílex poroso.

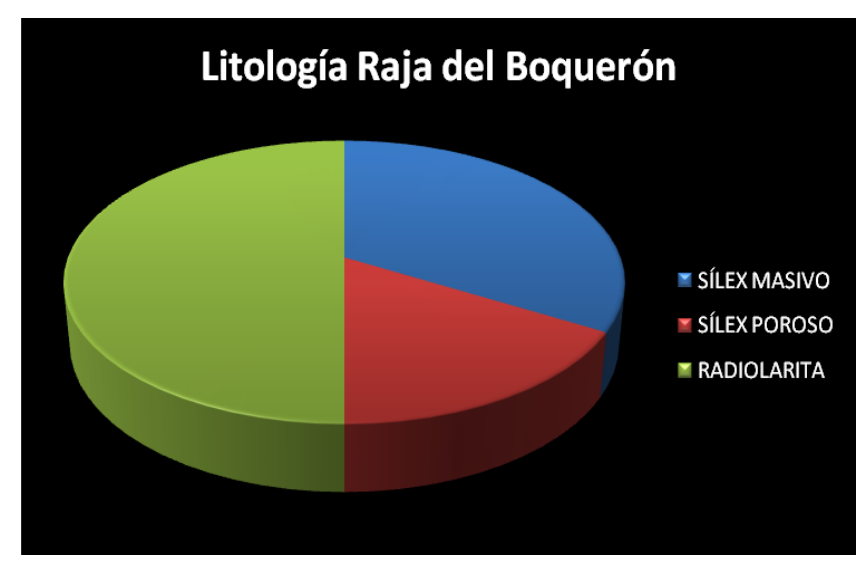

Figura 115. Materias primas de las piezas líticas recuperadas en el yacimiento de Raja del Boquerón.

En cuanto al estudio morfotécnico existe una presencia de Bases Naturales de Primera Generación (BN1G) de Bases Positivas (BP) y Bases Negativas de Segunda Generación (BN2G).

Las BN1G (tabla 25) corresponden a un ejemplar de radiolarita y otro de sílex masivo beige. Presentan un sistema de explotación unipolar y levallois, de tipo unifacial, con un carácter centrípeto de tipo 4C y 3C, con extracciones de ángulo simple y semiabrupto en ambas piezas y con unas longitudes de las extracciones profundas y totales. La arista frontal es convexa mientras que la sagital es sinuosa. 


\begin{tabular}{|c|c|c|c|c|c|c|c|c|c|c|c|c|c|c|}
\hline \multicolumn{15}{|c|}{ YACIMIENTOS ARDALES. ESTUDIO ANALÍTICO DE LAS BN1G } \\
\hline \multirow{2}{*}{\begin{tabular}{|c|} 
Nombre \\
R. del boquerón \\
\end{tabular}} & \multicolumn{5}{|c|}{ Materias primas y morfología } & \multicolumn{2}{|c|}{ Tipos de bases negativas } & \multicolumn{6}{|c|}{ Criterios analíticos de las BN1G } & \multirow[t]{2}{*}{ Tema operativo técnico } \\
\hline & $M$ & $\mathrm{R}$ & C & $\mathrm{P}$ & $T$ & $\mathrm{TN}$ & $\mathrm{BN}$ & CF & CC & $\mathrm{CO}$ & $\mathrm{CP}$ & CAF & CAS & \\
\hline RB-54 & $\mathrm{R}$ & B & 0 & B & NO & $U$ & BN1GE & $U$ & $3 C$ & S/SA & $\mathrm{p}$ & $c x$ & $\sin$ & T.O.T.I \\
\hline RB-127 & S & B & G & 0 & NO & C & BN1GE & U & $4 C$ & S/SA & $\mathrm{t}$ & $c x$ & $\sin$ & T.O.T.I \\
\hline
\end{tabular}

Tabla 25. Estudio analítico de las BN1G de Raja del Boquerón.

Las BP (tabla 26) analizadas muestran un predominio mayoritario de lascas, hay dos ejemplares de radiolarita y dos de sílex uno poroso y otro masivo. Todas presentan una pátina de color amarillo y muy rodadas. Se han documentado, uno ejemplar de BPSD (semidescortezado), dos ejemplares de BP-I (internas) y una BP-L (levallois). En cuanto al volumen todas son LP (largo plano). La delineación desde la cara ventral muestra un talón convexo en todas las piezas y un bulbo marcado en dos de ellas. Con talones abatidos en dos de ellos, uno facetado plano y el otro cortical, las superficies en plataforma y puntiforme. Las caras dorsales son no corticales en todos salvo en un ejemplar que es cortical dominante no cortical.

\begin{tabular}{|c|c|c|c|c|c|c|c|c|c|c|c|c|c|c|c|c|c|c|c|c|c|}
\hline \multicolumn{22}{|c|}{ YACIMIENTOS ARDALES. ESTUDIO ANALÍTICO DELLS BP } \\
\hline \multirow[t]{2}{*}{ Nombre } & \multicolumn{5}{|c|}{ Materias primas y morfología } & \multicolumn{3}{|c|}{ Tipos de bases positivas } & \multicolumn{3}{|c|}{ Dimensiones } & \multicolumn{10}{|c|}{ Criterios analíticos de las BP } \\
\hline & M & $R$ & c & p & $\mathrm{T}$ & LAS/LAM & TIPO & $\mathrm{L}$ & $A$ & TB & \begin{tabular}{l|l}
$B$ & VOL \\
\end{tabular} & & AVENTRAL & & CARA TA & LONAR & & & CARA DO & RSAL & \\
\hline Raja del Boquerón & & & & & & & & & & & & $F$ & $B$ & TIPO & \begin{tabular}{l|l} 
COR & $S$ \\
\end{tabular} & $T$ & $D$ & COR & SSAG & STR & A \\
\hline RB-2 & R & B & R & A & NO & LASCA & । & 4,4 & 3,3 & 0,9 & $18 \mathrm{LP}$ & $C X$ & M & $f p$ & NOCO PLA & $\mathrm{BF}$ & UA & NOCO & TRP & TRG & $\mathrm{Sl}$ \\
\hline RB-168 & s & B & B & A & NO & LASCA & । & 3,2 & 2,4 & 1,7 & $19 \mathrm{LP}$ & $C X$ & D & a & NOCO NO & nO & NO & NOCO & TRG & TRG & $\mathrm{SI}$ \\
\hline RB-192 & $R$ & M & $R$ & A & SI & LASCA & L & frag.d & 3,4 & $1,3 \mathrm{NO}$ & $0 \quad L P$ & $C X$ & M & a & NOCO PUN & MF & UA & NOCO & PTG & PTG & $\mathrm{SI}$ \\
\hline RB1-TL & S & M & B & A & NO & LASCA & SD & 9,5 & 6,9 & 1,9 & 17 LP & $C x$ & $D$ & $c$ & CO PLA & $\mathrm{NF}$ & $c x$ & CDNC & TRG & TRG & $\mathrm{SI}$ \\
\hline
\end{tabular}

Tabla 26. Estudio analítico de las BP de Raja del Boquerón.

En el estudio de las BN2G (tabla 27) hemos utilizado para su clasificación la nomenclatura del sistema tipológico de Laplace (Laplace, 1972) y los de la Lista-Tipo Bordes (Bordes, 1961). Es un ejemplar de sílex masivo beige con inclusiones negras. Corresponde a una raedera realizada sobre una lasca levallois. Con un volumen de tipo LP (largo plano). La delineación del talón desde la cara ventral es convexa y el bulbo difuso, no cortical, lineal y bifacetado. La cara dorsal es no cortical. El retoque en el lateral izquierdo es simple, marginal, directo y continuo, en el extremo distal abrupto, marginal, directo y continuo y en el lado derecho es plano, marginal, directo. Se trataría de una raedera lateral (R21) o una raedera lateral cóncavo-convexa según Bordes (17). 


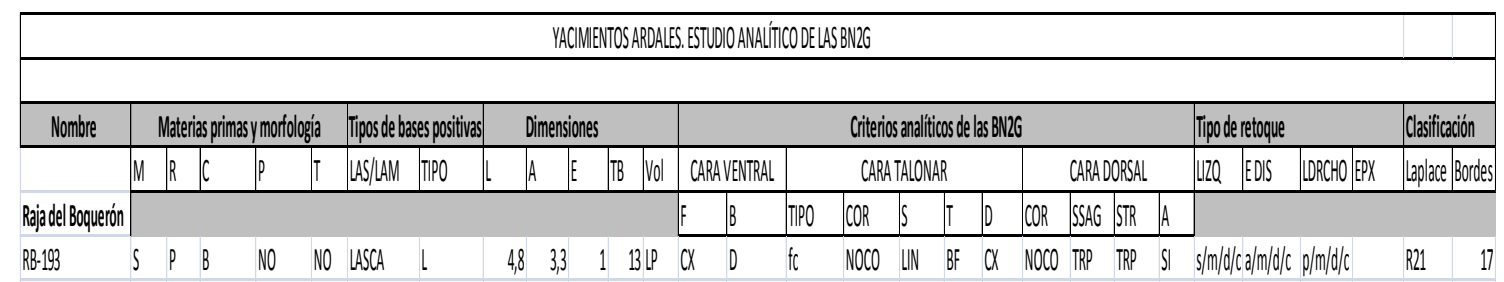

Tabla 27. Estudio analítico de las BN2G de Raja del Boquerón.

. Valoración y conclusiones

Su localización sobre una ladera y su situación, próximo a un nacimiento de agua, facilitaría la utilización de este espacio por grupos humanos del Paleolítico. Corresponde a un sitio utilizado desde el Pleistoceno medio y hasta momentos holocenos, situado junto a dos cursos de agua como son arroyo Alforzo y el arroyo del Águila, los cuales vierten sus aguas al curso principal, el río Turón. Desde el yacimiento se visualizan otros yacimientos como Morenito, Lomas del Infierno o la terraza de Las Grajeras, todos ellos a muy pocos metros.

Los procesos postdeposicionales, tanto naturales como antrópicos, han ocasionado la mezcla de materiales arqueológicos con adscripciones culturales diferentes por lo que el material seleccionado ha sido estudiado en base a criterios de pátina y rodamiento principalmente.

En cuanto a la tecnología destacamos una presencia mayoritaria de lascas, sin presencia de BP-SD (semidescortezado). Si hay BP-I (internas) y BP-L (levallois) de mediano y pequeño tamaño, todas ellas retocadas. Dentro del grupo de los productos retocados o $\mathrm{BN} 2 \mathrm{G}$, nos encontramos con un ejemplar correspondiente a una raedera.

La muestra arqueológica analizada es escasa en relación con la cantidad de material arqueológico de momentos holocenos que existe del yacimiento, sin embargo dicha muestra evidencia técnicas y características propias, en relación al rodamiento, pátina, materia prima etc., similares a los yacimientos de la zona circundante y que están asociados a nivel genérico a industrias del Paleolítico medio o Modo III. 


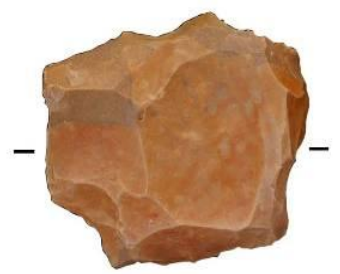

1
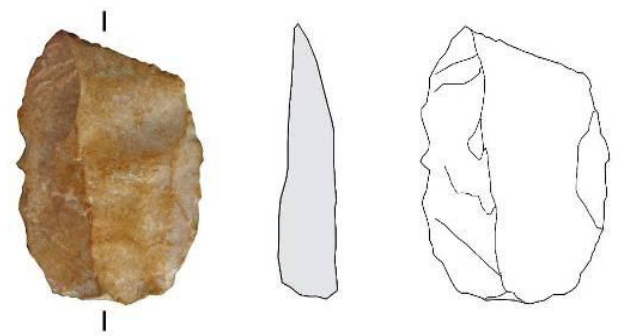

3
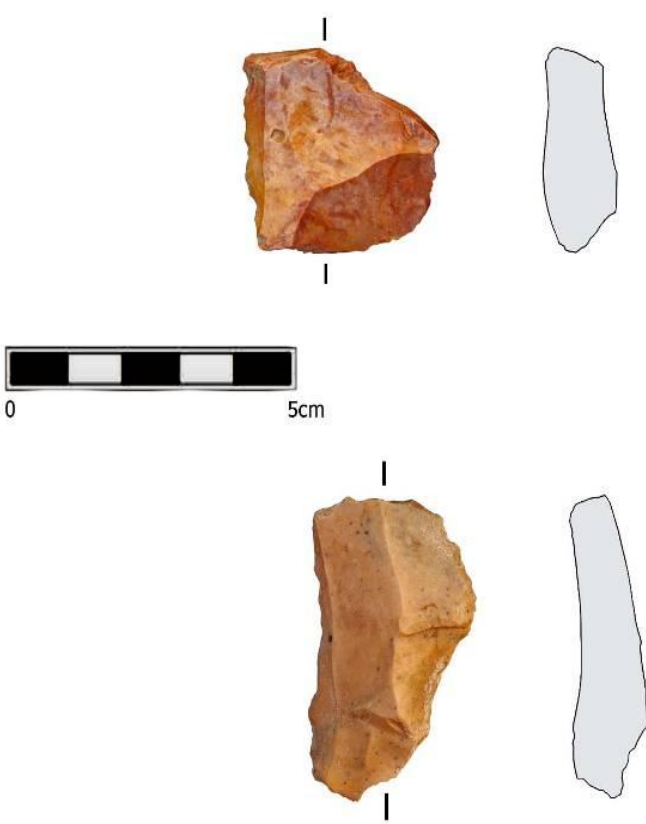

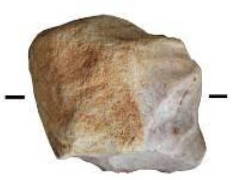

2
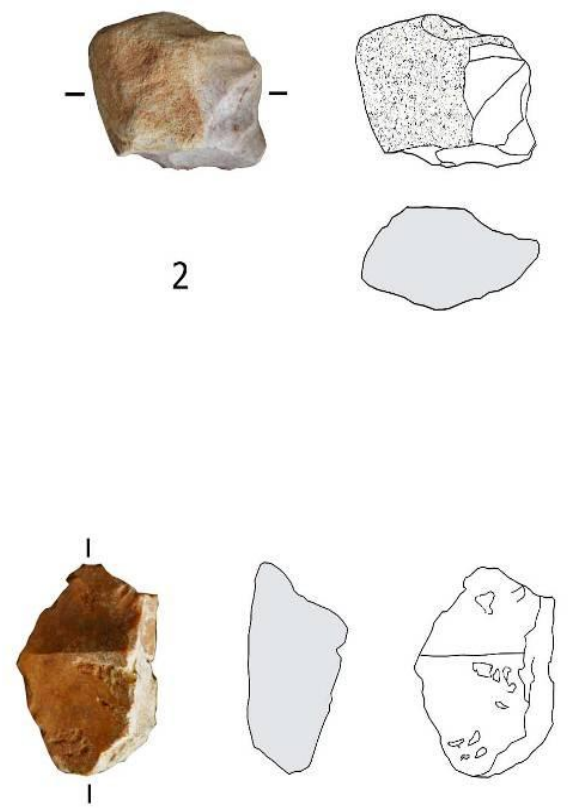

4
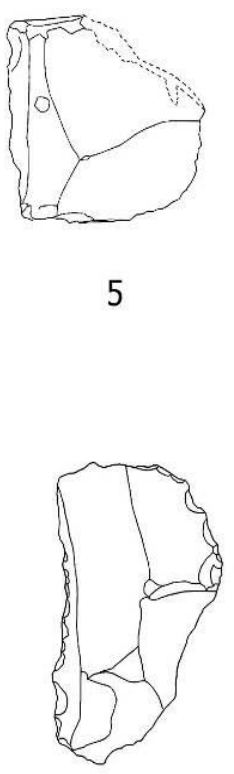

6

Figura 116. Raja del Boquerón (Ardales): 1, 2:BN1G-Núcleo levallois y unipolar; 3, 4, 5: BPLascas internas y levallois; 6: BN2G-Raedera doble cóncava-convexa. 


\subsubsection{Lomas del Infierno (Ardales)}

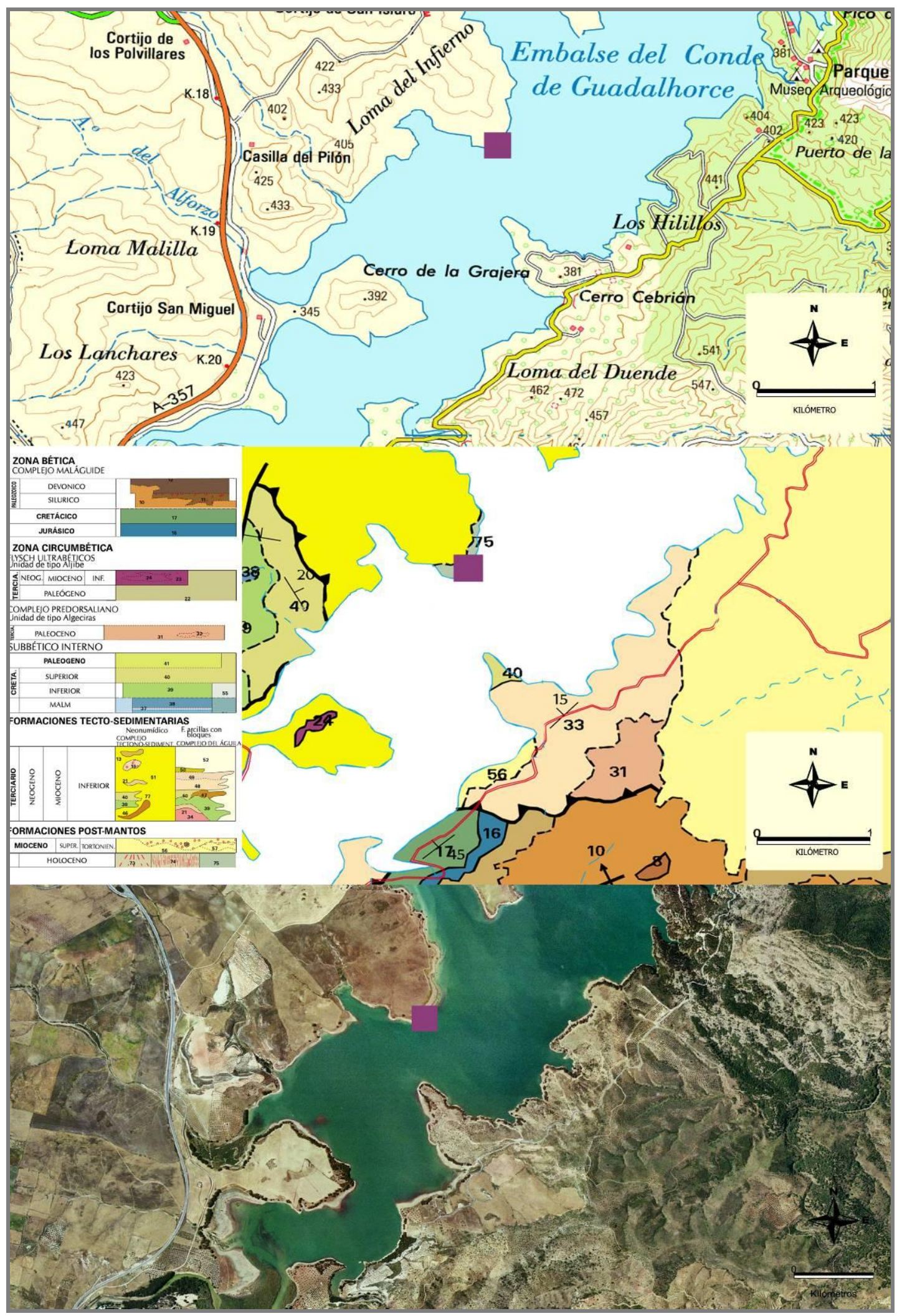


Situado en la orilla noroeste del embalse del Conde del Guadalhorce, en su margen izquierda, su acceso se realiza desde la carretera A-357 entre Ardales y Campillos, por un carril que conduce al cortijo San Isidro.

Sus coordenadas UTM ETRS89 30 son:

\begin{tabular}{|c|c|}
\hline $\mathbf{X}$ & $\mathbf{Y}$ \\
\hline 337710 & 4087810 \\
\hline 337832 & 4087541 \\
\hline 337807 & 4087265 \\
\hline 337611 & 4086991 \\
\hline 337412 & 4087175 \\
\hline 337569 & 4087385 \\
\hline 337541 & 4087692 \\
\hline
\end{tabular}

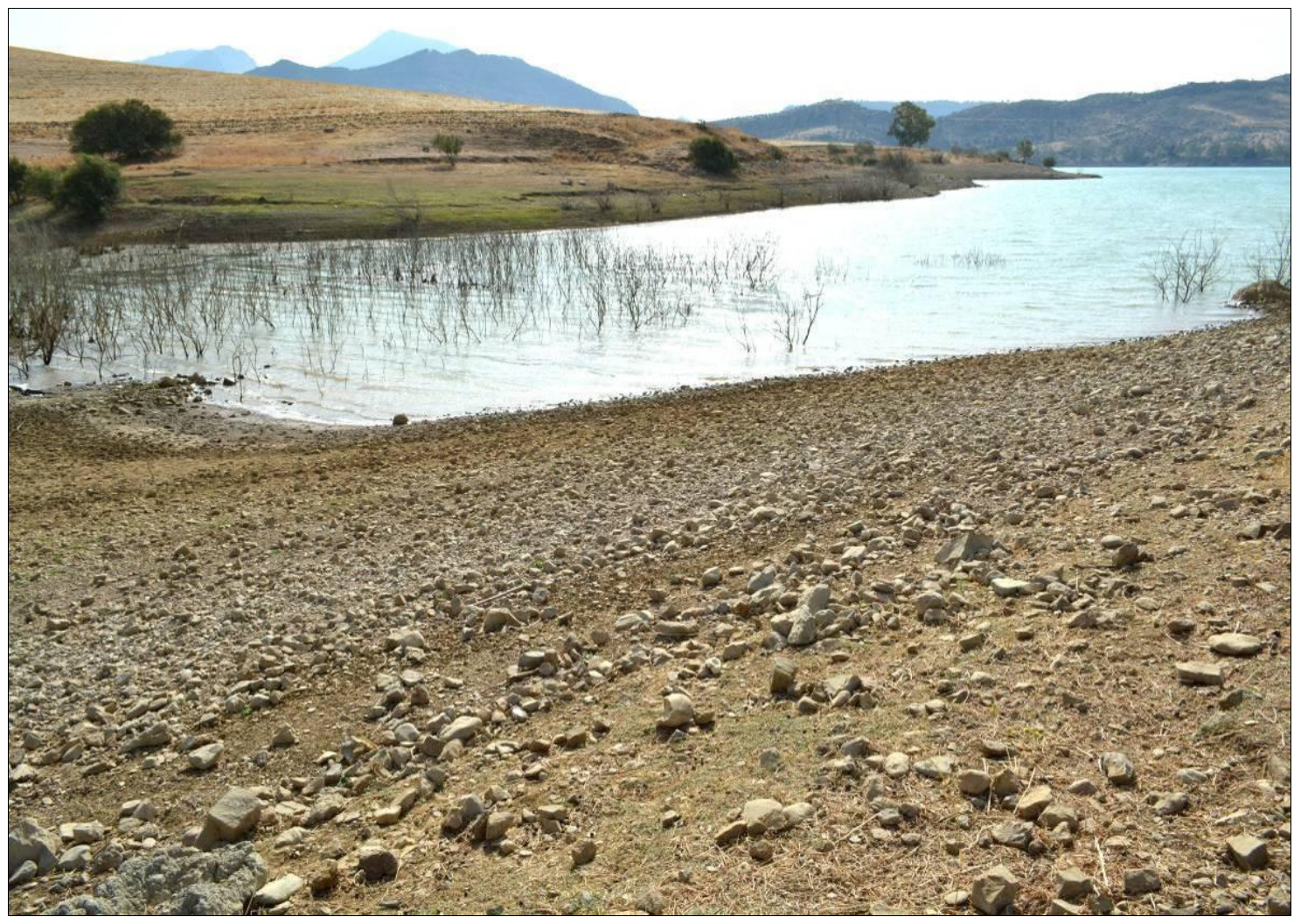

Figura 117. Vista general del yacimiento Lomas del Infierno.

Altitud: m s.n.m: 391 m.

Extensión: $186.486,83 \mathrm{~m}^{2}$

. Contexto geológico y geomorfológico

Los materiales geológicos presentes en el yacimiento pertenecen al Neonumídico y más concretamente a las formaciones tecto-sedimentarias del 
Cenozoico. Se trata de margas y arcillas marrones con presencia de klippes sedimentarios u olistolitos de distinta naturaleza y edad. Junto a estos materiales del Cenozoico afloran materiales de las formaciones post-mantos, con presencia de arcillas, arenas y cantos de origen aluvial.

\section{. Relación con la red fluvial}

En la actualidad se encuentra situado a pocos metros de la orilla del río Turón, viéndose afectado por las crecidas del embalse que inunda parte del yacimiento.

\section{. Procesos sedimentarios y procesos postdeposicionales}

Se trata de un yacimiento en superficie cuyos materiales han sido recuperados sobre una ladera con una suave pendiente hasta llegar al embalse, de tal forma que parte del yacimiento se encuentre bajo las aguas del embalse del Conde del Guadalhorce. Los procesos postdeposicionales que más afectan al yacimiento son principalmente los ocasionados por la acción del oleaje, que genera el desplazamiento y la pérdida de gran cantidad de material, ocasionando a su vez una alteración postdeposicional que origina la mezcla de los materiales que se localizan en este yacimiento y con una adscripción cronológica diferente. Junto a este proceso natural está también la acción antrópica, con la utilización del arado y la siembra de cereales.

\section{. Interpretación geoarqueológica}

Se trata de un yacimiento arqueológico que tiene como origen un abandono antrópico de los materiales líticos sobre la superficie, la cual ha sido transformada por el arado y la acción erosiva de las aguas del embalse del Conde del Guadalhorce, generando la removilización de los materiales arqueológicos del Paleolítico con los de la Prehistoria reciente. La industria lítica presenta filos con rodamiento medio generado principalmente por las tareas agrícolas y las subidas y bajadas del nivel del río.

\section{. Análisis de la industria lítica}

El estudio sobre el material lítico que aquí presentamos se realiza sobre el material recogido entre los años 85-90, tanto de las prospecciónes arqueológicas desarrolladas durante esos años en Ardales como de algunas piezas localizadas en superficie durante los muestreos geoarqueológicos desarrollados en el marco de las intervenciones puntuales realizadas en la zona durante los años 2011-2014. La revisión 
de los materiales del Centro de Interpretación de Ardales evidencia la existencia de material arqueológico del Pleistoceno. Del conjunto de materiales, se han analizado 27 piezas, las cuales corresponden a industrias del Paleolítico medio. Para su selección se han tenido en cuenta diferentes aspectos, tales como la pátina, la técnica levallois, o el rodamiento.

La materia prima (figura 118) predominante es el sílex masivo, en tonalidades gris/negro y beige, seguido por la cuarcita en tonalidades roja y blanca, arenisca compacta y con un reducido número de sílex poroso y radiolarita.

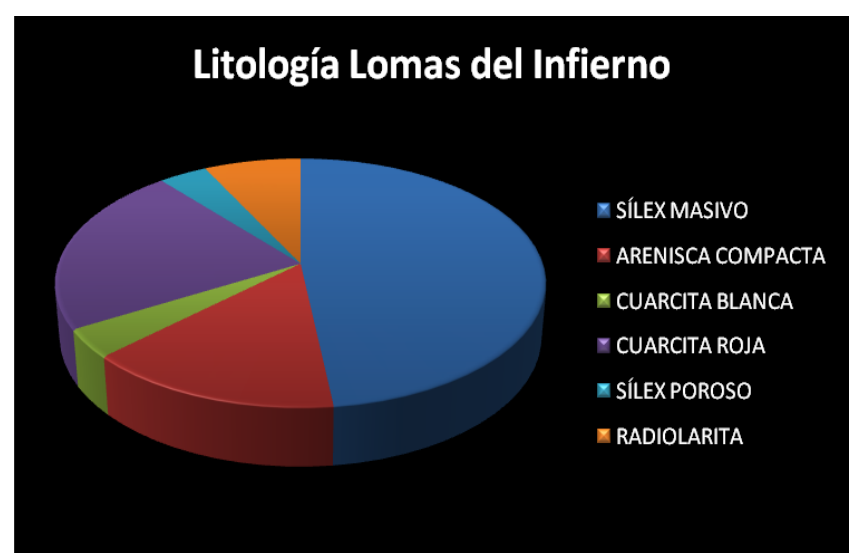

Figura 118. Materias primas de las piezas líticas recuperadas en el yacimiento de Lomas del Infierno.

Según el estudio morfotécnico aparecen Bases Naturales de Primera Generación (BN1G), Bases Positivas (BP) y Bases Negativas de Segunda Generación (BN2G).

Las BN1G (tabla 28) son: 2 ejemplares en arenisca gris, 1 en cuarcita roja y otras 4 de sílex masivo gris, todos con pátina, salvo un ejemplar. El sistema de explotación es unipolar en las cuarcitas, mientras que en las otras litologías son centrípetos, diverso y levallois sobre lasca. Tienen un carácter facial unifacial y bifacial y un ejemplar centrípeto. Presentan un carácter centrípeto casi completo predominando los de de tipo $3 \mathrm{C}$, dos ejemplares con $4 \mathrm{C}$ y un ejemplar de $\overline{\mathrm{C}}$ que corresponde a un canto tallado en cuarcita, con extracciones de ángulo simple en la mayoría de las piezas y con presencia minoritaria de semiabrupto o abrupto y plano. Las longitudes de las extracciones son variadas, desde profundas hasta marginales y totales. La arista frontal es convexa en todos los ejemplares mientras que la sagital es sinuosa. 


\begin{tabular}{|c|c|c|c|c|c|c|c|c|c|c|c|c|c|c|}
\hline \multicolumn{15}{|c|}{ YACIMIENTOS ARDALES. ESTUDIO ANALÍTICO DE LAS BN1G } \\
\hline \multirow{2}{*}{\begin{tabular}{|r|} 
Nombre \\
L. del Infierno
\end{tabular}} & \multicolumn{5}{|c|}{ Materias primas y morfología } & \multicolumn{2}{|c|}{ Tipos de bases negativas } & \multicolumn{6}{|c|}{ Criterios analíticos de las BN1G } & \multirow[t]{2}{*}{ Tema operativo técnico } \\
\hline & $M$ & $\mathrm{R}$ & C & P & $\mathrm{T}$ & TN & BN & CF & CC & $\mathrm{CO}$ & $\mathrm{CP}$ & CAF & CAS & \\
\hline L.I-334 & A & B & G & NO & NO & $\mathrm{U}$ & BN1GE & B & $\bar{C}$ & S & p & $\mathrm{cx}$ & $\sin$ & T.O.T.D \\
\hline L.I-306 & A & B & G & NO & NO & U & BN1GE & $\mathrm{U}$ & $4 C$ & $\mathrm{~s}$ & $\mathrm{mp}$ & $\mathrm{cx}$ & $\sin$ & T.O.T.I \\
\hline L.I-431 & $\mathrm{CU}$ & B & $\mathrm{R}$ & NO & NO & U & BN1GE & U & $3 C$ & SA & $P$ & $c x$ & $\sin$ & T.O.T.I \\
\hline L.I-457 & $S$ & B & G & A & NO & DIV & BN1GE & B & $3 C$ & $S$ & $\mathrm{~m}$ & $c x$ & $\sin$ & T.O.T.I \\
\hline L.I-4TL & S & B & G & B & NO & C & BN1GE & B & $3 C$ & $A / P$ & $\mathrm{~m}$ & $c x$ & $\sin$ & T.O.T.I \\
\hline L.I-5TL & $S$ & $M$ & G & $R$ & NO & $\mathrm{C} / \mathrm{SL}$ & BN1GE & $U$ & $4 C$ & $\mathrm{P} / \mathrm{S}$ & $\mathrm{t}$ & $c x$ & $\sin$ & T.O.T.I \\
\hline L.I-6TL & $S$ & $M$ & B & NO & NO & $\mathrm{C} / \mathrm{SL}$ & BN1GE & $C$ & $4 C$ & $\mathrm{~S}$ & $t$ & $c x$ & $\sin$ & T.O.T.I \\
\hline
\end{tabular}

Tabla 28. Estudio analítico de las BN1G de Lomas del Infierno.

Las BP (tabla 29) son en total 16 piezas: 5 ejemplares de cuarcita, 2 en arenisca, 7 de sílex y un ejemplar de radiolarita. Todos los sílex presentan una pátina de color amarillo o blanco y un alto grado de rodamiento. Se ha documentado 1 ejemplar de BPD (descortezado), 3 ejemplares de BP-SD (semidescortezado), 8 ejemplares de BP-I (internas) y 4 ejemplares de BP-L (levallois). En cuanto al volumen hay un predominio de LP (largo plano), un ejemplar de EP (espeso plano) y otro de LE (largo espeso). La delineación desde la cara ventral muestra un predominio de talones convexos, en total 8 , 5 con talón recto y 2 cóncavos, y un bulbo difuso en la mayoría. Con talones lisos, facetados diedros, abatidos y puntiforme. Predominan los talones no corticales y con superficies en plataforma, lineal y puntiforme, unifacetado en la mayoría de los ejemplares, frente a bifacetados y multifacetados, también presentes. Las caras dorsales son no corticales en todos, salvo en un ejemplar.

\begin{tabular}{|c|c|c|c|c|c|c|c|c|c|c|c|c|c|c|c|c|c|c|c|c|c|c|}
\hline \multicolumn{23}{|c|}{ YACIMIENTOS ARDALES. ESTUDIO ANALÍTICO DE LAS BP } \\
\hline \multirow{3}{*}{$\begin{array}{r}\text { Nombre } \\
\text { L. del Infierno }\end{array}$} & \multicolumn{5}{|c|}{ Materias primas y morfología } & \multicolumn{2}{|c|}{\begin{tabular}{|l|} 
Tipos de bases positivas \\
\end{tabular}} & \multicolumn{4}{|c|}{ Dimensiones } & \multicolumn{11}{|c|}{ Criterios analíticos de las BP } \\
\hline & M & R & c & p & T & LAS/LAM & TIPO & $\mathrm{L}$ & A & TB & VOL & \multicolumn{2}{|c|}{ CARA VENTRAL } & \multicolumn{5}{|c|}{ CARA TALONAR } & \multicolumn{4}{|c|}{ CARA DORSAL } \\
\hline & & & & & & & & & & & & $\mathrm{F}$ & $B$ & TIPO & COR & S & $\mathrm{T}$ & $\mathrm{D}$ & COR & SSAG & STR & A \\
\hline L.I.-75 & A & B & G & NO & NO & LASCA & D & 5,8 & 6,4 & 2,3 & $21 \mathrm{EP}$ & $c X$ & D & 1 & $\mathrm{CO}$ & PLA & $\mathrm{NF}$ & $C X$ & NOCO & TRG & TRG & NO \\
\hline L.I-117 & $\mathrm{s}$ & B & $\mathrm{N}$ & A & NO & LASCA & SD & 3,6 & 3,7 & 1 & $18 \mathrm{LP}$ & CC & D & a & NOCO & 0 LIN & UF & CC & NOCO & CDG & CDG & NO \\
\hline L.I-132 & CU & M & $\mathrm{R}$ & NO & NO & LASCA & SD & 5,4 & 3,7 & 1,1 & $13 \mathrm{LP}$ & RT & D & a & NOCO & O PLA & $\mathrm{NF}$ & RT & NOCO & TRP & TRP & $\mathrm{SI}$ \\
\hline L.I-435 & A & B & G & NO & NO & LASCA & SD & 7,1 & 3,7 & 2,2 & $13 \mathrm{LP}$ & RT & D & 1 & CDNC & C PLA & $\mathrm{BF}$ & RT & NCDC & TRG & TRG & $\mathrm{SI}$ \\
\hline L.I-261 & $\mathrm{s}$ & B & 0 & NO & NO & LASCA & 1 & 2,9 & 2,5 & 0,8 & $19 \mathrm{LP}$ & $c X$ & D & $\mathrm{p}$ & NOCO & O PUN & $\mathrm{BF}$ & UA & NOCO & CDG & CDG & $\mathrm{SI}$ \\
\hline L.I-331 & CU & M & $R$ & NO & NO & LASCA & 1 & 2,9 & 2,9 & 0,7 & $19 \mathrm{LP}$ & $c X$ & D & 1 & NOCO & 0 LIN & UF & RT & NOCO & TRP & TRP & SI \\
\hline L.I-377 & CU & M & $R$ & NO & NO & LASCA & 1 & 5,1 & 4 & 0,8 & $17 \mathrm{LP}$ & RT & D & 1 & NOCO & 0 PLA & UF & $C X$ & NOCO & CDG & OV & SI \\
\hline L.I-401 & CU & $B$ & $R$ & NO & NO & LASCA & 1 & 4,4 & 3,5 & 1,3 & $17 \mathrm{LP}$ & RT & D & 1 & CO & LIN & UF & RT & NOCO & OV & OV & $\mathrm{SI}$ \\
\hline L.I-1462 & S & B & 0 & A & NO & LASCA & 1 & 3,4 & 3,6 & 1,3 & $18 \mathrm{LE}$ & RT & D & 1 & NOCO & 0 LIN & UF & RT & NOCO & TRP & TRG & $\mathrm{SI}$ \\
\hline L.I-678 & S & $B$ & 0 & A & NO & LASCA & 1 & 4,3 & 3,6 & 1,1 & $17 \mathrm{LP}$ & $C X$ & D & $\mathrm{fd}$ & NOCO & O PUN & MF & UA & NOCO & CDG & TRG & $\mathrm{SI}$ \\
\hline L.I-37 & $R$ & $P$ & 0 & NO & NO & LASCA & L & 2,9 & 2,4 & 0,6 & $19 \mathrm{LP}$ & $C X$ & M & $\mathrm{fd}$ & NOCO & 0 PUN & MF & UA & NOCO & CDG & OV & SI \\
\hline L.I-182 & S & $M$ & $G$ & B & NO & LASCA & L & 3,4 & 2,4 & 1 & $19 \mathrm{LP}$ & $c x$ & D & $\mathrm{fd}$ & NOCO & O PUN & $\mathrm{BF}$ & UA & NOCO & TRG & TRG & $\mathrm{SI}$ \\
\hline L.I-386 & S & $B$ & $N$ & B & NO & LASCA & L & 3,2 & 2,8 & 1 & $18 \mathrm{LP}$ & CC & D & a & NOCO & 0 LIN & UF & RT & NOCO & TRP & TRP & $\mathrm{SI}$ \\
\hline L.II-1TL & CU & $B$ & 0 & A & NO & LASCA & 1 & $\mathrm{fp}$ & 3,7 & $0,9 \mathrm{NO}$ & $0 \quad L P$ & NO & NO & NO & NO & NO & NO & NO & NOCO & OV & TRG & $\mathrm{SI}$ \\
\hline L.I-2TL & S & $B$ & G & A & NO & LASCA & 1 & 4 & 4 & 1,3 & $18 \mathrm{LP}$ & $c X$ & D & 1 & NOCO & O PUN & BF & UA & NOCO & CDG & TRG & SI \\
\hline L.I-TTL & S & M & B & NO & NO & LASCA & L & 4,1 & 4,4 & 1,5 & $21 \mathrm{LP}$ & $c X$ & M & $\mathrm{fd}$ & NOCO & 0 PLA & MF & $C X$ & NOCO & TRP & TRG & $\mathrm{SI}$ \\
\hline
\end{tabular}

Tabla 29. Estudio analítico de las BP de Lomas del Infierno.

Las BN2G (tabla 30) corresponden a cuatro ejemplares, dos en sílex masivo negro/gris, uno en cuarcita y uno en radiolarita. La nomenclatura utilizada en su clasificación es la del sistema tipológico de Laplace (Laplace, 1972) y los de la ListaTipo Bordes (Bordes, 1961). Uno de los ejemplares es una muesca realizada sobre una 
lasca interna de radiolarita. Tiene un volumen de tipo LP (largo plano), la delineación del talón desde la cara ventral es recta y el bulbo difuso. La cara talonar presenta un talón liso, no cortical, lineal y unifacetado. La cara dorsal no cortical. El retoque está en el lateral izquierdo y es simple, profundo, directo y con muesca. Se trata de un denticulado según Laplace (D21) o una muesca según Bordes (42). Los otros tres ejemplares corresponden a raederas realizadas sobre dos lasca de semidescortezado y una interna.

La raedera en sílex masivo negro, presenta un volumen LP (largo plano), con una fractura en el extremo próximal. La cara dorsal es no cortical. El retoque en el lateral derecho es simple, marginal, directo y continuo. Corresponde a una raedera lateral según Laplace (R21) o raedera convexa según Bordes (10).

La raedera en sílex masivo gris presenta un volumen LP (largo plano), la delineación de la cara ventral es recta y el bulbo difuso. La cara talonar presenta un talón liso, no cortical, lineal, unifacial y recto. La cara dorsal es no cortical dominante cortical. Presenta un retoque en el lateral izquierdo plano, profundo, directo, continuo y un retoque en el extremo distal simple, profundo, directo y continuo. Es una raedera lateral según Laplace (R21) o una raedera retoque bifacial con retoque en el extremo distal según Bordes (28).

La raedera en cuarcita presenta un volumen LP (largo plano), la delineación de la cara ventral es recta con un bulbo difuso. La cara talonar con talón facetado plano, no cortical, lineal, bifacial y recto. La cara dorsal es cortical dominante no cortical. Presenta el retoque en el lateral derecho, simple, marginal, directo y continuo. Corresponde a una raedera lateral según Laplace (R21) o una raedera convexa según Bordes (10).

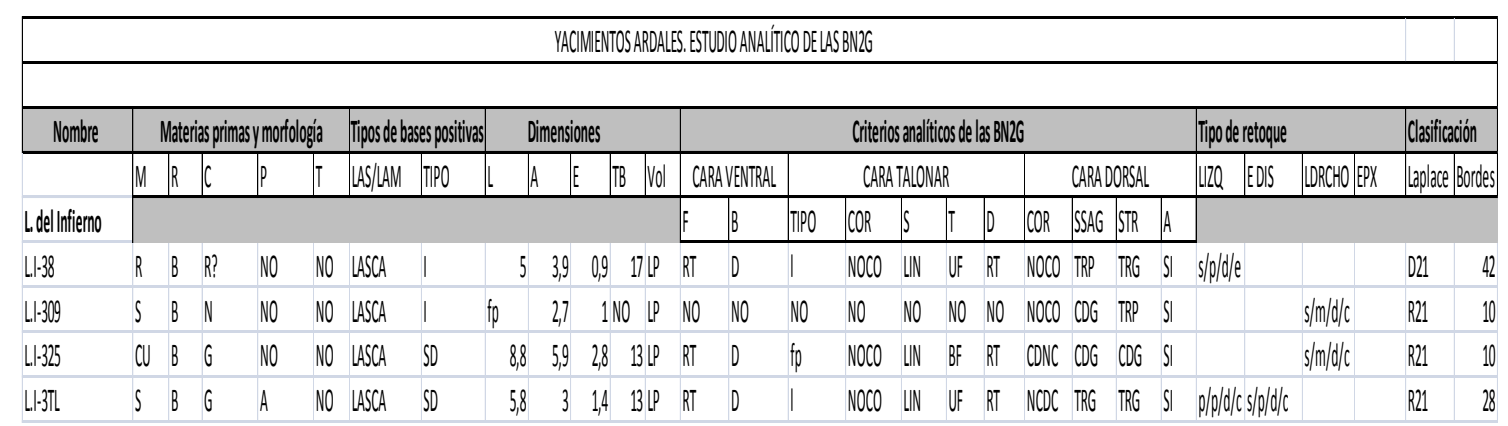

Tabla 30. Estudio analítico de las BN2G de Lomas del Infierno. 
- Valoración y conclusiones

Se sitúa en una zona llana muy próxima al río Turón con unas características similares a los anteriores yacimientos descritos. Aunque la materia prima predominante es el sílex, es llamativa la utilización de cuarcita o protocuarcita para las BN1G, BP Y BN2G.

Los procesos postdeposicionales tanto naturales como antrópicos han ocasionado la mezcla de materiales arqueológicos con adscripciones culturales diferentes por lo que el material seleccionado ha sido estudiado en función de criterios de pátina y rodamiento principalmente.

En el análisis de la industria lítica existe una presencia de BN1GE unipolares, bifaciales y levallois. Destacamos la presencia mayoritaria de BP- D (descortezado) y BP-SD (semidescortezado), de BP-I (internas) y BP-L (levallois). Dentro del grupo de los productos retocados o $\mathrm{BN} 2 \mathrm{G}$, nos encontramos con un ejemplar correspondiente a una muesca y tres raederas laterales, una de ellas con retoque bifacial y en el extremo distal.

La muestra arqueológica analizada permite ver la utilización de materias primas diferentes: por un lado, las cuarcitas o protocuarcitas, de dos tonalidades y, por otro, el sílex. Ambas materias primas aparecen en todo el proceso de la cadena operativa, desde los núcleos hasta las lascas y productos retocados. Todo esto permite un encuadre cultural genérico dentro del Paleolítico medio o Modo III. 

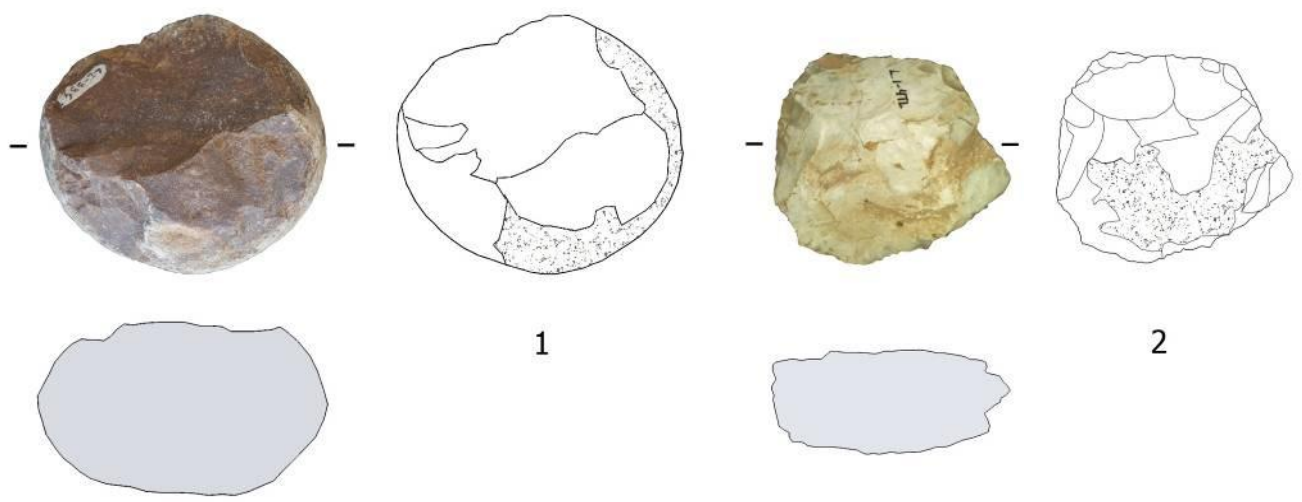

1

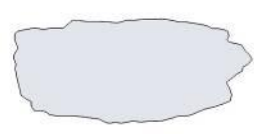

2
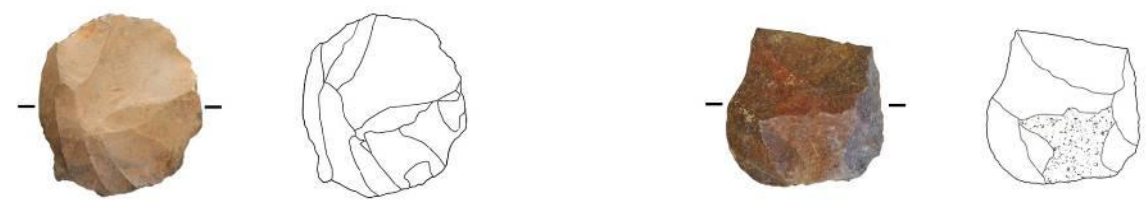

3

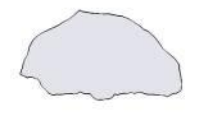

4
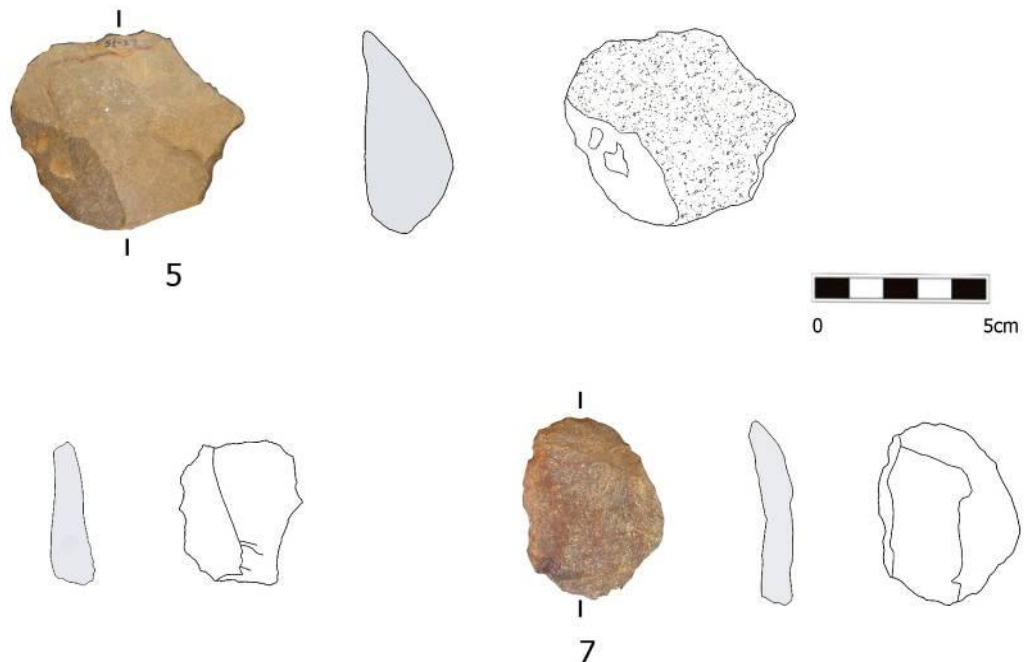

6

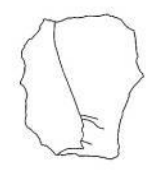

Figura 119. Lomas del Infierno (Ardales): $1,2,3,4$ :BN1G- Canto tallado, núcleo centrípeto, núcleo levallois sobre lasca y unipolar; 5, 6, 7: BP-Lasca de descortezado e internas. 


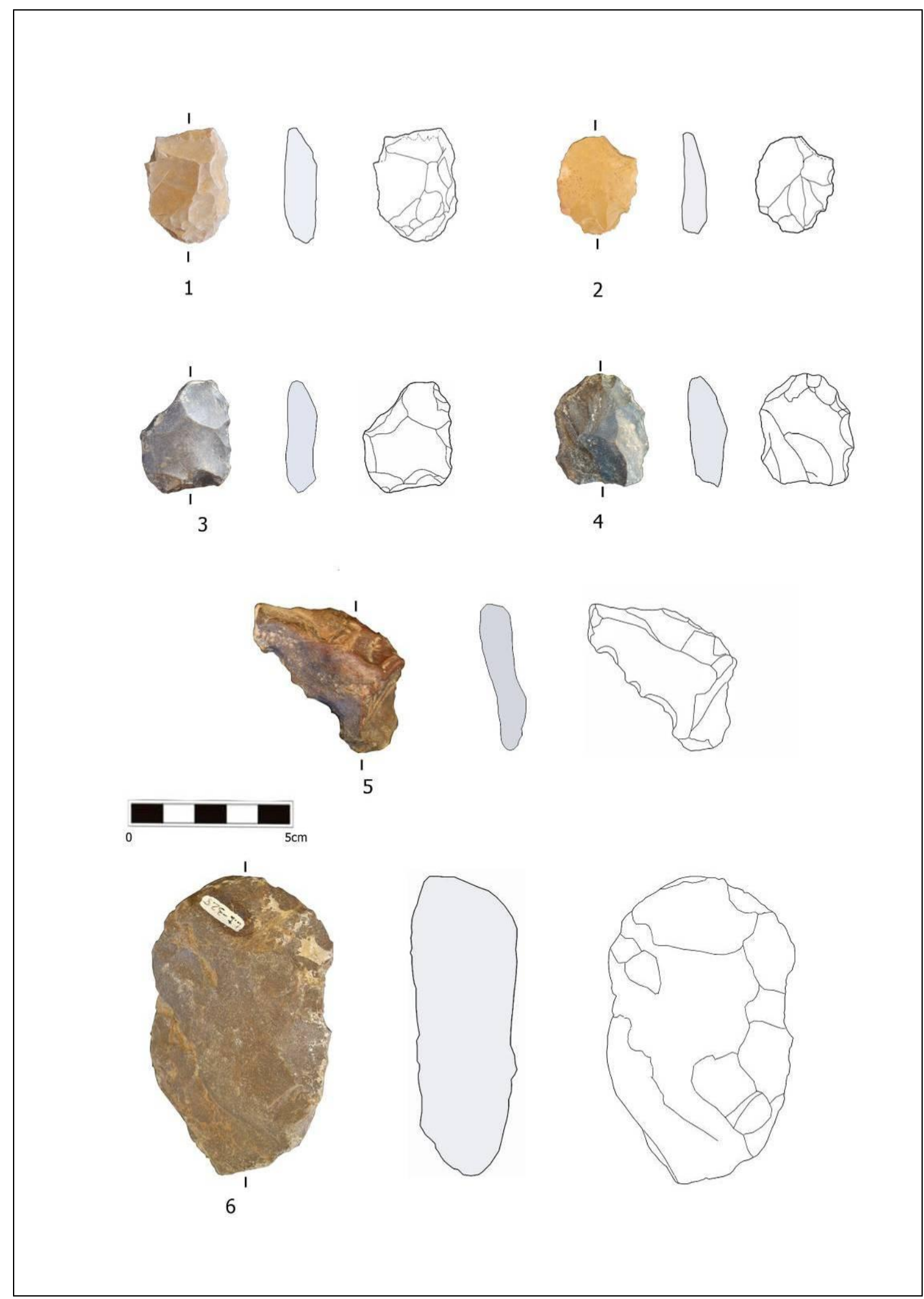

Figura 120. Lomas del Infierno (Ardales): 1, 2, 3 BP-Lascas levallois; 4, 6: BN2G-Raederas laterales; 5: Denticulado. 


\subsubsection{Cuenca del Guadalteba}

Asociados a la cuenca del Guadalteba se han estudiado 5 yacimientos, correspondientes a sistemas de terrazas fluviales, a yacimientos en superficie y a yacimientos en cuevas. Se presenta aquí un yacimiento inédito, el de La Puente, localizado durante los inicios de las prospecciones arqueológicas del P.G.I. El mapa topográfico de 1911-1920 (figura 121) vemos como la construcción del embalse del Gudalteba apenas afectó al curso original del río Guadalteba a diferencia de lo que ocurrió con el río Turón.

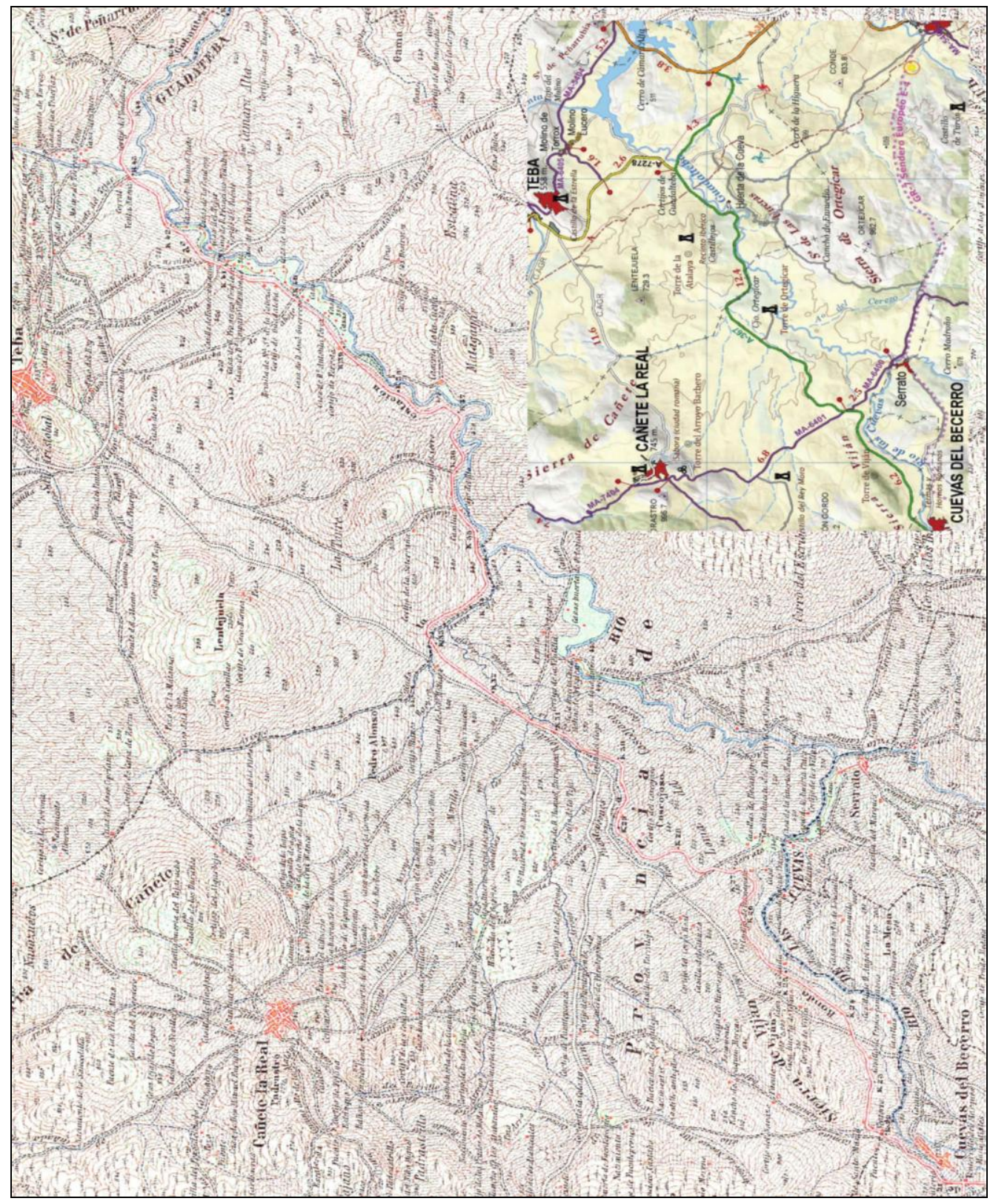

Figura 121. Mapa Topográfico Nacional de 1911-1920, con la cuenca original del río

Guadalteba. Escala 1:50.000 (MTN50) y embalse del Guadalteba en la actualidad. 


\subsubsection{Terraza de La Puente (Teba)}

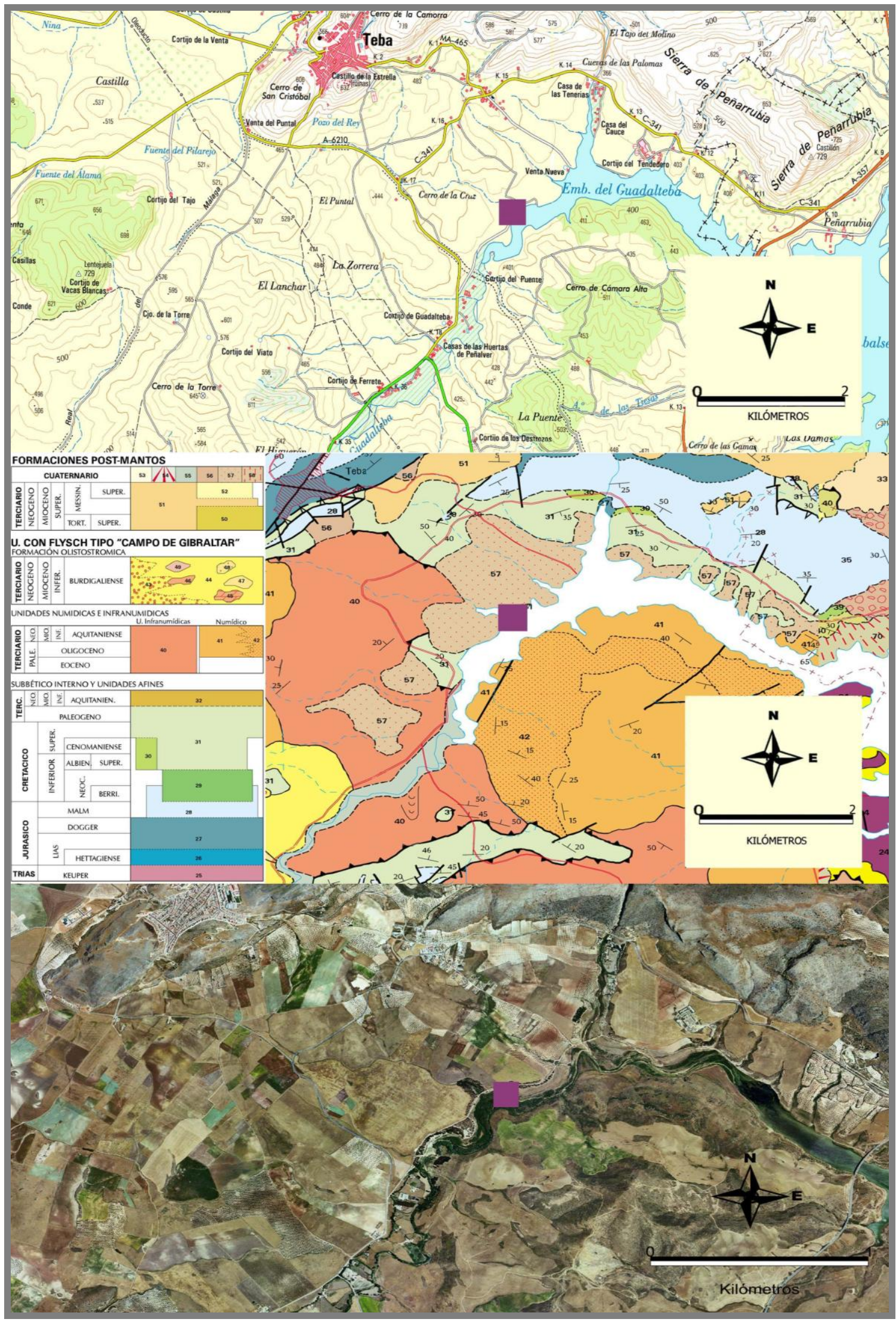


La terraza se localiza al sur de la población de Teba. Su acceso se realiza a través de la carretera C-341 que comunica Campillos con Ronda, pasando por Teba. Antes de llegar al punto kilométrico 18 desviarse hacia una carretera que se dirige al embalse hasta llegar a la zona conocida como La Puente.

Sus coordenadas UTM ETRS89 30 son:

\begin{tabular}{|c|c|}
\hline $\mathbf{X}$ & $\mathbf{Y}$ \\
\hline 331571 & 4092927 \\
\hline 331732 & 4092958 \\
\hline
\end{tabular}

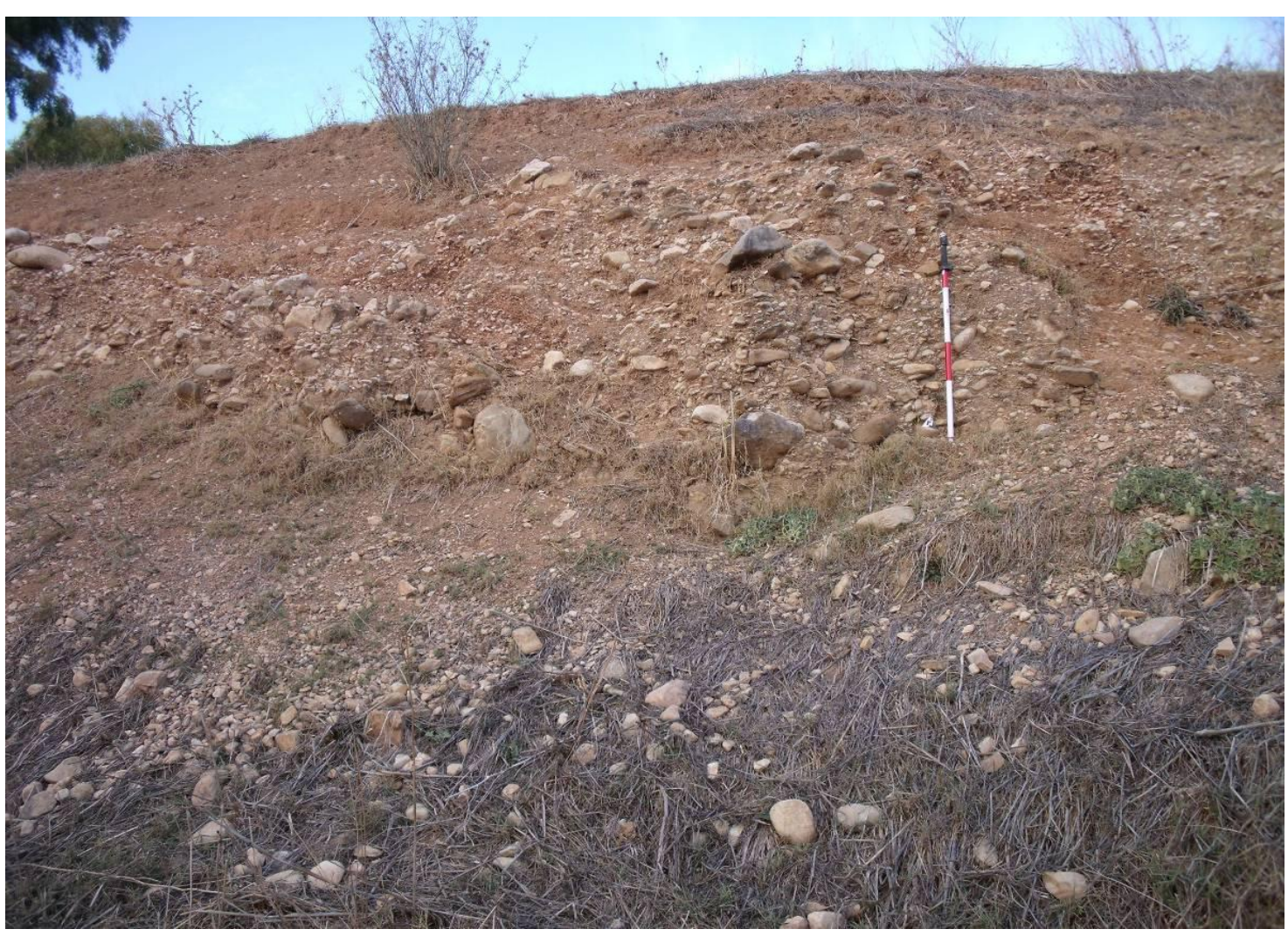

Figura 122. Vista general terraza La Puente.

Altitud: m s.n.m: 391/397 m

Extensión: 44.336,37 $\mathrm{m}^{2}$

. Contexto geológico y geomorfológico:

En toda la zona y áreas circundantes afloran materiales de la formación post mantos, que corresponden a terrazas aluviales antiguas con presencia de conglomerados de cantos predominantemente calizos, generalmente bien redondeados. En los alrededores afloran materiales del Subbético interno como calizas margosas, margocalizas y margas "Capas rojas" y de las Unidades Infranumídicas del Flysch compuestos por areniscas cuarzosas (del Aljibe), arcillas y margas arcillosas. 
Los estudios realizados sobre la evolución geomorfológica de la zona recogida en el mapa geológico del IGME (AA.VV. 1999 a) reflejan la existencia de varios niveles de terrazas asociados al río Guadalteba. Estos niveles junto con los travertinos datados han permitido establecer cuatro niveles de terrazas (AA.VV. 1999 a). La que nos ocupa corresponde al nivel II y es una terraza media, situada entre 15 o $20 \mathrm{~m}$. sobre el cauce actual (AA.VV. 1999 a).

Es un sistema formado por tres terrazas del río Guadalteba. La base de la terraza más alta se encuentra situada entre las cotas de 391 y 397 m s.n.m. y sobre el río se encuentra a $\pm 10 / 15 \mathrm{~m}$. Es un depósito discordante sobre las areniscas del sustrato que alcanza un espesor de 3 a $4 \mathrm{~m}$. Está formado por bloques y cantos, mayoritariamente de caliza y en menor medida de areniscas compactas, sílex blanco oolítico y radiolaritas. Los clastos aparecen tanto bien redondeados como poco redondeados, con tamaños máximos del orden del metro y media sobre los $20 \mathrm{~cm}$. Está estructurado en niveles donde predominan bloques y cantos, y niveles con predominio de cantos y gravas. Este depósito fluvial está cubierto por arenas y arcillas de aproximadamente $2 \mathrm{~m}$ de espesor que pueden corresponder a un depósito de llanura de inundación.

Aguas abajo aparece una terraza más baja, cuya base está situada a 375 m s.n.m. y a $\pm 5 \mathrm{~m}$ sobre el río. Al igual que la anterior, es un depósito de bloques y cantos de mediano y pequeño tamaño, de caliza, algún sílex y arenisca compacta. El techo de este depósito forma un extenso llano donde se observan en superficie cantos de mediano y pequeño tamaño, de litología variada.

Por debajo de esta terraza se encuentra una terraza más baja a $+3 \mathrm{~m}$ sobre el río Guadalteba, formada por depósitos de arcillas y arenas sin cantos. La conexión entre esta terraza y la anterior se produce mediante un derrame.

\section{. Procesos sedimentarios y procesos postdeposicionales}

En la terraza La Puente se produce una sedimentación de muy alta energía, aparecen paquetes de cantos rodados de diferentes tamaños han quedado de una forma irregular. Al tratarse de materiales arqueológicos englobados en una terraza, han sufrido un transporte desde su emplazamiento original.

\section{. Interpretación geoarqueológica}

Se trata de un sistema de tres terrazas, la más alta de las tres contiene restos líticos, algunos de ellos tallados, con los filos muy frescos, indicativo de que no se ha 
producido un rodamiento de los mismos y de que el material localizado dentro de la estratigrafía de la terraza se produjo en un momento de flujos de moderada energía y que el lugar originario de los mismos está muy próximo.

. Análisis de la industria lítica

El estudio sobre el material lítico que aquí presentamos se realiza sobre las piezas localizadas durante los muestreos geoarqueológicos desarrollados en el marco de las intervenciones puntuales realizadas en la zona durante los años 2011-2014. Los ejemplares recogidos, aunque en posición secundaria se encontraban en conexión estratigráfica dentro de la terraza más alta. Salvo un canto tallado que fue recogido en la segunda terraza y una raedera en superficie sobre la terraza más baja casi a nivel del río Guadalteba. Se recogieron un total de 9 muestras de sílex, una de ellas geológica y otra que corresponde a un resto de talla de radiolarita.

La materia prima (figura 123) predominante es el sílex masivo y oolítico en tonalidades claras como beige o gris con pátinas amarillentas, también hay sílex poroso de tonalidad blanca, arenisca compacta y radiolarita.

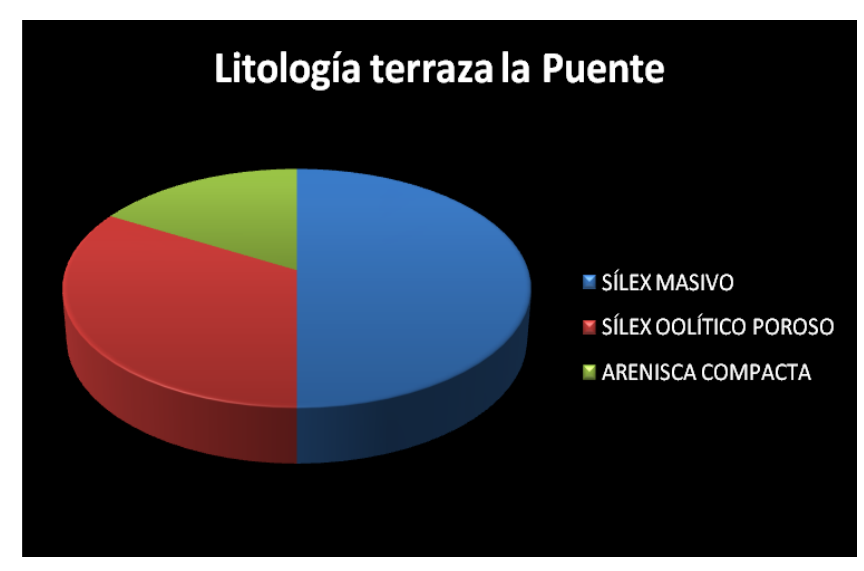

Figura 123. Materias primas de las piezas líticas recuperadas en la terraza La Puente.

En cuanto al estudio morfotécnico existe una presencia de Bases Naturales de Primera Generación (BN1G) de Bases Positivas (BP) y Bases Negativas de Segunda Generación (BN2G).

Las BN1G (tabla 31) están representadas por un ejemplar de sílex masivo beige con pátina amarillenta. Presentan un sistema de explotación unipolar y unifacial, con un carácter centrípeto de tipo $\mathrm{C}$, con extracciones de ángulo simple y con unas longitudes 
de las extracciones marginales. La arista frontal es convexa mientras que la sagital es incurvada.

\begin{tabular}{|c|c|c|c|c|c|c|c|c|c|c|c|c|c|}
\hline \multicolumn{14}{|c|}{ YACIMIENTOS TEBA. ESTUDIO ANALÍTICO DE LAS BN1G } \\
\hline Nombre & \multicolumn{5}{|c|}{ Materias primas y morfología } & \multicolumn{2}{|c|}{ Tipos de bases negativas } & \multicolumn{5}{|c|}{ Criterios analíticos de las BN1G } & \multirow[t]{2}{*}{ Tema operativo técnico } \\
\hline Terraza la Puente & M & $\mathrm{R}$ & C & P & $T$ & TN & BN & CF & $\mathrm{CC}$ & $\mathrm{CO}$ & $C P$ & \begin{tabular}{l|l|} 
CAF & CAS \\
\end{tabular} & \\
\hline TLP1-TL & $S$ & M & B & A & NO & U & BN1GE & U & C & $S$ & $\mathrm{~m}$ & inc & T.O.T.I \\
\hline
\end{tabular}

Tabla 31. Estudio analítico de las BN1G de la terraza La Puente.

Las BP (tabla 32) presentan un rodamiento medio y están elaboradas sobre sílex oolítico, sílex masivo negro y en arenisca compacta. Se han documentado 2 ejemplares de BP-I (internas) y 1 BP-L (levallois). En cuanto al volumen hay dos LE (largo espesa) y una EP (espesa plano). La delineación desde la cara ventral muestra un talón convexo en todas las piezas y un bulbo marcado en dos de ellas. Presentan talones lisos en dos de ellos y uno facetado diedro, los talones son no corticales y superficies en plataforma y uno lineal, unifacetado en dos de los ejemplares y multifacetado en otro. Las caras dorsales son no corticales en todos.

\begin{tabular}{|c|c|c|c|c|c|c|c|c|c|c|c|c|c|c|c|c|c|c|c|c|c|}
\hline \multicolumn{21}{|c|}{ YACIMIENTOS TEBA. ESTUDIO ANALLITICO DELAS BP } & \\
\hline Nombre & \multicolumn{5}{|c|}{ Materias primas y morfologia } & \multicolumn{3}{|c|}{ Tipos de bases positivas } & \multicolumn{3}{|c|}{ Dimensiones } & \multicolumn{10}{|c|}{ Criterios analíticos de las BP } \\
\hline \multirow[b]{2}{*}{ Terraza la Puente } & \multirow[t]{2}{*}{ M } & \multirow[t]{2}{*}{$R$} & \multirow[t]{2}{*}{ c } & \multirow[t]{2}{*}{ P } & \multirow[t]{2}{*}{$\mathrm{T}$} & \multirow{2}{*}{ LAS/LAM } & \multirow[t]{2}{*}{ TIPO } & \multirow[t]{2}{*}{ L } & \multirow[t]{2}{*}{\begin{tabular}{|l|l|}
$A$ & $E$ \\
\end{tabular}} & \multirow[t]{2}{*}{ TB } & \multirow[t]{2}{*}{ VOL } & \multicolumn{3}{|c|}{ CARAVENTRAL } & \multicolumn{3}{|c|}{ CARA TALONAR } & \multicolumn{4}{|c|}{ CARA DORSAL } \\
\hline & & & & & & & & & & & & $F$ & $B$ & TIPO & COR $S$ & $T$ & D & COR & SSAG & STR & A \\
\hline TLP2-TL & S & M & B & NO & NO & LASCA & । & $\mathrm{fd}$ & 2,1 & $0,7 \mathrm{NO}$ & $L P$ & $C x$ & M & $\mathrm{fd}$ & NOCO PLA & MF & $c x$ & NOCO & TRP & TRG & $\mathrm{SI}$ \\
\hline TLP3-TL & A & M & 0 & NO & NO & LASCA & L & 6,1 & 6,5 & 1,8 & $21 \mathrm{LE}$ & $C X$ & D & । & NOCO LIN & UF & $C X$ & NOCO & TRG & TRP & $S \mid$ \\
\hline TLP7-TL & S & M & $\mathrm{N}$ & NO & NO & LASCA & I & 1,5 & 1,8 & 0,5 & $24 \mathrm{LE}$ & $C x$ & M & I & NOCO PLA & UF & $C X$ & NOCO & TRG & TRG & SI \\
\hline
\end{tabular}

Tabla 32. Estudio analítico de las BP de la terraza de La Puente.

Las BN2G (tabla 33) son 3 ejemplares, uno en sílex masivo gris, otro en sílex masivo beige y otro en sílex poroso. Para su estudio analítico y su clasificación utilizamos la nomenclatura del sistema tipológico de Laplace (Laplace, 1972) y los de la Lista-Tipo Bordes (Bordes, 1961).

Corresponden a dos muescas sobre lascas levallois. Con un volumen de tipo LP (largo plano), con una delineación del talón desde la cara ventral convexa y con bulbo marcado en dos ejemplares y facetado convexo. La cara dorsal es variada con todos los tipos no corticales, cortical dominante no cortinal y no cortical dominante cortical. Presentan un retoque simple, marginal, directo y en muesca y en ambos ejemplares está localizada en el lateral izquierdo. Se trata de un denticulado según Laplace (D21) y una 
muesca según Bordes (42). El otro ejemplar corresponde a un raedera con un volumen LP (largo plano), con talón facetado diedro, no cortical, en plataforma y multifacetado. La cara dorsal es no cortical y presenta un retoque simple, profundo, directo y continuo en el lateral derecho, corresponde a una raedera lateral según Laplace (R21) y a una raedera simple convexa según Bordes (10).

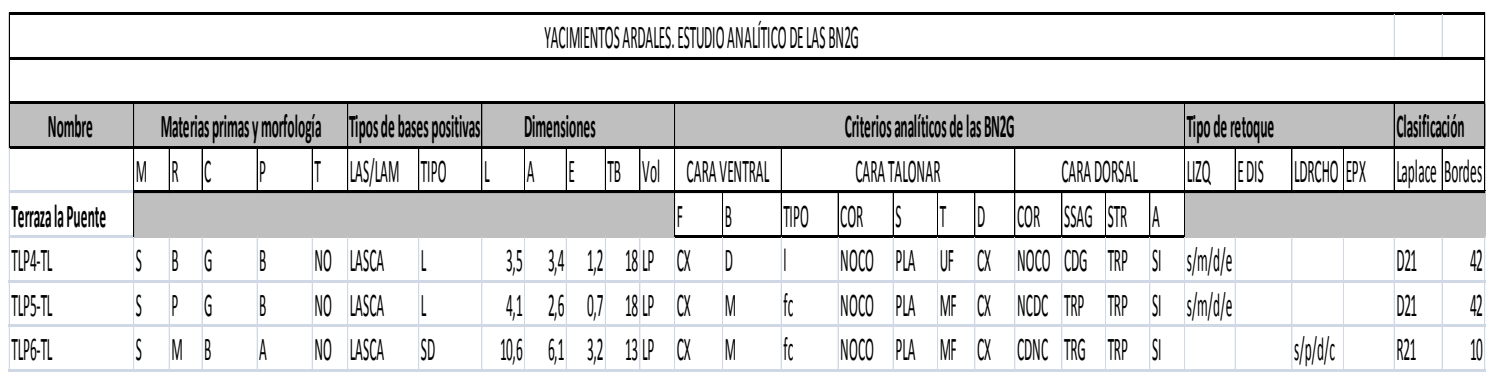

Tabla 33. Estudio analítico de las BN2G de la Terraza de La Puente.

. Valoración y conclusiones

La terraza más alta de La Puente se localiza a unos escasos 10-15 m por encima del nivel del río actual y cerca de la Sima de Las Palomas. La industria localizada dentro de la estratigrafía presenta unos filos muy frescos y aristas vivas, aparece sobre todo en los niveles más altos de la terraza asociados a los niveles con cantos de tamaño mediano pequeño y con un escaso rodamiento.

En cuanto a la tecnología, aunque el número de ejemplares es pequeño para establecer conclusiones definidas, es importante por su situación dentro de la estratigrafía de la terraza y para las comparativas con los demás hallazgos. Hay una escasa presencia de núcleos, algunas BP-I (internas) y BP-L (levallois) de pequeño tamaño, en el grupo de los productos retocados o $\mathrm{BN} 2 \mathrm{G}$, nos encontramos únicamente con 2 muescas y 1 raedera. La industria recogida de la terraza más alta y por los paralelismos con Sima de Las Palomas la podemos encuadrar genéricamente dentro del Paleolítico medio con industrias del modo III. Sin embargo, la pieza recogida en la terraza más baja parece estar más en conexión con los materiales del yacimiento La Puente situado a unos 3 o $4 \mathrm{~km}$ de la terraza y con industrias de gran tamaño sobre lascas, con presencia de bifaces y piezas bastante rodadas, que se pueden encuadrar dentro del Paleolítico inferior o Modo II. 


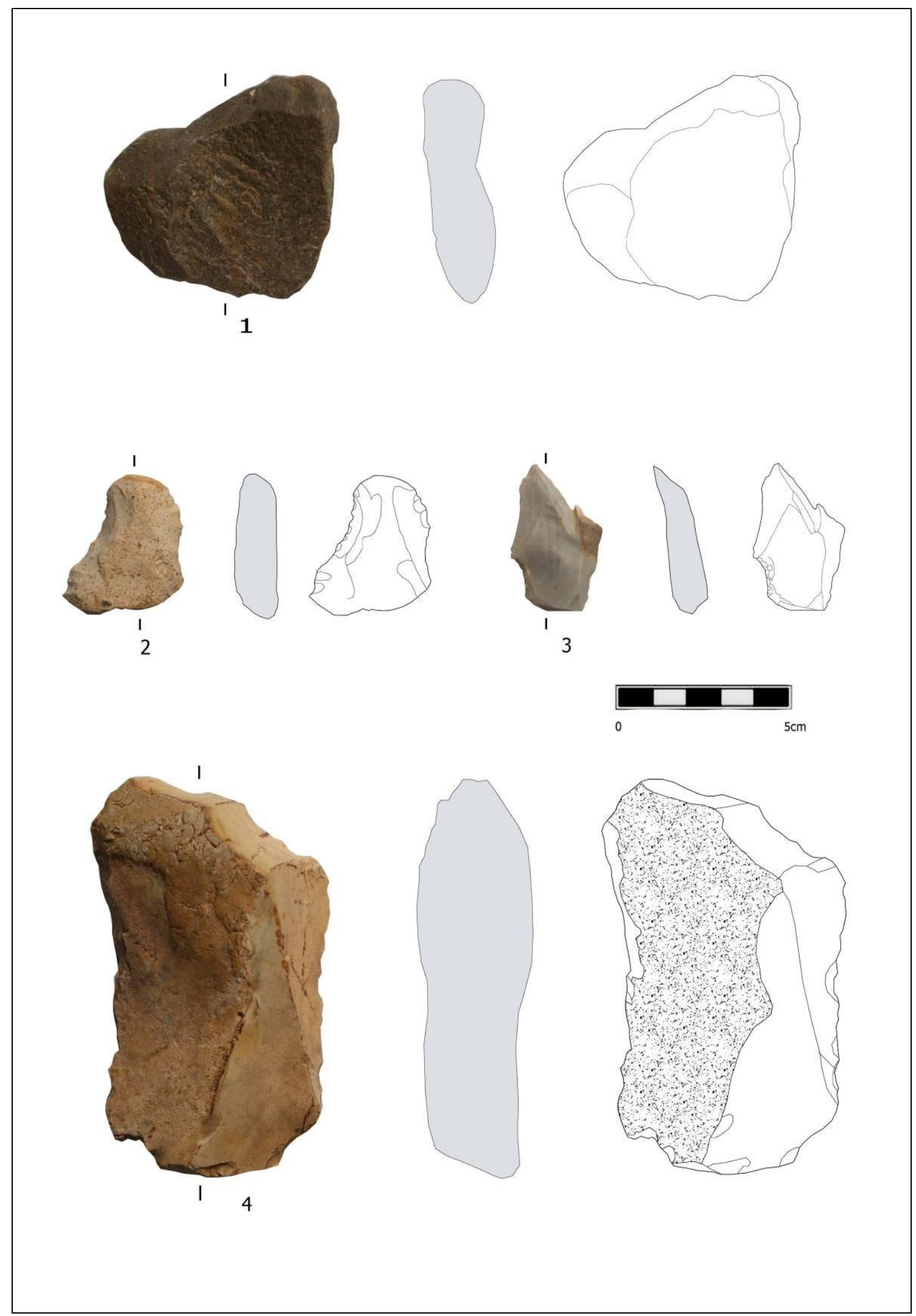

Figura 124. Terraza La Puente: 1. BP-Lasca levallois; 3, 4: BN2G-Muescas; 5: Raedera. 


\subsubsection{Sima de Las Palomas (Teba)}

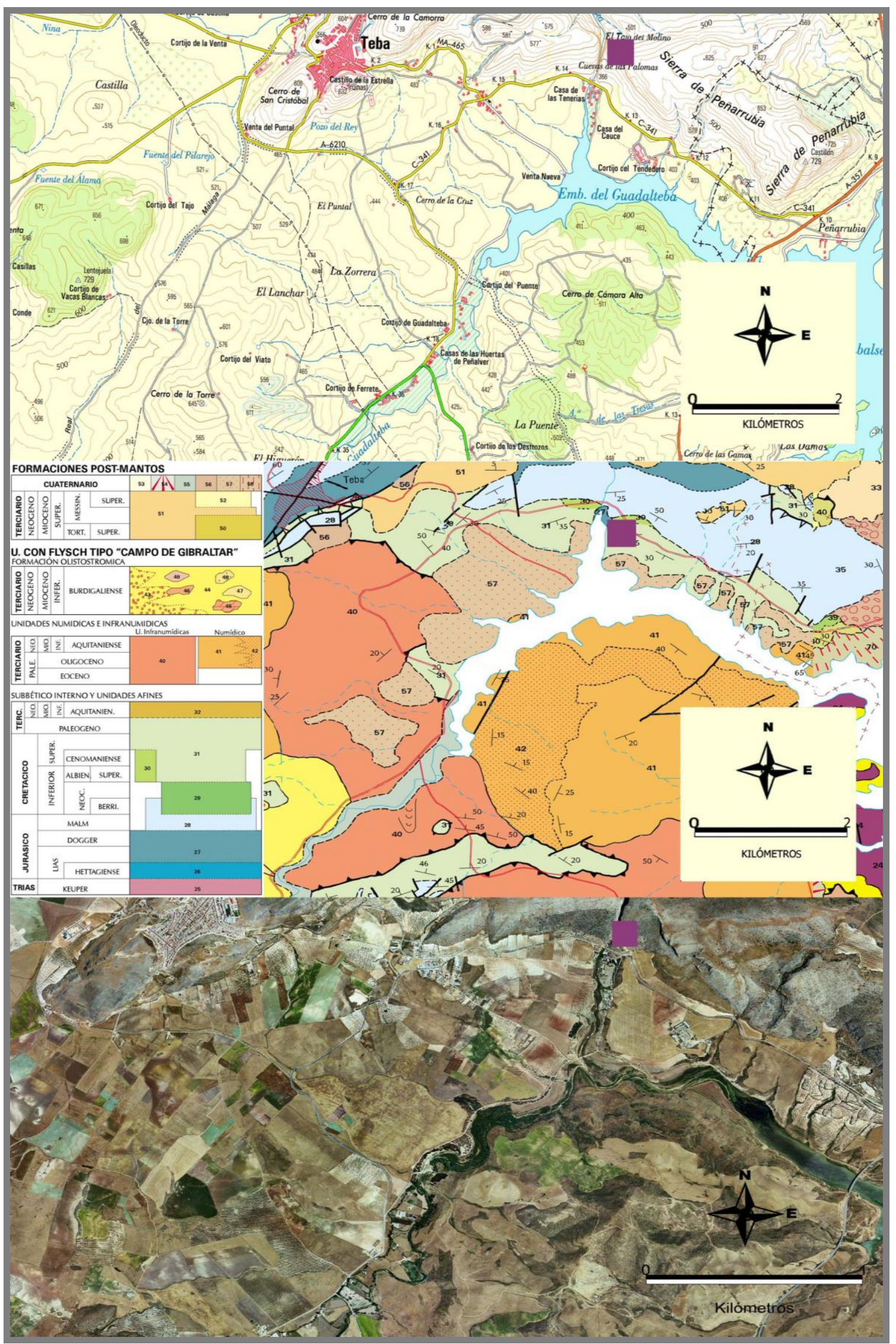


Situada en la zona occidental de la sierra de Peñarrubia-Teba, tiene su acceso a través de la carretera C-341, en dirección a la localidad de Teba. Antes de cruzar el Tajo del Molino tenemos que ascender por la montaña hasta llegar a la boca de la cueva y un poco más arriba hasta llegar a una dolina donde se ubica la sima. La Sima de Las Palomas forma parte del complejo kárstico de la cueva de Las Palomas y es también conocida en la historiografía como Sima del Sílex, denominada así por el grupo espeleológico de Campillos (García Alfonso et al., 1995: 38) a principios de los años 80.

Sus coordenadas UTM ETRS89 30 son:

\begin{tabular}{|c|c|}
\hline $\mathbf{X}$ & $\mathbf{Y}$ \\
\hline 332873 & 4094841 \\
\hline
\end{tabular}

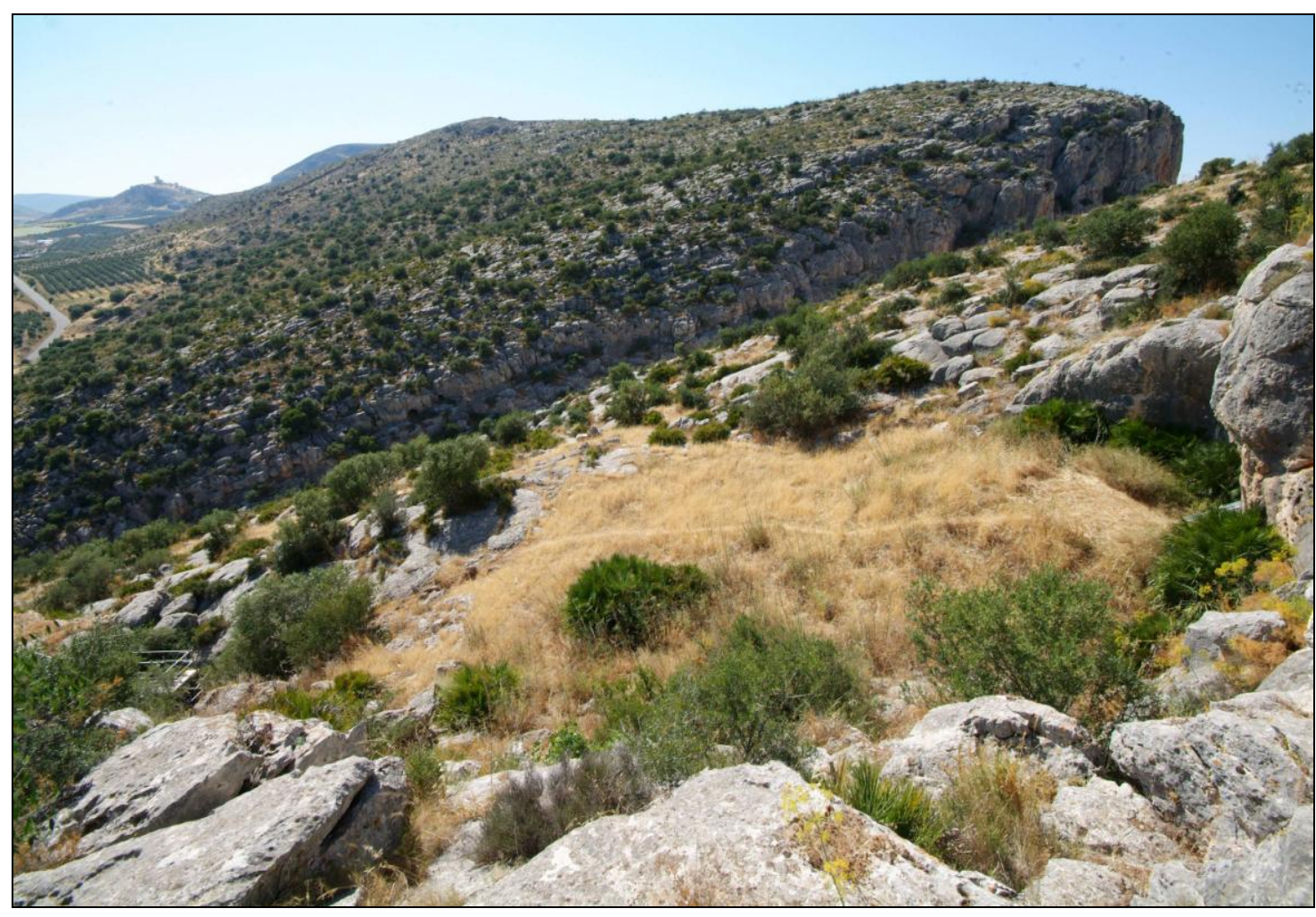

Figura 125. Vista general del yacimiento de la Sima de Las Palomas.

Altitud m s.n.m: 470/430 m

. Contex to geológico y geomorfológico

A nivel geológico se trata de una zona de gran complejidad. Aparte de los materiales del Mioceno superior de la cuenca de Ronda y las formaciones cuaternarias, están representadas en la zona unidades de las Zonas Internas y Externas de la 
Cordillera Bética, unidades asimilables al complejo de Flysch del Campo de Gibraltar y otros elementos más controvertidos, como la formación olistostrómica del Burdigaliense y los materiales triásicos en facies germano-andaluza (Domínguez-Bella et al., 2014: 106). Se desarrolla en calizas del Subbético interno mostrando una serie calcárea de edad jurásica compuesta por calizas nodulares rojas y brechoides del Malm, seguidas por calizas margosas del Cretácico y Paleógeno con abundantes nódulos de sílex, con capas rojas del Cretácico superior. Bajo el Jurásico se sitúa el Triásico del manto Antequera-Osuna. A techo se encuentran sobre el Paleógeno calcarenitas bioclásticas, conglomerados y margas de finales del Mioceno. Por último, entre los sedimentos cuaternarios hay una serie de paleoterrazas aluviales y travertinos (Duran Valsero, 2014: 27). La cavidad es una manifestación kárstica de la sierra de Teba que incluye una dolina de hundimiento y varias galerías, no siendo especialmente rica en espeleotemas. Sobre los espeleotemas se desarrolla un horizonte arcilloso y detrítico, seguido de una brecha cementada de bloques calcáreos y un nivel final de grandes bloques caídos (Duran Valsero, 2014: 28)

\section{. Relación con la red fluvial}

El yacimiento presenta una relación inmediata al río de la Venta, subsidiario de la cuenca hidrográfica del río Guadalteba. Se encuentra en la margen este del río en el Tajo del Molino, alcanzando una altitud sobre el lecho fluvial de varias decenas de metros. En cuanto al desfiladero o Tajo del Molino, se trata de un valle epigénico que da lugar a un espectacular cañón o valle encajado, en cuyo entorno se desarrolla la cueva (Durán Valsero, 2014: 28).

\section{. Procesos sedimentarios y postdeposicionales}

Los procesos sedimentarios que dieron lugar al yacimiento varían en cada una de las unidades estratigráficas. Los análisis micromorfológicos (Kehl, 2014) muestran como las unidades 10 y 9, que están en la base de la secuencia, por el momento y que contienen artefactos musterienses, huesos y carbón, representan capas que se conservan "in situ”.

Una parte del sellado de estas unidades indica una acumulación de sedimento gradual ocurrido durante la ocupación del yacimiento. Presenta una pronunciada orientación horizontal de los materiales arqueológicos y de los fragmentos de roca, lo 
que unido a un elevado grado de compactación sugiere que dicha compactación fue causada por pisoteo. La orientación de los hallazgos, el alto contenido en carbón y hueso así como un alto grado de compactación hace pensar en la imposibilidad de que los sedimentos estén revueltos.

La unidad 8, está compuesta por bloques caídos del techo. La unidad 7 presenta escaso material arqueológico con una deposición normal, donde los sedimentos muestran un grado de erosión menor que las unidades inferiores y superiores. Las unidades 6 a la 4 tienen una baja ocupación o representan paquetes movidos con material líticos dispersos, restos de hueso, carbón y fragmentos de moluscos. Aparecen clastos dispersos concentrados en paquetes sedimentarios discontinuos de forma caótica que parecen aflorar en la matriz.

La unidad 3 presenta sedimentos detríticos con "escasas inclusiones de material arqueológico. Las características esferulitas de calcita en el sustrato y los abundantes granos de calcita del tamaño medio de los limos ( 10-20 $\mu$ m de diámetro) así como los restos de excrementos animales (Lámina $8.1 \mathrm{~F}$ ) sugieren el cuidado de ovicápridos como la oveja y la cabra en el abrigo durante el proceso de acumulación de la unidad 3” (Kehl, 2014: 53).

La unidad 2 está compuesta por grandes rocas situadas o expuestas en la parte este del perfil y pueden ser indicativo del último derrumbe del techo o la cornisa. Por último en la unidad 1, lo sedimentos depositados son modernos aunque se desconoce la edad de los mismos.

En relación a los procesos postsedimentarios se producen alteraciones debidas tanto a causas naturales como antrópicas. Así, cada una de las unidades sedimentarias analizadas por M. Kehl (Kehl, 2014) muestran alteraciones que se manifiesta en el caso de la unidad 3, en una falta de materia orgánica producida por la acción de los insectos, los microbios y los procesos de quemado, a lo que se le une la presencia de madrigueras rellenadas parcialmente con gravillas orgánico-minerales de excrementos de insectos y el bajo índice de compactación del sedimento sugieren una fuerte bioturbación provocada por insectos como los escarabajos. Existe además una gran cantidad de raíces que alteran los sedimentos generen la mezcla de los materiales arqueológicos. Sin embargo, en las unidades sedimentarias más bajas, como la unidad 9, la bioturbación es menos elevada. Aparecen suelos sedimentarios formados por el depósito del flojo lateral de la boca de la sima. La unidad 10, si presenta de nuevo un alto grado de bioturbación 
producida sobre todo por roedores. Además en esta unidad aparecen sellados sedimentarios.

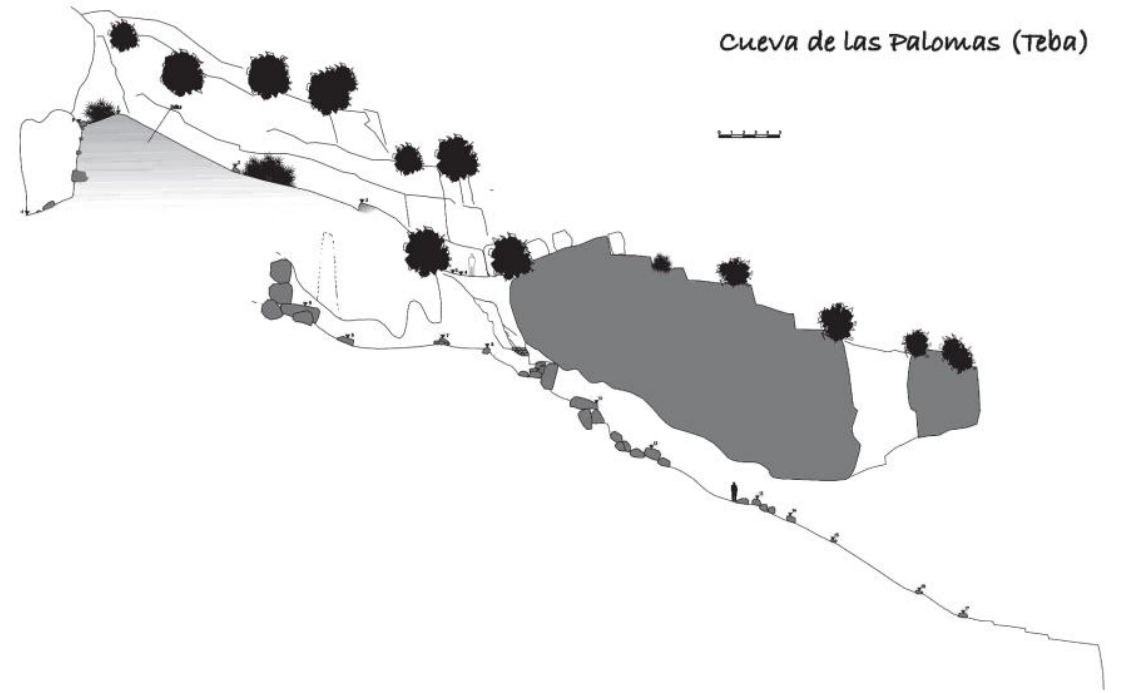

Figura 126. Sección del complejo kárstico de Las Palomas en Teba (Weniger et al., 2014: 25).

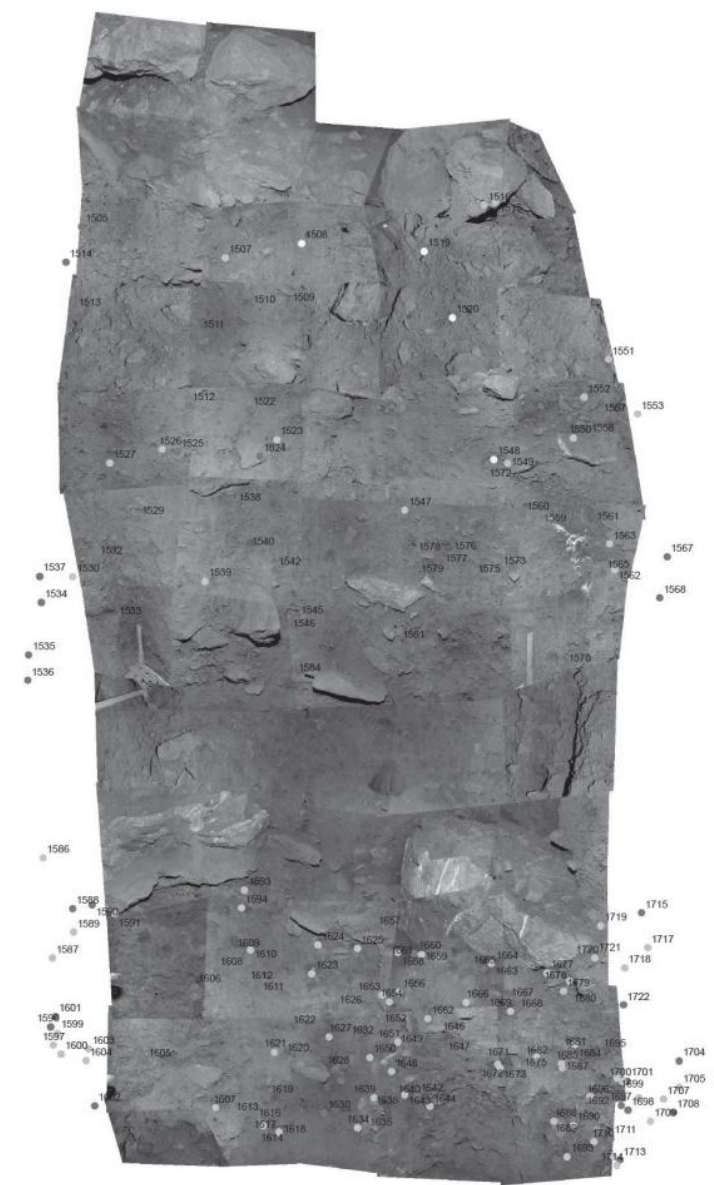

Figura 127. Ortofoto del perfil estratigráfico con los productos líticos tallados (Weniger et al., 2014: 39). 
. Interpretación geoarqueológica

Los materiales recuperados presentan filos frescos y con una escasez de pátinas, presentan además, tanto sílex como radiolaritas, cúpulas de termoalteración apareciendo en un gran porcentaje de las mismas. Se trata de materiales originados por un abandono antrópico dentro de lo que actualmente es la Sima de Las Palomas, estando presente todo el proceso de cadenas operativas, con materias primas de pequeño tamaño. Esto nos indica que en la sima se produjo un trabajo especializado de elaboración de productos utilizando núcleos ya preparados y de tamaño medianos, siendo numerosas las esquirlas y los desechos de talla.

\section{. Análisis de la industria lítica}

El estudio sobre el material lítico, que presentamos, se realiza sobre el material recogido entre los años 2011-2014, en el marco de las dos intervenciones puntuales realizadas en el yacimiento y en la Cueva de Ardales. Los resultados de la intervención arqueológica y el análisis de la industria lítica ha sido realizado y publicado con anterioridad a este trabajo (Weniger et al., 2014) por lo se expone una síntesis de los resultados. El total de la industria son 456 productos, 313 ejemplares corresponden a BN1G, BP y BN2G, y 143 ejemplares corresponden a restos de talla.

La materia prima predominante es el sílex (figura 128) sobre todo sílex masivo de diferentes coloraciones y en general sin pátinas, también aparecen sílex porosos claros blancos o cremas, radiolaritas rojas, verdes y gris-negra, con huellas de termoalteración, areniscas compactas de grano variable en tonalidades ocres o pardos y otros sílex minoritarios como son los oolíticos y los bandeados.

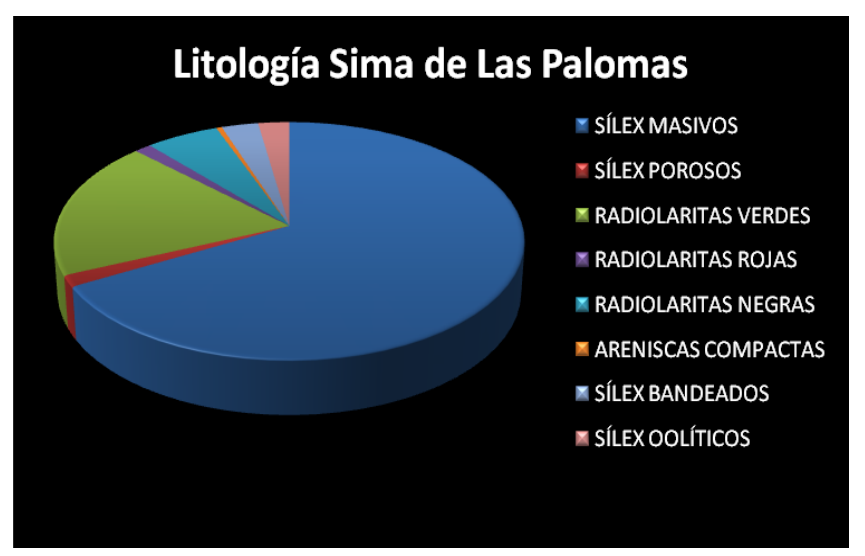

Figura 128. Materias primas de las piezas líticas recuperadas en la Sima de Las Palomas 
Según el estudio morfotécnico tenemos Bases Naturales de Primera Generación (BN1G), Bases Positivas (BP) y Bases Negativas de Segunda Generación (BN2G).

Se documentan 12 ejemplares de BN1GE, con un predominio de BN1G centrípeto multipolar de carácter facial de tipo bifacial y unifacial y una ausencia total de tipo trifacial y multifacial.

Destacan claramente las BN1G (tabla 34) donde la zona extraída ocupa prácticamente todo el borde, de tipo 4C, asociados básicamente a BN1G-CM. El carácter de oblicuidad nos da información sobre la inclinación del ángulo de extracción con respecto al plano de orientación de la pieza, predominan las BN1G con oblicuidad de tipo sp-Semiplano, seguidas por BN1G con oblicuidad s-Simple. Se constatan en los BN1G-CM y B. En relación al carácter de profundidad predominan claramente los totales vinculados a BN1G-CM (centrípeto multipolar) y B (bipolar).

La arista frontal es en todos los ejemplares convexa y el carácter de la arista sagital es sinuosa en la mayoría.

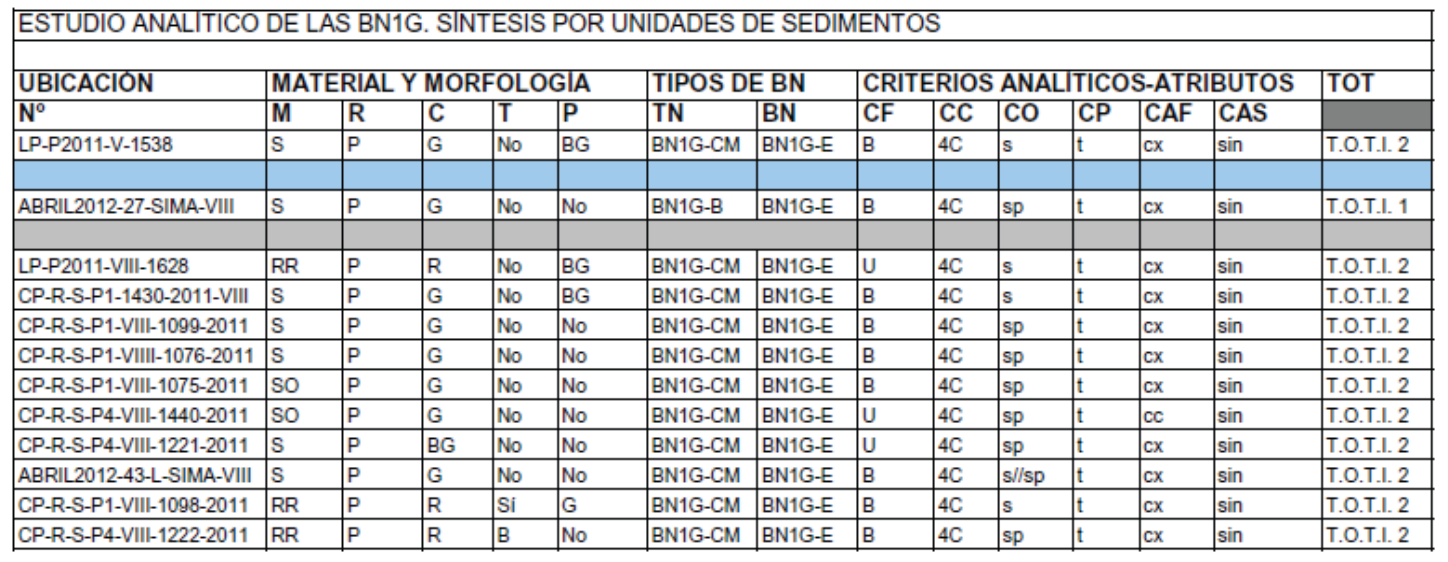

Tabla 34. Estudio analítico de las BN1G de la Sima de Las Palomas (Weniger et al., 2014: 129)

Las BP (tabla 35) analizadas corresponden a un total de 274 ejemplares, 258 lascas y 16 láminas, asociadas a todos los niveles estratigráficas localizadas en el perfil. Del total analizado destaca una escasa presencia de BP-D/SD (descortezado y semidescortezado). Se documentan un total de 2 ejemplares de BP-D (descortezado), 11 ejemplares de BP-SD (semidescortezado) vinculadas también al inicio de talla. Existe un predominio de BP-I (internas) con un total de 204 ejemplares, y una significativa presencia de las BP-L (levallois) con 54 ejemplares. Hay que mencionar también la presencia de puntas levallois y lascas en cresta o BP-C.

En cuanto al volumen, presencia mayoritaria de las LP (largo-plano) frente a LE (largo-espeso) y E (espeso) también presentes. La cara ventral nos ofrece un predominio 
de las rectas, 125 ejemplares, frente a las convexas con 100 ejemplares y cóncavas con 49 ejemplares, con bulbo marcado en la mayoría y con algunos ejemplares con bulbo difuso. Relativo a los talones existe un mayor número de talones facetados, siendo los más numerosos, seguidos de los talones lisos, puntiformes y corticales. Con un predominio de talones no corticales seguidos de los corticales. La cara talonar dominada por talones rectos frente a convexas y cóncavas, siendo predominantes los talones en plataforma, seguidos de los lineales y puntiformes. La cara dorsal destaca por una mayoría no cortical. 


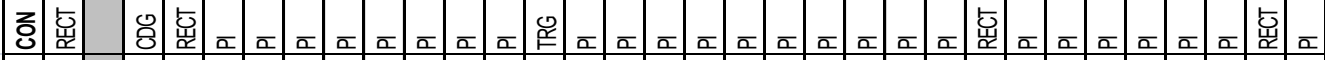

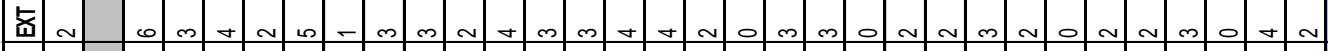
氡

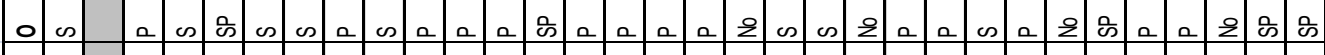

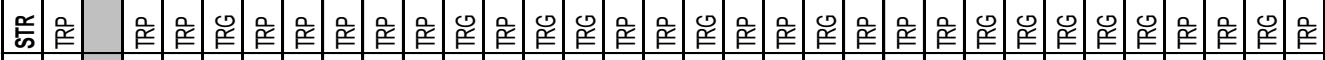

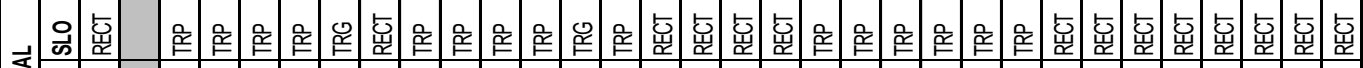

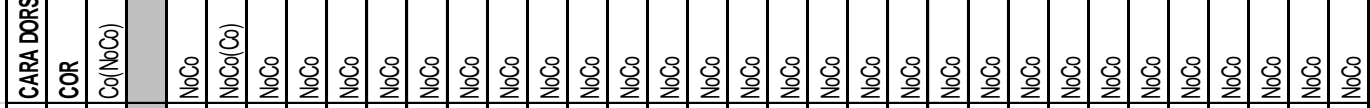

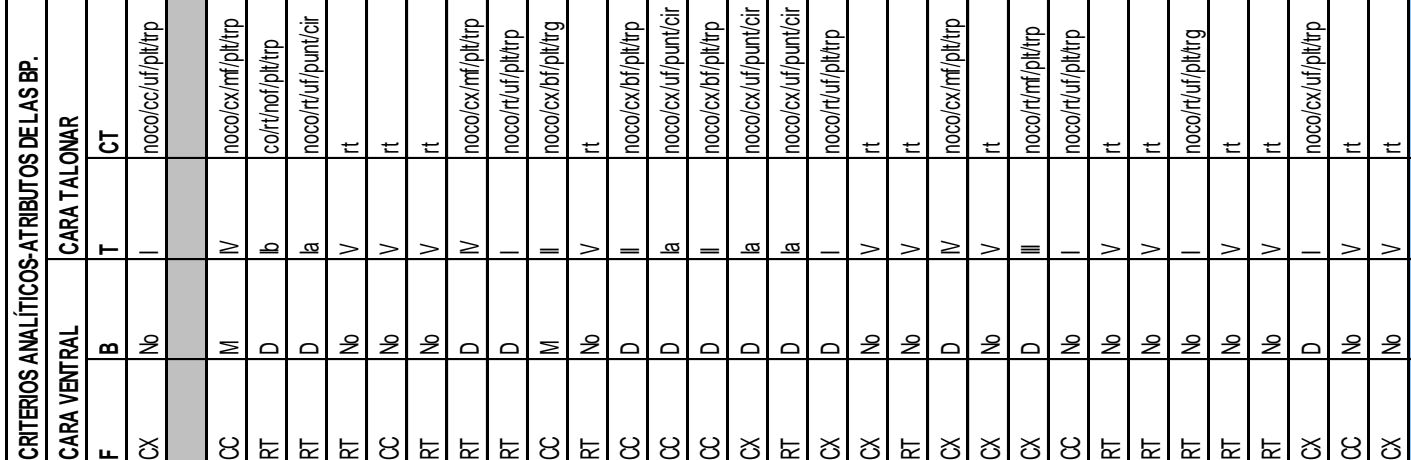

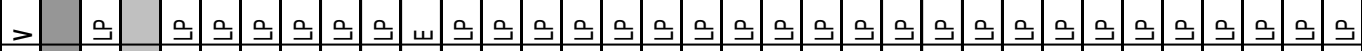

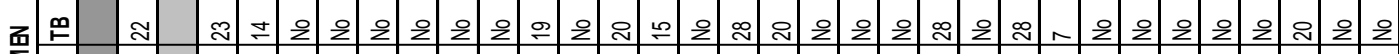

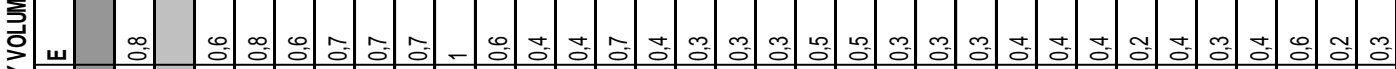

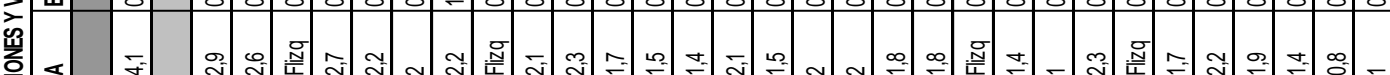

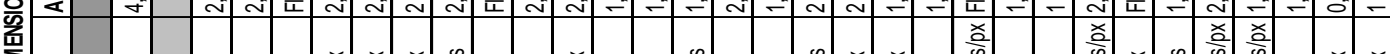
兽 के

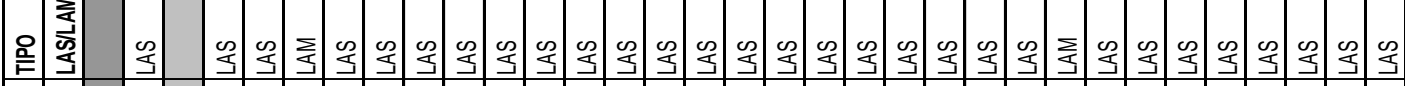

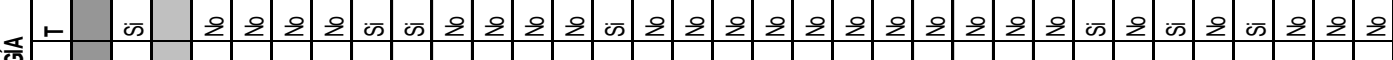

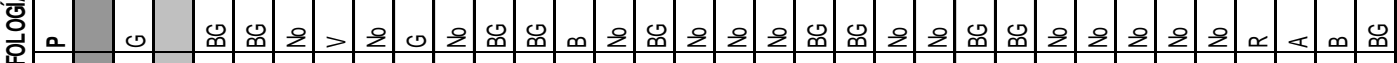

学

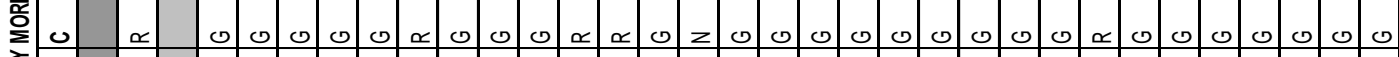
(⿻)

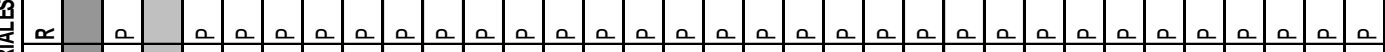
产悹

合

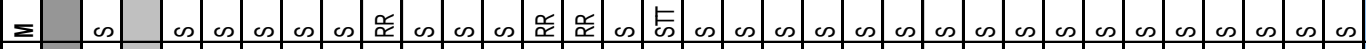




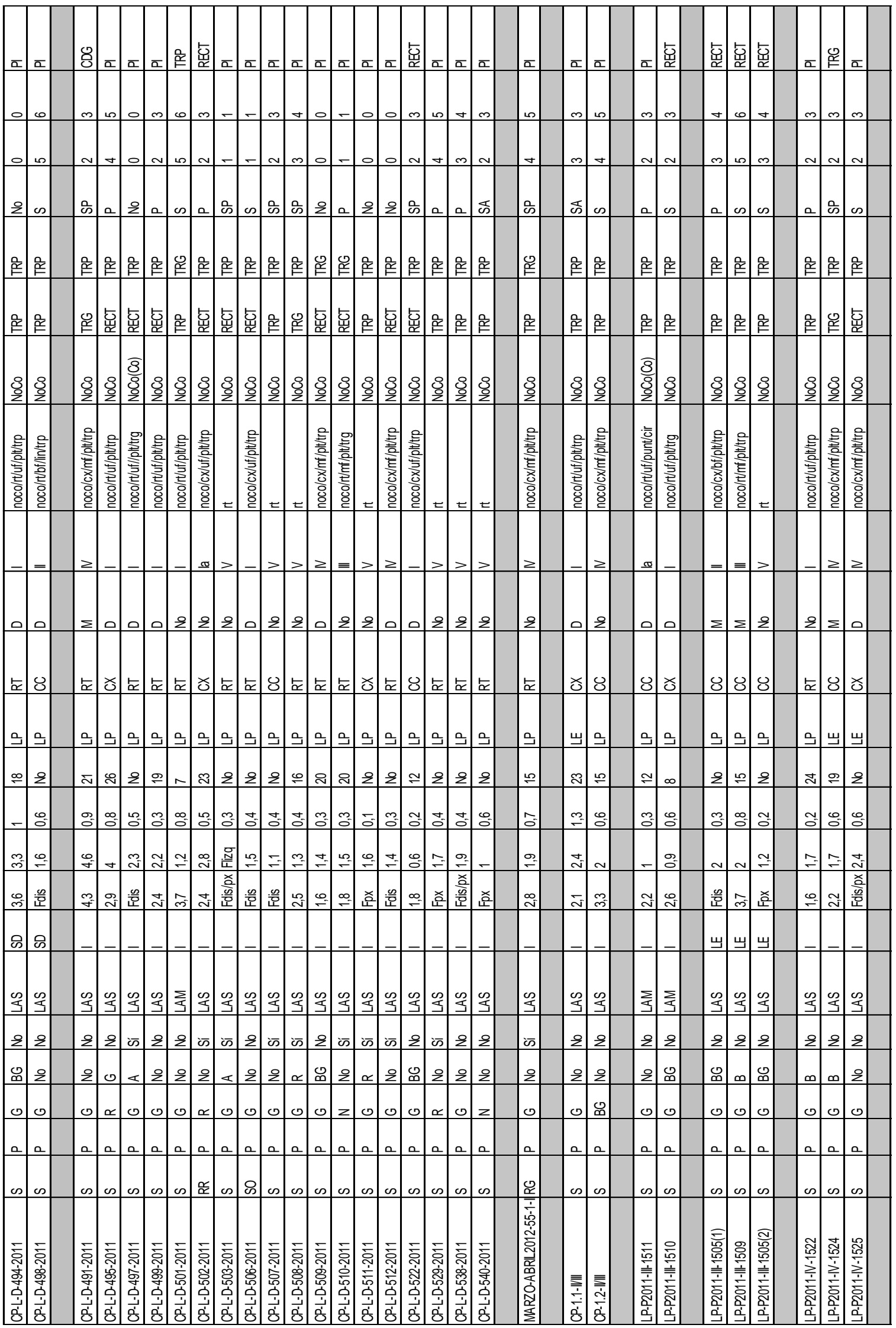




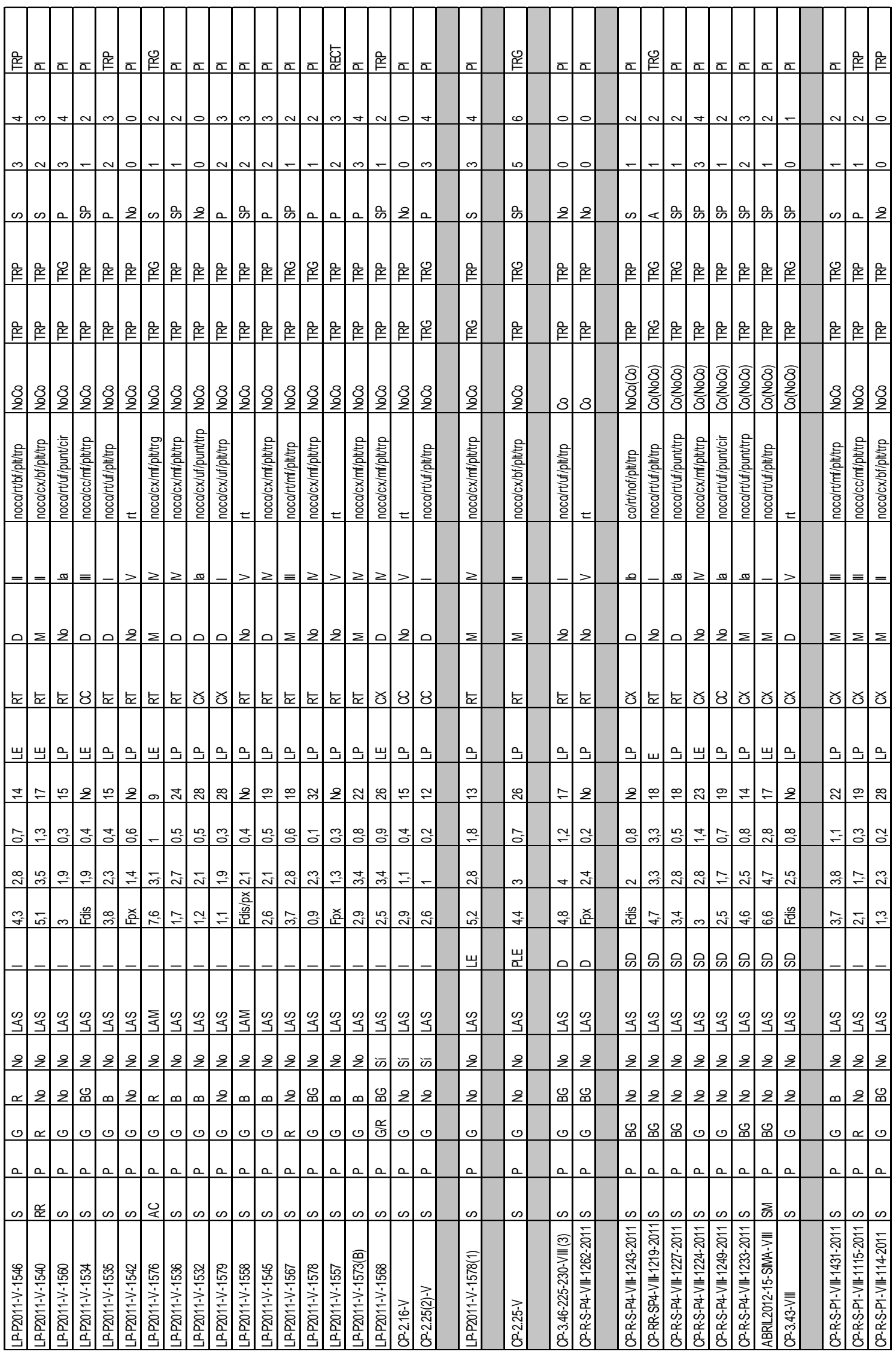




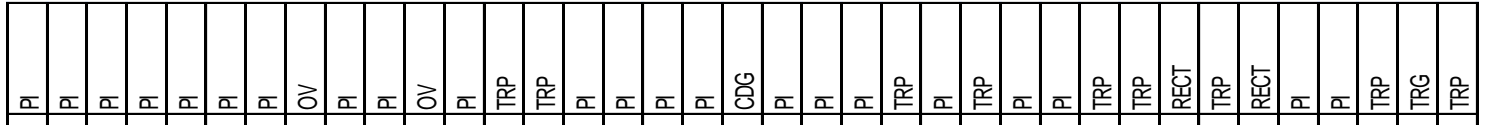

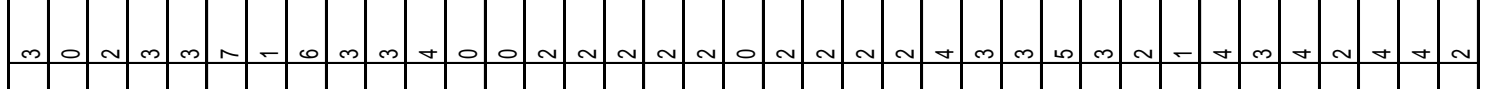

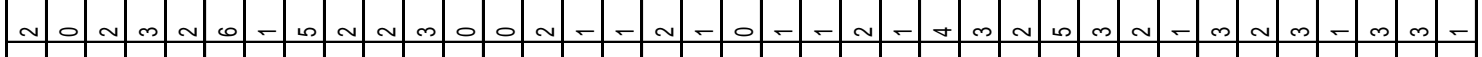

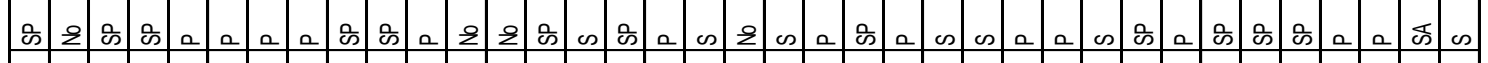

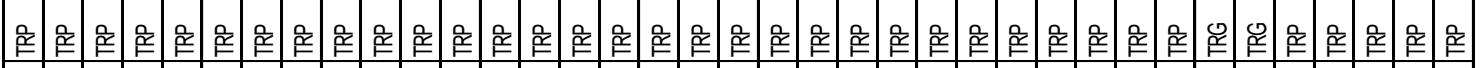

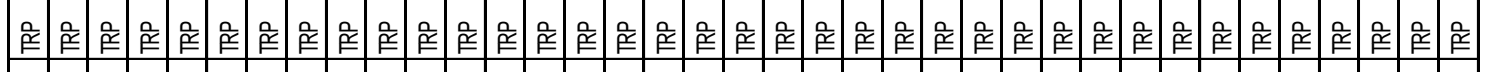

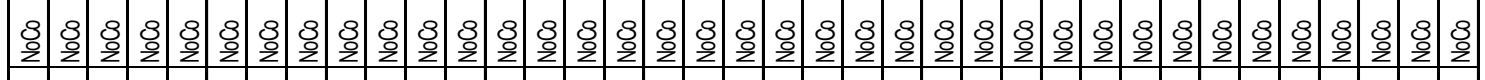

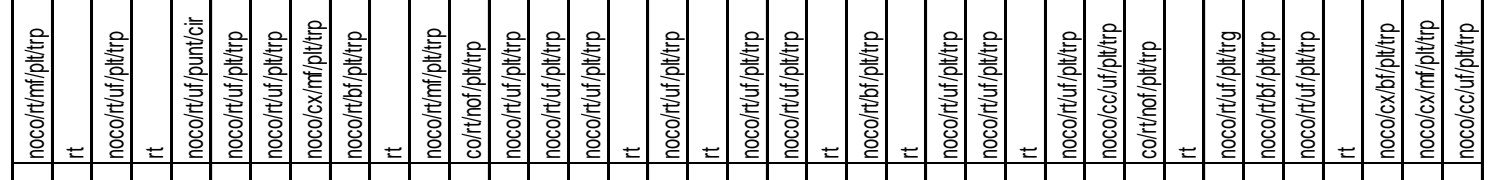

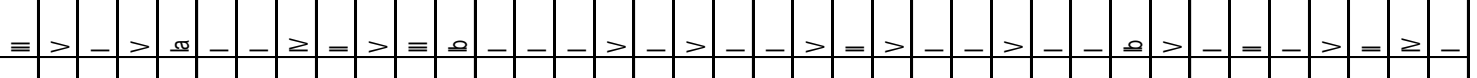

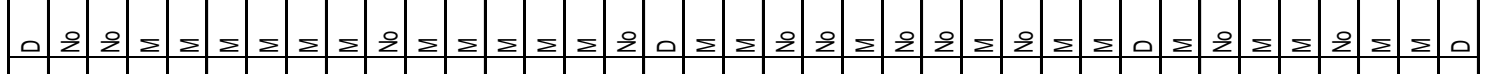

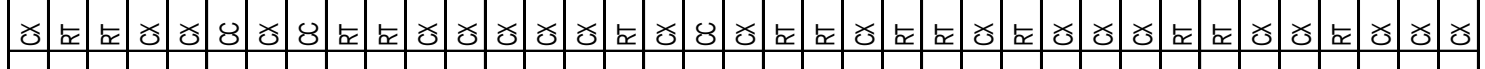
:

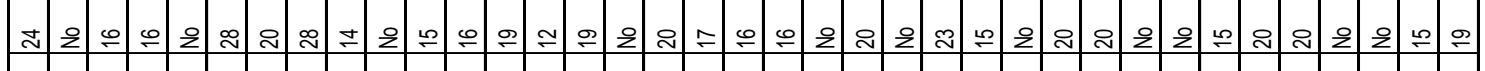
이의

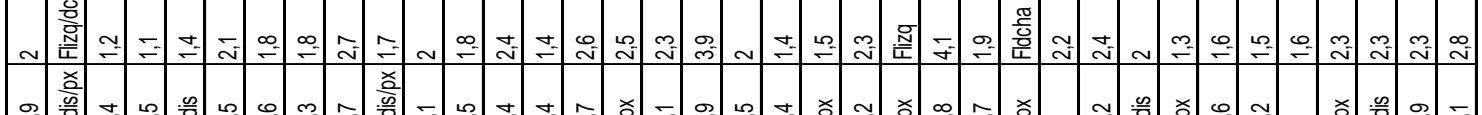

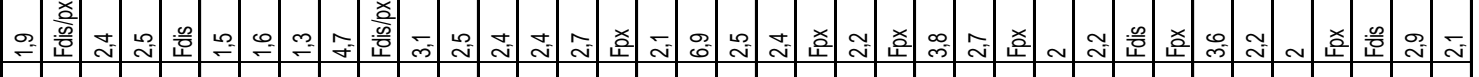

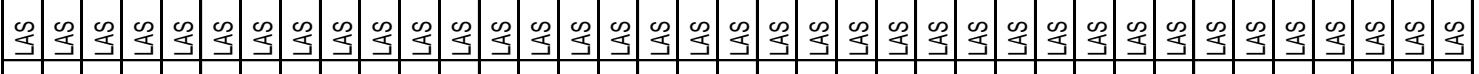

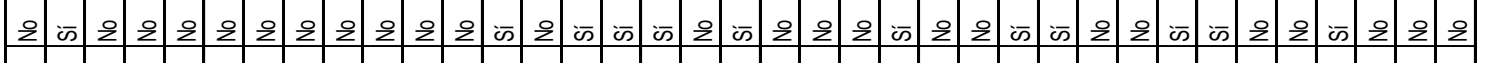

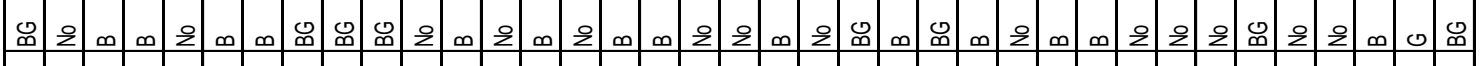

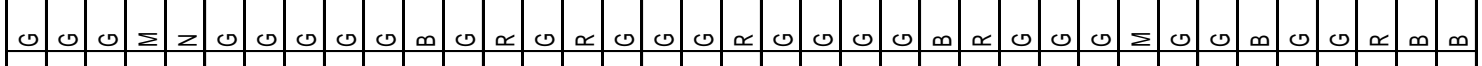

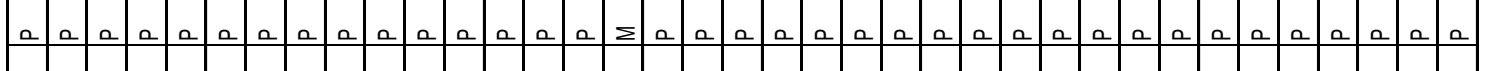

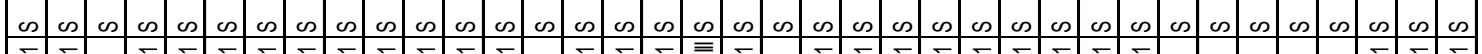

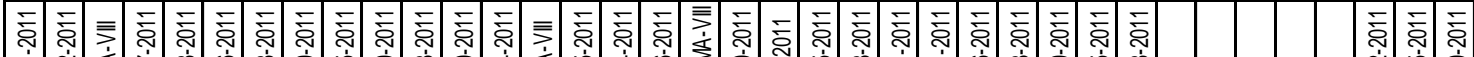

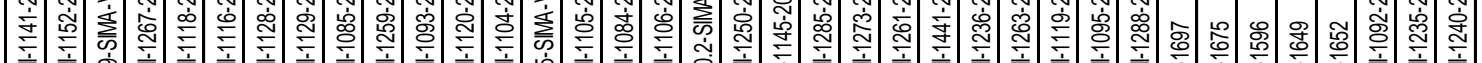

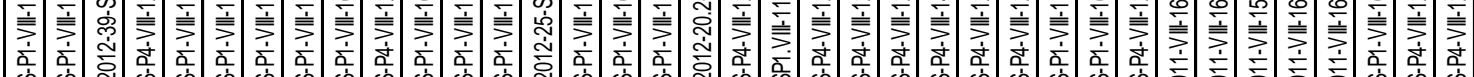

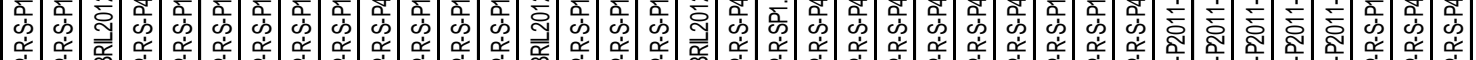

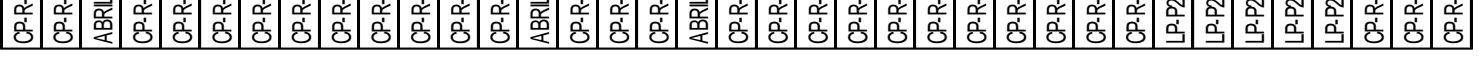




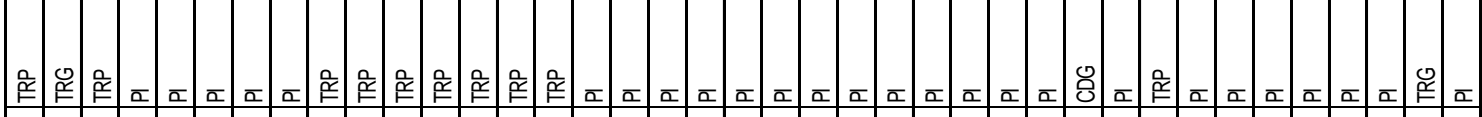

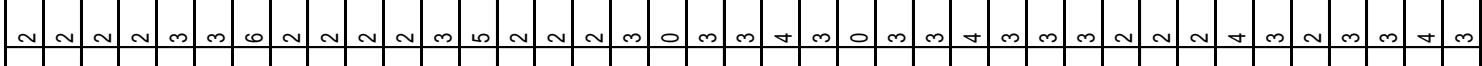

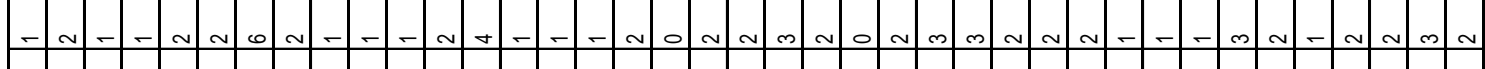

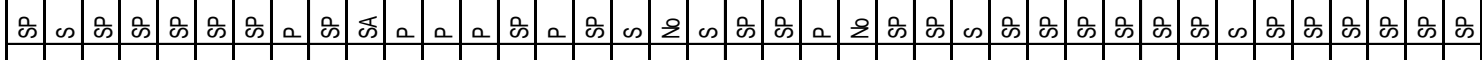

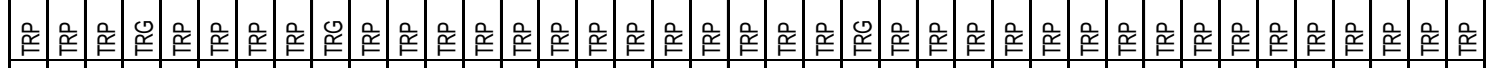

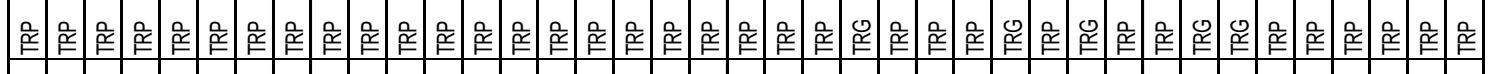

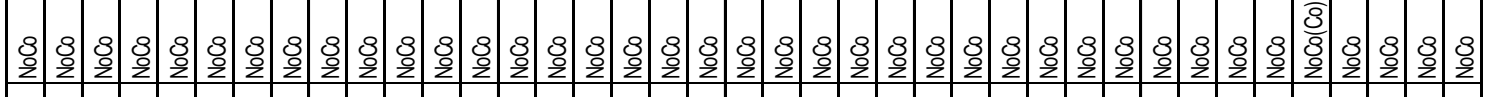

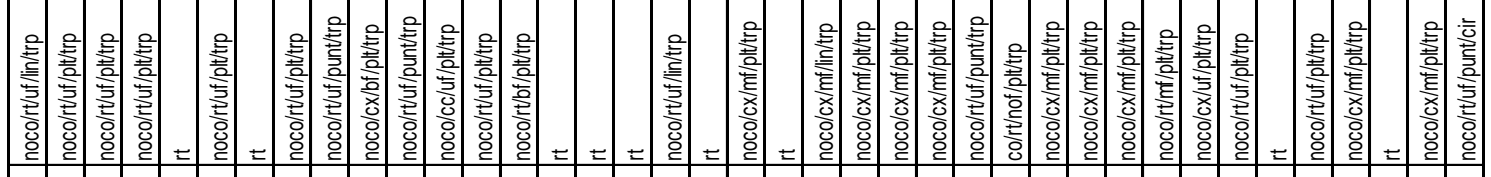

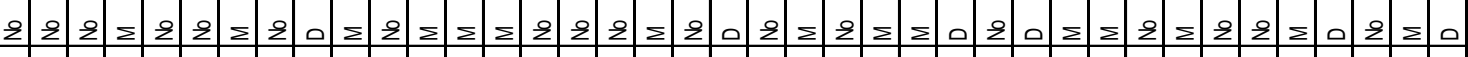

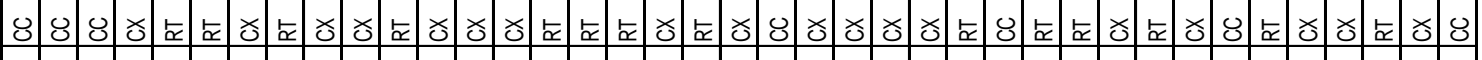

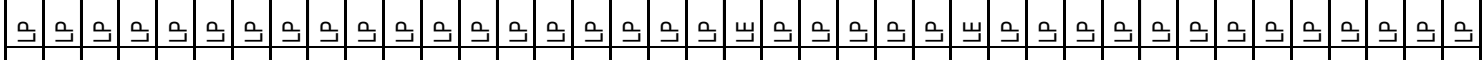

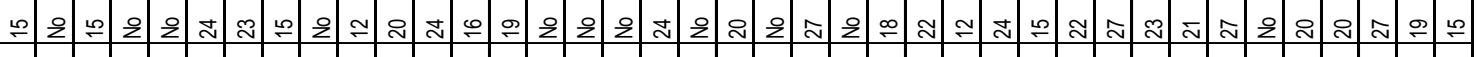

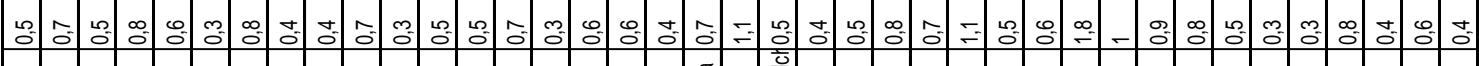

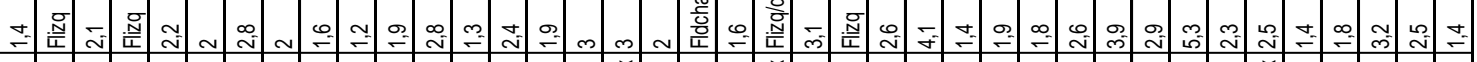

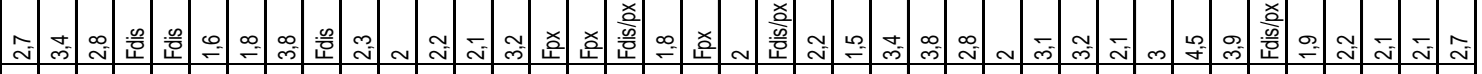

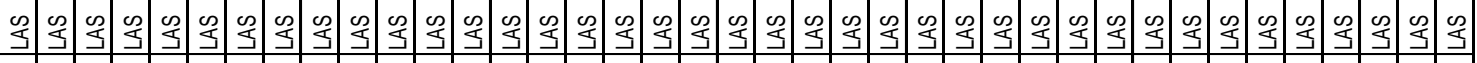

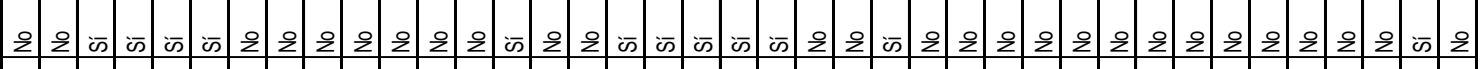

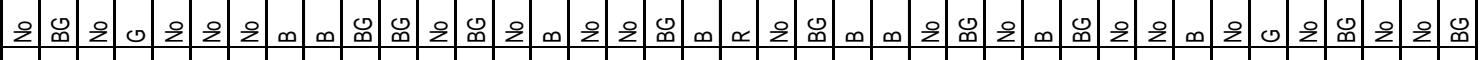

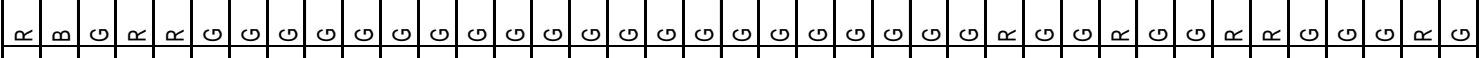

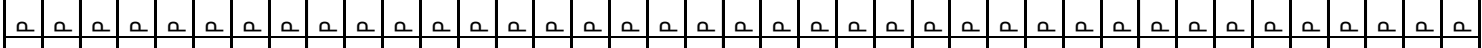

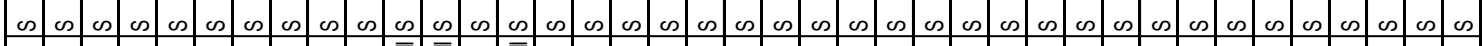

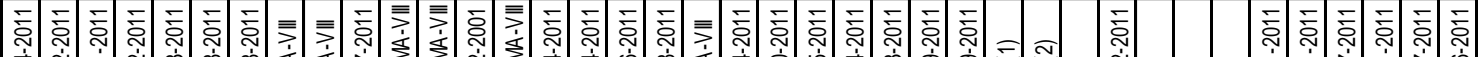

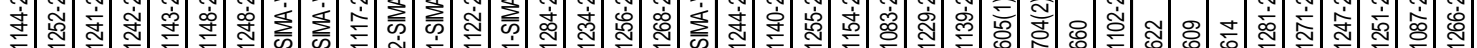

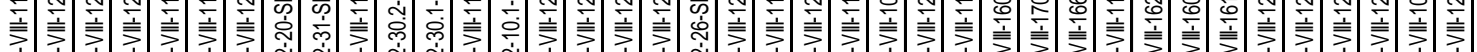

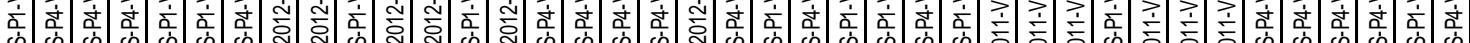

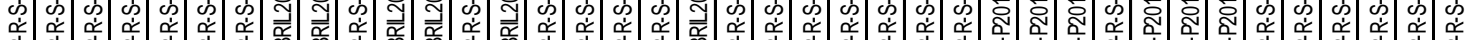

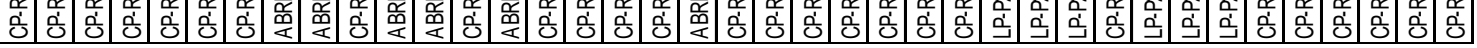




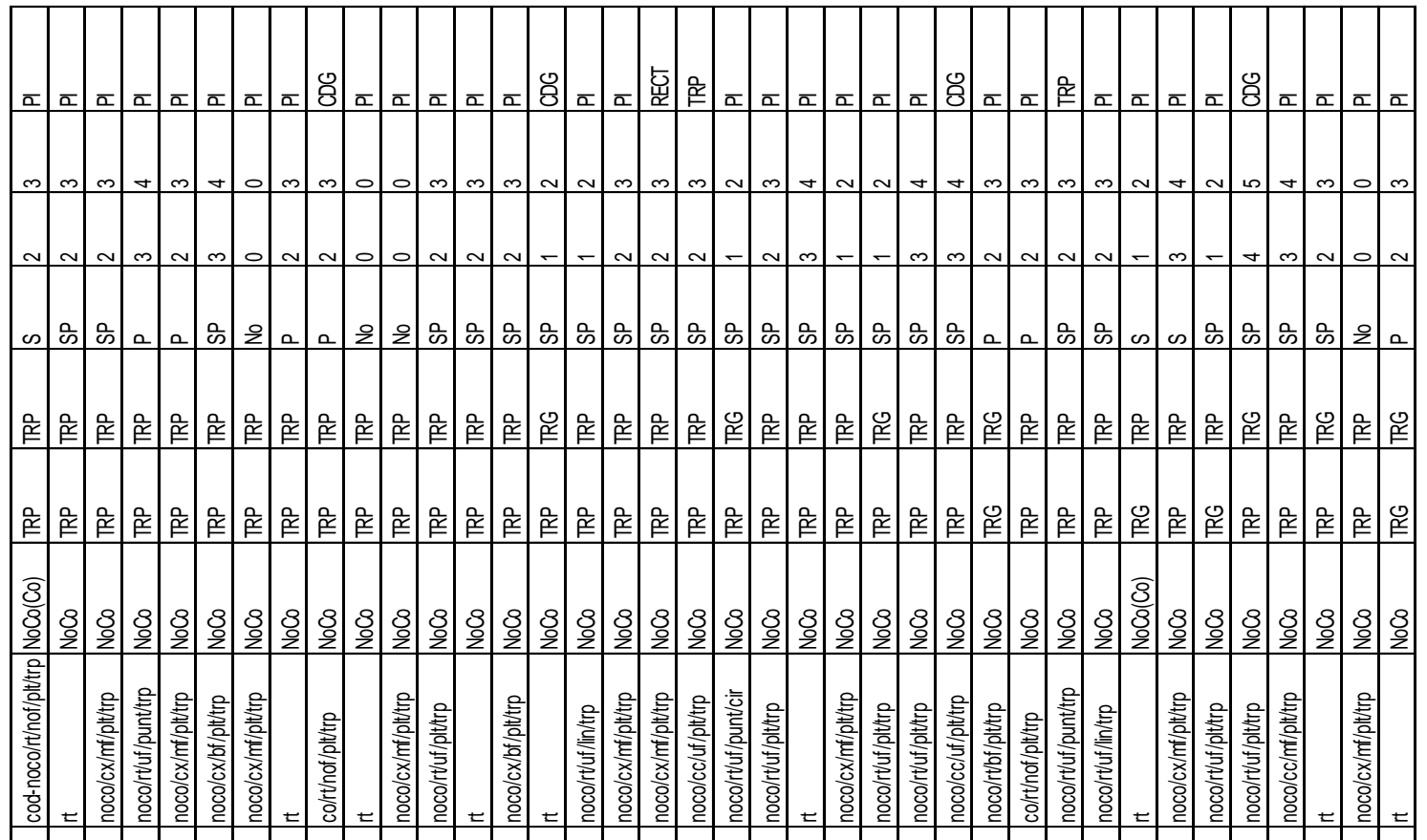

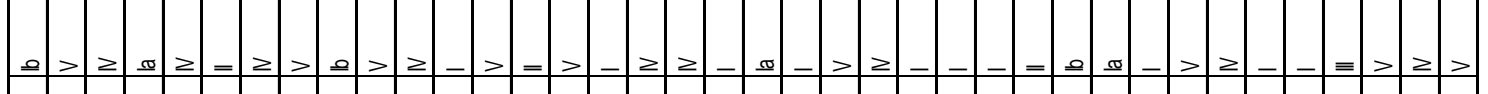

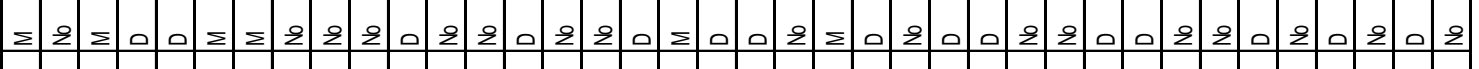

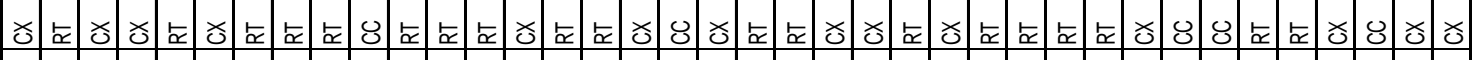

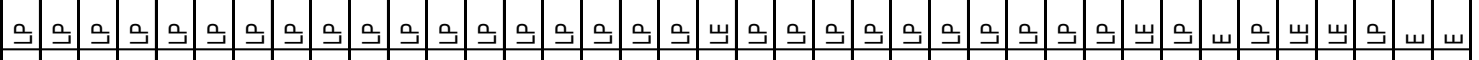

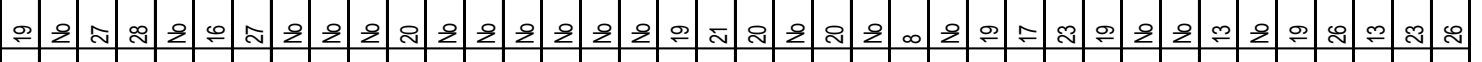

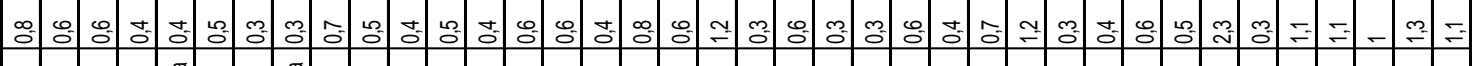

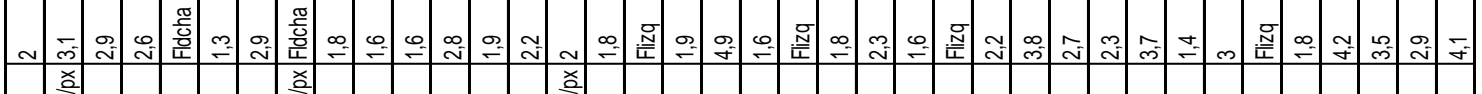

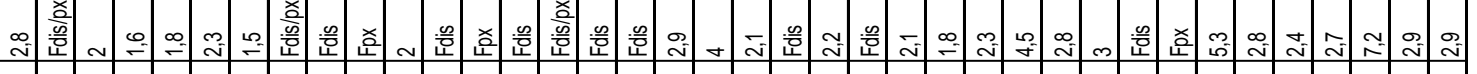

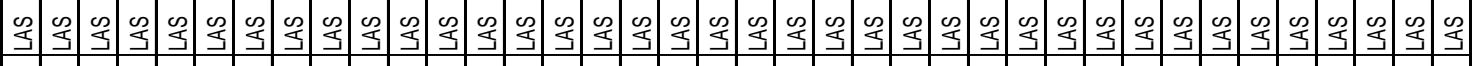

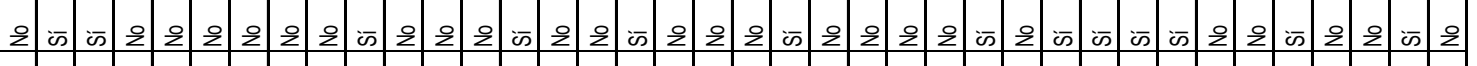

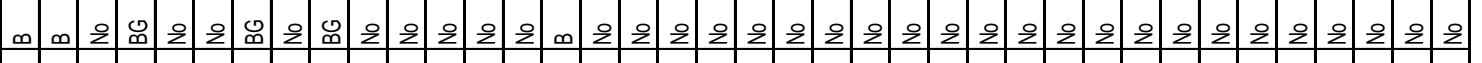

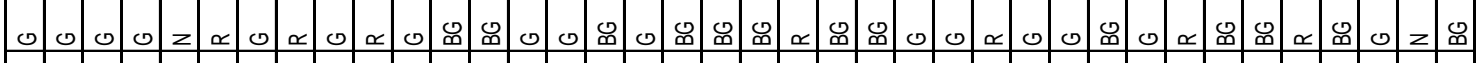

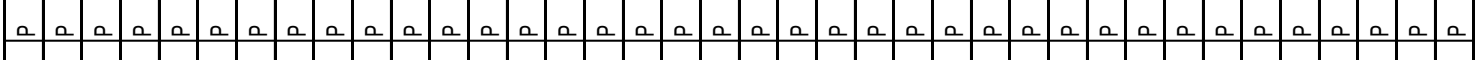

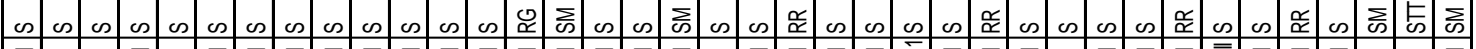

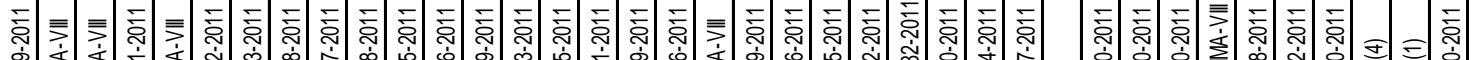

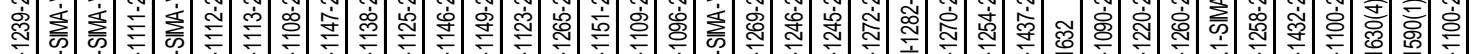
产宗完产 वิ సิ

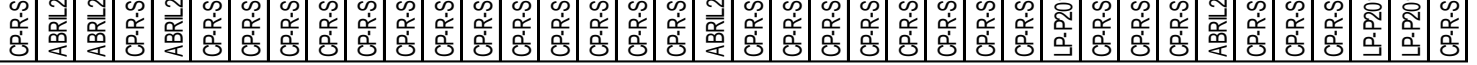




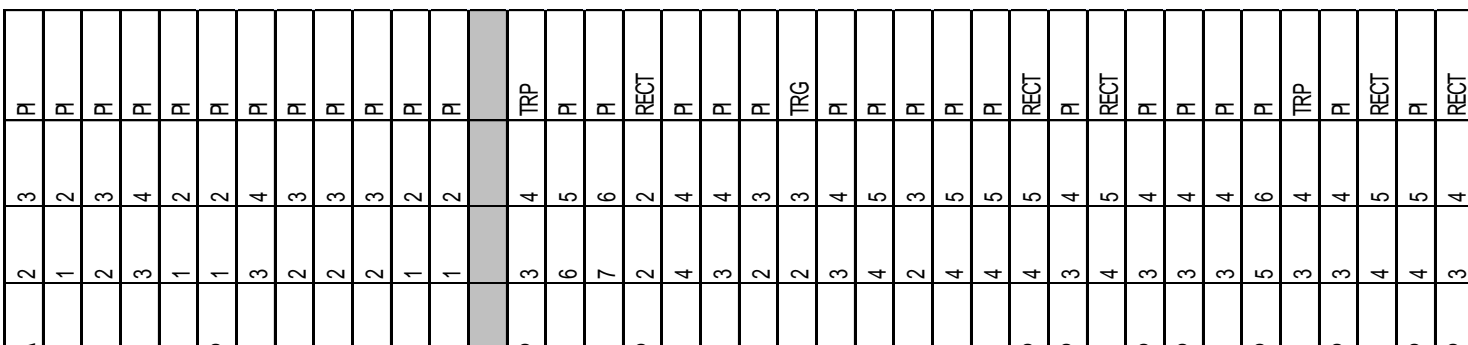

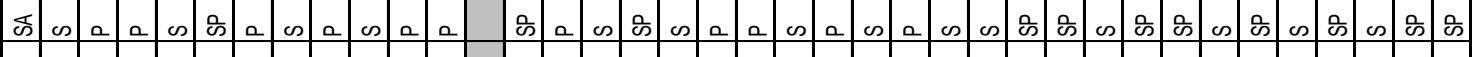

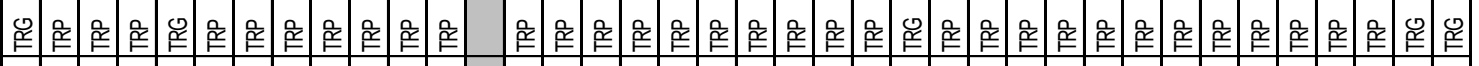

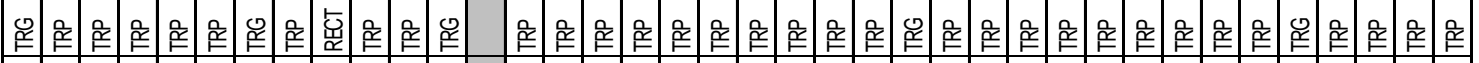

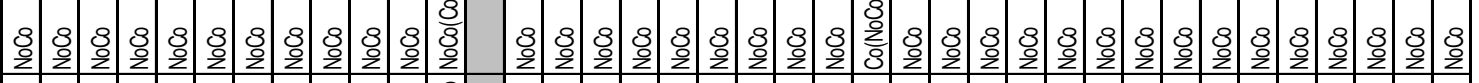

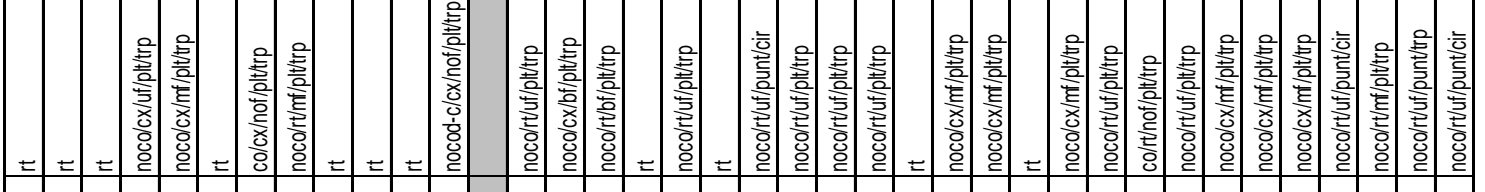

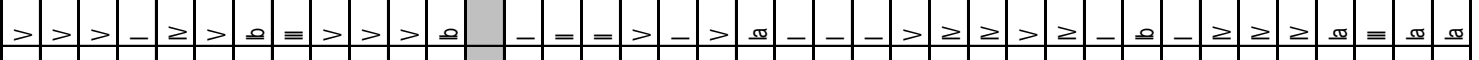

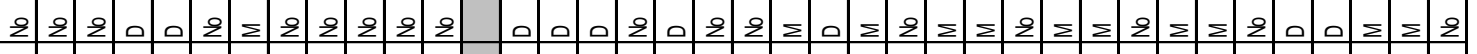

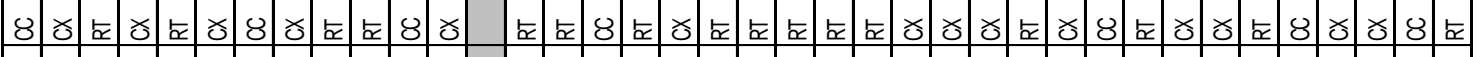
ب

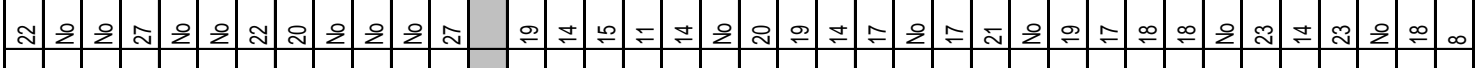
응 f

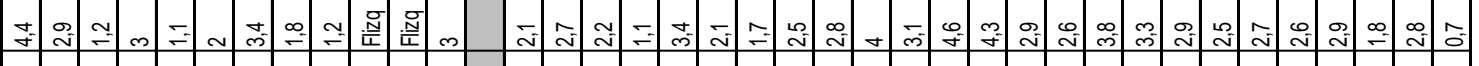
m щ山

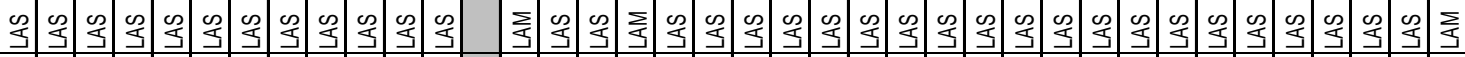

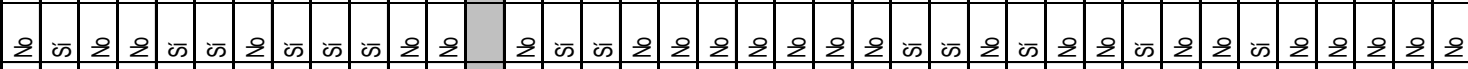

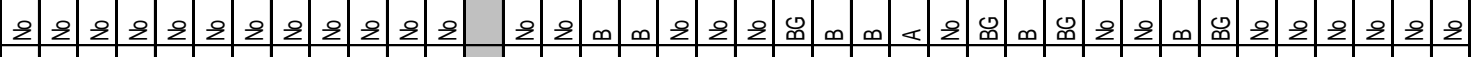

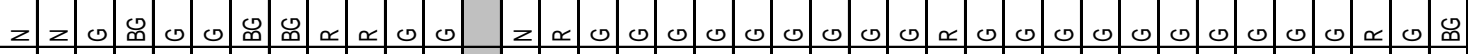

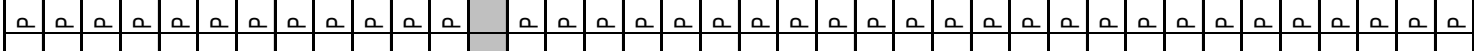

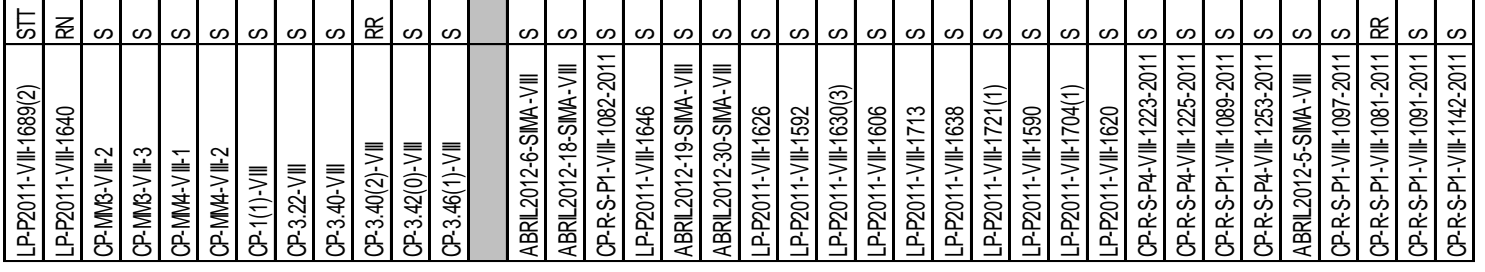




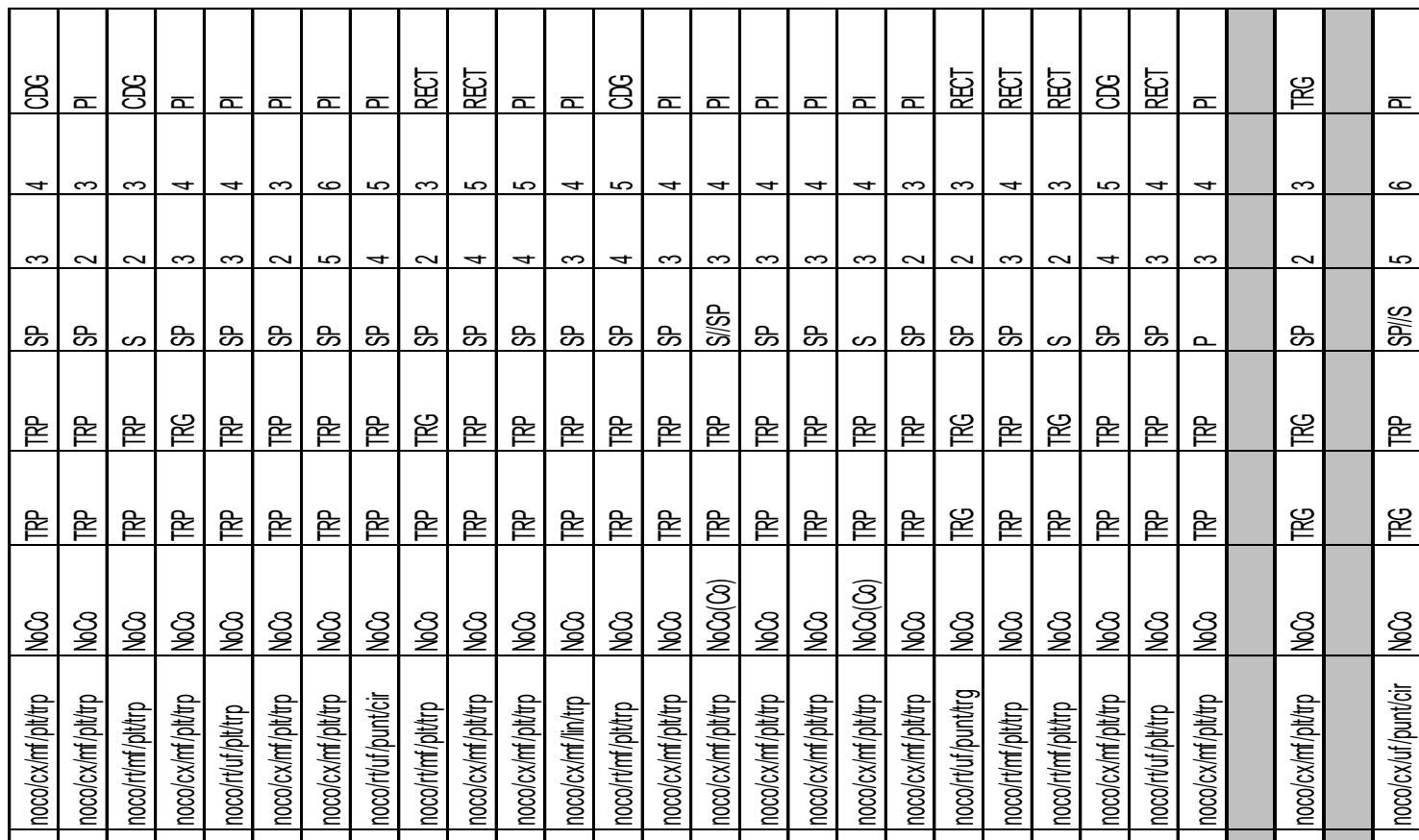

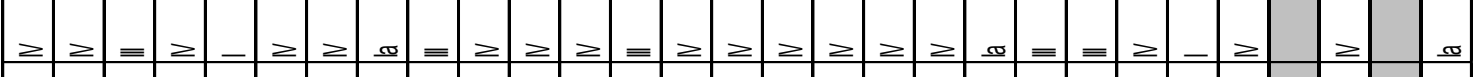

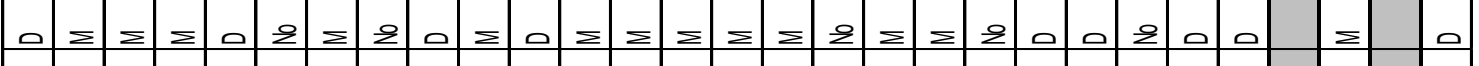

호 줄

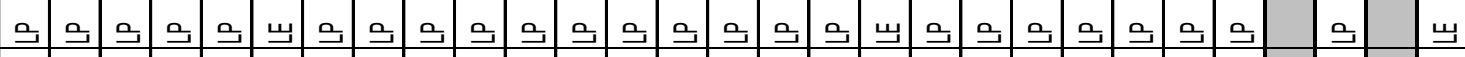

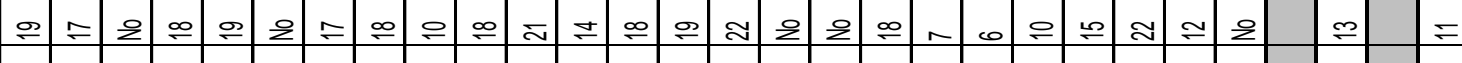

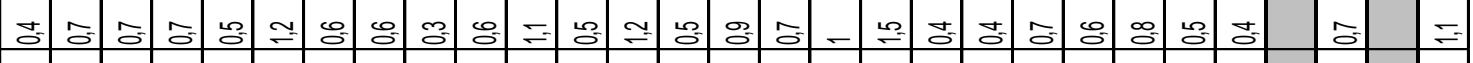

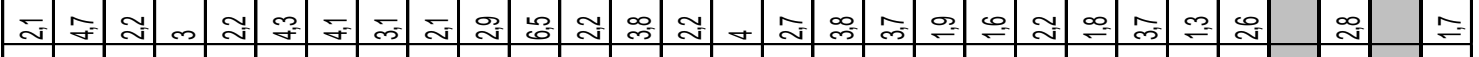

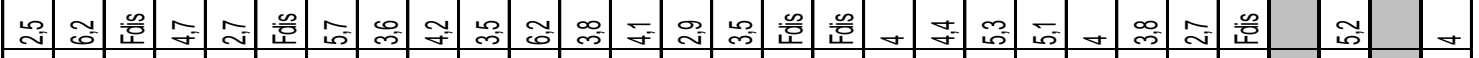

шщ山

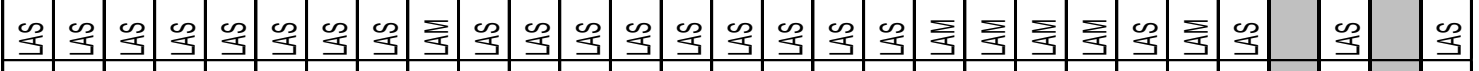

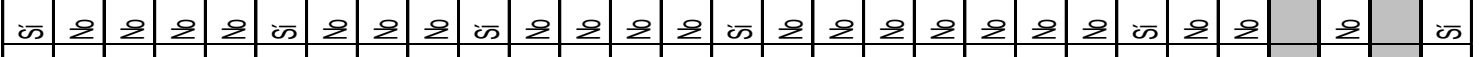

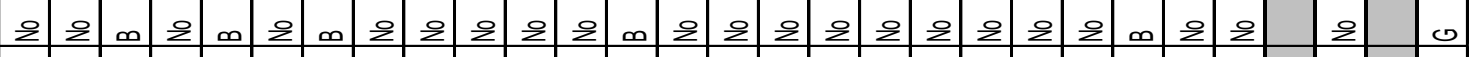

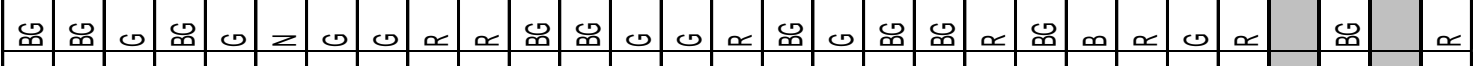
\begin{tabular}{lllllllllllllllllllllllllllllll}
$a$ & $a$ & $a$ & $a$ & $a$ & $a$ & $a$ & $a$ & $a$ & $a$ & $a$ & $a$ & $a$ & $a$ & $a$ & $a$ & $a$ & $a$ & $a$ & $a$ & $a$ & $a$ & $a$ & $a$ & $a$ & & $a$ & & $a$ \\
\hline
\end{tabular}

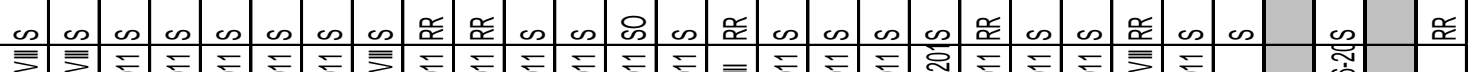

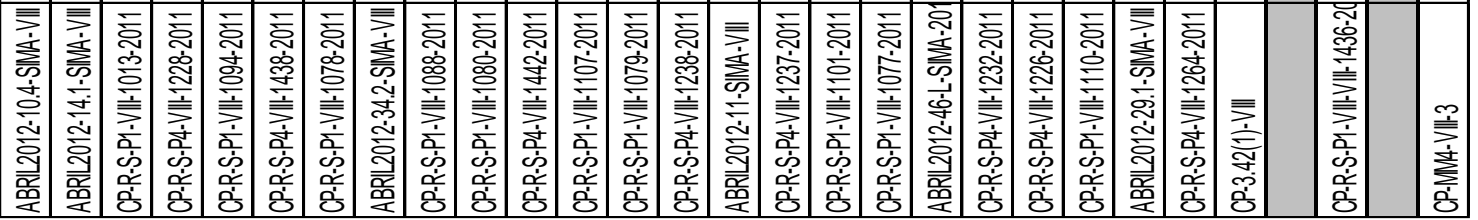

Tabla 35. Estudio analítico de las BP de la Sima de Las Palomas (Weniger et al., 2014: 134/139). 
Para la clasificación de los tipos y subtipos de las BN2G (tabla 36) utilizamos la la nomenclatura del sistema tipológico de Laplace (Laplace, 1972) y los de la Lista-Tipo Bordes (Bordes, 1961). Son un total de 27 ejemplares que corresponden a 12 raederas, 13 denticulados, 1 ejemplar de abrupto y 1 buril. Con un predominio de lascas frente a láminas.

Dentro del grupo de las raederas destacamos un predominio de las raederas planas, R1-R2, y la ausencia hasta el momento de R3-raederas carenadas. De ellas dos están realizadas en sílex gris y dos en sílex beige. Dentro de la clase de raederas laterales planas, se documentan los siguientes tipos primarios. Aparecen 4 ejemplares de raederas planas con retoques marginales laterales no carenadas. Corresponden, todas ellas, a raederas marginales según Laplace (R11). Según la tipología de Bordes distinguimos tres tipos una raedera simple derecha (9), una raedera simple cóncava (11) y dos raederas simples convexas (10). Tenemos 8 raederas planas con retoques profundos laterales no carenadas. Corresponden a una R21 según la tipología de Laplace y a raederas simples convexas (10) en el caso de 5 ejemplares, a raederas sobre cara plana (25) en 2 ejemplares y a una raedera simple derecha (9) en 1 ejemplar según Bordes.

En el grupo de los denticulados nos encontramos con un total de 9 muescas y 4 denticulados. Hay que distinguir entre los que presentan el retoque marginal y los que presentan el retoque profundo, así dentro de los D1-Denticulados planos con retoque marginal se documentan 2 tipos primarios: muescas planas con retoque marginal no carenada. Hay 3 ejemplares que corresponden a un D11 según Laplace y a un 42 según Bordes. Denticulados planos con retoques marginales no carenados. Se documentan con 2 ejemplares según Laplace (D13) y un denticulado según Bordes (43). Y dentro de los D2-Denticulados planos con retoque profundo, tenemos 6 ejemplares de muescas planas con retoques profundos no carenadas o según Laplace (D21) y muescas-escotaduras (42) y denticulados (43) según Bordes. También hay 2 ejemplares de raederas denticuladas con retoques profundos no carenadas D23 y 43.

Hay 1 ejemplar de A1-Abrupto marginal. Al documentarse en el desmonte del perfil y proceder de la limpieza de dicho sedimento es muy probable que proceda de la parte alta de la secuencia, de posible vinculación a Modo 4-Paleolítico Superior o posterior 
En cuanto al buril, se documenta 1 ejemplar del tipo primario B11-Buril sobre plano y que parece proceder de la misma parte que el abrupto y por tanto podría vincularse a Modo 4.

A partir del estudio de los productos retocados o BN2G se deduce un predominio de BP-I (internas) frente a BP-LE (levallois) o BP-SD (semidescortezado) con tan sólo un ejemplar. Esto nos confirma que los productos retocados están realizados sobre soportes de BP-Lascas en general de mayor tamaño que los productos no retocados de pequeños y mediano tamaño, estando representados algunos ejemplares sobre lascas laminares y hay algunos tipos de gran tamaño. En cuanto al volumen predominan, como entre los ejemplares de BP, los realizados sobre soportes de tipo LP (largo-plano) aunque también hay ejemplares con un volumen LE (largo espeso). La cara ventral con predominio de las rectas, sobre las convexas y cóncavas respectivamente. En cuanto al bulbo predominan las que no tienen bulbo reconocible o abatido con 10 ejemplares. Seguidas por 9 ejemplares con bulbo marcado y 8 con bulbo difuso. Con talones lisos en 4 ejemplares, talones corticales en 2 ejemplares y 10 ejemplares con talones facetados presentes en sus distintas variantes, 1 ejemplar con talón facetado diedro, 1 talón facetado diedro plano y 8 ejemplares con talón facetado convexo.

Su cara talonar es no cortical en la mayoría de ellos con presencia de algunos ejemplares cortical, con predominio de talones en plataforma salvo un ejemplar puntiforme. Su cara dorsal es no cortical en todas salvo en dos ejemplares uno de ellos la presenta no cortical dominante cortical, y el otro ejemplar es cortical dominante no cortical. 


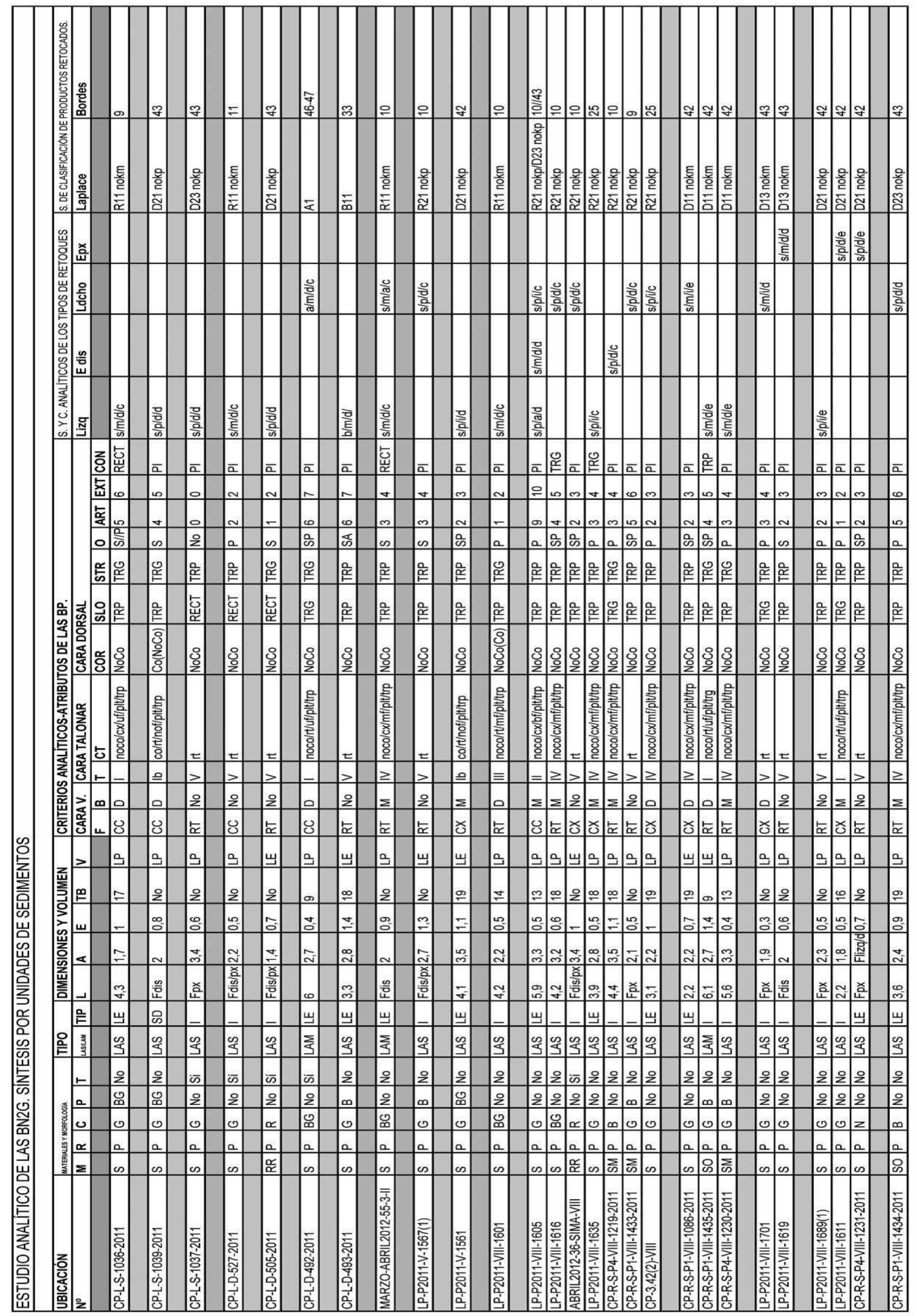

Tabla 36. Estudio analítico de las BN2G de la Sima de Las Palomas (Weniger et al., 2014:

$163)$. 
Junto a BN1G, BP y BN2G, es de destacar el elevado número de restos de talla indicadores de que proceso de talla, el desbaste y la configuración de productos fue realizado in situ en el propio yacimiento. Constituyen un total de 143 ejemplares, donde la mayoría son esquirlas con 119 ejemplares, desechos con 20 ejemplares y tablas de avivamiento con 4 ejemplares.

. Valoración y conclusiones

Se localiza junto a un cañon kárstico y cerca de un nacimiento de agua, lo que favorecía el oteo y la caza de herviboros propios de terrenos montañosos, como la cabra montes.

Los tipos de $\mathrm{BN} 1 \mathrm{G}$, sus rasgos morfológicos y características técnicas nos muestran en el marco de los sistemas técnicos de producción, los Temas Operativos Técnicos Indirectos (TOTI), como proceso técnico vinculado a la transformación y explotación de los soportes de base o BN1G, con el objetivo de obtener ciertos productos o BP-Lascas, con idea que tengan determinada función, en sí mismos, como auténticas herramientas en las mismas BP o en un nuevo proceso de configuración por medio de retoques y así alcanzar a ser BN2G-Productos retocados (Carbonell et al., 1992, 1999: 310; Rodríguez, 2004).

De los 456 ejemplares analizados, 60 ejemplares fueron recuperados en las tareas de limpieza de la dolina y 37 ejemplares aparecieron caídos a la sima desde el perfil estratigráfico.

A nivel general el estudio de la industria lítica muestra una escasa presencia de $\mathrm{Bn}$ y un reducido número de $\mathrm{BN} 1 \mathrm{G}$, un predominio mayoritario de $\mathrm{BP}$ sobre todo internas seguidas de las levallois y los restos de talla. Los productos retocados o BN2G, manifiestan un predominio de raederas, muescas y denticulados vinculados a la tecnología del modo 3. Para la elaboración de BN2G se han utilizado BP internas y levallois en sílex masivos y radiolaritas rojas "con 3 o más aristas y 4 o 5 extracciones, con talones en buena medida facetados, de pequeño y mediano tamaño” (Ramos Muñoz, et al., 214: 178). El análisis de la industria lítica y algunas de las dataciones realizadas en la sima sobre todo para los niveles más bajos (N10-9) (CP1:49.3 \pm 5.4 ka

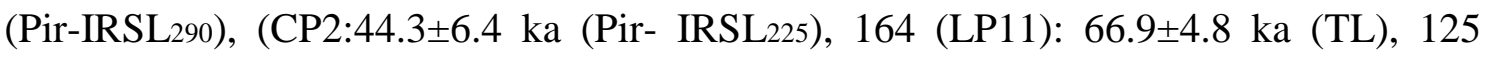

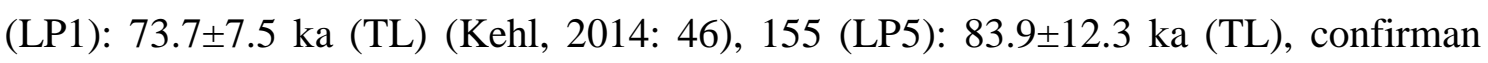
niveles de ocupación asociados a la industria del Paleolítico medio o Modo III. 


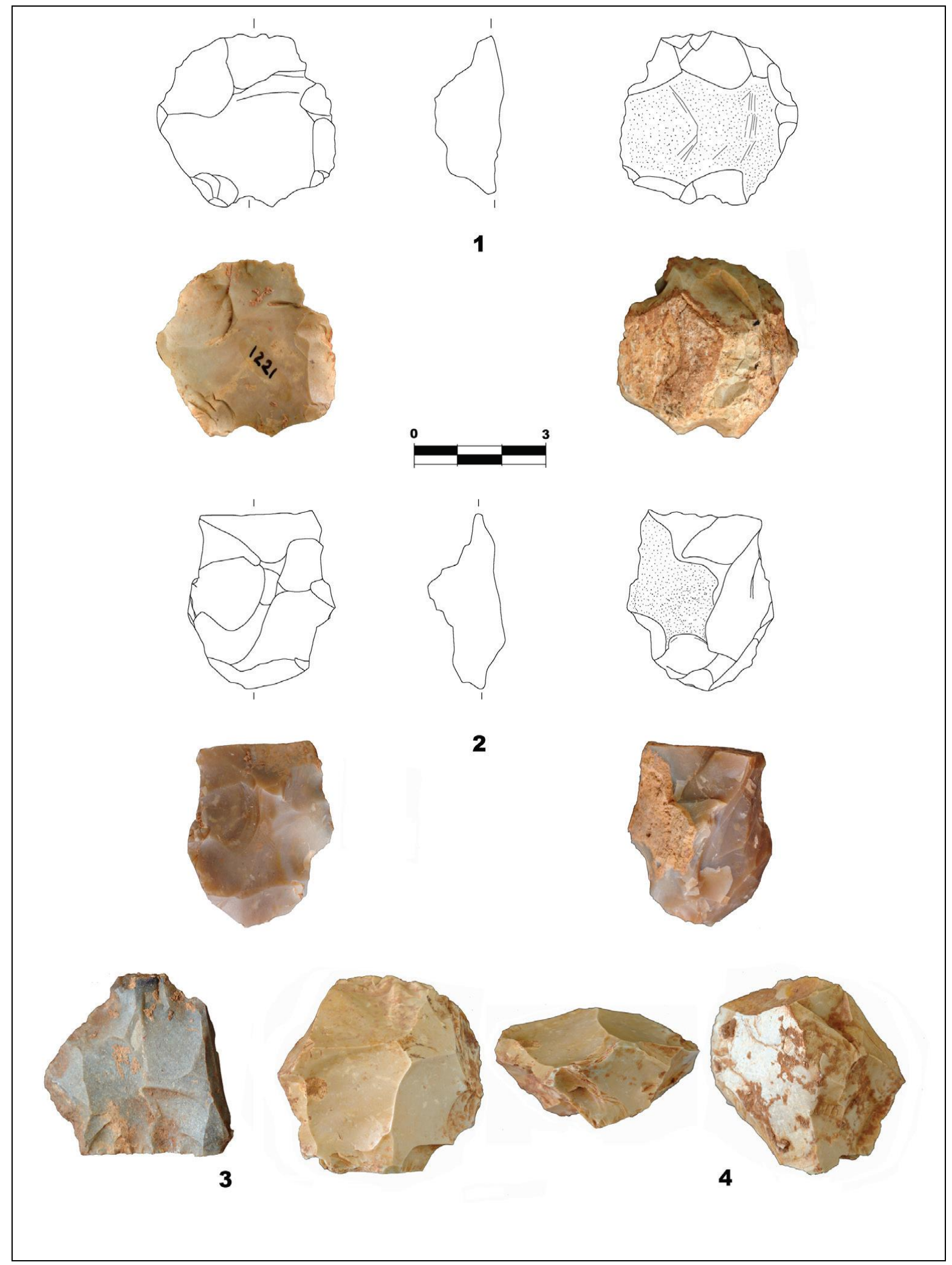

Figura 129. Sima de Las Palomas. Us. 9-10 (1 a 3) y Us 6 (4): BN1G-CM-Núcleos centrípetos multipolares (Weniger et al., 2014:128). 


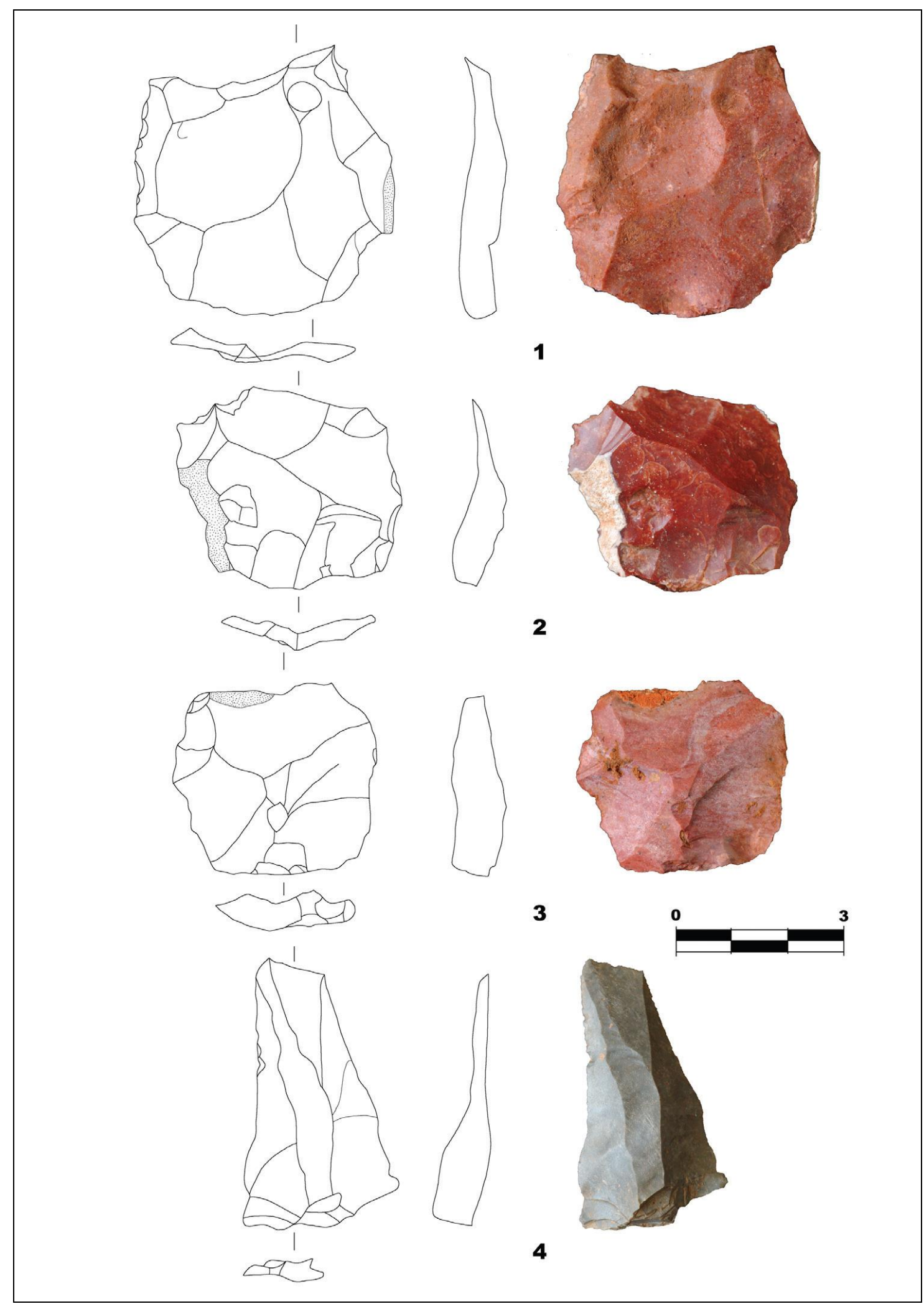

Figura 130. Sima de Las Palomas. Us. 9-10. BP-LE-Lascas levallois (Weniger et al., 2014: 142). 

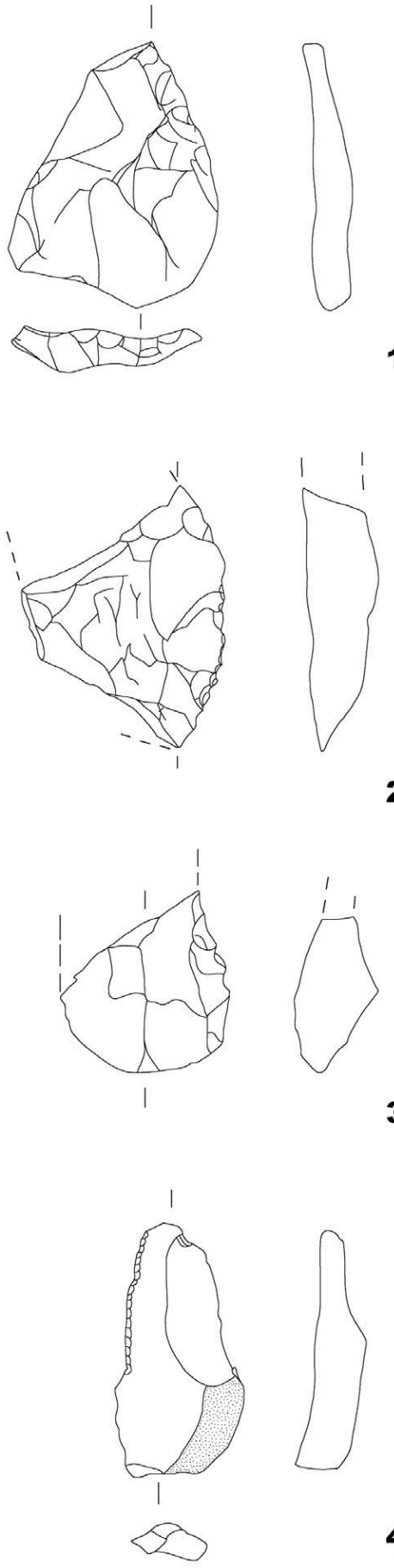

2

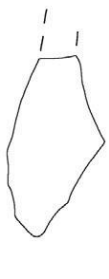

3

4
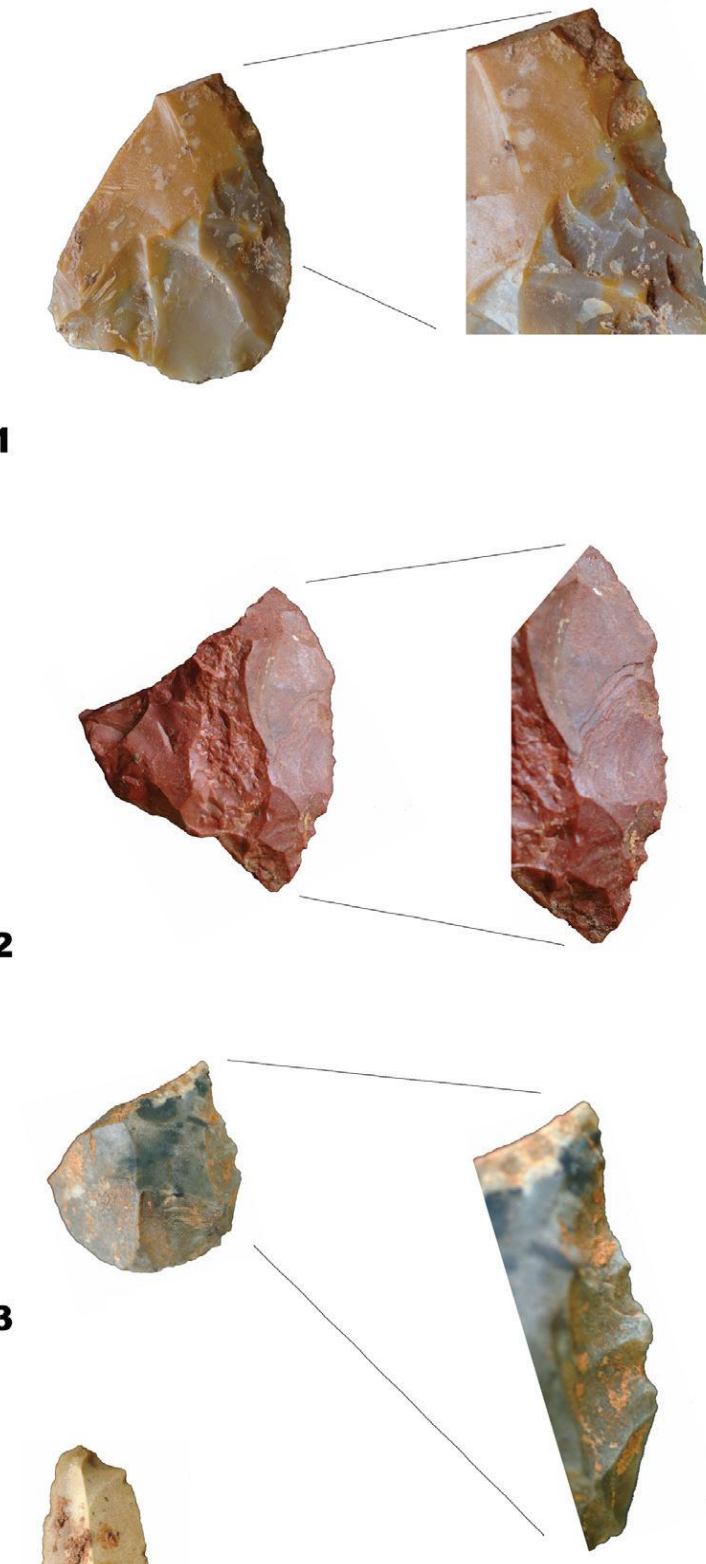

1
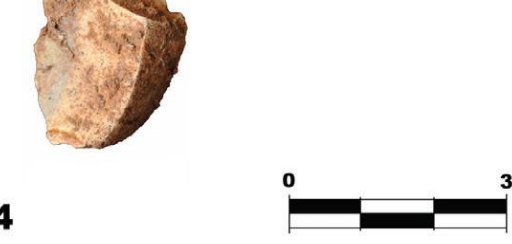

Figura 131. Sima de Las Palomas. Us. 9-10 (1 y 4) y Us. 6 (2 y 3). BN2G-R21nokp (1, 2 y 3 ) y BN2GR11nokm (Weniger et al., 2014: 161). 


\subsubsection{Terraza de Peñarrubia (Campillos)}

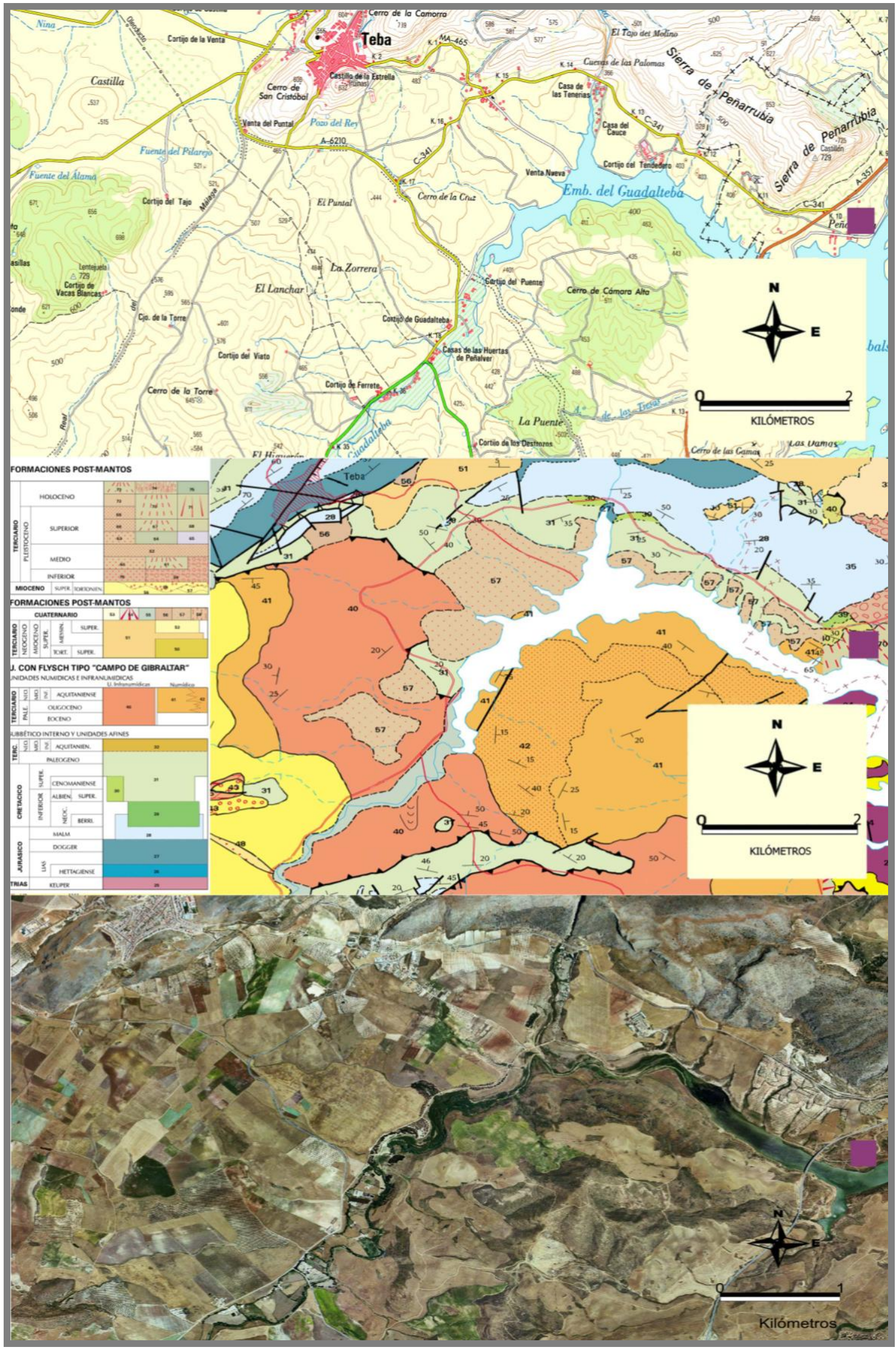


Se sitúa a unos $900 \mathrm{~m}$ del antiguo pueblo de Peñarrubia (Campillos). Se accede a través de la carretera A-357, entre Campillos y Ardales, a pocos metros después de la desviación hacia el pueblo de Teba. Es un yacimiento conocido y estudiado (Medianero Soto et al., 2006 y Medianero Soto et al., 2012), cuyos materiales se han encuadrado cronológicamente desde el Paleolítico hasta la Prehistoria reciente.

Sin embargo, al igual que en el resto de yacimientos ya conocidos hemos realizado un muestreo geoarqueológico del nivel de terraza más bajo y cuyo análisis se expone a continuación.

Sus coordenadas en UTM ETRS89 30 son:

\begin{tabular}{|c|c|}
\hline $\mathbf{X}$ & $\mathbf{Y}$ \\
\hline 335388 & 4092474 \\
\hline
\end{tabular}

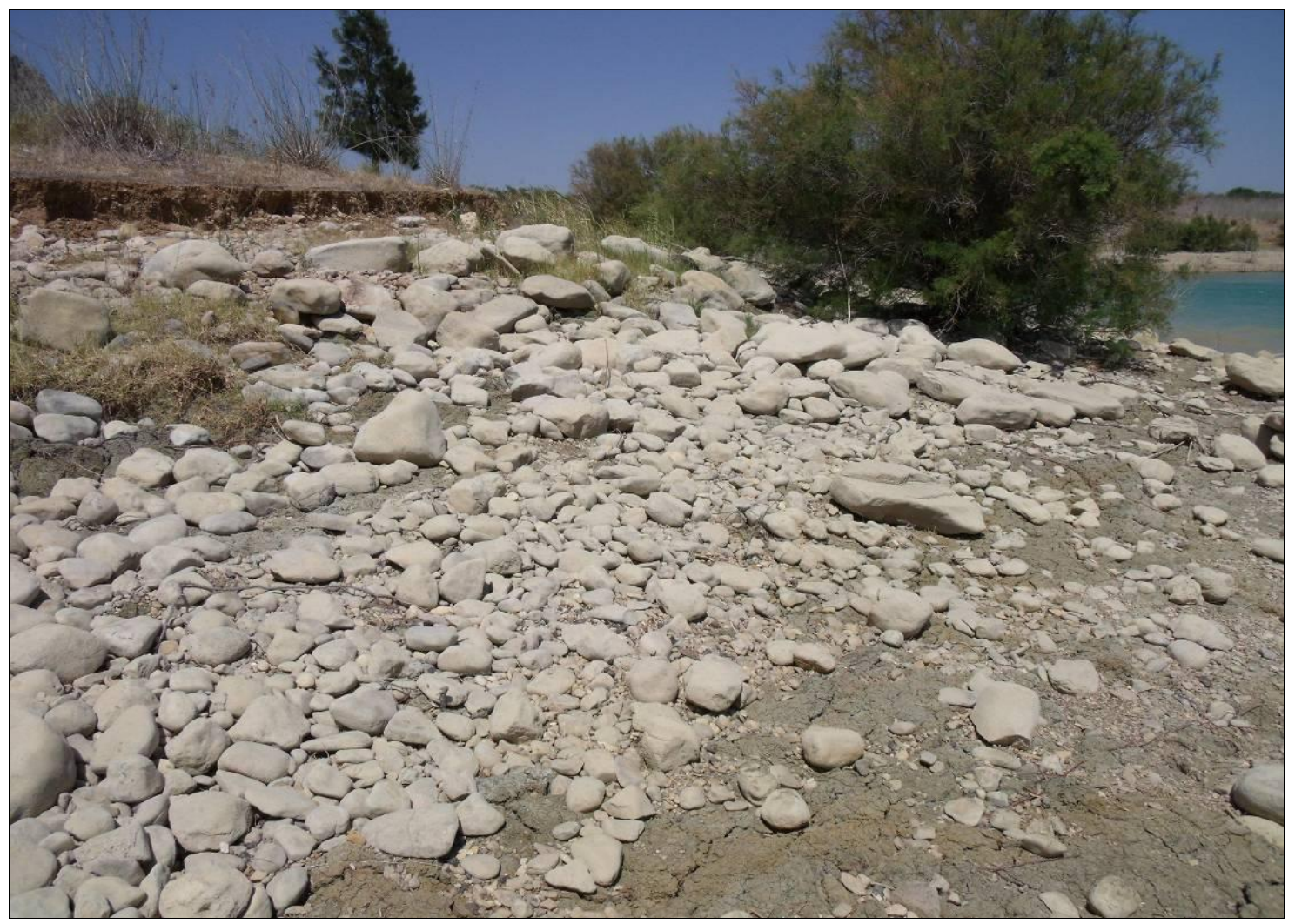

Figura 132. Vista general de la terraza de Peñarrubia.

Altitud m s. n. m.: 368 m

Extensión: $7.100 \mathrm{~m}^{2}$

. Contexto geológico y geomorfológico

A nivel geológico afloran materiales de la formación post-mantos como cantos, arenas y arcillas. Junto a estos materiales aparecen bloques y cantos calcáreos, arenas y 
arcillas (piedemonte muy cementado) junto a margocalizas rosadas "Capas rojas” del Subbético interno. Se trata de una terraza fluvial, situada a unos 2-3 m sobre el río Guadalteba. En su mayor parte desmantelada por la erosión ocasionada por las aguas del embalse del Guadalteba, a unos $\pm 10 \mathrm{~m}$ se localiza parte de una terraza cementada con cantos decimétricos y centimétricos, similares a los que se localizan en la parte más próxima al río y donde no se han localizado material arqueológico.

. Procesos sedimentarios y procesos postdeposicionales

Los procesos sedimentarios que configura el depósito son principalmente de tipo aluvial. Los procesos postdeposicionales están relacionados con las escorrentías y los desmantelamientos posteriores ya que la acción del oleaje del embalse actual origina un continuo desmantelamiento de esta terraza que hace que el material arqueológico aparezca directamente en superficie y no dentro de la terraza.

. Interpretación geoarqueológica

El material arqueológico se encuentra en superficie sobre una terraza desmantelada. Presenta unos filos de rodamiento medio/alto, y siempre se localizan fuera del paquete sedimentario, por lo tanto en posición secundaria. La ubicación de la terraza a unos escasos 2 o $3 \mathrm{~m}$ del río Guadalteba hace que la acción de oleaje sea alta y la removilización del material una constante a lo largo de sus orillas.

\section{. Análisis de la industria lítica}

Se han analizado un total de 26 ejemplares. La materia prima (figura 133) predominante es el sílex masivo, en tonalidades beige y gris, en total 12 ejemplares, en menor volumen el sílex oolítico con 3 ejemplares, y una escasa presencia de sílex bandeado, poroso y radiolarita, únicamente se documenta 1 ejemplar de cada uno, también hay presencia de arenisca compacta y cuarcita, 3 y 2 ejemplares respectivamente, así como cantos de caliza. 


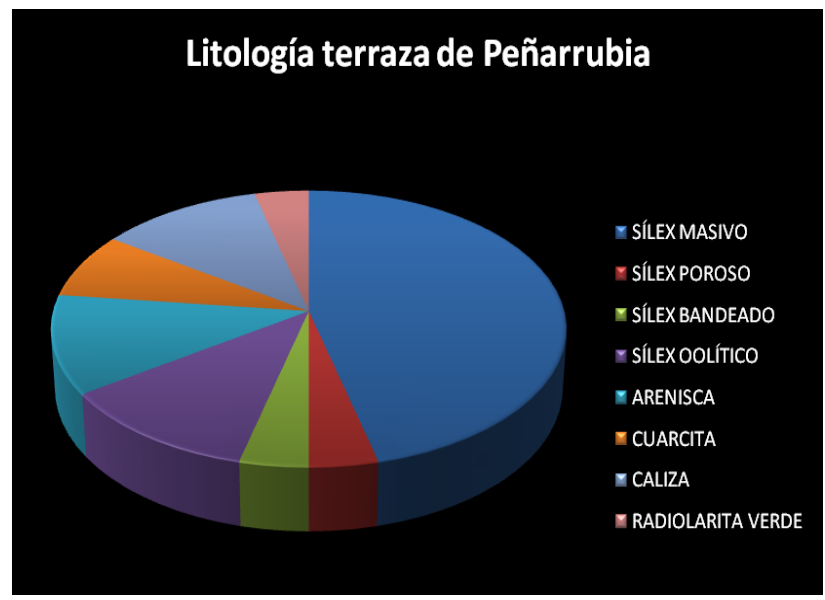

Figura 133. Materias primas de las piezas líticas recuperadas en el yacimiento terraza de Peñarrubia.

En cuanto al estudio morfotécnico existe una presencia de Bases Naturales de Primera Generación, tanto de configuración como de explotación (BN1GC/BN1GE) de Bases Positivas (BP) y Bases Negativas de Segunda Generación (BN2G).

Las BN1G (tabla 37) corresponden a 10 ejemplares en su mayoría de sílex masivos, algunos ejemplares en arenisca compacta y calizas, uno de sílex bandeado y uno en radiolarita. Presentan un sistema de explotación mayoritariamente unipolar frente a una escasa presencia de núcleos diversos y centrípetos. Tienen un carácter cortical casi completo de tipo $4 \mathrm{C}$ y $3 \mathrm{C}$, en la mayoría de los núcleos con un predominio de extracciones de ángulo simple y semiabrupto y con unas longitudes de las extracciones variadas predominando las muy profundas y totales en la gran mayoría. En cuanto a la arista frontal predominan las convexas, frente a las rectas también presentes, la sagital es sinuosa en la mayoría. Dentro de las BN1GC documentamos 2 hendedores uno de los ejemplares corresponde al tipo 5 de Tixier.

\begin{tabular}{|c|c|c|c|c|c|c|c|c|c|c|c|c|c|c|}
\hline \multicolumn{15}{|c|}{ YACIMIENTOS CAMPILLOS. ESTUDIO ANALÍTICO DE LAS BN1G } \\
\hline \multirow{2}{*}{\begin{tabular}{|c|} 
Nombre \\
Terrz. Peñarrubia \\
\end{tabular}} & \multicolumn{5}{|c|}{ Materias primas y morfología } & \multicolumn{2}{|c|}{ Tipos de bases negativas } & \multicolumn{6}{|c|}{ Criterios analíticos de las BN1G } & \multirow[t]{2}{*}{ Tema operativo técnicc } \\
\hline & M & $R$ & C & P & $\mathrm{T}$ & TN & BN & CF & CC & $\mathrm{CO}$ & CP & CAF & CAS & \\
\hline TPÑ1-TL & A & B & 0 & G & NO & $U$ & BN1GC & $U$ & $3 C$ & $\mathrm{SA} / \mathrm{S}$ & $\mathrm{mp}$ & $\mathrm{rt}$ & $\sin$ & T.O.T.D \\
\hline TPÑ2-TL & 0 & B & G & A & NO & U & BN1GC & U & $3 C$ & SA/S & $\mathrm{mp}$ & $c x$ & $\sin$ & T.O.T.D \\
\hline TPÑ3-TL & 0 & B & G & G & NO & $\mathrm{U}$ & BN1GE & $\mathrm{U}$ & $\bar{C}$ & $\mathrm{~s}$ & $\mathrm{mp}$ & $\mathrm{cx}$ & $\sin$ & T.O.T.I \\
\hline TPÑ12-TL & $S$ & B & B & NO & NO & U & BN1GE & $\mathrm{U}$ & $4 C$ & S & $\mathrm{mp}$ & $c x$ & $\sin$ & T.O.T.I \\
\hline TPÑ15-TL & $\mathrm{S}$ & B & B & A & NO & $U$ & BN1GE & B & $2 C / 3 C$ & $S / P$ & $p$ & rt & $\mathrm{rt}$ & T.O.T.I \\
\hline TPÑ17-TL & A & B & B & A & NO & $U$ & BN1GE & U & $2 C$ & $\mathrm{~A} / \mathrm{S}$ & $\mathrm{m}$ & $c x$ & $\sin$ & T.O.T.I \\
\hline TPÑ18-TL & $S$ & B & 0 & NO & NO & DIV & BN1GE & B & $4 C$ & $\mathrm{SA} / \mathrm{S}$ & $\mathrm{t}$ & $c x$ & $\sin$ & T.O.T.I \\
\hline TPÑ19-TL & $S$ & B & G & B & NO & C & BN1GE & U & $4 C$ & $\mathrm{~A} / \mathrm{S}$ & $\mathrm{t}$ & $c x$ & $\sin$ & T.O.T.I \\
\hline TPÑ21-TL & $S$ & B & G & B & NO & DIV & BN1GE & U & $2 C$ & $S$ & $\mathrm{~mm}$ & $\mathrm{rt}$ & rt & T.O.T.I \\
\hline TPÑ23-TL & $\mathrm{R}$ & B & 0 & $\mathrm{R}$ & NO & U & BN1GE & U & $4 C$ & $\mathrm{~S} / \mathrm{P}$ & $\mathrm{t}$ & $c x$ & $\sin$ & T.O.T.I \\
\hline
\end{tabular}

Tabla 37. Estudio analítico de las BN1G de la terraza de Peñarrubia. 
Las BP (tabla 38) presentan pátinas de color amarillo, blancas o rojas y con costras generadas por el contacto continuo con el agua y bastantes rodadas. Se han documentado un total de 11 ejemplares de los que 2 corresponden a BP-D (descortezado), 7 a BP-I (internas) y 2 a BP-L (levallois). El rasgo mayoritario de las lascas es un volumen de tipo LP (largo plano) y con un escasa presencia de LE (larga espesa) y EP (espesa plana). La delineación desde la cara ventral es variada estando presentes los tres caracteres utilizados (recto, cóncavo y convexo). Los talones muestran un predominio de los corticales y lisos en casi todos los ejemplares y una presencia muy escasa de los puntiformes y facetados, y en plataforma frente a los lineales. Las caras dorsales son no corticales en casi todos los ejemplares.

\begin{tabular}{|c|c|c|c|c|c|c|c|c|c|c|c|c|c|c|c|c|c|c|c|c|c|}
\hline \multicolumn{22}{|c|}{ YACIMIENTOS CAMPILLOS. ESTUDIO ANALÍTICO DE LAS BP } \\
\hline Nombre & \multicolumn{5}{|c|}{ Materias primas y morfología } & \multicolumn{2}{|c|}{ Tipos de bases positivas } & \multicolumn{4}{|c|}{ Dimensiones } & \multicolumn{10}{|c|}{ Criterios analíticos de las BP } \\
\hline & M & $R$ & c & p & T & LAS/LAM & TIPO & L & A & TB & VOL & \multicolumn{2}{|c|}{ CARA VENTRAL } & \multicolumn{4}{|c|}{ CARA TALONAR } & \multicolumn{4}{|c|}{ CARA DORSAL } \\
\hline Terrz. Peñarrubia & & & & & & & & & & & & $F$ & $B$ & TIPO & \begin{tabular}{|l|l|} 
COR & $S$ \\
\end{tabular} & $T$ & $D$ & COR & SSAG & STR & A \\
\hline TPÑ11-TL & 0 & $B$ & B & A & NO & LASCA & D & 6,4 & 6,1 & 2,3 & $21 \mathrm{LE}$ & RT & NO & NO & $\begin{array}{ll}\text { CO } & \text { PLA }\end{array}$ & $\mathrm{NF}$ & RT & NOCO & TRP & TRP & $\mathrm{SI}$ \\
\hline TPÑ18-TL & S & $B$ & G & B & NO & LASCA & D & 5,8 & 4 & 2,1 & $17 \mathrm{LP}$ & RT & NO & $f p$ & NOCO PLA & $\mathrm{MF} / \mathrm{NF}$ & RT & NOCO & TRP & TRG & SI \\
\hline TPÑ14-TL & $0 / 5$ & $B$ & B & B & NO & LASCA & L & 7,9 & 8,4 & 2,5 & $21 \mathrm{EP}$ & RT & M & I & NOCO PLA & UF & RT & CDNC & TRP & TRG & SI \\
\hline TPÑ20-TL & S & $B$ & 0 & $G$ & NO & LASCA & I & 5,1 & 3,6 & 1,2 & $13 L P$ & RT & D & $\mathrm{fd}$ & NOCO PLA & BF & UA & NCDC & CDG & TRG & SI \\
\hline TPÑ24-TL & CU & $B$ & $R$ & G & NO & LASCA & I & 10,7 & 5,3 & 2,1 & $13 \mathrm{LP}$ & $C C$ & NO & c & CO PLA & NF & $C C$ & CO & CDG & TRG & SI \\
\hline TPÑ25-TL & S & $B$ & G & B & NO & LASCA & L & $\mathrm{fd}$ & 4,7 & $2,4 \mathrm{NO}$ & $L P$ & RT & M & c & CO PLA & NF & RT & NOCO & CDG & TRG & $\mathrm{SI}$ \\
\hline TPÑ28-TL & A & $B$ & G & A & NO & LASCA & I & 11,3 & 7,2 & 3,4 & $13 \mathrm{LP}$ & $c X$ & NO & $p$ & NOCO PUN & SIN & $c x$ & NOCO & OV & TRG & SI \\
\hline TPÑ32-TL & S & $B$ & B & NO & NO & LASCA & 1 & 3,9 & 2,3 & 0,8 & $14 \mathrm{LP}$ & $c x$ & D & c & CO LIN & NF & $C X$ & NCDC & $C D G$ & $C D G$ & SI \\
\hline TPÑ33-TL & CU & M & $R$ & NO & NO & LASCA & 1 & 3,1 & 3 & 1,2 & $18 \mathrm{LP}$ & RT & M & I & NOCO PLA & UF & RT & NOCO & TRG & TRG & SI \\
\hline TPÑ35-TL & $S$ & $B$ & B & A & NO & LASCA & I & 5,8 & 3,2 & 1,5 & $13 \mathrm{LP}$ & RT & M & I & NOCO PLA & UF & RT & NOCO & CDG & TRG & SI \\
\hline TPÑ37-TL & S & $B$ & G & B & NO & LASCA & I & 5,3 & 2,7 & 1,3 & $14 \mathrm{LP}$ & RT & NO & c & CO PLA & $\mathrm{NF}$ & RT & NCDC & CDG & TRG & SI \\
\hline
\end{tabular}

Tabla 38. Estudio analítico de las BP de la terraza de Peñarrubia.

Las BN2G (tabla 39) constituyen 5 ejemplares del total, todos ellos en sílex masivo y oolítico. La nomenclatura utilizada para su clasificación es la del sistema tipológico de Laplace (Laplace, 1972) y los de la Lista-Tipo Bordes (Bordes, 1961). Hay 2 denticulados realizados sobre una lasca de semidescortezado y una levallois, respectivamente. El primer ejemplar presenta un volumen LE (largo espeso), la delineación del talón desde la cara ventral es recta y el bulbo difuso. La cara talonar presenta un talón liso, no cortical, en plataforma y unifacetado. La cara dorsal es no cortical. En relación al tipo de retoque, se encuentra en el lateral izquierdo y es simple, marginal, directo y denticulado. Se trata de un denticulado carenoide según Laplace (D3) o un denticulado según Bordes (43). El otro ejemplar tiene un volumen LP (largo plano) una delineación del talón desde la cara ventral cóncava y un bulbo difuso, la cara talonar presenta un talón liso, cortical dominante no cortical, en plataforma y 
unifacetado. La cara dorsal es no cortical dominante cortical. El retoque se encuentra en el lateral derecho y es simple, marginal, directo y denticulado. Se trata de una raedera de denticulado según Laplace (D23) o una raedera lateral convexa según Bordes (10). Tenemos 2 raederas, una en sílex masivo y la otra en sílex oolítico. Ambas presentan un volumen LP (largo plano), el talón es abatido en una y liso en la otra y ambas con una superficie lineal. La primera de ellas tiene el retoque simple, marginal, directo y continuo en el extremo distal y es una raedera trasversal según Laplace (R22) o una raedera trasversal convexa según Bordes (23).

Finalmente documentamos un perforador realizado sobre sílex masivo gris, con un retoque simple, marginal, alterno y continuo en el lateral izquierdo. Se trata de un bec desviado según Laplace (BC1) y un perforador según Bordes (34). También hay una raedera lateral (R21) o sobre cara plana (25).

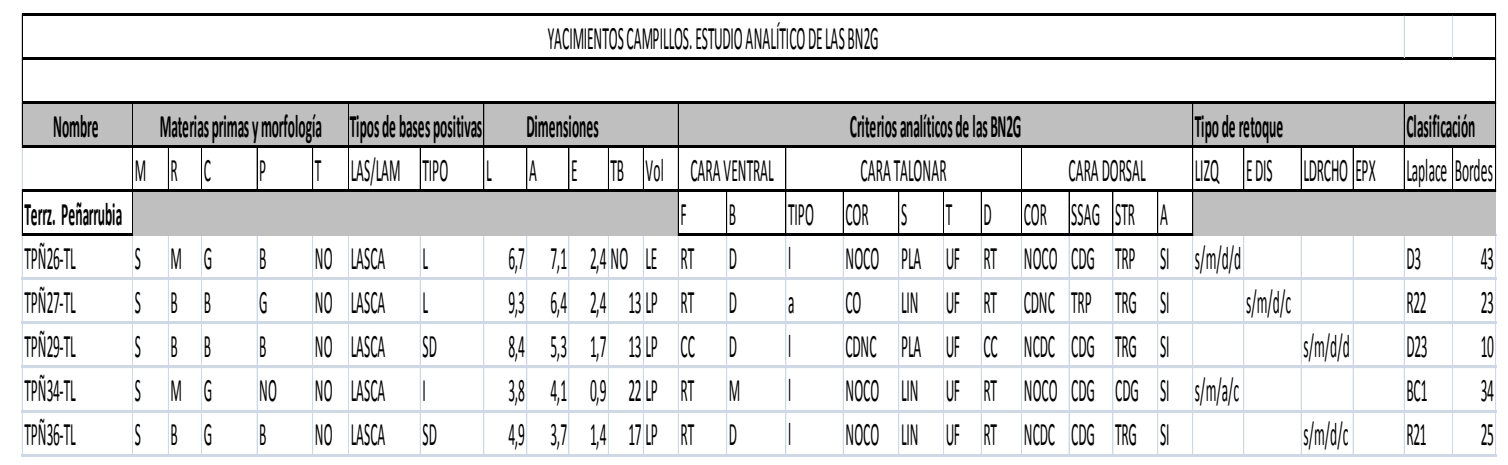

Tabla 39. Estudio analítico de las BN2G de la terraza de Peñarrubia.

. Valoración y conclusiones

La industria lítica recuperada de los muestreos y de las actividades arqueológicas realizadas con anterioridad en esta terraza manifiesta una presencia de BN1GC, tales como cantos tallados, hendedores, bifaces o triedros, asociados a las industrias del Paleolítico inferior o Modo II. Junto a estos productos aparecen BN1GE, BP y BN2G como raederas o denticulados que se pueden adscribir a Paleolítico medio o Modo III. Las materias primas utilizadas para los productos más antiguos son principalmente las areniscas compactas y alguna que otra cuarcita, pero en menor cantidad, para los materiales asociados a Paleolítico medio existe un predominio del sílex frente a las areniscas y cuarcitas, aunque se siguen utilizando. La materia prima parece tener un origen local aprovechando los propios materiales aflorantes en las cercanías y transportados por el río Guadalteba. 


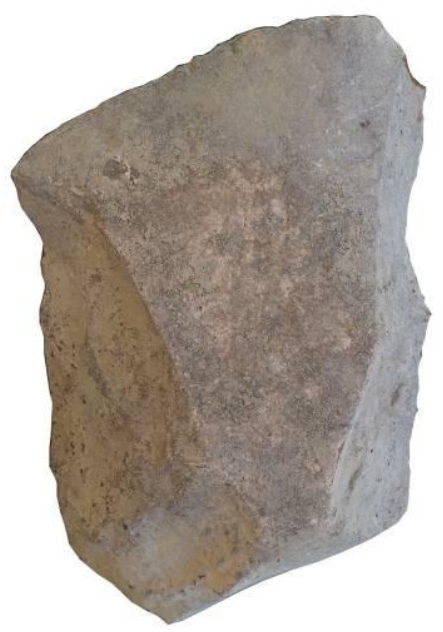

1
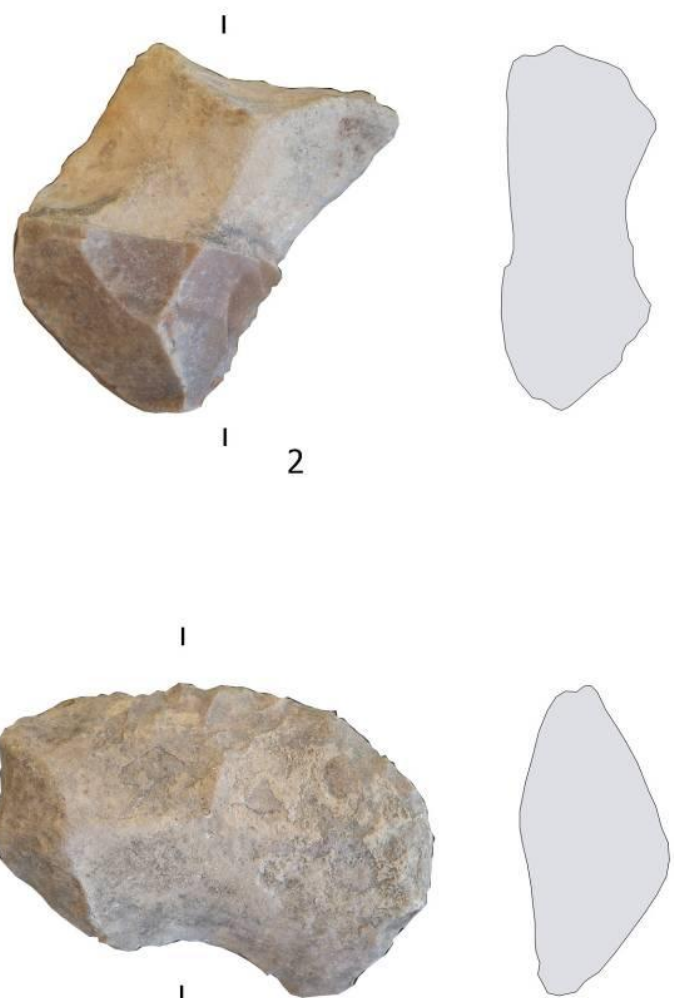

I

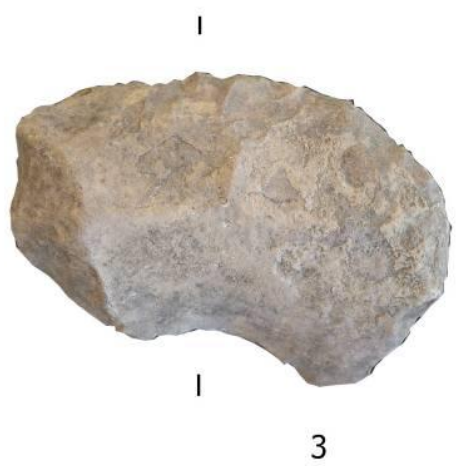

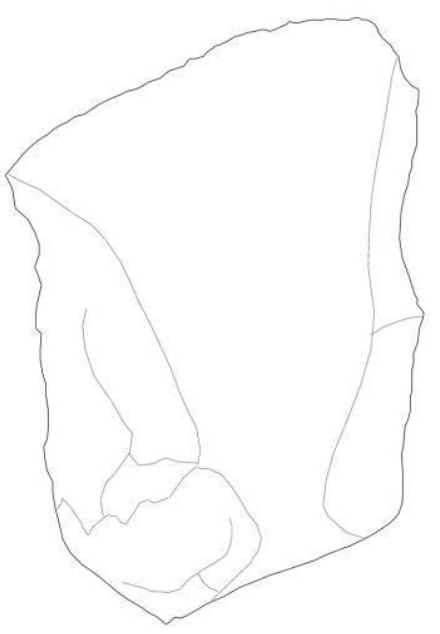
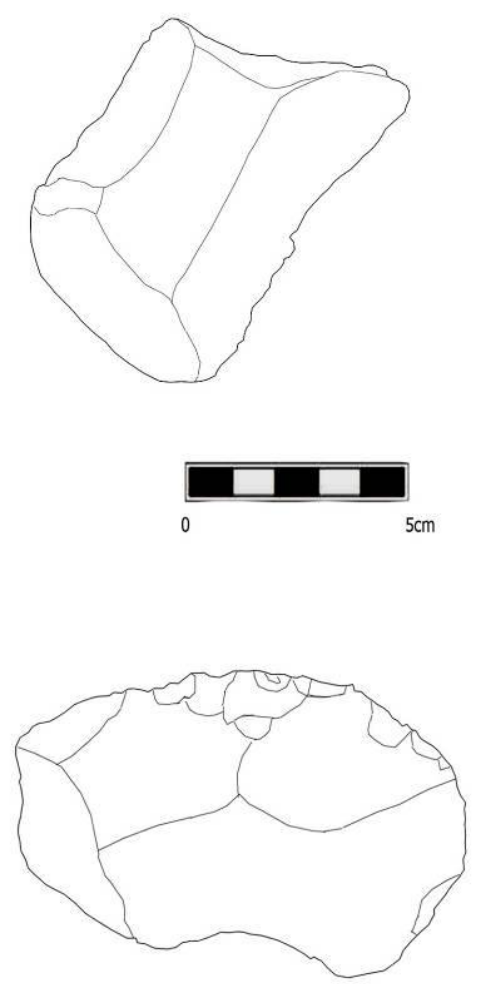

3

Figura 134. Terraza de Peñarrubia (Campillos): 1, BN1GC-Hendedor; 2, BP- Levallois; 3 : BN2G-Raedera trasversal. 


\subsubsection{La Puente (Teba)}

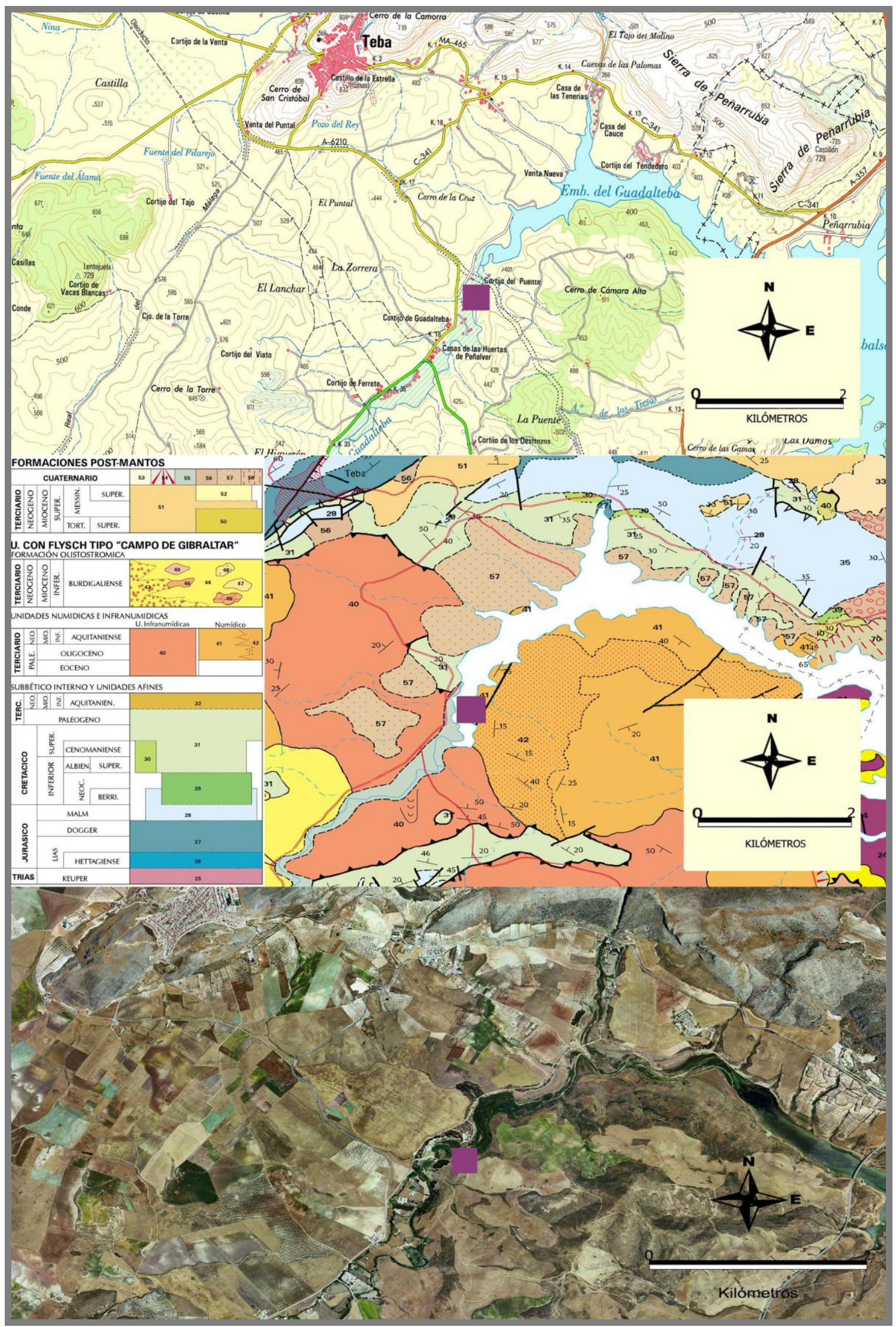


Se sitúa en la margen derecha del río Guadalteba en la zona conocida como La Puente nombre que le viene por un cortijo que existe en las inmediaciones. Su acceso se realiza a través de la carretera C-341 que une Campillos con Ronda, a su paso por Teba. Antes de llegar al punto kilométrico 18 hay que desviarse a la izquierda para coger la carretera que va paralela al río, debemos pasar la ermita y justo donde se inicia la zona recreativa cruzar el río y próxima al mismo localizamos el yacimiento.

Sus coordenadas UTM ETRS89 30 son:

\begin{tabular}{|c|c|}
\hline $\mathbf{X}$ & $\mathbf{Y}$ \\
\hline 331095 & 4092191 \\
\hline
\end{tabular}

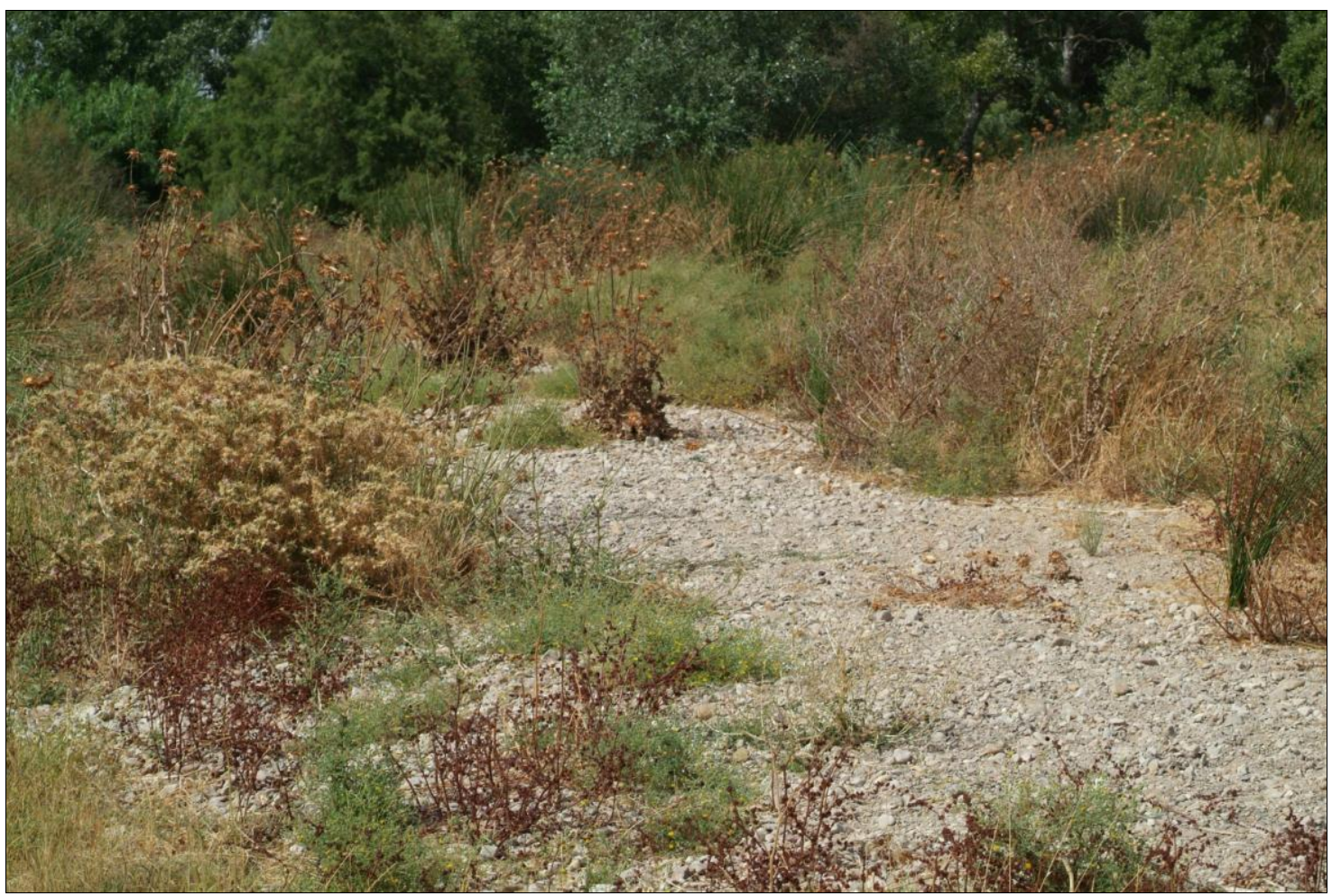

Figura 135. Vista del yacimiento La Puente.

Altitud m s.n.m: 380/ 375 m

Extensión: 8.213,60 $\mathrm{m}^{2}$

- Contexto geológico y geomorfológico

Los materiales aflorantes en la zona del yacimiento pertenecen a las unidades del Flych del Campo de Gibraltar y más concretamente a las unidades Numídicas, con litologías compuestas por areniscas cuarzosas (del Aljibe), arcillas, margas arcillosas y limos arcillosos. 
Corresponde a un yacimiento en superficie que se localiza a pocos metros del cauce actual del río, sobre un meandro del mismo con una zona de posible gravera vinculada al propio sistema fluvial. Este hecho no hace plantearnos la posibilidad de una ocupación posterior al sistema de terrazas próximas denominadas como terrazas de La Puente.

. Procesos sedimentarios y procesos postdeposicionales

La zona, por su proximidad al río, pudo haber sufrido la sedimentación propia de los materiales que fueron arrastrados por el río Guadalteba. En cuanto a los procesos postdeposicionales están en virtud del mismo proceso de cambio y variabilidad del nivel del río, que va aportando material a la zona.

. Interpretación geoarqueológica

Los restos de industria lítica recuperados se encuentran en posición secundaria, a escasos metros del río Guadalteba. El material aparece en un espacio reducido y sin una dispersión muy grande si bien presentan los filos con un rodamiento medio.

. Análisis de la industria lítica

El material fue recogido a finales del verano de 2015 durante las prospecciones aprobadas dentro del P.G.I. La materia prima predominante (figura 136) es el sílex masivo en tonalidades que van del marrón al beige y algunos ejemplares en blanco, pero son muy pocos, también hay presencia de sílex porosos y algún ejemplar de sílex oolítico y radiolarita. Son un total de 53 ejemplares.

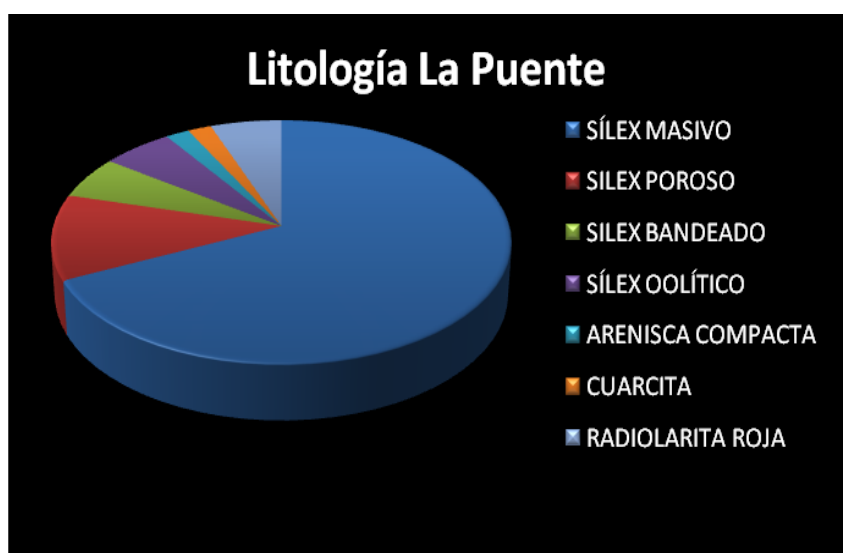

Figura 136. Materias primas de las piezas líticas recuperadas en el yacimiento La Puente. 
En relación con el estudio morfotécnico vemos una presencia de Bases Naturales de Primera Generación, tanto de Configuración como de Explotación (BN1GC y BN1GE), de Bases Positivas (BP) tanto de descortezado (D) como de semidescortezado (SD) junto a internas (I) y levallois (L) y Bases Negativas de Segunda Generación (BN2G).

Las BN1G (tabla 40) corresponden a 23 ejemplares, en su mayoría de sílex masivos, 1 ejemplar en arenisca compacta, 2 de sílex oolíticos y 4 porosos. Presentan un sistema de explotación variado, con presencia mayoritaria de los diversos frente a los unipolares, bipolares, poliédricos y centrípetos. Con un carácter cortical casi completo de tipo 4C y $3 \mathrm{C}$, en la mayoría de los núcleos existe un predominio de extracciones de ángulo plano y simple, y algunos ejemplares con ángulos semiabruptos y abruptos, quizás por la presencia casi exclusiva de sílex en tabletas utilizados como núcleos. En cuanto a la arista frontal predominan las convexas, frente a las rectas también presentes, la sagital es sinuosa en la mayoría. Dentro de las BN1GC documentamos dos bifaces en sílex sobre lascas.

\begin{tabular}{|c|c|c|c|c|c|c|c|c|c|c|c|c|c|c|}
\hline \multicolumn{15}{|c|}{ YACIMIENTOS TEBA. ESTUDIO ANALÍTICO DE LAS BN1G } \\
\hline \multirow{2}{*}{\begin{tabular}{|c|}
\multicolumn{1}{|c|}{ Nombre } \\
La Puente
\end{tabular}} & \multicolumn{5}{|c|}{ Materias primas y morfología } & \multicolumn{2}{|c|}{ Tipos de bases negativas } & \multicolumn{6}{|c|}{ Criterios analíticos de las BN1G } & \multirow[t]{2}{*}{ Tema operativo técnicc } \\
\hline & $M$ & $\mathrm{R}$ & C & $\mathrm{P}$ & $\mathrm{T}$ & TN & BN & $\mathrm{CF}$ & CC & $\mathrm{CO}$ & $\mathrm{CP}$ & CAF & CAS & \\
\hline LP2-TL & A & $M$ & 0 & A & NO & B & BN1GC & B & $3 C$ & S & $\mathrm{P}$ & $c x$ & $\sin$ & T.O.T.D \\
\hline LP3-TL & S & B & G & A & NO & B & BN1GC & B & $3 C$ & $S$ & $\mathrm{mp}$ & $c x$ & $\sin$ & T.O.T.D \\
\hline LP4-TL & $S$ & B & B & A & NO & U & BN1GE & U & C & SA/A & $\mathrm{mm}$ & $c x$ & rt & T.O.T.I \\
\hline LP5-TL & $S$ & $M$ & B & NO & NO & C & BN1GE & B & $3 C$ & $S$ & $\mathrm{mp}$ & $c x$ & $\sin$ & T.O.T.I \\
\hline LP6-TL & $S$ & $M$ & 0 & NO & NO & POL & BN1GE & $T$ & $4 C$ & $\mathrm{P} / \mathrm{S} / \mathrm{S}$ & $\Delta t$ & $c x$ & $\sin$ & T.O.T.I \\
\hline LP7-TL & $S$ & $M$ & G & A & NO & U & BN1GE & U & $2 C$ & $S$ & $p$ & $\mathrm{rt}$ & rt & T.O.T.I \\
\hline LP8-TL & $S$ & $M$ & 0 & A & NO & POL & BN1GE & $T$ & $2 C$ & $S / S A$ & $\mathrm{mp}$ & $\mathrm{rt}$ & $\sin$ & T.O.T.I \\
\hline LP9-TL & $S$ & $M$ & B & NO & NO & DIV & BN1GE & $T$ & $4 C$ & $\mathrm{P} / \mathrm{S}$ & $\mathrm{t}$ & $\mathrm{rt}$ & rt & T.O.T.I \\
\hline LP10-TL & $S$ & $M$ & B & A & NO & DIV & BN1GE & U & $4 C$ & $\mathrm{P} / \mathrm{S}$ & $\mathrm{t}$ & $c x$ & $\sin$ & T.O.T.I \\
\hline LP11-TL & $S$ & B & 0 & G & NO & C & BN1GE & U & $3 C$ & $\mathrm{P} / \mathrm{S}$ & $\mathrm{t}$ & $c x$ & $\sin$ & T.O.T.I \\
\hline LP12-TL & $S$ & B & 0 & G & NO & U & BN1GE & B & $3 C$ & $\mathrm{P} / \mathrm{S}$ & $p$ & $\mathrm{rt}$ & $\sin$ & T.O.T.I \\
\hline LP13-TL & $S$ & B & B & A & NO & B & BN1GE & B & $2 C$ & SA/A & $p$ & $c x$ & $\sin$ & T.O.T.I \\
\hline LP14-TL & $S$ & $M$ & B & NO & NO & DIV & BN1GE & $T$ & $2 C$ & $\mathrm{P} / \mathrm{S}$ & $\mathrm{m}$ & $\mathrm{rt}$ & rt & T.O.T.I \\
\hline LP15-TL & $S / R$ & $M$ & 0 & A & NO & C & BN1GE & B & $3 C$ & $\mathrm{P} / \mathrm{S}$ & $\mathrm{mp}$ & $c x$ & $\sin$ & T.O.T.I \\
\hline LP16-TL & $S$ & B & G & A & NO & B & BN1GE & $T$ & $4 C$ & $\mathrm{P} / \mathrm{S}$ & $\mathrm{mp}$ & $\mathrm{rt}$ & $\sin$ & T.O.T.I \\
\hline LP17-TL & $S$ & B & G & B & NO & DIV & BN1GE & U & $3 C$ & $\mathrm{P} / \mathrm{S}$ & $\mathrm{mp}$ & $\mathrm{rt}$ & $\sin$ & T.O.T.I \\
\hline LP18-TL & $S$ & B & G & A & NO & DIV & BN1GE & B & $4 C$ & $\mathrm{P} / \mathrm{S}$ & $t$ & $c x$ & $\sin$ & T.O.T.I \\
\hline LP19-TL & $S$ & $M$ & G & B & NO & C & BN1GE & B & $4 C$ & S & $\mathrm{t}$ & $\mathrm{rt}$ & $\sin$ & T.O.T.I \\
\hline LP20-TL & $S$ & $M$ & G & B & NO & DIV & BN1GE & B & $4 C$ & $S$ & $\mathrm{t}$ & $\mathrm{rt}$ & inc & T.O.T.I \\
\hline LP21-TL & $S$ & $M$ & G & 0 & NO & DIV & BN1GE & U & $2 C$ & $S$ & $\mathrm{~mm}$ & $\mathrm{rt}$ & $\sin$ & T.O.T.I \\
\hline LP22-TL & $S$ & $M$ & G & A & NO & U & BN1GE & B & $3 C$ & $S$ & $p$ & $c x$ & inc & T.O.T.I \\
\hline LP23-TL & $S$ & $M$ & 0 & NO & NO & DIV & BN1GE & B & $4 C$ & $\mathrm{SA} / \mathrm{S}$ & $t$ & $c x$ & $\sin$ & T.O.T.I \\
\hline LP51-TL & $S$ & $M$ & G & A & NO & POL & BN1GE & $T$ & $4 C$ & $\mathrm{P} / \mathrm{S}$ & $\mathrm{t}$ & $c x$ & $\sin$ & T.O.T.I \\
\hline
\end{tabular}

Tabla 40. Estudio analítico de las BN1G de La Puente.

Con relación a las BP (tabla 41) casi todas presentan pátinas de color amarillo, blancas o rojas. Se han documentado un total de 25 ejemplares, 2 corresponden a BP-D (descortezado), 7 a BP-SD (semidescortezado), 10 a BP-I (internas) y 6 a BP-L 
(levallois). En cuanto al volumen, el rasgo mayoritario de todas ellas es el LP (largo plano), con un escasa presencia de LE (larga espesa) y EP (espesa plana). La delineación desde la cara ventral es variada estando presentes los tres caracteres (recto, cóncavo y convexo). Los talones muestran un predominio de los no corticales y lisos en casi todos los ejemplares y una presencia muy escasa de los puntiformes y facetados, $\mathrm{y}$ en plataforma frente a los lineales.

\begin{tabular}{|c|c|c|c|c|c|c|c|c|c|c|c|c|c|c|c|c|c|c|c|c|c|}
\hline \multicolumn{22}{|c|}{ YACIMIENTOS TEBA. ESTUDIO ANALIITICO DE LAS BP } \\
\hline \multirow{3}{*}{\begin{tabular}{|l} 
Nombre \\
La Puente \\
\end{tabular}} & \multicolumn{5}{|c|}{ Materias primas y morfología } & \multicolumn{3}{|c|}{ Tipos de bases positivas } & \multicolumn{3}{|c|}{ Dimensiones } & \multicolumn{10}{|c|}{ Criterios analíticos de las BP } \\
\hline & \multirow[t]{2}{*}{ M } & \multirow[t]{2}{*}{ R } & \multirow[t]{2}{*}{ c } & \multirow[t]{2}{*}{ P } & \multirow[t]{2}{*}{$\mathrm{T}$} & \multirow[t]{2}{*}{ LAS/LAM } & \multirow[t]{2}{*}{ TIPO } & \multirow[t]{2}{*}{$\mathrm{L}$} & E & TB & VOL & \multicolumn{2}{|c|}{ CARA VENTRAL } & \multicolumn{4}{|c|}{ CARA TALONAR } & \multicolumn{4}{|c|}{ CARA DORSAL } \\
\hline & & & & & & & & & & & & $\mathrm{F}$ & $B$ & TIPO & \begin{tabular}{|l|l|} 
COR & $S$ \\
\end{tabular} & $\mathrm{~T}$ & D & COR & SSAG & STR & A \\
\hline LP1-TL & $c$ & M & A & G & NO & LASCA & SD & 12,3 & 9,7 & 2,6 & $17 \mathrm{LP}$ & $C C$ & $\mathrm{D}$ & I & NOCO PLA & UF & CC & CDNC & CDG & TRG & SI \\
\hline LP25-TL & S & M & B & A & NO & LASCA & SD & 6,8 & 4,4 & 2,6 & $13 \mathrm{LE}$ & RT & $M$ & 1 & CO PLA & $\mathrm{NF}$ & RT & CDNC & PTG & TRG & SI \\
\hline LP26-TL & $S$ & M & B & A & NO & LASCA & D & $\mathrm{fd}$ & 5 & $1,3 \mathrm{NO}$ & L LP & $\mathrm{CC}$ & D & 1 & NOCO PLA & UF & $C C$ & NOCO & TRG & TRG & SI \\
\hline LP27-TL & $S$ & $M$ & B & B & NO & LASCA & $S D$ & 5 & 3,1 & 1,3 & $14 \mathrm{LP}$ & $c x$ & $M$ & fc & NOCO LIN & MF & $C X$ & CDNC & TRP & TRG & SI \\
\hline LP28-TL & $S$ & $M$ & G & B & NO & LASCA & SD & 4,5 & 2,7 & 1,4 & $14 \mathrm{LP}$ & $c x$ & NO & $p$ & NOCO PUN & UF & $C X$ & NCDC & TRG & TRG & SI \\
\hline LP29-TL & $R$ & M & $R$ & NO & NO & LASCA & $S D$ & 2,7 & 2 & 0,7 & $19 \mathrm{LP}$ & $c x$ & NO & p & NOCO PUN & UF & $c x$ & NCDC & TRP & TRG & SI \\
\hline LP30-TL & $S$ & M & B & NO & NO & LASCA & I & 3,6 & 2,8 & 1,1 & $18 \mathrm{LP}$ & $c x$ & $M$ & 1 & NOCO PLA & UF & $c x$ & NOCO & CDG & TRP & SI \\
\hline LP31-TL & s & M & 0 & 0 & NO & LASCA & I & 2,5 & 2,7 & 0,7 & $23 \mathrm{LP}$ & RT & D & c & CO LIN & $\mathrm{NF}$ & $c x$ & CDNC & CDG & TRG & $\mathrm{SI}$ \\
\hline LP32-TL & $S$ & M & B & A & NO & LASCA & I & 4,5 & 2,4 & 0,8 & $14 \mathrm{LP}$ & RT & $D$ & 1 & NOCO LIN & UF & $c x$ & NOCO & CDG & TRG & SI \\
\hline LP33-TL & $S$ & M & B & NO & NO & LASCA & I & 2,7 & 2,4 & 1 & $19 \mathrm{LP}$ & $c x$ & NO & NO & NOCO NO & NO & $c x$ & NOCO & TRG & TRG & $\mathrm{SI}$ \\
\hline LP34-TL & $S$ & $M$ & G & A & NO & LASCA & I & 3,7 & 3 & 0,6 & $18 \mathrm{LP}$ & RT & $M$ & I & NOCO PLA & UF & RT & NOCO & CDG & CDG & SI \\
\hline LP35-TL & $S$ & M & G & B & NO & LASCA & I & 3,6 & 3,7 & 1,3 & $18 \mathrm{EP}$ & RT & D & 1 & NOCO PLA & UF & RT & NOCO & TRP & TRG & SI \\
\hline LP36-TL & $S$ & M & 0 & NO & NO & LASCA & I & 4,1 & 2,9 & 1,3 & $18 \mathrm{LP}$ & RT & M & 1 & NOCO LIN & UF & RT & NOCO & PTG & TRG & SI \\
\hline LP37-TL & $R$ & M & $R$ & NO & NO & LASCA & I & 2,9 & 2,7 & 1,8 & $19 \mathrm{LE}$ & RT & NO & NO & NO NO & NO & NO & NOCO & ov & TRG & SI \\
\hline LP38-TL & $S$ & M & 0 & A & NO & LASCA & I & 4,3 & 2,6 & 0,8 & $14 \mathrm{LP}$ & $c x$ & D & $p$ & CO PUN & $\mathrm{NF}$ & $c x$ & NCDC & CDG & TRP & SI \\
\hline LP39-TL & $S$ & M & B & NO & NO & LASCA & L & 4,9 & 3,9 & 1,9 & $17 \mathrm{LP}$ & $c x$ & D & $p$ & NOCO PUN & $B F$ & $c x$ & NCDC & TRG & TRP & SI \\
\hline LP4O-TL & $R$ & $M$ & $R$ & NO & NO & LASCA & L & 4,1 & 2,1 & 0,8 & $14 \mathrm{LP}$ & RT & $M$ & $a$ & NOCO PLA & MF & $c x$ & NCDC & TRP & TRP & SI \\
\hline LP41-TL & $S$ & $M$ & B & $R$ & NO & LASCA & L & 4,8 & 3,4 & 1,3 & $17 \mathrm{LP}$ & RT & NO & I & NOCO PLA & UF & $c x$ & NOCO & CDG & TRG & SI \\
\hline LP42-TL & $S$ & $M$ & B & A & NO & LASCA & L & 4,4 & 2,9 & 1,6 & $14 \mathrm{LP}$ & $c x$ & NO & $p$ & NOCO PUN & UF & $c x$ & NOCO & PTG & TRG & SI \\
\hline LP43-TL & $S$ & $M$ & 0 & A & NO & LASCA & L & 5,6 & 3,3 & 2 & $13 \mathrm{LP}$ & RT & D & I & NOCO PLA & UF & RT & NCDC & TRP & TRG & SI \\
\hline LP44-TL & $S$ & $M$ & G & B & NO & LASCA & SD & 6,8 & 4,2 & 1,2 & $13 \mathrm{LP}$ & RT & D & $\mathrm{fp}$ & NOCO PLA & MF & RT & CDNC & CDG & TRG & SI \\
\hline LP45-TL & $S$ & M & B & A & NO & LASCA & L & 4,9 & 6,3 & 1,9 & 25 EP & RT & D & I & NCDC PLA & UF & RT & NCDC & TRP & TRG & SI \\
\hline LP46-TL & $S$ & M & G & B & NO & LASCA & D & 2,4 & 4,9 & 0,9 & 26 EP & RT & NO & I & NOCO PLA & UF & RT & NOCO & CDG & TRG & SI \\
\hline LP52-TL & $S$ & $B$ & B & A & NO & LASCA & SD & 6,7 & 4,7 & 1,9 & $17 \mathrm{LP}$ & $\mathrm{RT}$ & $D$ & a & NOCO LIN & UF & RT & CDNC & TRP & TRG & SI \\
\hline LP53-TL & $S$ & M & G & NO & NO & LASCA & I & 8,2 & 3,5 & 1,8 & $9 L P$ & $c x$ & D & I & NOCO LIN & UF & $c x$ & NOCO & OV & TRG & SI \\
\hline
\end{tabular}

Tabla 41. Estudio analítico de las BP de La Puente.

Las BN2G (tabla 42) constituyen 5 ejemplares del total, todos ellos en sílex masivo en tonalidades grises y beige. Se ha utilizado la nomenclatura de la tipología de Laplace (Laplace, 1972) y los de la Lista-Tipo Bordes (Bordes, 1961), para la clasificación por tipos y subtipos.

Hay 3 raederas con un volumen LP (largo plano) y LE (largo espeso), una delineación del talón desde la cara ventral recta y un bulbo difuso en dos, la otra presenta el bulbo bien definido, liso en dos de ellas y facetado plano en la otra, no cortical, en plataforma en dos y lineal en una. La cara dorsal es no cortical dominante cortical en dos ejemplares mientras que en el otro es no cortical. Los retoques son simples, marginales, directos o inversos y continuos. Se trata de 3 raederas laterales 
según la tipología de Laplace (R21) y según Bordes corresponden a una raedera desviada (21), una raedera simple convexa (10) y a una raedera con retoque alterno (29).

Hay una punta sobre lasca interna en sílex masivo, con un volumen LP (largo plano), de talón facetado convexo, en plataforma, multifacetado y con la cara dorsal no cortical. Corresponde a una punta levallois marginal según Laplace (P1) y punta levallois según Bordes (3). Por último analizamos una muesca en sílex masivo marrón, con talón puntiforme y la cara dorsal no cortical. Es un denticulado según Laplace (D21) y una muesca según Bordes (42).

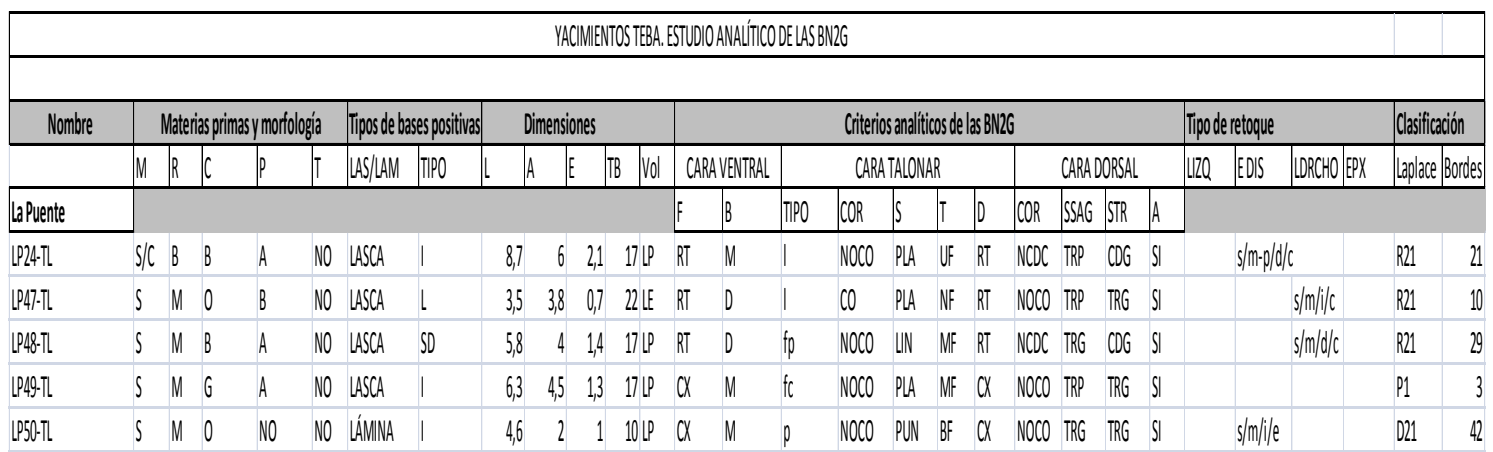

Tabla 42. Estudio analítico de las BN2G de La Puente.

. Valoración y conclusiones

El yacimiento se localiza en una zona de graveras donde afloran las areniscas compactas y en las inmediaciones del río Guadalteba, que aporta materias primas silíceas en tabletas desde los afloramientos geológicos ubicados en la cabecera del río.

En cuanto a la tecnología hay una utilización del sílex como materia prima, con bifaces sobre lascas y una presencia variada de núcleos y BP-D (descortezado) y BPSD (semidescortezado), mayor número de BP-I (internas) frente a BP-L (levallois) que tienen una escasa representación. En el grupo de los productos retocados o BN2G, nos encontramos con raederas, denticulados y puntas y con una industria que presenta un rodamiento medio en la gran mayoría de las piezas y de gran tamaño. El análisis de la industria lítica permite establecer una vinculación a nivel genérico dentro del Paleolítico inferior o modo II. 

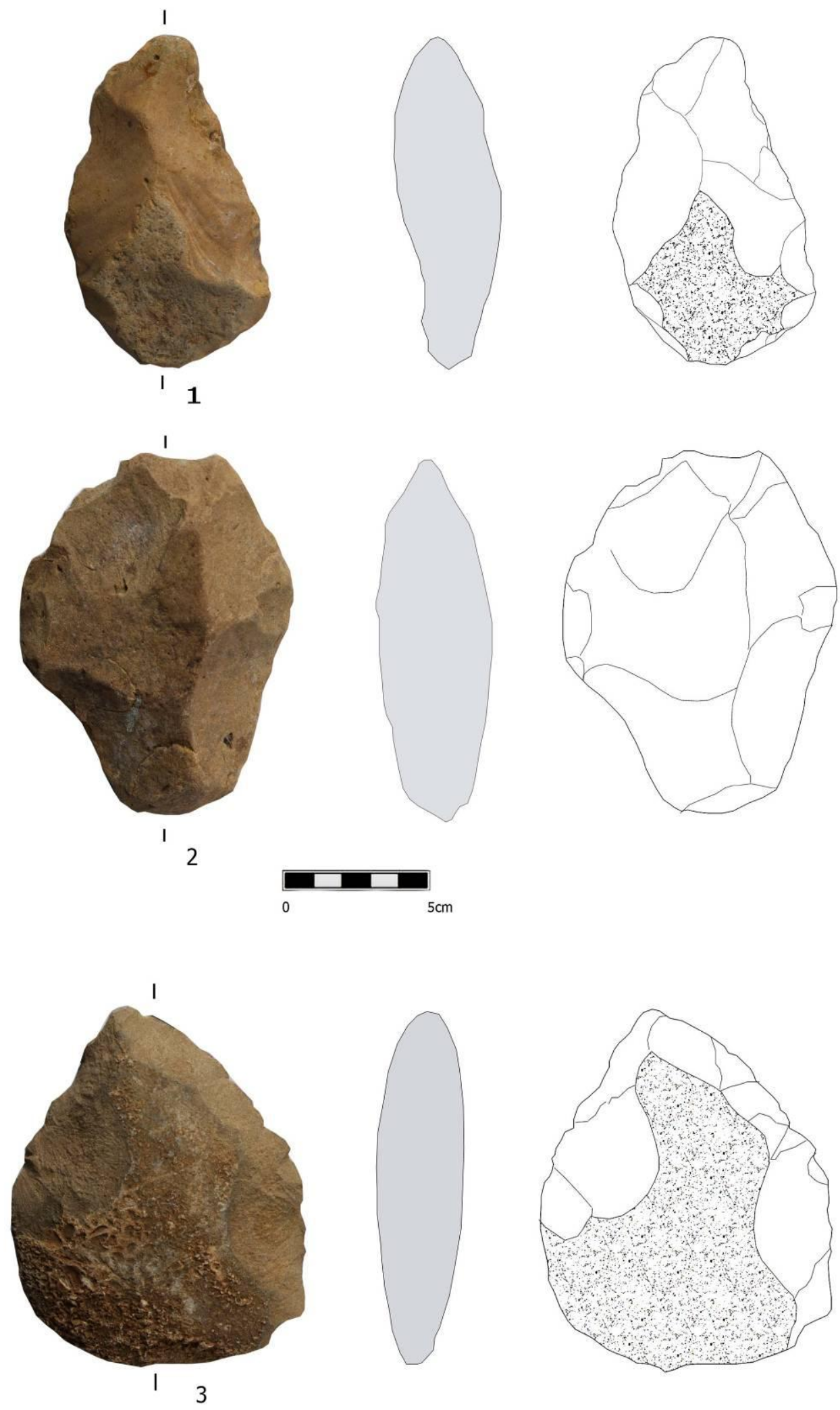

Figura 137. La Puente (Teba): 1, 2:BN1GC- Bifaces; 3: BP-Lasca de semidescortezado. 


\subsubsection{PEMA4 (Almargen)}

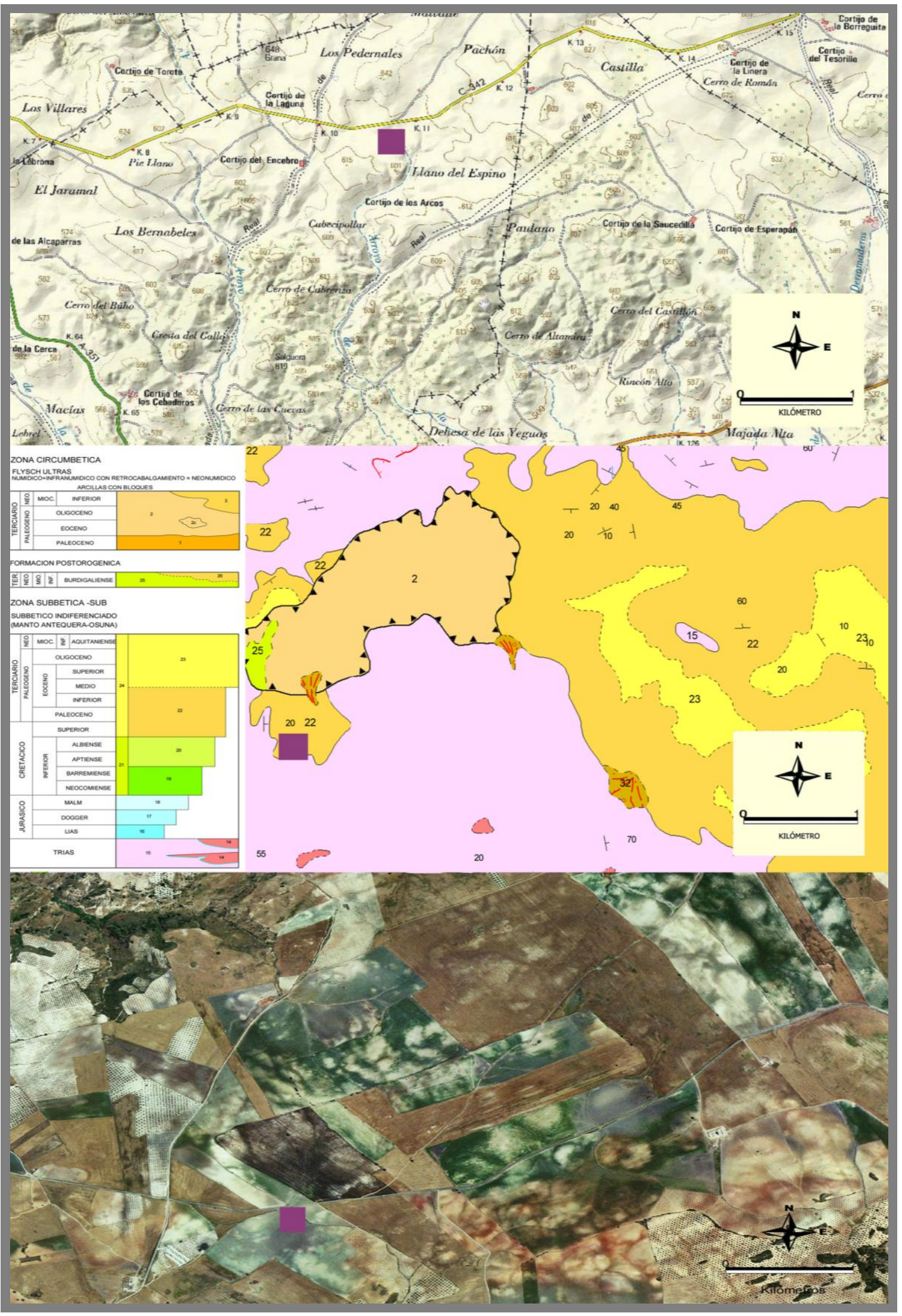


Se localiza en la zona baja de una ladera. Se accede desde el pueblo de Almargen a través de la cañada real de Ronda a Sevilla hasta enlazar con la carretera MA-6407 (carretera del Saucejo a Campillos), una vez allí coger dirección Campillos y recorrer un kilómetro y a la derecha de la carretera se encuentra el yacimiento.

Sus coordenadas UTM ETRS89 30 son:

\begin{tabular}{|c|c|}
\hline $\mathbf{X}$ & $\mathbf{Y}$ \\
\hline 321502 & 4101959 \\
\hline 321821 & 4101899 \\
\hline 321735 & 4101761 \\
\hline 321637 & 4101884 \\
\hline 321687 & 4102006 \\
\hline 321829 & 4101865 \\
\hline 321625 & 4101864 \\
\hline
\end{tabular}

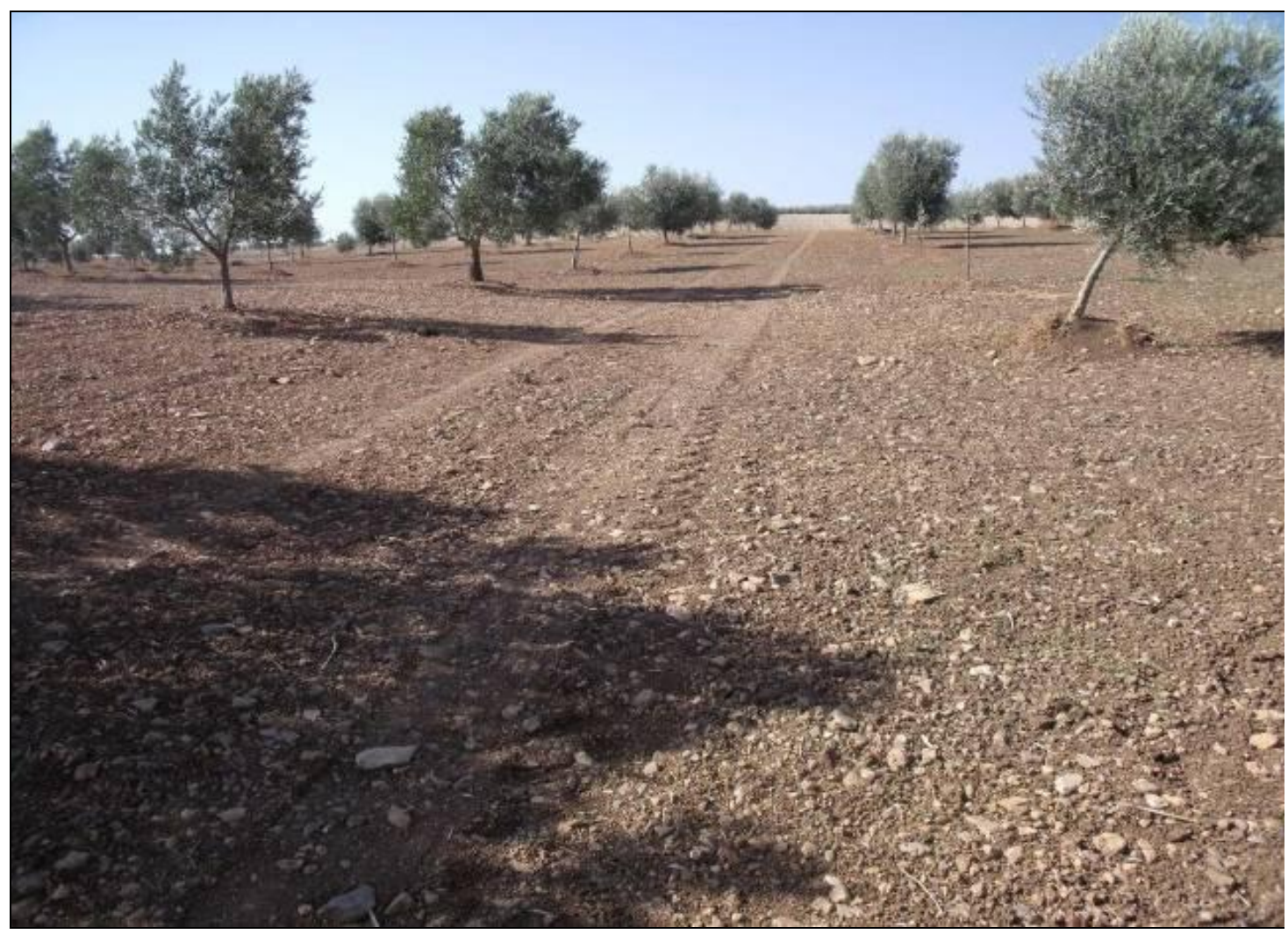

Figura 138. Vista general del yacimiento PEMA4.

Altitud m s.n.m.: $600 \mathrm{~m}$

Extensión: $37.500 \mathrm{~m}^{2}$ 


\section{. Contexto geológico y geomorfológico}

El yacimiento de desarrolla en un suelo formado sobre un estrato de margas y calizas del Triásico, con una fuerte erosión, sin cimentación o costras. Afloran gran cantidad de cantos y tabletas de sílex junto a margo calizas, calizas margosas y margas de color asalmonado y blanco del Cretácico superior-Luteciense medio pertenecientes al Subbético de Facies Keuper. Son materiales que descansan encima del Triásico, aflorando principalmente en la zona conocida como Los Barrancos y en el sector de Roman-Cerro de Quebrantaencinas.

\section{. Relación con red fluvial}

El yacimiento es atravesado por un arroyo, asociado a un arroyo principal, el de la Rana, que vierte sus aguas al río de Almargen subsidiario del río Guadalteba.

. Procesos sedimentarios y procesos postdeposicionales

Los procesos sedimentarios que afectan al yacimiento son ocasionados por los movimientos horizontales de las zonas más altas de las laderas circundantes, y del aporte de sedimentos por el arroyo que pasa justo al lado del yacimiento. Los procesos postdeposicionales que afectan principalmente al yacimiento se deben a la explotación extensiva de secano, como el olivar o el cereal y en menor medida por la acción del agua del arroyo que cruza el yacimiento. Uno de los procesos naturales que afecta al yacimiento es la reptación dado que en esta zona son muy frecuentes las heladas, que ocasionan el movimiento de los materiales por procesos de hielo y deshielo.

\section{. Interpretación geoarqueológica}

Es un yacimiento arqueológico que tiene como origen un abandono antrópico de los materiales líticos sobre la superficie. La utilización del arado y el cambio de cultivo de cereal a olivar ha generado continuos movimientos verticales de los materiales arqueológicos, a su vez las frecuentes arroyadas que se registran en la zona y el paso del arroyo de la Reina por el propio yacimiento ha generado la perdida y el arrastre de material hacia zonas más bajas.

\section{. Análisis de la industria lítica}

Los materiales analizados fueron localizados en el año 2013, durante la intervención arqueológica preventiva, bajo mi dirección, realizada a consecuencia de la construcción de un parque eólico en la zona de Almargen. El yacimiento arqueológico 
se localiza al aire libre y durante la recogida de material se establecieron dos zonas, cuyos materiales han sido separados y siglados de forma diferente, aunque estudiados de forma conjunta ya que presentan características similares y encuadrables dentro del Paleolítico medio.

Se han analizado un total de 165 ejemplares. La materia prima (figura 139) predominante es el sílex, mayoritariamente sílex oolítico, con 52 ejemplares, seguido de sílex poroso, con 7 ejemplares y sílex masivo con 6 ejemplares, seguido de radiolaritas rojas y verdes, 19 ejemplares en total y una muy reducida presencia de arenisca compacta y cuarcita, únicamente 2 y 3 ejemplares respectivamente.

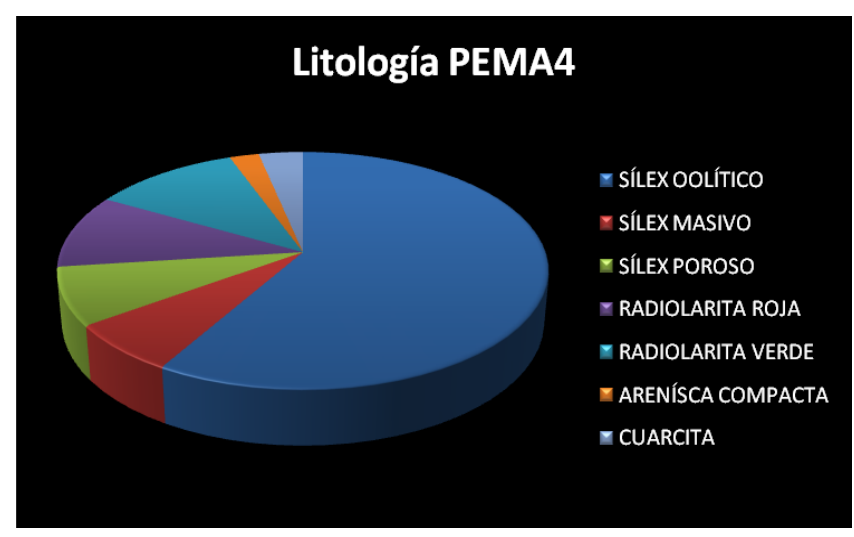

Figura 139. Materias primas de las piezas líticas recuperadas en el yacimiento PEMA4.

En cuanto al estudio morfotécnico existe una presencia de Bases Naturales de Primera Generación (BN1G) de Bases Positivas (BP) y Bases Negativas de Segunda Generación (BN2G).

Las BN1G (tabla 43) corresponden a 27 ejemplares en su mayoría de sílex masivos, algunos ejemplares de sílex oolítico y 2 radiolaritas, 1 ejemplar de cuarcita y 1 de arenisca compacta. Presentan un sistema de explotación variado, siendo mayor la presencia de núcleos diversos frente a centrípetos y poliédricos, hay además 2 ejemplares de talla unifacial y uno prismático. Presentan un carácter cortical casi completo de tipo 4C y 3C y un predominio de extracciones de ángulo abrupto y plano, (debido a que todos los ejemplares corresponden a sílex tabular), las longitudes de las extracciones son totales y profundos en la gran mayoría. En cuanto a la arista frontal predominan las convexas, frente a las rectas también presentes, la sagital es sinuosa en la mayoría. 


\begin{tabular}{|c|c|c|c|c|c|c|c|c|c|c|c|c|c|c|}
\hline \multicolumn{15}{|c|}{ YACIMIENTOS ALMARGEN. ESTUDIO ANALÍTICO DE LAS BN1G } \\
\hline \multirow{2}{*}{$\begin{array}{l}\text { Nombre } \\
\text { PEMA4 }\end{array}$} & \multicolumn{5}{|c|}{ Materias primas y morfología } & \multicolumn{2}{|c|}{ Tipos de bases negativas } & \multicolumn{6}{|c|}{ Criterios analíticos de las BN1G } & \multirow[t]{2}{*}{ Tema operativo técnico } \\
\hline & $M$ & $R$ & C & $\mathrm{P}$ & $T$ & TN & $\mathrm{BN}$ & CF & CC & $\mathrm{CO}$ & $\mathrm{CP}$ & CAF & CAS & \\
\hline PEMA4-00 & A & B & B & 0 & NO & B & BN1GC & B & $3 C$ & S & $\mathrm{m}$ & $\mathrm{CX}$ & $\sin$ & T.O.T.D \\
\hline PEMA4-01 & S & M & G & NO & NO & DIV & BN1GE & B & $3 C$ & $P$ & $p$ & RT & $\sin$ & T.O.T.I \\
\hline PEMA4-02 & $R$ & $M$ & 0 & NO & NO & DIV & BN1GE & $T$ & $4 C$ & $A / P$ & $\mathrm{mp}$ & $C X$ & $\sin$ & T.O.T.I \\
\hline PEMA4-03 & S & $M$ & G & NO & NO & DIV & BN1GE & $U$ & C & A & $\mathrm{m}$ & $C X$ & rt & T.O.T.I \\
\hline PEMA4-04 & S & $M$ & G & B & NO & DIV & BN1GE & B & $4 C$ & $A / P$ & $\mathrm{mp}$ & RT & inc & T.O.T.I \\
\hline PEMA4-05 & S & $M$ & G & NO & NO & DIV & BN1GE & $T$ & $4 C$ & A & $\mathrm{t}$ & $C X$ & $\sin$ & T.O.T.I \\
\hline PEMA4-06 & S & $M$ & G & NO & NO & DIV & BN1GE & B & $3 C$ & $A / P$ & $\mathrm{mp}$ & $C X$ & inc & T.O.T.I \\
\hline PEMA4-12 & S & $M$ & G & NO & NO & DIV & BN1GE & $U$ & $2 C$ & A & $\mathrm{mm}$ & $\mathrm{rt}$ & inc & T.O.T.I \\
\hline PEMA4-15 & S & $M$ & B & NO & NO & DIV & BN1GE & U & $2 C$ & A & $\mathrm{p}$ & RT & rt & T.O.T.I \\
\hline PEMA4-18 & S & B & G & B & NO & C & BN1GE & B & $3 C$ & S/SA & $p$ & $C x$ & $\sin$ & T.O.T.I \\
\hline PEMA4-30 & S & B & G & B & NO & C & BN1GE & $U$ & $3 C$ & $S / S A$ & $\mathrm{mp}$ & $C X$ & $\sin$ & T.O.T.I \\
\hline PEMA4-36 & S & B & G & A & NO & C & BN1GE & $U$ & $4 C$ & S/A & $\mathrm{t}$ & $C X$ & $\sin$ & T.O.T.I \\
\hline PEMA4-47 & S & B & G & B & NO & $\mathrm{C} / \mathrm{SL}$ & BN1GE & $U$ & $4 C$ & $P$ & $\mathrm{t}$ & $C X$ & rt & T.O.T.I \\
\hline PEMA4-50 & S & $M$ & B & NO & NO & B & BN1GE & B & $3 C$ & SP & $p$ & $C X$ & $\sin$ & T.O.T.I \\
\hline \multicolumn{15}{|l|}{ PEMA4* } \\
\hline PEMA4-2* & $R$ & $M$ & $R$ & B & NO & C & BN1GE & B & $4 C$ & S & $t$ & $C X$ & $\sin$ & T.O.T.I \\
\hline PEMA4-3* & S & $M$ & G & A & NO & $\mathrm{POL}$ & BN1GE & $\mathrm{T}$ & $4 C$ & A & $\mathrm{t}$ & $C X$ & $\sin$ & T.O.T.I \\
\hline PEMA4-4* & S & $M$ & B & NO & NO & $\mathrm{POL}$ & BN1GE & B & $3 C$ & $A / P$ & $\mathrm{~m} / \mathrm{t}$ & $C X$ & inc & T.O.T.I \\
\hline PEMA4-5* & S & $M$ & G & A & NO & DIV & BN1GE & $T$ & $4 C$ & A & $\mathrm{t}$ & $C X$ & inc & T.O.T.I \\
\hline PEMA4-6* & S & $M$ & G & B & NO & $C$ & BN1GE & B & $4 C$ & $\mathrm{SA} / \mathrm{S}$ & $\mathrm{t}$ & $c x$ & $\sin$ & T.O.T.I \\
\hline PEMA4-8* & S & $M$ & G & NO & NO & DIV & BN1GE & $\mathrm{T}$ & $4 C$ & A & $\mathrm{t}$ & $C X$ & $\sin$ & T.O.T.I \\
\hline PEMA4-9* & S & $M$ & G & B & NO & $\mathrm{POL}$ & BN1GE & B & $3 C$ & $A / P$ & $\mathrm{~mm}$ & RT & rt & T.O.T.I \\
\hline PEMA4-10* & $\mathrm{CU}$ & $M$ & $R$ & NO & NO & $U$ & BN1GE & B & $4 C$ & $A / P$ & $\mathrm{t}$ & $C X$ & $\sin$ & T.O.T.I \\
\hline PEMA4-12* & S & $M$ & G & B & NO & $\mathrm{POL}$ & BN1GE & B & $3 C$ & $A / P$ & $\mathrm{mp}$ & $C X$ & inc & T.O.T.I \\
\hline PEMA4-13* & S & $M$ & G & B & NO & $\mathrm{POL}$ & BN1GE & $T$ & $4 C$ & A & $\mathrm{t}$ & RT & $\mathrm{rt}$ & T.O.T.I \\
\hline PEMA4-18* & S & $M$ & G & A & NO & POL & BN1GE & B & $4 C$ & $\mathrm{~A} / \mathrm{S}$ & $\mathrm{t}$ & $C X$ & inc & T.O.T.I \\
\hline PEMA4-23* & S & $M$ & G & B & NO & C & BN1GE & B & $4 C$ & $P$ & $\mathrm{t}$ & $C X$ & $\sin$ & T.O.T.I \\
\hline PEMA4-31* & S & $M$ & G & NO & NO & C & BN1GE & B & $4 C$ & S & $t / m p$ & $c x$ & $\sin$ & T.O.T.I \\
\hline
\end{tabular}

Tabla 43. Estudio analítico de las BN1G de PEMA4.

Las BP (tabla 44) presentan un predominio mayoritario de lascas. Todas muestran pátinas de color amarillo o blancas, con un rodamiento medio y algunos ejemplares muy rodados. Se han documentado ejemplares de BP-D (descortezado) BPSD (semidescortezado), I (internas) y BP-L (levallois). En cuanto al volumen, el rasgo mayoritario de todas ellas es el LP (largo plano) con un porcentaje también elevado de EP (espeso plano). La delineación desde la cara ventral es variada estando presentes los tres caracteres utilizados (recto, cóncavo y convexo) muestra un talón convexo en todas las piezas y un bulbo marcado en dos de ellas. Muestran talones lisos y facetados en casi todos los ejemplares y una presencia muy escasa de los puntiformes, únicamente presentes en 8 ejemplares, hay un predominio de talones no corticales frente a no cortical dominante cortical y superficies en plataforma y lineales, unifacetados en la mayoría junto con multifacetados. Las caras dorsales son no corticales en casi todos los ejemplares. 


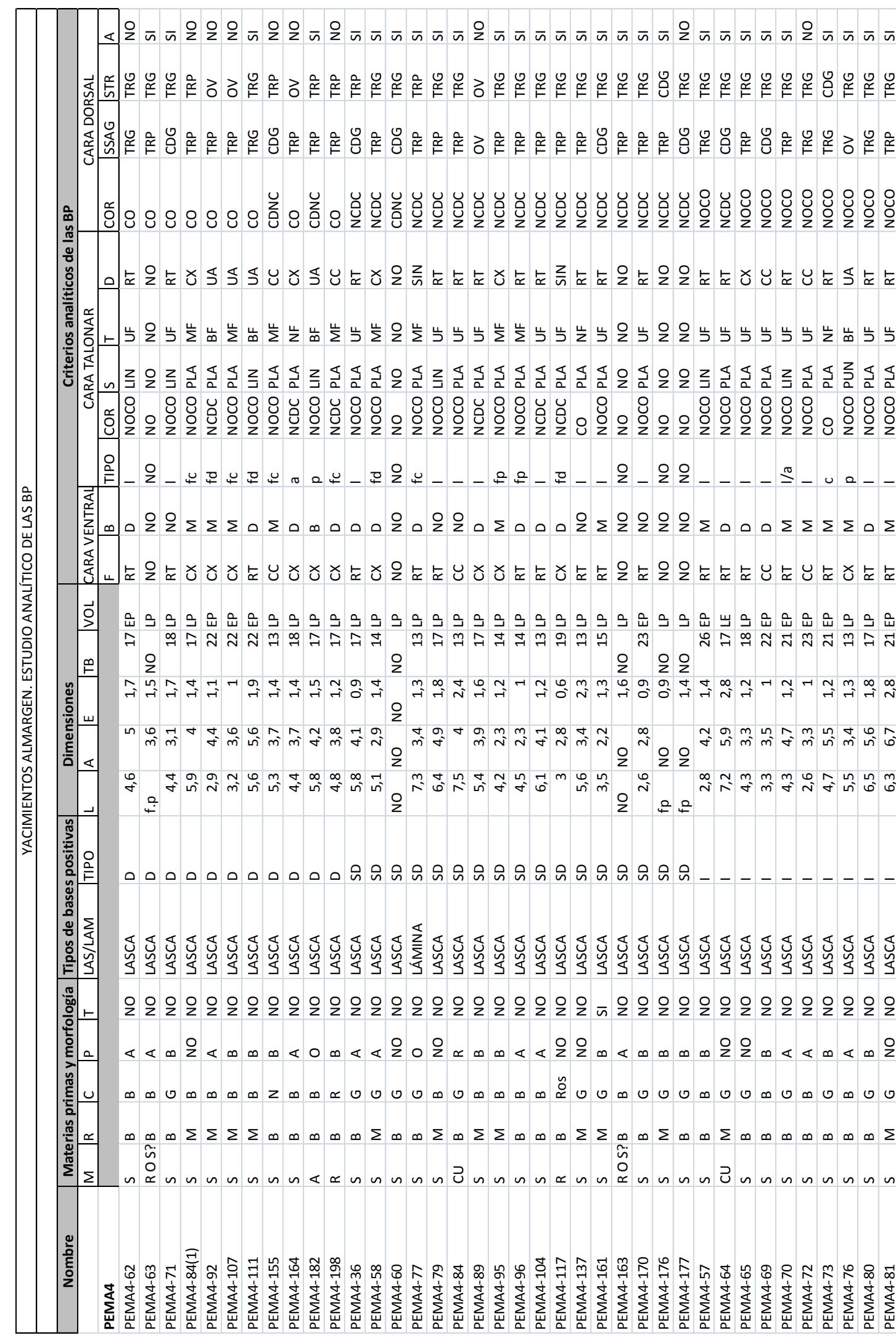




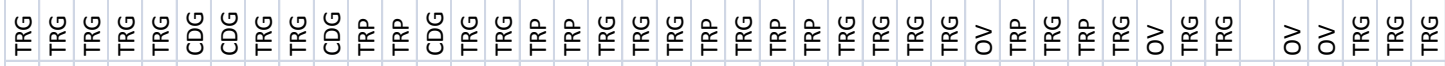

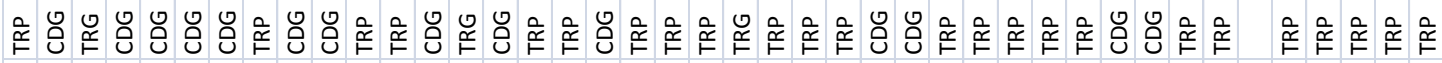
ơ

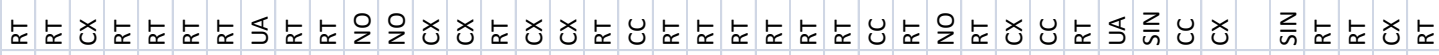

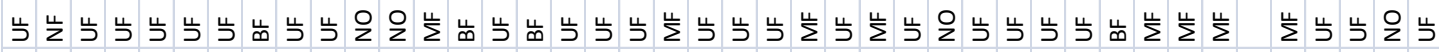

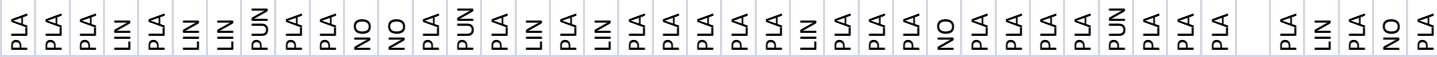
ơ ४

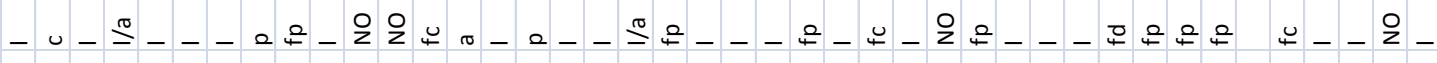

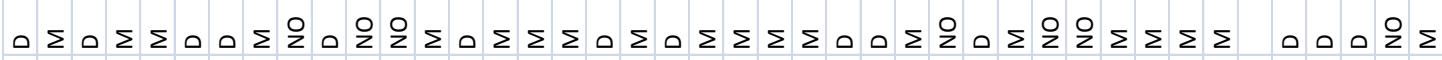

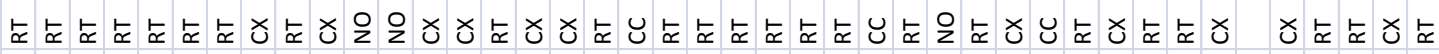

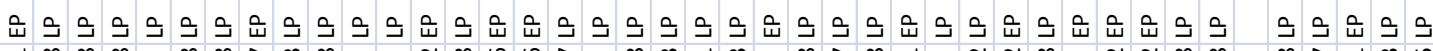

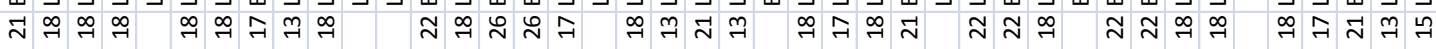

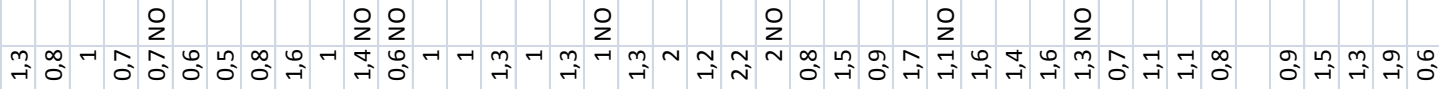

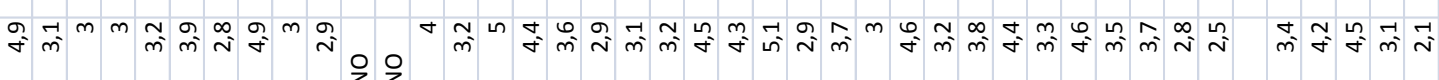

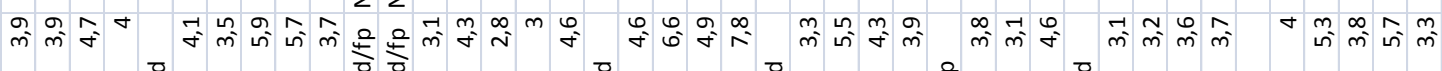

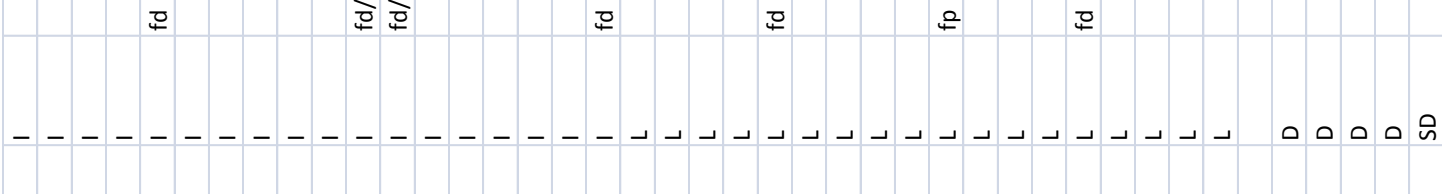

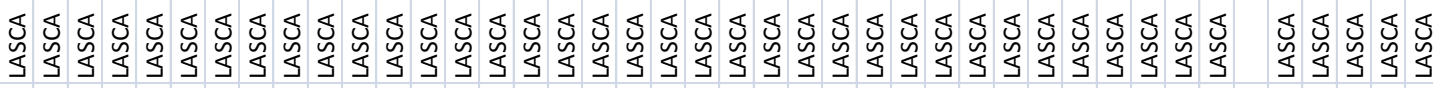

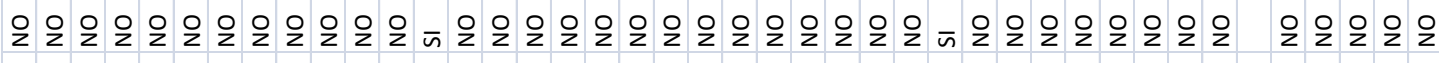

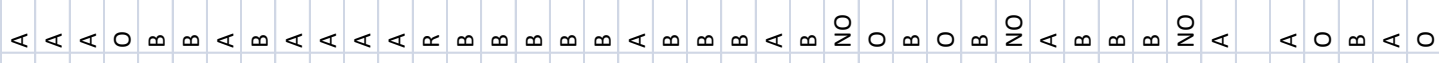
○

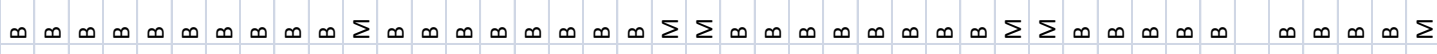

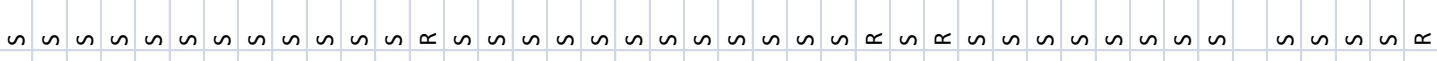

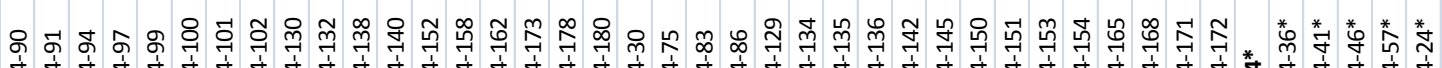

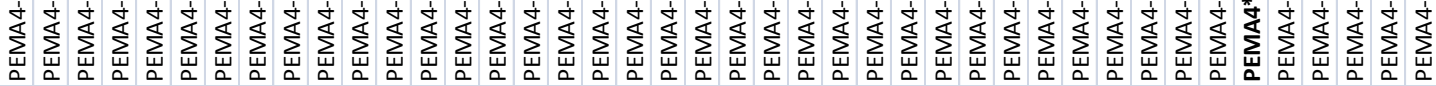




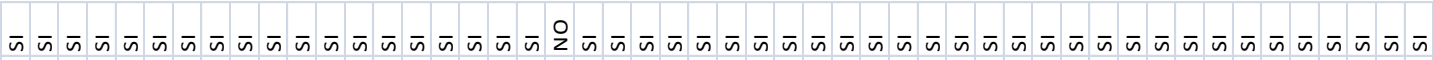

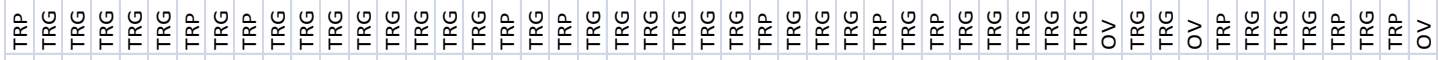

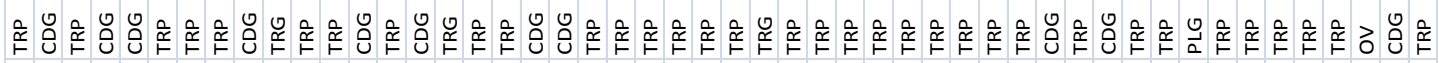

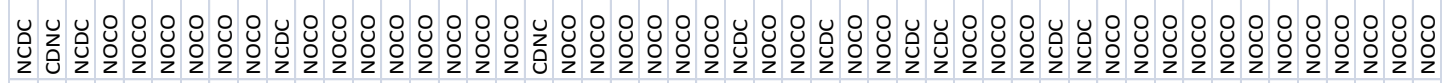

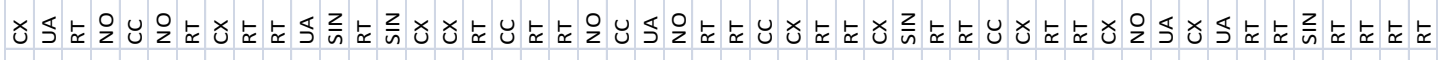

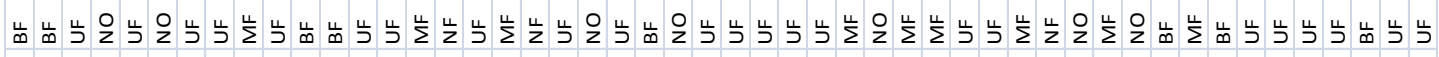

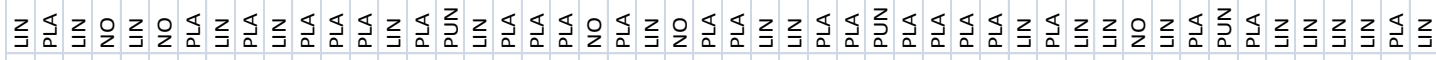

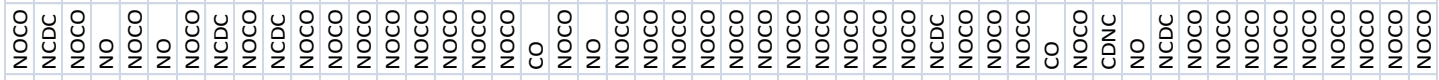

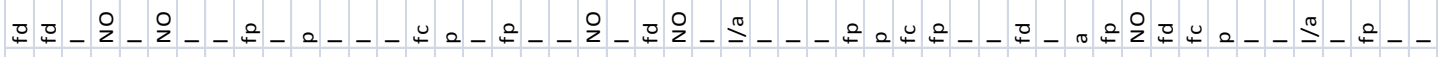

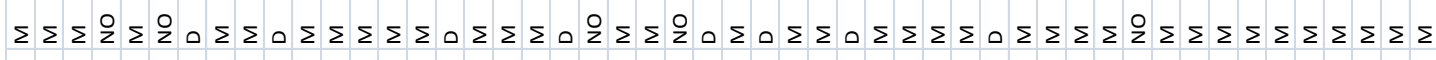

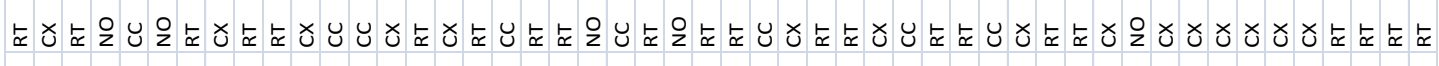
ษัง ง

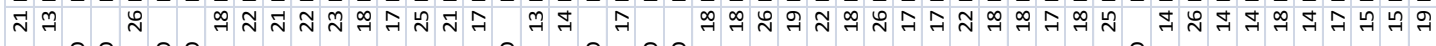

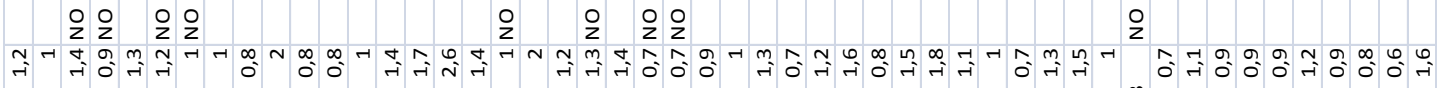
fं

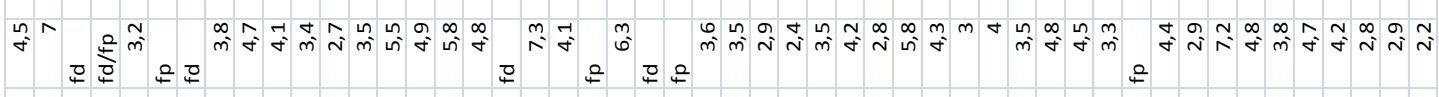
ถั ถิำ

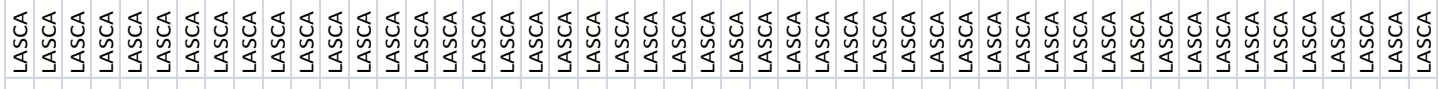

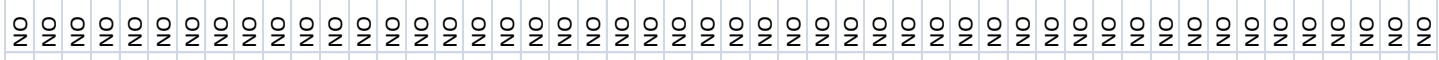

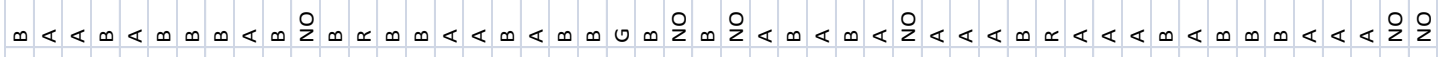

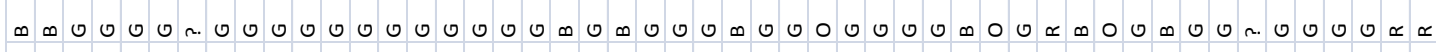

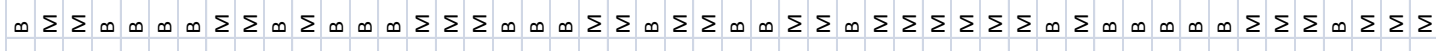

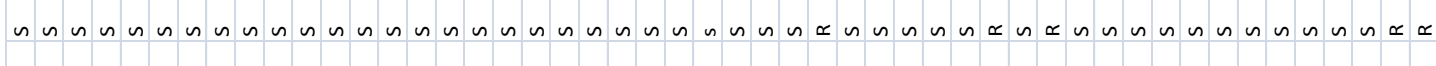

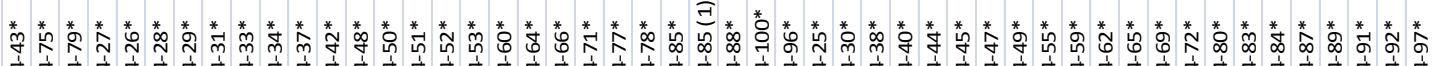

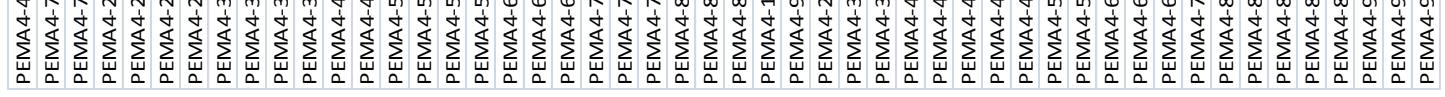

Tabla 44. Estudio analítico de las BP de PEMA4. 
Las BN2G (tabla 45) constituyen 10 ejemplares del total, 5 en sílex masivo, 4 en radiolarita verde y 1 en radiolarita roja. La nomenclatura utilizada para su clasificación ha sido la del sistema tipológico de Laplace (Laplace, 1972) y los de la Lista-Tipo Bordes (Bordes, 1961).

Uno de los ejemplares es una lasca truncada realizada sobre una lasca levallois. Con un volumen de tipo LP (largo plano), la delineación del talón desde la cara ventral es recta y el bulbo marcado. La cara talonar presenta un talón liso, no cortical, en plataforma y unifacetado. La cara dorsal es no cortical. En relación al tipo de retoque, este se encuentra en el extremo distal y es abrupto, profundo, directo y denticulado. Se trata de una truncadura según Laplace (T21) y una lasca truncada según Bordes (40).

Tres ejemplares corresponden a raspadores, realizados dos de ellos sobre dos lascas internas y el otro sobre una lasca levallois. Se trata de dos raspadores frontales simple, uno de ellos con retoque lateral (G11 y G12) según Laplace y (30) según Bordes, y un raspador denticulado (D25) según Laplace y (43) según Bordes.

También hay un perforador, sobre una lasca de semidescortezado en radiolarita verde, con un volumen LP (largo-plano), con los retoques en el extremo distal de tipo abrupto, marginal, inverso y continuo, enmarcado dentro de los perforadores rectos según Laplace (BC2) y perforador según Bordes (34). Aparece una muesca realizada sobre una lasca interna de radiolarita verde, con un volumen EP (espeso plano) y el retoque abrupto, profundo y directo en el lateral izquierdo.

Dentro del conjunto de BN2G, también hay una punta pseudo-levallois o punta musteriense desviada, con el eje de la pieza oblicua según Laplace (P1) y (5) según Bordes, realizada sobre una lasca levallois de radiolarita roja, con presencia de retoques simples y marginales y bifaciales en el lateral izquierdo y el lateral derecho.

Por último, hay 3 raederas: dos en radiolarita verde y una en sílex masivo marrón, una realizada sobre una lasca de semidescortezado y dos de ellas realizadas sobre una lasca levallois. Los talones son facetados diedros y en plataforma en 2 ejemplares y liso y lineal en uno. El retoque es variable en los 3 ejemplares, en una de ellas, la de semidescortezado, es simple, marginal, directo y continuo y se localiza en el lateral izquierdo se clasifica como raedera lateral (R21) o raedera simple convexa (10), otra de ellas está realizada sobre sílex masivo marrón, y presenta un retoque plano, profundo, inverso y continuo y se trataría de una raedera lateral (R21) o una raedera sobre cara plana (25). Sobre el último ejemplar que queda, presenta un retoque simple, 
marginal, inverso y continuo, se trata de una raedera simple cóncava $(\mathrm{R} 1)$ o raedera de retoque marginal (11).

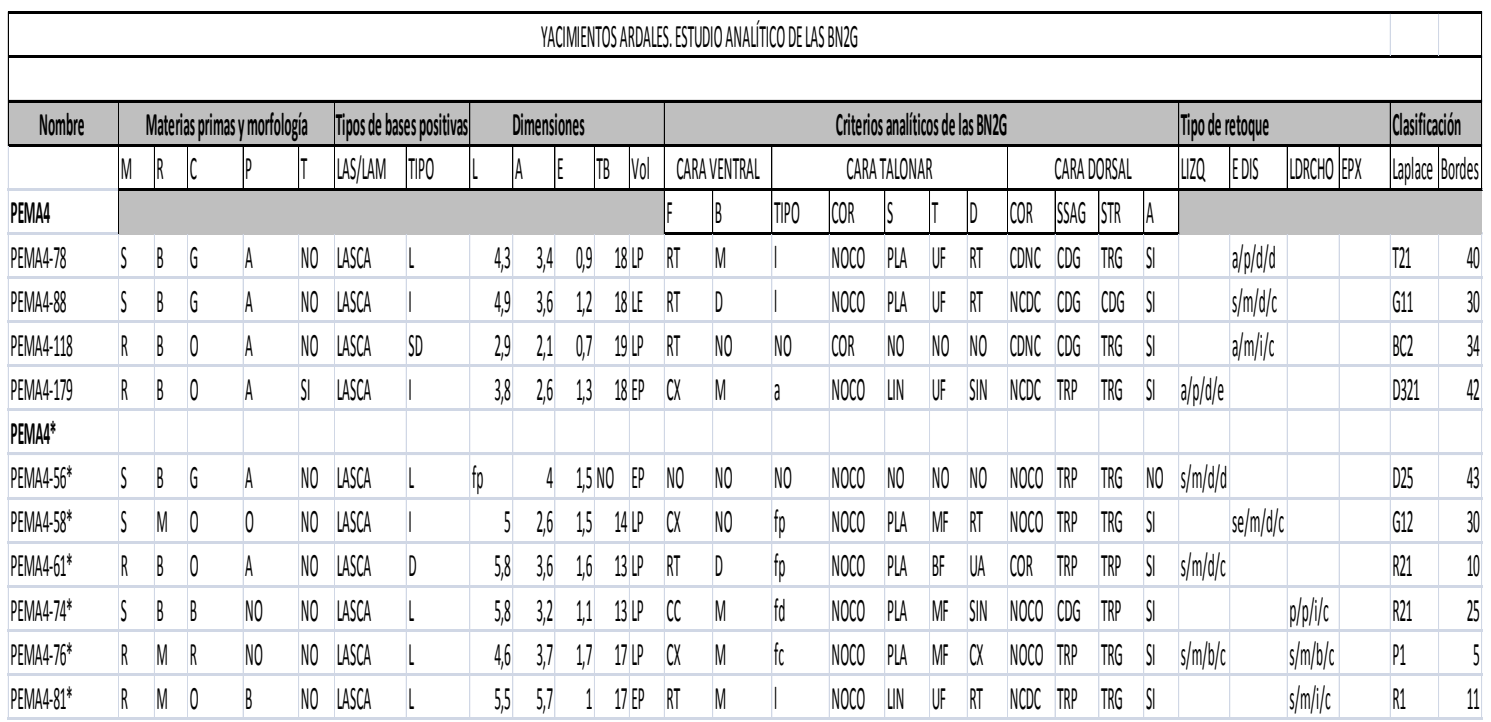

Tabla 45. Estudio analítico de las BN2G de PEMA4.

- Valoración y conclusiones

Se localiza en una ladera y en una zona con abundantes afloramientos de sílex y radiolaritas verdes y rojas, a no más de $8 \mathrm{~km}$, y situado a pocos kilómetros de un nacimiento de agua lo que facilitaría la utilización de este espacio por grupos humanos del Paleolítico, tanto para la talla como lugar de hábitat.

Los procesos postdeposicionales son sobre todo antrópicos, causados en su mayor parte por la acción de los arados junto con los cambios de cultivo, y dificulta en gran medida la compresión del yacimiento, ya que estas acciones han ocasionado la mezcla de materiales arqueológicos. Además hemos comprobado como en algunas piezas con un alto grado de rodamiento y con pátina se han realizado nuevos retoques originados por una utilización posterior, indicativo de una reutilización de este espacio y del material lítico más antiguo, sin embargo al ser muy pocas piezas las que presentan esta reutilización, el análisis de las mismas se ha realizado en función de su estado más antiguo. En cuanto a la tecnología destacamos una presencia mayoritaria de lascas, con presencia de BP-SD (semidescortezado), de BP-I (internas) y BP-L (levallois) dentro de las $\mathrm{BN} 2 \mathrm{G}$, nos encontramos con raederas, raspadores, una punta pseudolevallois asociada a núcleos discoides, un perforador y una lasca truncada. 
La muestra arqueológica analizada evidencia una actividad importante en zonas limítrofes a las cuenca principal, en este caso el Guadalteba y muy vinculadas a los afloramientos silíceos que están presentes en el propio yacimiento y en una extensión importante de kilómetros, a diferencia de lo que ocurre en los otros yacimientos analizados en este trabajo, la presencia de radiolarita termoalterada es innexistente si lo comparamos con el resto. Por el análisis de los materiales arqueológicos y por características como la pátina, el rodamiento o la materia prima utilizada se desprende que nos encontramos con un yacimiento del Paleolítico medio o Modo II a nivel genérico, donde la presencia de núcleos de talla diversa es mayoritaria, frente a los de talla centrípeta o poliédrico, con un único ejemplar de talla discoide, quizás relacionado con la forma de afloramiento de la materia prima en la zona, ya que aparece tableada, de ahí que los núcleos hallados en el yacimiento sean en su mayoría con retoques abruptos.

Importante mencionar el elevado número de piezas sobre todo lascas fabricadas en sílex oolítico, por el momento es el único yacimiento estudiado con una fuerte presencia de sílex de este tipo, al igual que los ejemplares de radiolarita verde y roja, para estas últimas tenemos localizado un posible lugar de aprovisionamiento a no más de $5 \mathrm{~km}$ de distancia, denominado Los Pedernales y donde aparece los mismos tipos de radiolaritas que las localizadas en el yacimiento, sin embargo no se descartan otros posibles lugares de aprovisionamiento cercanos, pero que por el momento no hemos localizado. 


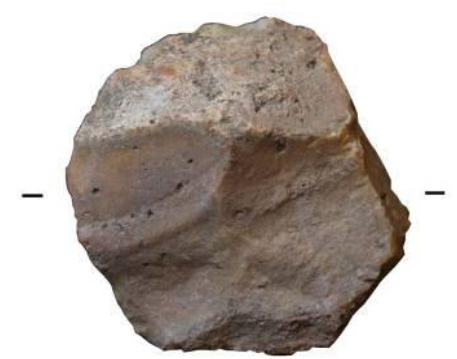

1

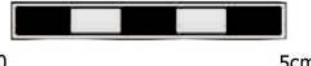

0

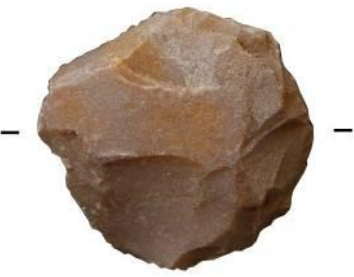

2

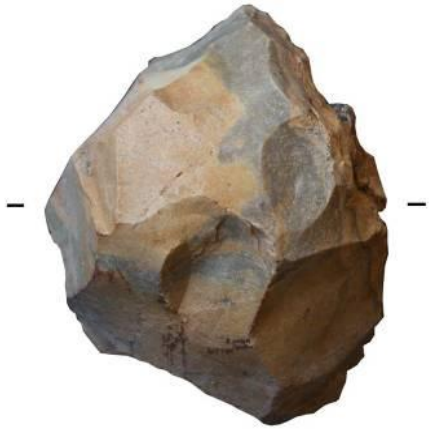

3

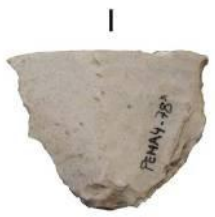

I

4
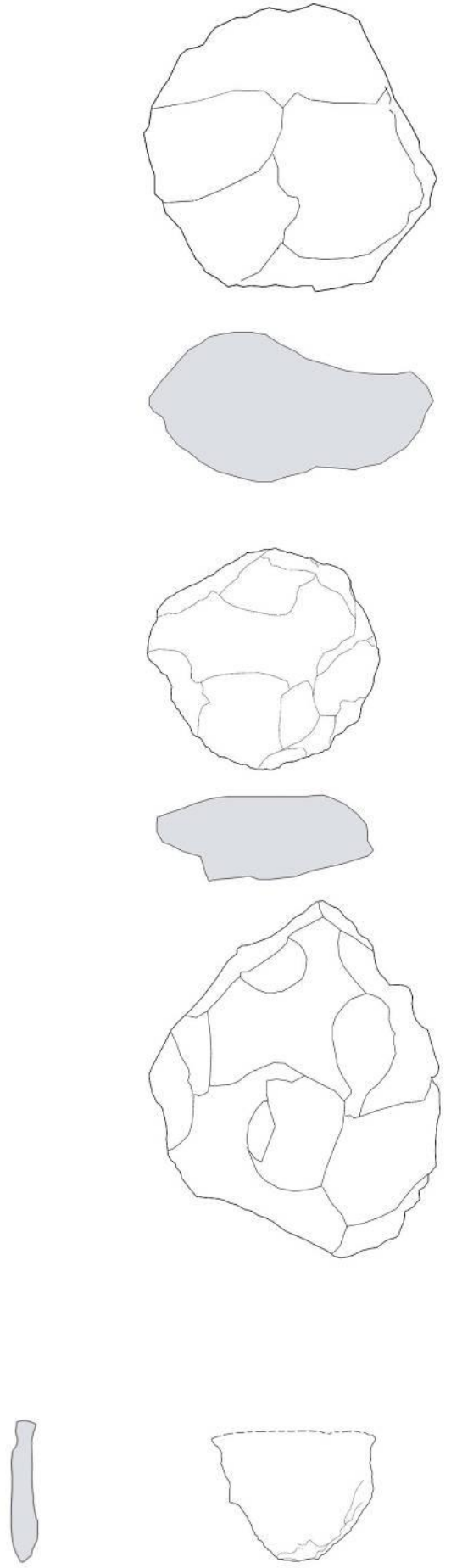

Figura 140. PEMA4 (Almargen): 1, 2, 3:BN1G- núcleos centrípeto y poliedrico; 4: BP-Lasca de interna. 

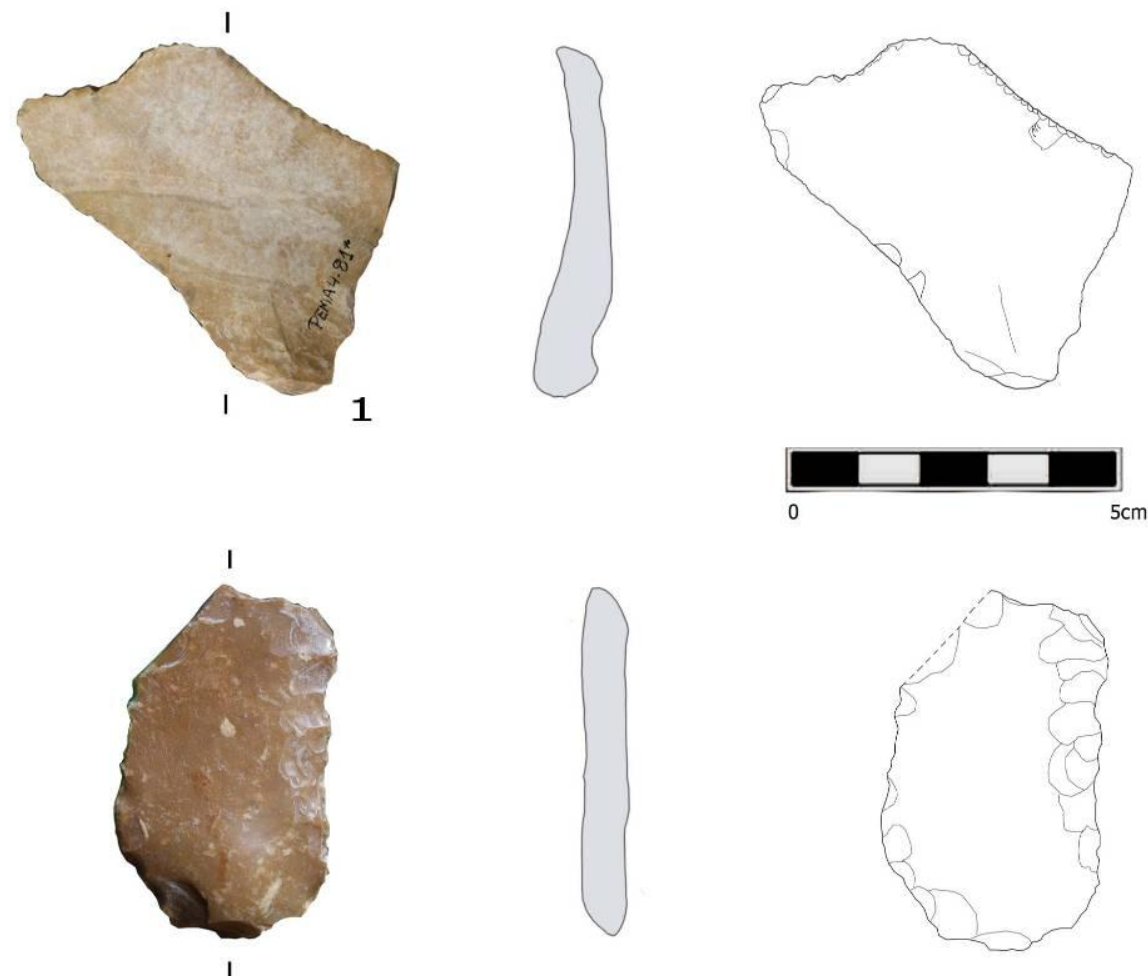

2
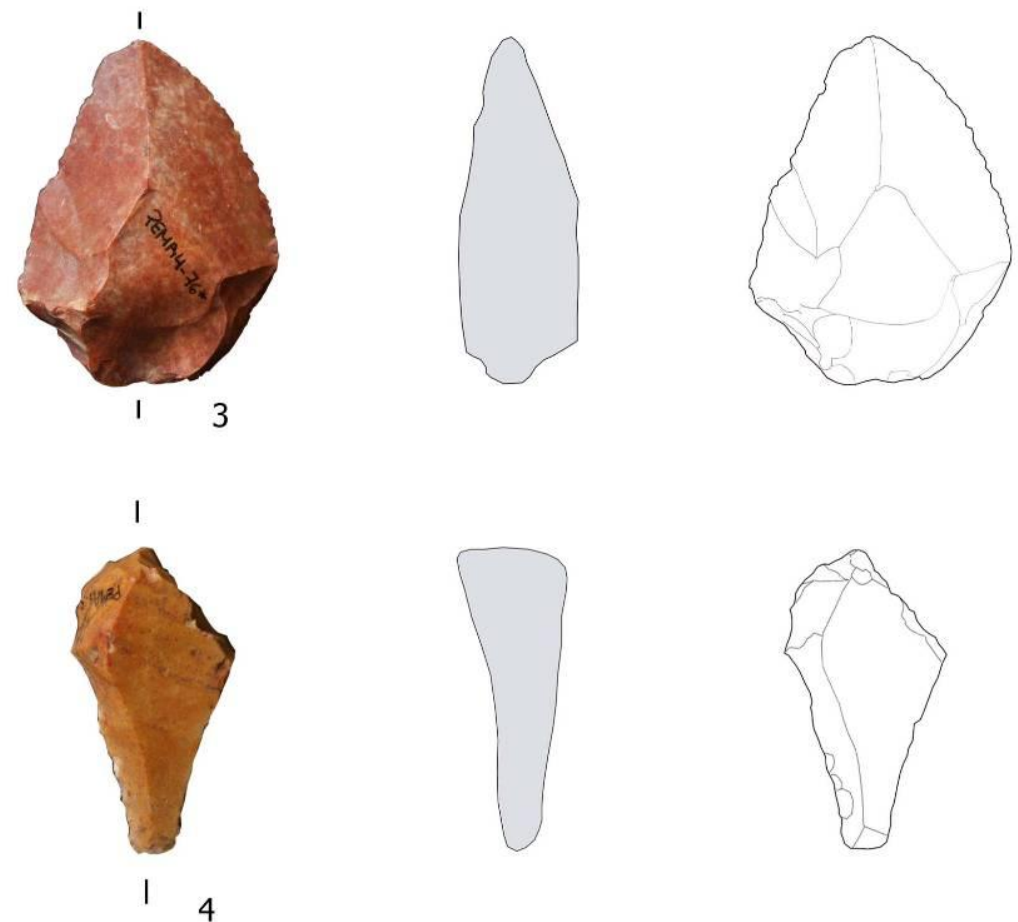

4

Figura 141. PEMA4 (Almargen): BN2G: 1, 2: Raederas; 3: Punta levallois; 4: Raspador. 


\subsubsection{Hallazgos aislados}

Incluimos en este apartado los dos bifaces localizados de forma fortuita en Teba y Cañete la Real. Únicamente el bifaz de Fuentepeones (Cañete la Real) cuenta con una ubicación exacta con coordenadas UTM.

La localización de ambos bifaces en el entorno de un manantial, hace plantearnos, la posibilidad de una caza oportunista de animales en el momento que estos acudían a beber, aprovechando las zonas de piedemonte y las depresiones de las zonas del interior, para el oteo de los grandes mamíferos.

\subsection{Bifaz de Nina Alta (Teba).}

El bifaz fue hallado por D. Francisco Guerrero Moreno, en el paraje de Nina Alta, entre las sierras de Almargen y la de Malandrejo (Cañete la Real). Se desconoce el lugar exacto de su localización y no disponemos de sus coordenadas exactas.

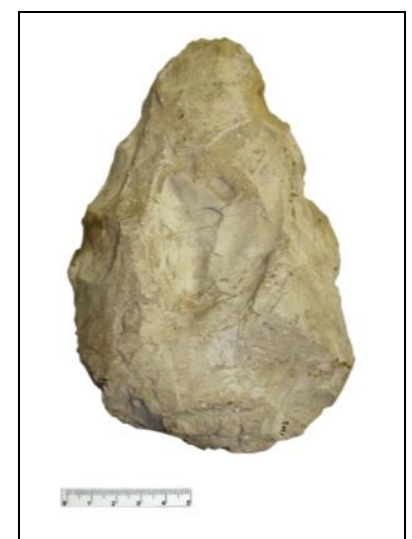

Figura 142. Bifaz de Nina Alta.

La materia prima es un sílex masivo beige con pátina blanca y ligeramente rodado. Según el estudio morfotécnico (tabla 46) corresponde a una BN1GC, con un carácter facial de tipo bifacial y un carácter centrípeto completo de tipo $4 \mathrm{C}$, cuyas extracciones son de tipo simple y semiabrupto. La arista frontal es convexa y la sagital sinuosa. Según la tipología de Bordes (Bordes, 1961) podría clasificarse como un bifaz oval.

HALLAZGO AISLADO TEBA. ESTUDIO ANALÍTICO DE LAS BN1G

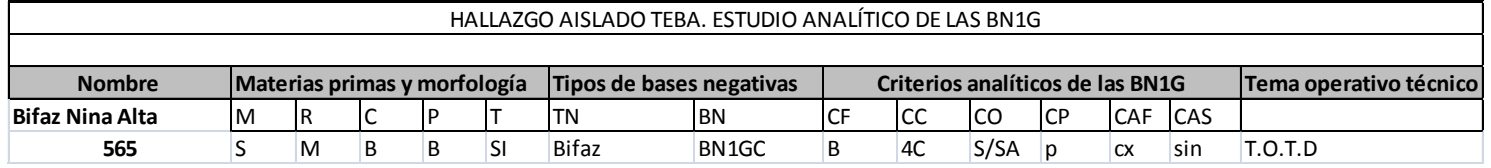

Tabla 46. Estudio analítico BN1G de Nina Alta. 


\subsection{Bifaz de Fuentepeones (Cañete la Real).}

Se localizó en las proximidades de la sierra de la Cabezuela (Cañete la Real) en las casas de Fuentepeones. La pieza proviene de un hallazgo casual, en las cercanías del cortijo de Fuentepeones (Cañete la Real) por D. Antonio Aranda Cruces, el cual la cedió al Centro de Interpretación "Los Vigías del Territorio" instalado en el castillo de Cañete la Real. El enclave donde apareció la pieza se encuentra a una cota sobre el nivel del mar de 675 m, en una zona de piedemonte que precede a la Sierra de Cañete. En la zona se ubica un manantial de agua del cual se abastece en parte el municipio de Cañete la Real.

\begin{tabular}{|c|c|}
\hline $\mathbf{X}$ & $\mathbf{Y}$ \\
\hline 318390 & 4087430 \\
\hline
\end{tabular}

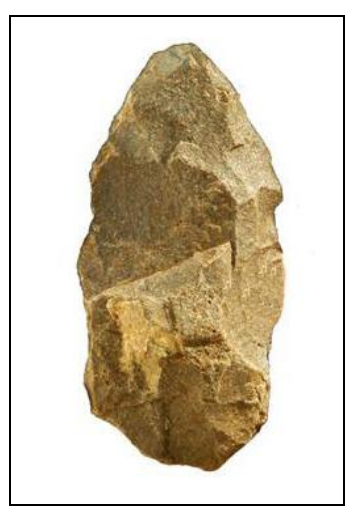

Figura 143. Bifaz de Fuentepeones.

La materia prima es la arenisca compacta. Su conservación es buena, aunque presenta algunos desconchados en la zona de filo cortante producto del rodamiento y presiones naturales. La pátina que recubre la pieza es uniforme en todo el utensilio.

El bifaz de Fuentepeones (tabla 47) tiene una talla bifacial y un carácter centrípeto completo o $4 \mathrm{C}$, con unas extracciones de tipo simple y semiabrupto, con un carácter de profundidad, muy profundo. La arista frontal es convexa mientras que la sagital es sinuosa. Según la tipología de Bordes (Bordes, 1961) podría clasificarse dentro del grupo III, o cordiforme alargado.

HALLAZGO AISLADO CAÑETE LA REAL. ESTUDIO ANALÍTICO DE LAS BN1G

\begin{tabular}{|c|c|c|c|c|c|c|c|c|c|c|c|c|c|c|}
\hline \multicolumn{15}{|c|}{ HALLAZGO AISLADO CAÑETE LA REAL. ESTUDIO ANALÍTICO DE LAS BN1G } \\
\hline \multirow[t]{2}{*}{ Nombre } & \multicolumn{5}{|c|}{ Materias primas y morfología } & \multicolumn{2}{|c|}{ Tipos de bases negativas } & \multicolumn{6}{|c|}{ Criterios analíticos de las BN1G } & \multirow[t]{2}{*}{ Tema operativo técnico } \\
\hline & $M$ & $\mathrm{R}$ & C & $\mathrm{P}$ & $\mathrm{T}$ & TN & $\mathrm{BN}$ & CF & CC & $\mathrm{CO}$ & CP & CAF & CAS & \\
\hline Bifaz Fuentepeones & A & $M$ & B & A & NO & Bifaz & BN1GC & B & $4 C$ & S/SA & $\mathrm{mp}$ & $c x$ & $\sin$ & T.O.T.D \\
\hline
\end{tabular}

Tabla 47. Estudio analítico BN1G de Fuentepeones. 


\section{Resultados}

La caracterización de los materiales líticos sirve para la comprensión de los patrones de movilidad y aprovisionamiento, dado que nos permite localizar las áreas de procedencia e interpretar su desplazamiento y de ese modo poder establecer la movilidad de las sociedades humanas de cazadores recolectores en un territorio determinado (Mangado Llach, 2006: 81).

Para conseguir este objetivo nos hemos servido de los muestreos geoarqueológicos que realizamos entre los años 2011-2014, del análisis de los materiales recogidos, a través de su caracterización arqueométrica, con la elaboración de láminas delgadas del material geológico y arqueológico y de las prospecciones arqueológicas superficiales en las cuencas del río Turón y Guadalteba que se iniciadas a finales del verano de 2015.

Así, los resultados obtenidos a través de nuestro estudio han permitido interpretar los patrones de asentamiento de los grupos humanos del Paleolítico a partir de las áreas de captación de las materias primas y la posible movilidad de estos grupos, en el área de estudio.

\subsection{Valoración de la prospección}

Con anterioridad a los trabajos de campo establecimos como sectores de prospección selectiva los yacimientos descritos en los planeamientos urbanísticos de la zona de estudio, con el fin de constatar la adscripción cronológica de los enclaves prehistóricos. Así mismo, las zonas no prospectadas fueron objeto de una prospección intensiva, centrándonos en los entornos fluviales y en los hitos geográficos susceptibles de ocupación durante la Prehistoria en función de las estrategias de distribución territorial de las sociedades cazadoras-recolectoras.

En el marco del Proyecto General de Investigación: Las sociedades prehistóricas (del Paleolítico medio al Neolítico final) en la Cueva de Ardales y Sima de Las Palomas de Teba (Málaga). Estudio geoarqueológico, cronológico y medioambiental, aprobado en junio de 2015, se autorizaron dos prospecciones arqueológicas, la del río Turón, bajo mi dirección, con un área a prospectar de 106 km² y la del río Guadalteba dirigidas por Serafín Becerra, con una superficie de prospección de $200 \mathrm{~km}^{2}$. 
Las prospecciones arqueológicas se iniciaron a finales de agosto de 2015, con una duración prevista de unos 2-3 meses, coincidiendo con el inicio de las excavaciones arqueológicas en la Cueva de Ardales y Sima de Las Palomas, también estudiadas en este trabajo. Es por esta circunstancia por la que los resultados de la prospección arqueológica superficial aquí expuestos son preliminares, dado que el número de localizaciones paleolíticas con las que contamos hasta el momento, podría verse alterado al finalizar los trabajos de prospección arqueológica.

Durante los trabajos de prospección se localizó un yacimiento del Paleolítico inferior o Modo II en la cuenca del Guadalteba, que fue denominado como La Puente. El yacimiento fue localizado en una zona de graveras, a pocos metros del río Guadalteba y presenta material arqueológico en superficie. Igualmente en la cuenca del Turón, a pocos kilómetros del pueblo de Ardales se documentó un depósito cuaternario con materiales arqueológicos dentro del paquete sedimentario, que denominamos depósito del Hundilón y cuyo material arqueológico presenta una asociación a industrias del Paleolítico medio o Modo III.

Con estos dos hallazgos el estudio del Paleolítico se ha centrado en 15 yacimientos, 13 al aire libre o en superficie y 2 en cuevas y con estratigrafía.

La continuidad de los trabajos de prospección establecerá una visión más completa del poblamiento humano vinculado a las cuencas del río Turón y Guadalteba y permitirá una mejor interpretación de la movilidad de estos grupos humanos durante el Pleistoceno.

\subsection{Estudio de las colecciones líticas}

Se han estudiado un total de 15 yacimientos arqueológicos, 10 de ellos vinculados al bajo Turón y 5 al bajo Guadalteba.

La selección de la industria lítica de los yacimientos ya conocidos y con atribuciones, algunos de ellos, a la Prehistoria reciente ha estado en función de ciertos caracteres como la pátina o el rodamiento. Las industrias asociadas al Paleolítico presentaban diferencias respecto a los de la Prehistoria reciente con relación a las pátinas, al rodamiento y a la presencia en algunos ejemplares de costras. Incluso la materia prima, a nivel general, es diferente con un predominio claro de sílex masivo, oolítico o poroso en tonalidades claras como beige, gris o marrón junto a las areniscas compactas y las cuarcitas, frente a sílex negro o gris tipo Turón, muy abundante en las industrias de la Prehistoria reciente. 
Para al estudio morfotécnico y tipológico de los ejemplares localizados y revisados hemos seguido el Sistema Lógico Analítico (SLA), el sistema de Bagolini (Bagolini, 1968), la tipología analítica de Laplace (Laplace, 1972) y la tipología de Bordes (Bordes, 1961). De forma conjunta se ha llevado a cabo el estudio de las materias primas utilizadas en la elaboración de la tecnología lítica, junto con una caracterización arqueométrica que ha permitido interpretar las posibles áreas de captación de las materias primas, caracterizándose un total de 116 láminas delgadas de las cuales 56 láminas delgadas (46 de muestras geológicas y 10 de muestras arqueológicas), son para nuestro estudio y el resto para industrias de la prehistoria reciente. A su vez se han analizado los distintos procesos sedimentarios y postdeposicionales que han afectado a los yacimientos y en consecuencia a la industria lítica recuperada y analizada en este trabajo.

El estudio de las colecciones líticas de los distintos yacimientos nos permite obtener una visión de conjunto del poblamiento humano del Paleolítico en el bajo Turón y el bajo Guadalteba, distinguiendo los rasgos comunes y diferenciadores de cada yacimiento y poder establecer las áreas de captación y aprovisionamiento de las materias primas asociadas a estos conjuntos líticos.

\subsubsection{Materias primas}

El objetivo principal, cuando abordamos este trabajo, era interpretar los patrones de asentamiento de los grupos humanos del Pleistoceno a partir de la captación de las materias primas. Para poder establecer posibles zonas de ocupación o utilización de un espacio por un grupo humano es fundamental localizar el origen de las materias primas que utilizaban, ya sean primarias o secundarias y de esa manera comprender como se articulaban estos cazadores-recolectores dentro de este territorio en función de los recursos existentes, ya sean bióticos o abióticos. Aunque relacionar la industria lítica con el punto determinado del afloramiento de sílex es casi imposible, si podemos relacionarlos con la formación geológica de la que procede.

Para el análisis de las materias primas era prioritario establecer una estrategia de muestreo adecuada. A partir de los mapas geológicos del IGME (1990 a y b) marcamos todas las zonas con afloramientos silíceos en su mayoría vinculados a las cuencas fluviales y las zonas limítrofes susceptibles de captación de dichas materias primas. Los muestreos geoarqueológicos se realizaron en todos los afloramientos geológicos 
localizados en los mapas geológicos y en aquellas zonas que habíamos detectado otros afloramientos y que no aparecían en estos mapas geológicos, así como en algunos de los yacimientos arqueológicos asociados a depósitos semiprimarios o secundarios.

La identificación de la materia prima tanto geológica como arqueológica se realizó primeramente de visu por medio de una lupa tipo triplete 10x-21mm de diámetro y posteriormente con la caracterización de las láminas delgadas que preparamos en el Departamento de Ciencias de la Tierra de la Facultad de Ciencias de la Universidad de Cádiz. En el capítulo 4, se explica detalladamente cada una de las láminas estudiadas tanto de las muestras geológicas como arqueológicas. Dicha caracterización se realizó por medio de microscopía óptica con luz polarizada (LP) o luz doblemente polarizada (LDP), que permitió la identificación de los minerales y establecer diferencias entre materias primas silíceas.

Los muestreos realizados sobre los afloramientos geológicos han sido predominantemente de sílex, aunque también se han muestreado areniscas compactas y cuarcitas. Los materiales recogidos pertenecen a varias unidades geológicas, con presencia de sílex cretácicos y sílex jurásicos junto a radiolaritas, areniscas y cuarcitas entre otros.

Los sílex cretácicos, en posición semiprimaria, aparecen en forma de tabletas y en nódulos. Los afloramientos muestreados (Los Canchos, Madroñales) han sido muy alterados debido a la erosión y a la acción mecánica de los arados. Estos sílex en bandas de edad Albo-cenomaniense aparecen junto a margas y margo calizas blanquecinas del Albiense superior y contiene fósiles como Rotalipora ticinensis (figura 144) y Biticinella beggiensis. Por su parte, las margas pizarrosas grises y verdosas del Cenomaniense contienen Planomalina buxtorfi, Rotalipora appenninica, Rotalipora cushumani y Praeglobotruncana stephani, que sirven para identificar el origen de las materias primas en el estudio de la industria lítica. 


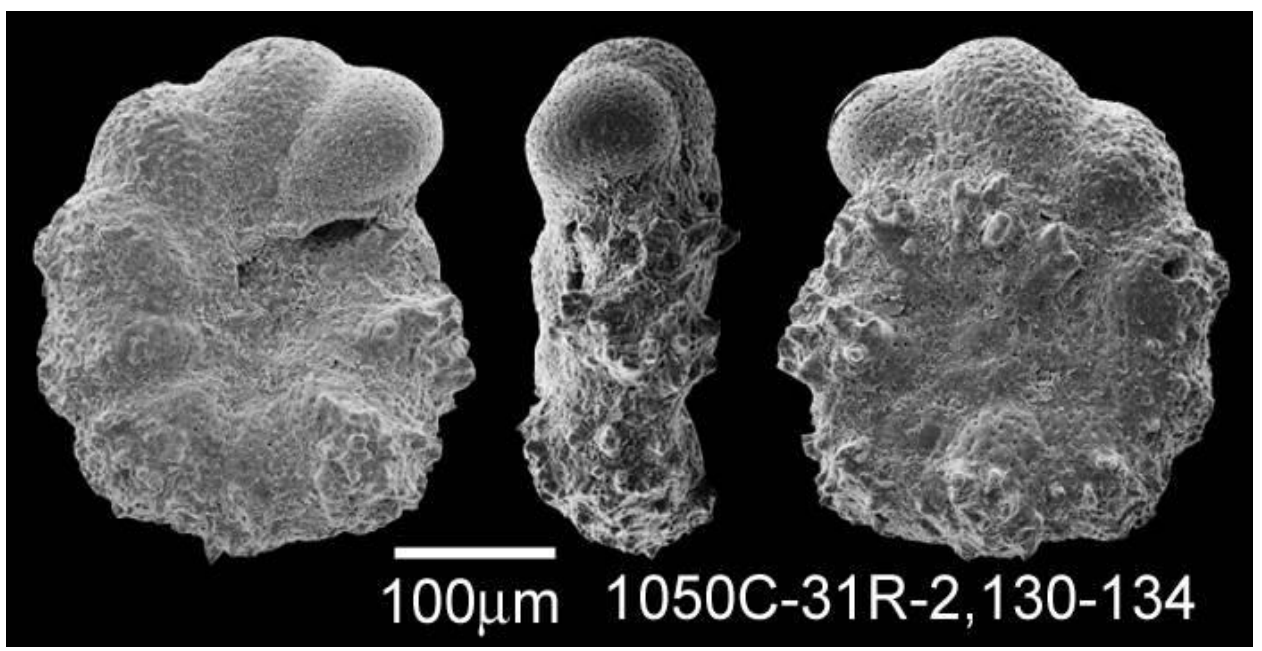

Figura 144. Imagen de Rotalipora ticinensis. www.chronos.org.

El análisis microscópico de los sílex cretácicos muestra unos sílex y radiolaritas muy heterogéneas, con sílex masivos, porosos, oolíticos, bandeados y radiolaritas verdes y rojas. En los Madroñales (Almargen), los sílex y las radiolaritas tienen una fuerte presencia de óxidos de hierro y gran cantidad de microfósiles (radiolarios, espículas, o fragmentos de concha en calcita) algunos de ellos rellenos de calcita monocristalina y calcita micrítica. Algunas muestras presentan un alto contenido en carbonatos de grano fino y esferas de calcedonia. Por el contrario, las muestras recogidas en Los Canchos (Cuevas del Becerro) se caracterizan por una presencia anecdótica de romboedros de dolomita, parches de calcita esparítica, con minerales opacos y algunos microfósiles.

Los sílex jurásicos en posición semiprimaria aparecen en tabletas. Los afloramientos muestreados pertenecen a diferentes unidades geológicas. Los del Subbético interno/medio (la Atalaya, la Mogea, la herriza de la Lapa y sierra de Humilladero) donde afloran calizas margosas y margocalizas con sílex, con intercalaciones de radiolaritas predominando hacia las zonas más altas radiolaritas oscuras con margo calizas tableadas con sílex en abundancia y presencia de microfósiles como la Nautiloculina oolithica. En la sierra de Humilladero junto a las calizas y dolomías aparecen margocalizas con sílex y margas verdes. Estas calizas con sílex aparecen con organismos silíceos como espículas y radiolarios.

Los muestreos del Complejo Maláguide y de las Unidades Frontales (castillo Turón, la Galeota, el Azulejo, sierra del Valle de Abdalajís y la herriza del Carnero) corresponden a un afloramiento que aparece como una intercalación de conglomerados 
dentro de las arcillas y las margas arcillosas terciarias, pertenecientes a la formación Numidoide del Complejo del Campo de Gibraltar. Adyacente a estos materiales se encuentra una alineación de calizas jurásicas perteneciente al Complejo Maláguide, con bloques de sílex de buena calidad. Estos conglomerados contienen rocas del Mesozoico y del Cenozoico originarias de la sucesión tipo Pereila, donde destacan la presencia de calizas grises con sílex del Jurásico.

El análisis microscópico de estos afloramientos muestra unos sílex y radiolaritas heterogéneos, con predominio de sílex masivos en diferentes tonalidades beige, grises o negros, sílex oolíticos, bandeados y radiolaritas. La Atalaya, la Mogea, la herriza de La Lapa y sierra de Humilladero, presentan multitud de inclusiones de tipo pellets, parches de calcita, algún cuarzo monocristalino y opacos pequeños. Con presencia de microfósiles como espículas y radiolarios y óxidos de hierro. En varias muestras de la herriza de La Lapa aparecen inclusiones planas y orientadas en paralelo que podrían ser posibles granos de estaurolitas. La muestra de la sierra de Humilladero también presenta inclusiones de todo tipo y con restos de fósiles en calcita esparítica. Las del castillo de Turón, la Galeota y el Azulejo muestran inclusiones de minerales opacos posiblemente óxidos de hierro y granos de cuarzo recristalizado. Abundantes espículas y fósiles rellenos de calcedonia, así como manchas de calcita esparítica. Todas las muestras presentan una marcada presencia de romboedros de dolomita, salvo en las recogidas en el Valle de Abdalajis, que se caracterizan por estar todas ellas muy fracturadas y con fisuras rellenas de calcedonia.

Los muestreos arqueológicos se realizaron en las terrazas fluviales de los ríos Guadalteba y Turón y están, tres de ellos, vinculados a varios yacimientos arqueológicos (terraza de Las Grajeras, terraza de Peñarrubia, Casilla de Vallejo y PEMA4). Los materiales muestreados han sido areniscas compactas, cuarcitas o protocuarcitas y sílex.

El análisis a microscópio de las areniscas, a nivel general, muestra granos de entre 3 y $5 \mathrm{~mm}$, con presencia de circones. Sin embargo, existen algunos rasgos distintitivos entre unas muestras y otras:

- En la terraza de Las Grajeras, hay una presencia de granos de plagioclasas y agujas de rutilo. Los granos de cuarzo con formas subredondeadas a angulares.

- En la terraza de Peñarrubia los clastos de cuarzo son redondeados y subangulares, con mucha variedad de tamaños de grano hasta $5 \mathrm{~mm}$. Presencia 
de cuarzo monocristalino, alterado en los bordes, con cemento enriquecido en óxidos de hierro amarillentos.

En cuanto a la cuarcita, suele presentar bordes termoalterados, los clastos aparecen bien imbricados unos con otros, con minerales de alteración, micáceos, rellenos de cuarzo y algún óxido de hierro. Presencia de moscovita, clorita y posibles circones. Se observa una posible presencia de feldespato potásico, cuarzo policristalino, silicatos y algún óxido de hierro dentro de los opacos.

En el análisis microscópico del sílex vemos que casi todas las muestras presentan las fisuras o los microfósiles rellenos de calcedonia fibrosa y otras de óxidos, sin embargo, también aparecen algunas diferencias entre unas muestras de sílex y otras.

- Los materiales del yacimiento PEMA4 presentan un predominio de sílex oolítico frente a los masivos o bandeados, junto a las radiolaritas. Aparecen gran cantidad de inclusiones de minerales opacos negros, calcita esparítica y abundantes nódulos de óxido de hierro.

- En los materiales de la terraza de Peñarrubia se observan inclusiones de tipo pellets, y otras de morfología alargadas negras y opacas posiblemente agujas de hematite, con presencia en las muestras de algunos casos de puntos de óxidos.

La caracterización microscópica de los sílex, de las areniscas compactas y las cuarcitas o protocuarcitas de los yacimientos arqueológicos, manifiestan una utilización de las materias primas autóctonas, con cualidades y características similares a las que afloran en zonas cercanas, aprovechando sobre todo las materias primas en posición secundaria vinculadas a los cursos fluviales. Dicho de otro modo, se explotan las materias primas más cercanas a su lugar de asentamiento u ocupación. Así, tenemos que la materia prima utilizada en la industria lítica de sílex de los yacimientos del bajo Turón procede de afloramientos como el Azulejo, castillo Turón, Raja del Boquerón y Lomas del Infierno principalmente, o de los pequeños afloramientos como el cerro de Las Grajeras, de las propias terrazas fluviales y de los cerros próximos al bajo Turón y bajo Guadalteba para las areniscas compactas. Para la industria lítica silícea, localizada en el bajo Guadalteba y vinculada a terrazas fluviales, lo más probable es que la materia prima proceda del tramo alto del río, donde se localizan afloramientos silíceos como la Atalaya, herriza La Lapa o Los Canchos, cuyos sílex presentan características similares a los recogidos en los muestreos de los depósitos secundarios. 
El estudio de las materias primas y su análisis comparativo muestra el empleo mayoritario de la arenisca compacta, procedente de los depósitos secundarios en terrazas, para la elaboración de las industrias más antiguas propias del Paleolítico inferior como son los bifaces, hendedores, triedros o cantos tallados, con una reducida presencia de cuarcita. Existe una mayor utilización del sílex y la radiolarita, para industrias más elaboradas, propias del Paleolítico medio y del Paleolítico superior, con un predominio de los sílex masivos en tonalidades claras como el beige, gris y marrón frente a oolíticos, porosos o bandeados, procedentes en su mayoría de depósitos secundarios vinculados a las terrazas fluviales o a depósitos semiprimarios, donde afloran los sílex en tabletas y nódulos. También en estas fases destaca una utilización de la radiolarita en tonalidades rojas, verdes y negras, con trazas de termoalteración.

\subsubsection{Tecnología}

En nuestro estudio, hemos analizado un total de 13 yacimientos al aire libre y 2 en cueva. Algunos de los conjuntos analizados habían sido encuadrados dentro de la Prehistoria reciente durante los estudios de los años 80, sin embargo, una revisión de los mismos ha puesto de manifiesto la existencia de industrias líticas del Pleistoceno y con varios tecnocomplejos en un mismo yacimiento. La selección se hizo principalmente en función de características como la pátina y el rodamiento, aunque también se tuvieron en cuenta las características morfotécnicas de algunas de ellas.

Del estudio de la tecnología lítica se desprende, a nivel general, que existen 3 conjuntos asociados a Paleolítico inferior o Modo II, 13 conjuntos asociados a industrias propias del Paleolítico medio o Modo III y 2 conjuntos al Paleolítico superior o Modo IV.

Tras nuestro estudio observamos, como las industrias más antiguas, propias del Paleolítico inferior, parecen adaptarse al tamaño de los cantos, en el caso de los ejemplares en arenisca compacta, en los que no parece existir un comportamiento selectivo de la materia prima, ya que los productos como bifaces, hendedores o triedros presentan tamaños similares a los cantos de arenisca geológicos. Para los elaborados en sílex si parece apreciarse una mayor selección de la materia prima y trabajo de los instrumentos. Por otra parte el sílex en sus diferentes variantes (masivo, oolítico, poroso, bandeado) y la radiolarita fueron utilizados para la producción de ejemplares que necesitaban una mayor elaboración como BP-I (internas), BP-L (Levallois) o BN2G. 
Antes de analizar las categorías estructurales del cómputo general nos centraremos en los temas operativos predominantes. En páginas anteriores explicamos el esquema conceptual de la sistematica, los Temas Operativos Técnicos o TOT y su clasificación en directos e indirectos y definimos los temas operativos técnicos directos o TOTD como las estrategias de configuración de los útiles sobre cantos, siendo denominadas como Base Negativa de Primera Generación de Configuración (BN1GC). Los temas operativos técnicos indirectos o TOTI están diriguidos a la obtención y producción de los productos de talla como las Bases Positivas (BP) y las Bases Negativas de Segunda Generación (BN2G) y son las estrategias de explotación de los núcleos, producción de soportes y configuración de útiles sobre lascas.

El análisis de la tecnología lítica muestra un predominio de los TOTI frente a los TOTD (figura 145) salvo en Hoyos de Barbú, donde hay un mayor porcentaje de temas operativos directos respecto a los demás y en la Cueva de Ardales y la terraza del arroyo Cantarranas, donde no hay presencia de BN1GC/E.

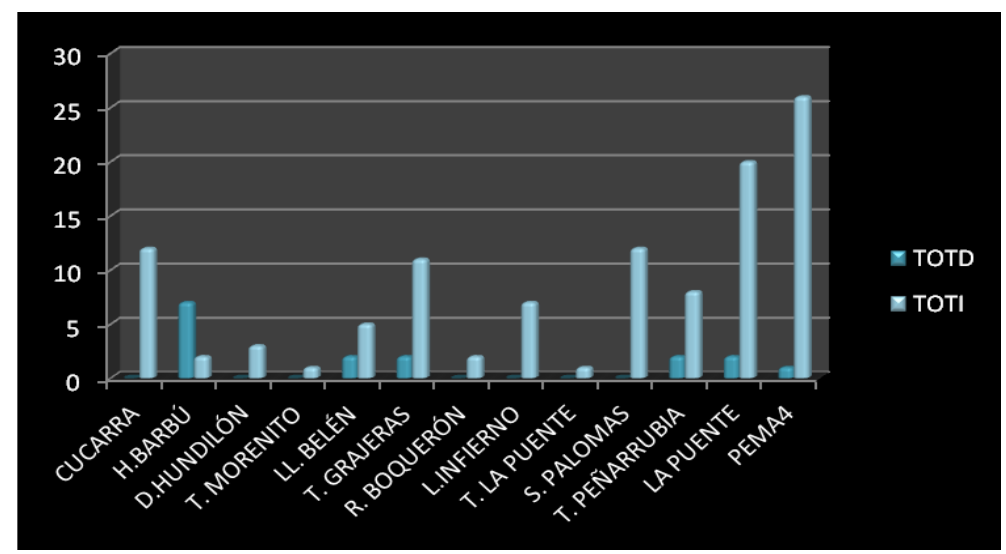

Figura 145. TOTD Y TOTI presentes en los yacimientos

estudiados

Los TOTD documentados son cantos tallados, bifaces, hendedores y triedros y están presentes en 6 yacimientos, en el cómputo general incluimos los dos hallazgos aislados de BN1GC, el de Nina Alta (Teba), estudiado por A. Morgado (García Alfonso et al., 1995) y el de Fuentepeones (Cañete la Real), ambos vinculados a un nacimiento de agua. La mayoría de estas industrias se localizan en las terrazas fluviales o en depósitos secundarios y para su elaboración utilizan como materia prima la arenisca compacta, seguida de la cuarcita y el sílex. El bifaz es el más representativo de todos 
con 9 ejemplares, seguidos de los hendedores con 5 ejemplares, los cantos tallados con 4 ejemplares y los triedros con 2 .

En cuanto a los TOTI están presentes en 13 de los yacimientos analizados (figura 146). En el estudio de los tipos de núcleos o BN1G según las extracciones se desprende a nivel general, un predominio de los núcleos centrípetos, dentro de los cuales hemos incluido los núcleos levallois por tener un sistema de talla similar, seguidos de los unipolares, de los diversos y los poliédricos y una escasa presencia de los núcleos bipolares.

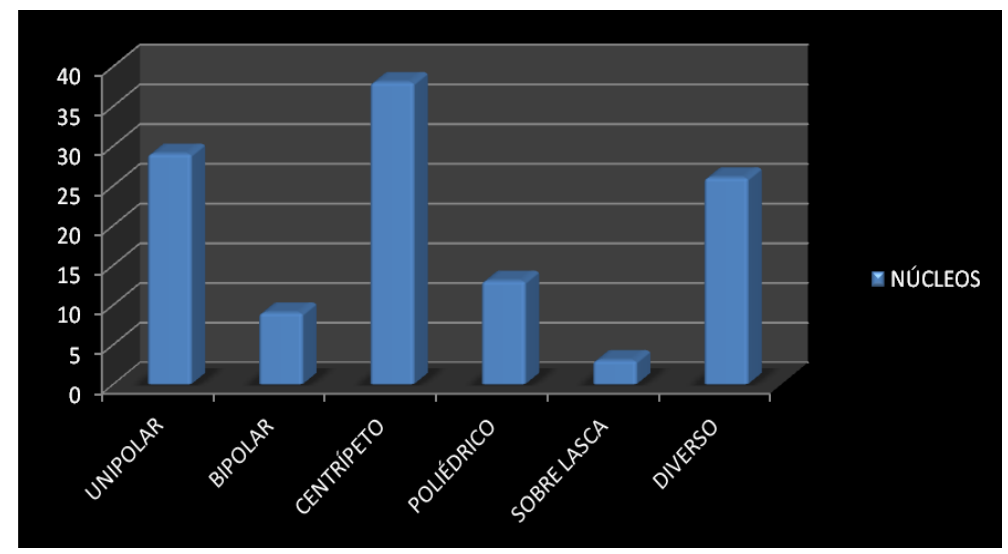

Figura 146. Computo general de TOTI presentes en los yacimientos estudiados.

Las Bases Positivas BP (figura 147) o lascas constituyen el grupo más numeroso de todos, con un total de 521 ejemplares y aparecen documentadas en todos los sitios. Hay que destacar una escasa presencia de los soportes relacionados con el inicio de talla, es decir, BP-D/SD (descortezado/semidescortezado), frente a las lascas vinculadas a la continuidad de talla o BP-I (internas), que constituyen el tipo más numeroso y que están asociadas a núcleos unipolares y centrípetos multipolares BN1G-U y BN1G-CM. El segundo grupo más numeroso está compuesto por las lascas levallois BP-L, que están asociadas a la explotación y desbaste de los núcleos centrípetos y levallois BN1G-C y BN1G-L. En cuanto a los rasgos técnicos debemos decir que aunque aparecen algunas diferencias, destacamos a nivel general una cierta similitud de los conjuntos. Las diferencias se podrían entender en función de diferentes actividades. 


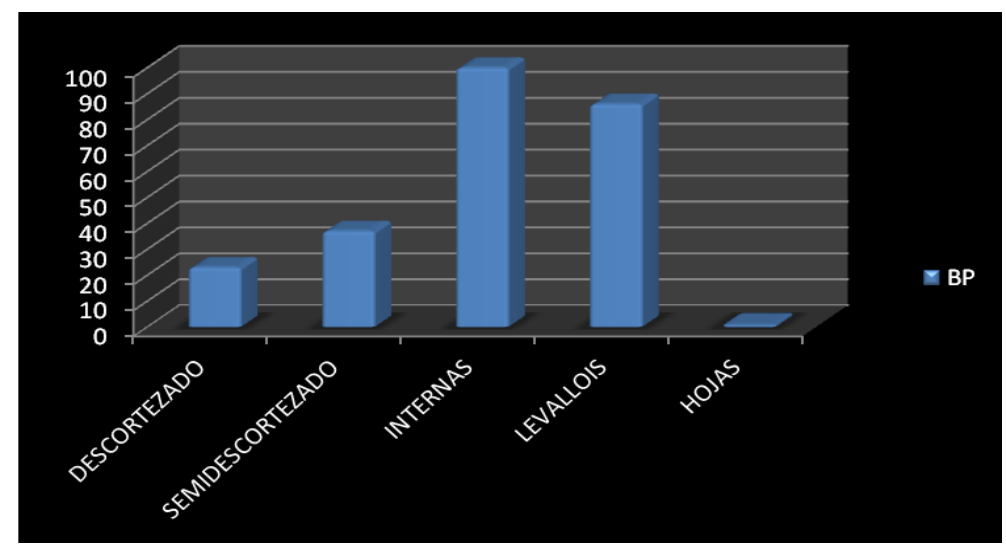

Figura 147. Computo general de BP presentes en los yacimientos estudiados.

El análisis de los tipos de dimensiones según los criterios de B. Bagolini (Bagolini, 1968) (tabla 48) establece un claro predominio de las lascas frente a las láminas, con buena presencia de lascas anchas y lascas laminares. En relación a los tamaños y aunque en alguno de los yacimientos estudiados como la Sima de Las Palomas hay una mayor presencia de lascas de tipo pequeño y muy pequeño (Ramos Muñoz et al, 2014: 155) en el computo general, sin incluir Sima de Las Palomas, destacamos el predominio de los tipos de mediano y gran tamaño.

\begin{tabular}{|c|c|c|}
\hline \multicolumn{3}{|c|}{$\begin{array}{c}\text { ANÁLISIS DIMENSIONAL DE BP SEGÚN B. } \\
\text { BAGOLINI VALORACIÓN POR GRUPOS Y } \\
\text { TAMAÑOS }\end{array}$} \\
\hline GRUPOS & No & $\%$ \\
\hline LÁMINA MUY ESTRECHA & 0 & 0 \\
\hline LÁMINA ESTRECHA & 9 & 2,3 \\
\hline LÁMINAS & 14 & 3,58 \\
\hline LASCA LAMINAR & 90 & 23,07 \\
\hline LASCA & 162 & 41,53 \\
\hline LASCA ANCHA & 76 & 19,48 \\
\hline LASCA MUY ANCHA & 38 & 9,74 \\
\hline LASCA ANCHÍSIMA & 1 & 0,25 \\
\hline TOTAL & 390 & 100 \\
\hline \multicolumn{3}{|l|}{ TAMAÑOS } \\
\hline MUY PEQUEÑO TAMAÑO & 58 & 14,87 \\
\hline PEQUEÑO TAMAÑO & 88 & 22,56 \\
\hline MEDIANO TAMAÑO & 130 & 33,33 \\
\hline GRAN TAMAÑO & 114 & 29,23 \\
\hline TOTAL & 390 & 100 \\
\hline
\end{tabular}

Tabla 48. Análisis dimensional de las BP según

B. Bagolini. Valoración por grupos y tamaño. 
En el análisis de las características de las caras talonares y caras dorsales de los 15 yacimientos hay variaciones de los totales ya que aparecen ejemplares que no están completos y por tanto no se pueden analizar (tabla 49).

\begin{tabular}{|c|c|c|c|c|c|c|c|c|}
\hline \multicolumn{9}{|c|}{ RASGOS TÉCNICOS DE LAS BP. CARA TALONAR Y CARA DORSAL } \\
\hline & & & & & & & & TOTAL \\
\hline \multirow{12}{*}{ 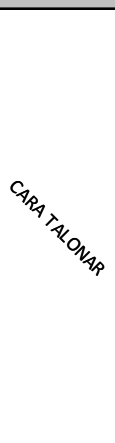 } & & & 1 & $\mathrm{p}$ & fac & a & c & \\
\hline & \multirow{2}{*}{ TIPO TALÓN } & № & 176 & 43 & 167 & 84 & 40 & 499 \\
\hline & & $\%$ & 35,27 & 8,61 & 33,46 & 16,83 & 8,01 & 100 \\
\hline & & & $\mathrm{CO}$ & CDNC & NCDC & NOCO & & \\
\hline & \multirow{2}{*}{ CORTICALIDAD } & № & 30 & 3 & 14 & 391 & - & 438 \\
\hline & & $\%$ & 6,84 & 0,68 & 3,19 & 89,26 & - & 100 \\
\hline & & & PLA & LIN & PUN & & & \\
\hline & \multirow{2}{*}{ SUPERFICIE } & № & 313 & 72 & 47 & - & - & 432 \\
\hline & & $\%$ & 72,45 & 16,66 & 10,87 & - & - & 100 \\
\hline & & & NF & UF & BF & MF & & \\
\hline & \multirow{2}{*}{ TRANSFORMACIÓN } & № & 34 & 218 & 50 & 128 & - & 430 \\
\hline & & $\%$ & 7,9 & 50,69 & 11,62 & 29,76 & - & 100 \\
\hline \multirow{3}{*}{ 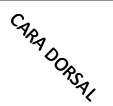 } & & & $\mathrm{CO}$ & CDNC & NCDC & $\mathrm{NOCO}$ & & \\
\hline & \multirow{2}{*}{ CORTICALIDAD } & № & 16 & 27 & 62 & 416 & - & 521 \\
\hline & & $\%$ & 3,07 & 5,18 & 11,9 & 79,84 & - & 100 \\
\hline
\end{tabular}

Tabla 49. Rasgos técnicos de las BP. Cara talonar y cara dorsal.

En cuanto a la cara talonar destacamos una presencia mayoritaria de los talones lisos-1 (176) y facetados-f (167) en número considerable, seguidos de los talones abatidos-a (90), puntiformes-p (43) y corticales-c (23). La mayor presencia de talones lisos está en relación con los núcleos unipolares BN1G-U, mientras que los facetados están relacionados con los núcleos centrípetos y levallois BN1G-C/L. Se observa un predominio de talones no corticales-NOCO (391) frente a talones corticales-CO (30), no corticales dominantes corticales-NCDC (14) y cortical dominante no cortical-CDNC (3). Las superficies aparecen con talones predominantemente en plataforma-PLA (313) frente a los lineales-LIN (72) y puntiformes-PUN (47) y con un predominio de los facetajes unifacetados-UF (218) y multifacetados-MF (128) frente a bifacetados-BF (50) y no facetados-NF (34).

En el análisis de la cara dorsal destaca el criterio de no corticalidad, con el predominio de no corticales-NOCO (416), seguidos de los no corticales dominantes corticales-NCDC (62), cortical dominate no cortical-CDNC (27) y corticales-CO (16). Las secciones sagitales predominantemente trapezoidales-TRP y las transversales triangulares-TRG.

La tendencia general del conjunto de BP analizadas muestra presencia de lascas con talones no corticales-NOCO, con superficies en plataforma-PLA y una cara dorsal 
no cortical-NOCO en la mayoría de los ejemplares. Salvo el caso de la Sima de Las Palomas, que presenta diferencias respecto a los talones (predominio de los facetados frente a los lisos), el resto de yacimientos analizados presentan rasgos muy similares respecto a su cara talonar y cara dorsal.

Tanto en los yacimientos al aire libre como en cueva destaca el reducido número de soportes relacionados con el inicio de la talla, BP-D (semidescortezado) y BP-SD (descortezado). En nuestro caso, planteamos la posibilidad de que esté relacionado con la forma en la que se encuentra la materia prima. Ya vimos en el apartado anterior que en los muestreos geoarqueológicos que realizamos tanto en los depósitos semiprimarios como secundarios, todo el material recogido y observado aparecía tableado, donde el cortex se reduce a la parte superior o inferior de la tableta en algunos casos, en otros ni siquiera aparece el cortex. Esto incluso podría explicar el elevado número de talones lisos.

Las BN2G se documentan en todos los sitios analizados salvo en el arroyo Cantarranas. Donde más productos retocados hay es en la Sima de Las Palomas (27) seguido de dos yacimientos al aire libre: Cucarra (15) y PEMA4 (10).

Los rasgos técnicos de las $\mathrm{BN} 2 \mathrm{G}$ muestran un predominio de los ejemplares realizados sobre lascas internas BP-I (41), seguido de las lascas levallois BP-L (33), con una menor presencia de productos sobre lascas de semidescortezado BP-SD (9) o descortezado BP-D (3). Según las características tipométricas analizadas en cada uno de los yacimientos y distinguiendo entre lugares al aire libre y en cuevas, se observa como los productos retocados analizados al aire libre tienen un predominio de lascas de gran tamaño, mientras que las localizadas en cuevas tienen una tendencia a tamaños medianos y pequeños. En relación a su cara talonar y dorsal existe un predominio de talones facetados-f (28) y lisos-1 (23), seguidos de los abatidos-a (16), corticales-c (4) y puntiformes-p (2) (tabla 50). El análisis del facetaje muestra un mayor porcentaje de talones unifacetados-UF (26), seguidos por los multifacetados-MF (19), los bifacetados BF (11) y los no facetados-NF (5). Casi todos los ejemplares presentan una cara talonar no cortical-NOCO (56) y en plataforma-PLA (44), ocurre lo mismo con la cara dorsal siendo predominante la no cortical-NOCO (51). Los productos o BN2G tienen secciones sagitales cuadrangulares $\mathrm{CDG}$ en su mayoría y secciones transversales triangulares-TRG. 


\begin{tabular}{|c|c|c|c|c|c|c|c|c|}
\hline \multicolumn{9}{|c|}{ RASGOS TÉCNICOS DE LAS BN2G. CARA TALONAR Y CARA DORSAL } \\
\hline & & & & & & & & TOTAL \\
\hline \multirow{12}{*}{ 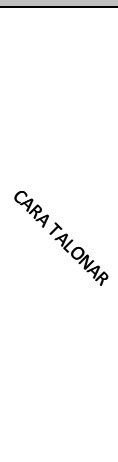 } & & & 1 & $p$ & $\mathrm{fac}$ & $a$ & $\mathrm{c}$ & \\
\hline & \multirow{2}{*}{ TIPO TALÓN } & № & 23 & 2 & 28 & 16 & 4 & 73 \\
\hline & & $\%$ & 31,5 & 2,73 & 38,35 & 21,91 & 5,47 & 100 \\
\hline & & & $\mathrm{CO}$ & CDNC & NCDC & $\mathrm{NOCO}$ & & \\
\hline & \multirow{2}{*}{ CORTICALIDAD } & № & 7 & 1 & 1 & 56 & - & 65 \\
\hline & & $\%$ & 10,76 & 1,53 & 1,53 & 86,15 & - & 100 \\
\hline & & & PLA & LIN & PUN & & & \\
\hline & \multirow{2}{*}{ SUPERFICIE } & № & 44 & 16 & 1 & - & - & 61 \\
\hline & & $\%$ & 72,13 & 26,22 & 1,63 & - & - & 100 \\
\hline & & & $\mathrm{NF}$ & UF & $\mathrm{BF}$ & MF & & \\
\hline & \multirow{2}{*}{ TRANSFORMACIÓN } & № & 5 & 26 & 11 & 19 & - & 61 \\
\hline & & $\%$ & 8,19 & 42,62 & 18,03 & 31,14 & - & 100 \\
\hline \multirow{3}{*}{ 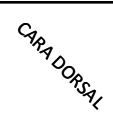 } & & & $\mathrm{CO}$ & CDNC & NCDC & $\mathrm{NOCO}$ & & \\
\hline & \multirow{2}{*}{ CORTICALIDAD } & № & 2 & 9 & 12 & 51 & - & 74 \\
\hline & & $\%$ & 2,7 & 12,16 & 16,21 & 68,91 & - & 100 \\
\hline
\end{tabular}

Tabla 50. Rasgos técnicos de las BN2G. Cara talonar y cara dorsal.

Con relación a los tipos primarios más representados nos encontramos ante el predominio de las raederas y las muescas tanto en yacimientos al aire libre como en cuevas y con algunos ejemplares de denticulados y raspadores, en proporciones similares. Los morfotipos menos frecuentes son los perforadores, puntas levallois, buriles y con una presencia anecdótica de un abrupto, una truncadura y una hoja de laurel (tabla 51).

\begin{tabular}{|l|c|c|c|}
\hline \multicolumn{4}{|c|}{ COMPUTO GENERAL DE BN2G. } \\
\hline & AIRE LIBRE & CUEVAS & TOTAL \\
\hline Raedera & 33 & 12 & 45 \\
\hline Muesca & 10 & 9 & 19 \\
\hline Denticulado & 4 & 4 & 8 \\
\hline Raspador & 4 & 1 & 5 \\
\hline Buril & 0 & 2 & 2 \\
\hline Perforador & 2 & 0 & 2 \\
\hline Punta Lev. & 2 & 0 & 2 \\
\hline Truncadura & 1 & 0 & 1 \\
\hline Abrupto & 0 & 1 & 1 \\
\hline Hoja de laurel & 0 & 1 & 1 \\
\hline TOTAL & 56 & 30 & $\mathbf{8 6}$ \\
\hline
\end{tabular}

Tabla 51. Morfotipos presentes en los yacimientos al aire libre y en cuevas. 
Aunque en la tipología analítica de Laplace las muescas se incluyen dentro del grupo de los denticulados en nuestro caso las hemos considerado de forma independiente y más teniendo en cuenta la entidad que presenta junto con las raederas dentro del computo general. El único rasgo diferenciador que nos aparece respecto a los morfotipos viene de la mano de los raspadores, pues al comparar todos los yacimientos vemos como los raspadores aparecen por el momento asociado a los que no se encuentran en las terrazas fluviales y por el contrario, se localizan en zonas altas como son los casos de los yacimientos asociados a Paleolítico medio de Cucarra, PEMA4 y Hoyos de Barbú y un ejemplar en Cueva de Ardales asociado al Paleolítico superior.

Destacamos en los tipos de retoques un dominio casi completo de los simples, frente a los abruptos y planos, con una amplitud marginal y casi siempre directos. Se han utilizado mayoritariamente lascas internas y levallois para la confección de productos retocados, aunque hay presencia de lascas de semidescortezado y descortezado que están relacionadas con productos de gran tamaño asociadas a las fases más antiguas del Paleolítico.

\subsubsection{Uso y alteraciones}

Establecer la funcionalidad de los instrumentos líticos es algo difícil, tanto por la complejidad y escasez de este tipo de estudios como por la incidencia de los factores postdeposicionales que afecta a la industria lítica, ya sean naturales o antrópicos, que se manifiestan por el rodamiento, la patina o las roturas posteriores, ya sean intencionadas o no, entre otros aspectos. En nuestro caso, se ha realizado un estudio preliminar por I. Clemente (Clemente Conte, 2014: 179-185) sobre las huellas de uso de algunos instrumentos líticos de la Sima de Las Palomas, asociados a los niveles del Paleolítico medio. Aunque los resultados aún no son concluyentes debido al reducido número de piezas analizadas, un total de 21 , este primer análisis ha permitido documentar dos actividades distintas, por un lado la relacionada con el procesado de carne y por otra la explotación de recursos vegetales.

Las evidencias aparecen en forma de melladuras de pequeño tamaño con formas diversas pero casi siempre semicirculares, junto con un filo graso, redondeamientos orientados y "bocetos" de estrías paralelas al filo que indican actividades de corte y corresponden a lascas de distinto tipo (semidescortezado, interna, levallois) y a una punta levallois). Las BP vinculadas a actividades cárnicas presentan como rasgo común 
unos filos activos muy agudos y mayormente usados sin retoque alguno. Las BP vinculadas al trabajo de la madera, presentan melladuras de tamaño medio que conforman un retoque directo, regular y continuo.

Independientemente del uso o funcionalidad de la industria, existen una serie de factores que alteran los artefactos una vez entran en contacto con el medio ambiente. Las piezas comienzan a sufrir alteraciones y modificaciones naturales ocasionadas fundamentalmente por procesos físico-químicos que provocan un deterioro y unos cambios en su aspecto original. El análisis de estos cambios nos informará sobre determinados aspectos como son los procesos postsedimentarios o la reutilización de la industria. Dentro de estas alteraciones o procesos de deterioro y que afectan a los conjuntos estudiados en el bajo Turón y bajo Guadalteba tenemos la pátina, el rodamiento, la desilicificación, las huellas de agentes hídricos o el seudoretoque.

La pátina, se refiere a la alteración química de la pieza que origina el cambio de color de la parte afectada, según los componentes de la materia. La presencia de pátina en los conjuntos líticos o en las piezas puede deberse a causas como un uso continuado, la meteorización o la eolización entre otras y que le afectan una vez están a la intemperie. En el estudio de los conjuntos analizados vemos una fuerte presencia de piezas con pátina siempre en los lugares al aire libre, con pátinas variadas predominando las de tonalidades amarillas, las piezas estudiadas en cuevas apenas presentan pátinas.

El rodamiento o estado de las aristas de nuestros conjuntos, es en su mayoría, de tipo medio. Los fenómenos que afectan a las industrias y que provocan que tengan un nivel de rodamiento u otro están en función de varias causas relacionadas con los fenómenos mecánicos de la erosión. Los conjuntos líticos aquí expuestos con un rodamiento de tipo medio han sido afectados principalmente por la erosión producida por el transporte fluvial, ya que la mayoría de ellos se encuentran en lugares vinculados a cursos fluviales. Sin embargo, los conjuntos asociados a cuevas o alejados de los cursos de los ríos presentan un rodamiento bajo o casi nulo y con unas aristas vivas.

La desilicificación (Panera Gallego et al., 1996: 37) es un proceso químico que afecta únicamente al sílex y rocas afines y provoca cambios moleculares que implica una pérdida de peso y dureza, al perder la sílice. Debido a ese proceso algunos de nuestros ejemplares debido a ese proceso presentan un color blanco y un aspecto similar al yeso. 
Los agentes hídricos son una de las causas de la alteración de la industria lítica, ya que la gran mayoría de los yacimientos estudiados están vinculados a ríos, arroyos o escorrentías. Hay ejemplares afectados por la acción del arrastre de los materiales que al chocar unos contra otros presentan huellas de golpeo u abrasiones, con presencia en muchos de ellos de costras al estar en contacto con el agua.

Por último, hemos decidido incluir los seudoretoques, considerándolos como procesos antrópicos no intencionados, como alteraciones a la industria lítica. Estos seudoretoques se originan por el pisoteo, o el transporte mecánico, como el producido por la acción de los arados. En el caso de los antrópicos intencionados, se han documentado en dos yacimientos al aire libre como son Cucarra y PEMA4, vemos como se ha alterado la pátina y aparecen en los filos o en los extremos laterales indicando una reutilización posterior de la industria lítica sin poder precisar con exactitud el lapso de tiempo existente entre una utilización y otra. 


\section{Interpretación y discusión}

A pesar del tamaño reducido de algunos de los conjuntos analizados, podemos confirmar la presencia de industrias asociadas a las distintas etapas del Paleolítico a nivel genérico. Este reducido número hay que entenderlo como consecuencia de desmantelamiento de parte de las terrazas fluviales que han alterado los depósitos, por la acción erosiva del embalse y por la superposición de la ocupación en fases de la Prehistoria reciente que se asentaron sobre los materiales más antiguos sepultados por los depósitos más antiguos. Sin embargo, la muestra obtenida es representativa, sobre todo teniendo en cuenta la dificultad de localizar industrias del Paleolítico inferior y medio al aire libre, dado que no hay que considerarlas como industrias aisladas en un espacio vacio sino que forman parte de un conjunto donde el estudio global de toda la industria lítica nos ha servido para interpretar las formas de subsistencia y la movilidad de estos grupos humanos.

\subsection{El contexto de las evidencias}

Las evidencias arqueológicas de la ocupación humana de la zona abarcan desde el Paleolítico inferior al Paleolítico superior con la existencia de yacimientos vinculados a cada uno de estos periodos culturales. Por un lado y asociados a industrias del Paleolítico inferior, tenemos la terraza de Peñarrubia, el yacimiento La Puente y Hoyos de Barbú, para el Paleolítico medio contamos con los yacimientos de Cucarra, arroyo Cantarranas, depósito del Hundilón, Llanos de Belén, Raja del Boquerón, Lomas del Infierno, terraza de Morenito, terraza La Puente y PEMA4, todos ellos al aire libre. El Paleolítico superior aparece en la Cueva de Ardales y con algunas evidencias en Sima de Las Palomas.

Para la contextualización de las evidencias arqueológicas asociadas a las terrazas fluviales contamos con las dataciones de radiocarbono de los travertinos localizados en el río Guadalteba que fueron realizadas por el IGME (AA.VV. 1990 a) y de las que hablamos en el capítulo 3.

La datación numérica del travertino más reciente es la del río de la Venta, que está situado sobre una terraza y se localiza en las proximidades de la Sima de Las Palomas. La datación de este travertino ofrece una edad de 8.872 \pm 151 BP (Lhenaff, 1967), considera que las terrazas de la cuenca del Guadalhorce a la que pertenecen el río Guadalteba y Turón son anteriores al Holoceno y por tanto pertenecientes al Pleistoceno 
o pre-holocenas. Las cronologías más antiguas de los travertinos están comprendidas entre $13.693 \pm 315$ BP al oeste del municipio de Serrato y $35.696 \pm 2188$ BP en Cañete la Real atribuidas al Pleistoceno superior.

A nivel general, estas cronologías permiten una asociación de las terrazas de nuestra zona de estudio a momentos pleistocénicos. Según estos estudios (AA.VV. 1990 a) existen varios niveles, las terrazas más altas se encuentran a unos 60-70 m y se localizan en el sector del cortijo Nuevo (entre Ardales y Teba) y al sur de la sierra de Peñarrubia (terrazas de Peñarrubia). Este nivel corresponde a la etapa postVillafranquiense (atribución cronológica de AA.VV. de la hoja 1037. Año 1990 a) de edad aproximada entre 2,97 Ma y 2,04/1,78 Ma. Existe un tercer nivel de terrazas (Riss, atribución cronológica de AA.VV. de la hoja 1037. Año 1990 a) que afloran al oeste de Ardales (terraza Hundilón y zona del castillo Turón) y que corresponden al Pleistoceno medio con una edad comprendida entre 250/128 ka. El segundo nivel de terrazas (Würm, atribución cronológica de AA.VV. de la hoja 1037. Año 1990 a), está asociado a un nivel medio, donde las terrazas se encuentran entre $15-20 \mathrm{~m}$ sobre el cauce actual y se localizan al sur de Teba (terraza La Puente) y al norte de Ardales (Llanos de Belén, Terraza de Las Grajeras y Morenito) y corresponden al Pleistoceno superior, periodo de edad comprendida entre 130/128 ka y 118/115 ka BP (Riss-Würm) y desde 118/115 ka BP hasta 11.784 años de calendario (Würm).

Para los yacimientos en cueva contamos con varias dataciones, en la Sima de Las Palomas para Paleolítico medio con una cronología máxima, hasta el momento, de 83.9 \pm 12.3 ka BP (Kehl, 2014: 45) y en la Cueva de Ardales para Paleolítico medio con

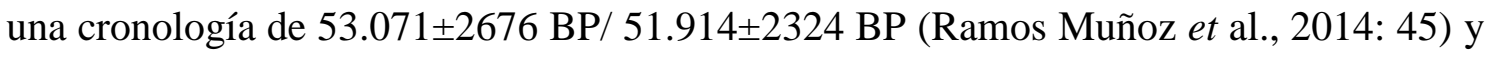
para Paleolítico superior contamos con una cronología de 15.945+60 BP (Ramos Muñoz et al., 2014: 44).

Las dataciones de los travertinos y los periodos de formación aproximados para las terrazas fluviales y su asociación con los materiales arqueológicos localizados manifiestan una ocupación humana muy antigua y una utilización de este territorio por grupos poblacionales distintos a los largo de la Prehistoria. El número de localizaciones estudiadas en esta tesis abre grandes posibilidades al conocimiento de las sociedades del Paleolítico, tanto en nuestra provincia como al sur de la Península Ibérica. 
Las sucesivas campañas de excavación arqueológica en la Sima de Las Palomas y en la Cueva de Ardales, así como las prospecciones arqueológicas superficiales, iniciadas a finales del 2015 nos permitirán profundizar en la movilidad y la captación de los recursos y las materias primas de estos grupos humanos y obtener información cronoestratigráfica y paleoecológica de la zona.

\subsection{Características tecnológicas}

Los conjuntos líticos estudiados y asociados a diferentes periodos culturales muestran unos rasgos generales que analizaremos a continuación.

En primer lugar, la materia prima predominante es el sílex jurásico frente al sílex cretácico también presente, utilizandose tanto en la configuración como en la explotación de la industria, al igual que la radiolarita. Para la macroindustria, como los bifaces, los hendedores y para los cantos tallados o triedros se utiliza principalmente arenisca compacta del Aljibe del Cenozoico, utilizandose únicamente para la configuración de esos grandes instrumentos. La cuarcita es menos utilizada aunque también aparece y suele utilizarse tanto en la configuración en forma de cantos tallados y bifaces sobre todo como en la explotación en forma núcleos-BN1G o en lascas-BP. Mientras que el sílex y las radiolaritas se documentan en los yacimientos al aire libre y en cuevas, las industrias realizadas en arenisca compacta o cuarcita aparecen únicamente al aire libre, vinculadas a cursos fluviales o nacimientos de agua.

Se observa como la radiolarita aunque presente en casi todos los conjuntos analizados, presenta un rasgo significativo en dos de ellos, como son Cucarra y Sima de Las Palomas y es la presencia de cúpulas de termoalteración que indican una posible utilización del fuego para trabajar la materia prima.

La configuración de la macroindustria asociada al Paleolítico inferior se documenta en tres yacimientos vinculados a las terrazas fluviales y a una zona de graveras a escasos metros del río Guadalteba. El bifaz es el morfotipo más representativo. Dos de los yacimientos se localizan en el río Guadalteba (terraza de Peñarrubia y La Puente) y uno en el río Turón (Hoyos de Barbú). Los hallazgos aislados de Fuentepeones (Cañete la Real) y Nina Alta (Teba) se localizan a escasos metros de un nacimiento de agua. En el caso del bifaz de Nina Alta, aunque con dificultades para su adscripción cultural, es posible que tenga una cronología más antigua, coincidiendo con ejemplares del Alto Vélez, en su mayoría ovales, muy similares al de Nina Alta y 
que se alejan de los típicos bifaces planos y triangulares de Paleolítico medio (García Alfonso et al., 1995: 37) y es muy similar al localizado en Hoyos de Barbú asociado a industrias del Paleolítico inferior.

En relación con las categorías estructurales, aunque ya hablamos de cada una de ellas en los apartados anteriores, exponemos aquí un resumen de las mismas. En cuanto a la estrategia de talla el estudio tecnológico manifiesta claramente un predominio de BN1G de talla centrípeta, seguido por la unipolar y la diversa, entendemos dentro de esta últimas aquellos núcleos o $\mathrm{BN} 1 \mathrm{G}$ de estilo centrípeto no bien definidos o los amorfos e indefinidos. Aparecen de manera significativa en Cucarra y Sima de Las Palomas.

Las lascas o BP se caracterizan por una escasa presencia de BP-D (descortezado) y BP-SD (semidescortezado), quizás a consecuencia de la forma en tabletas de la materia prima, que permite obtener lascas sin cortex, internas y con talones lisos y que se manifiesta en una presencia mayoritaria de BP-I (internas) y BP-L (levallois), en todos los yacimientos. Son lascas de mediano y gran tamaño, a nivel general, salvo en Sima de Las Palomas donde las lascas presentan tamaños pequeños y medianos.

Los productos retocados o $\mathrm{BN} 2 \mathrm{G}$ presentan unos formatos de mediano y gran tamaño, donde la única diferencia nos la encontramos en los productos de Sima de Las Palomas con tamaños pequeños y medianos, al igual que en ocurría en las lascas.

Los morfotipos más representados son las raederas, seguidas de las muescas y los denticulados, siendo predominantes tanto en cuevas como al aire libre. En menor proporción nos aparecen los raspadores, en los yacimientos localizados en zonas altas con industrias asociadas al Paleolítico medio y en la Cueva de Ardales para Paleolítico superior. De manera anedóctica, aparecen los buriles, los perforadores, las puntas levallois, las truncaduras, los abruptos y una hoja de laurel tanto en los yacimientos al aire libre como en los yacimientos en cuevas.

A rasgos generales vemos como los lugares al aire libre presentan características similares, si bien las diferencias las encontramos al compararlas con uno de los yacimientos en cueva, como es la Sima de Las Palomas, las diferencias como hemos visto radican principalmente en los tamaños de las lascas BP-I y BP-L y el reducido número de núcleos que presenta, en comparación con el volumen de industria lítica. 
Ante esto planteamos la posibilidad de que el trabajo de selección y las primeras fases de la cadena operativa se realizaran en el exterior de la sima y que allí sólo se llevasen lascas y pequeños núcleos ya configurados para la extracción de las mismas, teniendo en cuenta el elevado número de restos de talla que aparecen en la sima y que por el tamaño pudiesen ser producto de la configuración de los filos o los retoques de la industria.

\subsection{Aprovisionamiento y subsistencia}

Cuando hablamos del aprovisionamiento de materias primas no nos referimos únicamente a la recogida de la materia prima sino que consideramos al igual que $\mathrm{X}$. Terradas que existen otras actividades que se realizan con anterioridad a esta recogida, tales como la identificación de los distintos recursos y sus formas de reconocimiento (Terradas, 2002: 113). Esto implica un conocimiento exhaustivo del territorio que ocupan y saber elegir aquellos lugares para el aprovisionamiento con unas características concretas.

Sobre la captación de materias primas planteamos un aprovisionamiento del entorno inmediato aprovechando los depósitos secundarios, como ocurre en las terrazas fluviales, junto con la explotación de recursos semiprimarios donde la presencia de tabletas o cantos de sílex afloran en grandes cantidades a la superficie, un ejemplo lo tenemos en la zona de los Madroñales (Almargen) y donde localizamos PEMA4.

La aplicación de las técnicas arqueométricas para el análisis de los materiales geológicos y arqueológicos nos ha permitido observar una selección oportunista durante el Paleolítico inferior, manifestado en las similitudes litológicas respecto al depósito secundario, elaborando, utilizando y abandonando en el mismo lugar la industria que pasa a ser selectiva en momentos del Paleolítico medio y superior, dado que la materia prima muestra diferencias en la morfología, hecho que implica un cierto nivel tecnológico así como el conocimiento y el uso territorial del espacio y los recursos.

La industria de Paleolitico inferior no es muy numerosa y la materia prima predominante es la arenisca y alguna cuarcita o protocuarcita de origen local, con una utilización de los propios materiales de las terrazas o los depósitos antiguos asociados a los ríos como zonas de aprovisionamiento. En el Paleolítico medio y superior hay un aumento en la diversidad de las materias primas utilizadas, principalmente sílex y radilaritas. Aunque se sigue utilizando de forma esporádica la arenisca compacta en el 
Paleolítico medio que es inexistente en el Paleolítico superior. Los sílex predominantes son los sílex masivos en tonalidades claras como el beige, marrón o gris claro, aunque también son destacables los sílex oolíticos y en menor medida los silex bandeados o porosos, las radiolaritas más frecuentes son las de tonos rojos o verdes con algunos ejemplares en tonalidades negras o rosas.

Ya hemos dicho que los recursos líticos son de origen local pero observamos como casi todos los yacimientos al aire libre se sitúan muy próximos o encima de la materia prima, salvo Cucarra, que es un yacimiento en altura muy próximo a la Cueva de Ardales y cuya materia prima procede de las proximidades. En el caso de las cuevas, tanto en Ardales como Sima de Las Palomas, los recursos líticos proceden de zonas cercanas. Aunque ambas se situan en zonas elevadas, la Sima de Las Palomas se ubica próxima a un cañon kásrtico donde presumiblemente pudieron desarrollarse actividades de caza mediante emboscada y despeñamiento. La Cueva de Ardales también parece evidenciar un yacimiento para la caza, pues controla una zona de paso de animales desde la costa al interior y entre las zonas de valle de ambos ríos.

Los estudios realizados a nivel polínico y faunístico en la Cueva de Ardales y en la Sima de Las Palomas, nos permiten tener una visión preliminar de la vegetación y la fauna existente en la zona durante el Pleistoceno y por consiguiente de la formas de subsistencia de estos grupos humanos. Futuras intervenciones permitirán obtener una información continua en toda la secuencia analizada de ambas cuevas.

El estudio polínico (Ruiz et al., 2014: 76-77) para las fases asociadas a momentos del Paleolítico medio en la Sima de Las Palomas reflejan tres fases de muro a techo y manifiestan un dominio de bosque regional, seguido de una fase con bosques perennes y caducos con un retroceso de la masa forestal y por último un desarrollo de los bosques perennes y desaparición de los caducos con presencia de Juniperus, lo que hace pensar en unas condiciones más frescas y una perdida de la humedad. Después de estas etapas (entre 58. $5 \pm 6.5 \mathrm{ka} \mathrm{BP}$ y $37.1 \pm 4.9 \mathrm{ka} \mathrm{BP}$ ) se produce un aumento de la deforestación sin saber aún si se produce por causas climáticas o antrópicas. Las especies vegetales revelan un mosaico de ecosistemas con especies propias de zonas encharcadas y plantas herbáceas asociadas a espacios abiertos o prados que favorecen el pastoreo de hervíboros, plantas de monte bajo y una presencia muy pequeña de matorrales. Para las fases posteriores del Paleolítico superior en Cueva de Ardales los análisis preliminares establecen unas condiciones más frescas, con un escaso desarrollo de Quercus perennifolios y la inexistencia de los caducos, con una reducción de 
herbáceos xéricos y estépicos con presencia de Betula, indicadores de condiciones más secas y frías. Se produce una alternacia climática con una primera fase fresca y árida, una posterior fría y húmeda y una última fase cálida y húmeda.

En relación con el análisis de los restos faunísticos (Patrocinio Espigares et al., 2014) localizados en ambas cuevas, destaca la presencia de mamíferos de mediano y de gran tamaño como el ciervo o la cabra montes como el caballo, hay especies como el jabalí o el uro que únicamente se han documentado en la Sima de Las Palomas.

En la Sima de Las Palomas los restos óseos corresponden en su mayoría a dientes, a fragmentos de maxilar y mandíbulas con ausencia de huesos largos indicativo de una gestión y aprovechamiento cárnico, sin embargo la existencia de gran cantidad de fragmentos indeterminados y un estudio exhaustivo de los mismos podría aumentar el número de huesos largos que son los que más se modifican por la actividad humana por su alto contenido nutricional, la presencia de huesos quemados también hace pensar en la actividad humana de la sima. En la Cueva de Ardales hay que determinar aún si se llevan cadáveres completos o únicamente extremidades dado que hasta el momento no está del todo claro y es necesario avanzar en la excavación (Patrocinio Espigares et al., 2014: 104).

La microfauna, como el conejo o las aves, son frecuentes, sin embargo en ninguna de ellas se han determinado acción antrópica, aunque no se descarta (Patrocinio Espigares et al., 2014: 104).

Ante esta situación podemos decir que las condiciones climáticas y la fauna son las típicas del Pleistoceno superior. Sin embargo, debemos establecer alguna matización según sean los yacimientos al aire libre o en cuevas. Mientras que los yacimientos en cuevas parecen evidenciar un actividad de caza, donde se transportan partes de los animales capturados, no está tan claro para los yacimientos al aire libre, sobre todo en las terrazas fluviales, donde tal vez se realizaran diferentes actividades, como la caza, pesca o la recolección, teniendo un uso continuo de estos espacios.

Otro elemento fundamental para la subsistencia es el agua. Son varios los puntos de agua o manantiales en la zona y en cuyas cercanías se han localizado varios de los yacimientos estudiados, como son Raja del Boquerón, Cueva de Ardales, Sima de Las Palomas y los hallazgos aislados de Nina Alta (Teba) y Fuentepeones (Cañete la Real), estos últimos quizás vinculados a la caza oportunista de especies de animales que iban a beber a estos manantiales. El resto de yacimientos están ligados a los cursos fluviales 
hecho que nos indica que los ríos principales como el Turón y el Guadalteba tuvieron especial relevancia en la selección de la ubicación de los asentamientos. Únicamente el yacimiento PEMA4 no parece estar relacionado con ningún curso importante de agua, aunque tenemos constancia de que en la zona donde se situa son frecuentes las lagunas y también existe un nacimiento de agua.

Un rasgo que debemos destacar es la existencia de aguas sulfurosas en la zona y más concretamente en la Cueva de Ardales y cerca del pueblo de Ardales, en la denominada Fuente Hedionda, que desagua en el río Turón. El agua que surge en esta fuente mantiene un caudal constante $(0,2 \mathrm{l} / \mathrm{s})$, ya que es independiente de las precipitaciones y su análisis muestra que es potable (Villanúa Fungairiño et al., 1999: 402), surgiendo a unos $10^{\circ}-20^{\circ} \mathrm{C}$, por lo que se considera agua fría. No es extraño que los yacimientos paleolíticos se sitúen en las proximidades de estas surgencias de aguas sulfurosas dado que favorece unas buenas condiciones de habitabilidad, puesto que pueden dar lugar al crecimiento de vegetación, proporcionar agua estable y a su vez, atraer a las especies animales que podrían servir de alimento. Pero sobre las condiciones de habitabilidad y los patrones de asentamiento hablaremos en el próximo apartado.

\subsection{Patrones de asentamiento}

Los patrones de asentamiento constituyen la base de cualquier investigación para entender aspectos sociales y económicos del grupo humano que se estudie. Es por ello y por lo que el estudio de los materiales superficiales es de carácter primordial pues supone poder obtener resultados en relación a la interacción hombre-medio.

Para interpretar los patrones de asentamiento de los grupos de cazadoresrecolectores hay que comprender su movilidad en función de los recursos con los que podían contar. Hemos visto como los animales más consumidos, en el Paleolítico medio y Paleolítico superior, según los estudios zooarqueológicos, son el ciervo y la cabra montes, seguidos del caballo, el jabalí y el uro y como las condiciones ecológicas favorecían la existencia de una gran diversidad de ecosistemas y de especies propias de cada una de ellos, susceptibles de un aprovechamiento cárnico y vegetal.

Algunos de los yacimientos estudiados están situados estratégicamente para obtener los distintos recursos y donde el análisis de la industria lítica manifiesta actividades de caza y recolección. En estos sitios destacan como productos predominantes las raederas y las muescas, que eran utilizadas para raspar y cortar y los 
raspadores utilizados sobre todo para el trabajo de raspar las pieles o los buriles para la transformación de las materias animales duras.

Con todo ello podemos establecer algunas conclusiones en relación con los patrones de asentamiento según su localización y funcionalidad. Durante el Paleolítico inferior existe una preferencia por puntos muy concretos, todos ellos en terrazas fluviales cercanas a los cursos fluviales principales o próximos a los nacimientos de agua, donde los recursos líticos se obtienen directamente del depósito y con industrias líticas que no muestran una gran complejidad en los esquemas operativos. Son zonas que parecen manifestar una reiteración en su uso, continuando en épocas posteriores y donde se llevarían a cabo diversas actividades, como la caza, la pesca o la recolección.

En el Paleolítico medio parece producirse una diversificación de los lugares de ocupación con áreas de distinta funcionalidad, tenemos atestiguados lugares en terrazas fluviales, cerca de los cursos de agua principales en su mayoría, donde la materia prima es arrastrada en muchas ocasiones por el río desde las zonas de origen. También hay una ocupación de lugares elevados y en zonas de llanuras, donde la materia prima se localiza directamente en el yacimiento o en áreas próximas y donde el análisis traceológico de la industria lítica manifiesta un uso para la caza y el trabajo con vegetales. Es en los sítios elevados como Cucarra o PEMA4 donde observamos un reavivado de los filos en algunas de sus piezas, lo que nos indica que fueron visitados en sucesivas ocasiones. La localización en cueva, para este periodo, se encuentra en una zona elevada junto a un cañon kárstico que debió ser utilizado para capturar animales de montaña, mediante emboscadas y despeñamientos y donde se trabajaba sobre elementos vegetales y se procesaba carne como lo atestigua el estudio preliminar de traceología.

Ya en el Paleolítico superior, se produce una reducción de los lugares ocupados. En los muestreos geoarqueológicos y en las investigaciones anteriores no se ha localizado ningún yacimiento al aire libre, ni siquiera industria lítica propia de este periodo y que evidencie estos primeros momentos del cambio cultural. La única muestra más clara es en un raspador carenado localizado en Cucarra y que está en las cercanías de la Cueva de Ardales, el resto de las evidencias se centran en las dos cavidades objeto de nuestro estudio, Cueva de Ardales y Sima de Las Palomas y que están vinculadas a zonas elevadas para el control y observación de los animales.

Por el momento aunque sabemos que el descenso de la población de los grupos de final del Paleolítico medio es un fenómeno conocido en el sur de la Península, en 
nuestro caso aún no podemos explicar este cambio y lo interpretamos como un cambio brusco en las condiciones climáticas que propiciaron el acantonamiento en las cuevas de los grupos humanos a lo largo del Paleolítico superior. Los resultados que obtengamos de las intervenciones arqueológicas en las dos cavidades nos darán más información acerca de lo ocurrido en ese lapso de tiempo y, quizás, podamos saber que ocasionó ese cambio del patrón de asentamiento y si realmente se debió a un cambio brusco del clima o no.

Si analizamos los ambientes más utilizados observamos como en el Paleolítico inferior hay una utilización predominantemente en zonas fluviales, con ocupación de terrazas pleistocénas (Hoyos de Barbú, terraza de Peñarrubia y La Puente), en el Paleolítico medio hay una ampliación de las zonas ocupadas manteniendo los espacios en terrazas utilizados en el Paleolítico inferior (depósito Hundilón, Llanos de Belén, terraza de Las Grajeras, Morenito, terraza La Puente) y, alternando con algunas zonas de valle (Raja del Boquerón, Lomas del Infierno), localizaciones en zonas altas (Cucarra, PEMA4) y cuevas (Sima de Las Palomas). En el Paleolítico superior sólo se ha documentado por el momento una ocupación (Cueva de Ardales), aunque hay indicios arqueológicos en Sima de Las Palomas, serán ratificados a lo largo de las intervenciones arqueológicas. Podemos suponer con ello que tienen un gran control del territorio, explotando todos los ambientes disponibles.

Un rasgo que consideramos importante es que los yacimientos asociados a industrias del Paleolítico medio y que están localizados en las terrazas del río Turón se encuentran en la misma cota. Si observamos un mapa topográfico donde aparece el nivel del río original, podemos plantearnos una estrecha relación entre estos yacimientos considerados independientes y, que en nuestra opinión, formarían parte de un mismo asentamiento cuyos materiales están asociados a industrias del modo III o Musteriense, dado que la altura original sobre el río permitiría el paso favoreciendo la utilización de ambas orillas, aunque en la actualidad el embalse dificulta la interpretación real de este espacio.

Una vez analizados cada uno de los espacios donde se ubican los asentamientos, vemos, a nivel general, como todos, salvo PEMA4, se organizan en torno a los cursos de fluviales principales, el río Turón y el río Guadalteba. Aprovechan diferentes ambientes en terrazas, valles y zonas de montaña, donde las materias primas se localizan bajo los propios asentamientos o en zonas muy cercanas a ellos, sin necesidad de grandes desplazamientos para su obtención, lo que les permite un abastecimiento allí 
mismo y la posibilidad de realizar diversas actividades, como la caza, la pesca y la recolección.

Las evidencias arqueológicas más cercanas al área de estudio las documentamos a unos 40-50 km de distancia. Para el Paleolítico medio con las localizaciones en cueva como Bajondillo (Torremolinos), Complejo del Humo (Cala del Moral, Málaga) o la cueva de las Grajas (Archidona). Los yacimientos al aire libre son más escasos aunque no significa que sean inexistentes sino que hay que replantearse la revisión de sitios y aplicar una metodología apropiada. Para Paleolítico superior contamos con la cueva de la Pileta (Benaojan), la cueva del Tesoro (Rincón de la Victoria) o la cueva de Nerja. En el caso del Paleolítico inferior, las evidencias más cercanas las encontramos en las terrazas del río Corbones con abundante material lítico y en algunas cavidades como cueva de Bajondillo (Torremolinos) o Complejo del Humo (Cala del Moral, Málaga).

Ante esto, planteamos la posibilidad de que si existiese una movilidad de los grupos humanos del Paleolítico medio y superior, esta se realizaría con un desplazamiento norte-sur, hacia zonas las costeras, en aquellos momentos que consideraran oportunos, aprovechando los periodos de caza para desplazarse a zonas del interior. Sin embargo, las condiciones ecológicas de la zona y la abundancia de materias primas cercanas, sin necesidad de mucho esfuerzo para su obtención, con importantes cursos de agua y varias surgencias, así como la existencia de zonas lacustres dentro del área de estudio, también nos sugiere que los grupos humanos pudieron vivir en este entorno durante todo el año, haciendo incursiones esporádicas a otras zonas. 


\section{Conclusiones}

Cuando iniciamos este trabajo nos planteábamos la posibilidad de que existiese una relación directa entre los yacimientos del Pleistoceno y los recursos líticos localizados en las terrazas y en los afloramientos cercanos y así poder establecer unos patrones de asentamiento y un modelo de movilidad de estos grupos humanos en función de los recursos existentes. Pero, para poder llegar a este objetivo, era necesario analizar los yacimientos conocidos y localizar nuevos yacimientos durante el desarrollo de nuestra tesis y había que definir su secuencia cronológica para permitir su posterior comparación con las secuencias cronológicas de otros lugares. También era necesario analizar el registro arqueológico, con ayuda de otras disciplinas como la Arqueometría o la Geoarqueología.

Tras nuestra investigación destacamos la importancia del análisis del registro arqueológico de superficie. En este caso, realizamos muestreos geoarqueológicos primero y una prospección arqueológica después, siendo esta última la herramienta más efectiva para las localizaciones al aire libre, sobre todo para el Paleolítico inferior y medio. Nos interesó especialmente el reconocimieno espacial y territorial para esclarecer lo que denomina Butzer como escala macroespacial (Butzer, 2007: 272-273), donde el artefacto se convierte en la unidad básica de investigación y en la que la disponibilidad de los recursos tanto bióticos como abióticos generarán unos patrones de movilidad distintos.

La ayuda de otras ciencias interdisciplinares como la Arqueometría o la Geoarqueología también nos ha sido de gran importancia. Sin ellas no hubiesemos podido establecer las áreas de captación de la industria lítica ni comprender los procesos de formación y alteración que afectan a los yacimientos y, en consecuencia, a sus industrias.

Hemos muestreado y recogido gran cantidad material arqueológico y geológico de sílex, radiolaritas, areniscas compactas y cuarcitas. Con las muestras recogidas hemos elaborado un total de 56 láminas delgadas, cuyo análisis por medio de la microscopía óptica nos ha permitido caracterizar los materiales procedentes de las diferentes formaciones geológicas, las características que presentan cada una de ellas según su lugar de procedencia y por tanto sus peculiaridades y así poder identificar el material arqueológico y relacionarlo con las fuentes de materia prima de donde se ha extraido u obtenido. 
De todo ello se extraen las siguientes conclusiones en relación con la materia prima de la industria analizada:

- La materia prima predominante es el sílex jurásico frente al Cretácico.

- La materia prima es local y se localiza a poca distancia, en su mayoría arrastrada de los ríos o en afloramientos tabulares de depósitos semiprimarios, que en ocasiones se encuentran bajo el propio yacimiento arqueológico.

- La arenisca compacta y la cuarcita o protocuarcita es utilizada para la elaboración de macroutillaje y proceden de las propias terrazas fluviales y de afloramientos situados en las cercanías de las terrazas.

- El sílex y la radiolarita son utilizados para las industrias más elaboradas con predominio de los sílex masivos frente a los oolíticos, porosos o bandeados. La radiolarita únicamente aparece termoalterada en dos yacimientos Sima de Las Palomas y en Cucarra. En su mayoría proceden de depósitos secundarios asociados a los cursos fluviales donde la materia prima es abundante arrastrados de los afloramientos semiprimarios muy próximos a los cursos fluviales principales.

Con relación al análisis de la industria lítica hay unas características que definen tecnológicamente a cada uno de los conjuntos analizados:

- Las areniscas compactas y las cuarcitas o protocuarcitas no presentan una talla compleja y aprovechan las formas naturales de los cantos.

- Los cantos tabulares de sílex, debido a su morfología, son más propicios para la extracción de lascas. Son trabajados directamente sin una preparación previa de las tabletas de sílex.

- Los núcleos de sílex localizados no muestran un agotamiento excesivo, quizás por la abundancia de material. Estos núcleos en su mayoría proceden de cantos tabulares que facilitan la extracción de lascas sobre todo internas, desarrollando técnicas de talla más complejas.

- Existe una presencia mayoritaria de pátinas.

- Presencia mayoritaria de los temas operativos indirectos o TOTI para la obtención de BP y BN2G.

- Predominio de núcleos o BN1G de tipo centrípeto y unipolar. 
- Escasa presencia de BP-D (descortezado) y BP-SD (semidescortezado), tanto en los yacimientos al aire libre como en las cuevas, posiblemente por la forma de la materia prima en tabletas, en la que el cortex es casi inexistente.

- Las BP son el grupo más numeroso, con una buena presencia de lascas anchas y laminares.

- Las BP y los productos o BN2G son en su mayoría internas y levallois de mediano y gran tamaño.

- Las BP y las BN2G obtenidas en las dos cuevas analizadas presentan un predominio de talones facetados y tamaños medianos y pequeños. Sin embargo, en el resto de localizaciones al aire libre, son mayoritarios los talones lisos seguidos de los facetados.

- Las BN2G están realizadas en su mayoría sobre BP-I.

- Presencia mayoritaria de bifaces frente a hendedores o cantos trabajados.

- Predominio de raederas y muescas en todos los yacimientos.

- Los raspadores aparecen en los yacimientos situados en zonas altas y no vinculadas a terrazas fluviales.

- Hay un reavivado y, por tanto, una reutilización de las piezas en dos yacimientos del Paleolítico medio, como son Cucarra y PEMA4.

La funcionalidad de los asentamientos parece manifestar una estrategia de subsistencia basada en la utilización diferenciada del medio físico y de sus recursos:

- Los yacimientos localizados en las terrazas fluviales y en las zonas de valle o llanos parecen presentar tanto en el Paleolítico inferior como en el Paleolítico medio una diversidad funcional, para la caza, pesca y recolección, dado que son lugares en los que se pueden abastecer de los distintos recursos, con visitas esporádicas pero continuas y con una presencia de agua constante, no sólo de las surgencias.

- Las zonas altas y de cueva ejercen un control visual sobre los ambientes montañosos y valles, con evidencias de actividades de caza y del trabajo de elementos vegetales. 
Hay que decir que el hecho de que un yacimiento tenga más o menos material que otro no es indicativo de una escasa actividad o se deba considerar como un lugar de visitas esporádicas, dado que, en nuestro caso, el efecto erosivo de los embalses a alterado algunos de los yacimientos por lo que no podemos asegurar que tuviese visitas más o menos frecuentes.

El estudio de los travertinos de la zona permite correlacionar geocronológicamente los niveles de las terrazas del río Guadalteba y Turón con una etapa Post-Villafranquiense de edad aproximada entre los 2, 97 Ma y 2,04/1,78 Ma, con un Pleistoceno medio entre 250/128 ka BP y un Pleistoceno superior con un periodo de edad entre 130/128 ka BP y 118/115 ka BP hasta 11.784 años de calendario, estos datos a su vez permiten establecer su relación con las industrias líticas localizadas en dichas terrazas cuyas características tecnotipológicas corroboran la presencia humana en este territorio desde el Paleolítico inferior hasta el superior.

Cuando analizamos las materias primas localizadas en cada uno de los yacimientos estudiados y la distribución de las áreas de captación vemos que existe una ocupación de un territorio que se circunscribe en torno a las dos cuencas fluviales principales como son el río Guadalteba y el río Turón, donde las materias primas explotadas tienen un carácter local, y sin evidencias, hasta el momento, de sílex exógenos en el registro arqueológico. Ante esta circunstacia consideramos que, aunque existen varias posibilidades respecto a la movilidad de estos cazadores-recolectores, el territorio de la comarca del río Guadalteba durante el Paleolítico, en función de los estudios preliminares de las especies vegetales y animales, era un entorno con gran variedad de recursos, incluyendo importantes cursos fluviales, manantiales y surgencias de aguas sulfurosas, lo que favorece la habitabilidad de la zona durante todo el año, con la posibilidad de que se realizaran incursiones a otras zonas para una agregación social o para obtener otro tipo de recursos inexistentes en la zona, como pudieran ser los marinos.

En conclusión, podemos decir que futuras investigaciones en nuestra área de estudio, que se acometerán en breve, y en zonas cercanas a la misma, las cuales adolecen de una falta de investigación sobre el poblamiento humano al aire libre, nos permitirá, en un futuro, establecer posibles relaciones o diferencias entre los distintos grupos del Paleolítico y ver si, el modelo de ocupación territorial que planteamos en esta tesis doctoral, es extensible a otras zonas geográficas, en un intento de comprender el funcionamiento y la movilidad de estas sociedades humanas del Pleistoceno. 


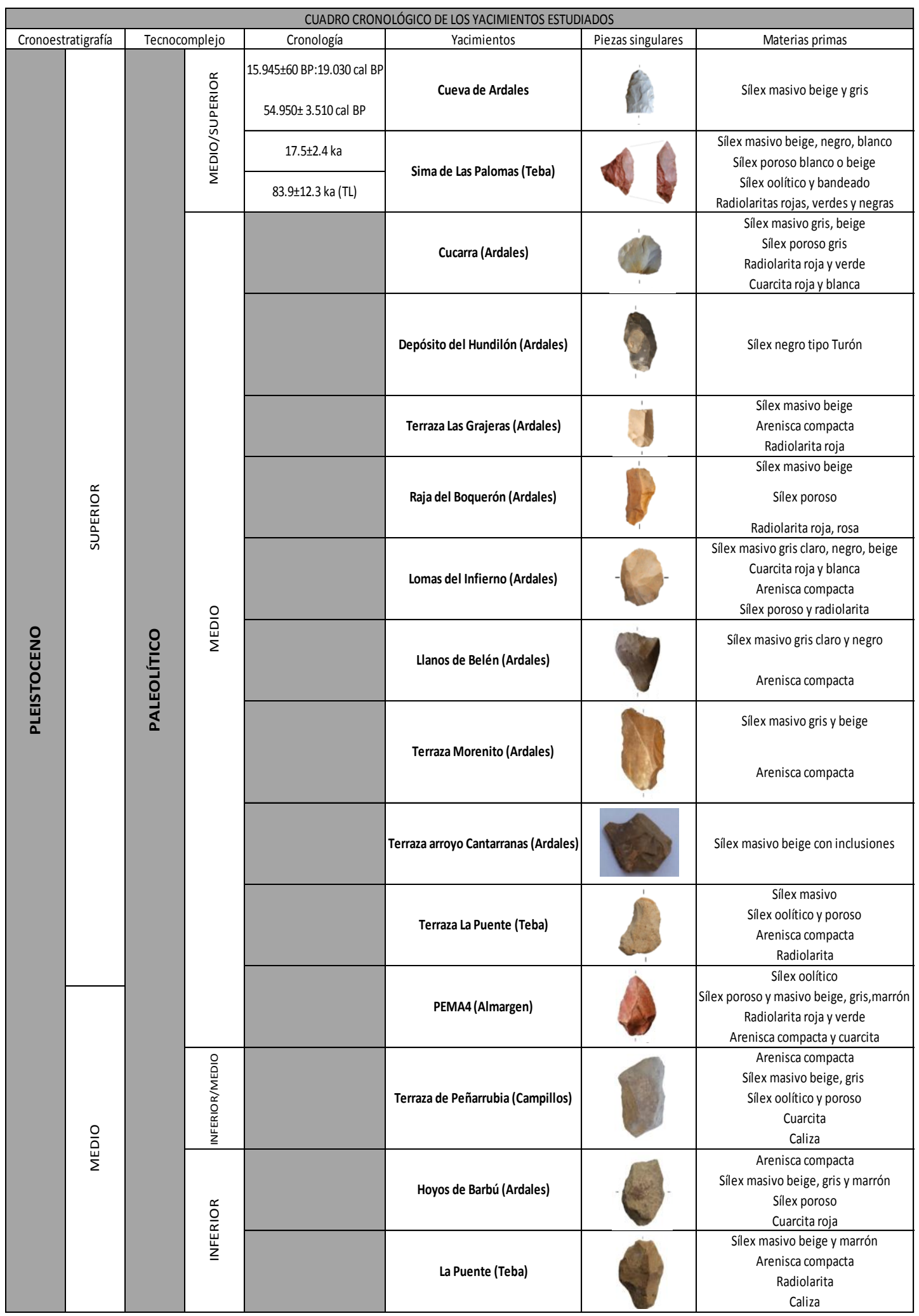

Figura 148. Cuadro cronológico con los yacimientos estudiados. 


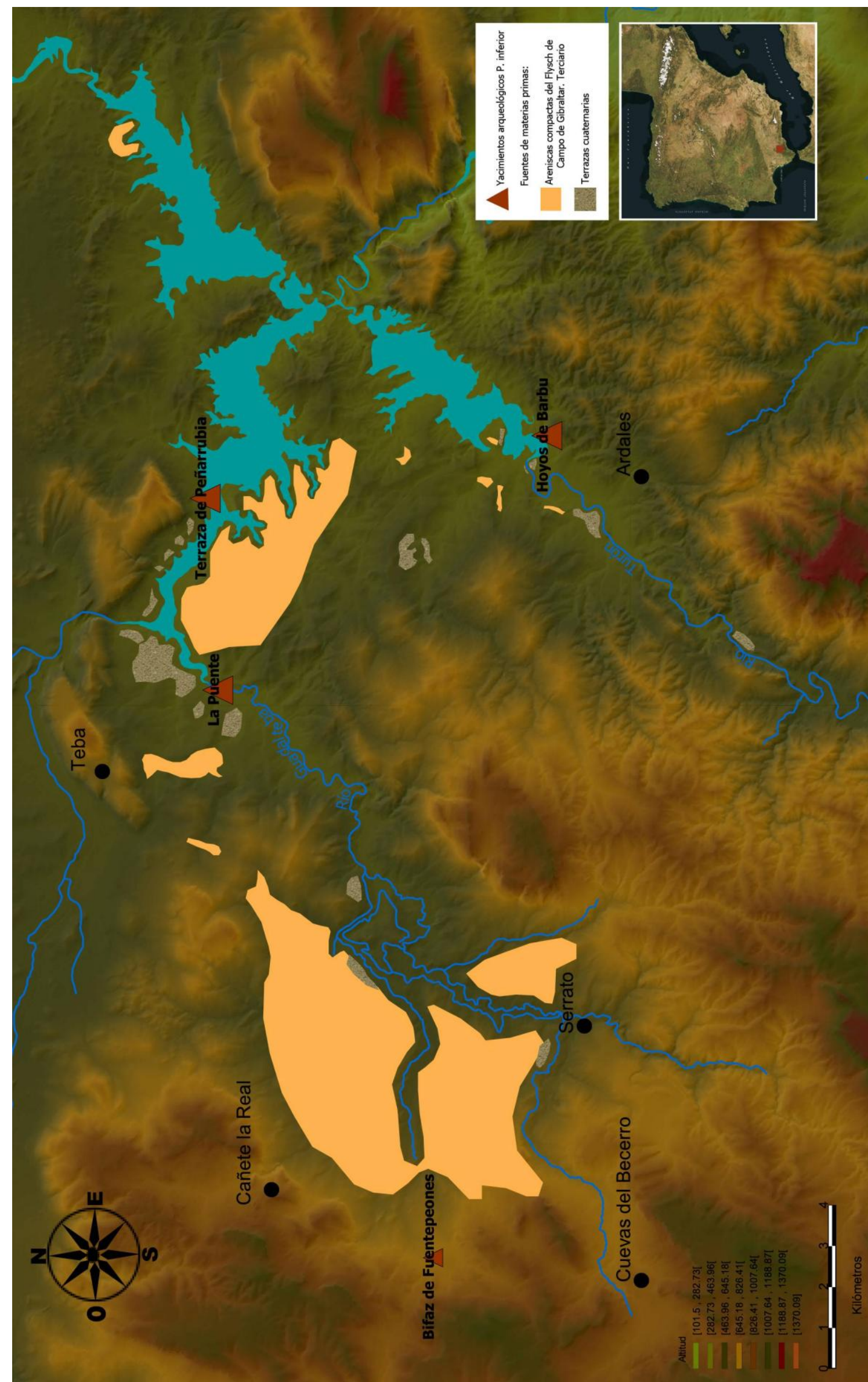

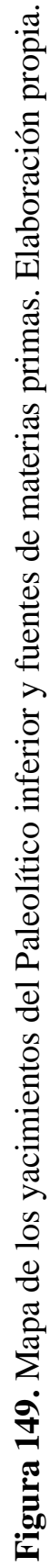




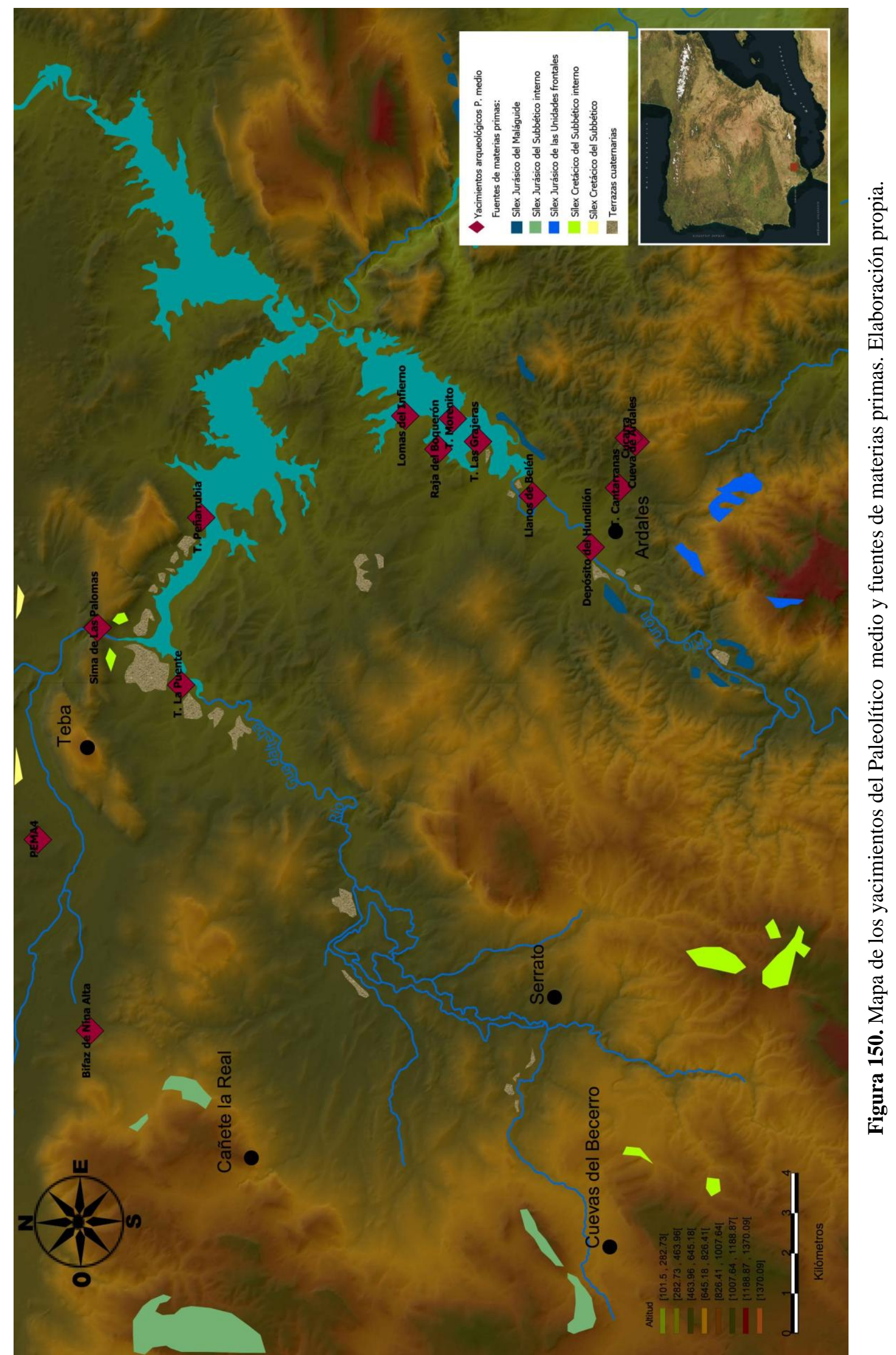




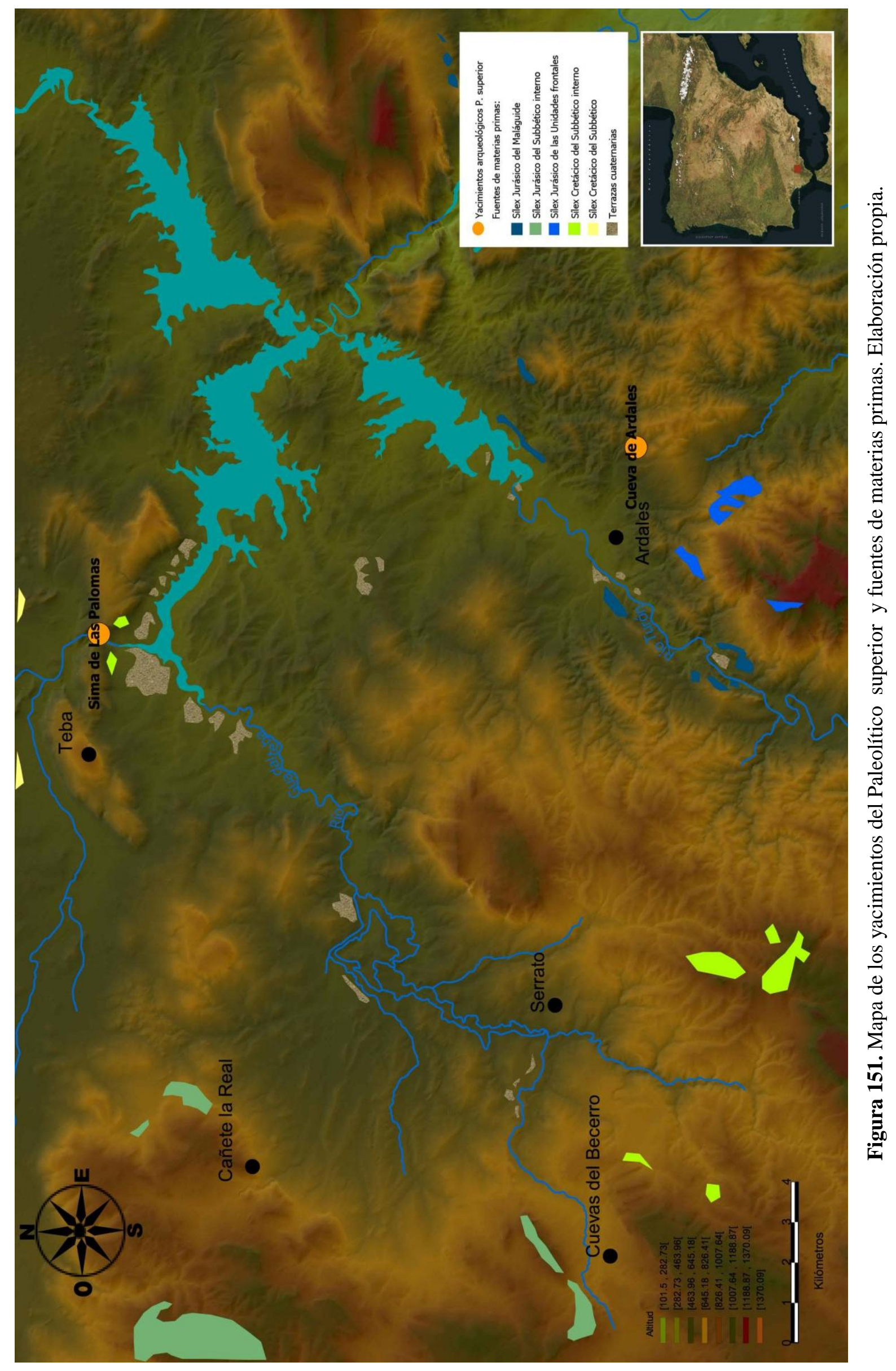




\section{Bibliografía}

- AA.VV. (1990a): Mapa Geológico de España, escala 1:50.000, Teba. Hoja 1037, 15-43. Segunda serie-primera edición. Instituto Tecnológico Geominero de España, Madrid.

- AA.VV. (1990b): Mapa Geológico de España, escala 1:50.000, Ardales. Hoja 1038, 16-43. Segunda serie-primera edición. Instituto Tecnológico Geominero de España, Madrid.

- AA.VV. (1986a): Mapa Geológico de España, escala 1:50.000, Campillos. Hoja 1022, 15-42. Segunda serie-primera edición. Instituto Tecnológico Geominero de España, Madrid.

- AA.VV. (1986b): Mapa geológico de España, escala 1:50.000, Antequera. Hoja 1023, 16-42. Segunda serie-primera edición. Instituto Tecnológico Geominero de España, Madrid.

- AA.VV. (1977): Mapa geotécnico general. Escala 1:200.000. Hoja 4-11/82. Morón de la Frontera. Instituto geológico y minero de España. Madrid.

- AA.VV. (1998): Atlas hidrogeológico de Andalucía. Instituto Tecnológico Geominero de España. Consejería de obras públicas y transportes de la Junta de Andalucía. Consejería de trabajo e industria de la Junta de Andalucía.

- AA.VV. (2008): Plan general de ordenación urbanística de Campillos. Ayuntamiento de Campillos. Málaga.

- AA.VV. (2007): Atlas hidrológico de la provincia de Málaga. Escala 1:200.000. Instituto geológico y minero de España; diputación de Málaga. Madrid.

- ABAD MIR, S. (2006): “Arqueología de la muerte. Algunos aspectos teóricos y metodológicos". Historiae, 3: 1-23.

- AMMERMAN, A.J. (1981): "Surveys and Archaeological Research". Annual Review of Anthropology, 10: 63-88.

- $\quad$ ANSCHUETZ, K. F. WILSHUSEN R. H.; SCHEICK CH. L. (2001): "Una arqueología de los paisajes: perspectivas y tendencias". Journal of Archaeological Research, 9 (2): 152-197.

- ARDILA, G. (2006): "Ingeniería y Territorio: una relación política indisoluble". Palimpsesto 5: 60-67. 
- ARDUENGO GARCÍA, D. A. (2007): "La formación del registro arqueológico en la villa de san Cristóbal de la Habana en el siglo XVI". XVI Congreso nacional de Arqueología Argentina, Jujuy.

- BLANCO FERNÁNDEZ, M. (2010): "Problemática del estudio de yacimientos superficiales del Paleolítico inferior y medio, en la provincia de Ávila”. El futuro del pasado, 1: 109-123.

- BAGOLINI, B. (1968): "Ricerche sulle dimensioni dei manufatti litici prehistorici non ritoccati”. Annalli dell'Universitá di Ferrara XV (I), 10 195219.

- BARABÁS, A.M. (2010): "El pensamiento sobre el territorio en las culturas indígenas de México". Avá, 17: 11-22.

- BARAÑANO CID, A. (2010): "Introducción a la Antropología Social y Cultural. Materiales docentes para su estudio”. E-Prints Complutense.

- BARRIOS, I. (1985): "La edafologia: origen, desarrollo y conceptos". Vasconia. Cuadernos de sección. História-Geografía, 5: 89-113.

- BARDAJÍ, T.; ZAZO, C. (2009): "El cuaternario: un "nuevo" periodo en la escala geocronológica global” Enseñanza de las Ciencias de la Tierra, 17.1: $37-43$.

- BECERRA PARRA, M. (2006): "Algunas consideraciones sobre flora amenazada presente en el entorno de los valles de los ríos Turón y Guadalteba (Comarca del Guadalteba, Málaga). Patrimonio Guadalteba. Revista de la Asociación para la defensa del Patrimonio Histórico y Natural de la Comarca del Guadalteba (Bobastro), 1: 126-132.

- BELLELI, C. (2001): “Arqueología: cómo el presente desvela el pasado”. La trama Cultural. Textos de antropología y arqueología. $2^{a}$ edición. Argentina: $61-74$.

- BELLÓ M. A. (2011): "Espacio y territorio en perspectiva antropológica. El caso de los purhépechas de Nurío y Michoacán en México". Revista CUHSO, 21 (1). Art. 119.

- BINFORD, L (1994): En busca del pasado. Ed. Crítica.

- BOISMIER, W.A. (1989): "Recognising and controlling for cultivationinduced patterning in surface artefact distributions" En Rahtz y Richards (eds.): Computer applications and quantitative methods in archaeology 1989. BAR, International Series, 548, Oxford: 133-145. 
- BORDES, F. (1961): Typologie du Paléolithique Ancien et Moyen. Bordeaux, Publications de l'Institut de Préhistorie de l'Université de Bordeux. Bordeaux. Mémorie 1.

- BREUIL, H. (1921): “Nouvelles Cavernes Ornées Paleolithiques dans la province de Málaga”. L`Antropologie, XXXI, París: 239-250.

- BREUIL, H.; BURKITT, M. (1929): Rock Paintings of Southern Andalusia. Oxford.

- BURILlO MOZOTA, F. (1997): "Prospección arqueológica y geoarqueología". Actas del II Encuentro sobre arqueología y Patrimonio, Granada: 117-132.

- BUTZER, K. (2007): Arqueología, una ecología del hombre. Ed. Bellaterra.

- CÁMARA SERRANO, J.A.: (2011): "El desarrollo de los estudios sobre la Prehistoria Reciente en Andalucía oriental a partir del análisis territorial. Los últimos 25 años. Memorial Luis Siret. I Congreso de Prehistoria de Andalucía. La tutela del patrimonio prehistórico, Antequera: 189-206.

- CANTALEJO DUARTE, P.; MAURA MIJARES, R.; ESPEJO HERRERÍAS, MåM.; RAMOS MUÑOZ, J.; MEDIANERO SOTO, J.; ARANDA CRUCES, A.; MORA DOMÍNGUEZ, J.; BECERRA PARRA, M.; CASTAÑEDA, V. (2003): “Sobre los temas, las técnicas de ejecución y representación del Arte Paleolítico conservado en la Cueva de Ardales (Málaga)". Avance Pliocénica, 3: 54-61.

- CANTALEJO DUARTE, P.; MAURA MIJARES, R.; ESPEJO HERRERÍA, MaM.; RAMOS MUÑOZ, J.; MEDIANERO SOTO, J.; ARANDA CRUCES, A.; CASTAÑEDA, V.; CÁCERES, I. (2004): “Cueva de Ardales (Málaga): Testimonios gráficos de la frecuentación por formaciones sociales de cazadores- recolectores durante el Pleistoceno Superior”. Jornadas temáticas andaluzas de Arqueología, Sevilla: 123-138.

- CANTALEJO DUARTE, P.; MAURA MIJARES, R.; ESPEJO HERRERÍAS, Ma.M.; RAMOS MUÑOZ, P.; MEDIANERO SOTO, J.; ARANDA CRUCES, A.; DURÁN VALSERO, J.J. (2006): La Cueva de Ardales: arte prehistórico y ocupación en el Paleolítico Superior. CEDMA. Diputación provincial de Málaga. 
- CANTALEJO DUARTE, P., MAURA MIJARES, R. y BECERRA PARRA, M. (2006): Arte rupestre prehistórico en la Serranía de Ronda. Ed. La Serranía. Ronda.

- CANTAlejO DUARTE, P. (2007): Naturaleza y Seres Humanos en la Comarca del Guadalteba. Ed. La Serranía. Ronda

- CARbonell, E., MOSQUera, M., Ollé, A., SAlA, R., VAQUERO, M. y VERGES, J. M. (1992): "New elements of the Logical Analytic System". Cahier noir, 6: 61.

- CARBONELL I ROIRA, E; RODRÍGUEZ, JP.; SALA, R.; VAN DER MADE, J.; LORENZO, C.; MOSQUERA, M.; VAQUERO, M.; ROSELL, J.; VALLVERDÚ, J.; BURJACHS, F.; HORTOLÁ, P. (2011): HOMÍNIDOS las primeras ocupaciones de los continentes. Ed. Ariel.

- CARBONELl I ROIRA, E.; RODRIGUEZ, X.P. (2002): “El Sistema Lógic Analític: origen, desenvolupament i Perspectives de futur". COTA ZERO, 17, Vic: 106-116.

- CARBONELl I ROIRA, E.; GUILBAUD, M.; MORA TORCAL, R. (1983): "Diferenciación morfotecnica y diacronismo en el paleolítico medio catalán" VI reunión do grupo español de traballo de quaternario, Galicia: 73-109.

- CARRIÓN MÉNDEZ, F.; GARCÍA GONZÁlEZ, D.; LOZANO RODRÍGUEZ, J.A. (2004): "Métodos y técnicas para la identificación de las fuentes de materias primas líticas durante la Prehistoria Reciente" III Reunión de trabajo. Aprovisionamiento de recursos abióticos en la Prehistoria. Loja: 45-61.

- CLEMENTE CONTE, I. (2014): "Estudio preliminar del análisis macro y microscópico de una selección de piezas líticas de Sima de Las Palomas”. En Weniger, G.; Ramos Muñoz, J. (eds.): Sima de Las Palomas Teba (Málaga). Resultados de las investigaciones 2011-2014: 179-185. Ed. Pinsapar.

- CERRATO CASADO, E. (2011): “La prospección arqueológica superficial. Un método no destructivo para una ciencia que sí lo es". Arte, arqueología e história, 18: 151-160. 
- CHAPA BRUNET, T.; URIARTE GONZÁLEZ, A.; VINCENT GARCÍA, J.M.; MAYORAL HERRERA, V.; PEREIRA SIESO, J. (2003): "Propuesta metodológica para una prospección arqueológica sistemática: el caso del Guadiana Menor (Jaén, España)". Trabajos de prehistoria 60 (1), Madrid: 11-34.

- COLINO POLO, F. (2007): "El concepto de paleolítico inferior y medio en las industrias de finales del Pleistoceno Medio". Arqueoweb. Revista sobre arqueología en internet. 9 (1).

- CONDE RUIZ, C.; BAENA PREYSLER, J.; CARRIÓN SANTAFÉ, E. (2000): “Los modelos de explotación de los recursos líticos durante el Pleistocenos en la región de Madrid”. SPAL 9: 145-166.

- CORTÉS SÁNCHEZ, M. (2007): El Paleolítico Medio y Superior en el sector central de Andalucía (Córdoba y Málaga). Monografías Museo de Altamira. Ministerio de Cultura.

- CRIADO BOADO, F (1995): "Construcción social del espacio y reconstrucción arqueológica del paisaje”. En La perspectiva espacial en arqueología, Tucuman, Buenos Aires: 75-111.

- DAVIDSON, I.; BAYLE, G.N. (1984): “Los yacimientos, sus territorios de explotación y la topografia”. Boletín del Museo Arqueológico Nacional II, Madrid: 25-46.

- DE LA PEÑA ALÓNSO, P. (2007): “La "piedra tallada" como instrumento para la Prehistoria: historiografía, aportaciones y reflexiones”. Arqueoweb. Revista sobre arqueología en internet. 9(1).

- DE LA PEÑA ALONSO, P. (2009): “Revisión crítica de los conjuntos líticos gravetienses y su contexto arqueológico en la Península Ibérica”. Complutum, 20 (1): 29-53.

- DE LA TORRE, I.; MARTÍNEZ-MORENO, J.; MORA, R. (2013): “Change and stasis in the Iberian middle paleolithic. Considerations on the Significance of Mousterian Technological Variability". Current Anthropology, 54. S8: 320-336.

- DELIBES DE CASTRO, G. (1999): “Arqueólogos, antropólogos, historiadores". Revista de Floklore, 221: 160-165. 
- DIEZ MARTÍN, F. (2010): "El arado y los yacimientos paleolíticos. Una década de investigación sobre el efecto del laboreo en los páramos del Duero". Complutum, 21 (1): 45-68.

- DIEZ MARTÍN, F. (2009): “La arqueología de los espacios arados. Algunas puntualizaciones". BSAA arqueología, LXXV: 23-40.

- DIEZ MARTÍN, F. (2007):'La arqueología del paisaje en la investigación paleolítica". Arqueoweb. Revista sobre arqueología en internet. 9 (1).

- DIEZ MARTÍN, F. (2003): "Las alteraciones inducidas por el laboreo agrícola: la influencia del movimiento vertical en los yacimientos paleolíticos de los páramos de Montemayor-corcos (Valladolid y Burgos)”. Zhephyrus, 56: 49-60.

- DIEZ MARTÍN, F. (1997): "Reflexiones sobre la arqueología superficial. Valoración de su problemática y utilidad potencial en los yacimientos paleolíticos de la Meseta". Boletín del Seminario de Estudios de Arte y Arqueología, 63: 9-29.

- DOMINGUEZ-BELLA, S.; RAMOS MUÑOZ, J.; WENIGER, GERD.; CANTALEJO DUARTE, P.; ESPEJO HERRERÍAS, M.Mª ; MEDIANERO SOTO, J.; BECERRA MARTÍN, S.; CABELLO LIGERO, L.( 2014): "Materias primas líticas. Estudios arqueomineralógicos y geoarqueologicos". En Ramos Muñoz, J.; Weniger, G.; Cantalejo Duarte, P.; Espejo Herrerías, M. $\mathrm{M}^{\mathrm{a}}$ (coords.): Cueva de Ardales 2011-2014. Intervenciones arqueológicas: 147-153. Ed. Pinsapar.

- DUNNELL, R. (1992): “The notion site”. En Rossignol y Wandsnider (eds.) Space, Time and Archaeological Landscape: 21-41. Plenum press.

- DUNNELL, R.; DANCEY, W. (1983):” The Siteless Survey: A Regional Scale Data Collection Strategy". Advances in Archaeological Method and Theory, 6: 267-287.

- DURÁN VALSERO, JJ. (1996): Los sistemas kársticos de la provincia de Málaga y su evolución: contribución al conocimiento paleoclimático del cuaternario en el mediterráneo occidental. Tesis doctoral. Universidad Complutense de Madrid. Facultad de Ciencias Geológicas. Departamento de Geodinámica.

- DURÁN VALSERO, JJ., ROBLEDO ARDILA, P. (2014): "Enmarque geológico. Génesis, evolución y geocronología". En Ramos Muñoz, J.; 
Weniger, G.; Cantalejo Duarte, P.; Espejo Herrerías, M.Ma (coords.). Cueva de Ardales 2011-2014. Intervenciones arqueológicas: 27-35. Ed. Pinsapar.

- DURÁN VALSERO, JJ. (1987): “Cueva de Ardales. Geología”. Cueva de Ardales su recuperación y estudio: 47-56. Ayuntamiento de Ardales.

- DURÁN VALSERO, J.J; GRÜN, R.; FORD, D. (1992): “Cueva de Ardales. Geocronología evolutiva desde el Pleistoceno Superior hasta la actualidad y su relación con los cambios paleoclimáticos". Cueva de Ardales. Su recuperación y estudio: 57-66. Ardales (Málaga).

- DYSON-HUDSON, R.; SMITH, E.A. (1978): "Human territoriality: an ecological reassessment". AMERICAN ANTHROPOLOGIST, 80 (1): 21-41.

- ESPEJO HERRERÍAS, Mª M.; CANTALEJO DUARTE, P. (1988):"Cueva de Árdales, yacimiento recuperado”. Revista de Arqueología, 84, Madrid: 14-24.

- ESPEJO HERRERÍAS, Màm; RAMOS MUÑOZ, J.; CANTALEJO DUARTE, P.; MARTÍN CÓRDOBA, E. (1989): “Análisis espacial e histórico en el valle del río Turón”. Revista de Arqueología, 93, Madrid: 2937.

- ESPEJO HERRERÍAS, M M M.; CANTALEJO DUARTE, P. (1990): "Informe sobre las prospecciones arqueológicas superficiales realizadas en el valle del río Turón. Málaga”. Anuario Arqueológico de Andalucía II, Sevilla: 108 y ss...

- ESPEJO HERRERÍAS, Ma.M.; RAMOS MUÑOZ, J.; RECIO RUIZ, A.; CANTALEJO DUARTE, P.; MARTÍN CÓRDOBA, E. (1994): “Cerro de las Aguilillas. Necrópolis colectiva de cuevas artificiales”. Revista de Arqueología, 161, Madrid: 14-23.

- FERNÁNDEZ CARO, J.J. (2007): “Las industrias líticas paleolíticas del Bajo Guadalquivir: Rio Corbones (I)". Carel Carmona: Revistas de estudios locales, 5: 1985-2147.

- FERRER PALMA, J.E.; MARQUÉS MERELO, I. (1978): “Avance de las campañas arqueológicas realizadas en la Cueva de las Palomas. Teba (Málaga)". Baética I, Málaga: 195-199. 
- FERRER PALMA, J.E. y FERNÁNDEZ RUIZ, J. (1986/87): “Avance al estudio de la industria en sílex de la Cueva de las Palomas (Teba, Málaga)”. Mainake VIII-IX, Málaga: 5-14.

- GAllardo, F.; CORNEJO, L. (1986): "El diseño de la prospección arqueológica: un caso de estudio". Revista Chungará, 16-17. Universidad de Tarapacá, Arica, Chile: 409-420.

- GARCÍA, J. L. (2007): “Antropología del Territorio”. Taller de Ediciones Josefina Betancor, Madrid: 13-21.

- GARCÍA SÁNCHEZ, J. (2012): “Arqueología y paisaje en el noroeste de Burgos: la transición de la segunda edad del hierro a época romana a través del registro material”. Tesis Doctoral Universidad de Cantabria. Capítulo 5: 141-177.

- GARCÍA ALFONSO, E. (2007): En la orilla de tartessos. Indígenas y fenicios en las tierras malagueñas. Siglos XI-IV A.C. Ed. Fundación Málaga.

- GARCÍA ALFONSO, E.; MARTÍNEZ ENAMORADO, V.; MORGADO RODRÍGUEZ, A. (1995): El Bajo Guadalteba (Málaga). Espacio y poblamiento. Una aproximación arqueológica a Teba y su entorno. Excmo. Ayuntamiento de Teba. Diputación provincial de Málaga.

- GARCÍA SAN JUÁN, L. (2004): "La prospección arqueológica de superficie y los S.I.G”. En Martín de la Cruz, J. C. (coord.): I Encuentro Internacional Informática Aplicada a la Investigación y la Gestión Arqueológicas, Córdoba: 185-209.

- GIANOTTI GARCÍA, C. (2004): “La prospección como estrategia metodológica para el estudio del paisaje monumental en las tierras bajas uruguayas". Arqueología espacial, 24-25, Teruel: 259-282.

- GÓMEZ TARAZAGA, I. (2006). "Prospección arqueológica, jerarquía de poblamiento y sistema de registro". Studia historia, $H^{a}$ medieval, 24: 243274.

- GOZÁlEZ RUIBAL, A. (2003): La experiencia del otro: Una introducción a la etnoarqueología. Ed. Akal.

- GOY, J.L.; ZAZO, C.; RODRÍGUEZ-VIDAL, J. (1994): “Cordilleras Béticas-Islas Baleares”. En Díaz del Olmo, F.; Díaz del Río, V.; Goy, J.L.; Gutierrez Elorza, M.; Martín Serrano, A.; Martínez Pisón, E.; Pedraza, J.; Peña Monné, J.L.; Pérez González, A.; Pol Méndez, C.; Quirantes, F.; 
Rodríguez- Vidal, J.; Sala, M.; Somoza, L.; Ugarte. F.M.; Zazo, C. (1994). Geomorfología de España. Gutiérrez Elorza (coord.). Ed. Rueda.

- GUTIÉRREZ SOLER, L. M.; BELlÓ RUIZ, J.P. (2001): "Métodos de investigación y técnicas de análisis arqueológico aplicadas al estudio del territorio". Revista Mundo de antes, 2. Tucumán. Argentina.

- GUTIÉRREZ SOLER, L. M.; BELLÓ RUIZ, J.P.; CEPRIÁN DEL CASTILLO. B. (2007): "La Veguilla (Úbeda, Jaén). Prospección de superficie y caracterización del registro arqueológico". Caesaraugusta, 78: 781-792.

- GANDARA VAZQUEZ, M. (1981): “Algunas observaciones sobre los estudios de superficie en arqueología”. Cuicuilco, 4, México: 409-420.

- STRAUS, L.G. (2012): "El Solutrense: 40 años de reflexiones por un arqueólogo norteamericano". Espacio, tiempo y forma. Serie I, Nueva época $n^{\circ} 5: 27-36$.

- HERVÁS, F. J. M. (2000). "Prospección y excavación: principios metodológicos básicos". En El patrimonio arqueológico de Ciudad Real: métodos de trabajo y actuaciones recientes, Valdepeñas-Ciudad Real: 355368.

- JIMÉNEZ MANZANARES, A.; MARTÍN BLANCO, P.; SANGUINO GONZÁLEZ, J.; GÓMEZ DE LA LAGUNA, J.A. (1995): “El gran abanico fluvial del Guadiana Alto. Reflexiones en torno al concepto de yacimiento". Zephyrus XLVIII: 75-100.

- JORDÁ PARDO, J.F.; ZARZALEJOS PRIETO, M. (2012): “Las técnicas de obtención del dato arqueológico (I): la prospección arqueológica”. En Peréx Agorreta, M.J. (coord.) Métodos y Técnicas de Investigación Histórica I. UNED, Madrid: 151-225.

- JORDÁ PARDO, J.F. (2014): "El Cuaternario: Marco cronológico y paleoambiental de la Prehistoria". En Ripoll López (coord.) Prehistoria I Las primeras etapas de la Humanidad: 21-74.

- JORDÁ PARDO, J.F. (2006-2009): “Geoarqueología, de la teoría la práctica: interpretación de un yacimiento de la Edad del Hierro en la Península Ibérica” Xama 19-23, Mendoza- Argentina: 45-61. 
- JORDÁ PARDO, J.F. (1995): "El cuaternario: definición, limite inferior y divisiones". Zephyrvs, XLVIII, Salamanca: 53-74.

- JORDÁ PARDO, J.F. (1994): “La geoarqueología en la España de hoy”. I Congresso e arqueología peninsular. Separata das actas dos trabalhos de antropología e etnología, 34 (3-4). Porto.

- KEHL, M. (2014): “Sedimentología y geoquímica”. En Weniger, G.; Ramos Muñoz, J (eds). Sima de Las Palomas Teba (Málaga). Resultados de las investigaciones 2011-2014. Ed. Pinsapar.

- KEHL, M. (2014): “Sedimentología y micromorfología”. En Ramos Muñoz, J.; Weniger, G.; Cantalejo Duarte, P.; Espejo Herrerías, M.Mª (coords.) Cueva de Ardales 2011-2014. Intervenciones arqueológicas. Ed. Pinsapar

- LAPLACE, G. (1972): "La typologie analytique et structurale: Base rationnelle d'ètude des industries lithiques et osseuses". Banques de données archéologiques 932: 91-143.

- LAGUARDIA MARTÍNEZ, J. (2008): “Antropología sociocultural: Una visión general". Monografías.com.

- LHENAFF, F. (1967): Problemés géomorphologiques de la Vallée du Guadalhorce (Andalousie). Mélanges Casa de Velásquez, III: 5-28.

- LEROI-GOURHAN, A. (2002): La prehistoria en el mundo. Ed. Akal.

- LOMBERA HERMIDA, A. (2005): “Aplicación del sistema lógico analítico al estudio de un yacimiento gallego. La industria lítica de A Piteira (Toén, Ourense)". Gallaecia, 24: 7-33.

- LÓPEZ MARTÍNEZ, J.; DURÁN VALSERO, JJ. (1995): “Evolución geológica y del drenaje regional desde el Mioceno Superior hasta el Cuaternario en el entorno de el Chorro". Geología y Arqueología prehistórica de Ardales. Ayto. de Ardales: 11-29.

- MADOZ, P. (1850): Diccionario Geográfico y Estadístico de España y sus posesiones de Ultramar. Madrid.

- MANGADO LLACH, J. (2006): “El aprovisionamiento en materias primas líticas: hacia una caracterización paleocultural de los comportamientos paleoeconómicos". Trabajos de Prehistoria 63, 2: 79-91.

- MANGADO LLACH, J. (2002): "El aprovechamiento de materias primas líticas durante el Paleolítico Superior y el Epipaleolítico de Cataluña”. Cypsela 14: 27-41. 
- MANGADO LLACH, J. (2000): "El aprovechamiento de recursos minerales durante el Paleolítico y el Neolítico de Europa”. Primer Simposio sobre la Minería y la Metalúrgia Antigua en el SW Europeo, Serós 2000, 1.0: 7-36

- MARÍN, A. (2006): "Patrimonio natural de la Comarca del Guadalteba. I. Guadalteba: Miscelánea natural". Patrimonio Guadalteba. Revista de la Asociación para la defensa del Patrimonio Histórico y Natural de la Comarca del Guadalteba (Bobastro), 1: 112-115.

- MARÍN ARROYO, A.B. (2008): "Demografía y cambio ambiental. Hipótesis para el cambio económico en el Cantábrico Oriental durante el Tardiglacial”. Complutum, 19 (1): 47-66.

- MARTÍN BLANCO, P.; JIMÉNEZ MANZANARES, A.; SANGUINO GONZÁlEZ, J.; GÓMEZ LAGUNA, A.J. (1994): "Identificación de cadenas operativas líticas. En el sitio arqueológico «casa de la mina II» (Argamasilla de Alba, C. Real). Consideraciones acerca de los yacimientos superficiales sin contexto estratigráfico". Zehpyrus, XLVII: 15-40.

- MARTÍN CASARES, A. (2006): Antropología del género: culturas, mitos y estereotipos sexuales. Universitat de València.

- MARTÍNEZ VEIGA, U. (2008): Historia de la Antropología. Teorías, praxis y lugares de estudio. Uned, Madrid.

- MEDIANERO SOTO, J.; WENIGER, G-CH.; RAMOS MUÑOZ, J.; CANTALEJO DUARTE, P. (2014): “Localización geográfica y descripción de la cavidad". En Weniger, G.; Ramos Muñoz, J (eds.). Sima de Las Palomas Teba (Málaga). Resultados de las investigaciones 2011 - 2014: 2125. Ed. Pinsapar.

- MEDIANERO SOTO, J.; RAMOS MUÑOZ, J.; CANTALEJO DUARTE, P.; DURAN VALSERO, J.J.; WENIGER, G.; DOMÍNGUEZ BELLA, S.; ESPEJO HERRERÍAS, Ma . M. (2012): “La ocupación del territorio de la Comarca del Guadalteba (Málaga, Sur de España) por sociedades del Pleistoceno. Revista de Prehistoria de Andalucía. MENGA 03: 59-81. 
- MEDIANERO SOTO, J.; RAMOS MUÑOZ, J.; PALMQVIST, P.; WENIGER, G.; RIQUELME CANTAL, J.; ESPEJO HERRERÍAS, M.Mª; CANTALEJO DUARTE, P.; ARANDA CRUCES, A.; PÉREZ-CLAROS, J.A.; FIGUEIRIDO, B.; ESPIGARES, P.; ROS-MONTOYA， S.; TORREGROSA, V.; LINSTAEDTER, J.; CABELlO LIGERO, L.; BECERRA MARTÍN, S.; LEDESMA CONEJO, P.; MEVDEV, I.; CASTRO, A.; ROMERO, M.; MARTINEZ-NAVARRO, B. (2011): “ The karstic site of Las Palomas (Guadalteba, County, Málaga, Spain): a preliminary study of its Middle- Late Pleistocene archaeolopaleontological record". Quaternary International 243: 127-136.

- MEDIANERO SOTO, J.; RAMOS MUÑOZ, J.; CANTALEJO DUARTE, P.; ESPEJO HERRERÍAS M.M ${ }^{a}$; MAURA MIJARES, R.; DURÁN VALSERO, J. (2006): “ Grupos de cazadores- recolectores en la cuenca baja del río Guadalteba. Zonificación del área y aproximación a sus producciones líticas y contexto social (Parque arqueológico Guadalteba Campillos. Málaga). Patrimonio Guadalteba. Revista de la Asociación para la defensa del Patrimonio Histórico y Natural de la Comarca del Guadalteba (Bobastro), 1: 9-25.

- MEDIANERO SOTO, J. (2006): "Parque Guadalteba: la necrópolis de época visigoda en la Plataforma de Peñarrubia. Propuestas a un proceso histórico desconocido". Mainake XXVIII: 501-517.

- MEDIANERO SOTO, J.; RAMOS MUÑOZ, J.; CANTALEJO DUARTE, P.; y ESPEJO HERRERÍAS, M. ${ }^{a}$ M..; MAURA MIJARES, R. (2005): "Evidencias de actividad prehistórica y nuevas estructuras romanas en las eras de Peñarrubia, Parque Guadalteba (Campillos, Málaga)". Mainake XXVII: 303-321.

- MEDIANERO SOTO, J.; CANTAlEJO DUARTE, P.; MARTÍN RUIZ, J.A.; ESPEJO HERRERÍAS Ma ${ }^{\mathrm{a}}$ M.; RAMOS MUÑOZ, J. (2004): "Intervención Arqueológica de Urgencia en la Plataforma de Peñarrubia (Campillos, Málaga)". Anuario Arqueológico Andaluz, 2001: 291-293.

- MEDIANERO SOTO, J.; CANTALEJO DUARTE, P.; ESPEJO HERRERÍAS, Mª.; RAMOS MUÑOZ, J.; MARTÍN RUIZ, J.A. (2002): "Intervención arqueológica de urgencia en la Plataforma de Peñarrubia (Campillos, Málaga)". Mainake, XXIV: 375-386. 
- MENDIOLA GALVÁN, F. (2008): "Espacio, territorio y territorialidad simbólica. Casos y problemática de la arqueología en el norte de México". Nóesis. Revista de Ciencias Sociales y Humanidades, 17 (33), México : 1244.

- MERINO, (1994): “Tipología lítica”. Munibe (Antropología-Arkeologia) 9, San Sebastian: 1-477.

- MIÑANO, S. (1826): Diccionario Geográfico-Estadístico de España y Portugal. Tomo II. Madrid.

- MORA TORCAL, R.; MARTÍNEZ-MORENO, J.; DE LA TORRE, I.; CASANOVA, J. (2008): "Variabilidad técnica en el Paleolítico Medio: algunas reflexiones en torno a una cuestión clásica". Treballs d'Arqueología, 14: 5-8.

- MORA TORCAL, R.; MARTINEZ MORENO, J.; TERRADAS BATLLE, X. (1991): "Un proyecto de análisis: el sistema lógico analítico (SLA)". Tecnología y Cadenas Operativas Lítica U.A.B. Treballs d'Arqueologia, I: 15-18.

- MORA TORCAL, R. (1994): "El sistema lógico analítico". Munibe: 368386.

- MORGADO RODRÍGUEZ, A. (2002): Transformación social y producción de hojas de sílex durante la Prehistoria reciente de Andalucía oriental. La estrategia de la complejidad. Tesis doctoral. Universidad de Granada.

- MORGADO RODRÍGUEZ, A. (2005): "Desarrollo local y diversificación regional del Neolítico de las Cordilleras Béticas: la Comarca del Guadalteba (Málaga)". Actas del III Congreso del Neolítico en el Península Ibérica, Santander: 1045-1055.

- MOSQUERA MARTÍNEZ, M.; CARBONELl I ROURA, E. (1992): “La talla lítica en Atapuerca”. Trabajos de Prehistoria, 49: 131-154.

- MUÑOZ IBÁÑEZ, F.J. (2002): "Evolución tecnotipológica del utillaje paleolítico”. Capt. 20. En Ripoll López. Economía sociedad e ideología de los cazadores recolectores. Uned. Madrid.

- $\quad$ NAVAZO RUIZ, M.; DÍEZ, C. (2008): "Redistribution of Archaeological Assemblages in Plowzones". Geoarchaeology: An International Journal, 23 (3): 323-333. 
- NAVAZO RUIZ, M. (2006): Sociedades cazadoras-recolectoras en la Sierra de Atapuerca durante el Paleolítico medio: patrones de asentamiento y estrategias de movilidad. Tesis Doctoral. Inédita.

- NAVAZO RUIZ, M.; JORDÁ PARDO, F.J.; DIEZ FERNÁNDEZ, C. (2005): “Geoarqueología y registro arqueológico del paleolítico medio en el entorno de la sierra de Atapuerca (Burgos)". En M. Santonja, A. PérezGonzález, M.J. Machado (eds.) Geoarqueología y patrimonio en la Península Ibérica y el entorno del Mediterráneo. Adema. Soria: 235-250.

- OBERMAIER, H. (1925): El hombre fósil. Memorias de la Comisión de Investigaciones Paleontológicas y Prehistóricas, $n^{\circ}$ 9. Madrid. $2^{a}$ edición.

- OLARIA PUYOLES, C.R. (1999): “Antecedentes, tendencias y estado actual de la investigación del magdaleniense mediterráneo peninsular". Cap.1. Monografías de Prehistoria y Arqueología Castellonenses, 5: Cueva Matutano (Vilafamés, Castellón).

- ORELlANA, M. (1995-1996): "En torno al pensamiento de Binford". Revista Chilena de Antropología, 13: 15-28.

- OREJAS SACO DEL VALLE, A. (1995): Del marco geográfico a la arqueología del paisaje: la aportación de la fotografía aérea. Ed. CSIC.

- OREJAS SACO DEL VALLE, A. (1991): “Arqueología del paisaje: Historia, problemas y perspectivas”. Aespa, 64: 191-230.

- ORTÍZ NIETO-MÁRQUEZ, I. (2012): "Redescubriendo la Nueva Arqueología" Revista Historia Autónoma, 1: 169-173.

- PANERA GAlleGO, J.; RUBIO JARA, S. (1996): "Propuesta de análisis tecnomorfológico para la industria lítica del Pleistoceno medio”. Espacio, Tiempo y Forma, Serie I, Prehistoria y Arqueología, 9: 33-67.

- PATROCINIO ESPIGARES, M.; ROS-MONTOYA, S.; RIQUELME CANTAL, J.A.; MARTÍNEZ NAVARRO, B.; PALMSQUIST, P. (2014): Informe paleontológico. En Ramos Muñoz, J.; Weniger, G.; Cantalejo Duarte, P.; Espejo Herrerías, M.Mª (coords.). Cueva de Ardales 2011-2014. Intervenciones arqueológicas. Ed. Pinsapar. 
- PATROCINIO ESPIGARES, M.; ROS-MONTOYA, S.; RIQUELME CANTAL, J.A.; MARTÍNEZ NAVARRO, B.; PALMSQUIST, P. (2014): Paleontología de la Sima de Las Palomas de Teba. En Weniger, G., Ramos Muñoz, J. (eds.). Sima de Las Palomas Teba (Málaga). Resultados de las investigaciones 2011-2014. Ed. Pinsapar.

- POLO DÍAZ, A. (2007-2008): “Geoarqueología y reconstrucción de contextos arqueológicos: contribución y nuevas perspectivas desde el área de Prehistoria de la Universidad del País Vasco". Veleia, 24-25: 689-700.

- PRIETO RODRIGUEZ M., (2011): “Los patrones de asentamiento: una herramienta metodológica para la reconstrucción del pasado". Boletín Antropológico, 82. Año29. Universidad de Los Andes. Museo Arqueológico / Centro de Investigaciones.

- PROUS POIRIER, A.P (2004): “Apuntes para análisis de industrias líticas”. Ortegalia 02. Monografías de Arqueología, Historia y Patrimonio. Ortigueira: 9-173.

- PUIG Y LARRAZ, G. (1986): Catálogo geográfico y geológico d elas cavidades naturales y minas primordiales de España. Madrid.

- QUEROL FERNÁNDEZ, M.A. (2010): Manual de gestión del Patrimonio Cultural. Ed. Akal.

- QUEROL, M.A.; BERNALDO DE QUIROS, F.; CABRERA, V.; CACHO, C.; GERARDO VEGA, L. (1981): "De tipología lítica". Jornadas de metodología de investigación prehistórica I. Soria: 113-130.

- QUEROL FERNÁNDEZ, M.A. (1990): “Desde el Pleistoceno: La génesis de un yacimiento". Xábiga 6: 12-18.

- RAMOS MUÑOZ, J.; WENIGER, G.; CANTALEJO DUARTE, P.; ESPEJO HERRERÍAS, M.Ma . (coords.) (2014): Cueva de Ardales 20112014. Intervenciones arqueológicas. Ed. Pinsapar. 
- RAMOS MUÑOZ, J.; WENIGER, G.; CANTALEJO DUARTE, P.; ESPEJO HERRERÍAS, M.Mª ; DOMINGUEZ-BELLA, S.; PASTOORS, A.; LINSTÄDTER, J.;MEDIANERO SOTO, J.; BECERRA MARTÍN, S.; CABELLO LIGERO, L.; GUTIERREZ LÓPEZ, J.M ${ }^{\mathrm{a}}$; BARRENA TOCINO, A.;VIJANDE, E.; CANTILLO, JJ. (2014): “Tecnología lítica tallada”. pp. 155-164. En Ramos Muñoz, J.; Weniger, G.; Cantalejo Duarte, P.; Espejo Herrerías, M.M ${ }^{\mathrm{a}}$ (coords.) Cueva de Ardales 2011-2014. Intervenciones arqueológicas. Ed. Pinsapar.

- RAMOS MUÑOZ, J.; WENIGER, G.; PASTOORS, A.; LINSTÄDTER, J.; BARRENA TOCINO, A.; GUTIERREZ LÓPEZ, J.M.; VIJANDE VILA, E.; CANTILLO DUARTE, J.J.; DOMÍNGUEZ-BELLA, S.; MEDIANERO SOTO, J.; CANTALEJO DUARTE, P.; ESPEJO HERRERÍAS, M.Ma .; BECERRA MARTÍN, S.; CABELLO LIGERO, L. (2014): “Tecnología lítica tallada". En Weniger, G.; Ramos Muñoz, J (eds.) Sima de Las Palomas Teba (Málaga). Resultados de las investigaciones 2011-2014. Ed. Pinsapar.

- RAMOS MUÑOZ, J., ESPEJO HERRERÍAS, M. Ma, CANTALEJO DUARTE, P., y RAMÍREZ, F. 1987. "Excavaciones arqueológicas de urgencia en una cista de la Edad del Bronce. Morenito I (Árdales, Málaga)”, Anuario Arqueológico de Andalucía 86, t. III, Sevilla: 236-244.

- RECIO RUÍZ, A. (1995-1996): “Arqueología y urbanismo. Prospecciones en la periferia de Antequera". Mainake XVII-XVIII: 261-273.

- RECIO RUÍZ, A. (2000): “Informe arqueológico de Campillos (Málaga)”. Mainake XIX-XX: 197-226.

- RENFREW, C.; BAHN, P. (2007/2011): Arqueología: teoría, métodos y práctica. Ed. Akal.

- RESTREPO, E. (2009): Escuelas de pensamiento antropológico 1. Clásicos. Programa de Antropología. Fundación Universitaria Claretiana. Quibdó. www.ram-wan.net/restrepo/clasicos.

- RODRIGUEZ ÁlvareZ, XP.; LOZANO RUIZ, M. (1999): “El Pleistoceno medio y superior inicial del noreste de la Península Ibérica”. Pyrenae, 30: 39-68. 
- RODRÍGUEZ VIDÁL, J.; GRACIA PRIETO, J. (2004): "Evolución geomorfológica del Sur de Iberia durante el Neogeno y el Cuaternario”. Miscelánea en homenaje a Emiliano Aguirre. Zona Arqueológica, 4 (1): 123-133.

- ROSKAMS, S. (2001): Teoría y Práctica de la excavación. Ed. Critica Arqueología.

- ROMERO GONZÁLEZ, M. (2006): “El patrimonio natural de la Comarca del Guadalteba (Málaga)”. Patrimonio Guadalteba. Revista de la Asociación para la defensa del Patrimonio Histórico y Natural de la Comarca del Guadalteba (Bobastro), 1: 97-111.

- ROMERO GONZÁLEZ, M; SALAZAR FERNÁNDEZ, J; MORENO CANTARERO, J.C; MEDIANERO SOTO, J. (2004): Los Gaitanes. El Chorro. Málaga.

- ROLLAND, N.; DIBBLE, H.L. (1990): “A new synthesis of middle paleolithic variability". American Antiquity, 55 (3): 480-499.

- RUÍZ DEL ÁRBOL MORO, M. (2005): La arqueología de los espacios cultivados: terrazas y explotación agraria romana en un área de montaña: La sierra de Francia (Salamanca). Anejos de AEspA XXXVI. Editorial CSIC. CSIC press.

- RUIZ TORRES, M.A. (2004): “Ciberetnografía: comunidad y territorio en el entorno virtual”. En Ardevól, E. Estalella, A. Domínguez, D. La mediación tecnológica en la práctica etnográfica: 117-132.

- RUIZ ZAPATA, B.; GIL GARCÍA, M.J (2014): "Estudio polínico de la secuencia”. En Weniger, G., Ramos Muñoz, J. (eds.) Sima de Las Palomas Teba (Málaga). Resultados de las investigaciones 2011-2014. Ed. Pinsapar.

- RUIZ ZAPATA, B.; GIL GARCÍA, M.J (2014): Estudio polínico de la secuencia AD. En Ramos Muñoz, J.; Weniger, G.; Cantalejo Duarte, P.; Espejo Herrerías, M.M ${ }^{\mathrm{a}}$ (coords). Cueva de Ardales 2011-2014. Intervenciones arqueológicas. Ed. Pinsapar.

- RUIZ ZAPATERO, G. (1996): "La prospección de superficie en la arqueología española". QUAD. PREH. ARQ. CAST. 17: 7-20. 
- RUIZ ZAPATERO, G.; BURILlO MOZOTA, F. (1988): "Metodología para la investigación en arqueología territorial". Munibe (Antropología y Arqueología) suplemento $n^{\circ}$ 6. San Sebastián: 45-64.

- RUIZ ZAPATERO, G. (1983): "Notas metodológicas sobre prospección en Arqueología". Revista de Investigación. Colegio Universitario de Soria, VII, 3, Soria: 7-23.

- SALAZAR, J. (2008): “Aportes de G. Willey a la compresión histórica de la arqueología americana". Comechingonia virtual, 4. Revista Electrónica de Arqueología: 245-254.

- SÁNCHEZ YUSTOS, P. (2012): “Crítica a la cultura fósil. La estructura económica como unidad de análisis del cambio cultural paleolítico”. Complutum, 23 (1): 27-40.

- SAN MIGUEL MATE, L.C. (1992): "El planteamiento y el análisis del desarrollo de la prospección: dos capítulos olvidados en los trabajos de arqueología territorial". Trabajos de Prehistoria. 4: 35-49.

- SANTONJA GÓMEZ, M. (1992): "La adaptación al medio en el Paleolítico Inferior de la Península Ibérica. Elementos para una reflexión”. En A. Moure (ed.) Elefantes, Ciervos y Ovicápridos. Economía y aprovechamiento del Medio en la Prehistoria de España. Universidad de Cantabria, Santander: $37-76$.

- SCHIFFER, M.; SULLIVAN, A.; KLINGER, T. (1978): "The desing of archaeological surveys". World archaeology, 10 (1). Field Techniques and Research Design: 1-28.

- SERRANO LOZANO, F.; GUERRA MERCHÁN, A. (2004): Geología Regional. El territorio de la provincia de Málaga en el ámbito de la cordillera Bética. Departamento de Ecología y Geología. Universidad de Málaga.

- SERRANO, E., ATENCIA, R.; MORAÑO, A. (1983): "Una necrópolis altoimperial romana en Peñarrubia (Málaga)". Jábega, 41: 11-16.

- SERRANO, E., ATENCIA, R.; DE LUQUE, A. (1985): "Memoria de las excavaciones del yacimiento arqueológico de «El Tesorillo» (TebaMálaga)”. AA.Hispánico, 26. Madrid.

- SIRET, L. (1891-2001): España prehistórica. L`Espagne préhistorique. Almería. 
- SUNYER MARTÍN, P. (1994): “La perspectiva geográfica en la edafología española". Scripta Vereta, 43. Suplementos. Materiales de trabajo intelectual: 87-97.

- THER RÍOS, F. (2012): “Antropología del territorio”. Polis 32: 2-14.

- TERRADAS, X. (1995): "Reconstrucción del proceso de fabricación de los instrumentos líticos". Treballs d'arqueologia, 3: 31-48.

- TERRADAS, X. (2001): "La gestión de los recursos minerales en las sociedades cazadoras-recolectoras". Treballs d'etnoarqueología, 4. CSIC.

- TURQ, A. (2007): "Hacia una nueva visión del musteriense del nordeste aquitano". En El universo neanderthal. Volumen 1. Madrid: 119-138.

- VALlESPÍ, E.; RAMOS MUÑOZ, J.; CANTALEJO DUARTE, P.; ESPEJO HERRERÍAS, M.; MARTÍN CÓRDOBA, E. (1988): "Picos campiñeses del tramo subbético de Málaga relacionables con el norte de África" Congreso Internacional El estrecho de Gibraltar. Ceuta, 1987. TomoI, UNED, Madrid: 271-284.

- VAQUERO, M. (2011-2012): “Una cuestión de método...o tal vez no. La variabilidad de la talla discoidal en el Paleolítico Medio del Abric Romaní". Mainake XXXIII: 233-250.

- VILLAFAÑEZ, E.A. (2011): “Entre la geografía y la arqueología: el espacio como objeto y representación”. Revista de Geografía Norte Grande, 50: 135-150.

- VILLANÚA FUNGAIRIÑO, L.; GARCÍA PUERTAS， P. (1999): Monografía XXIII. Balneario de Carratraca 1999. Monografía de aguas mineralo medicinales. Análisis de la Real Academia de Farmacia: 405-417.

- WENIGER, G.; RAMOS MUÑOZ, J. (eds.) (2014): Sima de Las Palomas Teba (Málaga). Resultados de las investigaciones 2011-2014. Ed. Pinsapar.

- WENIGER, G.; RAMOS MUÑOZ, J.; MEDIANERO SOTO, J.; CANTALEJO DUARTE, P. (2014): “Actividades arqueológicas y analíticas realizadas en Sima del complejo kárstico de Las Palomas”. En Weniger, G.; Ramos Muñoz. J (eds.). Sima de Las Palomas de Teba 2011-2014. Intervenciones arqueológicas. Ed. Pinsapar. 


\section{WEBGRAFÍA}

- www.comechingonia.com

- http://polis.revues.org

- http://www.revues.org

- http://www.antropologiamedica.com

- www.ram-wan.net/restrepo/clasicos

- http://www.revues.org

- www.monografias.com 


\section{9. Índice de figuras y tablas}

\section{FIGURAS}

Figura 1. Mapa de situación de la comarca del Guadalteba, en Málaga y España 1

Figura 2. Tipo de muestreo: A: Muestreo aleatorio, B: Muestreo estratificado, C: Muestreo sistemático, D: Muestreo sistemático estratificado o no alineado .....

Figura 3. Perfil de la Sima de Las Palomas de Teba con las unidades sedimentarias, las ubicaciones de las muestras y los resultados de las dataciones estimadas por luminiscencia

Figura 4. Topografía interior de la Cueva de Ardales con la localización de los sondeos ............... 43

Figura 5. Cueva de Ardales. Sondeo zona 2 ...................................................................... 44

Figura 6. Cueva de Ardales. Sondeo zona 4 ............................................................................. 45

Figura 7. Modelo de movilidad en Torralba Ambrona según Butzer .......................................... 55

Figura 8. Modelo de movilidad a macroescala según Butzer ........................................................ 56

Figura 9. Modelo de Robert Foley para las actividades dentro del territorio anual de una banda de cazadores-recolectores y las dispersiones de artefactos ........................................... 57

Figura 10. Modelo de ficha utilizado para los hallazgos arqueológicos .......................................... 65

Figura 11. Máquina cortadora y preparadora de láminas delgadas ................................................ 80

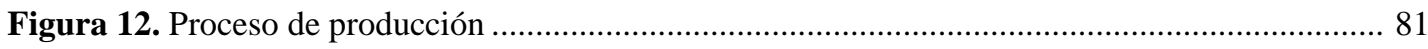

Figura 13. Cadena de producción y formación de las principales categorías estructurales ................ 82

Figura 14. Esquema conceptual del Sistema Lógico Analítico .................................................. 84

Figura 15. Planos para la descripción volumétrica de los objetos ................................................. 86

Figura 16. Esquema de las categorias de carácter facial............................................................... 86

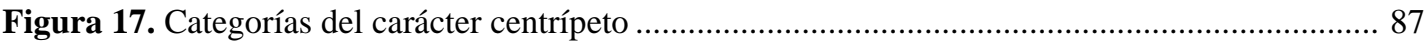

Figura 18. Esquema de las categorías del carácter de oblicuidad................................................... 87

Figura 19. Categorias del carácter de profundidad .................................................................. 88

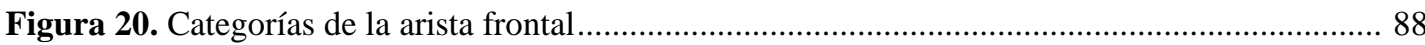

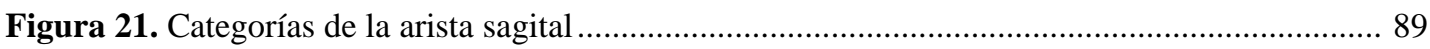

Figura 22. Algunos de los caracteres morfotécnicos considerados en el análisis de las BP............. 90

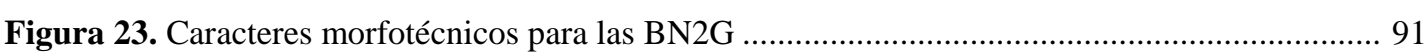

Figura 24. Modelos morfopotenciales aplicados a los filos de los artefactos líticos ....................... 92

Figura 25. Esquema geológico de la Cordillera Bética ........................................................... 98

Figura 26. Mapa geológico de la Cordillera Bética....................................................................... 98

Figura 27. Mapa geológico de Málaga (elaboración propia a partir del Mapa de la Comunidad Autónoma de Andalucía a escala 1:400.000) .............................................. 106

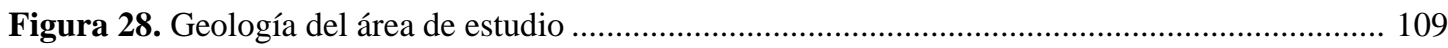

Figura 29.Tabla cronoestratigráfica del Cuaternario ............................................................ 117

Figura 30. Edafológia del área de estudio, modificado a partir del mapa de suelos deAndalucía, escala E: 1:400000.

Figura 31. Temperatura media anual de la provincia de Málaga................................................. 124

Figura 32. Mapa con las zonas de muestreo geológico .................................................................... 150 
Figura 33. A: Lámina delgada CÑAT-1. Textura llena de pellets. Foto con LDP x25 aumentos.

B: Sílex masivo. Foto con lupa tipo triplete10X.

Figura 34. A: Lámina delgada CÑAT-3. Interfase de la zona teñida y no teñido con espículas y radiolarios. Foto con LDP x100 aumentos. B: Radiolarita. Foto con lupa tipo triplete $10 \mathrm{X}$

Figura 35. A: Lámina delgada CÑAT-4. Estructura en pellets y restos de fósiles. Foto con LP x100 aumentos. B: Detalle fósil tipo molusco. Foto con LP x400 aumentos. C: Sílex masivo. Foto con lupa tipo triplete 10X.

Figura 36. A: Lámina delgada CÑAT-6. Aspecto general con radiolario en el centro. Foto con LDP x100 aumentos. B: Sílex masivo. Foto con lupa tipo triplete 10X.

Figura 37. A: Lámina delgada CÑAT-7. Cristal de calcita y relleno de calcedonia. Foto con LDP x 100 aumentos. B: Sílex masivo. Foto con lupa tipo triplete $10 \mathrm{X}$

Figura 38. A: Lámina delgada CÑAT-9. Foto general de parches con restos de fósiles y calcedonia. Foto con LDP x 100 aumentos. B: Sílex masivo. Foto con lupa tipo triplete $10 \mathrm{X}$

Figura 39. A: Lámina delgada CÑHL-1. Aspecto general de parches con los óxidos de hierro. Foto con LP x 100 aumentos. B: Radiolarita. Foto con lupa tipo triplete10X

Figura 40. A: Lámina delgada CÑHL-2. Foto de los oolitos muy pegados. Foto con LDP x 100 aumentos. B: Sílex oolítico. Foto con lupa tipo triplete 10X

Figura 41. A: Lámina delgada CÑHL-3. Aspecto general con inclusiones rellenas de calcedonia fibrosa. Foto con LDP x 100 aumentos. B: Sílex masivo. Foto con lupa tipo triplete $10 \mathrm{X}$

Figura 42. A: Lámina delgada CÑHL-4. Aspecto general con filón de calcita, con inclusiones oscuras carbonatadas y posible grano de estaurolita. Foto con LDP x100 aumentos. B: Sílex masivo. Foto con lupa tipo triplete 10X.

Figura 43. A: Lámina delgada LM (A)-1. Zona con presencia de posibles oolitos recristalizados y de carbonatos de calcedonia. Foto con LDP x100 aumentos. B: Sílex oolítico. Foto con lupa tipo triplete $10 \mathrm{X}$

Figura 44. A: Lámina delgada LC (A)-1. Detalle de romboedros de dolomita muy alterados y radiolarios rellenos de calcedonia. Foto con LDP x100 aumentos. B: Radiolarita bandeada. Foto con lupa tipo triplete 10X.

Figura 45. A: Lámina delgada LC(A)-2. Detalle de los radiolarios y vetas de calcita. Foto con LDP x40 aumentos. B: Sílex masivo. Foto con lupa tipo triplete 10X.

Figura 46. A: Lámina delgada LC(A)-3. Detalle de nódulos de óxido y radiolarios. Foto con LP x40 aumentos. B: Radiolarita roja. Foto con lupa tipo triplete $10 \mathrm{X}$

Figura 47. A: Lámina delgada LC(A)-4. Detalle de las bandas con los radiolarios. Foto con LDP x100 aumentos. B: Radiolarita. Foto con lupa tipo triplete10X 
Figura 48. A: Lámina delgada LC(A)-6. Detalle mancha de calcita micrítica con relleno de fantasmas de radiolarios y filón de esparita. Foto con LDP x40 aumentos.

B: Sílex masivo. Foto con lupa tipo triplete 10X.

Figura 49. A: Lámina delgada ALM1-1. Bandas de diferentes tonalidades con multitud de inclusiones. Foto con LP x40 aumentos. B: Sílex bandeado. Foto con lupa tipo triplete $10 \mathrm{X}$

Figura 50. A: Lámina delgada ALM1-2. Detalle de una zona con acumulación de radiolarios y óxidos. Foto con LP x100 aumentos. B: Radiolarita. Foto con lupa tipo triplete 10X ..... 144

Figura 51. A: Lámina delgada ALM1-3. Detalle de la matriz con multitud de restos fósiles. Foto con LP x100 aumentos. B: Sílex masivo con radiolarios. Foto con lupa tipo triplete $10 \mathrm{X}$

Figura 52. A: Lámina delgada ALM1-5. A: Detalle de los microfósiles y de los rellenos de calcedonia. Foto con LDP x100 aumentos. B: Sílex oolítico. Foto con lupa tipo triplete $10 \mathrm{X}$.

Figura 53. A: Lámina delgada PEMA4 (I). Detalle de los oolitos. Foto con LP x 25 aumentos.

B: Sílex oolítico. Foto con lupa tipo triplete10X.

Figura 54. A: Lámina delgada PEMA4 (II). Detalle de inclusiones y microfósiles, uno de ellos en forma de cono. Foto con LDP x100 aumentos. B: Radiolarita. Foto con lupa tipo triplete $10 \mathrm{X}$

Figura 55. A: Lámina delgada PEMA4 (III). Detalle de un posible resto de caparazón de radiolario. Foto con LP x100 aumentos. B: Sílex masivo. Foto con lupa tipo triplete10X 148

Figura 56. A: Lámina delgada PEMA4 (IV). Estructura con grumo rico en óxido con ooides y restos de fósiles. Foto con LP x25 aumentos. B: Sílex oolítico. Foto con lupa tipo triplete $10 \mathrm{X}$

Figura 57. A: Lámina delgada PEMA4 (V). Inclusiones de formas esféricas, restos de fósiles con cierto bandeado. Foto con LP x25 aumentos. B: Sílex masivo. Foto con lupa tipo triplete $10 \mathrm{X}$

Figura 58. A: Lámina delgada PEMA4 (VI). Estructura con parches de carbonatos y radiolarios. Foto con LP x100 aumentos. B: Sílex masivo. Foto con lupa tipo triplete 10X.

Figura 59. A: Lámina delgada AZ1-1. Banda más oscura con inclusiones de fósiles y zonas más claras con presencia de oolitos. Foto con LDP x40 aumentos. B: Sílex bandeado. Foto con lupa tipo triplete $10 \mathrm{X}$

Figura 60. A: Lámina delgada AZ1-2. Detalle de romboedros de dolomita y cristales de esparita. Foto con LP x400 aumentos. B: Sílex masivo. Foto con lupa tipo triplete 10X...... 151

Figura 61. A: Lámina delgada AZ2-46. Detalle de la matriz homogénea con romboedros de dolomita. Foto con LP x100 aumentos. B: Sílex masivo. Foto con lupatipo triplete $10 \mathrm{X}$ 
Figura 62. A: Lámina delgada AZ2-235. Detalle de la mancha alargada rellena de calcedonia y de romboedros de dolomita. Foto con LDP x100 aumentos. B: Sílex masivo. Foto con lupa tipo triplete $10 \mathrm{X}$

Figura 63. A: Lámina delgada AZ2-352. Detalle romboedros de dolomita e inclusiones de minerales opacos. Foto con LDP x100 aumentos. B: Sílex masivo. Foto con lupa tipo triplete $10 \mathrm{X}$

Figura 64. A: Lámina delgada AZ2-374. Detalle de los fantasmas de radiolarios rellenos de cuarzo. Foto con LDP x100 aumentos. B: Sílex con radiolarios. Foto con lupa tipo triplete $10 \mathrm{X}$

Figura 65. A: Lámina delgada AZ2-376. Detalle de oxidación arborescente. Foto con LP x100 aumentos. B: Sílex masivo con oxidaciones. Foto con lupa tipo triplete 10X

Figura 66. A: Lámina delgada GA-580. Detalle de la multitud de cristales de dolomita por toda la muestra. Foto con LP x100 aumentos. B: Sílex masivo. Foto con lupa tipo triplete $10 \mathrm{X}$

Figura 67. A: Lámina delgada LAGAL-ARD-1. Detalle de romboedros de dolomita y espícula rellena de calcedonia. Foto con LP x100 aumentos. B: Sílex masivo. Foto con lupa tipo triplete $10 \mathrm{X}$

Figura 68. A: Lámina delgada LAGAL-ARD-2. Detalle de romboedros de dolomita. Foto con LDP x100 aumentos. B: Sílex masivo. Foto con lupa tipo triplete 10X

Figura 69. A: Lámina delgada LAGAL-ARD-3. Detalle espículas rellenas de calcedonia, de romboedros de dolomita y de vena de calcita. Foto con LDP x100 aumentos. B: Sílex masivo. Foto con lupa tipo triplete $10 \mathrm{X}$

Figura 70. A: Lámina delgada CT-ARD-1. Filón de calcita, minerales opacos y romboedros de dolomita. Foto con LDP x40 aumentos. B: Sílex masivo con huellas de Phycosiphon. Foto con lupa tipo triplete10X

Figura 71. A: Lámina delgada CT-ARD-2. Detalle de romboedros de dolomita. Foto con LDP x100 aumentos . B: Sílex masivo. Foto con lupa tipo triplete 10X

Figura 72. A: Lámina delgada CT-ARD-3. Detalle de la abundancia de fósiles. Foto con LDP X40 aumentos. B: Sílex masivo. Foto con lupa tipo triplete $10 \mathrm{X}$

Figura 73. A: Lámina delgada CT-ARD-4. Detalle de espícula rellena de calcedonia y de romboedros de dolomita. Foto con LP x100 aumentos. B: Sílex masivo. Foto con lupa tipo triplete $10 \mathrm{X}$

Figura 74. A: Lámina delgada HC-1. Detalle romboedros de dolomita e inclusiones de minerales opacos. Foto con LP x100 aumentos. B: Sílex masivo. Foto con lupa tipo triplete $10 \mathrm{X}$

Figura 75. A: Lámina delgada VAAB-1. Aspecto general con microinclusiones, fisura llena de calcita esparítica y espículas en forma de V. Foto con LP x100 aumentos. B: Sílex masivo. Foto con lupa $10 \mathrm{X}$ 
Figura 76. A: Lámina delgada VAAB-2. Radiolarios, fracturas rellenas de calcita y óxidos de hierro. Foto con LP x100 aumentos. B: Radiolarita roja. Foto con lupa tipo triplete $10 \mathrm{X}$

Figura 77. A: Lámina delgada VAAB-3. Estructura brechificada con fisuras rellenas de calcita. Foto con LP x25 aumentos. B: Radiolarita roja. Foto con lupa tipo triplete 10X

Figura 78. A: Lámina delgada SHU. Estructura de calcita esparítica con parche de calcita teñido. Foto con LDP x100 aumentos. B: Sílex masivo. Foto con lupa tipo triplete 10X. 164

Figura 79. A: Lámina delgada TG12-TL. Granos con glauconita con cuarzo y calcita. Foto con LDP x100 aumentos . B: Detalle de las agujas de rutilo en un cuarzo. Foto con LDP x400 aumentos. C: Arenisca compacta. Foto con lupa tipo triplete 10X.

Figura 80. A: Lámina delgada TG13-TL. Estructura con grano de plagioclasa, moscovita y clorita. Foto con LDP x100 aumentos. B: Protocuarcita. Foto con lupa tipo triplete 10X 166

Figura 81. A: Lámina delgada A1-A01. Fisura rellena de calcedonia fibrosa y óxidos. Foto con LDP x100 aumentos . B: Sílex masivo. Foto con lupa tipo triplete 10X

Figura 82. A: Lámina delgada A1-A03. Estructura carbonatada con parches de calcedonia, microfósil esférico. Foto con LDP x100 aumentos. B: Sílex masivo. Foto con lupa tipo triplete $10 \mathrm{X}$

Figura 83. A: Lámina delgada A1-A04. Estructura carbonatada con un posible foraminífero con corona de calcedonia. Foto con LDP x100 aumentos. B: Sílex masivo. Foto con lupa tipo triplete $10 \mathrm{X}$

Figura 84. A: Lámina delgada TPÑ28-TL. Clastos de cuarzo redondeados y óxidos de hierro. Foto con LDP x100 aumentos. B: Arenisca. Foto con lupa tipo triplete 10X.....

Figura 85. A: Lámina delgada TPÑ2. Inclusiones y puntos negros y radiolario. Foto con LP x100 aumentos. B: Sílex masivo. Foto con lupa tipo triplete $10 \mathrm{X}$

Figura 86. A: Lámina delgada TT3-1. Estructura de relleno de cuarzo policristalino con posible moscovita o sillimanita. Foto con LDP x400 aumentos. B: Cuarcita. Foto con lupa tipo triplete $10 \mathrm{X}$

Figura 87. A: Lámina delgada TT3-2. Cuarzos mono y policristalinos y feldespato potásico, con relleno de calcedonia. Foto con LDP x100 aumentos. B: Arenisca. Foto con lupa tipo triplete $10 \mathrm{X}$

Figura 88. A: Lámina delgada TT3-3. Estructura de cuarzo redondeado policristalino con inclusiones de circón. Foto con LDP x400 aumentos. B: Arenisca. Foto con lupa tipo triplete $10 \mathrm{X}$

Figura 89. Mapa Topográfico Nacional de 1911-1920, con la cuenca del río Turón.

Escala 1:50.000 (MTN50) y embalse del Guadalhorce en la actualidad

Figura 90. Situación Cueva de Ardales 176

Figura 91. Cueva de Ardales. Zonas de sondeos arqueológicos. 177

Figura 92. Cueva de Ardales (Ardales): 1: BN2G-Foliaceo; 2: BN2G-Raspador simple 181

Figura 93. Vista general de Cucarra 183

Figura 94. Materias primas de las piezas líticas recuperadas en el yacimiento de Cucarra 185 
Figura 95. Cucarra (Ardales): 1, 2, 3, 4: BN2G-Raederas..................................................... 190

Figura 96. Depósito Hoyos de Barbú ............................................................................................ 192

Figura 97. Materias primas de las piezas líticas recuperadas del yacimiento Hoyos

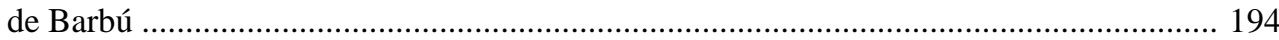

Figura 98. Hoyos de Barbú (Ardales): BN1GC-1:Triedro, 2: hendedor, 3:bifaz ............................ 198

Figura 99. Vista general de la terraza del arroyo Cantarranas .................................................... 200

Figura 100. BP- Levallois del arroyo Cantarranas ....................................................................... 202

Figura 101. Vista general del depósito del Hundilón .............................................................. 204

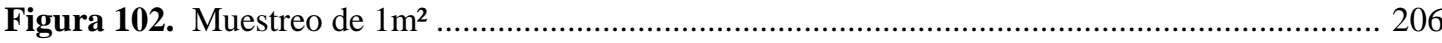

Figura 103. Depósito del Hundilón (Ardales): 1, 2:BN1G-Núcleo diverso y unipolar; 3: BP-Lasca de semidescortezado; 4: BN2G-Raedera lateral ..................................................... 209

Figura 104. Vista general de la terraza de Morenito ................................................................... 211

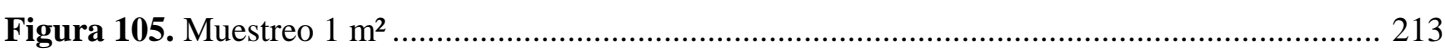

Figura 106. Materias primas de las piezas líticas recuperadas en el yacimiento de Morenito........... 214

Figura 107. Terraza de Morenito (Ardales): 1: BP-Lasca levallois; 2, 3: BN2G-Raederas .............. 217

Figura 108. Vista general de Llanos de Belén .............................................................................. 219

Figura 109. Materias primas de las piezas líticas recuperadasen el yacimiento Llanos de Belén

Figura 110. Llanos de Belén (Ardales): 1: BN1G-Núcleo centrípeto; 2,3: BP-Lascas levallois;

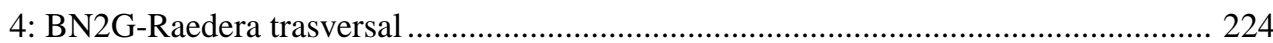

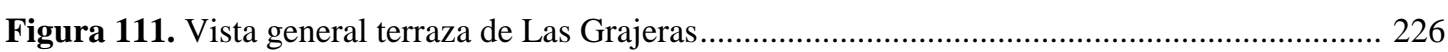

Figura 112. Materias primas de las piezas líticas recuperadasen el yacimiento de terraza de Las Grajeras

Figura 113. Terraza de Las Grajeras (Ardales): 1, 2:BN1G-Núcleo poliédrico y centrípeto multipolar; 3, 4, 5: BP-Lasca de semidescortezado y lascas levallois; 6: BN2G-Muesca

Figura 114. Vista general del yacimiento Raja del Boquerón 234

Figura 115. Materias primas de las piezas líticas recuperadas en el yacimiento de Raja del Boquerón 236

Figura 116. Raja del Boquerón (Ardales): 1, 2:BN1G-Núcleo levallois y unipolar; 3, 4, 5: BPLascas internas y levallois; 6: BN2G-Raedera doble cóncava-convexa 239

Figura 117. Vista general del yacimiento Lomas del Infierno ..... 241

Figura 118. Materias primas de las piezas líticas recuperadas en el yacimiento de Lomas del Infierno

Figura 119. Lomas del Infierno (Ardales): 1, 2, 3, 4:BN1G- Canto tallado, núcleo centrípeto, núcleo levallois sobre lasca y unipolar; 5, 6, 7: BP-Lasca de descortezado e internas

Figura 120. Lomas del Infierno (Ardales): 1, 2, 3 BP-Lascas levallois; 4, 6: BN2G-Raederas laterales; 5: Denticulado 
Figura 121. Mapa Topográfico Nacional de 1911-1920, con la cuenca original del río Guadalteba. Escala 1:50.000 (MTN50) y embalse del Guadalteba en la actualidad 249

Figura 122. Vista general terraza La Puente ...................................................................... 251

Figura 123. Materias primas de las piezas líticas recuperadas en la terraza La Puente.................... 253

Figura 124. Terraza La Puente: 1. BP-Lasca levallois; 3, 4: BN2G-Muescas; 5: Raedera .............. 256

Figura 125. Vista general del yacimiento de la Sima de Las Palomas ......................................... 258

Figura 126. Sección del complejo kárstico de Las Palomas en Teba .............................................. 261

Figura 127. Ortofoto del perfil estratigráfico con los productos líticos tallados .......................... 261

Figura 128. Materias primas de las piezas líticas recuperadas en la Sima de Las Palomas........... 262

Figura 129. Sima de Las Palomas. Us. 9-10 (1 a 3) y Us 6 (4): BN1G-CM-Núcleos centrípetos

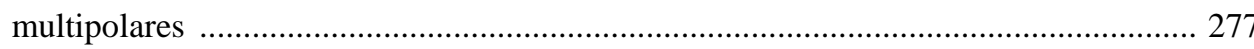

Figura 130. Sima de Las Palomas. Us. 9-10. BP-LE-Lascas levallois ............................................. 278

Figura 131. Sima de Las Palomas. Us. 9-10 (1 y 4) y Us. 6 (2 y 3). BN2G-R21nokp (1, 2 y 3) y

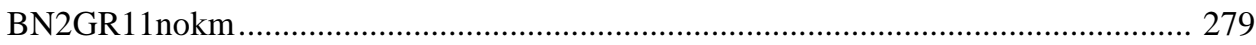

Figura 132. Vista general de la terraza de Peñarrubia ................................................................... 281

Figura 133. Materias primas de las piezas líticas recuperadas en el yacimiento terraza de Peñarrubia

Figura 134. Terraza de Peñarrubia (Campillos): 1, BN1GC-Hendedor; 2, BP- Levallois;

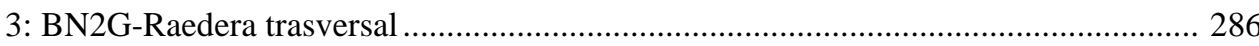

Figura 135. Vista del yacimiento La Puente............................................................................ 288

Figura 136. Materias primas de las piezas líticas recuperadas en el yacimiento La Puente .............. 289

Figura 137. La Puente (Teba): 1, 2:BN1GC- Bifaces; 3: BP-Lasca de semidescortezado ................ 293

Figura 138. Vista general del yacimiento PEMA4 ...................................................................... 295

Figura 139. Materias primas de las piezas líticas recuperadas en el yacimiento PEMA4 ................ 297

Figura 140. PEMA4 (Almargen): 1, 2, 3:BN1G- núcleos centrípeto y poliedrico; 4:

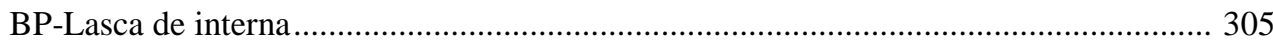

Figura 141. PEMA4 (Almargen): BN2G: 1, 2: Raederas; 3: Punta levallois; 4: Raspador ............... 306

Figura 142. Bifaz de Nina Alta........................................................................................... 307

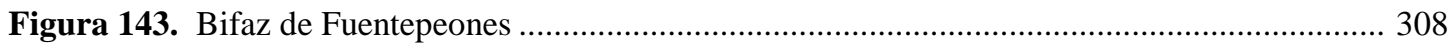

Figura 144. Imagen de Rotalipora ticinensis................................................................... 313

Figura 145. TOTD Y TOTI presentes en los yacimientos estudiados .......................................... 317

Figura 146. Computo general de TOTI presentes en los yacimientos estudiados .......................... 318

Figura 147. Computo general de BP presentes en los yacimientos estudiados ............................... 319

Figura 148. Cuadro cronológico con los yacimientos estudiados ............................................... 343

Figura 149. Mapa de los yacimientos del Paleolítico inferior y fuentes de materias primas........... 344

Figura 150. Mapa de los yacimientos del Paleolítico medio y fuentes de materias primas............... 345

Figura 151. Mapa de los yacimientos del Paleolítico inferior y fuentes de materias primas............ 346 


\section{TABLAS}

Tabla 1. Modelo de presentación de los datos de las BN1G. Tabla y leyenda .75

Tabla 2. Modelo de presentación de los datos de las BP. Tabla y leyenda..................................... 76

Tabla 3. Modelo de presentación de los datos de las BN2G. Tabla y leyenda ............................... 76

Tabla 4. Estudio analítico de las BP de Cueva de Ardales ............................................................ 179

Tabla 5. Estudio analítico de las BN2G de Cueva de Ardales..................................................... 179

Tabla 6. Estudio analítico de las BN1G de Cucarra ....................................................................... 185

Tabla 7. Estudio analítico de las BP de Cucarra .............................................................................. 186

Tabla 8. Estudio analítico de las BN2G de Cucarra ....................................................................... 188

Tabla 9. Estudio analítico de las BN1G de Hoyos de Barbú ............................................................ 195

Tabla 10. Estudio analítico de las BP de Hoyos de Barbú............................................................. 195

Tabla 11. Estudio analítico de las BN2G de Hoyos de Barbú ..................................................... 196

Tabla 12. Estudio analítico de las BP de la terraza del arroyo Cantarranas.................................... 202

Tabla 13 .Estudio analítico de las BN1G del Hundilón ............................................................. 207

Tabla 14 .Estudio analítico de las BP del Hundilón .................................................................... 207

Tabla 15. Estudio analítico de las BN2G del Hundilón ................................................................... 208

Tabla 16. Estudio analítico de las BN1G de la terraza de Morenito.................................................. 215

Tabla17. Estudio analítico de las BP de la terraza de Morenito ...................................................... 215

Tabla 18. Estudio analítico de las BN2G de la terraza de Morenito ........................................... 216

Tabla 19. Estudio analítico de las BN1G de Llanos de Belén ......................................................... 221

Tabla 20. Estudio analítico de las BP de Llanos de Belén................................................................ 222

Tabla 21. Estudio analítico de las BN2G de Llanos de Belén .................................................... 222

Tabla 22. Estudio analítico de las BN1G de la terraza de Las Grajeras ............................................. 229

Tabla 23. Estudio analítico de las BP de la terraza de Las Grajeras ............................................... 229

Tabla 24. Estudio analítico de las BN2G de la terraza de Las Grajeras ........................................ 230

Tabla 25. Estudio analítico de las BN1G de Raja del Boquerón ..................................................... 237

Tabla 26. Estudio analítico de las BP de Raja del Boquerón....................................................... 237

Tabla 27. Estudio analítico de las BN2G de Raja del Boquerón .................................................... 238

Tabla 28. Estudio analítico de las BN1G de Lomas del Infierno ..................................................... 244

Tabla 29. Estudio analítico de las BP de Lomas del Infierno .................................................... 244

Tabla 30. Estudio analítico de las BN2G de Lomas del Infierno ................................................... 245

Tabla 31. Estudio analítico de las BN1G de la terraza La Puente ................................................. 254

Tabla 32. Estudio analítico de las BP de la terraza de La Puente .................................................... 254

Tabla 33. Estudio analítico de las BN2G de la terraza de La Puente................................................ 255

Tabla 34. Estudio analítico de las BN1G de la Sima de Las Palomas ............................................. 263

Tabla 35. Estudio analítico de las BP de la Sima de Las Palomas.................................................265-272

Tabla 36. Estudio analítico de las BN2G de la Sima de Las Palomas ............................................ 275

Tabla 37. Estudio analítico de las BN1G de la terraza de Peñarrubia ............................................. 283

Tabla 38. Estudio analítico de las BP de la terraza de Peñarrubia ................................................. 284

Tabla 39. Estudio analítico de las BN2G de la terraza de Peñarrubia ......................................... 285 
Tabla 40. Estudio analítico de las BN1G de La Puente ............................................................... 290

Tabla 41. Estudio analítico de las BP de La Puente ................................................................ 291

Tabla 42. Estudio analítico de las BN2G de La Puente ................................................................ 292

Tabla 43. Estudio analítico de las BN1G de PEMA4 ..................................................................... 298

Tabla 44. Estudio analítico de las BP de PEMA4 .................................................................... 299-301

Tabla 45. Estudio analítico de las BN2G de PEMA4 ............................................................................. 303

Tabla 46. Estudio analítico BN1G de Nina Alta .......................................................................... 307

Tabla 47. Estudio analítico BN1G de Fuentepeones .............................................................. 308

Tabla 48. Análisis dimensional de las BP según B. Bagolini. Valoración por grupos y tamaño........ 319

Tabla 49. Rasgos técnicos de las BP. Cara talonar y cara dorsal................................................... 320

Tabla 50. Rasgos técnicos de las BN2G. Cara talonar y cara dorsal ........................................... 322

Tabla 51. Morfotipos presentes en los yacimientos al aire libre y en cuevas ................................... 322 